\title{
ISSUES IN THE SUSTAINABILITY OF MICROFINANCE
}

Three Empirical Essays at Micro and Macro Level

Dissertation zur Erlangung des wirtschaftswissenschaflichen Doktorgrades der Wirtschaftswissenschaftlichen Fakultät der Universität Göttingen

vorgelegt am 24.08.2009

von Ahmad Nawaz

aus Lahore, Pakistan 


\section{Eidesstattliche Erklärung}

Hiermit versichere ich an Eides statt, dass ich die eingereichte Dissertation

"ISSUES IN SUSTAINABILITY OF MICROFINANCE: Three Empirical Essays at Micro and Macro Level"

selbständig verfasst habe. Anderer als der von mir angegebenen Hilfsmittel und Schriften habe ich mich nicht bedient. Alle wörtlich oder sinngemäß den Schriften anderer Autoren entnommenen Stellen habe ich kenntlich gemacht.

Göttingen, den 24. August 2009, Ahmad Nawaz 
In loving memory of

\section{Riffat Nawaz}




\section{Acknowledgements}

I consider it a privilege to extend my deepest gratitude to my supervisor, Stephan Klasen, for his invaluable guidance and support throughout my doctoral studies. Without which, this dissertation would not have seen the daylight. I am greatly indebted to Bernhard Brümmer for his guidance and time when it mattered the most. I am also grateful to Carola Grün for her insightful comments which contributed significantly to the qualitative improvement in the final draft of the Thesis. I am also thankful to Prof. Jacob Yaron; Marek Hudon and Marc Labie of CERMi, Brussels and Roy Mersland of Agder University, Norway for their comments and suggestion during conferences.

I feel very privileged to have such wonderful and caring colleagues around during my stay that to single out any one or few of them would not do justice at all. I thank all of them for their advice, practical help and friendship.

I am thankful for the Higher Education Commission of Pakistan (HEC) and German Academic Exchange Program (DAAD) for funding my Doctoral studies and to my employment institute (PIDE) in Pakistan for keeping me intact on their payroll for the time of my Doctoral studies. I am also thankful to our chair for Development Economics, Göttingen Graduate School of Social Sciences (GGG) and KMU-network for providing me funds to attend different conferences, workshop and summer school during my doctoral studies.

Back home, I am greatly indebted to my father, Nawaz Khan for his love, affection, prayers, and blessings. He has always been a source of inspiration to me for his hard work and perseverance which really kept me going throughout particularly in testing times. I am also thankful to my siblings Ali and Ammara for 
their love, prayers and affection. Finally my wife, Alina owes a lot to the successful completion of my doctoral studies and deserves special appreciation. She managed the home affairs to perfection and took excellent care of our two kids Ayaan and Rania, thus allowing me the maximum time to concentrate on my doctoral studies. Having such remarkable teachers, colleagues, friends and family, I surely had a time of my life in Germany. 


\section{Contents}

$\begin{array}{ll}\text { List of Tables ix } & \text { ix }\end{array}$

List of Figures $\quad$ x

$1 \quad$ Introduction and Overview 1

$2 \quad$ Subsidization of Microfinance 9

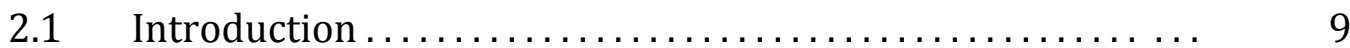

$2.2 \quad$ Data and Theoretical Framework .................... 12

2.2.1 Description of the Data $\ldots \ldots \ldots \ldots \ldots \ldots \ldots \ldots \ldots, 12$

2.2.2 The SDI Formula....................... 17

2.2.3 What Constitutes Subsidies? .................. 18

2.2.3.1 Equity Grants. ................... 19

2.2.3.2 Profit Grants. ........................ 19

2.2.3.3 True Profit. ............................ 21

2.2.4 Choice of Economic Opportunity cost of MFIs Concessional

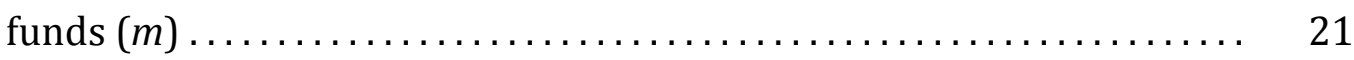

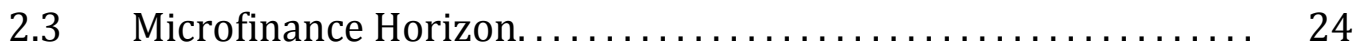

2.3.1 Subsidy Dependence Index.................... 24

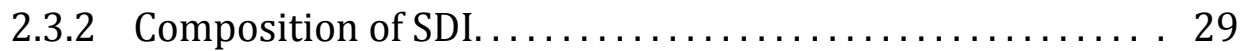

$2.4 \quad$ With and Without Subsidy Comparisons . . . . . . . . . . . . . . 30

2.4.1 Return on Equity (ROE) Vs Subsidy-Adjusted Return on

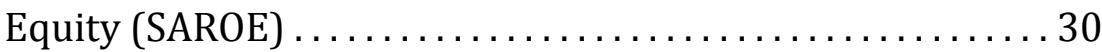

2.4.2 Return on Asset (ROA) Vs Subsidy-Adjusted Return on Asset

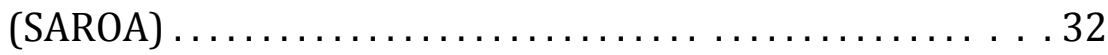

2.4.3 Actual Yield Vs Subsidy-Free Yield.................. 33

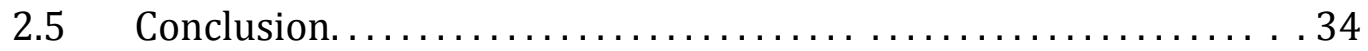

3 Efficiency and Productivity of Microfinance: Incorporating the Role of $\begin{array}{ll}\text { Subsidies } & 37\end{array}$

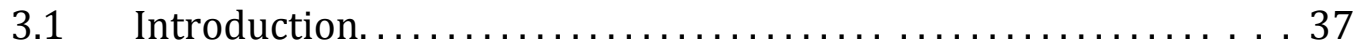

$3.2 \quad$ Microfinance Horizon. . . . . . . . . . . . . . . . . . . . . . . . . . 40

3.2.1 Subsidy Dependence Index (SDI) $\ldots \ldots \ldots \ldots \ldots \ldots \ldots \ldots 40$

3.2 .2 Description of the Data....................... . 42

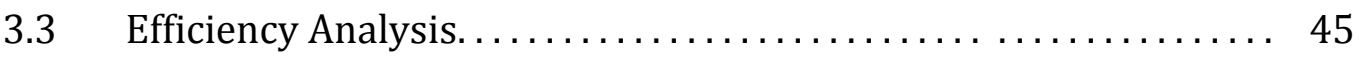




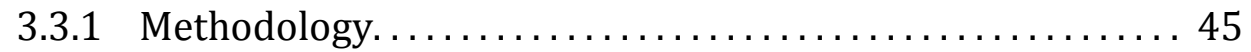

3.3.1.1 Data Envelopment Analysis (DEA) ........... . 45

3.3.1.2 The Malmquist Productivity Index............. 48

3.3.2 DEA Model and Input Output Variables.............. 49

3.3.3 Incorporation of Subsidies into DEA Framework........ 50

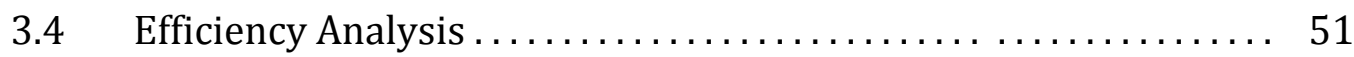

$3.5 \quad$ With and Without Subsidy Analysis $\ldots \ldots \ldots \ldots \ldots \ldots \ldots \ldots \ldots \ldots \ldots$

3.5.1 Efficiency Analysis $2005 \ldots \ldots \ldots \ldots \ldots \ldots \ldots \ldots \ldots$

3.5.2 Efficiency Analysis $2006 \ldots \ldots \ldots \ldots \ldots \ldots \ldots \ldots$

3.5.3 Malmquist Productivity Index Analysis. .............. 57

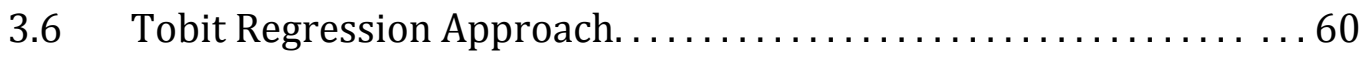

3.6.1 Methodology ................................ 60

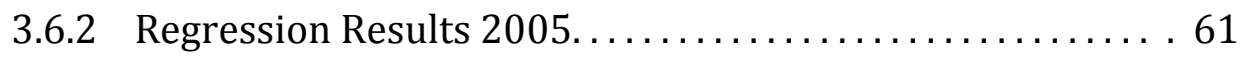

3.6.3 Regression Results $2006 \ldots \ldots \ldots \ldots \ldots \ldots \ldots \ldots \ldots \ldots \ldots \ldots$

3.6.4 Panel Data Results.......................... . 66

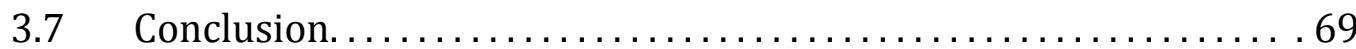

$4 \quad$ Sustainability of Microfinance: An Empirical Investigation 73

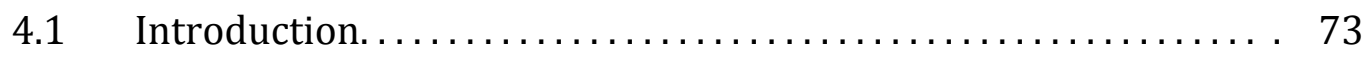

$4.2 \quad$ Data and Empirical Framework. $\ldots \ldots \ldots \ldots \ldots \ldots \ldots \ldots \ldots \ldots \ldots \ldots \ldots \ldots$

4.2.1 Description and Sources of Data. ............... . 77

4.2 .2 Measuring Sustainability $\ldots \ldots \ldots \ldots \ldots \ldots \ldots \ldots \ldots$

4.2 .3 Empirical Approach........................... 83

$4.3 \quad$ Interest Rate Policy $\ldots \ldots \ldots \ldots \ldots \ldots \ldots \ldots \ldots \ldots \ldots \ldots \ldots$

$4.3 .1 \quad$ Results. $\ldots \ldots \ldots \ldots \ldots \ldots \ldots \ldots \ldots \ldots \ldots \ldots \ldots \ldots \ldots, 84$

$4.4 \quad$ Profitability Regression $\ldots \ldots \ldots \ldots \ldots \ldots \ldots \ldots \ldots \ldots \ldots \ldots \ldots \ldots$

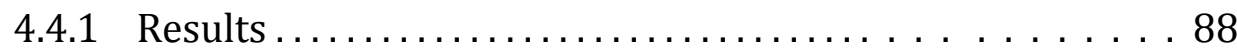

$4.5 \quad$ Efficiency and Productivity $\ldots \ldots \ldots \ldots \ldots \ldots \ldots \ldots \ldots \ldots \ldots \ldots$

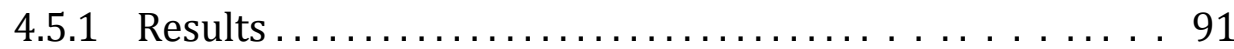

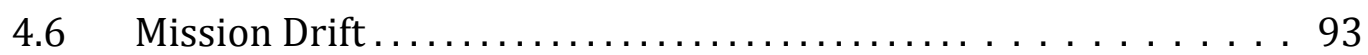

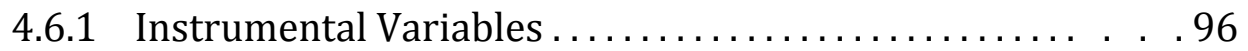

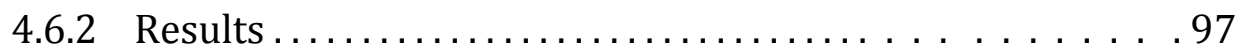

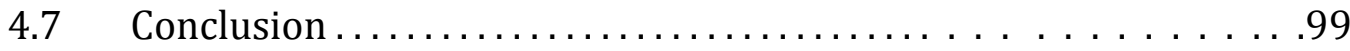

$\begin{array}{ll}\text { Appendix A } & 102\end{array}$

Appendix B 105

Appendix $C \quad 106$

Appendix D 123

$\begin{array}{ll}\text { Appendix E } & 126\end{array}$ 
Appendix $F$

128

Appendix $G$

129

Appendix $\mathrm{H}$

132

Appendix I

134

Appendix J

135

Appendix K

138

Appendix $L$

141

Appendix $M$

143

Bibliography

144 


\section{List of Tables}

2.1 Variable Description and Summary Statistics. . . . . . . . . . . . . 13

2.2 Categorical Variables. . . . . . . . . . . . . . . . . . . . . 14

2.3 Definition of Categorical Variables. . . . . . . . . . . . . . . . . . . . 15

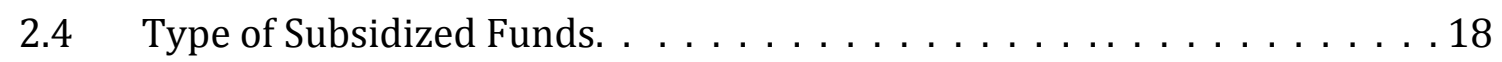

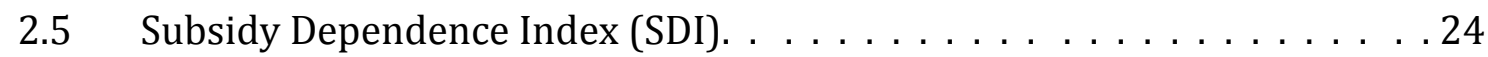

2.6 Subsidy Free MFIs in 2006. . . . . . . . . . . . . . . . . . . . 26

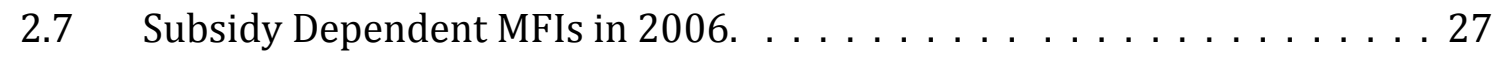

2.8 Opportunity cost of public debt comparison (No. of MFIs. . . . . . . . . 28

2.9 Correlations. . . . . . . . . . . . . . . . . . . 28

3.1 Subsidy Dependence Index (SDI). . . . . . . . . . . . . . . . . 41

3.2 Variable Description and Summary Statistics. . . . . . . . . . . . . . 43

3.3 Categorical Variables . . . . . . . . . . . . . . . . . . . . 44

3.4 Correlation . . . . . . . . . . . . . . . . . . . . . 44

3.5 Inputs and Outputs in Efficiency Specifications. . . . . . . . . . . . 50

3.6 Efficiency Analysis 2005 (With and Without Subsidies) . . . . . . . . . . 55

3.7 Efficiency Analysis 2005 (Subsidies as an Input) . . . . . . . . . . . . . . 55

3.8 Efficiency Analysis 2005 (Subsidies as an Output) . . . . . . . . . . . 55

3.9 Efficiency Analysis 2006 (With and Without Subsidies) . . . . . . . . . . 56

3.10 Efficiency Analysis 2006 (Subsidies as an Input) . . . . . . . . . . . . . 57

3.11 Efficiency Analysis 2006 (Subsidies as an Output) . . . . . . . . . . . 57

3.12 Malmquist DEA indices for 2006. . . . . . . . . . . . . . . . . . . 58

3.13 Malmquist DEA indices for 2006 (with and without subsidy) . . . . . . . 59

3.14 Malmquist DEA indices for 2006 (subsidy as an input) . . . . . . . . . . 59

3.15 Malmquist DEA indices for 2006 (subsidy as an output) . . . . . . . . . 59

3.16 Tobit Regression Analysis 2005 . . . . . . . . . . . . . . . . . . 62

3.17 Tobit Regression Analysis 2006. . . . . . . . . . . . . . . . . . 65

3.18 Tobit Regression Panel Analysis (Random Effect) . . . . . . . . . . . . . 68

$4.1 \quad$ Variable Description and Summary Statistics. . . . . . . . . . . . . . . 78

4.2 Categorical Variables . . . . . . . . . . . . . . . . . . . . . 79

4.3 Subsidy Dependence Index (SDI) . . . . . . . . . . . . . . 81

$4.4 \quad$ Correlations. . . . . . . . . . . . . . . . . . . . . . 82

4.5 Interest Rate Policy Regressions. . . . . . . . . . . . . . . 86

4.6 Profitability Regressions. . . . . . . . . . . . . . . . . . . . . . . . . 89

4.7 Efficiency and Productivity Regressions . . . . . . . . . . . . . . . 92

4.8 Mission Drift . . . . . . . . . . . . . . . . . . . . . . 98 


\section{List of Figures}

2.1 Descriptive Analysis of the Data . . . . . . . . . . . . . 16

2.2 Compositions of Subsidy Dependence Index (SDI) . . . . . . . . . . . . . 29

2.3 Return on Equity (ROE) \& Subsidy Adjusted Return on Equity (SAROE). . 31

2.4 Return on Asset (ROA) \& Subsidy Adjusted Return on Asset (SAROA). . . 32

2.5 Actual Yield (AY) Vs Nominal Subsidy-free Yield (NSFY) . . . . . . . . . . 34

3.1 Composition of Efficiency Scores for Specification LR-ACE (vrs) . . . . . . 52

3.2 Composition of Efficiency Scores for Specification LR-ACE (crs) . . . . . . . 52

3.3 Composition of Efficiency Scores for Specification LR-ACE (scale) . . . . . 53

$4.1 \quad$ Descriptive Analysis of the Data . . . . . . . . . . . . . . 80

4.2 Composition of Avg. Loan Size/GNI per capita. . . . . . . . . . . . . . . . . . . . . . . . . . . . .

4.3 Composition of Women Borrowers. . . . . . . . . . . . . . . . . . 95 


\section{Chapter 1}

\section{Introduction and Overview}

Since the days in the early 1970s when Muhammad Yunus of Grameen Bank started giving credit to marginalized people to his acceptance of the Nobel peace prize for improving the lives of millions of people around the globe in 2008, microfinance has come a long way. With more than a billion dollars of outside investment pouring in each year, it might seem out of place to question the future of microfinance. Microfinance promises not only poverty reduction but also financial self-sustainability. The preservation of this dual commitment of microfinance institutions to both social and commercial goals of poverty reduction and profitability whilst ensuring their progressive integration into the financial market and phasing out of subsidies is an intense topic of debate. The sustainability stresses the importance of being able to cover the cost of lending money out of the income generated from the outstanding loan portfolio and to reduce these costs as much as possible. Among other things, this increased focus on financial self-sustainability and efficiency is due to a number of developments the microfinance business has been recently confronted with, such as the increasing competition among Microfinance Institutions (MFIs), the commercialization of microfinance (i.e. the interest of commercial banks and investors to finance MFIs), technological change that also has become available for, and implemented in microfinance, financial liberalization and regulation policies of the government. Not to mention the important debate over the controversial role 
of subsidies in the efficiency of microfinance. The MIX 2006 benchmark data set of 704 MFIs reveals that $41 \%$ are not financially self-sustainable; they rely on donor support to keep afloat (Mersland and Strøm, 2009). Hence a deeper understanding of the true costs associated with subsidization of microfinance to the society, the determinants of subsidies and its impact on the financial and social efficiency of microfinance are required in order to evaluate the role of subsidies in the performance of microfinance institutions. Based on the cross-country data, this dissertation aims to provide evidence on the fulfillment of the dual mission of microfinance of reaching to poor and financial sustainability amid subsidization. Towards this aim, it contributes three empirical essays, measuring the social cost of subsidization to society, incorporating its role in the efficiency and productivity of microfinance and its impact on the financial performance of microfinance.

Traditionally the performance of MFIs has been measured by following either the welfarist approach or the institutionalist approach (Bhatt and Tang, 2001; Woller and Woodworth, 2001). Described by Morduch (2000) as "Microfinance Schism", the former put emphasis on assessing the impact on the welfare of the poor while later argues for the assessment in terms of the institutional success in achieving self-sustainability and breadth of outreach. However, economists have long been wondering about the true social cost of subsidization of development finance institutions to the society (Gittinger, 1982) and Microfinance Institutions are no exceptions. Frameworks for the quantitative analysis of subsidized MFIs include Christen (1997), Rosenberg et al. (1997), Von Pischke (1996b), Holtmann and Mommartz (1996), Alfaro (1996), Christen et al. (1995), SEEP (1995), IADB (1994), Rosenberg (1994), Benjamin (1994), and Yaron (1992a and 1992b). Nevertheless, the debate has not yet been settled to its logical conclusions. The social welfare concept associated with MFIs along with the shift towards commercialization warrants that their performance on the basis of traditional financial ratios without unearthing their degree of subsidy dependence provides only a partial and often meaningless or misleading picture of the social cost of maintaining the MFIs.

The first essay of this dissertation adds to this debate by estimating the sustainability of MFIs using the Yaron's Subsidy Dependence Index (SDI) (Yaron, 
1992a and 1992b) which measures the social cost of subsidized MFIs to the society. Unlike traditional financial ratios of measuring sustainability, the subsidy dependence index has not spurred an intense debate among researchers since its inception in 1992 despite its tremendous importance in evaluation of the true social cost of subsidization of microfinance. There exist only a few studies based on measuring the subsidy dependence index (Hulme and Mosley, 1996; Schreiner, 1997; Yaron et. al., 1997; Khandker et. al., 1995; Schreiner and Yaron, 1999 and 2001; Congo, 2002). Nevertheless, it was when some researchers started questioning the role of subsidies in the performance of microfinance that the whole issue of subsidization of microfinance came to the front (see Morduch, 1999a, 1999b, 2000). The measurement of the social cost of Development financial Institutions matters because funds earmarked for development are scarce. Subsidies for DFIs are not problematic unless they could improve social welfare more somewhere else (Schreiner and Yaron, 1999). The existing studies on the SDI measurement are based on sample of one or maximum few microfinance institutions located in one country or a region. This essay has analyzed the issue on much broader scale by measuring SDI for 204 MFIs in 54 countries across the globe for two consecutive years. For the proponents of the Win-Win proposition i.e. microfinance reduces poverty and in the course of that becomes subsidy free or sustainable, the overall evidence is not a good one on the sustainability front. The results show that on average, the cost of subsidization of microfinance to the society exceeds that of benefits. This essay has also analyzed the composition of subsidization in microfinance notwithstanding their status, geographical location, lending methodology and other organizational variables. Which reveal that MFIs located in Africa and South Asia are more subsidy dependent on average than the rest of the regions while Latin American (LA) MFIs are far less subsidized. MFIs with status of "Bank" and "NGO" are more subsidy dependent on average than the others. Notwithstanding the lending methodology, MFIs with group (solidarity) lending methodology are more subsidy dependent while MFIs which lend to individuals are on average relatively less subsidy dependent. While MFIs providing other services i.e education and health etc. in addition to finacial serivices are on average more subsidy dependent. The essay also presents a comparative analysis 
between the conventional financial ratios and their subsidy-adjusted values, thus showing the inability of the former to take into account the true social cost to society of the subsidization in microfinance sector. The essay also highlights the sensitivity of the SDI to the choice of interest rate by incorporating the risk of premium as described by Benjamin (1994) in the opportunuity cost of capital.

In retrospect, the conventional financial ratios have primarily been used to measure the efficiency and productivity in microfinance literature. Whereas in traditional banking literature, assessment of financial performance of an institution by employing non-parametric techniques, i.e. Data Envelopment Analysis (DEA) etc. (Charnes et al., 1978) has been widely employed in recent times (Sherman and Gold, 1985; Athanassopoulos, 1997; Seiford and Zhu, 1999 and Camanho and Dyson, 2005, among others). Like the traditional banking institutions, microfinance institutions do care for profits and sustainability, and therefore, on the same lines, some researchers have successfully replicated those non-parametric techniques to analyze the efficiency of microfinance institutions (see for example, Gutierrez-Nieto et. al, 2007; Balkenhol, 2007b and Hermes et al. 2008 among others). However the non-parametric efficiency analysis of MFIs based on conventional production and intermediation model approach is hard to grasp when it comes to subsidized MFIs. As pointed out by Cull et al. (2007), the overall equation linking capital and labor inputs into profits and social change still proves difficult to master without subsidy incorporation.

Against this backdrop, the second essay of this dissertation aims to investigate the impact of subsidies on the efficiency of microfinance by incorporating its role in the non-parametric efficiency analysis of MFIs. Further it empirically investigates the impact of different organizational, structural, financial and social variable on the efficiency of microfinance both with and without subsidies. In the course of that, the essay attempts to find out some specific relationships in the presence of subsidy. The way subsidy has been calculated in the first essay i.e. social cost of subsidized MFIs, allows us to successfully enter the positive subsidies as an input and negative subsidies as an output into the DEA efficiency specifications on the premise that the former distort public wealth while 
the later creates it. A comparison of efficiency scores with and without subsidies for various specifications reveals important information. Generally, in most of the specifications, the average efficiency scores are improved albeit only marginally when subsidies enter into the DEA framework. Though, specifically, there exist numbers of MFIs which become $100 \%$ efficient once subsidies have been incorporated into the specifications as an input and output. Similarly there exist MFIs which were previously $100 \%$ efficient but become less efficient once subsidies have been removed.

The issue of how efficiency relates to various organizational and structural variables has been addressed by employing Tobit regression techniques for each year separately (2005 \& 2006) and also collectively as a panel data set, taking efficiency scores as a left hand side variable. Hudon and Traca (2008) have found evidence that subsidies have contributed in raising the efficiency in the majority of their institutions in the sample, though to an extent. Beyond which the efficiency decreases. However their subsidy intensity variable only takes into account the subsidies in the equity. This essay finds most of the relationships between efficiency and other variables in line with the theory. The more MFIs become subsidy dependent, the more they become inefficient. The trade-off between costs and efficiency is also confirmed by the regression equations. Also evident is the fact that staff productivity and operational self sufficiency contribute towards the efficiency. An important result derived is that lending to women borrowers contributes towards efficiency. The coefficient of outreach variable as measured by the loan size/GNI per capita comes out as positive. Hence depicts that the more MFI's focus shifts away from the poor i.e. lending to well-off clients who can afford bigger loan sizes, the more it becomes efficient thus confirming the fact that lending to poor is relatively inefficient compared to well off clients.

The regression analyses have been further broken down into with and without subsidy equation. Important evidence obtained is that lending to women contributes to the financial efficiency in the presence of subsidies only, as the impact becomes insignificant without subsidies. This shows that MFIs exclusively targeting women tend to be financially efficient only because of the subsidies they 
receive. Panel data results also confirm this relationship. Geographically MFIs located in South Asia and Middle East \& North Africa and those having group lending methodology are found to be inefficient while those with individual lending methodology are efficient. MFIs with cooperative and Rural Bank status are less efficient while those having non-banking financial intermediary (NBFI) status are found to be efficient. Moreover MFIs with saving features tend to be less efficient while those providing other services in addition to financial services are efficient.

The first two essays in this dissertation focus on the subsidization of microfinance and its role in the financial efficiency and productivity of microfinance, where efficiency is defined in the context of non-parametric DEA paradigm. However, in microfinance sustainability literature, a number of interesting debates regarding some relationships and phenomenon are yet to reach to the logical conclusions. For example the determinants of the profitability of microfinance in general and its interest rate policy in particular, are an important area of research. Not to mention the determinants of the cost efficiency and productivity of MFIs. Last but not the least, an investigation into the "Mission drift" phenomenon, a tradeoff between outreach to the poor and profitability, is another topic of heated debate among researchers. The third and the last essay of this dissertation is an attempt to add to these debates by empirically investigating them using a high quality cross-country panel data set.

The role of interest rates in determining the sustainability of microfinance institution cannot be under-estimated. This formation of interest rate policy mainly depends on the financial performance and social objectives of an MFI. Consequently, the impact of financial and social efficiency of microfinance in shaping the interest rate policy, which ultimately has an effect on the sustainability of MFI, is a very interesting topic of research, as pointed out by Hudon and Traca, 2008. In addition to that, Armendariz and Szafarz (2009) call for integrating interest rates as a determinant of the sustainability while controlling for market structure is a step in the right direction, from an empirical standpoint. The third essay investigates the role of financial and social efficiency in determining the 
interest rate policy of microfinance institutions which directly affects the sustainability. Moreover, the inclusion of social efficiency variables, i.e. loan size and women borrowers into the equation also lend support to the existence of mission drift in microfinance.

Investigation into the determinants of the profitability of microfinance is also an interesting research avenue in microfinance. Conventionally, profitability is defined in term of traditional financial ratio i.e. operational self-sufficiency and Return of Assets etc. The third essay goes beyond and takes also the Subsidy dependence Index (SDI) as a measure of profitability. Some MFIs charge their clients exorbitant interest rates. Lewis (2008) calls them Microloan Sharks involved in not micro-lending but microloan-sharking. Cull et al. (2007) found evidence that raising interest rates resulted in increased profitability for individual based lending MFIs whereas for Group based lenders, the reverse is true. This essay finds evidence that raising the interest rates lead to improved financial performance and profitability with lower subsidy dependence and higher operational self-sufficiency. Whereas rising costs are associated with lower profitability. An important result is that clients with smaller loan sizes (MFIs with predominantly women borrowers) pay higher interest rates relatively to the clients with large loans because increase in transaction costs induces MFIs to raise interest rates.

The last essay also addresses the implications of subsidization on the cost efficiency and staff productivity of MFIs (Barrès Isabelle, 2007; Hudon and Traca 2008). The empirical evidence shows the inefficiency of subsidized MFIs due to higher costs associated with larger loan sizes. Which suggest that subsidized MFIs are obliged to hire qualified staff, offer better and innovative products to the relatively well off clients which resulted in higher administrative cost.

Moreover, an empirical investigation of the validity of mission drift phenomena has also been presented in the last essay. Mission Drift is a concern for socially driven MFIs, where the pressure to achieve financial sustainability and profitability forces many institutions to drift away from their initial mission and to work with less needy people (See Dichter \& Harper, 2007; Woodworth et al., 1999 
and Woller, 2002 among others etc.). Nevertheless, some studies found no evidence of Mission Drift (Rhyne, 1998; Christen, R. p., 2001; Christen and Drake, 2002; Hishigsuren, G., 2007; Cull et al., 2007 and more recently Mersland and Strom, 2009). Even after correcting for possible endogeneity, the empirical evidence in this thesis does lend some support to the mission drift phenomena in microfinance. Our results confirm that investors are inclined to direct funds to those MFIs which cater to relatively well-off clients with a lower percentage of women borrowers.

The three empirical essays in this dissertation add to the general debate about the efficiency and sustainability issues in microfinance with particular emphasis on the role of subsidies. To start with, the first essay of this dissertation assesses the state of sustainability in microfinance by measuring the cost of subsidization in microfinance to the society. Moreover, the second essay investigates the role of subsidies in the efficiency and productivity of microfinance in the non-parametric efficiency analysis framework. Finally the third essay provides empirical evidence about the determinants of profitability and interest rate policy of microfinance. Moreover it also investigates the validity of mission drift phenomena in microfinance. 


\title{
Chapter 2
}

\section{Subsidization of Microfinance}

\begin{abstract}
Unlike conventional finance institutions, Microfinance institutions (MFIs) strive for financial sustainability but also empowerment of the poor. This social nature of MFIs is mainly financed by subsidies from donors. This paper measures the extent of subsidization in MF sector for the years 2005 and 2006 using Yaron's Subsidy Dependence Index (SDI) which measures the social cost of subsidized MFIs in a short time frame. This latest data set has been generated from the audit reports of the 204 MFIs with 23 million borrowers in 54 Countries worldwide constituting a significant part of the microfinance outreach worldwide. Based on our subsidy calculations, for the year 2005, 153 MFIs out of 204 are subsidy dependent while for year 2006 it is 122 out of 179 MFIs. A with \& with-out subsidy analysis of conventional financial ratios confirm the fact that MFIs financial performance declines substantially without subsidies.
\end{abstract}

\subsection{Introduction}

Microfinance promises poverty reduction without subsidization. After four decades into the business this promise is yet to be fulfilled as the role of subsidies still persists despite recent surge for commercialization of microfinance ${ }^{1}$. This

\footnotetext{
${ }^{1}$ See for example, Armendáriz de Aghion and Jonathan Morduch(2004, 2005); Morduch (1999a); Morduch (1999b); Goodman (2005); Cull et al. (2007)
} 
social welfare concept associated with Microfinance Institutions (MFIs) along with the shift towards commercialization warrants that their performance on the basis of traditional financial ratios without unearthing their degree of subsidy dependence provides only a partial and often meaningless or misleading picture of the social cost of maintaining the MFIs (Yaron, 2004). Traditionally the performance of MFIs has been measured using either the welfarist or the institutionalist approach. The former put emphasis on assessing the impact on the welfare of the poor while later argues for the assessment in terms of the institution's success in achieving self-sustainability and breadth of outreach (Morduch, 2000). Basically, the institutionalist approach employs two measurements of success: outreach and sustainability. There is neither an agreed upon nor a widespread definition of a well-performing MFI. The performance criteria and indicators used vary significantly from one author to another or from one organization to another, since they depend on the methodological approach, which, in turn, depends on the determination to give priority to the supply side or to the demand side of the financial intermediation. This essay adopts an approach based on both performance criteria introduced by Yaron (1992b, 1997) and those proposed by CGAP (1996). These authors suggest two key criteria to evaluate the performance of MFIs: outreach and sustainability. Sustainability requires MFIs to have a positive return on equity (net of any subsidy received) while covering all transaction costs (loan losses, financial costs, administrative costs, etc.), and consequently to function without subsidies. The level of sustainability is measured through financial indicators such as the Subsidy Dependency Index (SDI), suggested by Yaron (1992a, 1997) or other more common measures such as the return on equity (ROE) or the return on assets (ROA). However the figures on the MFIs Profit and loss statements are questionable as most of the subsidy does not make it into the balance sheets of respective MFIs. Even if it does, the MFIs tend to under estimate the subsidy figures to make their accounts look more acceptable. Contrarily to the welfarist approach, subsidies adjustments are necessary under this approach, and they have to be reduced to a minimum level when an MFI is looking for sustainability (Rhyne, 1994). Notwithstanding these shortcomings, this paper calculates the sustainability of MFIs using the Yaron's Subsidy Dependence 
Index (SDI) which measures the social cost of subsidized MFIs. The measurement of the social cost of Development financial Institutions matters because funds earmarked for development are scarce. Subsidies for DFIs are not problematic unless they could improve social welfare more somewhere else (Schreiner and Yaron, 1999). This quality financial information has been generated directly from the audit reports ${ }^{2}$ of the 204 MFIs with 23 million borrowers in 54 Countries worldwide for years 2005 and 2006. This constitutes a significant part of the microfinance outreach worldwide.

For the proponents of the Win-Win proposition i.e. microfinance reduces poverty and in the course of that becomes subsidy free or sustainable, the overall evidence is not a good one on the sustainability front. Based on our SDI calculations for the year 2005, 153 MFIs out of 204 are subsidy dependent while for year 2006 it is 122 out of 179 MFIs. Further summary statics reveal that MFIs located in Africa and South Asia are more subsidy dependent on average than the rest of the regions while Latin American (LA) MFIs are far less subsidized. MFIs with status of "Bank" and "NGO" are more subsidy dependent on average than the others. Notwithstanding the lending methodology, MFIs with group (solidarity) lending methodology are more subsidy dependent while MFIs which lend to individuals are on average relatively less subsidy dependent. While MFIs providing other services i.e education and health etc. in addition to finacial serivices are on average more subsidy dependent. The study also shows the inability of conventional financial ratios i.e. ROA and ROE to take into account the true social cost to society of the subsidization in microfinance sector.

The paper is organized as follows. In the next section, a description of data and theoretical framework of calculating SDI is presented followed by the overall description of subsidy dependence of microfinance sector. Then a comparison between conventional nominal and subsidy-adjusted financial ratios is being presented. A conclusion is given at the end.

\footnotetext{
${ }^{2}$ The audit reports have been taken from the Mix Market Website (hhp://www.mixmarket.org). The MIX MARKET is a global, webbased microfinance information platform. It provides information to sector actors and the public at large on Microfinance Institutions (MFIs) worldwide, public and private funds that invest in microfinance, MFI networks, raters/external evaluators, advisory firms, and governmental and regulatory agencies
} 


\subsection{Data and Theoretical Framework}

\subsubsection{Description of the Data}

Table 2.1 gives an overview of variables used in the study along with summary statistics. It is summed up into two categories i.e. variables used in calculating SDI and variables depicting financial ratios. The definitions of the variables are also given as described by the Mixmarket website ${ }^{3}$ and CGAP, 2005. Through this information exchange platform individual MFI can provide financial and outreach data and the Mixmarket ranks these data for quality using a 5-star system, where 5 is the most complete data available, while 1 is the least complete data available (usually the number of borrowers and some other outreach indicators but little financial information). After carefully reviewing the Audit Reports of more than 300 5-star MFIs taken from the Mixmarket website, 204 MFIs in 54 countries have been chosen based on the clarity of their respective Audit Reports in general and subsidy figures in particular. The most important variable to extract from the audit reports for subsidy calculations is the public debt/concessional borrowing. Therefore MFIs have been selected in large part on the quality and clarity of public debt figures in their respective audit reports. All the MFIs adhere to the International Accounting Standards (IAS) in compilation of their respective audit reports. The subsidy figures for the 25 MFIs for the year 2006 are missing due to the unavailability of the data. Therefore, the sample in Table 2.1 consists of 383 observations (204 for the year 2005 plus 179 for the year 2006). The summary statistics reveal some important information. The average interest rate paid by the MFIs to acquire loanable funds is $7.4 \%$. Whereas, the average interest rate they charge by lending to the borrowers is $30.3 \%$. Further, the average value of 0.214 for SDI suggests that overall the average interest rate from lending to the borrowers has to be increased by $21.4 \%$ to make the microfinance sector subsidy-free.

\footnotetext{
${ }^{3}$ http://www.mixmarket.org/en/glossary
} 
Table 2.1

Variable Description and Summary Statistics

\begin{tabular}{|c|c|c|c|c|c|c|c|}
\hline $\begin{array}{c}\text { Variable used in } \\
\text { subsidy calculations }\end{array}$ & Obs & Definition & unit & Mean & Median & Min & $\operatorname{Max}$ \\
\hline $\begin{array}{l}\text { Average annual assets } \\
\qquad(A)\end{array}$ & 383 & $\begin{array}{l}\text { Average of current year }(t) \text { and previous year } \\
(t-1) \text { assets. It includes all asset accounts net of } \\
\text { all contra-asset accounts, such as the loan-loss } \\
\text { allowance and accumulated depreciation. }\end{array}$ & $\$$ & 37000 & 12000 & 323 & 521000 \\
\hline $\begin{array}{l}\text { Average annual equity } \\
(E)\end{array}$ & 383 & $\begin{array}{l}\text { Average of current }(t) \text { and previous year }(t-1) \\
\text { equity. Total assets less total liabilities. }\end{array}$ & $\$$ & 8229 & 3900 & $-1400^{4}$ & 180000 \\
\hline Subsidised equity & 383 & $\begin{array}{l}\text { Average equity }(E) \times 0 \text { pportunity cost of capital } \\
(\mathrm{m})\end{array}$ & $\$$ & 1249 & 531 & -140 & 27600 \\
\hline Average public debt $(A)$ & 383 & $\begin{array}{l}\text { Average annual outstanding concessionary- } \\
\text { borrowed funds }\end{array}$ & $\$$ & 10600 & 3300 & 0 & 100000 \\
\hline Interest cost on debt & 383 & $\begin{array}{l}\text { Actual interest rate }(\mathrm{c}) \times \text { Average public debt } \\
(A)\end{array}$ & $\$$ & 779 & 267 & 0 & 8629 \\
\hline Actual interest rate(c) & 383 & $\begin{array}{l}\text { interest cost paid on concessionary borrowed } \\
\text { funds/ Average public debt }(A)\end{array}$ & $\%$ & 7.4 & 7.2 & 0 & 32.1 \\
\hline $\begin{array}{l}\text { Opportunity cost of } \\
\text { capital }(m)\end{array}$ & 383 & $\begin{array}{l}\text { Market lending rate } 5 \text {. Lending rate is the bank } \\
\text { rate that usually meets the short and medium } \\
\text { term financing needs of the private sector. This } \\
\text { rate is normally differentiated according to the } \\
\text { creditworthiness of borrowers and objectives } \\
\text { of financing. }\end{array}$ & $\%$ & 15.0 & 12.9 & 7.0 & 67.7 \\
\hline Discount o & 383 & $A \times(m-c)$ & $\$$ & 709 & 155 & \begin{tabular}{|l|}
-1044 \\
\end{tabular} & 13900 \\
\hline Revenue grants & 383 & $\begin{array}{l}\text { Cash gifts except for the accounting choice to } \\
\text { record them as revenues rather than as direct } \\
\text { injection to equity. }\end{array}$ & $\$$ & 526 & 1.144 & 0 & 79800 \\
\hline $\mathrm{K}$ & 383 & $\begin{array}{l}\begin{array}{l}\text { Sum of revenue grants and discount on } \\
\text { expenses }\end{array} \\
\end{array}$ & $\$$ & 526 & 1.144 & 0 & 79800 \\
\hline Accounting profit & 383 & $\begin{array}{l}\text { Total revenue less total expenses, operating } \\
\text { and non-operating, Including all donations and } \\
\text { taxes, if any }\end{array}$ & $\$$ & 1793 & 510 & -5643 & 41300 \\
\hline Tax & 383 & $\begin{array}{l}\text { Includes all taxes paid on net income or other } \\
\text { measure of profits as defined by local tax } \\
\text { authorities. This item may also include any } \\
\text { revenue tax. }\end{array}$ & $\$$ & 282 & 0.403 & -158 & 7078 \\
\hline Profit net of $\operatorname{tax}(P)$ & 383 & Accounting Profit - Taxes & $\$$ & 1510 & 461 & -5899 & 41300 \\
\hline Subsidy $(S)$ & \begin{tabular}{|l|}
383 \\
\end{tabular} & {$[E \times m+A(m-c)+K-P]$} & $\$$ & 967 & 220 & -18100 & 76900 \\
\hline Average loan portfolio & 383 & Average annual outstanding loan portfolio & $\$$ & 89100 & 8411 & 48 & $\begin{array}{c}2410000 \\
0\end{array}$ \\
\hline $\begin{array}{l}\text { Revenues from loan } \\
\text { portfolio }\end{array}$ & 383 & $\begin{array}{l}\text { Revenue from interest earned, fees, and } \\
\text { commissions (including late fees and } \\
\text { penalties) on the gross loan portfolio only. }\end{array}$ & $\$$ & 27700 & 2401 & 0 & 8040000 \\
\hline
\end{tabular}

\footnotetext{
${ }^{4}$ Negative equity value for the MFI Kando Jagima of Mali.

5 Market lending interest rate has been taken from the International Financial Statistics, IMF for the years 2005 and 2006

${ }^{6}$ For the sake of simplicity, the discount on expenses is assumed to be zero.
} 


\begin{tabular}{|c|c|c|c|c|c|c|c|}
\hline Intrest rate/Yield & 383 & $\begin{array}{l}\text { Average on lending interest rate/yield on } \\
\text { lending }\end{array}$ & $\%$ & 30.3 & 26.7 & 0.02 & 128.1 \\
\hline $\begin{array}{l}\text { Subsidy dependence } \\
\text { index }(S D I)\end{array}$ & 383 & Subsidy $(S) /$ Revenue from lending $(R)$ & & 0.214 & 0.122 & -1.914 & $4.568^{7}$ \\
\hline \multicolumn{8}{|l|}{ Financial Ratios } \\
\hline change in yield ${ }^{8}$ & 383 & SDI× (actual yield from lending) & $\%$ & 6.9 & 2.8 & -76.6 & 171.5 \\
\hline $\begin{array}{l}\text { Nominal subsidy free } \\
\text { yield }\end{array}$ & 383 & Change in yield + actual yield on lending & $\%$ & 37.2 & 30.8 & -39.6 & 253.3 \\
\hline Inflation ${ }^{9}$ & 383 & $\begin{array}{l}\text { Indices shown for consumer prices are the } \\
\text { most frequently used indicators of inflation } \\
\text { and reflect changes in the cost of acquiring a } \\
\text { fixed basket of goods and services by the } \\
\text { average consumer }\end{array}$ & $\%$ & 6.65 & 6.24 & 0.64 & 24.03 \\
\hline Real subsidy free yield & 383 & $\begin{array}{l}\text { (Nominal subsidy free yield- } \\
\text { inflation }) /(1+\text { inflation })\end{array}$ & $\%$ & 30.9 & 25.1 & -33.7 & 229.6 \\
\hline True profit & 383 & Accounting profit- Profit grants & $\$$ & 282 & 112 & -50300 & 38500 \\
\hline Return on assets $(R O A)$ & 383 & $\begin{array}{l}\text { (Net operating income less Taxes)/ Period } \\
\text { average assets }\end{array}$ & $\%$ & 5.23 & 4.4 & -68.5 & 61.6 \\
\hline $\begin{array}{l}\text { Subsidy adjusted ROA } \\
\text { (SAROA) }\end{array}$ & 383 & True profit/ Period average assets & $\%$ & 0.64 & 1.20 & -95.1 & 52.1 \\
\hline Return on equity $(R O E)$ & 383 & $\begin{array}{l}\text { (Net operating income, less taxes)/ Period } \\
\text { average equity }\end{array}$ & $\%$ & 14.56 & 16.94 & -1723 & 853.5 \\
\hline $\begin{array}{l}\text { Subsidy adjusted ROE } \\
(\text { SAROE })\end{array}$ & 383 & True profit/ Period average equity & $\%$ & -3.32 & 05.87 & -1763.9 & 1468.3 \\
\hline $\begin{array}{l}\text { Operational self } \\
\text { sufficiency }(O S S)\end{array}$ & 383 & $\begin{array}{l}\text { Financial revenue }(\text { Total)/ (Financial expense } \\
\text { + Loan loss provision expense + Operating } \\
\text { expense) }\end{array}$ & $\%$ & 123.4 & 120.7 & 3.57 & 254.9 \\
\hline
\end{tabular}

Source: Author's own calculation based on the Audit Reports of MFIs taken from Microfinance Information eXange Inc website. All the values in USD are in '000s'. Exchange rates are also taken from Mixmarket website. Some definitions are taken from CGAP (2003)

The Dummy variables along with their categories used in this study have been presented in Table 2.2. The categories are based on the Mixmarket classification. Further, Table 2.3 highlights the definitions of their respective categories.

Table 2.2

Categorical Variables

\begin{tabular}{|c|l|}
\hline Variables & \multicolumn{1}{c|}{ Description } \\
\hline Region & $\begin{array}{l}\text { Geographic region in which the MFI operates classified into 6 } \\
\text { regions: Africa }(A) ; \text { East Asia and the Pacific }(E A \& P) ; \text { Eastern Europe } \\
\text { and Central Asia }(E E \& C A) ; \text { Middle East and North Africa }(M E N A) ;\end{array}$ \\
\hline
\end{tabular}

\footnotetext{
7 The maximum value of SDI is 4.568 for MFI "PADME" of Benin.

8 The actual yield after accounted for the SDI.

${ }^{9}$ taken from the World bank's World Development Indicators (WDI), 2005 \& 2006
} 


\begin{tabular}{|c|c|}
\hline & Latin America and the Caribbean $(L A C)$; South Asia $(S A)$. \\
\hline Lending Methodology & $\begin{array}{l}\text { Lending methodology is classified into } 4 \text { categories: Individual }(I) \text {; } \\
\text { Individual \& Solidarity/Group }(I S) \text {; Group/Solidarity }(S) \text {; Village } \\
\text { banking }(V) \text {. }\end{array}$ \\
\hline Status & $\begin{array}{l}\text { Classified into } 5 \text { categories: Nongovernmental organizations }(N G O) \text {; } \\
\text { Bank }(B) \text {; Non-banking financial intermediaries (NBFI); Rural Bank } \\
(R B) \text {; Cooperatives (Coop.). }\end{array}$ \\
\hline Other services & $\begin{array}{l}\text { Whether MFI provides other services i.e. health, education etc in } \\
\text { addition to providing financial services or not. }\end{array}$ \\
\hline Saving & Whether saving (voluntary or Compulsory) is a feature of MFI or not. \\
\hline Regulated & Whether MFI is regulated by some authority like central bank etc. or not. \\
\hline
\end{tabular}

Table 2.3

Definitions of Categorical variables

\begin{tabular}{|c|c|}
\hline Lending Methodology & \\
\hline Individual $(I)$ & MFIs which give loans to individual borrowers. \\
\hline Solidarity or Group $(S)$ & MFIs which give loans to group of borrowers collectively. \\
\hline $\begin{array}{l}\text { Individual \& Group } \\
\text { both }(I S)\end{array}$ & $\begin{array}{l}\text { MFIs which give loans to both individual borrowers and Group of } \\
\text { borrowers. }\end{array}$ \\
\hline Village Banking $(V)$ & $\begin{array}{l}\text { Village Banking methodology, developed by FINCA International, provides } \\
\text { loan to informal self-help support group of 20-30 members, } \\
\text { predominantly female heads-of-household. }\end{array}$ \\
\hline \multicolumn{2}{|l|}{ Status of an MFI } \\
\hline $\begin{array}{l}\text { Non Governmental } \\
\text { Organisation }(N G O)\end{array}$ & $\begin{array}{l}\text { An organization registered as a non profit for tax purposes or some other } \\
\text { legal charter. Its financial services are usually more restricted, usually not } \\
\text { including deposit taking. These institutions are typically not regulated by a } \\
\text { banking supervisory agency. }\end{array}$ \\
\hline Bank $(B)$ & $\begin{array}{l}\text { A licensed financial intermediary regulated by a state banking supervisory } \\
\text { agency. It may provide any of a number of financial services, including: } \\
\text { deposit taking, lending, payment services, and money transfers. }\end{array}$ \\
\hline $\begin{array}{l}\text { Non-Banking Financial } \\
\text { Intermediaries }(N B F I)\end{array}$ & $\begin{array}{l}\text { An institution that provides similar services to those of a Bank, but is } \\
\text { licensed under a separate category. The separate license may be due to } \\
\text { lower capital requirements, to limitations on financial service offerings, or } \\
\text { to supervision under a different state agency. In some countries this } \\
\text { corresponds to a special category created for microfinance institutions. }\end{array}$ \\
\hline Rural Bank $(R B)$ & $\begin{array}{l}\text { Banking institution that targets clients who live and work in non-urban } \\
\text { areas and who are generally involved in agricultural-related activities. }\end{array}$ \\
\hline Cooperative (Coop.) & $\begin{array}{l}\text { A non profit, member-based financial intermediary. It may offer a range of } \\
\text { financial services, including lending and deposit taking, for the benefit of } \\
\text { its members. While not regulated by a state banking supervisory agency, it } \\
\text { may come under the supervision of regional or national cooperative } \\
\text { council. }\end{array}$ \\
\hline Regulated $(R)$ & Regulations on MFI can be in the form of entry restriction and /or some \\
\hline
\end{tabular}




\begin{tabular}{|l|l|}
\hline \multirow{5}{*}{$\begin{array}{l}\text { prudential supervision by some authority. Mostly regulated MFIs are } \\
\text { allowed to collect deposits and increase their loanable funds (Campion } \\
\text { and White, 1999). In most countries, typical banking regulations do not } \\
\text { cover microfinance activities. Currently, MFIs can operate as regulated or } \\
\text { nonregulated or, in some countries, can choose between being regulated } \\
\text { and being unregulated. Overall, MFIs can be subject to either mandatory } \\
\text { entry regulation, prudential regulation, or some sort of entry regulation } \\
\text { and consequent monitoring (tiered regulation) (hartarska and Nadolnyak, } \\
\text { 2007). }\end{array}$} \\
\hline Saving & $\begin{array}{l}\text { MFIs which collect savings (deposits). The data does not distinguish } \\
\text { between compulsory savings and voluntary savings. }\end{array}$ \\
\hline Other Services & $\begin{array}{l}\text { MFIs which provide other services in addition to loans i.e. related to } \\
\text { training, enterprise development, health, education, environment, } \\
\text { agriculture etc. }\end{array}$ \\
\hline
\end{tabular}

Source: Mixmarket Website

Figure 2.1 depicts graphical display of the nature of the data used in this study. NGOs (46\%) dominate the microfinance sector followed by the NBFIs (29\%). MFIs with "Bank" status constitute only 16.29\% of total sample. Almost half

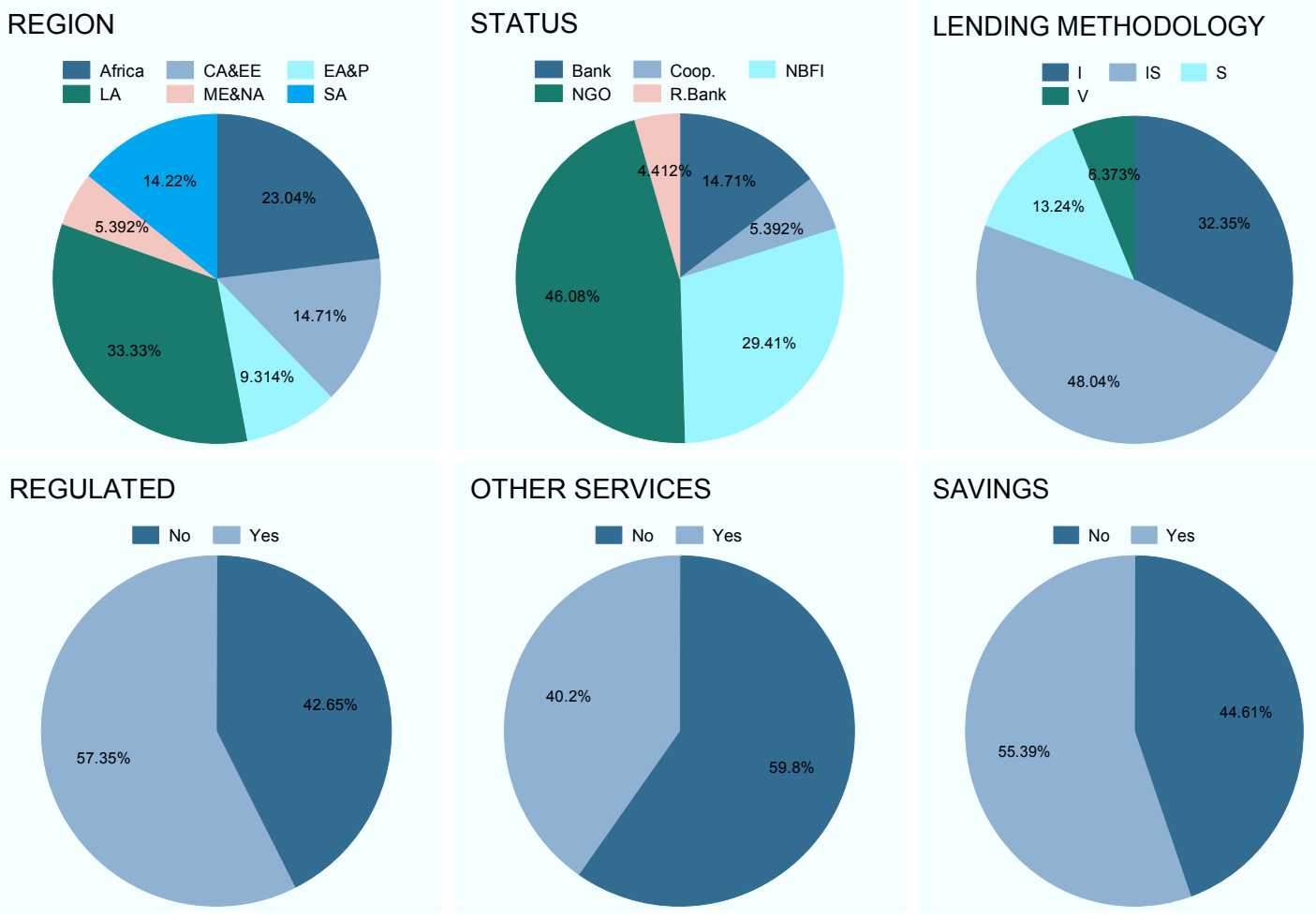

Figure 2.1 Descriptive analysis of Data

Source: Information taken from the mix market website based on the sample of 204 MFIs

*Individual (I); Individual \& Solidarity (IS); Solidarity (S); Village Banking (V) 
of the MFIs (48\%) offer both group and individual lending services followed by MFIs which lend exclusively to the individuals (32\%). Geographically one-third of MFIs locate in Latin America (33\%) and almost one-fourth in Africa (23\%). South Asian MFIs constitute only about 14\% of the total MFIs in the sample. Majority of the MFIs in the sample are regulated (57\%) and provide deposits/savings services (55\%) to the clients. About $40 \%$ of the MFIs in the sample provide other services to the clients in addition to providing financial services. A complete list of the names of the 204 microfinance institutions in the sample is given at the end in

\section{Appendix A.}

\subsubsection{The SDI Formula}

This paper calculates subsidies using Yaron's Subsidy Dependence Index ${ }^{10}$ (SDI) (Yaron, 1992a and 1992b) which measures the social cost of subsidized MFIs. The SDI is a summary measure of sustainability. It is the ratio of subsidy received by a MFI to revenue from loans to the target group; it indicates whether a MFI could compensate society for the opportunity cost of public funds used in a short time frame and still show a profit.

The Formula for SDI is:

$$
S D I=\frac{\text { Subsdies }}{\text { Revenues from lending }}=\frac{[E \times m+A(m-c)+K-P]}{(L P \times i)}
$$

Where:

$$
\begin{aligned}
& E=\text { average annual equity; } \\
& m=\text { Market Interest rate/Interest rate the MFI is assumed to pay for } \\
& \text { borrowed funds if access to concessional borrowed funds were eliminated. } \\
& A=\text { Average annual outstanding concessionary-borrowed funds / Average } \\
& \text { public debt } \\
& C=\text { interest rate paid on concessionary borrowed funds / Public debt } \\
& P=\text { Reported annual profit / accounting profits }
\end{aligned}
$$

\footnotetext{
${ }^{10}$ To examine SDI calculations in past studies see for example Hulme and Mosley(1996); Schreiner (1997); Schreiner and Yaron (1999 and 2001); Jehangir (2005); Sharma (204); Congo (2002)
} 
$K=$ Other Subsidies i.e. Revenue Grant $(R G)+$ Discount on Expenses $(D X)$

$L P=$ Average annual outstanding loan portfolio of the MFI

$i=$ lending interest rate / yield on lending

The SDI has a lower bound of -100 percent but no upper bound (Benjamin 1994). An SDI of zero means that an MFI has achieved full self-sustainability. An SDI of 100 percent indicates that a doubling of the prevailing average on-lending interest rate would be required to eliminate subsidies. A negative SDI indicates that an RFI has achieved full self-sustainability and that its annual profits exceeded the total annual value of any subsidies received by the MFI. Such an MFI could lower its average on-lending interest rate, eliminate all subsidies and remain selfsustainable.

In the above SDI formula, worth mentioning is what constitute subsidies and the choice of opportunity cost of MFIs concessional borrowings or the choice of Market interest rate.

\subsubsection{What Constitute Subsidies ${ }^{11 ?}$}

These are subsidized/public funds from government or donors and come in six forms as shown in Table 2.4 below.

Table 2.4

Type of Subsidized Funds

\begin{tabular}{|l|c|c|}
\hline \multicolumn{1}{|c|}{ TYPE } & Notation & Type of grant \\
\hline 1. Direct Grant & $D G$ & \multirow{2}{*}{ Equity Grant $(E G)$} \\
\hline 2. Paid-up-capital & $P C$ & \multirow{2}{*}{ Profit Grant (PG) } \\
\hline 3. Revenue Grant & $R G$ & \\
\hline 4. Discount on Public Debt & $A \cdot(m-c)$ & Equity Grant $(E G)$ \\
\hline 5. Discount on Expenses & $D X$ & \\
\hline 6. True Profit & $T P$ & \\
\hline
\end{tabular}

Source: Schreiner and Yaron (1999)

\footnotetext{
${ }^{11}$ This section is primarily based on Schreiner and Yaron (1999)
} 
Three are equity grants that increase net worth but do not directly change the accounting profit reported in the year received. The other three are profit grants that do directly increase the accounting profit reported in the year received since they inflate revenues and/or deflate expenses. This increases retained earnings at year-end and thus increases net worth. Compared with the case without the grant, all six forms of subsidized funds increase net worth one-for-one. All six forms have the same social opportunity cost. As in Yaron (1992b), the dividends and taxes on profits are ignored for simplicity.

\subsubsection{Equity grants}

The first two forms of subsidized funds are equity grants $E G$. These cash gifts increase net worth but do not change accounting profit directly. Equity grants are the sum of direct grants $D G$ and paid-in capital $P C$ :

$$
\begin{gathered}
\text { Equity grants }=\text { Direct grants }+ \text { Paid in capital, } \\
E G=D G+P C
\end{gathered}
$$

Direct grants $D G$ are cash gifts. Direct grants increase net worth, but they do not pass through the income statement, and hence they do not inflate accounting profit. Direct grants include both gifts in cash and gifts in kind such as computers or trucks that are recorded in the accounts.

Paid-in capital $P C$ comes from sales of shares to donors or government. Such a sale is like a direct grant since public funds pay for the shares. Furthermore, most public entities do not act like private owners. We assume that all paid-in capital comes from public sources.

\subsubsection{Profit grants}

Profit grants $P G$ are the third through fifth forms of subsidized funds (Table). Like all equity grants, all forms of profit grants increase net worth since they inflate accounting profit or reduce accounting loss and wind up in net worth through retained earnings at the end of the year. Profit grants distort accounting profit $P$ and thus ROE since they depend on the arbitrary choices made in practice by administrators and accountants. Donors can and often do use profit grants to 
nudge accounting profit higher. In contrast, the SDI recognizes the economic fact that a dollar treated as a profit grant has the same effect on the business performance of a DFI as a dollar treated as an equity grant.

Profit grants are the sum of revenue grants $R G$, discounts on public debt $A$. $(m-c)$, and discounts on expenses $D X$ :

$$
\begin{aligned}
& \text { Profit grants }=\text { Rev. grants }+ \text { Discount public debt }+ \text { Discount on expenses } \\
& \qquad P G=R G+A(m-c)+D X .
\end{aligned}
$$

Revenue grants $R G$ are cash gifts. They are just like equity grants except for the accounting choice to record them as revenue rather than as direct injections to equity. Revenue grants increase net worth, but only after they pass through the income statement and increase reported accounting profit. This is misleading since revenue grants are not the product of business operations.

Discounts on public debt $A \times(m-c)$ and discounts on expenses $D X$ are the fourth and fifth forms of subsidized funds. They are non-cash gifts, expenses paid on behalf of the development finance institution (DFI) by someone else. Discounts increase the cash held by the DFI since they decrease the cash spent by the DFI.

The discount on public debt $A \times(m-c)$ is the opportunity cost of public debt less what the DFI paid, where $A$ is average public debt, $c$ is the rate paid by the DFI, and $m$ is the opportunity cost of public debt for society:

Discount public debt $=$ Average public debt (Opp. Cost of public debt - Rate paid)

$$
=A \times(m-c)
$$

Discounts on public debt are subsidized funds that inflate profit and boost net worth since they cut expenses. Public debt is like private debt linked to a grant of $A \times(m-c)$ (Inter-American Development Bank, 1994). Unlike the discount on public debt $A \times(m-c)$, public debt $(A)$ itself does not increase net worth directly.

Discounts on expenses $D X$ are costs absorbed by government or donors that the DFI does not record as expenses. Classic examples are technical assistance, free deposit insurance, coverage of organization costs or feasibility studies, debt 
guarantees, consultant services, classes for loan officers, and travel for employees. This paper assumes $D X$ to be zero in all cases as MFIs do not categorically disclose it in the audit reports.

\subsubsection{True profit}

True profit $T P$, a non-cash equity grant, is the sixth form of subsidized funds (Table 1.2). It is accounting profit $(P)$ less profit grants:

True profit $=$ Accounting profit - Profit grants,

$$
T P=P-[R G+A(m-c)+D X]
$$

All else constant, true profit is the change in retained earnings that would obtain in the absence of profit grants. Positive true profits are a benefit since society could withdraw them for use elsewhere. Negative true profits (true losses) are social costs.

\subsubsection{Choice of Economic Opportunity cost of MFIs Concessional funds $(m)$}

There is always a controversy about the best possible alternative for the use of MFIs concessional funds. Most researchers ${ }^{12}$ in this context have followed the rate what Yaron (1992a, 1992b, 1994, and 1997) has prescribed from investors point of view where Finance Institution replaces public debt with deposits. He described it as the rate of interest on deposits ${ }^{13}$ i.e. interest rate for treasury bills or, certificates of deposit with maturities of six months to one year. Or equivalently, the rate paid for time deposits by state-owned DFIs plus a mark-up for the expected cost of administration and reserve requirements, commonly assumed to be about two to three percentage points but adjustable to the specific

\footnotetext{
12 Khandker, Khalily, and Khan, (1995) as Rate on three year Deposit (Bangladesh) ; Hashemi and Schuler (1997) as Transaction costs (3\%) + Bangladesh Bank deposit rate (IMF) ; Morduch, (1999) as Bangladesh Bank deposit rate(IMF) + 3\% transaction costs; Sacay, Randhawa, and Agabin, 1996 as deposit rate ; Yaron, Benjamin and Piprek (1997) as market deposit rate; Schreiner and Yaron (1999) as Deposit rate paid by MFI + 3\% transaction costs

${ }^{13}$ Benchmark market rate for local currency obligations is the average deposit rate (line 60I) from the International Monetary Fund, International Financial Statistics
} 
case. But scepticism abounds as only few MFIs take deposits. Even deposit taking MFIs replace some soft debt with market debt.

A point worth mentioning is that all the studies follow Yaron's (1992) approach assumes both the opportunity cost of Public debt and equity to be the same. However Benjamin (1994) adds a premium for risk to the local prime rate for the opportunity cost of debt on the premise that MFIs equity are more riskier than the debt and they draw private funds from their own markets (Von Pischke, 1991; Mehra and Prescott, 1985; Modigliani and Miller, 1958). Schreiner (1999, 2003) also based his calculations of market interest rate ${ }^{14}(\mathrm{~m})$ on the same lines. Where the risk premium is:

Premium for risk $=$ premium for age + premium for profitability

Where Premium for age is:

$$
=(2 / 100 / n)
$$

Where $n=$ Number of years of operation of an MFI

And, Premium of profitability is:

$$
\text { If } \begin{array}{rrr}
R O E<0 & \text { then add } 0.03 \\
0<R O E<\text { Prime rate } & \text { then add } 0.02
\end{array}
$$

And the price of market equity is:

Price of Market Equity $(r)=m(1.1+0.1 L)$

Where

Leverage $(L)=$ average liabilities / average equity

$r>m$, as equity is more riskier than debt

Besides that some other studies ${ }^{15}$ opted for rate of inflation as proxy for opportunity cost of public fund. But as suggested by Schreiner (1997), this would mean a real opportunity cost of zero, and that is too low. Another proxy used in the literature for the opportunity cost of Public debt is " $10 \% 16$ in real terms" from poor or donors point of view. Most governments and donors such as the World

\footnotetext{
$1417 \%$ (Local prime rate + risk adjustment). Took lending rate (IFS) as local prime rate

15 (Rosenberg, Christen, and Helms, 1997; Holtmann and Mommartz, 1996; Christen et al., 1995; SEEP, 1995; IADB, 1994

16 (Belli, 1996; Katz and Welch, 1993; Gittinger, 1982; Sharma,2004)
} 
Bank have used a rule of thumb of 10 or 12 percent per year in real terms. Nevertheless, no one knows about the true opportunity cost for the poor. It could be higher or lower, but 10 percent seems like a good rule of thumb. If this rate is too high, then it unjustly values people now and in the near future more than people in the distant future. In practice, the point is moot. MFOs compete for public funds now against all other projects funded by the budget earmarked to help the poor. To compare these projects, donors must use the same opportunity cost for all of them. This opportunity cost should be just high enough so the projects that pass a benefit-cost test exhaust all the funds earmarked to help the poor. The burden of proof for some other opportunity cost rests on the analyst (Gittinger, 1982).

The debate seems to be going on endlessly. According to Schreiner and Yaron (1999), the choice should meet four criteria. First, the number should be meaningful, that is, credibly close to the true opportunity cost. Second, all publicsector analyses should use the same opportunity cost because all public projects compete for public funds and because comparisons across projects require the use of a uniform opportunity cost. Third, higher rates are preferred to lower rates, all else constant. This protects society from those who would use low rates to give a false sense of rigor to support their pet projects. Fourth, the rate chosen must be credible.

Based on the above discussion, this study uses the cost of private debt (local prime rate i.e. lending rate ${ }^{17}$ ) as an opportunity cost for MFIs concessional borrowings in calculating subsidy dependence index (SDI) on the premise that private debt replaces public debt. For few countries where reliable estimates of Lending rate are not available, $10 \%$ rate is used as a proxy.

For comparative analysis purpose, in addition to using market lending rate $(m)$, this paper also calculates SDI using Benjamin (1994) formula by adding the risk premium to the lending rate as described above. The calculated SDI values using Benjamin formula have been presented at the end in Appendix $\boldsymbol{B}^{\mathbf{1 8}}$.

\footnotetext{
17 Taken from the International Financial Statistics (IFS) 2005 \& 2006.

${ }^{18}$ The detailed calculations of SDI according to Benjamin (1994) formula for all MFIs are available upon request
} 


\subsection{Microfinance Horizon}

\subsubsection{Subsidy Dependence Index (SDI)}

Table 2.5 depicts the calculated SDI values for years $2005 \& 2006$ using the lending rate as the market interest rate. A detailed set of calculations for all the MFIs are given at the end in Appendix C. SDI values for 25 MFIs for the year 2006 are missing due to the unavailability of their Audit Reports for year 2006. Out of the total 204 MFIs in year 2005, 153 MFIs are subsidy dependent while for year 2006, it is 122 out of total 179 MFIs. All the values taken from the respective MFI's Audit reports have been converted into the USD using exchange rates provided by

Table 2.5

Subsidy Dependence Index (SDI)

\begin{tabular}{|c|c|c|c|c|c|c|c|c|c|c|c|}
\hline MFIs & 2005 & 2006 & MFIs & 2005 & 2006 & MFIs & 2005 & 2006 & MFIs & 2005 & 2006 \\
\hline \multicolumn{3}{|c|}{ AFRICA } & HORIZON & 0.124 & 0.076 & FIE & 0.218 & 0.099 & EDPY.EDYF & 0.230 & 0.436 \\
\hline CDS & 0.161 & 0.109 & INECO & -0.028 & 0.068 & FONCRESOL & 0.359 & - & FINCA-PER & 0.269 & 0.380 \\
\hline ACSI & -0.250 & -0.388 & CRED-AGRO & 0.687 & 0.000 & FUNBODEM & 0.416 & 0.172 & FONDESURCO & 0.264 & 0.519 \\
\hline ADCSI & 0.179 & 0.704 & ACCESS & 0.461 & 0.404 & PRODEM & 0.157 & 0.012 & IDESI-LL & 0.022 & - \\
\hline BG & 0.809 & 0.026 & NORMICRO & 0.183 & 0.290 & PROMUJAR & 0.407 & 0.241 & MIBANCO & -0.089 & 0.034 \\
\hline DECSI & -0.074 & \begin{tabular}{|l|}
-0.108 \\
\end{tabular} & VIATOR & -0.121 & 0.082 & CMM-BOG & 0.122 & 0.096 & MOVIM.-M-R & 0.114 & 0.222 \\
\hline OMO & 0.484 & -0.003 & EKI & 0.146 & -0.173 & FINAMERICA & 0.121 & 0.170 & PROMUJER & 0.256 & 0.167 \\
\hline WISDOM & 0.491 & -0.061 & MIKROFIN & -0.045 & -0.354 & FMM-BUCA & -0.174 & -0.183 & MCHL & .490 & $y_{2}$ \\
\hline NOVOBANCO & 2.774 & \begin{tabular}{|l|}
0.347 \\
\end{tabular} & PARTNER & 0.091 & -0.125 & -POP & -0.135 & 0.047 & BANGENTE & 0.664 & 0.351 \\
\hline ALIDE & 1.169 & 0.588 & SUNRISE & 0.021 & -0.176 & WMM-MED & 0.212 & 0.023 & \multicolumn{3}{|c|}{ ME \& NA } \\
\hline FECECAM & 0.054 & 1.382 & C-FUND & 0.216 & 0.309 & WWB-CA & 0.020 & 0.075 & AL-TADAMUN & 0.975 & -0.720 \\
\hline PADME & 0.287 & 194.565 & CONSTANTA & 0.548 & 0.369 & CREDIMUJER & 0.623 & 0.292 & DBACD & 0.242 & 0.025 \\
\hline VF & 0.205 & 0.254 & CREDO & 0.728 & 0.426 & FUNDECOCA & 0.826 & - & LEAD & 1.330 & -0.470 \\
\hline RCPB & -0.051 & \begin{tabular}{|l|}
-0.094 \\
\end{tabular} & LAZIKA & 0.850 & 0.346 & ADEMI & 0.170 & - & Tamweelcom & -0.062 & -0.040 \\
\hline ACEP-CA & 1.246 & 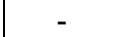 & KMF & -0.098 & -0.097 & BANC & 0.003 & 0.156 & & -0.125 & 0.010 \\
\hline KSF & 0.196 & - & AIYL-BANK & 0.937 & 0.886 & COAC-JARDIN & 0.122 & 0.118 & AL-A & .008 & 0.012 \\
\hline OI-SASL & 0.189 & -0.092 & & 1.164 & 0.554 & $\mathrm{COH}$ & 0.045 & 0.147 & AL-K & -0.110 & 0.011 \\
\hline PCRED GHA & -0.068 & -0.028 & FMCC & 0.508 & -0.004 & CO & 0.137 & 0.140 & FO & -0.022 & -0.330 \\
\hline SAT & -0.013 & 0.053 & CRED. M & 0.457 & 0.407 & D-I & -0.075 & -0.278 & IN & -0.004 & -0.090 \\
\hline EBS & -0.238 & -0.320 & KHAN-BANK & 0.052 & -0.063 & FINCA-ECU & -0.611 & -0.275 & ZAKOURA & -0.037 & 0.061 \\
\hline KADET & 0.582 & 0.849 & FORUS & 0.095 & 0.332 & FODEMI & -0.055 & -0.091 & ENDA & $\mid-0.044$ & -0.320 \\
\hline KREP & 0.188 & 0.038 & AGROINVEST & 0.258 & 0.125 & FUNDACION-ES & -0.315 & -0.423 & \multicolumn{3}{|c|}{ SOUTH ASIA } \\
\hline KWFT & 0.134 & 0.160 & \multicolumn{2}{|c|}{ BANK ESKHATA 0.0075} & 0.272 & PROCRED-ECU & 0.055 & -0.001 & ARMP & 0.653 & 0.182 \\
\hline MDSL & 0.151 & -1.914 & FMFB-TAJ & 1.509 & 0.815 & AMC-DE-RL & 0.164 & 0.401 & BRAC-AFG & 1.200 & 0.646 \\
\hline SMEP & 0.232 & 0.309 & IMON & 0.824 & 0.301 & FUNDACION & 0.242 & 0.469 & FMFB-AFG & 1.034 & 0.077 \\
\hline FINCA-MAL & 0.313 & 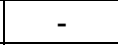 & MICROINVEST & 0.237 & 0.261 & FAFIDESS & -0.117 & - & ASA & -0.286 & -0.226 \\
\hline KAN.JAGIMA & -0.380 & - & \multicolumn{3}{|c|}{ E. ASIA \& PACIFIC } & FUNDACION-M & 0.794 & - & BRAC-BAN & 1.035 & 0.859 \\
\hline SORO-Y & 0.952 & 1.506 & ACLEDA & 0.099 & 0.066 & FUNDEA & 0.219 & - & B-TANGAIL & -0.136 & -0.023 \\
\hline FCC & 1.46 & 0.180 & AMRET & 0.132 & 0.070 & GENESIS-EM & 0.131 & 0.155 & DESHA & 0.045 & - \\
\hline
\end{tabular}

\footnotetext{
${ }^{19} \mathrm{~A}$ high SDI value here signifies large negative profit due to the sharp decline in revenues from the lending operations.
} 


\begin{tabular}{|c|c|c|c|c|c|c|c|c|c|c|c|}
\hline NOV.BANCO & 0.377 & -0.104 & SATHAPNA & 0.194 & $\mid 0.383$ & ACME & 0.188 & $|0.261|$ & IDF & $|-0.071|$ & -0.059 \\
\hline SOCREMO & 0.350 & 0.193 & HKL & 0.242 & 0.086 & FINCA-HON & 0.194 & 0.124 & RDRS & 1.195 & 1.287 \\
\hline TCHUMA & 0.255 & 0.217 & PRASAC & 0.347 & 0.301 & HDH & 0.240 & 0.890 & SHAKTI & 0.179 & -0.008 \\
\hline LAPO & 0.012 & -0.072 & MBK-VENTU & 0.384 & 0.211 & WORLD-REL & 0.122 & 0.098 & TMSS & 0.753 & 0.591 \\
\hline SEAP & -0.180 & -0.305 & ASHI & 0.331 & 0.082 & ACODEP & -0.113 & -0.154 & BANDHAN & 0.095 & -0.215 \\
\hline SEF-ZAF & 0.300 & 0.161 & BCB & -0.272 & -0.196 & FAMA & -0.218 & & BASIX & 0.119 & 0.088 \\
\hline ACEP & 0.421 & - & BANGKO-KA & -0.113 & -0.157 & FDL & -0.176 & -0.051 & CASHPOOR & 0.746 & 0.386 \\
\hline CMS & 0.361 & 0.313 & CBMO & -0.227 & -0.253 & BANEX & 0.006 & -0.037 & ESAF & 0.243 & -0.083 \\
\hline PAMECAS & 0.052 & -0.103 & DIGOS & -0.010 & -0.099 & FJN & -0.149 & - & GK & 0.130 & -0.059 \\
\hline FINCA-TAN & 0.065 & - & GREEN & -0.003 & - & FUNDENUSE & -0.482 & - & IASC & 0.088 & - \\
\hline PRIDE & 0.017 & 0.074 & IST-VALLEY & 0.1982 & $2-0.234$ & PROCRED-NIC & 0.031 & 0.116 & KBSLAB & 0.462 & 0.478 \\
\hline CBANK & 0.009 & -0.074 & NWFT & 0.0767 & $7-0.013$ & PRODESA & -0.282 & -0.311 & MAHASEMAN & -0.100 & - \\
\hline CML & 0.024 & 0.189 & SOLANO & -0.241 & -0.269 & FIELCO & 0.049 & 0.091 & SHARE-MF & -0.116 & 0.158 \\
\hline FAULU & 0.211 & 0.436 & TSPI & -0.050 & -0.070 & INTERFISA & 0.128 & 0.002 & SNFL & 0.639 & 0.531 \\
\hline FINCA-UGA & 0.047 & 0.125 & SPBD & 0.503 & 0.371 & BANTRA & 0.053 & 0.158 & CBB & 0.296 & -0.029 \\
\hline MEDNET & 0.179 & 3.008 & CEP & -0.070 & -0.117 & CAJA-NOR & 0.030 & 0.087 & NIRDHAN & 0.250 & 0.265 \\
\hline UML & 0.759 & 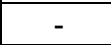 & TYM & -0.110 & -0.010 & CARITAS & 0.646 & 0.438 & NSSC & 0.105 & - \\
\hline CETZAM & 2.342 & 0.830 & AGROCAPITAL & 0.615 & 0.265 & CMAC-ARQ & -0.084 & -0.073 & PGBB & 0.533 & - \\
\hline FINCA-ZAM & 0.519 & 0.034 & \multicolumn{3}{|c|}{ LATIN AMERICA } & CMAC-CUS & -0.082 & - & VYCCU & -0.182 & - \\
\hline \multicolumn{3}{|c|}{ C. ASIA \& E. EUROPE } & BANCOSOL & 0.114 & 0.000 & CMAC-MAY & 0.078 & 0.070 & ASASAH & 0.211 & 1.015 \\
\hline BESA & 0.2403 & 0.010 & BNACO-L-A & 0.311 & 0.124 & CMAC-TAC & 0.056 & 0.138 & FMBL & 2.125 & 0.514 \\
\hline PCRED-ALB & 0.052 & 0.006 & CRECER & 0.039 & -0.028 & CMAC-TRU & 0.033 & 0.018 & KASHF & 0.036 & 0.045 \\
\hline Opportunity & 0.285 & 0.059 & ECO-FUTURO & 0.118 & 0.013 & EDPY.-C-T & 0.196 & 0.370 & & & \\
\hline ACBA & 0.283 & 0.271 & FADES & 0.547 & 0.249 & EDPY.-COF. & 0.256 & 0.631 & & & \\
\hline
\end{tabular}

The Mixmarket website. The interpretation of SDI values is straight forward. Take the value of year 2005 of $1^{\text {st }}$ MFI "CDS" in Table 1.3 for example. The positive value of 0.161 means that CDS is subsidy dependent as it distorts public wealth. It has to raise the interest rates on loans by $16.1 \%$ in order to become subsidy free. CDS is actually charging $19.3 \%$ interest rate on loans to borrowers. This suggests that CDS, in order to be subsidy free should charge $22.41 \%$ interest rate to borrowers on loans. On the other hand the $2^{\text {nd }}$ MFI "ACSI" in $1^{\text {st }}$ column has a negative value of -0.250 which shows that it is subsidy-free and thus creating public wealth. This suggests that it can reduce interest rate on loan by $25 \%$ and still remains subsidyfree. MFI "ACSI" actually charges $8.6 \%$ interest rate on loans to the borrowers. A $25 \%$ reduction in interest rate suggests that it can reduce interest rate to $6.45 \%$ and still remain subsidy-free.

Yaron et al. (1997) pin down four factors critical in eliminating subsidy dependence as adequate on-lending rates, high rates of loan collection, savings mobilization, and control of administrative costs. Calculating SDI for two 
consecutive years enables us to track down the movement and causes of subsidization of each MFI.

Table 2.6

Subsidy-free MFIs in 2006 (subsidy-dependents in 2005)

\begin{tabular}{|c|c|}
\hline MFIs & Contributing factors \\
\hline OMO & $\begin{array}{l}\text { Profits increased by almost } 4 \text { times. Revenues from lending almost } \\
\text { doubled. }\end{array}$ \\
\hline WISDOM & $\begin{array}{l}\text { Profits increased by more than } 6 \text { times. Revenues from lending more } \\
\text { than doubled. }\end{array}$ \\
\hline Ol-SASL & Profits increased by almost 29 times. \\
\hline MDSL & $\begin{array}{l}\text { Profits increased by almost } 18 \text { times. Interest cost to loanable funds } \\
\text { significantly decreased. }\end{array}$ \\
\hline $\begin{array}{l}\text { NOVO } \\
\text { BANCO }\end{array}$ & $\begin{array}{l}\text { Profits were negative in 2005. In year } 2006 \text { it has positive profits. } \\
\text { Market lending rate decreased. }\end{array}$ \\
\hline LAPO & $\begin{array}{l}\text { No revenue grants for year 2006. In 2005, it was } 467677 \text { USD as } \\
\text { operating grant. Market lending rate also decreased. }\end{array}$ \\
\hline PAMECAS & Profits increased by more than double. Interest income increased too. \\
\hline $\begin{array}{l}\text { Centenary } \\
\text { Bank }\end{array}$ & $\begin{array}{l}\text { No concessional loans. Increased profits due to investment income by } \\
\text { taking deposits and interest income. }\end{array}$ \\
\hline EKI & $\begin{array}{l}\text { Profits increased by } 3 \text { times last year. Market lending rate decreased in } \\
\text { year } 2006 .\end{array}$ \\
\hline PARTNER & $\begin{array}{l}\text { Profits increased by } 3 \text { times last year. Market lending rate decreased in } \\
\text { year } 2006 \text {. }\end{array}$ \\
\hline SUNRISE & $\begin{array}{l}\text { Profits doubled last year. Market lending rate decreased, making } \\
\text { borrowing cheap. }\end{array}$ \\
\hline FMCC & Profits more than tripled due to increase in investment income. \\
\hline KHAN BANK & $\begin{array}{l}\text { Profits more than doubled. Interest income from loans and investment } \\
\text { both increased. Market lending rate decreased for year } 2006 \text {. }\end{array}$ \\
\hline 1st VALLEY & $\begin{array}{l}\text { Interest paid for borrowing was greater than market rate for } 2006 \text {. } \\
\text { Profit increased due to increased interest income and investment. } \\
\text { Revenue grants also eliminated. }\end{array}$ \\
\hline NWFT & $\begin{array}{l}\text { Interest paid for borrowing was greater than market rate for } 2006 \text {. } \\
\text { Revenue grants eliminated. }\end{array}$ \\
\hline CRECER & Market lending rate fell significantly in 2006 to $11 \%$ from $17 \%$ in 2005. \\
\hline $\begin{array}{l}\text { AL } \\
\text { TADAMUN }\end{array}$ & $\begin{array}{l}\text { Revenue grants decreased significantly. While interest income from } \\
\text { lending increased. }\end{array}$ \\
\hline LEAD & $\begin{array}{l}\text { Revenue grants decreased. Interest income from loans increased } \\
\text { sharply. }\end{array}$ \\
\hline SHAKTI & Profits increased. Discount on borrowing also decreased in 2006. \\
\hline BANDHAN & Profits in 2006 increased sharply. \\
\hline ESAF & $\begin{array}{l}\text { Revenue grants decreased. While revenue from lending increased } \\
\text { significantly. }\end{array}$ \\
\hline GK & $\begin{array}{l}\text { Revenue grants decreased. While revenue from lending increased } \\
\text { significantly. }\end{array}$ \\
\hline CBB & Profit tripled. \\
\hline
\end{tabular}

Source: Author's own calculation based on the Audit Reports of respective MFIs 
Table 2.6 lists those MFIs which have enhanced their financial sustainability and become subsidy free in year 2006, but were previously subsidy dependent in year 2005. The contributing factors to this increase in financial sustainability are also listed for respective MFIs with the most important one as the increase in the overall profits. This increase in profits is mainly attributed to an increase in the revenues from lending and investments, a decrease in the market lending rate thus making borrowing cheaper and to do away with grants.

Similarly Table 2.7 lists those MFIs which have become worse in terms of financial sustainability by becoming subsidy dependent in year 2006, but were previously subsidy-free in year 2005. The contributing factors relevant to this decline in the financial sustainability (or become subsidy dependent) are also listed for the respective MFIs. The main contributing factors attribute to this decline in sustainability are decrease in the profits due to an increase in the administrative costs and also increase in the cost of loanable funds (borrowing).

Table 2.7

Subsidy-dependent MFIs in 2006 (subsidy-free in 2005)

\begin{tabular}{|l|l|}
\hline MFIs & Contributing factors \\
\hline SAT & Profits decreased to half in 2006. \\
\hline INECO & $\begin{array}{l}\text { Borrowing more than doubled which doubled the discount on } \\
\text { borrowings. Increases in revenues from lending and investment } \\
\text { did not offset that. }\end{array}$ \\
\hline VIATOR & $\begin{array}{l}\text { Discount on borrowing more than doubled due to decrease in } \\
\text { actual cost of borrowing. Profit also decreased. }\end{array}$ \\
\hline FMM POP & Profits decreased. \\
\hline MIBANCO & Market lending rate increased by 30\%. \\
\hline MFW & $\begin{array}{l}\text { Profit fell sharply due to increase in costs (Administrative and } \\
\text { interest). }\end{array}$ \\
\hline AL AMANA & Borrowing increased almost 4 times. \\
\hline AL KARAMA & Revenue grants increased 4 times. \\
\hline ZAKOURA & Actual cost of borrowing decreased. \\
\hline SHARE MF & $\begin{array}{l}\text { Profits decreased by almost } 6 \text { times the previous year mainly due } \\
\text { to decrease in interest income from loans. }\end{array}$ \\
\hline Source: Author's own calculation based on the Audit Reports of respective MFIs
\end{tabular}

Table 2.8 shows a comparison of MFIs by calculating SDI using the Benjamin (1994) formula, taking into account the risk premium in the market lending rate as 
described in the previous section with SDI values by taking market lending rate as a proxy for opportunity cost to society. Out of 204 MFIs in year 2005, now 179 MFIs become subsidy dependent as compared to the 153 MFIs (only market

Table 2.8

Opportunity cost of public debt comparison (No. of MFIs)

\begin{tabular}{|c|c|c|c|c|}
\hline & \multicolumn{2}{|c|}{ Year 2005 } & \multicolumn{2}{c|}{ Year 2006 } \\
\hline & $\begin{array}{c}\text { SDI (Lending } \\
\text { rate) }\end{array}$ & $\begin{array}{c}\text { SDI (Benjamin, } \\
\text { 1994) }\end{array}$ & $\begin{array}{c}\text { SDI (Lending } \\
\text { rate) }\end{array}$ & $\begin{array}{c}\text { SDI (Benjamin, } \\
\text { 1994) }\end{array}$ \\
\hline & $\begin{array}{c}\text { No risk } \\
\text { premium }\end{array}$ & $\begin{array}{c}\text { with risk } \\
\text { premium }\end{array}$ & $\begin{array}{c}\text { No risk } \\
\text { premium }\end{array}$ & $\begin{array}{c}\text { with risk } \\
\text { premium }\end{array}$ \\
\hline $\begin{array}{c}\text { Subsidy } \\
\text { Dependent }\end{array}$ & 153 & 179 & 122 & 155 \\
\hline Subsidy Free & 51 & 25 & 57 & 24 \\
\hline Total & 204 & 204 & 179 & 179 \\
\hline
\end{tabular}

Source: Author's own calculation based on the Audit Reports of MFIs and Microfinance Information eXange Inc.

lending rate i.e. no risk premium) while for year 2006, it is 155 out of total 178 MFIs compared to 122 MFIs (no risk premium). This shows that using Benjamin (1994) formula by adding risk premium to the market interest rate, the number of subsidy free MFIs reduce to 25 from 51 and to 24 from 55 for years 2005 and 2006 respectively.

Table 2.9

Correlations

\begin{tabular}{|c|c|c|c|c|c|c|c|c|c|c|c|c|c|c|c|c|c|c|c|}
\hline & Asset & Equity & Debt & $\begin{array}{c}\text { Debt } \\
\text { Int }\end{array}$ & $\begin{array}{l}\text { Debt } \\
\text { Dis. }\end{array}$ & Grant & Profit & Subsidy & Loan & Revnue & SDI & \begin{tabular}{|c|} 
Change \\
yield
\end{tabular} & NSFY & R-SFY & \begin{tabular}{|c|} 
True \\
Profit
\end{tabular} & ROA & SAROA & ROE & SAROE \\
\hline Asset & 1.00 & & & & & & & & & & & & & & & & & & \\
\hline Equity & 0.798* & 1.00 & & & & & & & & & & & & & & & & & \\
\hline Debt & $0.738^{*}$ & $0.535^{*}$ & 1.00 & & & & & & & & & & & & & & & & \\
\hline Debt Int. & -0.076 & \begin{tabular}{|l|}
-0.031 \\
\end{tabular} & -0.011 & 1.00 & & & & & & & & & & & & & & & \\
\hline DebtDisc. & 0.661* & \begin{tabular}{|l|l|}
$0.436^{*}$ \\
\end{tabular} & $0.765^{*}$ & \begin{tabular}{|l|}
-0.094 \\
\end{tabular} & 1.00 & & & & & & & & & & & & & & \\
\hline Grant & $0.476^{*}$ & $0.628^{*}$ & $0.298^{*}$ & 0.015 & $0.193^{*}$ & 1.00 & & & & & & & & & & & & & \\
\hline Profit & $0.750^{*}$ & 0.727* & 0.531* & \begin{tabular}{|l|}
-0.022 \\
\end{tabular} & 0.504* & $0.461^{*}$ & 1.00 & & & & & & & & & & & & \\
\hline Subsidy & 0.537* & $0.662 *$ & $0.383^{*}$ & -0.002 & $0.378^{*}$ & 0.897* & $0.292 *$ & 1.00 & & & & & & & & & & & \\
\hline Loan & 0.015 & 0.020 & 0.006 & -0.010 & 0.013 & 0.008 & 0.012 & 0.015 & 1.00 & & & & & & & & & & \\
\hline Revenue & 0.008 & 0.016 & -0.000 & \begin{tabular}{|l|}
-0.009 \\
\end{tabular} & 0.011 & 0.007 & 0.010 & 0.014 & 0.999* & 1.00 & & & & & & & & & \\
\hline SDI & 0.044 & 0.057 & $0.155^{*}$ & -0.084 & 0.099 & 0.070 & -0.054 & \begin{tabular}{|l|}
$0.138^{*}$ \\
\end{tabular} & -0.013 & -0.018 & 1.00 & & & & & & & & \\
\hline chayield & -0.080 & -0.024 & -0.095 & $-0.120^{*}$ & -0.020 & 0.095 & $-0.129 *$ & $0.156^{*}$ & -0.022 & -0.021 & $0.455^{*}$ & 1.00 & & & & & & & \\
\hline nomsfy & $-0.139 *$ & -0.075 & $-0.174^{*}$ & 0.085 & -0.059 & 0.063 & $-0.120 *$ & 0.099 & -0.012 & -0.008 & $0.272^{*}$ & 0.849* & 1.00 & & & & & & \\
\hline realsfy & $-0.123 *$ & -0.071 & $-0.161^{*}$ & \begin{tabular}{|l|}
0.066 \\
\end{tabular} & -0.035 & 0.055 & $-0.108^{*}$ & 0.095 & -0.000 & 0.003 & 0.257* & 0.808* & $0.974 *$ & 1.00 & & & & & \\
\hline trueprof & $-0.186 *$ & $-0.255^{*}$ & $-0.169^{*}$ & -0.003 & $-0.164^{*}$ & $-0.789 *$ & 0.097 & $-0.885^{*}$ & -0.005 & -0.005 & $-0.146^{*}$ & $-0.198^{*}$ & $-0.144^{*}$ & $-0.136^{*}$ & 1.00 & & & & \\
\hline ROA & -0.077 & \begin{tabular}{|l|}
0.001 \\
\end{tabular} & -0.062 & 0.049 & -0.045 & 0.025 & $0.132 *$ & $\mid-0.086$ & 0.001 & 0.002 & $-0.269^{*}$ & $-0.476^{*}$ & $-0.290^{*}$ & $-0.306^{*}$ & 0.110* & 1.00 & & & \\
\hline SAROA & \begin{tabular}{|l|}
0.007 \\
\end{tabular} & 0.025 & -0.014 & $0.157^{*}$ & -0.072 & $-0.100 *$ & $0.135^{*}$ & \begin{tabular}{|l|l|}
$-0.185^{*}$ \\
\end{tabular} & 0.005 & 0.005 & $-0.412^{*}$ & $-0.823^{*}$ & $-0.654^{*}$ & $-0.653^{*}$ & 0.248* & 0.694* & 1.00 & & \\
\hline ROE & 0.001 & 0.013 & 0.026 & 0.000 & 0.021 & 0.003 & 0.074 & -0.031 & -0.001 & -0.001 & 0.055 & $0.166^{*}$ & $0.115^{*}$ & $0.108^{*}$ & 0.051 & $-0.217^{*}$ & $-0.232^{*}$ & 1.00 & \\
\hline SAROE & 0.014 & 0.029 & 0.021 & 0.040 & -0.005 & -0.000 & 0.076 & \begin{tabular}{|l|}
-0.037 \\
\end{tabular} & 0.002 & 0.002 & 0.022 & $0.107 *$ & 0.061 & 0.056 & 0.065 & $-0.197 *$ & $-0.136^{*}$ & $0.892^{*}$ & 1.00 \\
\hline
\end{tabular}
Source: Author's own calculation based on the Audit Reports of MFIs and Microfinance Information eXange Inc.

*Refers to significant at $5 \%$ level of confidence. 
The correlation matrix in Table 2.9 shows the strength of the relationship among the variables used to calculate SDI in this study. It is interesting to look at the relationship between some variables. SDI has significant positive relationship with accounting profit, public debt and nominal and real subsidy-free yield. On the other hand, it has a significant negative relationship with nominal and subsidyadjusted ROA, real subsidy-free yield and true profits.

\subsubsection{Composition of SDI}

Figure 2.2 depicts the SDI composition using the lending rate as a proxy for market interest rate. MFIs located in Africa and South Asia are more subsidy dependent on average than the rest of the regions. Latin American (LA) MFIs which constitute one-third of the sample are far less subsidized. MFIs with status

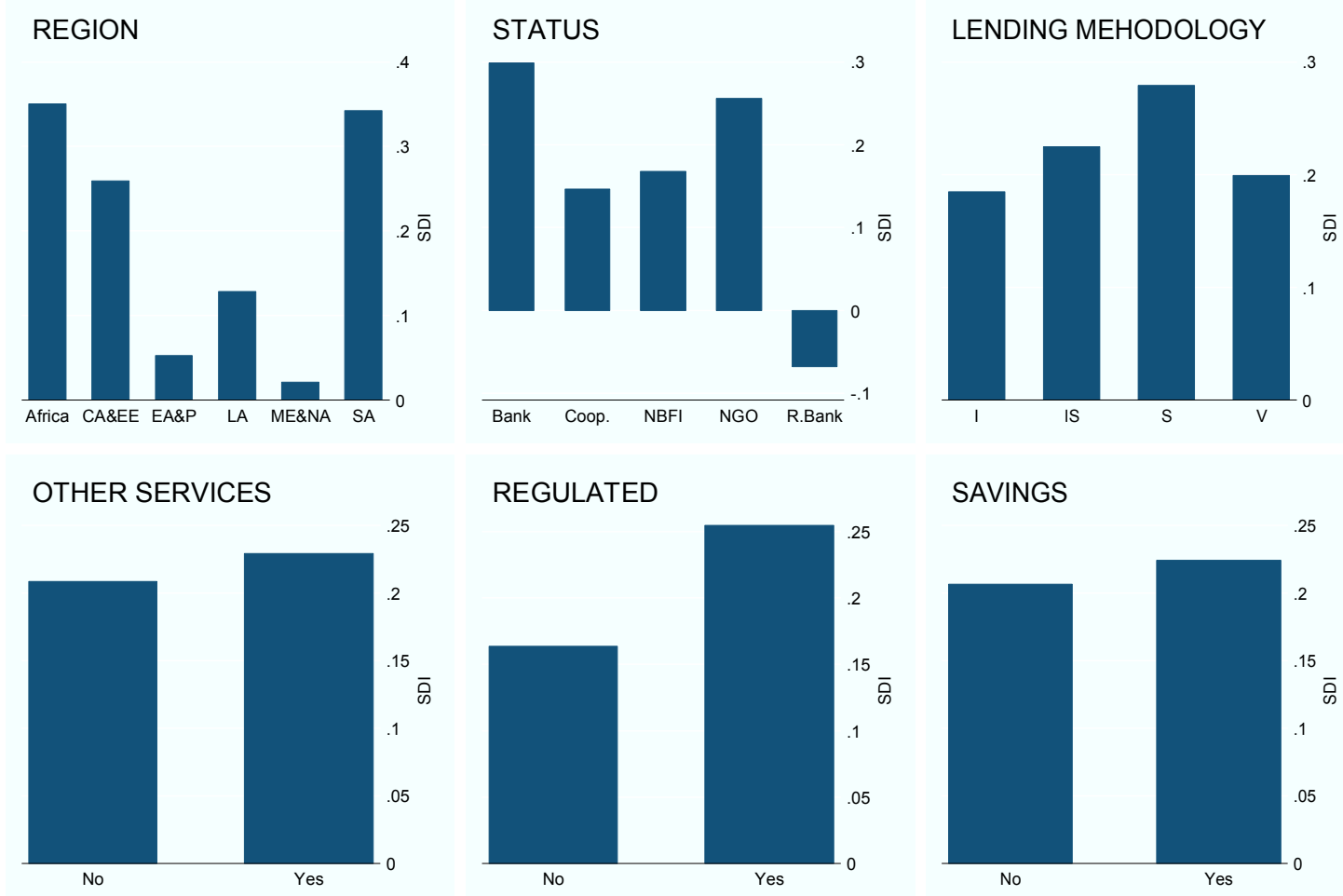

Fig. 2.2 Compositions of Subsidy Dependence Index (SDI) Source: Based on authors own calculation from the data taken from audit reports of 204 MFIs 
of Banks and NGOs are more subsidy dependent on average than the others. Rural Banks ${ }^{20}$ are exception as they are on average subsidy free. Notwithstanding the lending methodology, MFIs with solidarity (group) lending methodology are more subsidy dependent. While, MFIs which lend to individuals are on average relatively less subsidy dependent. This is because lending to relatively poor clients with group lending features requires higher transaction costs which demands more subsidized credit. Whereas lending to relatively well off individual clients require less subsidised credit. Moreover, MFIs providing other services i.e education and health etc. in addition to finacial serivices are on average more subsidy dependent. Also evident is that Regulated MFIs are more subsidy denpendent on average than unregulated ones. While those MFIs with saving feature are on average slightly more subsidy dependent.

\subsection{With and without subsidy comparisons}

The financial performance of an MFI as depicted by its inflated financial ratios looks very rosy in the presence of subsidies. Therefore, a counterfactual question "What would have been MFIs performance had there been no subsidies?" is worthy to investigate. This essay attempts to answer that question notwithstanding a comparison between the traditional benchmark measures of financial performance of nominal values of the Return on Equity (ROE) and Assets (ROA) with their subsidy-adjusted values.

\subsubsection{Return on Equity ${ }^{21}$ (ROE) Vs Subsidy adjusted Return on Equity (SAROE)}

ROE is the single most-common accounting measure of the financial performance of a private firm from the point of view of investors. It signals the rate of return earned on the invested equity and allows investors and donors to determine how their investment in a particular MFI compares against alternative investment. The ratio assumes importance as increasing numbers of MFIs seek

\footnotetext{
${ }^{20}$ All the rural banks exist in Philippines and comprised of only $4 \%$ of the whole sample.

21 Albeit it is not a good measure of the financial performance of subsidized MFIs since it depends on the form accountants and donors give to subsidized funds (Schreiner and Yaron, 1999).
} 
private funds. A subsidy adjusted ROE would compare not accounting profit but rather true profit with average Equity. Hence a negative SDI implies an SAROE higher than the social opportunity cost $m$ and vice versa.

Fig. 2.3 depicts a comparison between the average Return on Equity (ROE) figures and after adjusting for the subsidy (SAROE). The average values of Subsidy adjusted ROE are well below their nominal values for all the categories. African MFIs have negative ROE value on average, which becomes worse when adjusted for subsidy. South Asian MFIs suffer the most as the difference between the nominal and subsidy adjusted ROE is highest for them, while the decrease in the performance of Latin American MFIs seems less relative to the MFIs in other region. Notwithstanding the status of MFIs, Cooperatives are the worst performers having both negative nominal and subsidy adjusted values. However, NGOs seem to suffer most relatively to the others on average, as their performance decline sharply once accounted for subsidies. NBFIs too have negative ROE once adjusted for the subsidies. Further the decrease in financial performance is particularly
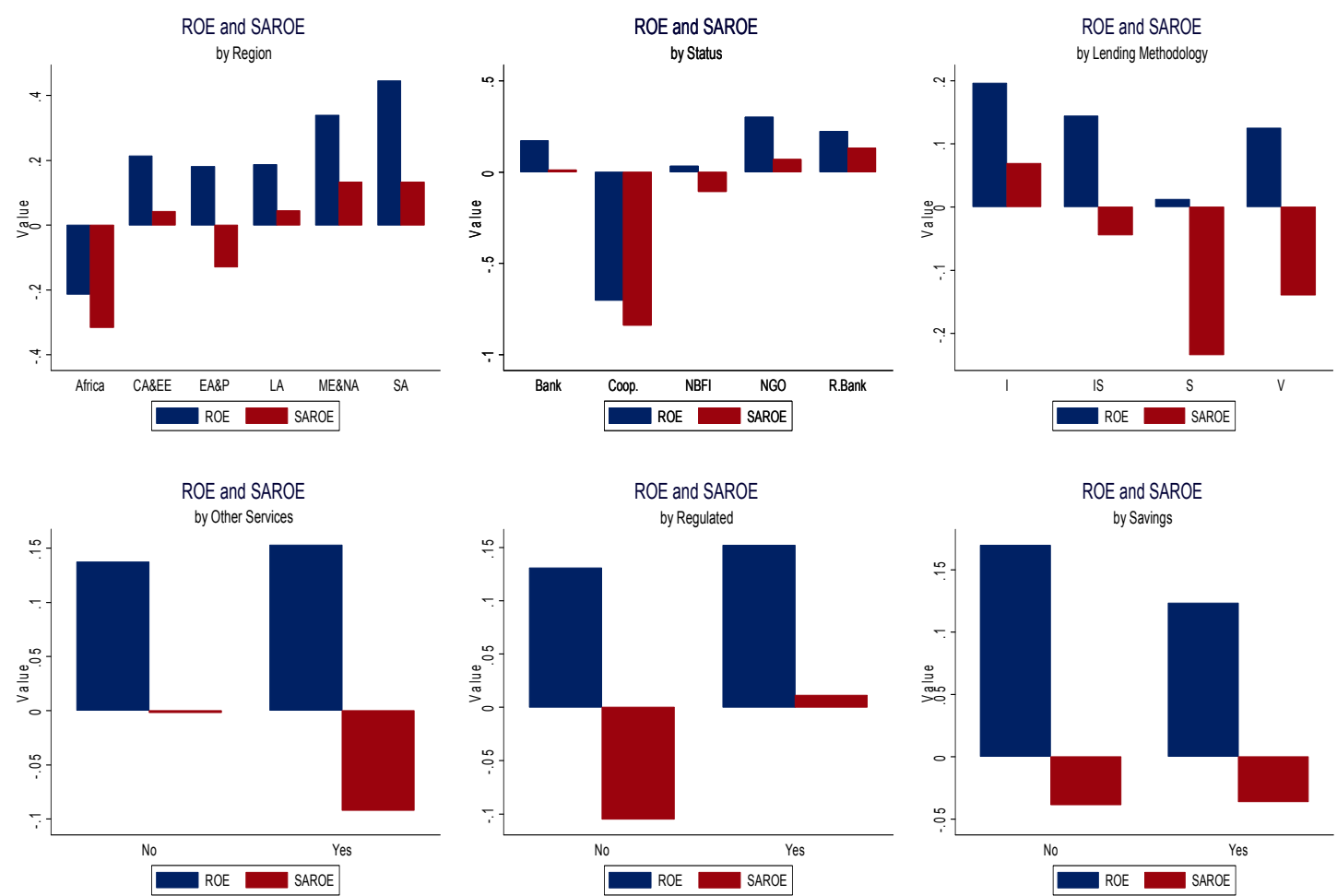

Fig.2.3 Return on Equity (ROE) \& Subsidy Adjusted Return on Equity (SAROE) Source: Based on authors own calculation from the data taken from audit reports of 204 MFIs 
resounding for MFIs which are solidarity and village lending methodologies, other service providers, not regulated and for those with no saving features.

\subsubsection{Return on Asset (ROA) Vs Subsidy adjusted Return on Asset (SAROA)}

The return on assets (ROA) depicts how well an MFI has used its asset base to generate income. It measures the return on funds (total assets, which includes both liabilities and equity) that are owned by the MFI. While SAROA takes into account only true profits like SAROE. Fig. 2.4 shows that when average nominal value of ROA is adjusted for subsidies, the subsidy adjusted ROA value decreases
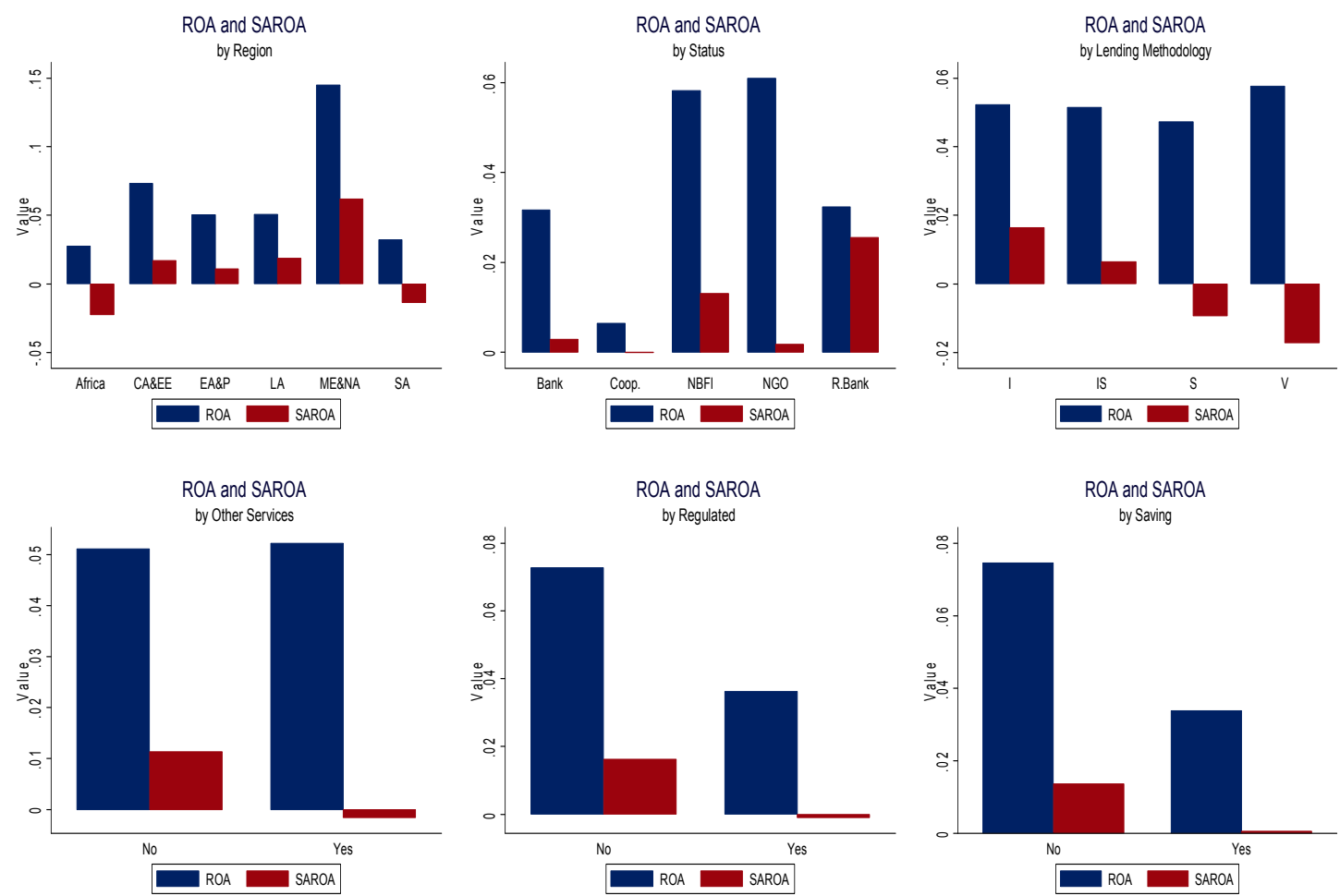

Fig.2.4 Return on Asset (ROA) \& Subsidy Adjusted Return on Asset (SAROA) Source: Based on authors own calculation from the data taken from audit reports of 204 MFIs

substantially for all the categories. Insight some points are note worthy. For African and South Asian MFIs on average, the returns turn positive to negative once subsidies are adjusted for. In fact these are the two most impoverished regions inhabiting the highest number of poverty stricken people. Therefore they 
get more subsidized funds than any other region which are mainly directed towards the social uplift of the poor. Therefore, their financial performance declines substantially without subsidies. On the other hand, the decline in the performance for MFIs in Latin American region is less significant relative to the others due to the fact that most of them are deposit-taking commercially oriented institutions. MFIs having NGOs status have the largest drop in the performance followed by MFIs with NBFI and bank status. NGOs are non-profit institutions heavily rely on subsidized funds to carry on their social mission. Evidently their financial performance decline once subsidies are being stripped off. Notwithstanding the lending methodology, MFIs with Solidarity and Village banking Methodology have the highest drop in performance and their average returns turn positive to negative. Whereas, MFIs which lend to the individual borrowers, seem relatively less affected because their borrowers consists of mainly less poor clients. Moreover MFIs providing other services, those which are not regulated and those without saving features also have large substantial drop in their performance compared to their respective counterparts.

\subsubsection{Actual yield (AY) Vs Subsidy Free Yield (SFY)}

Fig. 1.5 shows the difference between the average Actual Yield $(A Y)$ and the average Nominal Subsidy-free Yield (NSFY). Actual Yield is what the nominal yield or the interest rate on lending is, while Subsidy free yield is what yield or interest rate ought to be if all the subsidies are stripped away. In line with the previous analysis of returns, for all the categories, the average value of the subsidy-free yield is more than the actual yield thus showing overall subsidy dependence of MFIs. Notwithstanding the regions, MFIs located in SA and Africa have to increase the interest rates on lending more than MFIs in other regions to account for subsidies. Further, MFIs which are NGOs and those with village banking methodology have to raise interest rates on average more than the others in the absence of subsidies. Moreover, MFIs providing other services have to raise interest rates more than those MFIs which provide no other services in the 
absence of subsidies. Interestingly, MFIs which collect deposits and saving need not to increase interest rates as much as those MFIs with no saving feature once subsidies are stripped off because of the extra income they generate by taking deposits.
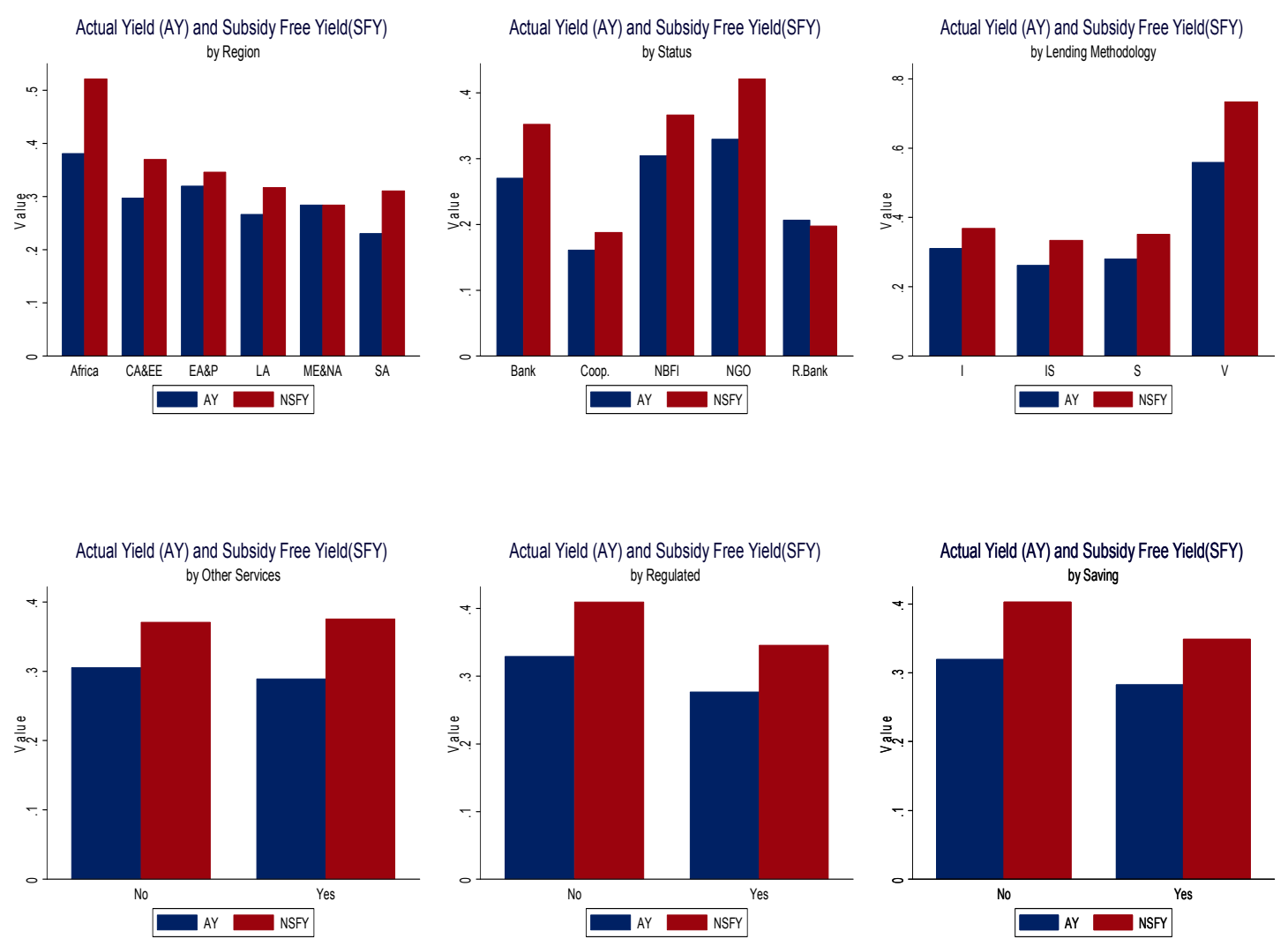

Fig. 2.5Actual Yield (AY) Vs Nominal Subsidy-free Yield (NSFY)

Source: Based on authors own calculation from the data taken from audit reports of 204 MFIs

\subsection{CONCLUSION}

The aim of this essay is to measure the sustainability of microfinance Sector. Towards this aim, Yaron's Subsidy Dependence Index (SDI) has been calculated which measures the social cost of the subsidization of microfinance sector to the society. This quality financial information has been obtained directly from the audit reports of the 204 MFIs with 23 million borrowers in 54 Countries worldwide for the years 2005 and 2006. This constitutes a significant part of the microfinance outreach worldwide. Nevertheless, the study has its limitations. The debate over the true social discount rate is far from being settled and rests more 
on the researcher's discretion. As shown in this paper, using another discount rate can significantly change the results of the subsidy dependence index. Moreover, judging MFIs performance only from financial aspect would not do justice and should include the social impact analysis in the overall performance. However, in the context of presenting a broader picture of the financial sustainability of Microfinance Sector, this study is revealing in many aspects.

On the whole, the analysis suggests that Microfinance sector is highly subsidized. Using market lending rate as a discount rate in SDI calculations, out of the 204 MFIs in year 2005, 153 MFIs are subsidy dependent while for year 2006, it is 122 out of total 179 MFIs. This study also shows the SDI's sensitivity to the changes in the discount rate. Where the overall subsidization increases further once a risk premium has been added to the market lending rate in SDI calculations. Based on the subsidy calculations, this essay also highlights the factors which are instrumental in causing substantial change (positive and negative) in the subsidy dependence index. Results depict that MFIs located in Africa and South Asia are more subsidy dependent on average than the rest of the regions while Latin American (LA) MFIs are less subsidized. MFIs with status of "Banks" and "NGOs" are more subsidy dependent on average than the others. The analysis further reveals that MFIs with solidarity (group) lending methodology are more subsidy dependent while MFIs which lend to individuals are on average relatively less subsidy dependent. Moreover MFIs providing other services i.e education and health etc. in addition to financial services are on average more subsidy dependent. Our results are in line with the ground reality. Majority of MFIs in South Asia and Africa follow group lending methodology and lend to the poor in general and to women in particular. Consequently they require more subsidized funds than their counterparts in Latin America, who predominantly lend to less poor individuals. By ccomparing the averages of the nominal financial ratios of return on assets (ROA) and return on equity (ROE) with their subsidy-adjusted ratios, this paper also highlights the inadequacy of the conventional financial ratios in measuring the financial performance of microfinance institutions by not taking into account the subsidies. And the results show that when adjusted for subsidies, the financial performance of MFIs decline substantially. 
What are the policy implications of these findings and are there any wider lessons to be learned for the stakeholders in microfinance? We suggest four. First, for governments and donors, measurement of social cost of subsidization helps them taking informed policy decisions in making the best use of public funds earmarked for the poor. Second, for the microfinance practitioners in general and the practitioners for sample MFIs in this study in particular, the essay not only puts a price tag on their institution in terms of costs to the society but also pins down the important factors which contribute towards financial sustainability by reducing subsidy dependence. Third, for social investors, it serves as a guide to the in evaluating their investment in projects which increase the public wealth of the society at large. And finally for microfinance clients, it is awareness towards the importance of transparent prices in microfinance particularly for those clients to whom MFIs charge exorbitant interest rates. 


\section{Chapter 3}

\section{Efficiency and Productivity of Microfinance: Incorporating the Role of Subsidies}

The social nature of MFIs is mainly financed by subsidies from donors. Therefore, the role of subsidies cannot be under estimated in MFIs efficiency and productivity analysis. This paper is a first attempt to measure the financial efficiency and productivity of Microfinance Institutions (MFIs) worldwide taking into account the subsidies received by MFIs by using the non-parametric Data Envelopment Analysis (DEA). Towards this aim, a three-stage analysis is carried out. Firstly, technical and pure efficiency scores are calculated by splitting subsidies into input and output and entered into the DEA framework specifications depending on whether they are generating benifits (negative subsidies) or cost (positive subsidies) to the society. Secondly DEA-based Malmquist indices are calculated to analyze the intertemporal productivity change. Thirdly, Tobit Regression analysis are carried out to test a series of hypotheses concerning the relationship between financial efficiency and other indicators related to MFIs productivity, organization, outreach, sustainability and social impact. Overall subsidies contribute to financial efficiency of MFIs albeit marginally. Results uphold the tradeoff between outreach to the poor and financial efficiency. Thus MFIs which cater to the poor tend to bemore inefficient than those with clients relatively well off. Also evident is the fact that lending to women is efficient only in the presence of subsidies. MFIs in South Asia and Middle East \& North Africa tend to be less efficient than the others.

\subsection{Introduction}

Microfinance promises poverty reduction and financial self-sustainability ${ }^{1}$. Recently, from a research perspective, much focus has been shifted to the issues in

\footnotetext{
${ }^{1}$ Armendáriz de Aghion and Jonathan Morduch(2004); Morduch (1999a); Morduch (1999b); Goodman (2005): Cull etal. (2007)
} 
financial sustainability and efficiency of Microfinance Institutions (MFIs). Among other things, this increased focus on financial sustainability and efficiency is an outcome of a number of developments the microfinance business has been recently confronted with, such as the increasing competition among MFIs, the commercialization of microfinance, technological change that also has become available for, and implemented in microfinance, and financial liberalization and regulation policies of the government (Rhyne and Otero, 2006). These developments have induced microfinance institutions to change their behavior, and to broaden their services and activities (Hermes, et al., 2008).

Like the conventional financial institutions, the efficiency and productivity of MFIs has generally been measured by conventional financial ratios. In addition to applying conventional financial ratios, their assessment can also be done by employing non-parametric efficiency techniques on the premise that like the conventional banking institutions, microfinance institutions also do care about their sustainability especially in recent times when private investors eye it as a good investment opportunity. In traditional Banking Literature, the evaluation of financial performance by using non parametric efficiency techniques i.e. Data Envelopment Analysis (DEA), is a very common practice ${ }^{2}$. However, its application to the microfinance institutions is more recent phenomenon. Nevertheless, some researchers have replicated these techniques for the efficiency analysis of MFIs ${ }^{3}$.

However the efficiency analysis of MFIs based on conventional production and intermediation model approach in non-parametric efficiency analysis framework is hard to justify because of their reliance on subsidies. The overall equation linking capital and labor inputs into profits and social change still proves difficult to master without accommodating the subsidized inputs (Cull et al. 2007). Therefore, measuring their efficiency demands the role of subsidies to be accounted for, an area, largely neglected in the efficiency and productivity analysis of microfinance institutions. To date only a few studies have been done which have taken into account the role of subsidies into the assessment of financial

\footnotetext{
2 Examples of the use of DEA in banking are Sherman and Gold (1985), Athanassopoulos (1997), Seiford and Zhu (1999), and Camanho and Dyson (2005) among others.

${ }^{3}$ See for example Gutierrez-Nieto et al. (2007, 2009); Balkenhol, 2007b; Hermes et a.I 2008
} 
performance of MFIs by employing parametric techniques ${ }^{4}$, let alone nonparametric efficiency analysis.

In this backdrop, this essay is a first attempt to addresses the issue of incorporating the role of subsidies in the efficiency and productivity analysis of MFIs. This quality financial information has been generated directly from the audit reports ${ }^{5}$ of the 204 MFIs with 23 million borrowers in 54 Countries worldwide for years 2005 and 2006. This constitutes a significant part of the whole microfinance outreach worldwide. As a starting point, this essay calculates subsidies using Yaron's Subsidy Dependence Index ${ }^{6}$ (SDI) which measures the social cost of subsidized MFIs.

With subsidy data at our disposal, this study aims to resolve some key issues. Can we incorporate these subsidies into the non-parametric DEA framework in order to gauge their impact on the financial efficiency of microfinance? Do these subsidies improve the performance of microfinance institutions by enhancing their efficiency? What is the impact of different organizational, structural, financial and social variable on the efficiency of microfinance both with and without subsidies? To that extent, this study aims to investigate in particular, some specific hypothesis related to the efficiency of microfinance by employing with and without subsidy analysis. Does staff productivity enhance the financial efficiency whereas financial costs reduce it? An interesting relationship to investigate is about the impact of outreach on MFIs efficiency. Where Loan size is used as a proxy for the outreach of MFI and the lower the loan size, the more MFI reaches to the poor (outreach). Another important relationship to be estimated is between the efficiency of MFIs with their financial sustainability and subsidization. The impact of lending to women borrowers on the financial efficiency of MFIs amid subsidies is another important issue to investigate. Last but not the least, the presence of many categorical

\footnotetext{
${ }^{4}$ Hudon \& Traca, (2006, 2008); Cull et al.(2007); Hudon (2006)

${ }^{5}$ The audit reports have been taken from the Mix Market Website (hhp://www.mixmarket.org). The MIX MARKET is a global, webbased microfinance information platform. It provides information to sector actors and the public at large on Microfinance Institutions (MFIs) worldwide, public and private funds that invest in microfinance, MFI networks, raters/external evaluators, advisory firms, and governmental and regulatory agencies

${ }^{6}$ To examine SDI calculations in past studies see for example Congo (2002); Sharma (2004); Hulme and Mosley(1996); Schreiner (19977); Schreiner and Yaron (1999 and 2001) and Jehangir (2005)
} 
variables allows us to find out the efficient MFIs notwithstanding their regional location, lending methodologies and organizational features i.e. status, regulations and savings.

For the proponents of the Win-Win proposition7, the overall evidence is not a good one. Based on our subsidy calculations, for the year 2005, 153 MFIs out of 204 are subsidy dependent while for year 2006 it is 122 out of 179 MFIs. The DEA efficiency scores and Malmquist Productivity index show a marginal positive impact of subsidies on the financial efficiency of MFIs. However, the empirical evidence based on the regression analysis to identify the determinants of efficiency, is revealing in many respects. From a social perspective, the empirical evidence suggests that lending credit to the poor is financially inefficient. Further, MFIs which lend predominantly to women are found to be efficient only in the presence of subsidies. From financial perspective, the negative impact of costs and subsidization on the efficiency of microfinance is confirmed by the empirical evidence. On the other hand, staff productivity contributes to efficiency.

The paper is organized as follows. In the next section, to start off, some descriptive statistic about the inputs and output used in the efficiency analysis in general and subsidy dependence index (SDI) in particular are given. The third section provides the theoretical background of non parametric efficiency analysis followed by an overview of the efficiency of microfinance sector. The fourth section illustrates the role of subsidies into the non-parametric efficiency analysis of MFIs. The fifth section highlights the empirical evidence by employing the regression analysis. Finally, a conclusion is given at the end.

\subsection{Microfinance Horizon}

\subsubsection{Subsidy Dependence Index (SDI)}

After carefully reviewing the Audit Reports of more than 300 MFIs, 204 MFIs in 54 countries have been chosen based on the clarity of their respective

\footnotetext{
${ }^{7}$ That microfinance reduces poverty and in the course of that becomes subsidy free or sustainable
} 
Balance sheets in general and subsidy ${ }^{8}$ figures in particular. All the MFIs adhere to the International Accounting Standards (IAS). Subsidies have been calculated for the years 2005 and 2006 in a unique way using Yaron's Subsidy Dependence Index $^{9}$ (SDI) which measures the social cost of subsidized MFIs in a short time frame (Yaron, 1992a). Table 3.1 depicts the calculated SDI values for years 2005 \& 2006.

Table 3.1

Subsidy Dependence Index (SDI)

\begin{tabular}{|c|c|c|c|c|c|c|c|c|c|c|c|}
\hline \multicolumn{3}{|c|}{ AFRICA } & MFIs & 2005 & 2006 & MFIs & 2005 & 2006 & MFIs & 2005 & 2006 \\
\hline MFIs & 2005 & 2006 & HORIZON & 0.124 & 0.076 & FIE & 0.218 & 0.099 & EDPY.EDYF & 0.230 & 0.436 \\
\hline CDS & $0.161^{10}$ & 0.109 & INECO & -0.028 & 0.068 & FONCRESOL & 0.359 & - & FINCA-PER & 0.269 & 0.380 \\
\hline ACSI & $-0.250^{11}$ & $\mid-0.388$ & CRED-AGRO & 0.687 & 0.000 & FUNBODEM & 0.416 & 0.172 & FONDESURCO & 0.264 & 0.519 \\
\hline ADCSI & 0.179 & 0.704 & ACCESS & 461 & 0.404 & PRODEM & 0.157 & 0.012 & IDESI-LL & 0.022 & - \\
\hline BG & 0.809 & 0.026 & NORMICRO & 0.183 & 0.290 & PROMUJAR & 0.407 & 0.241 & MIBANCO & $-0.08 \mathrm{c}$ & 0.034 \\
\hline DECSI & -0.074 & $\mid-0.108$ & VIATOR & -0.121 & 0.082 & CMM-BOG & 0.122 & 0.096 & MOVIM.-M-R & 0.114 & 0.222 \\
\hline OMO & 0.484 & -0.003 & EKI & 0.146 & -0.173 & FINAMERICA & 0.121 & 0.170 & PROMUJER & 0.256 & 0.167 \\
\hline WISDOM & 0.427 & -0.061 & MIKROFIN & -0.045 & -0.354 & FMM-BUCA & -0.174 & -0.183 & MCHL & 0.490 & - \\
\hline NOVOBANCO & 2.774 & 0.347 & PARTNER & 0.091 & -0.125 & FMM-POP & -0.135 & 0.047 & BANGENTE & 0.664 & 0.351 \\
\hline ALIDE & 169 & 0.588 & SUNRISE & 0.021 & -0.176 & WMM-MED & 0.212 & 0.023 & ME & NA & \\
\hline FECECAM & 0.054 & 1.382 & C-FUND & 0.216 & 0.309 & WWB-CA & 0.020 & 0.075 & -TADAMUN & 0.975 & -0.72 \\
\hline PADME & 0.287 & 4.565 & CONSTANTA & 0.548 & 0.369 & CREDIMUJER & 0.623 & 0.292 & DBACD & 0.242 & 0.025 \\
\hline VF & 0.205 & 0.254 & CREDO & 0.728 & 0.426 & FUNDECOCA & 0.826 & - & LEAD & $1.330-$ & -0.470 \\
\hline RCPB & -0.051 & -0.094 & LAZIKA & 0.850 & 0.346 & ADEMI & 0.170 & - & TAMWELCOM & -0.062 & -0.040 \\
\hline ACEP-CAM & 1.246 & - & KMF & -0.098 & -0.097 & BANCO-SOL & 0.003 & 0.156 & MFW & -0.125 & 0.010 \\
\hline KSF & 196 & - & IYL-BANK & 0.937 & 0.886 & COAC-JARDIN & 0.122 & 0.118 & AL-AMANA & -0.008 & 0.012 \\
\hline OI-SASL & 0.189 & -0.092 & BTFF & 1.164 & 0.554 & COAC-S-JOSE & 0.045 & 0.147 & AL-KARAMA & -0.110 & 0.011 \\
\hline PROCRED-GHA & -0.068 & -0.028 & FMCC & 0.508 & -0.004 & COAC-SAC & 0.137 & 0.140 & FONDEP & -0.022 & -0.330 \\
\hline SAT & \begin{tabular}{|l|}
-0.013 \\
\end{tabular} & 0.053 & CRED. MONGOL & 0.457 & 0.407 & D-MIRO & -0.075 & -0.278 & INMAA & -0.004 - & -0.090 \\
\hline EBS & -0.238 & -0.320 & KHAN-BANK & 0.052 & -0.063 & FINCA-ECU & -0.611 & -0.275 & ZAKOURA & -0.037 & 0.061 \\
\hline KADET & 0.582 & 0.849 & FORUS & 0.095 & 0.332 & FODEMI & -0.055 & -0.091 & ENDA & -0.044 & -0.320 \\
\hline KREP & 0.188 & 0.038 & AGROINVEST & 0.258 & 0.125 & FUNDACION-ES & -0.315 & -0.423 & SOU & I ASIA & \\
\hline KWFT & 0.134 & 0.160 & 3ANK ESKHATA & 0.0075 & 0.272 & PROCRED-ECU & 0.055 & -0.001 & ARMP & 0.653 & 0.182 \\
\hline MDSL & 0.151 & -1.914 & FMFB-TAJ & 1.509 & 0.815 & AMC-DE-RL & 0.164 & 0.401 & BRAC-AFG & 1.200 & 0.646 \\
\hline
\end{tabular}

8 Extracting subsidy information from the balance sheet needs deliberation. These are subsidized/public funds from government or donors and come in six forms :

$\begin{array}{lcl}\text { Type } & \text { Notion } & \text { Type of Grant } \\ \text { Direct Grant } & \text { DG } & \text { Equity Grant (EG) } \\ \text { Paid-up-capital } & \text { PC } & \text { Equity Grant (EG) } \\ \text { Revenue Grant } & \text { RG } & \text { Profit Grant (PG) } \\ \text { Discount on Public Debt } & \text { A.(m-c) } & \text { Profit Grant (PG) } \\ \text { Discount on Expenses } & \text { DX } & \text { Profit Grant (PG) } \\ \text { True Profit } & \text { TP } & \text { Equity Grant (EG) }\end{array}$

${ }^{9} \mathrm{SDI}=$ subsidies $(\mathrm{S}) /$ revenues from lending $(\mathrm{LP} * \mathrm{i})$

Equity Grant (EG)

$=(E * m+A(m-c)+K-P) /(L P * i)$

Where: $\mathrm{E}=$ average annual equity; $\mathrm{m}=$ Market Interest rate/Interest rate the MFI is assumed to pay for borrowed funds if access to concessional borrowed funds were eliminated.; $A$ = Average annual outstanding concessionary-borrowed funds/ Average public debt ; $c$ = interest rate paid on concessionary borrowed funds/ interest rate paid on Public debt ; $P=$ Reported annual profit /accounting profits; $K$ = Other Subsidies received by the MFI i.e. Revenue Grant (RG) + Discount on Expenses (DX) $\mathrm{LP}=$ Average annual outstanding loan portfolio of the MFI $; \mathrm{i}=$ lending interest rate/ yield on lending

${ }^{10} \mathrm{SDI}$ value of 0.161 means that the MFI has to raise the interest rates on loans by $16.1 \%$ to be subsidy free

${ }^{11} \mathrm{SDI}$ value of -0.250 means that the MFI is subsidy free even if it reduces interest rate on loans by $25 \%$ 


\begin{tabular}{|c|c|c|c|c|c|c|c|c|c|c|c|}
\hline SMEP & 0.232 & $|0.309|$ & IMON & 0.824 & |0.301 & FUNDACION & $0.242 \mid$ & 0.469 & FMFB-AFG & $|1.034|$ & $|0.077|$ \\
\hline FINCA-MAL & 0.313 & - & CROINVEST & 0.237 & 0.261 & FAFIDESS & $\mid-0.117$ & - & ASA & -0.286 & -0.226 \\
\hline ANDO-JAGIMA & .380 & - & \multicolumn{3}{|c|}{ E. ASIA \& PACIFIC } & FUNDACION-M & 0.794 & - & BRAC-BAN & 1.035 & 0.859 \\
\hline SORO-Y & 0.952 & 506 & ACLEDA & \begin{tabular}{|l|}
0.099 \\
\end{tabular} & 0.066 & FUNDEA & 0.219 & - & B-TANGAIL & $-0.136-$ & -0.023 \\
\hline FCC & 1.46 & 180 & & 132 & 0.070 & $\overline{\mathrm{EN}}$ & 0.131 & 0.155 & & 0.045 & \\
\hline NOVO-BANCO & 0.377 & .104 & THAF & 194 & 0.383 & ACME & 0.188 & 0.261 & & 0.071 - & -0.059 \\
\hline SOCREMO & 0.350 & 193 & HKL & 0.242 & 0.086 & INCA-HON & 0.194 & 0.124 & RDRS & 1.195 & 1.287 \\
\hline TCHUMA & 255 & 0.217 & PRA & 0.347 & 0.301 & HDH & 0.240 & 0.890 & 11 & 0.179 & -0.008 \\
\hline LAPO & .012 & -0.072 & $3 \mathrm{~K}-\mathrm{V}$ & 384 & 0.211 & ORL & 0.122 & 0.098 & $\mathbf{S}$ & 0.753 & 0.591 \\
\hline SEAP & -0.180 & -0.305 & ASHI & 0.331 & 0.082 & DEP & -0.113 & -0.154 & ND & 0.095 & -0.215 \\
\hline SEF-ZAF & 0.300 & 0.161 & BCB & -0.272 & -0.196 & IA & -0.218 & - & BASIX & 0.119 & 0.088 \\
\hline EP & 421 & - & NGKO- & -0.113 & -0.157 & & -0.176 & -0.051 & HI & 0.746 & 0.386 \\
\hline CMS & 0.361 & 0.313 & CBMO & -0.227 & -0.253 & ANEX & 0.006 & -0.037 & ESAF & 0.243 & -0.083 \\
\hline PAMECAS & 0.052 & -0.103 & DIGOS & -0.010 & -0.099 & $\overline{\text { FJN }}$ & -0.149 & 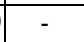 & GF & 0.130 & -0.059 \\
\hline FINC & 065 & & $\mathbf{N}$ & -0.003 & - & & 0.482 & - & & 0.088 & \\
\hline PRIDE & .017 & 0.074 & T-VALLEY & 0.1982 & -0.234 & \begin{tabular}{|l|} 
PROCRED-NIC \\
\end{tabular} & 0.031 & 0.116 & KBSLAB & 0.462 & 0.478 \\
\hline CBANK & 0.009 & -0.074 & WFT & 0.0767 & -0.013 & $A$ & -0.282 & -0.311 & MAHAS & -0.100 & - \\
\hline $\mathbf{I L}$ & 024 & 0.189 & LANO & -0.241 & -0.269 & $\mathbf{F}$ & 0.049 & 0.091 & SHAR & -0.116 & 0.158 \\
\hline AULU & 0.211 & 0.436 & TSPI & -0.050 & -0.070 & NTERFISA & 0.128 & 0.002 & SNFL & 0.639 & 0.531 \\
\hline FINCA-UG & 0.047 & 0.125 & PBD & 0.503 & 0.371 & 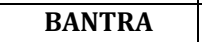 & 0.053 & 0.158 & $\mathrm{CE}$ & $0.296-$ & -0.029 \\
\hline MEDNET & 179 & 3.008 & & -0.070 & \begin{tabular}{|c|}
-0.117 \\
\end{tabular} & $\square$ & 0.030 & 0.087 & D & 0.250 & 0.265 \\
\hline ML & 759 & - & TYM & $\mid-0.110$ & -0.010 & $\mathbf{A S}$ & 0.646 & 0.438 & $\mathbf{C}$ & 0.105 & - \\
\hline CETZAM & 2.342 & 0.830 & OCAPITAL & 0.615 & 0.265 & CMAC-ARQ & -0.084 & -0.073 & PGBB & 0.533 & \\
\hline FINCA-ZAM & 0.519 & 0.034 & \multicolumn{3}{|c|}{ LATIN AMERICA } & CMAC-CUS & -0.082 & - & VYCCU & -0.182 & - \\
\hline \multicolumn{3}{|c|}{ C. ASIA \& E. EUROPE } & INCOSOL & 0.114 & 0.000 & CMAC-MAY & 0.078 & 0.070 & ASASAH & 0.211 & 1.015 \\
\hline BESA & 0.2403 & 0.010 & BNACO-L-A & 0.311 & 0.124 & CMAC-TAC & 0.056 & 0.138 & FMBL & 2.125 & 0.514 \\
\hline PROCRED-ALB & 0.052 & 0.006 & CRECER & 0.039 & -0.028 & CMAC-TRU & 0.033 & 0.018 & KA & 0.036 & 0.045 \\
\hline Opportunity & 0.285 & 0.059 & CO-FUTURO & 0.118 & 0.013 & & 0.196 & 0.370 & & & \\
\hline ACBA & 0.283 & 0.271 & FADES & 0.547 & 0.249 & EDPY.-COF. & 0.256 & 0.631 & & & \\
\hline
\end{tabular}

Source: Author own calculations based on the Balance sheets of 204 MFIs for year $2004 \& 2005$

SDI values for 26 MFIs for the year 2006 are missing due to the unavailability of their Audit Reports. Out of 204 MFIs in year 2005, 153 MFIs are subsidy dependent while for year 2006, it is 122 out of total 179 MFIs. We proceed further without going into the details of SDI calculation as it is beyond this paper's main theme (see chapter 2 of this dissertation).

\subsubsection{Description of the Data}

Table 3.2 presents a summary statistics of the variables used in this essay as an inputs and outputs in the DEA framework along with other social and organizational variables used in the regression framework. The subsidy figures for the 25 MFIs for the year 2006 are missing due to the unavailability of the data. Therefore, the sample in Table 2.1 consists of 383 observations (204 for the year 2005 plus 179 for the year 2006). 
Table 3.2

Variable Description and Summary Statistics

\begin{tabular}{|c|c|c|c|c|c|c|c|}
\hline Inputs \& Outputs & Obs & Definition & Unit & Mean & Med. & Min & $\operatorname{Max}$ \\
\hline Average annual asset $(A)$ & 383 & $\begin{array}{l}\text { Average of current year }(t) \text { and previous } \\
\text { year }(t-1) \text { assets. It includes all asset } \\
\text { accounts net of all contra-asset accounts, } \\
\text { such as the loan-loss allowance and } \\
\text { accumulated depreciation. }\end{array}$ & $\$$ & 37000 & 12000 & 323 & 521000 \\
\hline Subsidy $(S)$ & 383 & {$[E \times m+A(m-c)+K-P]$} & $\$$ & 967 & 220 & -18100 & 76900 \\
\hline Average Loan Portfolio & 383 & $\begin{array}{l}\text { Average annual outstanding loan } \\
\text { portfolio }\end{array}$ & $\$$ & 89100 & 8411 & 48 & $\begin{array}{c}241000 \\
00\end{array}$ \\
\hline Fiancial Revenues & 383 & $\begin{array}{l}\text { Revenue generated from the gross loan } \\
\text { portfolio and from investments plus } \\
\text { other operating revenue }\end{array}$ & $\$$ & 85470 & 3100 & 71 & 149800 \\
\hline Operational cost $(C)$ & 383 & $\begin{array}{l}\text { Expenses related to operations, such as } \\
\text { all personnel expenses, rent and utilities, } \\
\text { transportation, office supplies, and } \\
\text { depreciation }\end{array}$ & $\$$ & 4400 & 1900 & 18 & 77300 \\
\hline \multicolumn{8}{|l|}{$\begin{array}{l}\text { Organizational } \\
\text { variables }\end{array}$} \\
\hline GNI per capita (current) & 383 & $\begin{array}{l}\text { Gross national income divided by the } \\
\text { population. }\end{array}$ & $\$$ & 1402 & 1000 & 160 & 10300 \\
\hline Borrowers & 383 & $\begin{array}{l}\text { The number of individuals who currently } \\
\text { have an outstanding loan balance with } \\
\text { the MFI or are responsible for repaying } \\
\text { any portion of the Gross Loan Portfolio }\end{array}$ & In & 104 & 23 & 0.949 & 5163 \\
\hline MFI age & 383 & $\begin{array}{l}\text { The years since MFI has started } \\
\text { operations }\end{array}$ & No. & 14.15 & 12 & 3 & 51 \\
\hline Women borrowers & $371^{12}$ & Percentage of borrowers who are women & $\%$ & 64.47 & 61.5 & 8.6 & 100 \\
\hline Average loan size & 383 & $\begin{array}{l}\text { Gross Loan Portfolio / Number of active } \\
\text { borrowers }\end{array}$ & $\$$ & 797.88 & 487 & 34 & 11198 \\
\hline $\operatorname{Staff}(E)$ & 383 & $\begin{array}{l}\text { The number of individuals who are } \\
\text { actively employed by the MFI. }\end{array}$ & No. & 578 & 204 & 7 & 24457 \\
\hline Operating Cost per Staff & 383 & Operating cost per staff & $\$$ & 12.127 & 11.906 & 3.89 & 47.714 \\
\hline Borrower per Staff* & 383 & Borrower per Staff & No. & 143.89 & 136.74 & 2.83 & 454.8 \\
\hline Loansize/GNIpc & 383 & Average loan size/GNI per capita & $\$$ & 0.911 & 0.444 & .026 & 33.93 \\
\hline $\begin{array}{l}\text { Subsidy Dependence } \\
\text { Index }(S D I)\end{array}$ & 383 & $\operatorname{Subsidy}(S) /$ Revenue from lending $(R)$ & & 0.214 & 0.122 & -1.914 & 4.568 \\
\hline $\begin{array}{l}\text { Operational Self } \\
\text { Sufficiency }(O S S)\end{array}$ & 383 & $\begin{array}{l}\text { Financial Revenue (Total)/ (Financial } \\
\text { expense + Loan loss provision expense + } \\
\text { Operating expense) }\end{array}$ & $(\%)$ & 123.4 & 120.7 & 3.57 & 254.9 \\
\hline Intrest rate/Yield & 383 & $\begin{array}{l}\text { Average on lending interest rate/yield on } \\
\text { lending }\end{array}$ & $(\%)$ & 30.2 & 26.7 & 0 & 1.281 \\
\hline
\end{tabular}

Source: Author's own calculation based on the Audit Reports of MFIs taken from Microfinance Information eXange Inc website. All the values in USD are in 000s. Exchange rates are also taken from Mixmarket website. Some definitions are taken from CGAP (2003)

Table 3.3 presents the categorical variables used in this essay. The classification of all the categorical variables is based on the information provided on the Mix Market web site.

\footnotetext{
1212 observations have been reduced because Six MFIs have no women borrowers information available.
} 
Table 3.3

\section{Categorical Variables}

\begin{tabular}{|c|c|}
\hline Variables & Description \\
\hline Region & $\begin{array}{l}\text { Geographic region in which the MFI operates classified into } 6 \\
\text { regions: Africa }(A) \text {; East Asia and the Pacific }(E A \& P) \text {; Eastern Europe } \\
\text { and Central Asia }(E E \& C A) \text {; Middle East and North Africa }(M E N A) \text {; } \\
\text { Latin America and the Caribbean }(L A C) \text {; South Asia }(S A) \text {. }\end{array}$ \\
\hline Lending Methodology & $\begin{array}{l}\text { Lending methodology is classified into } 4 \text { categories: Individual }(I) \text {; } \\
\text { Individual \& Solidarity/Group }(I S) \text {; Group/Solidarity }(S) \text {; Village } \\
\text { banking }(V) \text {. }\end{array}$ \\
\hline Status & $\begin{array}{l}\text { Classified into } 5 \text { categories: Nongovernmental organizations }(N G O) \text {; } \\
\text { Bank }(B) \text {; Non-banking financial intermediaries (NBFI); Rural Bank } \\
(R B) \text {; Cooperatives (Coop.). }\end{array}$ \\
\hline Other services & $\begin{array}{l}\text { Whether MFI provides other services i.e. health, education etc in } \\
\text { addition to providing financial services or not. }\end{array}$ \\
\hline Saving & Whether saving (voluntary or Compulsory) is a feature of MFI or not. \\
\hline Regulated & Whether MFI is regulated by some authority like central bank etc. or not. \\
\hline
\end{tabular}

Table 3.4

Correlations

\begin{tabular}{|c|c|c|c|c|c|c|c|c|c|c|c|}
\hline & SDI & \begin{tabular}{|c|} 
Subsid \\
$y$
\end{tabular} & OSS & Age & $\begin{array}{c}\text { Wome } \\
n\end{array}$ & $\begin{array}{c}\text { Loan } \\
\text { size }\end{array}$ & $\begin{array}{c}\text { borr/ } \\
\text { staff }\end{array}$ & $\begin{array}{l}\text { cost/ } \\
\text { staff }\end{array}$ & $\begin{array}{c}\text { True } \\
\text { Profit }\end{array}$ & Equity & Rev. \\
\hline SDI & $\begin{array}{r}1.00 \\
(381) \\
\end{array}$ & & & & & & & & & & \\
\hline Subsidy & \begin{tabular}{|c|}
$0.228^{*}$ \\
$(381)$ \\
\end{tabular} & $\begin{array}{c}1.00 \\
(381)\end{array}$ & & & & & & & & & \\
\hline OSS & $\begin{array}{c}-0.402^{*} \\
(378) \\
\end{array}$ & $\begin{array}{l}-0.029 \\
(378)\end{array}$ & $\begin{array}{c}1.00 \\
(397) \\
\end{array}$ & & & & & & & & \\
\hline Age & $\begin{array}{c}-0.139 * \\
(381)\end{array}$ & $\begin{array}{l}0.154^{*} \\
(381)\end{array}$ & $\begin{array}{l}0.089 \\
(397)\end{array}$ & $\begin{array}{c}1.00 \\
(406)\end{array}$ & & & & & & & \\
\hline Women & \begin{tabular}{|c|}
-0.033 \\
$(369)$ \\
\end{tabular} & $\begin{array}{l}0.046 \\
(369)\end{array}$ & $\begin{array}{c}-0.136^{*} \\
(384) \\
\end{array}$ & $\begin{array}{l}0.044 \\
(389) \\
\end{array}$ & $\begin{array}{c}1.00 \\
(389) \\
\end{array}$ & & & & & & \\
\hline Loan size $^{13}$ & $\begin{array}{l}0.047 \\
(378) \\
\end{array}$ & $\begin{array}{l}0.004 \\
(378)\end{array}$ & $\begin{array}{l}0.069 \\
(394) \\
\end{array}$ & $\begin{array}{c}-0.125^{*} \\
(399) \\
\end{array}$ & $\begin{array}{c}-0.270^{*} \\
(386)\end{array}$ & $\begin{array}{c}1.00 \\
(399) \\
\end{array}$ & & & & & \\
\hline $\begin{array}{c}\text { Borr/ } \\
\text { Staff } \\
\end{array}$ & $\begin{array}{c}-0.204^{*} \\
(381) \\
\end{array}$ & $\begin{array}{l}0.012 \\
(381) \\
\end{array}$ & $\begin{array}{c}0.197^{*} \\
(397) \\
\end{array}$ & $\begin{array}{c}0.106^{*} \\
(402)\end{array}$ & $\begin{array}{c}0.343^{*} \\
(389) \\
\end{array}$ & $\begin{array}{c}-0.315^{*} \\
(399)\end{array}$ & $\begin{array}{c}1.00 \\
(402) \\
\end{array}$ & & & & \\
\hline $\begin{array}{l}\text { Cost/ } \\
\text { Staff } \\
\end{array}$ & $\begin{array}{c}-0.046 \\
(381) \\
\end{array}$ & $\begin{array}{c}-0.053 \\
(381) \\
\end{array}$ & $\begin{array}{c}-0.042 \\
(390) \\
\end{array}$ & $\begin{array}{l}0.026 \\
(393) \\
\end{array}$ & $\begin{array}{c}-0.380^{*} \\
(381) \\
\end{array}$ & $\begin{array}{l}0.001 \\
(390) \\
\end{array}$ & \begin{tabular}{|c|}
$-0.100^{*}$ \\
$(393)$ \\
\end{tabular} & $\begin{array}{c}1.00 \\
(393) \\
\end{array}$ & & & \\
\hline $\begin{array}{c}\text { True } \\
\text { Profit }\end{array}$ & $\begin{array}{c}-0.273^{*} \\
(381)\end{array}$ & $\begin{array}{c}-0.885^{*} \\
(381)\end{array}$ & $\begin{array}{c}0.219^{*} \\
(380)\end{array}$ & $\begin{array}{c}-0.067 \\
(383)\end{array}$ & $\begin{array}{c}-0.085 \\
(371) \\
\end{array}$ & $\begin{array}{l}0.020 \\
(380)\end{array}$ & $\begin{array}{l}0.047 \\
(383)\end{array}$ & $\begin{array}{l}0.111^{*} \\
(383)\end{array}$ & $\begin{array}{c}1.00 \\
(383)\end{array}$ & & \\
\hline Equity & $\begin{array}{l}0.017 \\
(381)\end{array}$ & $\begin{array}{c}0.664^{*} \\
(381)\end{array}$ & $\begin{array}{c}0.319^{*} \\
(381)\end{array}$ & $\begin{array}{c}0.219^{*} \\
(385)\end{array}$ & $\begin{array}{l}-0.027 \\
(373)\end{array}$ & $\begin{array}{l}0.014 \\
(382)\end{array}$ & \begin{tabular}{|c|}
$0.148^{*}$ \\
$(385)$ \\
\end{tabular} & $\begin{array}{l}0.041 \\
(384)\end{array}$ & $\begin{array}{c}-0.259^{*} \\
(381)\end{array}$ & $\begin{array}{c}1.00 \\
(385)\end{array}$ & \\
\hline Rev. & $\begin{array}{l}-0.075 \\
(381)\end{array}$ & $\begin{array}{l}0.463^{*} \\
(381)\end{array}$ & \begin{tabular}{|l|}
$0.148^{*}$ \\
$(386)$ \\
\end{tabular} & $\begin{array}{c}0.173^{*} \\
(389) \\
\end{array}$ & $\begin{array}{c}-0.111^{*} \\
(377)\end{array}$ & $\begin{array}{l}0.021 \\
(386) \\
\end{array}$ & \begin{tabular}{|c|}
-0.055 \\
$(389)$ \\
\end{tabular} & $\begin{array}{l}0.302^{*} \\
(389)\end{array}$ & $\begin{array}{c}-0.113^{*} \\
(383) \\
\end{array}$ & $\begin{array}{l}0.720^{*} \\
(384)\end{array}$ & $\begin{array}{c}1.00 \\
(389) \\
\end{array}$ \\
\hline
\end{tabular}

Source: Authors own calculations

Numbers of Observations are in parentheses

*Significance level at $5 \%$ or better

\footnotetext{
${ }^{13}$ loan size divided by the GNI per capita is used as a porxy for he outreach. The lower the ratio, the higher the Outreach i.e. MFI caters to poor who can only afford small loan sizes
} 
The correlation matrix in Table 3.4 reveals important relationships among the financial, organizational and social variables used in this study. Most of the relationships are in line with the theory. The next section describes the theory behind the non-parametric efficiency analysis and its application to the microfinance institutions.

\subsection{Efficiency Analysis}

For the efficiency analysis of the microfinance institutions, a two-stage analysis has been carried out. Firstly, Data Envelopment Analysis (DEA) approach is used to estimate technical and pure efficiency scores of the MFIs for the year 2005 and 2006 separately. Secondly, DEA-based Malmquist indices are calculated to analyze inter-temporal productivity change. The advantages of using the DEA technique to gauge efficiency are well documented in the literature. DEA framework can handle multiple outputs and inputs. Thus, in the context of MFIs efficiency analysis, it can incorporate both the outputs of outreach and sustainability along with other inputs into a single framework. Neither has it required any price information for the dual cost function nor parametric functional form for the production function. In the next subsections only a brief description of DEA approach and Malmquist productivity index will be given.

\subsubsection{Methodology}

\subsubsection{Data Envelopment Analysis}

DEA was first introduced by Charnes, Cooper and Rhodes (1978), famously known as the CCR model after their names, as a generalization of efficiency proposed by Farrell (1957). We assume that there are $n$ Decision Making Units (DMUs), and each DMU has $m$ inputs to produce $s$ outputs. This model measures the relative efficiency ratio of a given DMU $\left(h_{o}\right)$ by the sum of its weighted outputs to the sum of its weighted inputs. It can be formulated as follows, known as the input-oriented CCR model: 
$\max h_{o}=\frac{\sum_{r=1}^{s} u_{r} y_{r o}}{\sum_{i=1}^{m} v_{i} x_{i o}}$

subject to

$$
\begin{aligned}
& \frac{\sum_{r=1}^{s} u_{r} y_{r j}}{\sum_{i=1}^{m} v_{i} x_{i j}} \leq 1, \\
& u_{r}, v_{i} \geq 0, i=1, \ldots, m, \quad j=1, \ldots, n, \quad r=1, \ldots, s,
\end{aligned}
$$

where $h_{o}$ is the efficiency ratio of the $\mathrm{DMU}_{o} ; v_{i}, u_{r}$ are virtual multipliers (weights) for the $i$ th input and the $r$ th output, respectively; $m$ is the number of inputs, $s$ is the number of outputs and $n$ is the number of DMUs; $x_{i o}$ is the value of the input $i$ for $\mathrm{DMU}_{o}, y_{r o}$ is the value of the output $r$ for $\mathrm{DMU}_{o}$.

The equation (1) is fractional programming and has an infinite number of solutions. It can be solved by adding an additional constraint, $\quad \sum_{i=1}^{m} v_{i} x_{i o}=1$. The form then converts to the multiplier form of the DEA LP problem:

$\max h_{o}=\sum_{r=1}^{s} \mu_{r} y_{r o}$

subject to

$$
\begin{aligned}
& \sum_{r=1}^{s} \mu_{r} y_{r j}-\sum_{i=1}^{m} v_{i} x_{i j} \leq 0, \quad j=1, \ldots, n, \\
& \sum_{i=1}^{m} v_{i} x_{i o}=1 \\
& \mu_{r}, v_{i} \geq \varepsilon>0, i=1, \ldots, m, r=1, \ldots, s,
\end{aligned}
$$

To reflect the transformation, the variables from $(u, v)$ have been replaced by $(\mu$, $\nu$ ). $\varepsilon$ is a non-Archimedean quantity defined to be smaller than any positive real number. The dual form of equation (2) can be written as an equivalent envelopment form as follows:

$\min h_{o}=\theta_{o}-\varepsilon\left(\sum_{i=1}^{m} s_{i}^{-}+\sum_{r=1}^{s} s_{r}^{+}\right)$

subject to 


$$
\begin{aligned}
& \sum_{j=1}^{n} x_{i j} \lambda_{j}+s_{i}^{-}=\theta x_{i o}, \quad i=1, \ldots, m, \\
& \sum_{j=1}^{n} y_{r j} \lambda_{j}-s_{r}^{+}=y_{r o}, \quad r=1, \ldots, s, \\
& \lambda_{j}, s_{i}^{-}, s_{r}^{+} \geq 0, \varepsilon>0, \quad j=1, \ldots, n,
\end{aligned}
$$

Where $\theta_{o}$ is the proportion of $\mathrm{DMU}_{o}$ 's inputs needed to produce a quantity of outputs equivalent to its benchmarked DMUs identified and weighted by the $\lambda_{j} . s_{i}$ and $s_{r}{ }^{+}$are the slack variables of input and output respectively. $\lambda_{j}$ is a $(n \times 1)$ column vector of constants and can indicate benchmarked DMUs of $\mathrm{DMU}_{o}$. If $h_{o}{ }^{*}=1$ is meant efficient and $h_{o}{ }^{*}<1$ is meant inefficient where the symbol "*” represents the optimal value.

However, the CCR model is calculated with the constant returns to scale (CRS) assumption. This assumption is not supportable in imperfectly competitive markets. The BCC model proposed by Banker, Charnes and Cooper (1984) modifies the CCR model by allowing variable returns to scale (VRS). The CRS LP problem can be easily modified to account for VRS by adding the convexity constraint

$$
\sum_{j=1}^{n} \lambda_{j}=1 \text { to equation } 3 \text { to provide }
$$

$\min h_{o}=\theta_{o}-\varepsilon\left(\sum_{i=1}^{m} s_{i}^{-}+\sum_{r=1}^{s} s_{r}^{+}\right)$

subject to

$$
\begin{aligned}
& \sum_{j=1}^{n} x_{i j} \lambda_{j}+s_{i}^{-}=\theta x_{i o}, \quad i=1, \ldots, m, \\
& \sum_{j=1}^{n} y_{r j} \lambda_{j}-s_{r}^{+}=y_{r o}, \quad r=1, \ldots, s, \\
& \sum_{j=1}^{n} \lambda_{j}=1, \\
& \lambda_{j}, s_{i}^{-}, s_{r}^{+} \geq 0, \varepsilon>0, j=1, \ldots, n,
\end{aligned}
$$

The Overall Technical Efficiency (OTE) from CCR model can be decomposed into Pure Technical Efficiency (PTE) and Scale Efficiency (SE). The PTE can be obtained 
from BCC model. We can measure the $S E$ for a $\mathrm{DMU}_{o}$ by using CCR and BCC model as follow:

$S E=O T E / P T E$,

If the ratio is equal to 1 then a $\mathrm{DMU}_{o}$ is scale efficient, otherwise if the ratio is less than one then a $\mathrm{DMU}_{o}$ is scale inefficient.

\subsubsection{The Malmquist Productivity Index}

To define the Malmquist index, Fare et al. (1994) defined distance functions with respect to two different time periods:

$$
D_{0}^{t}\left(x^{t+1}, y^{t+1}\right)=\inf \left\{\theta \mid\left(x^{t+1}, y^{t+1} / \theta\right) \in S^{t}\right\}
$$

and

$$
D_{0}^{t+1}\left(x^{t}, y^{t}\right)=\inf \left\{\theta \mid\left(x^{t}, y^{t} / \theta\right) \in S^{t+1}\right\}
$$

The distance function in (6) measures the maximal proportional change in output required to make $\left(x^{t+1}, y^{t+1}\right)$ feasible in relation to technology at time $t$. Similarly, the distance function in (7) measures the maximal proportional change in output required to make $\left(x^{t}, y^{t}\right)$ feasible in relation to technology at time $t+1$. The output Malmquist TFP productivity index can then be expressed as:

$$
M_{o}\left(x^{t+1}, y^{t+1}, x^{t}, y^{t}\right)=\frac{D_{o}^{t+1}\left(x^{t+1}, y^{t+1}\right)}{D_{o}^{t}\left(x^{t}, y^{t}\right)}\left[\frac{D_{o}^{t}\left(x^{t+1}, y^{t+1}\right)}{D_{o}^{t+1}\left(x^{t+1}, y^{t+1}\right)} \frac{D_{o}^{t}\left(x^{t}, y^{t}\right)}{D_{o}^{t+1}\left(x^{t}, y^{t}\right)}\right]^{\frac{1}{2}}
$$

The term outside the brackets shows the change in technical efficiency while the geometric mean of the two ratios inside the brackets measures the shift in technology between the two period's $t$ and $t+1$; this could be called technological progress. So:

$$
\text { Efficiency change }=\frac{D_{o}^{t+1}\left(x^{t+1}, y^{t+1}\right)}{D_{o}^{t}\left(x^{t}, y^{t}\right)}
$$


Technical change $=\left[\frac{D_{o}^{t}\left(x^{t+1}, y^{t+1}\right)}{D_{o}^{t+1}\left(x^{t+1}, y^{t+1}\right)} \frac{D_{o}^{t}\left(x^{t}, y^{t}\right)}{D_{o}^{t+1}\left(x^{t}, y^{t}\right)}\right]^{\frac{1}{2}}$

\subsubsection{DEA Model and Input Output Variable}

Table 3.5 depicts the summary of inputs and outputs selected for this study. The main objective of estimating a production function is to explain the quantity of output produced given certain levels of inputs and other relevant factors that might explain the quantity of output produced. In traditional financial literature two models i.e. Production Model and Intermediation Model are popular depending upon what one thinks an institution do. The majority of the studies in banking efficiency literature are based on the input oriented constant returns to scale CCR model (Charnes et al, 1978). In the production model approach, financial institutions are treated as firms that use physical input, employees and expend money in order to obtain deposits, grant loans and collect revenues. We assume the output oriented Production model with variable returns to scale is better suited to microfinance institutions rather than constant returns to scale model. Because MFIs are more interested in increasing outreach i.e. lending loans to poor people which commensurate with not only their social mission but also contributes towards sustainability as well by collecting more revenues from lending. In addition to that they compete in an imperfect economic environment as the markets for MFIs are not as well developed as the conventional banking sector ${ }^{14}$. And they always have restricted amount of money and human resource (Inputs) to spend on unlike commercial banks which can generate money from shareholders. In the context of output oriented model, this essay asks a specific question "By how much the output quantities be proportionally expanded without altering the input quantities used?. The selection of specifications with correct inputs and outputs in the context of MFIs is very important. This study uses LR$\mathrm{ACE}^{15}$ as a general specification where gross loan portfolio and financial revenues are taken as an output and assets, operating costs and number of staff as an input.

\footnotetext{
${ }^{14}$ Stiglitz and Weiss (1983) provides the analytical underpinnings of the imperfect information paradigm

${ }^{15}$ The left part in all the specifications show outputs and the right part depict inputs.
} 
In addition to that, we have also used specifications L-ACE and R-ACE, where the former put emphasis on granting loan as main objective of MFIs and latter signifies revenue collection as main objective of MFIs. The other specifications used are basically the different combination of treating subsidies as an input and output with the above general specifications.

Table 3.5

Inputs and Outputs in Efficiency Specifications

\begin{tabular}{|c|c|c|c|c|}
\hline $\begin{array}{c}\text { Variabl } \\
\text { e }\end{array}$ & Variable name & Not. & Definition & Unit \\
\hline Input & Total assets 16 & A & Total of all net asset accounts & $(\$)$ \\
\hline Input & $\begin{array}{l}\text { Operating } \\
\text { Cost }^{17}\end{array}$ & $\mathrm{C}$ & $\begin{array}{l}\text { Expenses related to operations, such as all personnel } \\
\text { expenses, rent and utilities, transportation, office } \\
\text { supplies, and depreciation }\end{array}$ & $(\$)$ \\
\hline Input & $\begin{array}{l}\text { Number of } \\
\text { Staff } 18\end{array}$ & $\mathrm{E}$ & $\begin{array}{l}\text { The number of individuals who are actively employed } \\
\text { by the MFI. This includes contract employees or } \\
\text { advisors who dedicate the majority of their time to } \\
\text { the MFI, even if they are not on the MFI's roster of } \\
\text { employees }\end{array}$ & No. \\
\hline Input & Total subsidies & $\mathrm{S}^{\mathrm{i}}$ & $\left(\mathrm{E}^{*} \mathrm{~m}+\mathrm{A}(\mathrm{m}-\mathrm{c})+\mathrm{K}-\mathrm{P}\right)$ in case a positive value & $(\$)$ \\
\hline Output & Total subsidies & $\mathrm{S}^{\circ}$ & $(\mathrm{E} * \mathrm{~m}+\mathrm{A}(\mathrm{m}-\mathrm{c})+\mathrm{K}-\mathrm{P})$ in case a negative value & \\
\hline Output & $\begin{array}{l}\text { Gross loan } \\
\text { portfolio }^{19}\end{array}$ & $\mathrm{~L}$ & $\begin{array}{l}\text { Outstanding principal balance of all of the MFI's } \\
\text { outstanding loans including current, delinquent and } \\
\text { restructured loans, but not loans that have been } \\
\text { written off. It does not include interest receivable }\end{array}$ & $(\$)$ \\
\hline Output & $\begin{array}{l}\text { Financial } \\
\text { revenue }^{20}\end{array}$ & $\mathrm{R}$ & $\begin{array}{l}\text { Revenue generated from the gross loan portfolio and } \\
\text { from investments plus other operating revenue }\end{array}$ & $(\$)$ \\
\hline Output & $\begin{array}{l}\text { Revenue- } \\
\text { Subsidy }\end{array}$ & $\mathrm{R}^{\mathrm{s}}$ & Financial revenues without subsidies (R-S) & $(\$)$ \\
\hline
\end{tabular}

Source: Authors own calculation based on data taken from audit reports and MixMarket website.

\subsubsection{Incorporation of Subsidies into DEA Framework}

In this study, subsidies have been splitted between the positive subsidies and negative subsidies. They have entered into the DEA framework on the premise that positive subsidies distort public wealth while negatives subsidies create it. Where positive subsidies have been treated as an input, while negative subsidies

\footnotetext{
${ }^{16}$ Berger and Humphrey (1997), Seiford and Zhu (1999) and Luo (2003).

${ }^{17}$ Athanassopoulos (1997), Berger and Humphrey (1997) and Pastor (1999).

${ }^{18}$ Athanassopoulos (1997), Berger and Humphrey (1997), Sherman and Gold (1985), Seiford and Zhu (1999) and Luo (2003) among others

${ }^{19}$ (Sherman and Gold, 1985; Athanassopoulos, 1997; Berger and Humphrey, 1997; Wheelock and Wilson, (1999).

${ }^{20}$ Pastor (1999) and Seiford and Zhu (1999)
} 
as an output in all the efficiency specifications. This is due to the fact that our calculated subsidies are in fact the social cost to the society of subsidized MFIs. Where a positive subsidy $(\mathrm{E} * \mathrm{~m}+\mathrm{A}(\mathrm{m}-\mathrm{c})+\mathrm{K}-\mathrm{P})>0)$ means the MFI is distorting public wealth so it is entered into the efficiency model as an input. While a negative subsidy $\left.\left(\mathrm{E}^{*} \mathrm{~m}+\mathrm{A}(\mathrm{m}-\mathrm{c})+\mathrm{K}-\mathrm{P}\right)<0\right)$ shows that MFI is creating public wealth so it is entered into the efficiency framework as an output. Subsidies as an input and output have been denoted by $S^{i}$ and $S^{\circ}$ respectively, where superscripts $i$ and $o$ refers to input and output respectively.

\subsection{Efficiency Analysis}

The efficiency analysis have been carried out for both years i.e. 2005 and 2006 separately and also jointly by calculating Malmquist productivity index for year 2006 relative to the year 2005. The results for technical efficiency have been bifurcated into constant returns to scale efficiency (crs), variable return to scale efficiency (vrs) and scale efficiency (Scale). In this paper, the focus of the analysis is on the variable returns to scale efficiency scores for the reasons as described in section 3.3.2. Nevertheless the average efficiency scores of constant returns to scale and scale efficiency have also been presented in the following figures.

Fig 3.1 shows the average efficiency scores for specification LR-ACE employing variable returns to scale. Latin American MFIs are the efficient ones while South Asians are the worst ones relatively. MFIs with Non-banking financial intermediary status are more efficient than others while MFIs with individual and village lending methodology are more efficient than others.

Fig 3.2 presents the average efficiency scores assuming constant returns to scale. The results are by and large same as with variable returns to scale. Latin American MFIs are found to be efficient ones whereas South Asian MFIs turn out to be less efficient than the rest. MFIs with status "NBFI" are the efficient one while MFIs with individual and village lending methodology are the efficient one relative to others. Again MFIs with no saving designs and are not regulated are more efficient than their counterparts. 

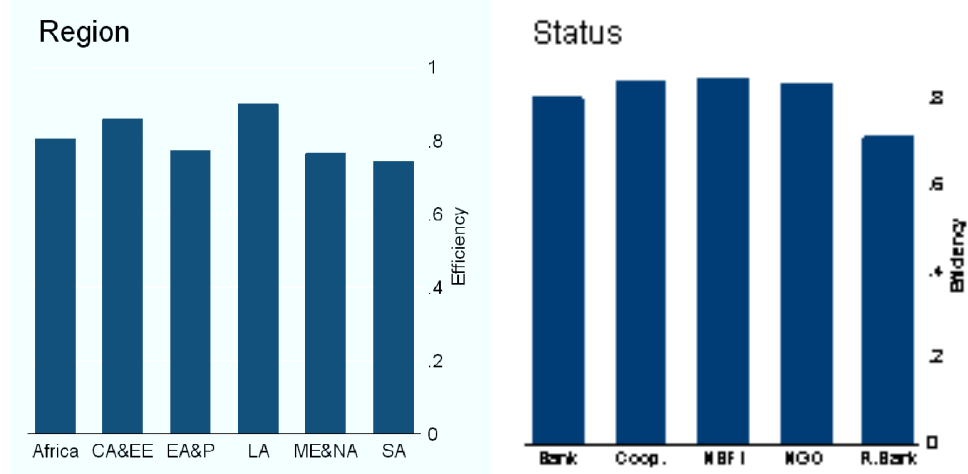

Lending Methodology
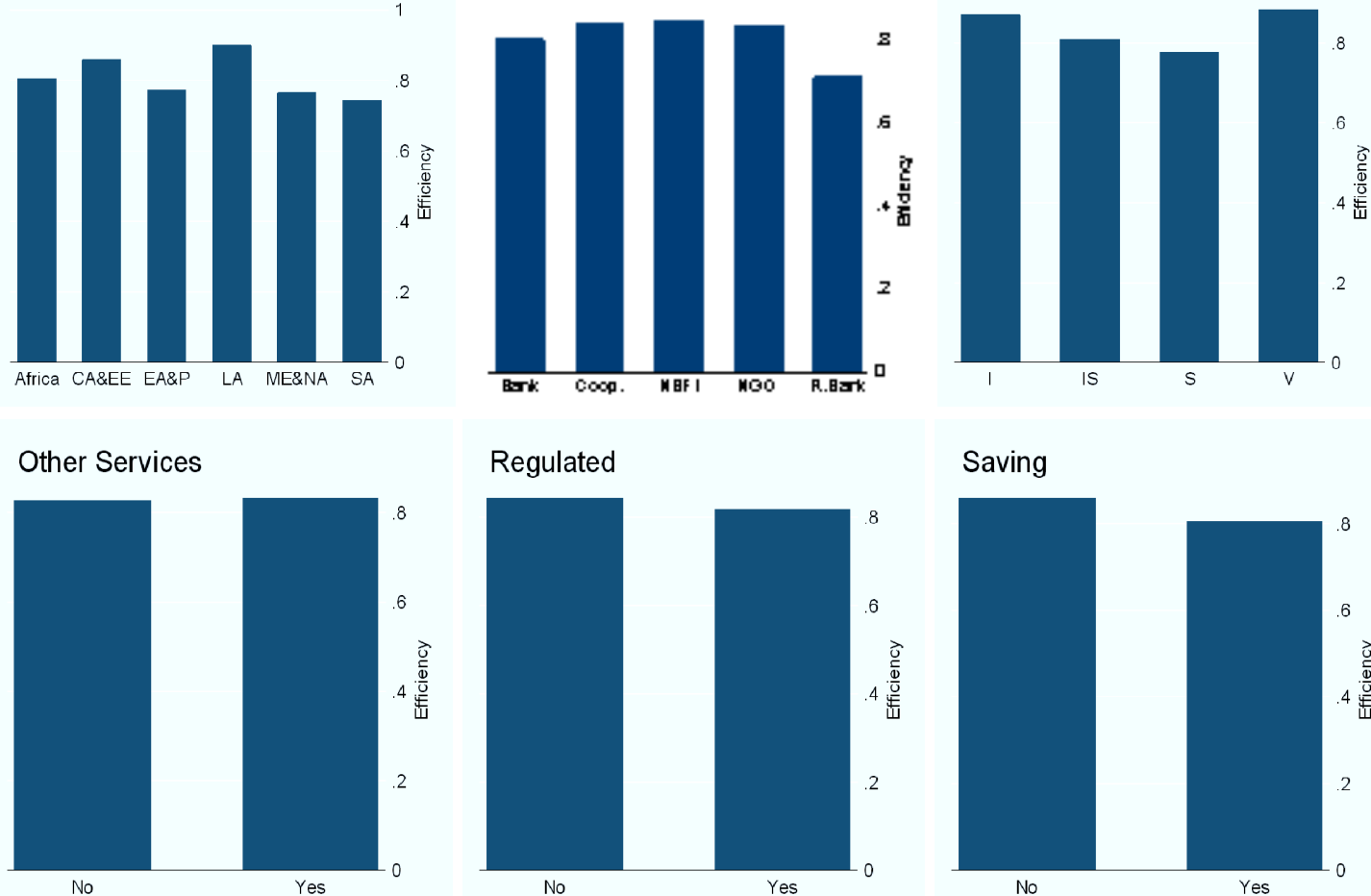

Saving

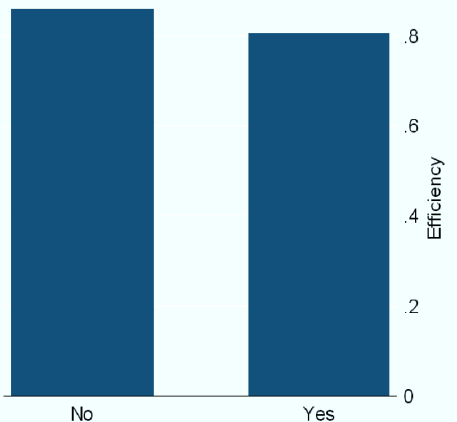

Fig.3.1 Composition of Efficiency Scores for Specification LR-ACE (vrs) Source: Based on authors own calculations.
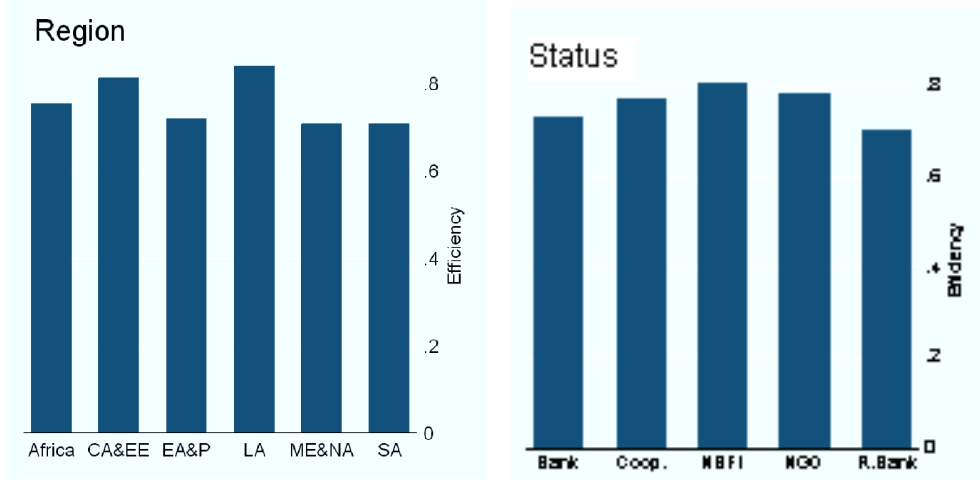

Lending Methodology
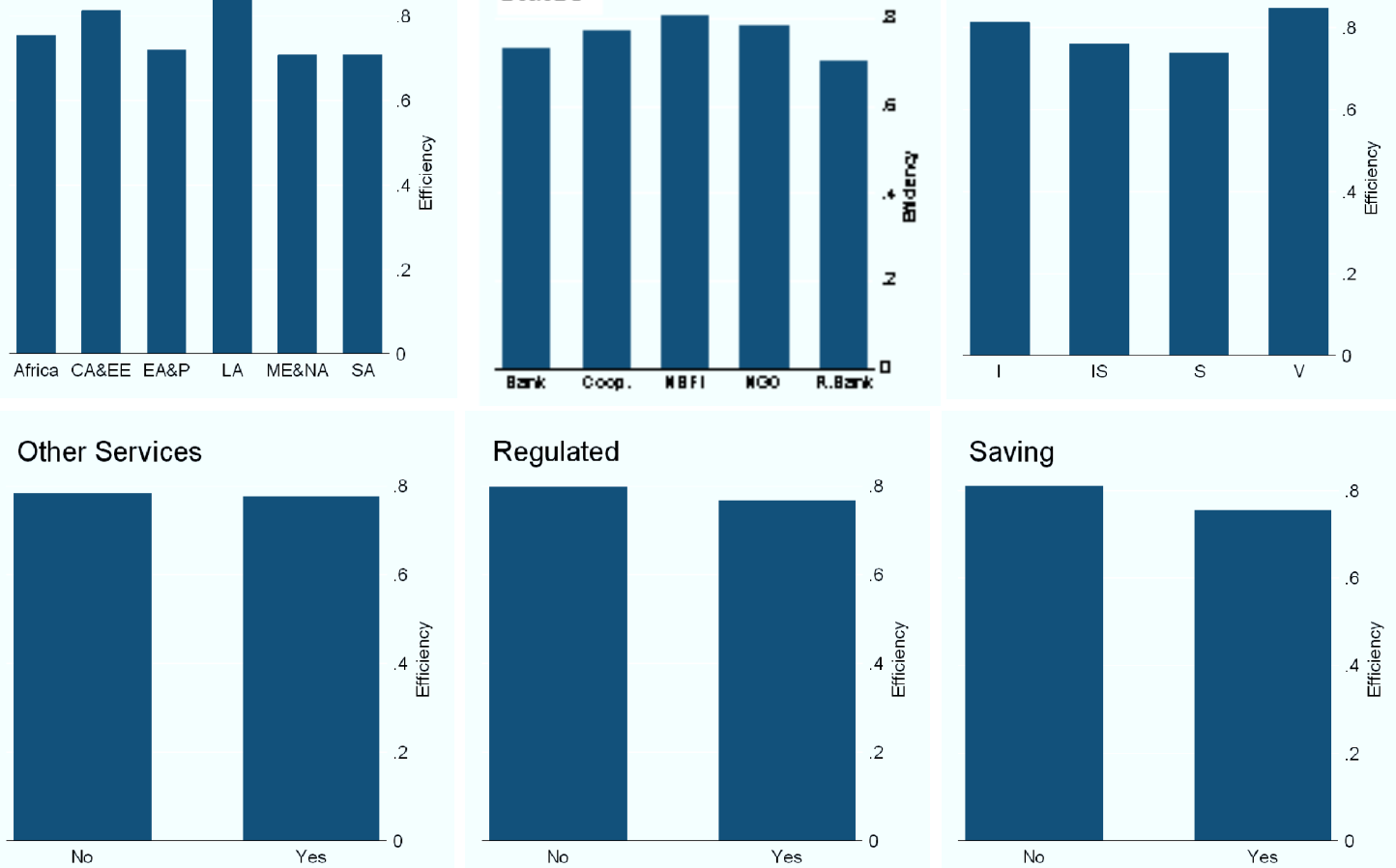

Saving

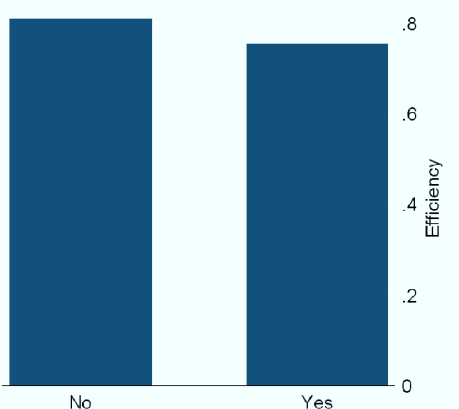

Fig.3.2 Composition of Efficiency Scores for Specification LR-ACE (crs) Source: Based on authors own calculations. 
The average scale efficiency scores have been presented in Fig. 3.3. The average scores show that NBFIs along with Rural Banks are scale efficient. MFIs located in South Asia are on average more scale efficient than others.
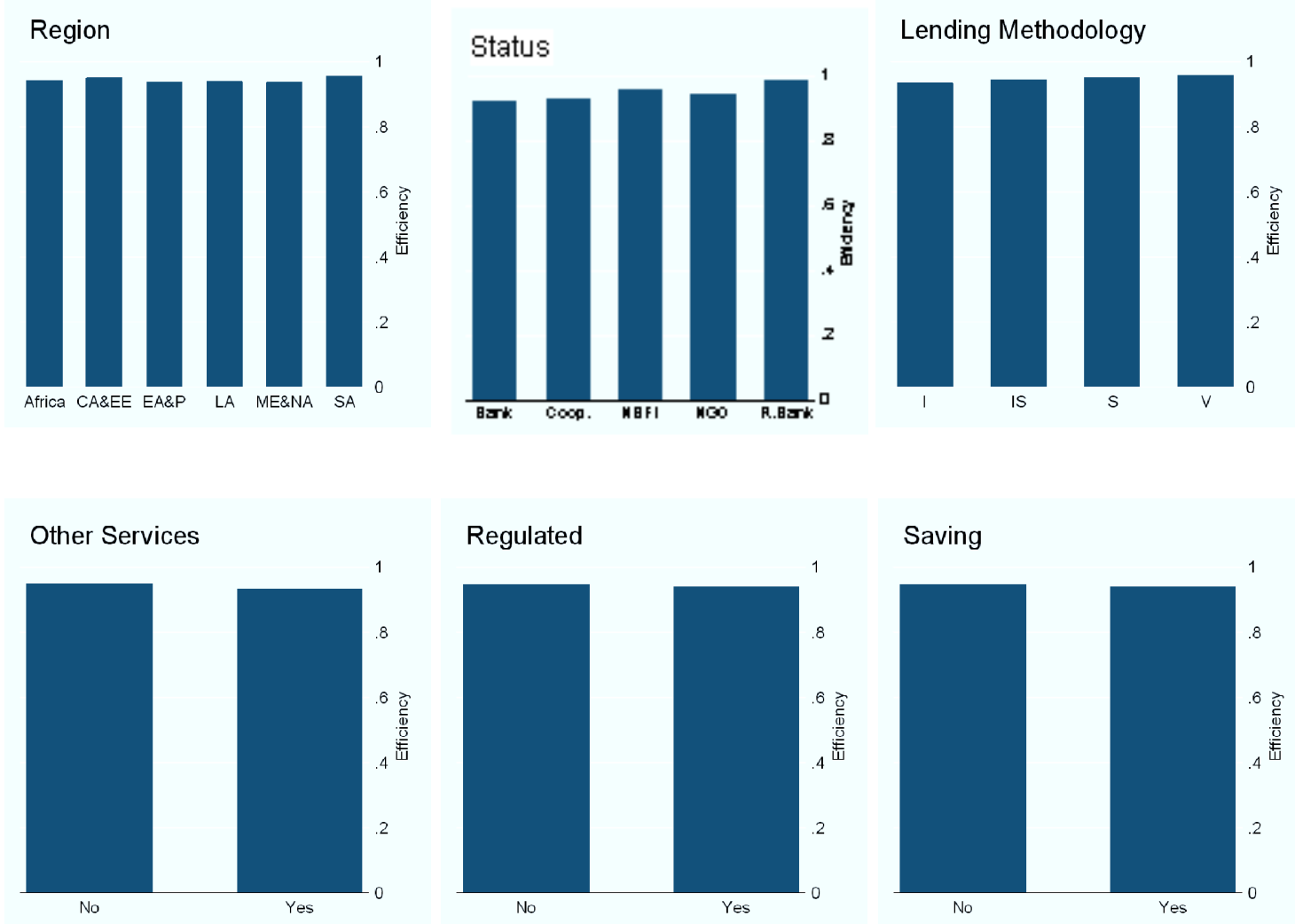

Fig.3.3 Composition of Efficiency Scores for Specification LR-ACE (scale) Source: Based on authors own calculations.

\subsection{With and Without Subsidy Analysis}

\subsubsection{Efficiency Analysis 2005}

Table 3.6 presents the average values of the technical efficiency results of with and without subsidy specifications. The specifications entertained are LR-ACE vs. LR ${ }^{s}$-ACE (without subsidies) and R-ACE vs. Rs-ACE (without subsidies). The sample consists of all the MFIs in the data for year 2005. The detailed efficiency results of all the MFIs are presented in Appendix D. Comparing the general

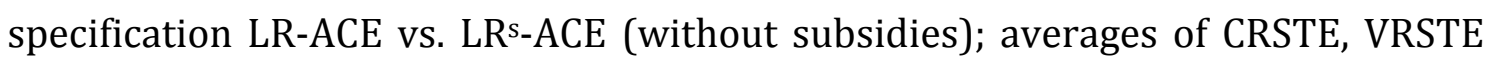
and SE have decreased from $0.786,0.833$, and 0.945 to $0.700,0.881$ and 0.900 
respectively. The average efficiency scores can also be interpreted in another way. For example, score of 0.833 shows that average output of MFIs can be increased by $16.7 \%$ with the same use of inputs assuming variable returns to scale. Considering specification R-ACE (where MFIs objective is to increase revenues), the decrease in efficiency is more resounding when subsidies have been subtracted from the revenues in specification $\mathrm{R}^{\mathrm{s}}$-ACE (without subsidy). MFIs which were previously $100 \%$ efficient under LR-ACE become less efficient after taking subsidies out of the revenues, are FADES, CredMujer, ADEMI, C Fund, ACME, FINCA-Mali, SEF-ZAF, Finca-UGA, PRIDE and CETZAM. The exceptions are INNMA and DIGOS which become $100 \%$ efficient by taking out subsidies. MFIs remained 100\% efficient for both with and without subsidies are BESA, ASA, ALIDE, MIKROFIN, FMM Pop, WWB CA, Fundecoca, Bancosol, Coac Jardin, Coac Sac, FINCA-ECU, ADCSI, DECSI, KSF, AIYL Bank, Al AMANA, VYCCU, Prodesa, SEAP, BANTRA, CMAC Arq, CMAC Cus, Mibanco and ACEP.

Table 3.7 shows the average efficiency values of MFIs for year 2005 with positive subsidies entering into the specifications as an input. The sample consists of only subsidy dependent MFIs with positive subsidies. The detailed efficiency results of all the MFIs are presented in Appendix E. There is only a slight increase in the average efficiencies for specification LR-ACES ${ }^{i}$ where subsidy enters into the model as an input i.e. from $0.790,0.843$ and 0.939 to $0.812,0.860$ and 0.946 respectively. For other specifications of L-ACE and R-ACE, adding subsidies as an input also result in a small increase in the efficiencies. However considering the base specification LR-ACE, MFIs which become 100\% efficient with subsidies are SUNRISE, Coac S Jose, C Fund, MDSL, FINDESA, ASASAH, FIELCO, Bank Eskhata and CMFL. For specification L-ACES, those MFIs are DESHA, SUNRISE, COAC S JOSE, NSSC, FINDESA and Bank Eskhata. While for specification R-ACE, HORIZON, MDSL, LAPO, BANTRA, Bank Eskhata and PRIDE become fully efficient.

Table 3.8 depicts average efficiency results for MFIs with negative subsidies entering into the model as an output. The sample consists of only those MFIs with negative subsidies. The detailed efficiency results of all the MFIs are presented in Appendix F. Again treating subsidies as an output only slightly improves the 
average efficiency scores for all the specifications. Only Fundenuse becomes 100\% efficient once subsidies enter into the specifications as an output for specifications LR-ACE and R-ACE. Whereas for specification L-ACE, FMM Pop, Finca-ECU, and Fundenuse become fully efficient.

Table 3.6

Efficiency Analysis 2005 (With and Without Subsidies)

\begin{tabular}{|c|c|c|c|c|}
\hline & \multicolumn{2}{|c|}{ LR-ACE } & \multicolumn{2}{c|}{ R-ACE } \\
\hline technical efficiency & with subsidies & without subsidies & with subsidies & without subsidies \\
\hline constant (CRSTE) & 0.786 & 0.700 & 0.707 & 0.222 \\
\hline variable (VRSTE) & 0.833 & 0.781 & 0.735 & 0.369 \\
\hline scale efficiency (SE) & 0.945 & 0.900 & 0.966 & 0.691 \\
\hline
\end{tabular}

Source: Author's own calculations. All values are average of the efficiencies of the total MFIs.

Table 3.7

Efficiency Analysis 2005 (Subsidies as an Input)

\begin{tabular}{|c|c|c|c|c|c|c|}
\hline & \multicolumn{2}{|c|}{ LR-ACE } & \multicolumn{2}{c|}{ L-ACE } & \multicolumn{2}{c|}{ R-ACE } \\
\hline \multirow{2}{*}{ technical efficiency } & $\begin{array}{c}\text { without } \\
\text { subsidy }\end{array}$ & $\begin{array}{c}\text { with } \\
\text { subsidy } \\
\text { Input }\end{array}$ & $\begin{array}{c}\text { without } \\
\text { subsidy }\end{array}$ & $\begin{array}{c}\text { with } \\
\text { subsidy } \\
\text { Input }\end{array}$ & $\begin{array}{c}\text { without } \\
\text { subsidy }\end{array}$ & $\begin{array}{c}\text { with } \\
\text { subsidy } \\
\text { Input }\end{array}$ \\
\hline constant (CRSTE) & 0.790 & 0.812 & 0.656 & 0.688 & 0.691 & 0.737 \\
\hline variable (VRSTE) & 0.843 & 0.860 & 0.745 & 0.767 & 0.739 & 0.780 \\
\hline scale efficiency (SE) & 0.939 & 0.946 & 0.889 & 0.903 & 0.940 & 0.948 \\
\hline
\end{tabular}

Source: Author's own calculations. All values are average of the efficiencies of the total MFIs.

Table 3.8

Efficiency Analysis 2005 (Subsidies as an Output)

\begin{tabular}{|c|c|c|c|c|c|c|}
\hline & \multicolumn{2}{|c|}{ LR-ACE } & \multicolumn{2}{c|}{ L-ACE } & \multicolumn{2}{c|}{ R-ACE } \\
\hline technical efficiency & $\begin{array}{c}\text { without } \\
\text { subsidy }\end{array}$ & $\begin{array}{c}\text { with } \\
\text { subsidy } \\
\text { output }\end{array}$ & $\begin{array}{c}\text { without } \\
\text { subsidy }\end{array}$ & $\begin{array}{c}\text { with } \\
\text { subsidy } \\
\text { output }\end{array}$ & $\begin{array}{c}\text { without } \\
\text { subsidy }\end{array}$ & $\begin{array}{c}\text { with } \\
\text { subsidy } \\
\text { output }\end{array}$ \\
\hline constant (CRSTE) & 0.894 & 0.897 & 0.837 & 0.853 & 0.812 & 0.816 \\
\hline variable (VRSTE) & 0.912 & 0.915 & 0.857 & 0.875 & 0.839 & 0.842 \\
\hline scale efficiency (SE) & 0.980 & 0.980 & 0.977 & 0.973 & 0.968 & 0.969 \\
\hline
\end{tabular}

Source: Author's own calculations. All values are average of the efficiencies of the total MFIs.

\subsubsection{Efficiency Analysis 2006}

Like year 2005, the efficiency analysis has been carried out on the same lines for the year 2006. Table 3.9 presents the average efficiency results for all the MFIs in year 2006 with and without subsidies. The detailed efficiency analysis for all the MFIs in the sample for year 2006 has been presented in Appendix G. Again 
average efficiencies decrease for both specifications LR-ACE and R-ACE once subsidies have been removed from the revenues. Like previous year analysis, for base specification LR-ACE, this decrease in efficiency is small. But for the specification R-ACE, the decrease in efficiency is more pronounced. The MFIs previously $100 \%$ efficient but after removing subsidies become less efficient are C FUND, INTERFISA, Promujer-PERU, IMON, and CETZAM for specification LR-ACE. Whereas for specification R-ACE, ASA, BRAC-BAN, C FUND, Interfisa and CETZAM become less efficient. MFIs which remain fully efficient irrespective of subsidies for specification LR-ACE are BESA, Cred. Agro, IDF, EKI, Mikrofin, Partner, Sunrise, WWB Ca, C Mujer-CR, Bancosol-ECU, C Jardin, Finca-ECU, ACSI, DECSI, Bandhan, SNFL, MDSL, SMEP, AIYL, Khan Bank, Al Amana, Fondep, Vovo Banco, Acodep, Bantra, Findesa, CMAC Arq, EDPY C Tac and Mibanco.

Average efficiency results for treating positive subsidies as an input is presented in Table 3.10. The detailed efficiency analysis for all the MFIs in the sample for year 2006 is being presented in Appendix H. The Specifications entertained are LR-ACE, L-ACE and R-ACE. The average efficiency scores increase slightly after adding subsidy input in all the specifications. The MFIs becoming $100 \%$ efficient after subsidy input for base specification LR-ACE are Procred-ALB, Horizon, Viator, BANCOSOL, FMM Pop, DBACD, BG, MFW, AL Karama, SEF-ZAF, PRIDE, and Finca-ZAM. For specification L-ACE, MFIs become 100\% efficient with subsidy input are Procred-ALB, Bancosol, FMM Pop, BG and Al Karama. Similarly for specification R-ACE, Besa, Procred-ALB, Horizon, Bancosol, BG, DBACD, Al Karama, and Finca-ZAM have become fully efficient after subsidy input.

Table 3.9

Efficiency Analysis 2006 (With and Without Subsidies)

\begin{tabular}{|c|c|c|c|c|}
\hline & \multicolumn{2}{|c|}{ LR-ACE } & \multicolumn{2}{c|}{ R-ACE } \\
\hline technical efficiency & with subsidies & without subsidies & with subsidies & without subsidies \\
\hline constant (CRSTE) & 0.835 & 0.776 & 0.732 & 0.428 \\
\hline variable (VRSTE) & 0.859 & 0.823 & 0.751 & 0.561 \\
\hline scale efficiency (SE) & 0.973 & 0.944 & 0.976 & 0.773 \\
\hline
\end{tabular}

Source: Author's own calculations. All values are average of the efficiencies of the total MFIs. 
Table 3.10

Efficiency Analysis 2006 (Subsidies as an Input)

\begin{tabular}{|c|c|c|c|c|c|c|}
\hline & \multicolumn{2}{|c|}{ LR-ACE } & \multicolumn{2}{c|}{ L-ACE } & \multicolumn{2}{c|}{ R-ACE } \\
\hline technical efficiency & $\begin{array}{c}\text { without } \\
\text { subsidy }\end{array}$ & $\begin{array}{c}\text { with } \\
\text { subsidy } \\
\text { Input }\end{array}$ & $\begin{array}{c}\text { without } \\
\text { subsidy }\end{array}$ & $\begin{array}{c}\text { with } \\
\text { subsidy } \\
\text { Input }\end{array}$ & $\begin{array}{c}\text { without } \\
\text { subsidy }\end{array}$ & $\begin{array}{c}\text { with } \\
\text { subsidy } \\
\text { Input }\end{array}$ \\
\hline constant (CRSTE) & 0.844 & 0.864 & 0.758 & 0.768 & 0.758 & 0.783 \\
\hline variable (VRSTE) & 0.864 & 0.881 & 0.793 & 0.806 & 0.776 & 0.799 \\
\hline scale efficiency (SE) & 0.977 & 0.981 & 0.961 & 0.957 & 0.978 & 0.980 \\
\hline
\end{tabular}

Source: Author's own calculations. All values are average of the efficiencies of the total MFIs.

Table 3.11

Efficiency Analysis 2006 (Subsidies as an Output)

\begin{tabular}{|c|c|c|c|c|c|c|}
\hline & \multicolumn{2}{|c|}{ LR-ACE } & \multicolumn{2}{c|}{ L-ACE } & \multicolumn{2}{c|}{ R-ACE } \\
\hline technical efficiency & $\begin{array}{c}\text { without } \\
\text { subsidy }\end{array}$ & $\begin{array}{c}\text { with } \\
\text { subsidy } \\
\text { output }\end{array}$ & $\begin{array}{c}\text { without } \\
\text { subsidy }\end{array}$ & $\begin{array}{c}\text { with } \\
\text { subsidy } \\
\text { output }\end{array}$ & $\begin{array}{c}\text { without } \\
\text { subsidy }\end{array}$ & $\begin{array}{c}\text { with } \\
\text { subsidy } \\
\text { output }\end{array}$ \\
\hline constant (CRSTE) & 0.868 & 0.868 & 0.778 & 0.786 & 0.765 & 0.773 \\
\hline variable (VRSTE) & 0.901 & 0.901 & 0.825 & 0.839 & 0.801 & 0.809 \\
\hline scale efficiency (SE) & 0.964 & 0.964 & 0.946 & 0.941 & 0.958 & 0.958 \\
\hline
\end{tabular}

Source: Author's own calculations. All values are average of the efficiencies of the total MFIs.

Average efficiency scores for treating negative subsidies as an output is presented in Table 3.11. The detailed efficiency analysis for all the MFIs in the sample for year 2006 is being presented in Appendix I. Overall the average efficiency scores remain the same for the base specification LR-ACE but increased marginally for specification L-ACE and R-ACE. For specification L-ACE, only EBS becomes $100 \%$ efficient after subsidy output whereas for specification R-ACE, Mikrofin and ACSI becomes 100\% efficient after subsidy output.

\subsubsection{Malmquist Productivity Index}

Now we turn to the Panel Data efficiency analysis where the Malmquist Productivity indices are presented. All the efficiency scores in this analysis are for year 2006 relative to the previous year 2005. The five indices are technical efficiency change, technological change, pure technical efficiency change, scale efficiency change and total factor productivity (TFP) change. Table 3.12 presents the overall average efficiency scores for specifications LR-ACE, L-ACE and R-ACE. A 
detailed efficiency analysis of all the MFIs is given in Appendix J. Average scores for all the indices have increased for 2006 relative to previous year except for technological change indices which has a value less than one.

Table 3.13 compares averages of Malmquist productivity indices with and without subsidies for base specification LR-ACE. A detailed efficiency analysis of all the MFIs is given in Appendix $\mathbf{K}$. Taking subsidies out of the revenues decreases the average scores slightly for the technological change and total factor productivity indices. While for the technical efficiency, pure technical efficiency and scale efficiency, it actually increases the average efficiency score marginally. Moreover without subsidy, total factor productivity indices become less than one.

Table 3.14 depicts averages of malmquist indices for treating positive subsidies as an input into the specification LR-ACE and L-ACE. A detailed efficiency analysis of all the MFIs is given in Appendix L. For specification LR-ACE, average indices scores show little improvement when subsidy as an input enters into the model for all the efficiencies except scale efficiency. For specification L-ACE, the average productivity indices scores decrease with subsidy input except for technological change and total factor productivity indices.

Table 3.15 presents the average efficiency indices of treating negative subsidies as an output in to the specifications LR-ACE, L-ACE and R-ACE. A detailed efficiency analysis of all the MFIs is given in Appendix M. For all the three specifications, the magnitude of change in efficiency indices before and after

Table 3.12

Malmquist DEA indices for 2006

\begin{tabular}{|c|c|c|c|}
\hline & LR-ACE & L-ACE & R-ACE \\
\hline technical efficiency (CRS) & 1.081 & 1.127 & 1.123 \\
\hline technological change & 0.935 & 0.903 & 0.899 \\
\hline pure tech. efficiency (VRS) & 1.034 & 1.049 & 1.059 \\
\hline scale efficiency & 1.046 & 1.074 & 1.061 \\
\hline total factor productivity & 1.011 & 1.017 & 1.011 \\
\hline
\end{tabular}

Source: Author's own calculations. All values are average of the efficiencies of the total MFIs. 
subsidy output is same. For technical, pure technical and scale efficiencies, the average indices scores decrease with subsidy output. Whereas, for technological change and total factor productivity indices, average indices scores increase with subsidy input.

Table 3.13

Malmquist DEA indices for 2006 (with and without subsidy)

\begin{tabular}{|c|c|c|}
\hline & \multicolumn{2}{|c|}{ LR-ACE } \\
\hline & with subsidy & without subsidy \\
\hline technical efficiency (CRS) & 1.071 & 1.108 \\
\hline technological change & 0.943 & 0.895 \\
\hline pure tech. efficiency (VRS) & 1.029 & 1.041 \\
\hline scale efficiency & 1.041 & 1.064 \\
\hline total factor productivity & 1.010 & 0.992 \\
\hline
\end{tabular}

Source: Author's own calculations. All values are average of the efficiencies of the total MFIs.

Table 3.14

Malmquist DEA indices for 2006 (subsidy as an input)

\begin{tabular}{|c|c|c|c|c|}
\hline & \multicolumn{2}{|c|}{ LR-ACE } & \multicolumn{2}{c|}{ L-ACE } \\
\hline & $\begin{array}{c}\text { without } \\
\text { subsidy input }\end{array}$ & $\begin{array}{c}\text { with subsidy } \\
\text { input }\end{array}$ & $\begin{array}{c}\text { without } \\
\text { subsidy input }\end{array}$ & $\begin{array}{c}\text { with subsidy } \\
\text { input }\end{array}$ \\
\hline technical efficiency (CRS) & 1.074 & 1.076 & 1.158 & 1.134 \\
\hline technological change & 0.929 & 0.943 & 0.866 & 0.903 \\
\hline pure tech. efficiency (VRS) & 1.019 & 1.024 & 1.052 & 1.050 \\
\hline scale efficiency & 1.054 & 1.051 & 1.101 & 1.080 \\
\hline total factor productivity & 0.998 & 1.015 & 1.003 & 1.024 \\
\hline
\end{tabular}

Source: Author's own calculations. All values are average of the efficiencies of the total MFIs.

Table 3.15

Malmquist DEA indices for 2006 (subsidy as an output)

\begin{tabular}{|c|c|c|c|c|c|c|}
\hline & \multicolumn{2}{|c|}{ LR-ACE } & \multicolumn{2}{c|}{ L-ACE } & \multicolumn{2}{c|}{ R-ACE } \\
\hline & $\begin{array}{c}\text { without } \\
\text { subsidy } \\
\text { output }\end{array}$ & $\begin{array}{c}\text { with } \\
\text { subsidy } \\
\text { output }\end{array}$ & $\begin{array}{c}\text { without } \\
\text { subsidy } \\
\text { output }\end{array}$ & $\begin{array}{c}\text { with } \\
\text { subsidy } \\
\text { output }\end{array}$ & $\begin{array}{c}\text { without } \\
\text { subsidy } \\
\text { input }\end{array}$ & $\begin{array}{c}\text { with } \\
\text { subsidy } \\
\text { input }\end{array}$ \\
\hline technical efficiency (CRS) & 0.978 & 0.965 & 0.963 & 0.939 & 0.994 & 0.989 \\
\hline technological change & 1.016 & 1.079 & 1.051 & 1.146 & 1.005 & 1.074 \\
\hline pure tech. efficiency (VRS) & 0.986 & 0.979 & 1.001 & 0.976 & 1.013 & 1.010 \\
\hline scale efficiency & 0.992 & 0.986 & 0.962 & 0.962 & 0.982 & 0.980 \\
\hline total factor productivity & 0.993 & 1.041 & 1.013 & 1.076 & 0.999 & 1.062 \\
\hline
\end{tabular}

Source: Author's own calculations. All values are average of the efficiencies of the total MFIs. 


\subsection{Tobit Regression Approach}

\subsubsection{Methodology}

Tobit Regression analysis are carried out to test a series of hypotheses concerning the relationship between financial efficiency and other indicators related to MFIs productivity, organizational, outreach, sustainability and social impact amid subsidies. The model is censored if one can at least observe the exogenous variables and truncated if the observations outside a specified range are totally lost" (Amemiya,1984:3). In this case, a Tobit censored regression model is appropriate ${ }^{21}$ because it can accommodate the censored DEA efficiency score since the values of the dependent variable lie between 0 and 1 with some values achieving the highest value of 1 . This study has taken the output oriented technical efficiency as dependent variable for Tobit regressions for year 2005 and 2006.

The Equation is as follows

$\log$ Efficiency $_{i}=\alpha+\beta_{2} \log (\text { cost } / \text { staff })_{i}+\beta_{3}(O S S)_{I}+\beta_{4}(S D I)+\beta_{5} \log (\text { borrower } / \text { staff })_{i}+$ $\beta_{6} \log ($ Loan size $/$ GNI per capita $\left.)\right)_{I}+\beta_{6} \log (\text { age })_{i}+\beta_{7} \log (\text { women })_{i}+\gamma_{3} C_{i}+\varepsilon_{i}$

Where $C_{i}$ are the controls for Region, Status, Lending Methodology, Saving, Regulated and Other services.

The omitted variable categories are: for region, Africa; for status, Non Banking Financial Institution (NBFI); for lending methodology, Individual lending; and others are MFIs with no saving feature, not regulated and no other services.

The base regression describes the correlates of efficiency with particular emphasis on the role of productivity variables i.e. cost per staff and borrowers per staff. Another important aspect to understand is the impact of outreach on the efficiency. Further also of interest is to know how efficiency relates to the subsidy dependence and sustainability.

\footnotetext{
${ }^{21}$ For literature see for example Chakraborty et al., 2001 ; McCarty and Yaisawarng, 1993; Gilen and lall, 1997 and Chilingerian, 1995 among others
} 
For each year 2005 and 2006, we have started from the overall regressions with PTE score of LR-ACE as dependent variable followed by the Tobit regressions where dependent variable consists of specifications with and without subsidies. Then follow the equations where subsidies have been treated as an input and as an output. The relationship between financial efficiency and other indicators related to MFIs productivity, outreach, sustainability and social impact have been tested which reveal important information about the tradeoff between outreach to the poor and efficiency of MFIs and also about the inefficiencies which leads to lower productivity etc. Finally, Tobit random effect model has been employed to analyze the panel data.

\subsubsection{Regression Results (2005)}

Table 3.16 gives results from the estimation of equation (1) above. Regression (1) and (2) are overall regression equation with base specification LRACE as dependent variable and include all the 204 MFIs as sample. Regression 2 includes operational self sufficiency (OSS) and SDI as independent variables in addition to the other variables. The results showing the tradeoff between efficiency and cost per staff and positive relationship between efficiency and borrower per staff (productivity) are in line with the theory and also are significant. The regression equations confirm the negative association between subsidy dependence and efficiency of MFIs. While operational self sufficiency (OSS) contributes toward efficiency, though, the coefficient is significant only in Equation (2). The outreach indicator has significant positive impact on efficiency showing that as outreach increases i.e. lower loan size, the efficiency decreases. In other words, MFIs which cater to poor tend to be inefficient than those with relatively well off clients. However, lending to women borrowers significantly increases the efficiency. Impact of MFI age on efficiency is also positive though insignificant. Turning to covariates, MFIs with status of Rural Banks are inefficient ones while Non Banking financial intermediaries (NBFI) which is omitted variable category are efficient though not significant. The rest of MFIs with status as Banks, NGOs and 
Table 3.16

Tobit Regression Analysis 2005

\begin{tabular}{|c|c|c|c|c|c|c|c|c|}
\hline & \multicolumn{2}{|c|}{$\begin{array}{c}\text { Base } \\
\text { Specification }\end{array}$} & \multicolumn{2}{|c|}{$\begin{array}{l}\text { with/without } \\
\text { subsidies }\end{array}$} & \multicolumn{2}{|c|}{$\begin{array}{l}\text { +ve Subsidies } \\
\text { (As Input) }\end{array}$} & \multicolumn{2}{|c|}{$\begin{array}{c}\text {-veSubsidies } \\
\text { (As Output) }\end{array}$} \\
\hline & LR-ACE & LR-ACE & LR-ACE & LR $^{\text {s-ACE }}$ & LR-ACE & LR-ACES & LR-ACE & LRS $^{\circ}$-ACE \\
\hline SDI & & $\begin{array}{c}-0.075 \\
(-2.37)^{* *}\end{array}$ & $\begin{array}{c}-0.09 \\
(-2.86)^{* * *}\end{array}$ & $\begin{array}{c}-0.045 \\
(-3.07)^{* * *}\end{array}$ & $\begin{array}{l}-0.067 \\
(-1.83)^{*}\end{array}$ & $\begin{array}{c}-0.091 \\
(-2.51)^{* *}\end{array}$ & $\begin{array}{c}0,265 \\
(1.72)^{*}\end{array}$ & $\begin{array}{c}0,23 \\
(1.56)\end{array}$ \\
\hline Loan Size/GNIpc & $\begin{array}{c}0.114 \\
(4.10)^{* * *}\end{array}$ & $\begin{array}{c}0.092 \\
(3.29)^{* * * *}\end{array}$ & $\begin{array}{c}0.077 \\
(2.86)^{* * * *}\end{array}$ & $\begin{array}{c}0.127 \\
(4.14)^{* * *}\end{array}$ & $\begin{array}{c}0.055 \\
(1.77)^{*}\end{array}$ & $\begin{array}{l}0.035 \\
(1.07)\end{array}$ & $\begin{array}{c}0,08 \\
(1.95)^{*}\end{array}$ & $\begin{array}{c}0.08 \\
(2.02)^{*}\end{array}$ \\
\hline Borrower/Staff & $\begin{array}{c}0.106 \\
(3.82)^{* * *}\end{array}$ & $\begin{array}{c}0.078 \\
(2.74)^{* * *}\end{array}$ & $\begin{array}{c}0.079 \\
(2.88)^{* * * *}\end{array}$ & $\begin{array}{c}0.165 \\
(5.27)^{* * *}\end{array}$ & $\begin{array}{l}0.029 \\
(0.90)\end{array}$ & $\begin{array}{l}0.007 \\
(0.17)\end{array}$ & $\begin{array}{c}-0,01 \\
(-0.29)\end{array}$ & $\begin{array}{c}-0,01 \\
(-0.26)\end{array}$ \\
\hline GNIpc & $\begin{array}{c}0.144 \\
(4.17)^{* * * *}\end{array}$ & $\begin{array}{c}0.127 \\
(3.67)^{* * *}\end{array}$ & $\begin{array}{c}0.091 \\
(2.71)^{* * * *}\end{array}$ & $\begin{array}{c}0.156 \\
(4.02)^{* * * *}\end{array}$ & $\begin{array}{c}0.079 \\
(2.14)^{* *}\end{array}$ & $\begin{array}{l}0.059 \\
(1.52)\end{array}$ & $\begin{array}{c}0,11 \\
(1.63)\end{array}$ & $\begin{array}{c}0,11 \\
(1.76)^{*}\end{array}$ \\
\hline Women Borrower & $\begin{array}{c}0.088 \\
(2.48)^{\text {** }}\end{array}$ & $\begin{array}{c}0.072 \\
(2.05)^{* *}\end{array}$ & $\begin{array}{c}0.071 \\
(2.27)^{* *}\end{array}$ & $\begin{array}{l}0.035 \\
(0.99)\end{array}$ & $\begin{array}{c}0.095 \\
(2.81)^{* * *}\end{array}$ & $\begin{array}{c}0.092 \\
(2.71)^{* * *}\end{array}$ & $\begin{array}{c}-0,07 \\
(-1.04)\end{array}$ & $\begin{array}{c}-0,08 \\
(-1.12)\end{array}$ \\
\hline Bank & $\begin{array}{l}-0.031 \\
(-0.66)\end{array}$ & $\begin{array}{l}-0.009 \\
(-0.19)\end{array}$ & $\begin{array}{l}-0.026 \\
(-0.58)\end{array}$ & $\begin{array}{l}-0.034 \\
(-0.66)\end{array}$ & $\begin{array}{l}0.023 \\
(0.46)\end{array}$ & $\begin{array}{l}0.009 \\
(0.21)\end{array}$ & $\begin{array}{c}-0,02 \\
(-0.27)\end{array}$ & $\begin{array}{c}-0,02 \\
(-0.31)\end{array}$ \\
\hline Cooperatives & $\begin{array}{l}-0.063 \\
(-0.95)\end{array}$ & $\begin{array}{l}-0.055 \\
(-0.85)\end{array}$ & $\begin{array}{l}-0.036 \\
(-0.58)\end{array}$ & $\begin{array}{l}-0.043 \\
(-0.60)\end{array}$ & $\begin{array}{l}0.029 \\
(0.40)\end{array}$ & $\begin{array}{l}0.042 \\
(0.60)\end{array}$ & $\begin{array}{c}-0,22 \\
(-2.18)^{* *}\end{array}$ & $\begin{array}{c}-0,22 \\
(-2.23)^{* *}\end{array}$ \\
\hline NGOs & $\begin{array}{l}-0.020 \\
(-0.53)\end{array}$ & $\begin{array}{l}-0.016 \\
(-0.44)\end{array}$ & $\begin{array}{l}-0.020 \\
(-0.57)\end{array}$ & $\begin{array}{c}0.002 \\
(-0.04)\end{array}$ & $\begin{array}{l}-0.018 \\
(-0.43)\end{array}$ & $\begin{array}{l}-0.034 \\
(-0.85)\end{array}$ & $\begin{array}{c}0,06 \\
(1.39)\end{array}$ & $\begin{array}{c}0,06 \\
(1.42)\end{array}$ \\
\hline Rural Bank & $\begin{array}{l}-0.149 \\
(-1.83)^{*}\end{array}$ & $\begin{array}{l}-0.148 \\
(-1.87)^{*}\end{array}$ & $\begin{array}{c}-0.134 \\
(-1.77)^{*}\end{array}$ & $\begin{array}{c}-0.190 \\
(-2.18)^{* *}\end{array}$ & $\begin{array}{l}0.119 \\
(1.14)\end{array}$ & $\begin{array}{l}0.096 \\
(0.90) \\
\end{array}$ & $\begin{array}{c}-0.23 \\
(-2.31)^{* *}\end{array}$ & $\begin{array}{c}-0,24 \\
(-2.42)^{* *}\end{array}$ \\
\hline Individual \& Group & $\begin{array}{c}0.080 \\
(-2.48)^{* *}\end{array}$ & $\begin{array}{c}-0.075 \\
(-2.37)^{* *}\end{array}$ & $\begin{array}{c}-0.075 \\
(-2.46)^{* *}\end{array}$ & $\begin{array}{c}-0.063 \\
(-1.81)^{*}\end{array}$ & $\begin{array}{c}-0.083 \\
(-2.34)^{* *}\end{array}$ & $\begin{array}{c}-0.093 \\
(-2.61)^{* *}\end{array}$ & $\begin{array}{c}-0,06 \\
(-1.77)^{*}\end{array}$ & $\begin{array}{c}-0,06 \\
(-1.82)^{*}\end{array}$ \\
\hline Latin America & $\begin{array}{l}-0.037 \\
(-0.68)\end{array}$ & $\begin{array}{l}-0.054 \\
(-1.02)\end{array}$ & $\begin{array}{l}0.011 \\
(0.21)\end{array}$ & $\begin{array}{l}0.010 \\
(0.17)\end{array}$ & $\begin{array}{l}-0.033 \\
(-0.58)\end{array}$ & $\begin{array}{l}-0.049 \\
(-0.85)\end{array}$ & $\begin{array}{c}0,19 \\
(1.77)^{*}\end{array}$ & $\begin{array}{c}0,18 \\
(1.71)^{*}\end{array}$ \\
\hline M. East \& N. Africa & $\begin{array}{c}-0.185 \\
(-2.49)^{* *}\end{array}$ & $\begin{array}{c}-0.210 \\
(-2.89)^{* * *}\end{array}$ & $\begin{array}{l}-0.090 \\
(-1.25)\end{array}$ & $\begin{array}{l}-0.107 \\
(-1.30)\end{array}$ & $\begin{array}{c}-0.341 \\
(-3.14)^{\text {*** }}\end{array}$ & $\begin{array}{c}-0.288 \\
(-2.65)^{* * *}\end{array}$ & $\begin{array}{c}0,12 \\
(1.10)\end{array}$ & $\begin{array}{c}0,11 \\
(1.02)\end{array}$ \\
\hline S. Asia & $\begin{array}{c}-0.159 \\
(-3.01)^{* * *}\end{array}$ & $\begin{array}{c}-0.155 \\
(-3.01)^{* * *}\end{array}$ & $\begin{array}{c}-0.126 \\
(-2.52)^{* *}\end{array}$ & $\begin{array}{l}-0.085 \\
(-1.48)\end{array}$ & $\begin{array}{c}-0.157 \\
(-2.81)^{\text {**** }}\end{array}$ & $\begin{array}{c}-0.160 \\
(-2.75)^{* * *}\end{array}$ & $\begin{array}{c}0,16 \\
(2.33)^{\text {*** }}\end{array}$ & $\begin{array}{c}0,15 \\
(2.27)^{* *}\end{array}$ \\
\hline Savings & $\begin{array}{l}-0.068 \\
(-1.89)^{*}\end{array}$ & $\begin{array}{c}-0.075 \\
(-2.12)^{* *}\end{array}$ & $\begin{array}{l}-0.056 \\
(-1.63)\end{array}$ & $\begin{array}{l}-0.065 \\
(-1.65)\end{array}$ & $\begin{array}{c}-0.079 \\
(-2.01)^{* *}\end{array}$ & $\begin{array}{c}-0.072 \\
(-1.88)^{*}\end{array}$ & $\begin{array}{c}0,01 \\
(0.29)\end{array}$ & $\begin{array}{c}0,01 \\
(0.24)\end{array}$ \\
\hline Other Services & $\begin{array}{l}0.045 \\
(1.51) \\
\end{array}$ & $\begin{array}{l}0.046 \\
(1.58) \\
\end{array}$ & $\begin{array}{l}0.035 \\
(1.24) \\
\end{array}$ & $\begin{array}{l}0.035 \\
(1.10) \\
\end{array}$ & $\begin{array}{c}0.061 \\
(1.89)^{*}\end{array}$ & $\begin{array}{c}0.074 \\
(2.32)^{* *}\end{array}$ & $\begin{array}{c}0,01 \\
(0.33) \\
\end{array}$ & $\begin{array}{c}0,01 \\
(0.40) \\
\end{array}$ \\
\hline Regulated & $\begin{array}{l}0.031 \\
(1.00)\end{array}$ & $\begin{array}{l}0.032 \\
(1.04)\end{array}$ & $\begin{array}{l}0.018 \\
(0.62)\end{array}$ & $\begin{array}{l}0.046 \\
(1.37)\end{array}$ & $\begin{array}{l}0.025 \\
(0.77) \\
\end{array}$ & $\begin{array}{l}0.013 \\
(0.33) \\
\end{array}$ & $\begin{array}{c}0,003 \\
(0.10)\end{array}$ & $\begin{array}{c}0,00 \\
(0.11)\end{array}$ \\
\hline Constant & $\begin{array}{c}-1.17 \\
(-4.05)^{* * *}\end{array}$ & $\begin{array}{c}-1.263 \\
(-3.79)^{* * *}\end{array}$ & $\begin{array}{c}-0.984 \\
(-3.12)^{* * *}\end{array}$ & $\begin{array}{c}-1.552 \\
(-4.30)^{* * *}\end{array}$ & $\begin{array}{c}-1.661 \\
(-3.76)^{* * *}\end{array}$ & $\begin{array}{c}-1.721 \\
(-3.91)^{* * *}\end{array}$ & $\begin{array}{c}0,57 \\
(1.26)\end{array}$ & $\begin{array}{c}0,58 \\
(1.31)\end{array}$ \\
\hline Log Likelihood & 67.53 & 72.48 & 80.53 & 54.30 & 60.56 & 59.58 & 54.94 & 56.09 \\
\hline LR Chi-Square & 82.26 & 92.16 & 88.35 & 105.49 & 77.31 & 78.33 & 66.82 & 67.62 \\
\hline Prob > Chi-Square & 0.00 & 0.00 & 0.00 & 0.00 & 0.00 & 0.00 & 0.00 & 0.00 \\
\hline No. of Obs. & $198^{22}$ & 198 & $193^{23}$ & 193 & $149^{24}$ & 149 & 4925 & 49 \\
\hline
\end{tabular}

T-values in parentheses

*significant at $10 \%$; ${ }^{* *}$ significant at $5 \%$; ${ }^{* * *}$ significant at $1 \%$

Source: Authors calculations based on data compiled from the audit reports of MFIs and from the Mix Market website.

\footnotetext{
22 Six MFIs are dropped due to unavailability of women borrowers information

${ }^{23} 5$ MFIs have been dropped for which subsidies exceed revenues in addition to the six MFIs

${ }^{24} 149$ MFIs which are subsidy dependant i.e. they have positive subsidy value

${ }^{25} 49$ MFIs are subsidy free i.e. they have negative subsidy value
} 
Cooperatives are negatively related to efficiency though the relationship is insignificant. MFIs which cater to both individuals and groups are clearly inefficient. While those with only group lending feature are also inefficient but by adding SDI and OSS into the regression framework makes the impact insignificant. MFIs operating in South Asia and M. East \& N. Africa are inefficient than the MFIs operating in the rest of the regions. African MFIs have positive efficiency but insignificant. MFIs promoting savings are significantly inefficient while the ones which are regulated and provide other services are efficient though the relationship is insignificant.

The next two regression equations (3) \& (4) show a comparison between with and without subsidies. Where in the dependent variable LRs-ACE in Equation (4), the subsidies have been deducted from the revenues. Comparing Equation (3) and (4), few differences are worth mentioning. Without subsidies, the positive impact of giving loans to women on financial efficiency has turned insignificant. Moreover the significance levels of Positive impact of staff productivity and negative impact of operational costs on financial efficiency. Notwithstanding the dummy variables, the inefficiency of South Asian MFIs becomes insignificant without subsidies.

Regression (5) and (6) depicts a comparison between general specification (LR-ACE) and treating positive subsidies as an input into the specification (LRACESi). So the sample consists of only subsidy dependant MFIs. The negative relationship between costs and efficiency becomes insignificant once subsidies entered as an input into the specification. Positive impact of outreach on efficiency also becomes insignificant. On the covariate front, the significance level of the positive impact of MFIs providing other services on their efficiency is improved with subsidies.

Regression (7) and (8) present a comparison between general specification (LR-ACE) and incorporating negative subsidies as an output into the efficiency specification (LRS-ACE). In other words only subsidy free MFIs are included in the sample. There is not much difference between the two regressions however when compared to previous Regressions (1) to (6), the impact of SDI on efficiency 
becomes positive which is due to the fact that the sample consists of only those MFIs which are subsidy free. Also the impact of women borrowers on efficiency turn negative though insignificant. Moreover MFIs with cooperative status become inefficient.

\subsubsection{Regression Results (2006)}

Table 3.17 presents the efficiency regressions for the year 2006. Regression equations (9) and (10) present the regression results of taking the base specification efficiency LR-ACE as dependant variable. Compared to the results in year 2005, the positive impact of lending to women on efficiency is no longer significant. MFIs with cooperative status become significantly inefficient while rural banks remain still inefficient though the impact is insignificant. MFIs located in ME\&NA region are still inefficient but insignificant. The other results are same as in year 2005. Costs have a significant negative impact on the efficiency while Staff Productivity contributes significantly towards the efficiency. Lending to relatively well off clients which can afford larger loan sizes, again turns out to be efficient in 2006. MFIs which lend to both individual and groups and exclusively to groups are inefficient. Whereas MFIs which lend to individuals remain efficient. MFIs with saving feature and those located in South Asia and ME\&NA region are again turned out to be inefficient.

Regression equations (11) and (12) depict a comparison of with and without subsidy regression equations. Where the efficiency scores of the specifications LR-ACE (revenues including subsidies) and LR ${ }^{\text {s-ACE (revenues }}$ excluding subsidies) have been treated as a dependent variables. Comparing Equations (11) and (12), the negative impact of SDI on the efficiency becomes significant once subsidies are deducted from the revenues. Whereas the positive impact of OSS on efficiency turns insignificant without subsidies. This shows that the conventional financial ratios look good only in the presence of subsidies. Regarding dummy variables, MFIs with village banking methodology become significantly inefficient without subsidies. Geographically, the inefficiency of SA MFIs becomes insignificant once subsidies are taken out from revenues. This 
Table 3.17

Tobit Regressions Analysis 2006

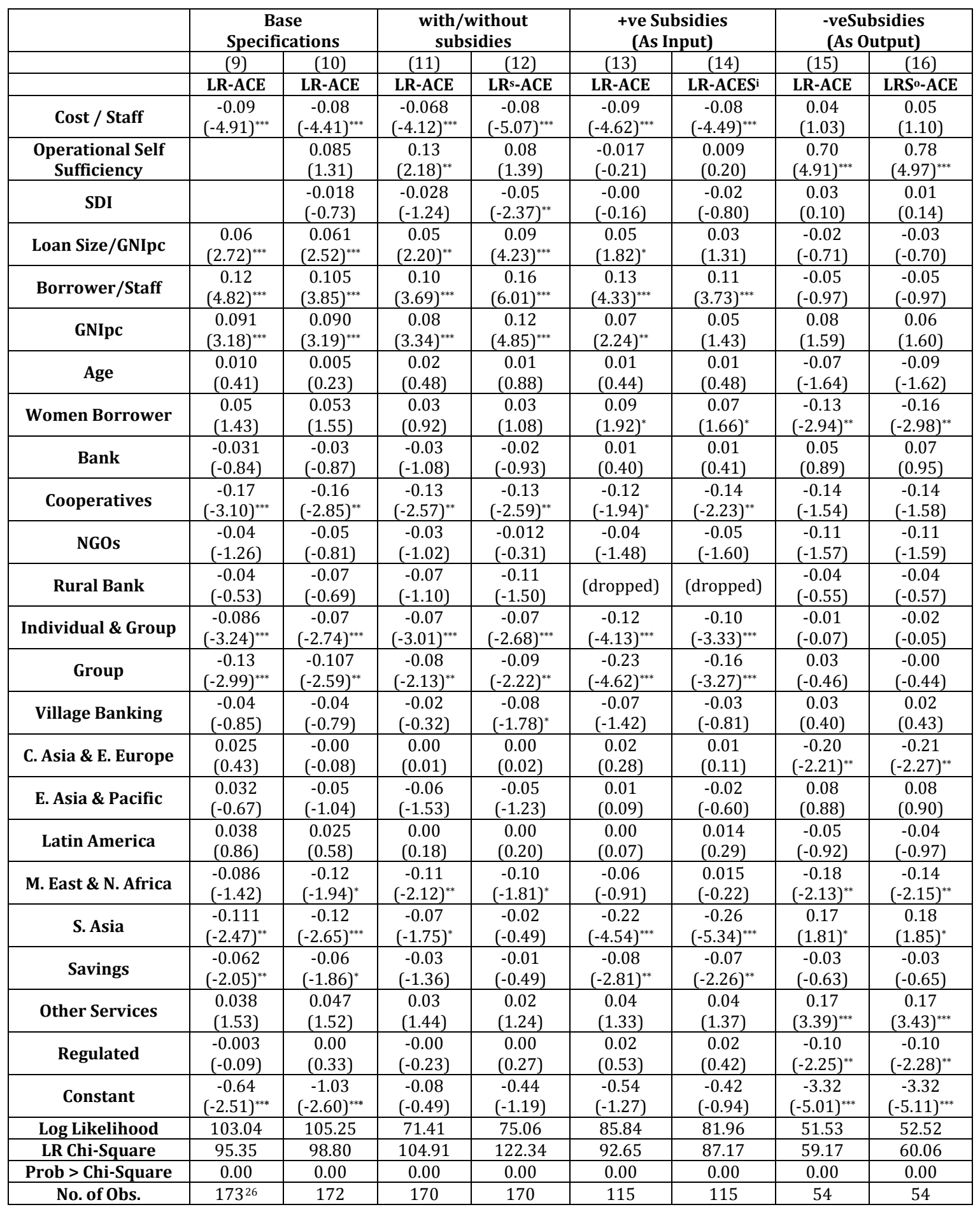

T-values in parentheses

*significant at $10 \%$; ${ }^{* *}$ significant at $5 \%$; ${ }^{* *}$ significant at $1 \%$.

Source: Authors calculations based on data compiled from the audit reports of MFIs and from the Mix Market website.

\footnotetext{
${ }^{26}$ Out of total 179 MFIs, 9 have been dropped for 2006 analysis (5 MFIs with no women borrower info., 1 with no OSS info., and one MFIs as an outlier)
} 
shows that subsidies do more harm than improving the financial efficiency for South Asian MFIs.

Regression (13) and (14) depicts the case where dependent variables consist of general efficiency specification LR-ACE and LR-ACESi (treating positive subsidies as an input) respectively. Thus the sample consist of only those MFIs which have positive subsidies i.e. subsidy dependent MFIs. Comparing both regressions, the positive impact of average loan size per borrower on efficiency becomes insignificant when subsidies included as an input. Thus shows that subsidy input in ineffective if lending is directed to relatively well off individual clients or in other words, subsidy input works efficiently if the focus of lending is towards poor clients. In both regressions, the coefficient of women borrowers turns out to be positive and significant. This shows that lending to women contributes to efficiency.

Regression (15) and (16) compares the equation with dependent variables LR-ACE and LRSo-ACE (subsidies enter into the specification as an output). Only those MFIs which are subsidy-free are considered in these regressions. Therefore, caution warrants to interpret these results in the context of subsidy free MFIs. Both equations have no significant difference as all the dependent variables behave in the same fashion. However unlike previous regressions, MFIs which lend to women become significantly inefficient. This result is driven by the fact that sample consists of only subsidy free MFIs which primarily lend to individual clients with fewer women borrowers. The regressions also provide evidence of the inefficiency of the regulated MFIs. Moreover, MFIs which provide other services in addition to the financial services become highly efficient. While MFIs located in CA \&EE region become inefficient.

\subsubsection{Panel data Results}

The same sequence of regression equations have been tested for the both years as a panel data set using tobit random effect regression technique in Table 
3.18. The Hausman test for all the equations have been conducted to choose between random and fixed effect model. The regression results are by and large in line with the previous tobit regression analysis for respective years.

Equations (17) \& (18) present the overall regression equation with base efficiency specification LR-ACE. The sample consists of 179 MFIs for which we have both two year SDI values. Out of which 5 MFIs have been dropped due to unavailability of women borrower information. While 38 more MFIs have been dropped for further analysis of treating subsidies as an input and output because their subsidy values change signs between two years i.e. from +ve to -ve and vice versa. Like previous year wise tobit regression results, cost per staff significantly reduces the efficiency while staff productivity and lending to women significantly contribute towards efficiency. The negative relationship between subsidy dependence and efficiency is also confirmed by the regression equations. Again evidence is there that reducing the loan size i.e. reaching out to the poor, decreases the efficiency or lending to relatively well-off clients contributes towards efficiency. Moreover MFIs which are of cooperative status, lend to individuals and groups, those with saving features and those operating in South Asia and M. East and North Africa, are inefficient. Whereas, MFIs which lend exclusively to individual borrowers, those which provide other services and those with the status of non banking financial intermediaries (omitted variable category) are efficient.

Comparison between with and without subsidy regression equations (19) \& (20) reveal important results. The positive impact of Lending to women on financial efficiency becomes insignificant once the subsidies have been removed from the revenue. Thus highlighting the fact that MFIs program's exclusively targeting women are highly subsidized which without subsidization become less financially efficient. Further the significantly inefficient MFIs with group lending methodology turn insignificant though still inefficient, once subsidies have been deducted from the revenues in equation (20). Moreover removing subsidies from the revenues further enhances impact of staff productivity on efficiency. Geographically the inefficiency of South Asian MFIs becomes insignificant without 
Table 3.18

Tobit Regression Panel Analysis (Random Effect)

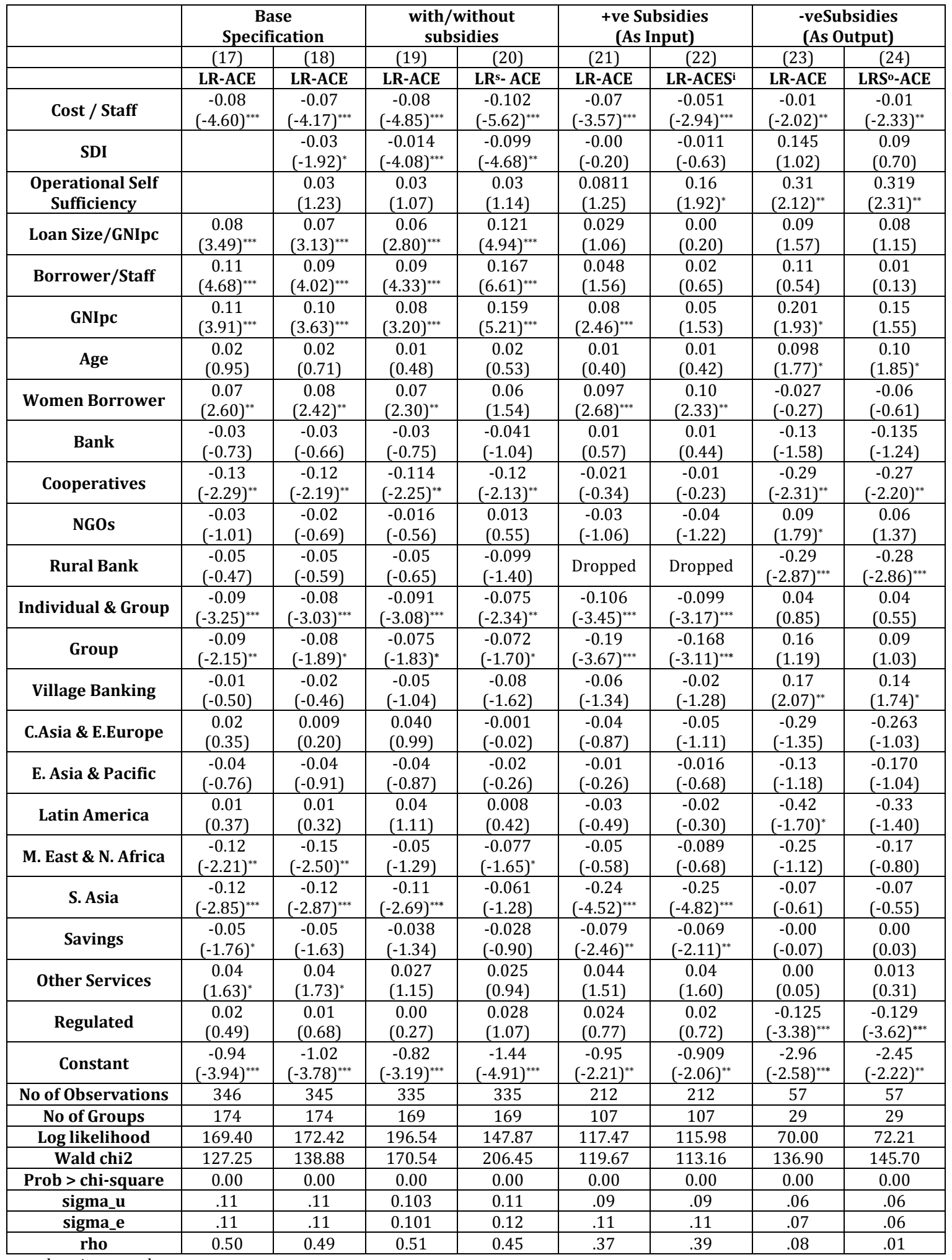

t-values in parentheses

*significant at $10 \%$; ** significant at $5 \%$; *** significant at $1 \%$.

Source: Authors calculations based on data compiled from the audit reports of MFIs and from the Mix Market website. 
subsidies while M East \& N African MFIs turn significantly inefficient without subsidies.

Regression equations (21) and (22) provide a comparison between general efficiency specification (LR-ACE) and treating positive subsidy as an input into the specification (LR-ACESi) respectively. In other words it takes into account only subsidy dependant MFIs. Therefore, the sample consists of only 107 MFIs which have positive subsidies in both years i.e. they are subsidy dependant. Evidence generated shows that OSS significantly contributes to efficiency once subsidies are added as an input. Also the inclusion of subsidies as an input makes the positive impact of per capita income on the efficiency insignificant. The rest of the variables behave in the same fashion.

Regression equations (23) and (24) present a comparison between the general base specification (LR-ACE) and the specification where negative subsidies have been treated as an output (LRS-ACE) respectively. Thus the sample for the regressions consists of only 29 subsidy-free MFIs. Again the inclusion of subsidies as an output makes the positive impact of per capita income on the efficiency insignificant. Moreover, the positive coefficient for NGO becomes insignificant with the inclusion of subsidies as an output. Geographically, the inefficiency of LA MFIs turns insignificant with subsidies included as an output. Unlike previous regressions, the coefficient of group lending methodology turns positive though insignificant once only the subsidy-free MFIs are considered.

\subsection{Conclusion}

At the outset of this paper, we endeavored to resolve few key issues. How to incorporate the subsidies into the non parametric DEA framework to investigate the efficiency of microfinance institutions? What factors are important in determining the efficiency of microfinance and how much of these factors are driven by the subsidies in determining the efficiency of MFIs? In other words, How efficiency relates to the various organizational and structural variables amid the 
presence of subsidies? The way subsidy has been calculated in this paper i.e. social cost of subsidized MFIs, allows us to successfully enter the positive subsidies as an input and negative subsidies as an output in to the DEA efficiency specifications on the premise that the former distort public wealth while the later creates it. A comparison of efficiency scores with and without subsidies for various specifications reveals important information. Generally, in most of the specifications, the average efficiency scores are improved albeit only marginally when subsidies enter into the DEA framework. However specifically, there exist numbers of MFIs which become $100 \%$ efficient once subsidies have been incorporated into the specifications as an input and output. Conversely, there exist MFIs which were previously $100 \%$ efficient but become less efficient once subsidies have been removed.

The issue of how efficiency relates to various organizational, social and structural variables has been addressed by employing Tobit regression technique for each year (2005 \& 2006) separately and also as panel data, taking efficiency as a left hand side variable. Notwithstanding the general regression equations, most of the relationships between efficiency and other variables are in line with the theory. The regression equations strongly confirm the trade-off between costs and efficiency. The evidence of negative association between subsidy dependence and efficiency is also established. Also evident is the fact that staff productivity significantly contributes to the financial efficiency of MFIs. Overall, operational self sustainability (OSS) does not significantly contribute to efficiency except for subsidy-free MFIs. From social perspective, lending to women borrowers contribute to efficiency as suggested by its significant positive coefficient in regression. The outreach variable (loan size/GNI per capita) has significant positive coefficient. This depicts that as the outreach increases i.e. loan size decreases, the financial efficiency also decreases. In other words, the more MFI's focus shifts away from the poor i.e. lending to well-off clients who can afford bigger loan sizes, the more it becomes efficient thus confirming the fact that lending to poor is relatively inefficient compared to well off clients. 
However once we compare the regressions with and without subsidies, the results become quite revealing in some aspects. Important evidence obtained is that lending to women contributes to the financial efficiency in the presence of subsidies only, as the impact becomes insignificant without subsidies. Thus showing that MFIs exclusively targeting women tend to be financially efficient only because of the subsidies they receive. Once we take out the subsidies from the equation, the positive impact of lending to women on the efficiency turns insignificant. The panel data results also confirm this relationship. Not surprisingly, treating subsidies as an input into the specification makes the negative relationship between costs and efficiency insignificant. Moreover, the positive impact of catering to wealthy clients on efficiency also becomes insignificant. The same sequence of regression equations has been tested for the both years as a panel data set using tobit Random effect model technique and the results are by and large in line with the previous tobit regression analysis for respective years.

Notwithstanding the categorical variables, geographically, MFIs located in South Asia and Middle East \& North Africa are tended to be inefficient. MFIs with group lending methodology are found to be inefficient while those with individual lending methodology are efficient. MFIs with cooperative and Rural Bank status are less efficient while those with non-banking financial intermediary's status are found to be efficient. Also found is some evidence for MFIs with saving features to be less efficient while those providing other services in addition to financial services as being efficient.

This essay adds to the existing literature by taking on the issue of subsidies for the first time in evaluating the efficiency of microfinance by generating data for 204 MFIs worldwide. From policy perspective, valuable lessons can be drawn for the entire stakeholder in microfinance Industry on the basis of this research work. For microfinance practitioners, it serves as a performance evaluation guide to enhance the efficiency and in the course of that meeting the dual objectives of outreach and sustainability. A with and without subsidy analysis based on the efficiency scores of their respective MFIs can help them identify the efficiency- 
enhancing role of subsidies. In particular, the message is very clear for those socially driven MFIs with outreach to women borrowers, to devise new income enhancing and enterprise development schemes which can go a long way in enhancing efficiency without subsidies. From private investor's perspective, it identifies those MFIs which are successful in achieving maximum efficiency by a proper mix of inputs and outputs. Even the social investors can benefit by analyzing mission-driven MFIs in the sample which have successful in increasing their outreach. For academics and researchers, this research opens a new avenue of research by bringing the subsidy issue to the forefront. Future research in this context should be directed to specifically investigate the role of subsidies in the social efficiency of microfinance. 


\title{
Chapter 4
}

\section{Sustainability of Microfinance: An Empirical Investigation}

\begin{abstract}
The social nature of Microfinance Institutions (MFIs) is mainly financed by subsidies received from the donors. This paper investigates the relationship between the sustainability and the efficiency of microfinance. Using Yaron's Subsidy Dependence Index (SDI) as a measure of sustainability, a panel data set has been generated from the audit reports of the 179 MFIs worldwide. This essay empirically investigates some important relationships and phenomenons in microfinance. Even after correcting for the endogeneity bias, the results lend some support to the existence of mission drift tendency in microfinance. Notwithstanding interest rate policy, evidence is found that MFIs do charge higher interest rate to women borrowers with small loan sizes. Further, the determinants of MFIs profitability and sustainability have also been identified. Furthermore the evidence does not support the trade-off between outreach and sustainability, however, the trade-off between costs and sustainability of MFIs is well supported. While the productivity and efficiency of MFIs contributes towards sustainability.
\end{abstract}

\subsection{Introduction}

Microfinance promises not only poverty reduction but also financial sustainability. After almost four decades into the business this promise is yet to be 
fulfilled because the role of the subsidies still persists which hinders the Microfinance Institutions (MFIs) to achieve self-sustainability ${ }^{1}$. According to CGAP research, the stock of foreign capital investment in the microfinance sector more than tripled to $\$ 4$ billion between year 2004 and 2006, much of it drawn by microfinance strong profit growth and reputation for doing good. This interest is driving big changes in the industry: it is forcing MFIs to become more commercial, to restructure them, to come to terms with a wider world (MBB, issue 16).

This paper attempts, in general, to address the key issues notwithstanding the twin objective of microfinance institutions of poverty reduction and financial sustainability. Towards this aim, the paper empirically investigates the determinants of the profitability of microfinance, Mission drift tendency, subsidization and efficiency relationship and interest rate implication on the financial performance of microfinance in particular. These issues have spurred intense debate in recent times. Nevertheless, there exist only a few studies that have empirically investigated the validity of those phenomenons. Cull et el. (2008) found evidence of the possibility of earning profits while serving poor, but a tradeoff emerges between profitability and serving the poorest using data of the 124 MFIs in 49 countries. They have defined the sustainability by the traditional financial ratios of Operational Self-sustainability (OSS) and Return on Assets (ROA) in their paper. Hudon and Traca (2008) look at the issue from purely financial aspect by investigation the effects of subsidization on the financial efficiency of 79 microfinance institution where the subsidy intensity covers only subsidies in the form of equity. The main drawback of all the existing studies is lack of reliability of the data due to small sample size mainly concentrating in one region and the accuracy of the subsidy figures in measuring sustainability. Bank on the high quality cross-country panel data set for 179 MFIs in 54 countries worldwide, this paper attempts to fill that void by taking on these issues in more definitive way on much larger scale.

Traditionally, the performance of microfinance institutions has been measured following either the welfarist approach or the institutionalist approach.

\footnotetext{
${ }^{1}$ Armendáriz de Aghion and Jonathan Morduch (2004); Morduch (1999a; 1999b); Morduch (2004); Goodman (2005) and Cull et.al (2007) are skeptical about the subsidization. On the other hand some see its role in reaching poor borrowers (Zeller and Meyer ,2002) and in covering start up costs .i.e. the notion of smart subsidies (Armendáriz and Morduch, 2005; Morduch, 2005 \& 2007)
} 
The former put emphasis on assessing the impact on the welfare of the poor while the latter argues for the assessment in terms of the institution success in achieving self-sustainability and breadth of outreach (Morduch, 2000). To start with, this paper estimates the sustainability of MFIs by employing the Yaron's Subsidy Dependence Index (SDI) (Yaron, 1992a and 1992b) which measures the social cost of subsidized MFIs. Based on the data of 179 MFIs, 139 MFIs are found to be subsidy dependent for year 2005, whereas it is reduced to 122 MFIs for the year $2006^{2}$.

The role of interest rates in determining the sustainability of MFIs cannot be under-estimated. Resultantly, what drives an MFI to devise its interest rate policy becomes a question of immense importance. This formation of interest rate policy mainly depends on the financial performance and social objectives of an MFI. Consequently, the impact of financial and social efficiency of microfinance in shaping the interest rate policy, which ultimately has an effect on the sustainability of MFI, is a very interesting topic of research, as pointed out by Hudon and Traca, 2008. In addition to that, Armendariz and Szafarz (2009) call for integrating interest rates as a determinant of the sustainability while controlling for market structure is a step in the right direction, from an empirical standpoint. This essay investigates the role of financial and social efficiency in determining the interest rate policy of MFIs which directly affects the sustainability. Moreover, the inclusion of social efficiency variables i.e. Loan size and women borrowers into the equation also lend support to the existence of mission drift in microfinance.

Investigation into the determinants of the profitability of microfinance is also an interesting research avenue in microfinance. Conventionally, profitability is defined in term of traditional financial ratio i.e. operational self-sufficiency and return of assets etc. This paper goes beyond and takes also Subsidy Dependence Index (SDI) as a measure of profitability. Some MFIs charge their clients exorbitant interest rates. Lewis (2008) calls them Microloan Sharks involved in not micro lending but microloan-sharking. Cull et al. (2007) found evidence that raising interest rates resulted in increased profitability for individual based

\footnotetext{
${ }^{2}$ See chapter 2 for detailed SDI measurement.
} 
lending MFIs whereas for solidarity based lenders, the reverse is true. This paper also found evidence that raising the interest rates lead to improved financial performance and profitability with lower subsidy dependence and higher operational self-sufficiency. Whereas rising costs are associated with lower profitability. An important result is that clients with smaller loan sizes (MFIs with predominantly women borrowers) pay higher interest rates relatively to the clients with large loans because increase in transaction costs induces MFIs to raise interest rates.

The paper also addresses the implications of subsidization on the cost efficiency and staff productivity of MFIs as measured by cost per borrowers and borrowers per staff respectively ${ }^{3}$. In line with the results of Hudon and Traca (2008), the productivity regressions show the inefficiency of subsidized MFIs due to higher costs associated with larger loan sizes. This suggests that subsidized MFIs are obliged to hire qualified staff and offer better and innovative products to relatively well off clients which contributes towards higher administrative cost. The results also lend support to the trade-off between staff productivity and subsidy dependence.

This essay also addresses the mission drift phenomenon in microfinance, a concern for socially driven MFIs, where the pressure to achieve financial sustainability forces many institutions to drift away from their initial mission and to work with less needy people. Most surprising and controversial are those microfinance institutions that have been transformed from charities to profitable companies through hugely successful initial public offerings. The most notorious, Mexico's Compartamos ("Let's Share") used a \$6m investment to turn itself into a billion-dollar company in less than a decade, expanding rapidly while charging very high rates to borrowers. What was once an idealistic movement is now a fastgrowing industry which is rapidly losing its innocence. The majority of microfinance practitioners, eager to gain access to capital and commercial expertise are concerned that competitive market forces may not help the poorest ${ }^{4}$.

\footnotetext{
3 Importance of efficiency and productivity measures in MFIs performance has been stressed by many authors. See for example Barrès Isabelle (2007)

4 Financial times, December 6, 2008 www.ft.com; MFI Solutions (2008). For case studies in commercialization issues, see for example, Charitonenko (2003); Charitonenko and Rahman (2002) and Charitonenko et al. (2004) among others.
} 
Even the two pioneers of group-based lending (the Grameen Bank of Bangladesh and Bancosol of Bolivia) have now started individual-based lending models (Cull et. al. 2007). Armendariz and Szafarz (2009), by employing one-period framework, argue that this tendency is not driven by transaction cost minimization alone. Instead, poverty-oriented microfinance institutions could potentially deviate from their mission by extending larger loan sizes neither because of "progressive lending" nor because of "cross-subsidization" but because of the interplay between their own mission, the cost differentials between poor and unbanked wealthier clients, and region-specific characteristics pertaining the heterogeneity of their clientele. More recently, Mersland and Strøm (2009) investigated mission drift using average loan size, MFIs lending methodology, main market, and gender bias as proxies for the mission drift measures by employing a large data set of rated MFIs spanning 11 years. They found no evidence of mission drift as the average loan size has not increased in the industry as a whole, nor is there a tendency toward more individual loans or a higher proportion of lending to urban costumers.

After correcting for the possible endogeneity bias, the empirical estimates in this chapter provide some evidence of the existence of mission drift phenomenon. Where investors tend to direct funds to those MFIs which cater to well-off clients which can afford to pay back higher loans. And in this process they lend increasingly fewer loans to women borrowers and hence deviate from their mission of serving the poor clients.

The essay is structured as follows. In the next section, a description of data and theoretical framework has been given. Then a discussion over the hypotheses and the empirical estimation has been presented. A conclusion is presented at the end.

\subsection{Data and Empirical Framework}

\subsubsection{Description and source of the Data}

Table 4.1 gives an overview of variables used in this essay along with their summary statistics. The definitions of the variables are also given as described by 
the Mix market website and CGAP, 2003. After carefully reviewing the Audit Reports of more than 300 MFIs, 204 MFIs in 54 countries have been chosen based on the clarity of their respective Audit Reports in general and subsidy figures in particular. These audit reports have been taken from the MixMarket website ${ }^{5}$.

Table 4.1

Variable Description and Summary Statistics

\begin{tabular}{|c|c|c|c|c|c|c|c|}
\hline $\begin{array}{l}\text { Variable used in subsidy } \\
\text { calculations }\end{array}$ & Obs & Definition & unit & Mean & Med. & Min & $\operatorname{Max}$ \\
\hline Yield/ interest rate on loan & 358 & revenues from loan/average of loans & $(\%)$ & 30.6 & 27.4 & 2.8 & 128.1 \\
\hline Real interest rate & 358 & Nominal interest rate - rate of inflation & (\%) & 24 & 20.7 & -7.3 & 109.7 \\
\hline Subsidy Dependence Index & 358 & Subsidy(S)/ Revenue from lending(R) & $(\%)$ & 21.42 & 12.23 & -191.4 & 456.8 \\
\hline Inflation 6 & 358 & $\begin{array}{l}\text { Indices shown for Consumer Prices are the } \\
\text { most frequently used indicators of inflation } \\
\text { and reflect changes in the cost of acquiring a } \\
\text { fixed basket of goods and services by the } \\
\text { average consumer }\end{array}$ & (\%) & 6.6 & 6.0 & 0.64 & 24.03 \\
\hline Admn. cost per staff & 358 & Administrative cost per staff & (\$) & 12166 & 11937 & 389 & 47714 \\
\hline Admn. cost per borrower & 358 & Administrative cost per borrower & $(\$)$ & 131.09 & 90.42 & 3.48 & 1694 \\
\hline GNI per capita (ppp) & 358 & $\begin{array}{l}\text { Gross national income divided by the } \\
\text { population. Calculated by Purchasing poverty } \\
\text { parity method (ppp) }\end{array}$ & $(\$)$ & 3476 & 3200 & 630 & 12810 \\
\hline GNI per capita (current) & 358 & $\begin{array}{l}\text { Gross national income divided by the } \\
\text { population (current USD). }\end{array}$ & $(\$)$ & 1385 & 1045 & 160 & 6070 \\
\hline borrower/staff & 358 & borrowers per staff (staff productivity) & No. & 143 & 137 & 2.8 & 407 \\
\hline MFI age & 358 & The years since MFI has started operations & No. & 14.15 & 12 & 3 & 51 \\
\hline Women borrowers & 348 & Percentage of women borrowers out of total & $(\%)$ & 64.07 & 61.0 & 8.6 & 100 \\
\hline Average loan size & 358 & $\begin{array}{l}\text { Gross Loan Portfolio / Number of active } \\
\text { borrowers }\end{array}$ & (\$) & 808 & 491 & 34 & 11198 \\
\hline Loan size/GNIpc (ppp) & 358 & Average Loan Size/ GNI per capita (ppp) & & 0.3095 & 0.170 & 0.112 & 7.831 \\
\hline Loan size/GNIpc (curr.) & 358 & Average loan size/ GNI per capita & & 0.9281 & 0.4442 & 0.0261 & 33.933 \\
\hline Return on assets (ROA) & 358 & $\begin{array}{l}\text { (Net Operating Income. less Taxes)/ Period } \\
\text { average assets }\end{array}$ & $(\%)$ & 5.26 & 4.43 & -68.49 & 61.61 \\
\hline Financial cost & 358 & interest rate paid on the borrowing or debt & $(\%)$ & 7.30 & 7.16 & 0 & 32.11 \\
\hline Admn. cost/asset & 358 & Administrative cost / Average of asset & $(\$)$ & 0.1767 & 0.1455 & .0183 & 0.9964 \\
\hline Financial cost/asset & 358 & Interest paid on borrowing / Average of asset & $(\$)$ & 0.0280 & 0.0217 & 0 & 0.1699 \\
\hline Loans/asset & 358 & Gross loan portfolio / average of asset & $(\$)$ & 9.4013 & 0.7668 & .0004 & 3104.1 \\
\hline $\begin{array}{l}\text { Operational Self } \\
\text { Sufficiency(OSS) }\end{array}$ & 358 & $\begin{array}{l}\text { Financial Revenue (Total)/ (Financial } \\
\text { Expense + Loan Loss Provision Expense + } \\
\text { Operating Expense) }\end{array}$ & $(\%)$ & 123.0 & 120.78 & 3.57 & 254.88 \\
\hline
\end{tabular}

Source: Author's own calculation based on the Audit Reports of MFIs taken from Microfinance Information eXange Inc website. Definitions are taken from the Micro banking Bulletin and CGAP (2003)

\footnotetext{
${ }^{5}$ The MIX MARKET is a global, web-based microfinance information platform. It provides information to sector actors and the public at large on Microfinance Institutions (MFIs) worldwide, public and private funds that invest in microfinance, MFI networks, raters/external evaluators, advisory firms, and governmental and regulatory agencies

${ }^{6}$ taken from the World bank's World Development Indicators (WDI)
} 
The most important variable to extract from the audit reports for subsidy calculations is the public debt/concessional borrowing. Therefore MFIs have been selected in large part on quality and clarity of public debt variable. All the MFIs adhere to the International Accounting Standards (IAS) for their audit reports. The data has been generated for two years i.e. 2005 and 2006. For year 2006, only 179 MFIs have been included in the sample due to the unavailability of the data to calculate the subsidy figures for 25 MFIs. Therefore in the final panel data analysis our sample has been restricted to 179 MFIs with each institution has two values for each year. A complete list of the names of the microfinance institutions used in the sample is given at the end as Annex. B. The summary statistics reveal some important information. Average interest rate paid by the MFIs to acquire loanable funds is $7.3 \%$. While the average interest rate they charge to the borrowers is $30.6 \%$. Average value of SDI comes out as 0.2142 with maximum value of 4.568 for MFI "PADME" of Benin. The means and medians for profitability variables i.e. ROA and OSS are all within the expected range though the minimum and maximum values suggest a wide range for each variable. Information about the women borrowers for 5 MFIs is missing due to the unavailability.

Table 4.2

Categorical Variables

\begin{tabular}{|c|c|}
\hline Variables & Description \\
\hline Region & $\begin{array}{l}\text { Geographic region in which the MFI operates classified into } 6 \\
\text { regions: Africa }(A) \text {; East Asia and the Pacific }(E A \& P) \text {; Eastern Europe } \\
\text { and Central Asia }(E E \& C A) \text {; Middle East and North Africa }(M E N A) \text {; } \\
\text { Latin America and the Caribbean }(L A C) \text {; South Asia }(S A) \text {. }\end{array}$ \\
\hline Lending Methodology & $\begin{array}{l}\text { Lending methodology is classified into } 4 \text { categories: Individual }(I) \text {; } \\
\text { Individual \& Solidarity/Group (IS); Group/Solidarity }(S) \text {; Village } \\
\text { banking }(V) \text {. }\end{array}$ \\
\hline Status & $\begin{array}{l}\text { Classified into } 5 \text { categories: Nongovernmental organizations }(N G O) \text {; } \\
\text { Bank }(B) \text {; Non-banking financial intermediaries (NBFI); Rural Bank } \\
(R B) \text {; Cooperatives (Coop.). }\end{array}$ \\
\hline Other services & $\begin{array}{l}\text { Whether MFI provides other services i.e. health, education etc in } \\
\text { addition to providing financial services or not. }\end{array}$ \\
\hline Saving & Whether saving (voluntary or Compulsory) is a feature of MFI or not. \\
\hline Regulated & Whether MFI is regulated by some authority like central bank etc. or not. \\
\hline
\end{tabular}


The categorical variables along with their description used in this study have been presented in Table 4.2. Omitted variable categories in the following regression analysis have also been presented.

Figure 4.1 depicts graphical display of the nature of the data used in this study. NGO (43\%) dominates the microfinance sector followed by the NBFIs (31\%). MFIs with "Bank" status constitute only 15\% of total sample. Almost half of the MFIs offer both group and individual lending services (47\%) followed by MFIs which lend specifically to individuals (34\%). Geographically almost one-third of MFIs locate in Latin America (31\%) and one-fourth in Africa (23\%). South Asian MFIs represent only about $13 \%$ of the overall MFIs in the sample. Majority of the MFIs in the sample are regulated (59\%) and provide deposits/savings services $(58 \%)$ to the clients. Moreover only $37 \%$ of the MFIs in the sample provide other services to the clients in addition to providing financial services.
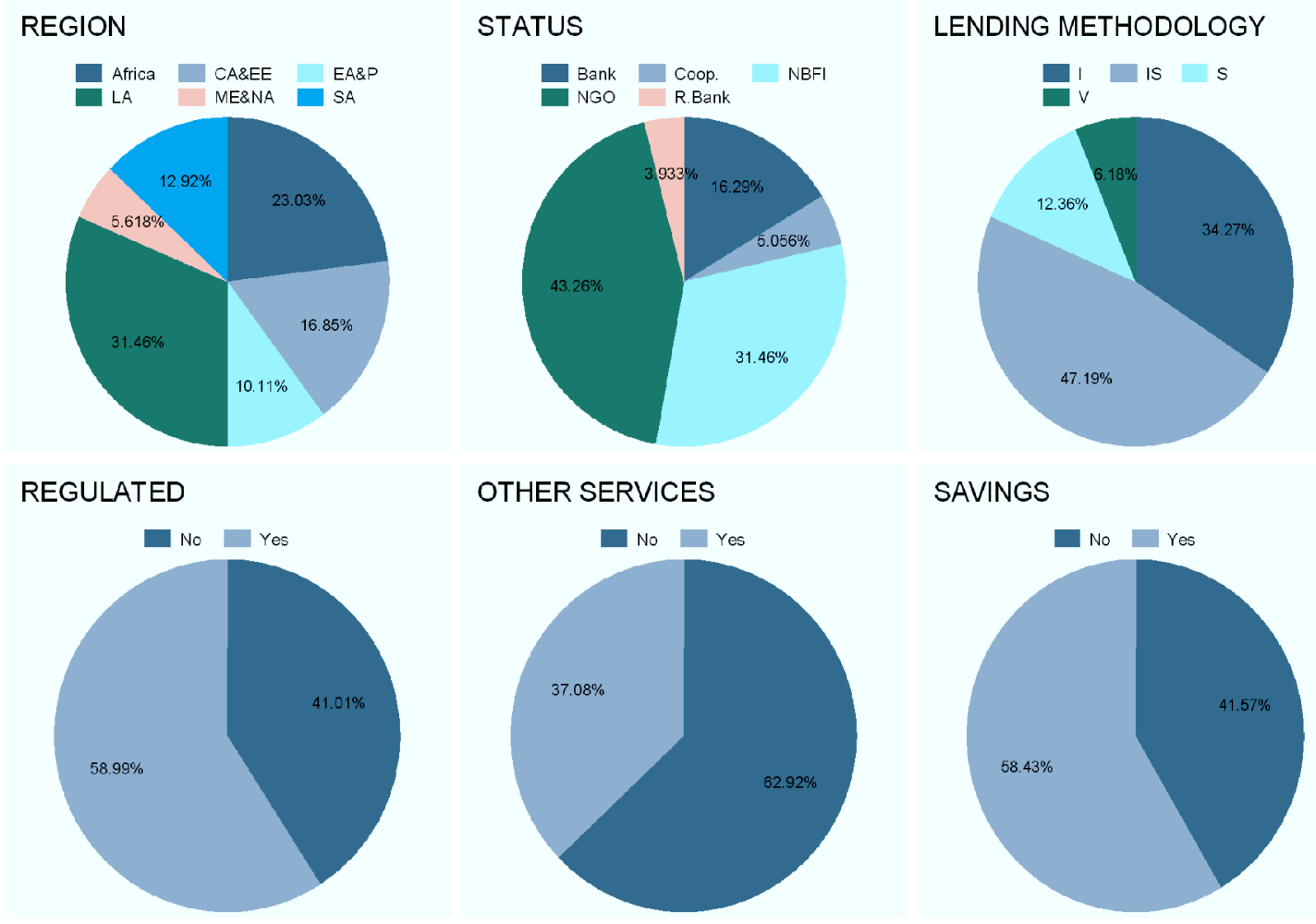

Figure 4.1 Descriptive analysis of Data

Source: Information taken from the mix market website based on the sample of 204 MFIs *Individual (I); Individual \& Solidarity (IS); Solidarity (S); Village Banking (V) 


\subsubsection{Measuring Sustainability}

Table 4.3 depicts the calculated SDI values of 179 MFIs for years 2005 \& 2006. SDI values for 25 MFIs for the year 2006 are missing due to the unavailability of their Audit Reports. Those MFIs have been dropped for the empirical analysis in this paper to make the balanced panel data for 179 MFIs. For the year 2005, 139 MFIs are subsidy dependent while for year 2006, it has been

Table 4.3

Subsidy Dependence Index (SDI)

\begin{tabular}{|c|c|c|c|c|c|c|c|c|c|c|c|}
\hline MFIs & 2005 & 6 & MFIs & 005 & 2006 & MFIs & 2005 & & & 005 & \\
\hline \multicolumn{3}{|c|}{ AFRICA } & ICROINVEST & $\mid 0.237$ & 0.261 & CEP & $|-0.070|$ & 117 & AJA NOR & .030 & $0 \varepsilon$ \\
\hline CDS & $0.161^{7}$ & 0.109 & ACBA & \begin{tabular}{|l|}
0.283 \\
\end{tabular} & 0.271 & TYM & .110 & 010 & ARITAS & 646 & 100 \\
\hline ACSI & & 88 & ON & 124 & 0.076 & ROCAPITAL & 0.615 & 0.265 & $\mathbf{R Q}$ & .08 & 0.07 \\
\hline ADCSI & 179 & 704 & & .028 & 0.068 & LATIN AN & MERICA & & IAY & .078 & 0.070 \\
\hline BG & 309 & 0.026 & RED & 687 & 0.000 & $\mathbf{L}$ & 0.114 & 0.000 & $\overline{\mathrm{AC}}$ & 0.056 & 0.138 \\
\hline DEC & 74 & $\mid-0.108$ & & 61 & 0.404 & & 11 & 124 & & .033 & 0.018 \\
\hline OMO & 84 & -0.003 & & 183 & 0.290 & & .039 & $\mid-0.028$ & & .196 & 0.370 \\
\hline WISD & 27 & -0.061 & & 121 & 0.082 & TURO & 0.118 & 0.013 & DF. & .256 & 0.631 \\
\hline & 74 & 7 & & 46 & -0.173 & & 547 & 0.249 & & 230 & .436 \\
\hline IDE & 169 & 588 & & 045 - & -0.354 & FI & 218 & 0.099 & & 0.269 & 0.380 \\
\hline $\mathbf{F E}$ & 54 & 382 & & 091 & -0.125 & FUNBODEM & 0.416 & 0.172 & JRCO & 0.264 & 0.519 \\
\hline & & & & 21 - & -0.176 & & & 012 & & .08 & .034 \\
\hline & 05 & 254 & & 16 & 0.309 & & 407 & 0.241 & A-R & \begin{tabular}{|l|}
0.114 \\
\end{tabular} & 222 \\
\hline СРB & 051 & -0.094 & ONS & 548 & 0.369 & MM-BOG & 0.122 & 0.096 & JER & 0.256 & 0.167 \\
\hline & & -0.092 & & 28 & 0.426 & & 21 & 0.170 & NTE & 0.664 & 351 \\
\hline OCR & 68 & \begin{tabular}{|c|c|}
-0.028 \\
\end{tabular} & & 50 & 0.346 & & .174 & $\mid-0.183$ & \multicolumn{3}{|c|}{ ME \& NA } \\
\hline SAT & -0.013 & 0.053 & KMF & 0.098 & -0.097 & DP & -0.135 & 0.047 & ML & 0.975 & -0.720 \\
\hline & 38 & 320 & & 37 & 0.886 & & 0.212 & 0.023 & & 0.242 & 0.025 \\
\hline $\mathrm{n}$ & 82 & 349 & & 64 & 0.554 & & 0.020 & 0.075 & & 1.330 & -0.47 \\
\hline & 88 & 38 & & 08 & -0.004 & & 0.623 & 0.292 & $\mathbf{m v}$ & -0.062 & -0.0 \\
\hline & 34 & 160 & $\mathbf{L}$ & 457 & 0.407 & OL & 0.003 & 0.156 & & $\mid-0.125$ & 0.01 \\
\hline & 51. & 1.914 & HAI & 052 & -0.063 & IN & 0.122 & 0.118 & & -0.008 & 0.012 \\
\hline & 32 & 309 & & 95 & 332 & DSE & 0.045 & 0.147 & AMA & -0.110 & 0.011 \\
\hline & 52 & 1.506 & OI & 0.258 & 0.125 & $\mathrm{AC}$ & 0.137 & 0.140 & & -0.022 & -0.331 \\
\hline & 46 & 0.180 & BANK & 075 & 0.272 & & -0.075- & -0.278 & & -0.004 & -0.09 \\
\hline JOVO-BA & .377 & -0.104 & & 09 & 0.815 & & -0.611 - & -0.275 & URA & $\mid-0.037$ & 0.061 \\
\hline SOCREMO & 350 & 193 & IMON & \begin{tabular}{|l|}
0.824 \\
\end{tabular} & 0.301 & MI & -0.055 & -0.091 & NDA & $\mid-0.044$ & 0.320 \\
\hline $\mathrm{TC}$ & 55 & 17 & \multicolumn{3}{|c|}{ E. ASIA \& PACIFIC } & $\mathrm{NDA}$ & -0.3 & -0.423 & \multicolumn{3}{|c|}{ SOUTH ASIA } \\
\hline & 0.012 & -0.072 & & \begin{tabular}{|l|l|}
0.099 \\
\end{tabular} & 0.066 & D ECU & 0.055 & -0.001 & & -0.071 & -0.05 \\
\hline$\overline{\mathbf{A P}}$ & -0.180 & -0.305 & & 32 & 0.070 & E RL & 0.164 & 0.401 & & 1.195 & 1.287 \\
\hline & & & & & 0.383 & & 0.242 & & & 0.179 & 0.0 \\
\hline CMS & 0.361 & 0.313 & $\mathbf{n n}$ & 0.242 & 0.086 & GENESIS EM. & 0.131 & 0.155 & TMSS & 0.753 & 0.591 \\
\hline
\end{tabular}

${ }^{7} \mathrm{SDI}$ value of 0.161 means that the MFI has to raise the interest rates on loans by $16.1 \%$ to be subsidy free

${ }^{8} \mathrm{SDI}$ value of -0.250 means that the MFI is subsidy free even if it reduces interest rate on loan by $25 \%$ 


\begin{tabular}{|c|c|c|c|c|c|c|c|c|c|c|c|} 
PAMECAS & 0.052 & -0.103 & PRASAC & 0.347 & 0.301 & ACME & 0.188 & 0.261 & BANDHAN & 0.095 & -0.215 \\
\hline PRIDE & 0.017 & 0.074 & MBK-VENTU & 0.384 & 0.211 & FINCA-HON & 0.194 & 0.124 & BASIX & 0.119 & 0.088 \\
\hline CBANK & 0.009 & -0.074 & ASHI & 0.331 & 0.082 & HDH & 0.240 & 0.890 & CASHPOOR & 0.746 & 0.386 \\
\hline CML & 0.024 & 0.189 & BCB & -0.272 & -0.196 & WORLD-REL & 0.122 & 0.098 & ESAF & 0.243 & -0.083 \\
\hline FAULU & 0.211 & 0.436 & BANGKO-KA & -0.113 & -0.157 & ACODEP & -0.113 & -0.154 & GK & 0.130 & -0.059 \\
\hline FINCA-UGA & 0.047 & 0.125 & CBMO & -0.227 & -0.253 & FDL & -0.176 & -0.051 & KBSLAB & 0.462 & 0.478 \\
\hline MEDNET & 0.179 & 3.008 & DIGOS & -0.010 & -0.099 & BANEX & 0.006 & -0.037 & SHARE-MF & -0.116 & 0.158 \\
\hline CETZAM & 2.342 & 0.830 & IST-VALLEY & 0.1982 & -0.234 & PROCRED-NIC & 0.031 & 0.116 & SNFL & 0.639 & 0.531 \\
\hline FINCA-ZAM & 0.519 & 0.034 & NWFT & 0.0767 & -0.013 & PRODESA & -0.282 & -0.311 & CBB & 0.296 & -0.029 \\
\hline C. ASIA \& E. EUROPE & SOLANO & -0.241 & -0.269 & FIELCO & 0.049 & 0.091 & NIRDHAN & 0.250 & 0.265 \\
\hline BESA & 0.2403 & 0.010 & TSPI & -0.050 & -0.070 & INTERFISA & 0.128 & 0.002 & ASASAH & 0.211 & 1.015 \\
\hline PROCRED-ALB & 0.052 & 0.006 & SPBD & 0.503 & 0.371 & BANTRA & 0.053 & 0.158 & FMBL & 2.125 & 0.514 \\
\hline & & & B-TANGAIL & -0.136 & -0.023 & ARMP & 0.653 & 0.182 & KASHF & 0.036 & 0.045 \\
\hline & & & & & & ASA & -0.286 & -0.226 & BRAC-AFG & 1.200 & 0.646 \\
\hline & & & & & & BRAC-BAN & 1.035 & 0.859 & FMFB-AFG & 1.034 & 0.077 \\
\hline
\end{tabular}

Source: Author own calculations based on the Balance sheets of 204 MFIs for year $2004 \& 2005$

reduced to 122 MFIs. All the values taken from the respective MFI's audit reports have been converted into the USD using exchange rates provided by the Mix Market website. SDI values have been calculated using the lending rate as a proxy for opportunity cost of capital.

Table 4.4

Correlations

\begin{tabular}{|c|c|c|c|c|c|c|c|c|c|c|c|c|c|}
\hline & SDI & GNIpc & Loansize & cost/staff & Borr/staff & women i & inflation & Age & $\begin{array}{c}\text { interest } \\
\text { on loan }\end{array}$ & fin. cost & cost/bor & OSS & ROA \\
\hline SDI & 1.000 & & & & & & & & & & & & \\
\hline GNIpc & $-0.1931 *$ & 1.000 & & & & & & & & & & & \\
\hline Loansize & $0.1020^{*}$ & $-0.3660 *$ & 1.000 & & & & & & & & & & \\
\hline cost/staff & -0.0720 & $0.5230^{*}$ & $0.2954^{*}$ & 1.000 & & & & & & & & & \\
\hline borr/staff & $-0.1966 *$ & $0.1158^{*}$ & $-0.6272 *$ & -0.0539 & 1.000 & & & & & & & & \\
\hline Women & -0.0297 & 0.0020 & $-0.6622 *$ & $-0.3953^{*}$ & $0.3383^{*}$ & 1.000 & & & & & & & \\
\hline Inflation & $0.1154^{*}$ & $-0.5097^{*}$ & $0.2080^{*}$ & $-0.2420^{*}$ & $-0.2138^{*}$ & -0.0086 & 1.000 & & & & & & \\
\hline Age & $-0.1380 *$ & $0.1197 *$ & $-0.1189 *$ & 0.0333 & $0.1857^{*}$ & 0.0499 & $-0.1055^{*}$ & 1.000 & & & & & \\
\hline $\begin{array}{c}\text { interest on } \\
\text { loans }\end{array}$ & 0.0592 & $-0.0970^{*}$ & $-0.1368 *$ & 0.0651 & $-0.1831^{*}$ & $0.2494^{*}$ & $0.2782^{*}$ & $-0.1511^{*}$ & 1.000 & & & & \\
\hline fin. Cost & $-0.1359 *$ & -0.0457 & 0.0161 & 0.0293 & $-0.1273^{*}$ & 0.0682 & $0.1140^{*}$ & 0.0241 & $0.2650^{*}$ & 1.000 & & & \\
\hline cost/borr & 0.0616 & $0.3349 *$ & $0.6019^{*}$ & $0.8036^{*}$ & $-0.6376^{*}$ & $-0.5064^{*}$ & -0.0592 & -0.0850 & $0.1594 *$ & $0.0993^{*}$ & 1.000 & & \\
\hline OSS & $-0.4223 *$ & 0.0770 & 0.0230 & $-0.1216^{*}$ & $0.1551^{*}$ & $-0.1031 *$ & -0.0590 & $0.1009 *$ & $-0.1872 *$ & -0.0796 & $-0.1862 *$ & 1.000 & \\
\hline ROA & $-0.4203 *$ & $0.1313^{*}$ & $-0.1932 *$ & -0.0522 & $0.1393^{*}$ & $0.0972 *$ & 0.0374 & -0.0794 & 0.0466 & 0.0496 & $-0.1233^{*}$ & $0.3391 *$ & 1.000 \\
\hline
\end{tabular}


The correlation matrix in Table 4.4 shows the strength of the relationship among some important variables used in this study. SDI has a negative significant relationship with both financial ratios (OSS and ROA), financial cost of acquiring loans, age and staff productivity. On the other hand it has a significant positive relationship with outreach (loan size/GNIpc) and inflation. Relationship between women borrowers and outreach is negative and significant thus showing the fact that women are predominantly the borrowers of small loans. Interest rate charged to the clients has significant negative relationship with outreach variable while a significant positive relationship with women variable. This highlights the fact that MFIs tend to charge higher rates to poor clients which are predominantly women. Regression analysis allow us to investigate these relationships after controlling for various covariates i.e. region, lending methodology and status etc.

\subsubsection{Empirical approach}

The empirical approach regarding all the relationships is discussed separately in their respective sections below. As we have one value for each two years for all the variables, therefore, regression analysis have been carried out by employing Panel data Random effect model for 179 MFIs dropping 25 MFIs for which the subsidy figures are unavailable for year 2006. Hausman test has been carried out for each specification separately to choose between fixed effect model and random effect model.

In the regression analysis throughout the paper we have used the same set of categorical variables as described in detail in Table 4.2. The omitted variable categories are: Non-banking Financial Institutions (NBFIs) for MFIs formal status category; Individual lending methodology for the lending methodology category: Africa for Regional dummy and in addition to that dummies for MFIs with saving features, regulated and those providing other services have been used.

\subsection{Interest rate policy}


The impact of efficiency on the interest rate policy of microfinance, though a topic of immense importance, is an issue not addressed at length in the microfinance literature so far probably due to the data limitations (Hudon and Trace, 2008). Most recently Armendariz and Szafarz (2009) in their paper on "Mission Drift in Microfinance" stress the importance of the inclusion of interest rates into the equation to investigate the mission drift phenomenon. The case of real interest rates charged by the MFI taken as a dependent variable is presented in the regressions below. The idea is to identify the variables important in determining the interest rate policy of MFIs. Administrative cost per borrower and costs incurred to access the loanable funds are used as a proxy for financial efficiency. While Loansize/GNIpc and percentage of women borrowers represent the social efficiency variables measuring the outreach of MFIs.

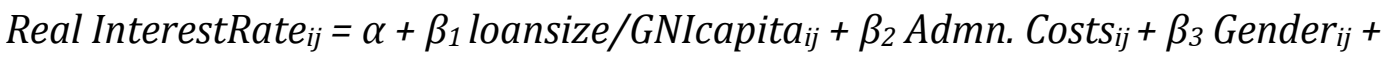
$\beta_{4}$ Age $_{i j}+$ B $_{5}$ GNICapita $_{i j}+\beta_{6}$ Inflation $_{i j}+\beta_{7}$ FinacialCost $_{i j}+\beta_{8}$ Status $_{i j}+\beta_{9}$ LendingType $_{i j}+\beta_{10 \text { Region }_{i j}}+\beta_{11 \text { Saving }_{i j}}+\beta_{12}$ OtherServices $_{i j}+\beta_{13}$ Regulated $_{i j}+\varepsilon_{i}$ (1)

Where real interest rate is actual interest rate minus the rate of inflation. The control variables are administrative cost, financial cost to loanable funds including the rate of inflation, which determine MFIs unit cost. The study also control for characteristics of the client base including women borrowers, GNI per capita and average loan size. As usual, the same set of dummy variables is included. In addition to that, the dummies for region of MFI, their status and their lending methodology are included with Africa, Non-banking Financial Intermediaries (NBFIs) and Individual lending as the omitted categories respectively. Moreover three other dummies are included whether MFI is regulated, have saving design and provide other services.

\subsubsection{Results}

The regression results of the above specification (1) are presented in equations (1-5) in Table 4.5 below. The significant negative coefficient of Loan size 
in all the equations depict the fact that clients with smaller loan sizes have to pay higher interest rates relatively to the clients with large loan size. In other words, MFIs tend to charge higher interest rates for small loan sizes. This is due to fact that delivering small loans are considered to be expensive because of the higher transaction costs associated with it, a fact well documented in microfinance literature. Both the cost variables (administrative cost and cost of acquiring loanable funds) have significant positive coefficients, thus suggesting that increase in administrative cost and cost of borrowing induce MFIs to raise interest rates on loans to the borrowers. The coefficient of women borrowers is positive and significant in all the regression even after controlling for loan size. This confirms the fact that the MFIs which have predominantly women borrower, charge higher interest rates to their clients. The significant negative coefficient of age in Eq (2) and (3) depicts that with the passage of time, MFIs tend to charge lower interest rates. Moreover, microfinance borrowers in relatively poor countries pay higher interest rates as shown by the significant negative coefficient of per capita income variable. Or this may be due the fact that on average MFIs in poor countries lend to the marginally better off poor rather than to very poor people. Interestingly, the dummy for the "Other Services" turn up to be insignificant in all the regression estimates. The possible reason is that MFIs normally finance their provision of other service through subsidies which is irrespective of the interest rates charged to the borrowers. The results above also strongly support the notion of the importance of interest rate policy in the "Mission Drift" phenomena in microfinance. Notwithstanding the dummy variable, MFIs with cooperative status charge lower interest rates while those which are NBFIs charge higher interest rates. Lending methodology dummies suggest that MFIs with group lending features charge lower while those with individual and village banking lending methodology charge higher interest rates. Except African MFIs, MFIs in other regions charge lower interest rates. Moreover MFIs which collect savings/deposits do charge lower interest rates to their clients. 
Table 4.5

Interest Rate Policy Regressions

\begin{tabular}{|c|c|c|c|c|c|}
\hline \multicolumn{6}{|c|}{ Real Interest rate on loans } \\
\hline & (1) & (2) & (3) & (4) & (5) \\
\hline Loansize/GNIpc & $\begin{array}{c}-0.086 \\
(-6.16)^{* * *}\end{array}$ & $\begin{array}{c}-0.022 \\
(-1.86)^{*}\end{array}$ & $\begin{array}{c}-0.021 \\
(-1.91)^{*}\end{array}$ & $\begin{array}{c}-0.077 \\
(-5.38)^{* * *}\end{array}$ & $\begin{array}{c}-0.075 \\
(-5.28)^{* * *}\end{array}$ \\
\hline Admn.Cost/borrower & $\begin{array}{c}0.077 \\
(6.35)^{* * *}\end{array}$ & & & $\begin{array}{c}0.076 \\
(6.10)^{* * *}\end{array}$ & $\begin{array}{c}0.072 \\
(5.90)^{* * *}\end{array}$ \\
\hline Women & & $\begin{array}{c}0.059 \\
(3.19)^{* * *} \\
\end{array}$ & $\begin{array}{c}0.060 \\
(3.28)^{* * *}\end{array}$ & $\begin{array}{c}0.062 \\
(3.45)^{* * *}\end{array}$ & $\begin{array}{c}0.062 \\
(3.50)^{* * *}\end{array}$ \\
\hline Age of an MFI & & $\begin{array}{c}-0.040 \\
(-2.10)^{* *}\end{array}$ & $\begin{array}{c}-0.045 \\
(-2.36)^{* *}\end{array}$ & $\begin{array}{l}-0.022 \\
(-1.25)\end{array}$ & $\begin{array}{l}-0.026 \\
(-1.50)\end{array}$ \\
\hline GNI per capita & $\begin{array}{c}-0.059 \\
(-3.18)^{* * *}\end{array}$ & $\begin{array}{l}0.013 \\
(0.77) \\
\end{array}$ & $\begin{array}{l}0.010 \\
(0.58)\end{array}$ & $\begin{array}{c}-0.053 \\
(-2.76)^{* * *} \\
\end{array}$ & $\begin{array}{c}-0.052 \\
(-2.76)^{* * *}\end{array}$ \\
\hline Inflation & $\begin{array}{c}0.577 \\
(4.09)^{* * *}\end{array}$ & $\begin{array}{c}0.583 \\
(4.05)^{* * *}\end{array}$ & $\begin{array}{c}0.580 \\
(4.10)^{* * *}\end{array}$ & $\begin{array}{c}0.618 \\
(4.25)^{* * *}\end{array}$ & $\begin{array}{c}0.614 \\
(4.31)^{* * *}\end{array}$ \\
\hline Financial cost & & & $\begin{array}{c}0.298 \\
(3.51)^{* * *}\end{array}$ & & $\begin{array}{c}0.284 \\
(3.30)^{* * *}\end{array}$ \\
\hline Bank & $\begin{array}{l}-0.043 \\
(-1.47) \\
\end{array}$ & $\begin{array}{l}-0.005 \\
(-0.16) \\
\end{array}$ & $\begin{array}{c}-0.002 \\
(-0.05) \\
\end{array}$ & $\begin{array}{l}-0.037 \\
(-1.23) \\
\end{array}$ & $\begin{array}{l}-0.032 \\
(-1.08) \\
\end{array}$ \\
\hline Cooperatives & $\begin{array}{c}-0.110 \\
(-2.56)^{* * *}\end{array}$ & $\begin{array}{l}-0.081 \\
(-1.63) \\
\end{array}$ & $\begin{array}{l}-0.072 \\
(-1.46) \\
\end{array}$ & $\begin{array}{c}-0.074 \\
(-1.71)^{*}\end{array}$ & $\begin{array}{l}-0.067 \\
(-1.54)\end{array}$ \\
\hline NGOs & $\begin{array}{l}0.007 \\
(0.32)\end{array}$ & $\begin{array}{l}0.014 \\
(0.51)\end{array}$ & $\begin{array}{l}0.011 \\
(0.43)\end{array}$ & $\begin{array}{l}0.001 \\
(0.05)\end{array}$ & $\begin{array}{l}-0.000 \\
(-0.02)\end{array}$ \\
\hline Rural Bank & $\begin{array}{c}-0.115 \\
(-2.21)^{* *}\end{array}$ & $\begin{array}{l}-0.051 \\
(-0.78) \\
\end{array}$ & $\begin{array}{l}-0.049 \\
(-0.77) \\
\end{array}$ & $\begin{array}{l}-0.077 \\
(-1.37) \\
\end{array}$ & $\begin{array}{l}-0.076 \\
(-1.35) \\
\end{array}$ \\
\hline Individual \& Group & $\begin{array}{c}-0.055 \\
(-2.58)^{* * *}\end{array}$ & $\begin{array}{c}-0.071 \\
(-2.89)^{* * *}\end{array}$ & $\begin{array}{c}-0.069 \\
(-2.85)^{* * *} \\
\end{array}$ & $\begin{array}{c}-0.061 \\
(-2.81)^{* * *} \\
\end{array}$ & $\begin{array}{c}-0.059 \\
(-2.75)^{* * *}\end{array}$ \\
\hline Group & $\begin{array}{c}-0.033 \\
(-2.87)^{* * *}\end{array}$ & $\begin{array}{c}-0.132 \\
(-3.38)^{* * *}\end{array}$ & $\begin{array}{c}-0.126 \\
(-3.27)^{* * *}\end{array}$ & $\begin{array}{c}-0.121 \\
(-3.52)^{* * *}\end{array}$ & $\begin{array}{c}-0.114 \\
(-3.36)^{* * *}\end{array}$ \\
\hline Village Banking & $\begin{array}{c}0.132 \\
(3.26)^{* * *}\end{array}$ & $\begin{array}{c}0.138 \\
(2.97)^{* * *}\end{array}$ & $\begin{array}{c}0.138 \\
(3.02)^{* * *}\end{array}$ & $\begin{array}{c}0.110 \\
(2.70)^{* * *}\end{array}$ & $\begin{array}{c}0.112 \\
(2.77)^{* * *}\end{array}$ \\
\hline C. Asia \& E. Europe & $\begin{array}{c}-0.083 \\
(-2.28)^{*}\end{array}$ & $\begin{array}{c}-0.125 \\
(-2.93)^{* * *}\end{array}$ & $\begin{array}{c}-0.123 \\
(-2.92)^{* * *}\end{array}$ & $\begin{array}{c}-0.079 \\
(-2.07)^{* *}\end{array}$ & $\begin{array}{c}-0.080 \\
(-2.09)^{* *}\end{array}$ \\
\hline E. Asia \& Pacific & $\begin{array}{l}-0.001 \\
(-0.03) \\
\end{array}$ & $\begin{array}{l}-0.026 \\
(-0.59) \\
\end{array}$ & $\begin{array}{c}-0.022 \\
(-0.52) \\
\end{array}$ & $\begin{array}{l}-0.002 \\
(-0.07) \\
\end{array}$ & $\begin{array}{l}-0.001 \\
(-0.02) \\
\end{array}$ \\
\hline Latin America & $\begin{array}{c}-0.125 \\
(-3.76)^{* * *}\end{array}$ & $\begin{array}{c}-0.167 \\
(-4.52)^{* * *}\end{array}$ & $\begin{array}{c}-0.162 \\
(-4.43)^{* * *}\end{array}$ & $\begin{array}{c}-0.124 \\
(-3.70)^{* *}\end{array}$ & $\begin{array}{c}-0.122 \\
(-3.67)^{* *}\end{array}$ \\
\hline M. East \& N. Africa & $\begin{array}{c}-0.095 \\
(-2.01)^{* *}\end{array}$ & $\begin{array}{c}-0.163 \\
(-3.02)^{* * *}\end{array}$ & $\begin{array}{c}-0.157 \\
(-2.94)^{* * *}\end{array}$ & $\begin{array}{c}-0.103 \\
(-2.15)^{* *}\end{array}$ & $\begin{array}{c}-0.101 \\
(-2.10)^{* *}\end{array}$ \\
\hline S. Asia & $\begin{array}{c}-0.090 \\
(-2.60)^{* * *}\end{array}$ & $\begin{array}{c}-0.172 \\
(-4.64)^{* * *}\end{array}$ & $\begin{array}{c}-0.172 \\
(-4.73)^{* * *}\end{array}$ & $\begin{array}{c}-0.091 \\
(-2.62)^{* *}\end{array}$ & $\begin{array}{c}-0.095 \\
(-2.75)^{* * *}\end{array}$ \\
\hline Savings & $\begin{array}{l}-0.035 \\
(-1.46) \\
\end{array}$ & $\begin{array}{l}-0.045 \\
(-1.63) \\
\end{array}$ & $\begin{array}{c}-0.048 \\
(-1.75)^{*}\end{array}$ & $\begin{array}{l}-0.039 \\
(-1.62) \\
\end{array}$ & $\begin{array}{c}-0.042 \\
(-1.74)^{*}\end{array}$ \\
\hline Other Services & $\begin{array}{l}-0.024 \\
(-1.16)\end{array}$ & $\begin{array}{l}-0.017 \\
(-0.76) \\
\end{array}$ & $\begin{array}{l}-0.015 \\
(-0.66) \\
\end{array}$ & $\begin{array}{l}-0.024 \\
(-1.18) \\
\end{array}$ & $\begin{array}{l}-0.021 \\
(-1.07) \\
\end{array}$ \\
\hline Regulated & $\begin{array}{l}-0.001 \\
(-0.05) \\
\end{array}$ & $\begin{array}{l}-0.006 \\
(-0.28) \\
\end{array}$ & $\begin{array}{l}-0.008 \\
(-0.35) \\
\end{array}$ & $\begin{array}{l}-0.001 \\
(-0.08) \\
\end{array}$ & $\begin{array}{l}-0.003 \\
(-0.17) \\
\end{array}$ \\
\hline Constant & $\begin{array}{c}0.416 \\
(3.89)^{* * *}\end{array}$ & $\begin{array}{l}0.204 \\
(1.49)\end{array}$ & $\begin{array}{l}0.212 \\
(1.58)\end{array}$ & $\begin{array}{l}0.197 \\
(1.53)\end{array}$ & $\begin{array}{l}0.199 \\
(1.56)\end{array}$ \\
\hline Observations & 358 & 348 & 348 & 348 & 348 \\
\hline No of Groups & 179 & 1749 & 174 & 174 & 174 \\
\hline R-Square & 0.52 & 0.40 & 0.41 & 0.53 & 0.54 \\
\hline Wald chi2 & 179 & 120 & 136 & 190 & 202 \\
\hline Prob > & 0.00 & 0.00 & 0.00 & 0.00 & 0.00 \\
\hline
\end{tabular}

Z-values in parentheses

${ }^{*}$ significant at $10 \%$; ${ }^{* *}$ significant at $5 \%$; ${ }^{* *}$ significant at $1 \%$

Source: Authors calculations based on data taken from audit reports directly and from the Mix Market website

${ }^{9}$ The no. of groups reduce to $174 \mathrm{MFIs}$ because the women borrower information for $5 \mathrm{MFIs}$ is not available 


\subsection{Profitability Regressions}

This study uses Subsidy dependence index (SDI), Return on Asset (ROA) and Operational Self-sufficiency (OSS) as a proxy for the profitability of MFIs and have been taken as a left hand side variables. Where increase in profitability and sustainability is associated with decrease in SDI and increase in ROA and OSS figures. Notwithstanding the determinants of the profitability and sustainability, the regression specifically focuses on its relationship with the cost (administrative), interest rates charged on the loans to borrowers, MFIs age and women borrowers among others. In addition to that, the regression Eq (2) below also aims to investigate the relationship between outreach and sustainability. The existing literature provide evidence of the existence of trade-off between outreach and sustainability (see for example Navajas et al., 2002, Schreiner, 2002, Rhyne, 1998, Von Pischke, 1998). As argued by Manos and Yaron, 2009, Sustainability is important in the long run for improving outreach. However, in the short run, MFI performance reflects the best use of knowledge, technology, pricing of financial product and modes of operations in serving the target clientele. Thus in the short term, an MFI must reduce its financial sustainability in order to increase outreach and vise versa.

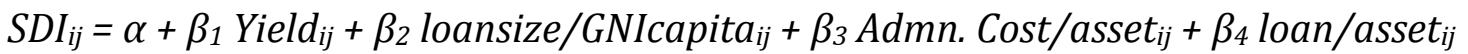

$+\beta_{5}$ Age $_{i j}+\beta 6$ Women $_{i j}+\beta_{7}$ Status $_{i j}+\beta_{8}$ LendingType $_{i j}+\beta_{9}$ Region $_{i j}+\beta_{10}$ Savings $_{i j}+$ $\beta_{11}$ OtherServices $_{i j}+\beta_{12}$ Regulated $_{i j}+\varepsilon_{i j}$

Where $S D I$ is subsidy dependence index of microfinance institution $i$. The same set of explanatory variables has also been regressed on return on assets (ROA) and operational self-sufficiency (OSS). Yield is the interest rate faced by the borrowers of MFIs. The summary statistics of all the variables are given in Table 1 and the mean and median values fall in the expected range. The microfinance institution's business practice is best described by three variables: the ratio of loans to assets, the average loan size and the dummy variable of MFIs formal status with Non-banking Financial Institutions (NBFIs) as the omitted category. In 
addition to that, as usual, the dummies for region and lending methodology are included with Africa and Individual lending as the omitted category respectively along with three other dummies for saving, other services and regulations.

\subsubsection{Results}

The results of the estimation of specification (2) above are presented in equations (6-8) in table 4.6 below. It shows that raising the yield or interest rates on loan leads to improved financial performance as the interest rate coefficient in both SDI and OSS equations is significant. Thus higher interest rates are associated with lower subsidy dependence and higher OSS. Increase in the administrative cost leads to reduced profitability in all their profitability measures with higher subsidy dependence and reduced OSS and ROA. MFIs age significantly contributes to the financial performance by improving their profitability with lower Subsidy dependence and higher OSS. On the other hand, giving credit to women has no significant impact on the profitability. The loan size variable does explain variation in Profitability. Where increase in loan size leads to lower profitability and sustainability with higher subsidy dependence and lower ROA. This is due to the fact that clients which afford higher loan sizes require better services. Hence this relationaship also confirms the trade-off between outreach and sustainability of microfinance. The dummy for "status" explain some variation in financial profitability. NGO are found to be less profitable with high dependence on subsidies along with the Cooperatives which are less profitable with significantly lower OSS. On the other hand, NBFIs, the omitted variable category, seem more profitable with significant positive coefficients of ROA and OSS. Dummy for "lending methodology" also exhibits some variations where MFIs where group lending leads to less profitability with lower OSS while Individual lending is profitable with significant positive coefficients for ROA and OSS. Notwithstanding the regional dummies, Middle East \& North African MFIs have better profitability in terms of OSS and ROA. Moreover, the regulated MFIs exhibit lower profitability 
Table 4.6

Profitability Regressions

\begin{tabular}{|c|c|c|c|}
\hline & SDI & ROA & OSS \\
\hline & (6) & (7) & (8) \\
\hline Interest rate (Yield) & $\begin{array}{c}-0.483 \\
(-1.72)^{*}\end{array}$ & $\begin{array}{l}0.053 \\
(1.23) \\
\end{array}$ & $\begin{array}{c}0.299 \\
(1.98)^{* *}\end{array}$ \\
\hline Loansize/GNIpc & $\begin{array}{c}0.088 \\
(2.12)^{* *}\end{array}$ & $\begin{array}{c}-0.015 \\
(-2.35)^{* *}\end{array}$ & $\begin{array}{l}-0.020 \\
(-0.84)\end{array}$ \\
\hline Cost/asset & $\begin{array}{c}1.206 \\
(3.30)^{* * *}\end{array}$ & $\begin{array}{c}-0.194 \\
(-3.40)^{* * *}\end{array}$ & $\begin{array}{c}-1.175 \\
(-6.35)^{* * *}\end{array}$ \\
\hline Loan/asset & $\begin{array}{c}-0.000 \\
(-0.68)\end{array}$ & $\begin{array}{l}-0.000 \\
(-0.32)\end{array}$ & $\begin{array}{c}0.000 \\
(0.52)\end{array}$ \\
\hline Age of an MFI & $\begin{array}{c}-0.115 \\
(-1.67)^{*}\end{array}$ & $\begin{array}{l}-0.010 \\
(-0.97)\end{array}$ & $\begin{array}{c}0.086 \\
(2.19)^{* *}\end{array}$ \\
\hline Women & $\begin{array}{l}-0.098 \\
(-1.08)\end{array}$ & $\begin{array}{l}0.015 \\
(1.09)\end{array}$ & $\begin{array}{l}0.006 \\
(0.12)\end{array}$ \\
\hline Bank & $\begin{array}{l}-0.036 \\
(-0.34)\end{array}$ & $\begin{array}{c}-0.006 \\
(-0.38)\end{array}$ & $\begin{array}{l}-0.101 \\
(-1.62)\end{array}$ \\
\hline Cooperatives & $\begin{array}{c}-0.081 \\
(-0.52)\end{array}$ & $\begin{array}{r}-0.025 \\
(-1.05)\end{array}$ & $\begin{array}{c}-0.234 \\
(-2.55)^{* *}\end{array}$ \\
\hline NGOs & $\begin{array}{c}0.252 \\
(2.94)^{* * *}\end{array}$ & $\begin{array}{l}-0.020 \\
(-1.50)\end{array}$ & $\begin{array}{l}-0.043 \\
(-0.86)\end{array}$ \\
\hline Rural Bank & $\begin{array}{c}-0.194 \\
(-0.95)\end{array}$ & $\begin{array}{l}-0.005 \\
(-0.15)\end{array}$ & $\begin{array}{l}0.021 \\
(0.18)\end{array}$ \\
\hline Individual \& Group & $\begin{array}{l}0.119 \\
(1.50) \\
\end{array}$ & $\begin{array}{l}-0.015 \\
(-1.27)\end{array}$ & $\begin{array}{l}-0.074 \\
(-1.60)\end{array}$ \\
\hline Group & $\begin{array}{c}0.114 \\
(0.88) \\
\end{array}$ & $\begin{array}{l}-0.026 \\
(-1.29)\end{array}$ & $\begin{array}{c}-0.165 \\
(-2.18)^{* *}\end{array}$ \\
\hline Village Banking & $\begin{array}{c}0.090 \\
(0.60) \\
\end{array}$ & $\begin{array}{l}-0.008 \\
(-0.30)\end{array}$ & $\begin{array}{l}-0.036 \\
(-0.42)\end{array}$ \\
\hline C. Asia \& E. Europe & $\begin{array}{l}-0.006 \\
(-0.05)\end{array}$ & $\begin{array}{c}0.017 \\
(0.87) \\
\end{array}$ & $\begin{array}{c}0.168 \\
(2.25)^{* *}\end{array}$ \\
\hline E. Asia \& Pacific & $\begin{array}{l}-0.038 \\
(-0.28)\end{array}$ & $\begin{array}{l}0.002 \\
(0.06) \\
\end{array}$ & $\begin{array}{l}-0.022 \\
(-0.28)\end{array}$ \\
\hline Latin America & $\begin{array}{l}-0.042 \\
(-0.40)\end{array}$ & $\begin{array}{l}-0.018 \\
(-1.17)\end{array}$ & $\begin{array}{l}-0.003 \\
(-0.05)\end{array}$ \\
\hline M. East \& N. Africa & $\begin{array}{l}-0.197 \\
(-1.15)\end{array}$ & $\begin{array}{c}0.061 \\
(2.35)^{* *}\end{array}$ & $\begin{array}{c}0.177 \\
(1.76)^{*}\end{array}$ \\
\hline S. Asia & $\begin{array}{l}0.161 \\
(1.31)\end{array}$ & $\begin{array}{l}-0.029 \\
(-1.47)\end{array}$ & $\begin{array}{l}0.015 \\
(0.20)\end{array}$ \\
\hline Savings & $\begin{array}{l}0.040 \\
(0.45)\end{array}$ & $\begin{array}{l}-0.017 \\
(-1.32)\end{array}$ & $\begin{array}{l}0.014 \\
(0.28)\end{array}$ \\
\hline Other Services & $\begin{array}{l}-0.040 \\
(-0.55)\end{array}$ & $\begin{array}{l}-0.009 \\
(-0.77)\end{array}$ & $\begin{array}{l}0.009 \\
(0.20)\end{array}$ \\
\hline Regulated & $\begin{array}{l}0.101 \\
(1.39)\end{array}$ & $\begin{array}{c}-0.034 \\
(-3.05)^{* * *}\end{array}$ & $\begin{array}{l}-0.006 \\
(-0.15)\end{array}$ \\
\hline Constant & $\begin{array}{c}0.668 \\
(1.68)^{*}\end{array}$ & $\begin{array}{l}0.082 \\
(1.34)\end{array}$ & $\begin{array}{c}1.146 \\
(5.10)^{* * *}\end{array}$ \\
\hline Observations & 348 & 348 & 348 \\
\hline No of Groups & 174 & 174 & 174 \\
\hline R-Square & 0.16 & 0.23 & 0.32 \\
\hline Wald chi2 & 52 & 79 & 103 \\
\hline Prob > & 0.00 & 0.00 & 0.00 \\
\hline
\end{tabular}

z-values in parentheses. *significant at $10 \%$; ${ }^{* *}$ significant at $5 \%$; ${ }^{* *}$ significant at $1 \%$.

Source: Authors calculations based on data taken from audit reports directly and from the Mix Market website 
with low return on assets ${ }^{10}$. The existing evidence of the impact of regulations on the profitability of MFI is mixed as it has both positive and negative consequences. Non- involvement by the regulators makes establishing and operating an MFI easier. This is exactly what 'immensely' helped MFIs in some Latin American Countries in their early stages and helped create the sector (Christen and Rosenberg, 2000). On the other hand, regulatory ambiguity leaves MFI vulnerable to regulatory discretion in the interpretation of the legal basis for lending activity, as in the case of Russia (Safavian, et al. 2000).

\subsection{Efficiency and productivity}

Theoretically the effect of subsidies on the efficiency of microfinance can be positive and negative. The arguments for negative impact on subsidies rest on the effects of soft-budget constraints where donor-funded bailouts of poorly performing MFIs reduce the incentive for cost-cutting and hence decrease the efficiency (Dewatripont and Maskin, 1995; Kornai et al., 2003). Moreover the moral hazard argument where staff of the MFIs takes advantage of the lack of costly monitoring by donors to shirk, gather perks or extract wage-rent. Thus results in decreased efficiency due to higher costs. On the other hand, subsidies may contribute to efficiency by increasing opportunities for the MFIs to invest in capacity building, develop and expand the infrastructure and quality of services.

MFIs have to incur costs in various forms in order to continue their loan granting activities to the clients. These costs include among others, the financial cost to the accessible loans, administrative costs in the provision of credit and some fixed costs for the whole organization. For simplicity, like Hudon and Traca, 2008, we assume that all the administrative expenses comprise of relationship costs with borrowers. In theory, these costs will depend on the actual number of borrowers, the numbers of loans provided to each, and the value of each loan. However, once a relationship with a client is established, the marginal costs of providing additional or larger loans amount only to the financial cost of the funds

\footnotetext{
10 The result in not surprisingly. Hartarska and Nadolnyak (2007) among others find no evidence that regulated MFIs perform better in terms of either sustainability of outreach as compared to non-regulated MFIs.
} 
lent, while the marginal administrative cost is small. Thus cost per borrower is an efficiency indicator that neutralizes the effect of loan size (Christen, 2000). Moreover, notwithstanding the various lending methodologies in microfinance, the costs incurred in the process of borrower's monitoring, information and payment collection are vital in gauging the efficiency on microfinance. Hence the following Eq (3) has been estimated taking administrative cost per borrowers as a dependent variable.

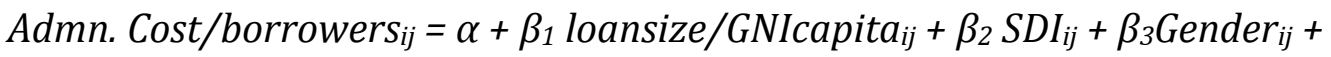
$\beta_{4}$ GNICapita $_{i j}+\beta_{5}$ Age $_{i j}+\beta_{6}$ Status $_{i j}+\beta_{7}$ LendingType $_{i j}+\beta_{8}$ Region $_{i j}+\beta_{9}$ Savings $_{i j}+$ $\beta_{10}$ OtherServices $_{i j}+\beta_{11}$ Regulated $_{i j}+\varepsilon_{i j}$

The effect of subsidization on the staff cost can ultimately has an impact on staff productivity. That effect relates to the impact of subsidization on the incentives for effort and innovation by managers and staff, as well as availability of funds to finance key investment on human resource and physical assets (Hudon and Traca, 2008). Hence the staff productivity as measured by borrowers per staff has also been used as a dependent variable in the following Eq (4).

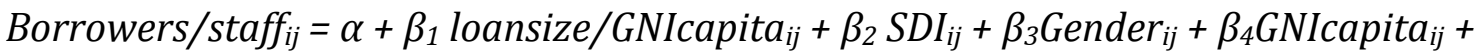
$\beta_{5}$ Age $_{i j}+\beta_{6}$ Status $_{i j}+\beta_{7}$ Lending Type $_{i j}+\beta_{8}$ Region $_{i j}+\beta_{9}$ Savings $_{i j}+\beta_{10}$ OtherServices $_{i j}+$ $\beta_{11}$ Regulated $_{i j}+\varepsilon_{i j}$

\subsubsection{Results}

Equations (9) \& (10) below in Table 4.7 present the regression results of the above specification (3) by taking administrative costs as a dependent variable. Overall the $R^{2}$ is high and most of the covariates have statistically significant signs in line with the predictions. Though simple correlation in table 4.3 depicts an insignificant relationship between cost and SDI, nevertheless, the regression estimates below depict a highly significant positive relationship. This suggests that the subsidy dependent MFIs are less efficient because of the higher costs associated with granting loans. The evidence further shows that an increase in the loan size raises 
Table 4.7

Efficiency and Productivity Regressions

\begin{tabular}{|c|c|c|c|c|}
\hline & \multicolumn{2}{|c|}{ Admn. Costs per Borrower } & \multicolumn{2}{|c|}{ Borrowers per staff } \\
\hline & (9) & $(10)$ & $(11)$ & $(12)$ \\
\hline Loan size/GNIpc & $\begin{array}{c}0.692 \\
(14.95)^{* * *}\end{array}$ & $\begin{array}{c}0.703 \\
(14.88)^{* * *}\end{array}$ & $\begin{array}{c}-0.421 \\
(-9.57)^{* * *}\end{array}$ & $\begin{array}{c}-0.448 \\
(-7.52)^{* * *}\end{array}$ \\
\hline SDI & $\begin{array}{c}0.151 \\
(5.68)^{* * *}\end{array}$ & $\begin{array}{c}0.140 \\
(5.17)^{* * *}\end{array}$ & $\begin{array}{c}-0.068 \\
(-2.60)^{* * *}\end{array}$ & $\begin{array}{l}-0.058 \\
(-1.52)\end{array}$ \\
\hline Women & & $\begin{array}{l}-0.007 \\
(-0.10)\end{array}$ & & $\begin{array}{l}-0.112 \\
(-1.27)\end{array}$ \\
\hline Age of an MFI & & $\begin{array}{c}-0.212 \\
(-2.65)^{* * *}\end{array}$ & & $\begin{array}{c}0.246 \\
(2.64)^{* * *} \\
\end{array}$ \\
\hline GNI per capita & $\begin{array}{c}0.833 \\
(12.39)^{* * *}\end{array}$ & $\begin{array}{c}0.878 \\
(12.53)^{* * *}\end{array}$ & $\begin{array}{c}-0.114 \\
(-1.80)^{*}\end{array}$ & $\begin{array}{c}-0.164 \\
(-2.32)^{* *}\end{array}$ \\
\hline Bank & $\begin{array}{c}0.434 \\
(3.21)^{* * *}\end{array}$ & $\begin{array}{c}0.424 \\
(3.04)^{* * *}\end{array}$ & $\begin{array}{l}-0.136 \\
(-1.08)\end{array}$ & $\begin{array}{l}-0.149 \\
(-1.21)\end{array}$ \\
\hline Cooperatives & $\begin{array}{l}-0.063 \\
(-0.32)\end{array}$ & $\begin{array}{l}-0.037 \\
(-0.18)\end{array}$ & $\begin{array}{l}0.109 \\
(0.60) \\
\end{array}$ & $\begin{array}{l}0.021 \\
(0.11) \\
\end{array}$ \\
\hline NGOs & $\begin{array}{r}0.082 \\
(0.74) \\
\end{array}$ & $\begin{array}{l}0.119 \\
(1.06) \\
\end{array}$ & $\begin{array}{l}-0.138 \\
(-1.35)\end{array}$ & $\begin{array}{l}-0.165 \\
(-1.62)\end{array}$ \\
\hline Rural Bank & $\begin{array}{l}0.158 \\
(0.64)\end{array}$ & $\begin{array}{l}0.372 \\
(1.41)\end{array}$ & $\begin{array}{l}-0.030 \\
(-0.13)\end{array}$ & $\begin{array}{l}-0.328 \\
(-1.08)\end{array}$ \\
\hline Individual \& Group & $\begin{array}{c}-0.180 \\
(-1.78)^{*}\end{array}$ & $\begin{array}{c}-0.167 \\
(-1.65)^{*}\end{array}$ & $\begin{array}{l}0.139 \\
(1.50)\end{array}$ & $\begin{array}{l}0.131 \\
(1.52)\end{array}$ \\
\hline Group & $\begin{array}{l}-0.156 \\
(-0.99)\end{array}$ & $\begin{array}{l}-0.193 \\
(-1.21)\end{array}$ & $\begin{array}{l}-0.061 \\
(-0.42)\end{array}$ & $\begin{array}{l}0.018 \\
(0.13)\end{array}$ \\
\hline Village Banking & $\begin{array}{c}0.355 \\
(1.88)^{*}\end{array}$ & $\begin{array}{c}0.327 \\
(1.72)^{*}\end{array}$ & $\begin{array}{l}-0.248 \\
(-1.43)\end{array}$ & $\begin{array}{l}-0.178 \\
(-1.06)\end{array}$ \\
\hline C. Asia \& E. Europe & $\begin{array}{c}-0.480 \\
(-2.87)^{* * *}\end{array}$ & $\begin{array}{c}-0.564 \\
(-3.22)^{* * *}\end{array}$ & $\begin{array}{c}-0.363 \\
(-2.36)^{* *}\end{array}$ & $\begin{array}{l}-0.259 \\
(-1.27)\end{array}$ \\
\hline E. Asia \& Pacific & $\begin{array}{c}-0.322 \\
(-1.79)^{*}\end{array}$ & $\begin{array}{c}-0.299 \\
(-1.67)^{*}\end{array}$ & $\begin{array}{c}-0.307 \\
(-1.86)^{*}\end{array}$ & $\begin{array}{c}-0.329 \\
(-2.11)^{* *}\end{array}$ \\
\hline Latin America & $\begin{array}{c}-0.532 \\
(-3.54)^{* * *}\end{array}$ & $\begin{array}{c}-0.533 \\
(-3.54)^{* * *}\end{array}$ & $\begin{array}{l}-0.089 \\
(-0.64)\end{array}$ & $\begin{array}{l}0.077 \\
(0.49)\end{array}$ \\
\hline M. East \& N. Africa & $\begin{array}{c}-0.648 \\
(-2.97)^{* * *}\end{array}$ & $\begin{array}{c}-0.736 \\
(-3.33)^{* * *}\end{array}$ & $\begin{array}{l}-0.126 \\
(-0.63) \\
\end{array}$ & $\begin{array}{l}-0.018 \\
(-0.09) \\
\end{array}$ \\
\hline S. Asia & $\begin{array}{c}-1.05 \\
(-6.93)^{* * *}\end{array}$ & $\begin{array}{c}-1.070 \\
(-7.09)^{* * *}\end{array}$ & $\begin{array}{l}-0.139 \\
(-1.00)\end{array}$ & $\begin{array}{l}-0.118 \\
(-0.81)\end{array}$ \\
\hline Savings & $\begin{array}{l}-0.132 \\
(-1.16)\end{array}$ & $\begin{array}{l}-0.083 \\
(-0.73)\end{array}$ & $\begin{array}{l}0.006 \\
(0.06)\end{array}$ & $\begin{array}{l}-0.026 \\
(-0.24)\end{array}$ \\
\hline Other Services & $\begin{array}{l}0.051 \\
(0.54) \\
\end{array}$ & $\begin{array}{l}0.082 \\
(0.86) \\
\end{array}$ & $\begin{array}{l}-0.026 \\
(-0.30)\end{array}$ & $\begin{array}{l}-0.057 \\
(-0.65)\end{array}$ \\
\hline Regulated & $\begin{array}{l}-0.027 \\
(-0.29)\end{array}$ & $\begin{array}{l}-0.065 \\
(-0.69)\end{array}$ & $\begin{array}{l}-0.023 \\
(-0.26)\end{array}$ & $\begin{array}{c}0.005 \\
(0.06)\end{array}$ \\
\hline Constant & $\begin{array}{l}-0.395 \\
(-0.88)\end{array}$ & $\begin{array}{l}-0.148 \\
(-0.28)\end{array}$ & $\begin{array}{c}5.39 \\
(12.84)^{* * *}\end{array}$ & $\begin{array}{c}5.56 \\
(10.04)^{* * *}\end{array}$ \\
\hline Observations & 358 & 346 & 358 & 348 \\
\hline No of Groups & 179 & 173 & 179 & 174 \\
\hline R-Square & 0.80 & 0.80 & 0.52 & 0.55 \\
\hline Wald chi2 & 777 & 780 & 221 & 267 \\
\hline Prob > & 0.00 & 0.00 & 0.00 & 0.00 \\
\hline
\end{tabular}

Z-values in parentheses. Values for GNIpercapita for Samao and Veitnam for 2006 are proxies by the last year values ${ }^{*}$ significant at $10 \%$; ${ }^{* *}$ significant at $5 \%$; ${ }^{* *}$ significant at $1 \%$.

Source: Authors calculations based on data taken from audit reports directly and from the Mix Market website 
the cost per borrowers thus suggesting that borrowers having larger loans require higher and better level of services which leads to higher costs. With experience, MFIs learn to reduce cost per borrowers as depicted by the significant negative age coefficient. Furthermore, MFIs operating in high income per capita countries do incur higher costs per borrower and they have lower staff productivity because of the lower outreach. Notwithstanding the dummy variables, MFIs with "Bank" status are clearly less efficient due to the high costs per borrower. But this result is driven by the fact that Banks mainly cater to wealthy individual clients which keep their per borrower cost always high. Regional dummies depict that African MFIs are less efficient with higher per borrower cost compared to the other regions. Estimates further suggest that MFIs with village lending methodology are less efficient while those with group lending features are relatively more efficient.

The last two equations (11) and (12) present estimates of specification (4) above taking borrowers per staff member, a measure of staff's productivity as a dependent variable. Like the simple correlation in Table 4.3, regression estimates reveal a significant negative relationship between staff productivity and subsidization in Eq (11). However once controlled for age and women borrowers, the impact becomes insignificant. The estimates also lend support to the trade-off between outreach and productivity. Where lower outreach (increase in the loan size) is associated with lower staff productivity because fewer clients can afford to borrow larger loans. And in return clients demand higher attention and better level of services from the institution which also results in higher costs as well. Further, significant positive coefficient of age variable suggests that the productivity increases over time. Furthermore, MFIs operating in higher income countries have lower staff productivity than the others because their clients consist of few individual borrowers. Regarding "status" dummy variable, there is some evidence that NBFIs are relatively productive than the rest. Regional dummies show that MFIs located in the EA\&Pacific and CA\&EE regions are less productive while those in Africa are productive.

\subsection{Mission drift}


Mission drift is a concern of socially driven MFIs. As clients mature and develop their businesses they should be able to increase the loan size and their income should rise. In other words, it is a tendency reviewed by numerous microfinance institutions to extend larger average loan sizes in the process of scaling-up. It is a shift in the composition of new clients, or a re-orientation from poorer to wealthier clients among existing clients (Cull et al. 2007; Armendariz and Szafarz, 2009). In microfinance literature, the depth of outreach is commonly be used as a proxy for the poverty level. In the absence of any other decent measure of poverty due to data limitations, this study uses the average loan size divided by the GNI per capita as a proxy for measuring the depth of outreach. The assumption is that the smaller the loan size, the deeper is the outreach or the poorer the clients. Consistent with the other cross country studies ${ }^{11}$, the Average loan size variable can also be deflated by GNI per capita calculated by purchasing poverty parity (ppp) method in order to normalize it to provide an adjustment for the overall wealth of a country. Because microfinance programs are usually associated with low income countries with higher income inequalities in their societies. A more consistent approach is to divide the average loan size by the income per capita of poorest $20 \%$ of the population to normalize the inconsistencies caused by the higher income inequalities. However the criticism of using the average loan size as a proxy for poverty level is also very well documented in the microfinance literature ${ }^{12}$. Nevertheless, some recent studies find no significant differences in the empirical evidence between average loan size divided by the per capita income and per capita income of the poorest $20 \%$ households (cull et al. 2007; OlivaresPolanco, 2004) ${ }^{13}$. Fig 4.2 depicts the composition of the average share of Outreach in different categories where the average loan size over GNI per capita (PPP) has been used as a proxy for the outreach. ME \& NA MFIs and SA MFIs have done better in terms of outreach to the poor, whereas, CA \& EE MFIs and African MFIs have less outreach. The status category suggests that NGOs and rural banks are

\footnotetext{
${ }^{11}$ See for example Balkenhol, 2007a; Hudon and Traca, 2008; Christen, 2007

${ }^{12}$ See for example Schreiner 2001; Woller \& Woodworth, 2001; Dunford, 2002; Hatch \& Frederick, 1998 and more recently Beatriz Armendariz \& Ariane Szafarz (2009)

${ }^{13}$ This study also confirms this phenomena. The regressions have been estimated using the average loan size divided by the GNIpc PPP(purchasing power parity) but the results have not been significantly different.
} 

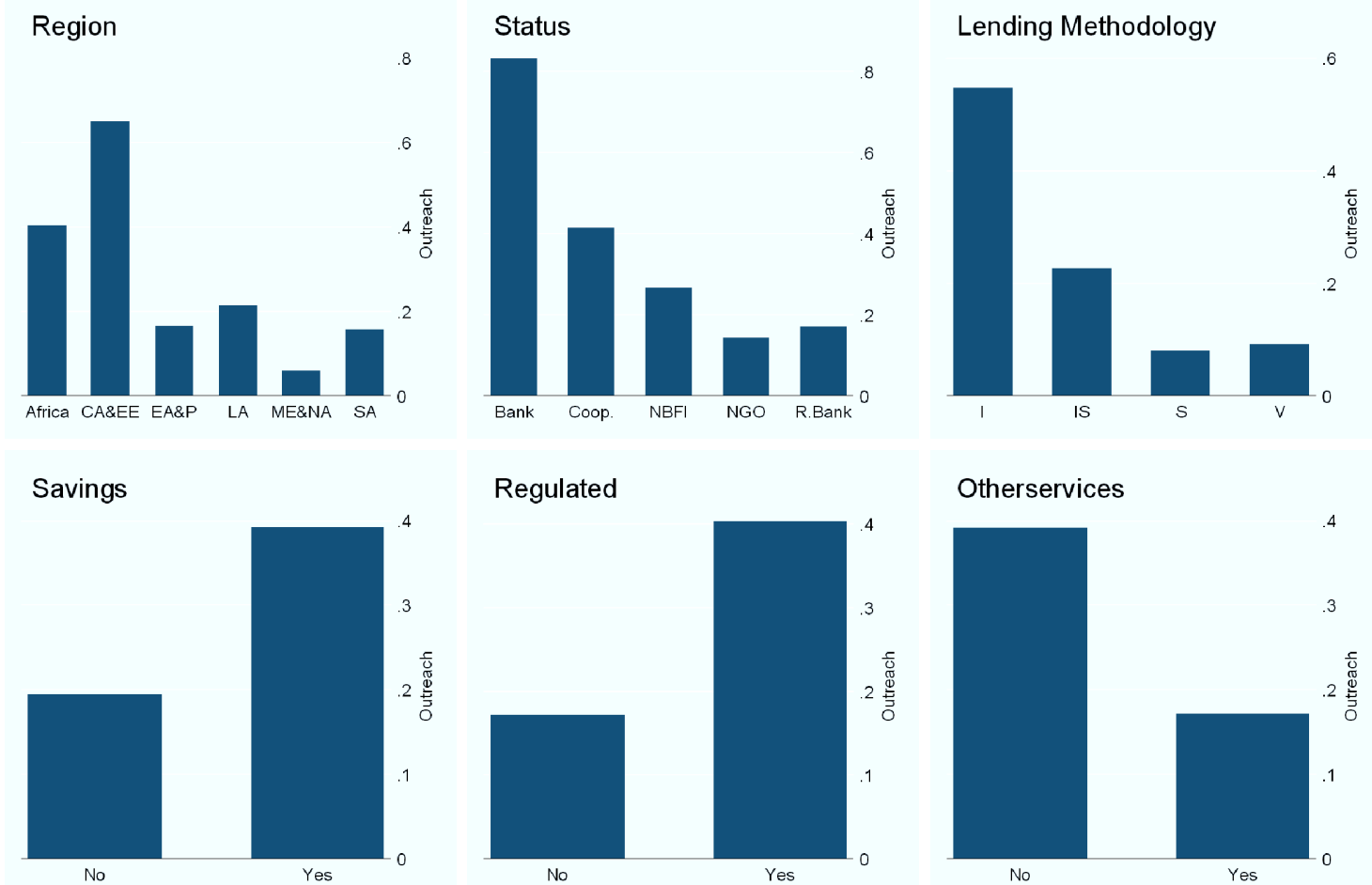

Fig. 4.2 Composition of Avg. Loan Size/GNI per capita

Source: Authors own calculations based on the data from MixMarket website
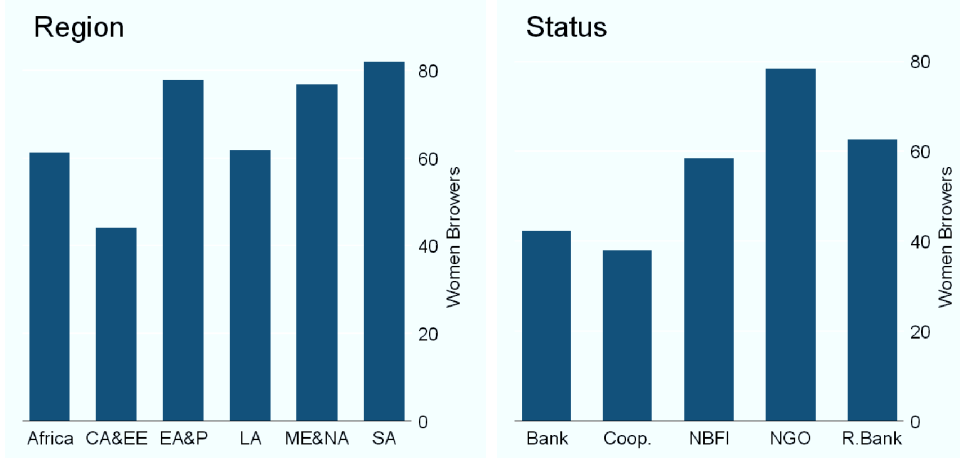

Otherservices

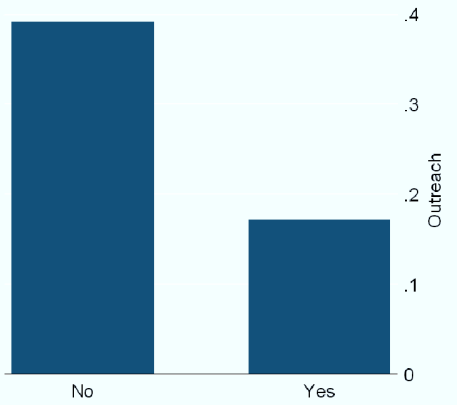

$$
\text { . }
$$

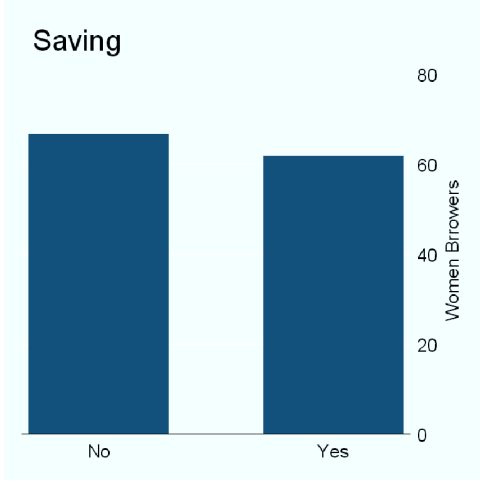

Regulated
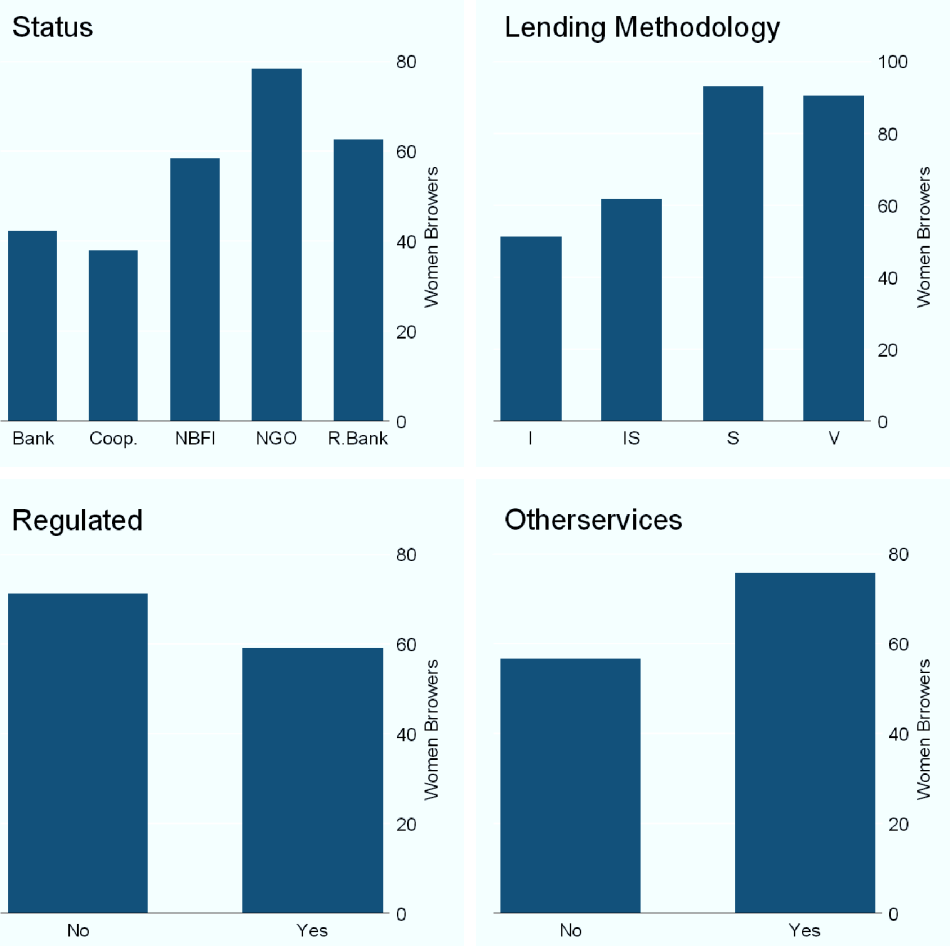

Otherservices

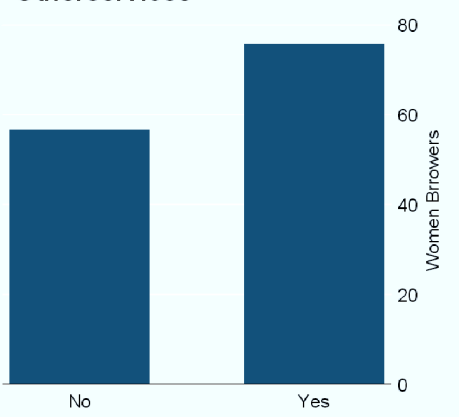

Fig. 4.3 Composition of Women Borrowers

Source: Authors own calculations based on the data from MixMarket website 
better in reaching to poor while Banks have the lowest outreach as they cater to less poor clients. Similarly MFIs with Group lending features are better in reaching to poor as apposed to MFIs which lend to individuals. Further MFIs which do not provide savings, those not regulated and provide other services have better outreach to poor. In addition to using loan size, percentage of female borrowers has also been used as a proxy for outreach which is also consistent with the social objective of MFIs from gender perspective. Fig 4.3 highlights the share of women borrowers bifurcated into different categories. South Asian MFIs have on average highest share of female borrowers. While MFIs with NGO and Rural Bank status have more share of women borrowers. Further MFIs with group lending and village banking methodology have more female borrowers than the others. Furthermore, MFIs with no saving feature, are not regulated and those providing other services have more women borrowers than the others.

In this backdrop, this essay empirically estimates the following equations (5) and (6) taking loan size and women borrowers as dependent variable respectively.

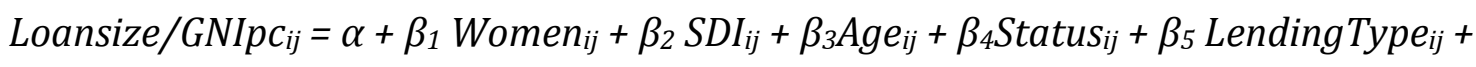
$\beta_{6}$ Region $_{i j}+\beta_{7}$ Savings $_{i j}+\beta_{8}$ OtherServices $_{i j}+\beta_{9}$ Regulated $_{i j}+\varepsilon_{i j}$

Women $_{i j}=\alpha+\beta_{1}$ SDI $_{i j}+\beta_{2}$ Age $_{i j}+\beta_{3}$ Status $_{i j}+\beta_{4}$ LendingType $_{i j}+\beta_{5}$ Region $_{i j}+$ $\beta_{6}$ Savings $_{i j}+\beta_{7}$ OtherServices $_{i j}+\beta_{8}$ Regulated $_{i j}+\varepsilon_{i j}$

\subsubsection{Instrumental Variables}

A main issue in the above regression equations arises because of the possible endogeneity of MFIs subsidy dependence. It can be argued that MFIs providing credit to relatively poor clients with small loan sizes tend to get more subsidies because of the donors preferences. In other words, donors have a bias to inject subsidies to those less sustainable and high transaction cost MFIs which give loans to poor and primarily to women. 
To account for this endogeneity, this study adopts a two-stage procedure of correcting for this endogeneity given in Hudon and Traca (2008) paper. In the first stage, the components of subsidy dependence index orthogonal to the sustainability of MFI are computed. In the second-stage, those are used in estimating equations (1) and (2) above.

The estimates of first-stage regression are as follows:

$$
S D I=3.162-0.6178 \ln O S S \quad \text { Adj } R^{2}=0.1451, n=358
$$

The signs of the coefficients are as expected and significant at 1\%. Further a new variable of subsidy dependence index has been constructed : SDI(IV) $=e_{i}-$ $\min \left(e_{i}\right)$, where $e_{i}$ is the residual of the above regression for $M F I_{i}$ and $S D I(I V)>0$. The new variable become orthogonal to lnOSS and is unaffected by the desire of donors to support MFIs which cater to poor and thus are less sustainable.

\subsubsection{Results}

Columns 13-16 in Table 3.8 show results about the relationship between profitability and outreach as measured by the average loan size/GNI per capita (ppp). Unlike the simple correlations case in Table 3, the regression result in equation (14) show that the Subsidy dependence is significantly related to the outreach measure. Further, when instrumented with the new SDI explanatory variable in Equation (15) and (16), the impact becomes more significant. Further, the coefficient of women borrower turns out to be significantly negative which shows that the women borrowers get smaller loan sizes or in other words, beneficiaries of larger loan are predominantly males rather than women borrowers. The above empirical evidence lend support to the Mission drift phenomena where more funds are directed to those MFIs which cater to relatively well-off clients with capacity to afford higher loan sizes. However, the fact that MFIs reaching to well off clients (higher loan size) with the time is also not supported by our estimates as the age variable does not explain any significant variation in outreach. Equation (17) and (18) present estimates of taking women 
Table 4.8

Mission Drift

\begin{tabular}{|c|c|c|c|c|c|c|}
\hline & \multicolumn{4}{|c|}{ Loan Size/ GNIpc } & \multicolumn{2}{|c|}{ \% women borrowers } \\
\hline & & & & & & IV \\
\hline & (13) & (14) & (15) & (16) & (17) & (18) \\
\hline Women borrower & $\begin{array}{c}-0.239 \\
(-2.69)^{* * *}\end{array}$ & & $\begin{array}{c}-0.241 \\
(-2.71)^{* * *}\end{array}$ & & & \\
\hline SDI & $\begin{array}{l}0.042 \\
(1.43) \\
\end{array}$ & $\begin{array}{c}0.048 \\
(1.67)^{*}\end{array}$ & $\begin{array}{c}0.054 \\
(1.71)^{*}\end{array}$ & $\begin{array}{c}0.060 \\
(1.91)^{*}\end{array}$ & $\begin{array}{c}-0.035 \\
(-1.69)^{*}\end{array}$ & $\begin{array}{l}-0.033 \\
(-1.46)\end{array}$ \\
\hline Age of an MFI & $\begin{array}{l}0.015 \\
(0.14)\end{array}$ & $\begin{array}{l}-0.028 \\
(-0.28)\end{array}$ & $\begin{array}{l}0.015 \\
(0.15)\end{array}$ & $\begin{array}{l}-0.028 \\
(-0.28)\end{array}$ & $\begin{array}{l}0.055 \\
(1.03)\end{array}$ & $\begin{array}{l}0.058 \\
(1.10)\end{array}$ \\
\hline Bank & $\begin{array}{c}0.534 \\
(2.69)^{* * *}\end{array}$ & $\begin{array}{c}0.554 \\
(2.82)^{* * *}\end{array}$ & $\begin{array}{c}0.536 \\
(2.71)^{* * *}\end{array}$ & $\begin{array}{c}0.556 \\
(2.84)^{* * *}\end{array}$ & $\begin{array}{c}-0.261 \\
(-2.89)^{* * *}\end{array}$ & $\begin{array}{c}-0.263 \\
(-2.93)^{* * *}\end{array}$ \\
\hline Cooperatives & $\begin{array}{l}0.077 \\
(0.27) \\
\end{array}$ & $\begin{array}{l}0.203 \\
(0.70)\end{array}$ & $\begin{array}{l}0.082 \\
(0.28) \\
\end{array}$ & $\begin{array}{l}0.209 \\
(0.72)\end{array}$ & $\begin{array}{c}-0.520 \\
(-3.98)^{* * *}\end{array}$ & $\begin{array}{c}-0.524 \\
(-4.02)^{* * *}\end{array}$ \\
\hline NGOs & $\begin{array}{c}-0.411 \\
(-2.56)^{* * *}\end{array}$ & $\begin{array}{c}-0.464 \\
(-2.86)^{* * *}\end{array}$ & $\begin{array}{c}-0.412 \\
(-2.57)^{* *}\end{array}$ & $\begin{array}{c}-0.464 \\
(-2.87)^{* * *}\end{array}$ & $\begin{array}{c}0.208 \\
(2.84)^{* * *}\end{array}$ & $\begin{array}{c}0.206 \\
(2.83)^{* * *}\end{array}$ \\
\hline Rural Bank & $\begin{array}{c}0.138 \\
(0.36) \\
\end{array}$ & $\begin{array}{c}0.211 \\
(0.57) \\
\end{array}$ & $\begin{array}{c}0.138 \\
(0.36) \\
\end{array}$ & $\begin{array}{l}0.209 \\
(0.56) \\
\end{array}$ & $\begin{array}{c}-0.341 \\
(-1.94)^{*}\end{array}$ & $\begin{array}{c}-0.342 \\
(-1.96)^{*}\end{array}$ \\
\hline Individual \& Group & $\begin{array}{c}-0.265 \\
(-1.81)^{*}\end{array}$ & $\begin{array}{c}-0.293 \\
(-1.98)^{* *}\end{array}$ & $\begin{array}{c}-0.263 \\
(-1.80)^{*}\end{array}$ & $\begin{array}{c}-0.292 \\
(-1.98)^{* *}\end{array}$ & $\begin{array}{c}0.129 \\
(1.94)^{*}\end{array}$ & $\begin{array}{c}0.128 \\
(1.93)^{*}\end{array}$ \\
\hline Group & $\begin{array}{c}-0.834 \\
(-3.69)^{* * *}\end{array}$ & $\begin{array}{c}-0.948 \\
(-4.17)^{* * *}\end{array}$ & $\begin{array}{c}-0.824 \\
(-3.67)^{* * *}\end{array}$ & $\begin{array}{c}-0.943 \\
(-4.15)^{* * *}\end{array}$ & $\begin{array}{c}0.413 \\
(4.04)^{* * *}\end{array}$ & $\begin{array}{c}0.410 \\
(4.02)^{* * *}\end{array}$ \\
\hline Village Banking & $\begin{array}{c}-0.706 \\
(-2.62)^{* * *}\end{array}$ & $\begin{array}{c}-0.817 \\
(-3.00)^{* * *}\end{array}$ & $\begin{array}{c}-0.700 \\
(-2.61)^{* * *}\end{array}$ & $\begin{array}{c}-0.813 \\
(-3.00)^{* * *}\end{array}$ & $\begin{array}{c}0.427 \\
(3.50)^{* * *}\end{array}$ & $\begin{array}{c}0.426 \\
(3.49)^{* * *}\end{array}$ \\
\hline C. Asia \& E. Europe & $\begin{array}{l}0.121 \\
(0.53) \\
\end{array}$ & $\begin{array}{l}0.113 \\
(0.50) \\
\end{array}$ & $\begin{array}{c}0.113 \\
(0.50)\end{array}$ & $\begin{array}{c}0.106 \\
(0.47) \\
\end{array}$ & $\begin{array}{c}-0.204 \\
(-1.95) *\end{array}$ & $\begin{array}{c}-0.199 \\
(-1.91)^{*}\end{array}$ \\
\hline E. Asia \& Pacific & $\begin{array}{c}-0.759 \\
(-2.99)^{* * *}\end{array}$ & $\begin{array}{c}-0.787 \\
(-3.05)^{* * *}\end{array}$ & $\begin{array}{c}-0.759 \\
(-2.99)^{* * *}\end{array}$ & $\begin{array}{c}-0.791 \\
(-3.06)^{* * *}\end{array}$ & $\begin{array}{c}0.177 \\
(1.53)\end{array}$ & $\begin{array}{c}0.177 \\
(1.53)\end{array}$ \\
\hline Latin America & $\begin{array}{c}-0.460 \\
(-2.62)^{* * *}\end{array}$ & $\begin{array}{c}-0.459 \\
(-2.57)^{* * *}\end{array}$ & $\begin{array}{c}-0.462 \\
(-2.63)^{* * *}\end{array}$ & $\begin{array}{c}-0.463 \\
(-2.58)^{* * *}\end{array}$ & $\begin{array}{r}0.019 \\
(0.24) \\
\end{array}$ & $\begin{array}{c}0.021 \\
(0.26) \\
\end{array}$ \\
\hline M. East \& N. Africa & $\begin{array}{c}-1.17 \\
(-3.93)^{* * *}\end{array}$ & $\begin{array}{c}-1.232 \\
(-4.08)^{* * *}\end{array}$ & $\begin{array}{c}-1.172 \\
(-3.94)^{* * *}\end{array}$ & $\begin{array}{c}-1.24 \\
(-4.11)^{* * *}\end{array}$ & $\begin{array}{r}0.118 \\
(0.87) \\
\end{array}$ & $\begin{array}{r}0.124 \\
(0.92) \\
\end{array}$ \\
\hline S. Asia & $\begin{array}{c}-0.352 \\
(-3.51)^{* * *}\end{array}$ & $\begin{array}{c}-0.770 \\
(-3.52)^{* * *}\end{array}$ & $\begin{array}{c}-0.758 \\
(-3.53)^{* * *}\end{array}$ & $\begin{array}{c}-0.774 \\
(-3.55)^{* * *}\end{array}$ & $\begin{array}{c}0.078 \\
(0.80) \\
\end{array}$ & $\begin{array}{c}0.081 \\
(0.83) \\
\end{array}$ \\
\hline Savings & $\begin{array}{c}0.152 \\
(0.92) \\
\end{array}$ & $\begin{array}{c}0.103 \\
(0.62) \\
\end{array}$ & $\begin{array}{c}0.153 \\
(0.91) \\
\end{array}$ & $\begin{array}{l}0.104 \\
(0.63) \\
\end{array}$ & $\begin{array}{l}0.070 \\
(0.92) \\
\end{array}$ & $\begin{array}{r}0.071 \\
(0.94) \\
\end{array}$ \\
\hline Other Services & $\begin{array}{l}-0.091 \\
(-0.65)\end{array}$ & $\begin{array}{l}-0.100 \\
(-0.71)\end{array}$ & $\begin{array}{l}-0.091 \\
(-0.65)\end{array}$ & $\begin{array}{l}-0.101 \\
(-0.71)\end{array}$ & $\begin{array}{l}0.065 \\
(1.01) \\
\end{array}$ & $\begin{array}{l}0.064 \\
(1.01)\end{array}$ \\
\hline Regulated & $\begin{array}{c}0.044 \\
(0.32) \\
\end{array}$ & $\begin{array}{l}0.061 \\
(0.44) \\
\end{array}$ & $\begin{array}{c}0.044 \\
(0.31)\end{array}$ & $\begin{array}{l}0.062 \\
(0.43)\end{array}$ & $\begin{array}{c}0.029 \\
(0.47)\end{array}$ & $\begin{array}{r}0.029 \\
(0.46) \\
\end{array}$ \\
\hline Constant & $\begin{array}{l}0.767 \\
(1.60)\end{array}$ & $\begin{array}{l}-0.031 \\
(-0.09)\end{array}$ & $\begin{array}{l}0.662 \\
(1.35)\end{array}$ & $\begin{array}{l}-0.146 \\
(-0.40)\end{array}$ & $\begin{array}{c}3.685 \\
(21.33)^{* * *}\end{array}$ & $\begin{array}{c}3.738 \\
(20.58)^{* * *}\end{array}$ \\
\hline Observations & 348 & 358 & 348 & 358 & 358 & 358 \\
\hline No of Groups & 17414 & 179 & 174 & 179 & 179 & 179 \\
\hline R-Square & 0.57 & 0.55 & 0.57 & 0.55 & 0.50 & 0.50 \\
\hline Wald chi2 & 219 & 210 & 220 & 211 & 168 & 168 \\
\hline Prob > & 0.00 & 0.00 & 0.00 & 0.00 & 0.00 & 0.00 \\
\hline
\end{tabular}

Z-values in parentheses.

*significant at $10 \%$; ${ }^{* *}$ significant at $5 \%$; *** significant at $1 \%$.

Source: Authors calculations based on data taken from audit reports directly and from the Mix Market website

\footnotetext{
${ }^{14}$ Sample reduced to $174 \mathrm{MFI}$ because of the $6 \mathrm{MFIs}$ missing values on women borrowers
} 
borrowers as dependent variable. The coefficient of SDI turns out to be negative and significant at $10 \%$ in Equation (17), thus suggesting that more subsidy dependent MFIs tend to concentrate more on male borrowers. In other words, most of the subsidies are directed to MFIs which cater less to women borrowers which leads to lower sustainability because wealthy clients require better services which increase the costs. However, after correcting for the endogeneity bias in Equation (18) with instrumented SDI variable, the negative coefficient of SDI becomes insignificant. These results should be interpreted with caution. The argument for the existence of the mission drift phenomena in microfinance literature is based on the high transaction costs associated with giving small amount of credit to poor, particularly to women. Therefore, from commercial perspective, more funds are directed to those MFIs which lend large loans to relatively well-off male borrowers. Notwithstanding the dummy variables, MFIs with 'Banks' status have less outreach as they lend relatively higher loan sizes and their clients consist of predominantly male borrowers. While NGOs, on the other hand, primarily lend to female borrowers with small loan sizes. Considering lending methodology, MFIs with Group lending and Village banking methodology have better outreach as they lend small amount of loans to predominantly women borrowers. While individual lending is mainly directed to relatively well-off clients who could afford to pay back big loans. Notwithstanding the regional dummies, MFIs located in Latin America, ME \& NA, South Asia and EA \& Pacific, all have significant outreach because of small loan sizes.

\subsection{CONCLUSION}

This essay aims to contribute to the ongoing debate on the sustainability issues in microfinance in the wake of increasing commercialization. Unlike the current literature on these issues, this essay goes beyond the traditional financial ratios by incorporating the subsidy dependence index (SDI) as a measure of sustainability into the empirical framework. To this extent, empirical evidence about important relationships and phenomenon related to sustainability issues in 
microfinance literature, have been investigated amid high quality data set comprised of 179 MFIs in 54 Countries worldwide.

The empirical evidence lends support to the importance of financial and social efficiency in determining the interest rate policy of microfinance Institutions. On the social efficiency front, delivering credit to the poor in small sizes tend to be costly with higher transaction cost. Thus inducing MFIs to charge higher interest rates to poor borrowers with small loan sizes. Consequently an important evidence found is that MFIs which lend predominantly to women borrowers who require small loan sizes, charge higher interest rates to their clients. Nevertheless these high interest rates seldom translate into profits. In other words, these results also support the notion of the importance of interest rate policy in the "Mission Drift" in microfinance. From the financial efficiency perspective, increase in both the administrative cost and cost of acquiring loanable funds induce MFIs to raise interest rates on loans to the borrowers.

Concerning the importance of interest rates and cost in determining the profitability of microfinance, the evidence shows that raising the interest rates charged on loans to the clients leads to improved financial performance by lowering subsidy dependence and improving sustainability. On the other hand, Increase in the administrative cost reduces the profitabilty. Further, the regression results do not support the trade-off between sustainability and outreach. Where lending in small loan sizes (greater outreach) to relatively more poor borrowers leads to an increase in the profitability and sustainability of MFIs with lowering the subsidy dependence and increasing the ROA. However, lending to women borrowers do not explain any variation in the profitability of an MFI.

The evidence about the determinants of efficiency and productivity of microfinance are by and large, in line with the theory. The results confirm that subsidization of microfinance leads to cost-inefficiencies and decrease in the staff productivity. The fact that more the MFIs cater to well-off clients with large loan sizes, the more their costs rise, suggests that MFIs having customers with larger loans require better and high level of services.

Last but not the least, this essay also empirically examines the validity of mission drift tendency in microfinance. Having corrected for the endogeneity bias, 
the empirical evidence lend some support to the existence of mission drift phenomenon. Due to the commercialization of microfinance, investors are increasingly directing their funds to those MFIs which serve the relatively less poor or well-off clients who can afford to pay back larger loan sizes. Moreover, evidence has also been found that beneficiaries of larger loans are predominantly male borrowers rather than the women borrowers who require relatively small loans. Further, those relatively well-off borrowers require better and improved services in return of their higher loan sizes which leads to increase in subsidy dependence due to an increase in the costs of providing those services. In other words, the evidence found runs contrary to the trade off between sustainability and outreach of microfinance.

The findings in this paper have policy implications and there are lessons to be learned for the stakeholders in microfinance. It is high time for practitioners and social investors to realize that cost efficiencies as a result of good governance and management can significantly contribute towards expanding the outreach to poor. Whereas, lending to well-off clients in larger loan sizes, and thus gradually deviating from their social mission in anticipation of reaping exorbitant profits, can not guarantee profitability because it ultimately leads to the increase in costs. Resultantly MFI's subsidy dependence increases and the Return on Asset (ROA) declines. Policies and trainings related to small scale income generating activities and enterprise development which in the long run can contribute to profitability of lending to women should be encouraged. This will not only help in increasing the profitability of an MFI but also go a long way in stemming the higher interest rates charged from the women borrowers. 


\section{APPENDIX A MICROFINANCE INSTITUTIONS}

\section{PAKISTAN}

KASHF- Kashf Foundation

FMFB- First Microfinance Bank Ltd. Pakistan

ASASAH- Asasah

NEPAL

NSSC- Neighbourhood Society Service Centre

VYCCU- VYCCU Saving \& Credit Cooperative Society Ltd.

NIRDHAN- Nirdhan Utthan Bank Ltd.

PGBB- Western Region Grameen Bikas Bank

CBB-Chhimek Bikas Bank Ltd.

INDIA

BANDHAN-Bandhan (Society and NBFC)

BASIX-Bhartiya Samruddhi Finance Limited

SHARE- SHARE Microfin Ltd.

MAHASEMAN- Mahasemam-SMILE

CASHPOR-Cashpor Microcredit

IASC-Indian Association for Savings and Credit

KBSLAB- Krishna Bhima Samruddhi Local Area Bank

Limited

ESAF- Evangelical Social Action Forum

SNF- Sarvodaya Nano Finance Limited

GK- Grameen Koota

BANGLADESH

BURO- BURO Bangladesh

DESHA - DESHA

ASA- $A S A$

BRAC- Bangladesh Rural Advancement Committee

RDRS- RDRS Bangladesh

Shakti- Shakti Foundation for Disadvantaged Women

TMSS- Thengamara Mohila Sabuj Sangha

IDF- Integrated Development Foundation

AFGHANISTAN

FMFB - The First MicroFinanceBank - Afghanistan

BRAC- BRAC Afghanistan

ARMP-Afghanistan Rural Microcredit Programme

AFRICA

KENYA

K-REPK-Rep Bank

EBS-Equity Bank

KADET-Kenya Agency to Development of Enterprise and Technology

KWFT-Kenya Women Finance Trust

MDSL-Microenterprise Development Services Ltd

SMEP-Small and Micro Enterprise Project

BURKINA FASO

RCPB-Réseau des caisses populaires du Burkina

SENEGAL

PAMECAS-Programme d'Appui aux Mutuelles d'Épargne et de Crédit au Sénégal

ACEP-Alliance de Credit et d'Epargne pour la Production CMS

MALI

SORO Y-Soro Yiriwaso

KANDO JAGIM-Kondo Jigima

\section{CAMEROON}

ACEP-Agence de Crédit pour l'Entreprise Privée Cameroun

CDS-Crédit du Sahel

GHANA

PROCREDIT -ProCredit SLC Ghana
KSF -Kraban Support Foundation

OISL -Opportunity International Savings and Loans Limited

SAT -Sinapi Aba Trust

BENIN

ALIDE-Association de Lutte pour la promotion des Initiatives de Développement

VF -Vital Finance

PADME -Association pour la Promotion et l' Appui au Développement de MicroEntreprises

FACECAM -Fédération des caisses d'épargne et de crédit agricole mutuel

ANGOLA

NovoBanco - NovoBanco Angola

ETHIOPIA

DECSI-Dedebit Credit and Savings Institution

ADCSI- Addis Credit \& Savings Institution

ACSI- Amhara Credit and Savings Institution

WISDOM- Wisdom

OMO-Omo Microfinance Institution

BG- Buusaa Gonofaa

TANZANIA

PRIDE - PRIDE Tanzania

FINCA -FINCA Tanzania

UGANDA

CML-Commercial Microfinance Limited

FAULA - Faulu Uganda

MED-Net-Micro Enterprise Development Network

FINCA- Finca Uganda

UML- Uganda Microfinance Limited

CENTENARY-Centenary Rural Development Bank Ltd.

MALAWI

FINCA- FINCA Malawi

MOZAMBIQUE

SOCREMO- Banco de Microfinanças de Moçambique

FCC- Fundo de Credito Comunitario

Tchuma- Tchuma Cooperativa de Crédito e Poupança

NovoBanco - NovoBanco Mozambique

NIGERIA

LAPO- Lift Above Poverty Organisation

SEAP-Self-Reliance Economic Advancement Programme

SOUTH AFRICA

SEF-ZAF- Small Enterprise Foundation South Africa

ZAMBIA

CETZAM- CETZAM Opportunity

FINCA - FINCA Zambia

LATIN AMERICA

\section{BOLIVIA}

ProMujer - Pro Mujer in Bolivia

CRECER-Crédito con Educación Rural

PRODEM- Fondo Financiero Privado PRODEM

FIE- Financiero Privado paral Fomentoa Iniciativas

Economicas

ProCredit - Banco Los Andes ProCredit

FADES- Fundación para Alternativas de Desarrollo

AgroCapital- Fundación AgroCapital

FONCRESOL-foncresol

FUNBODEM- Fundación Boliviana para el Desarrollo de la Mujer

BancoSol- BancoSol 


\begin{tabular}{|c|c|}
\hline 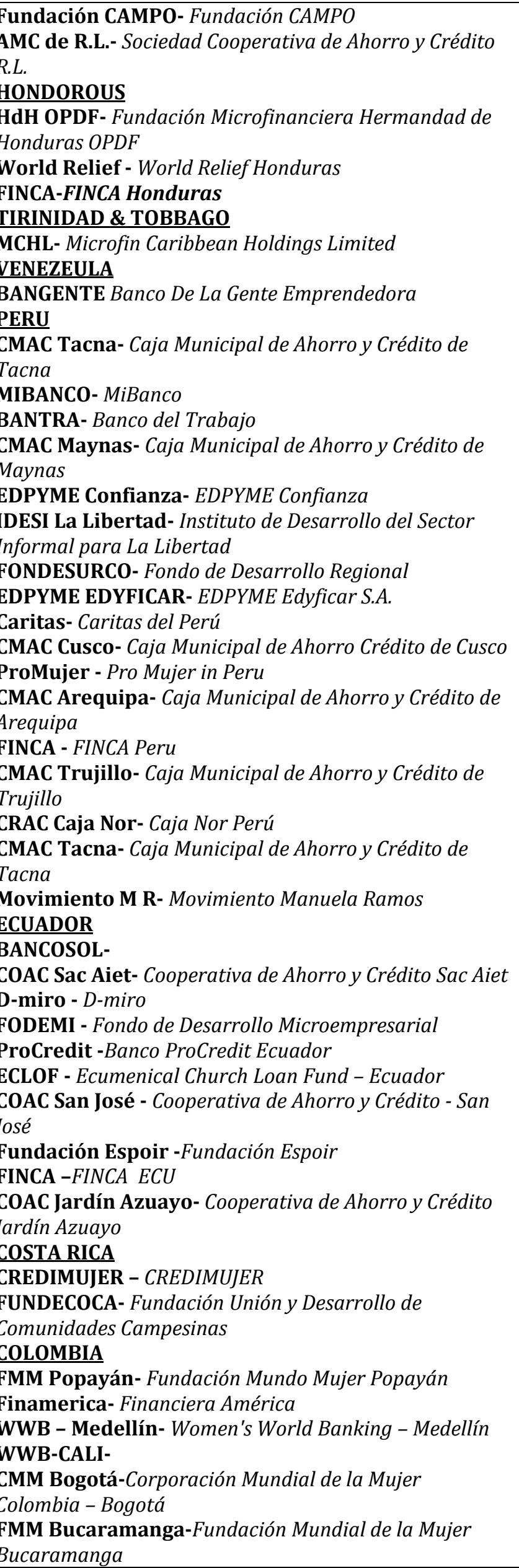 & 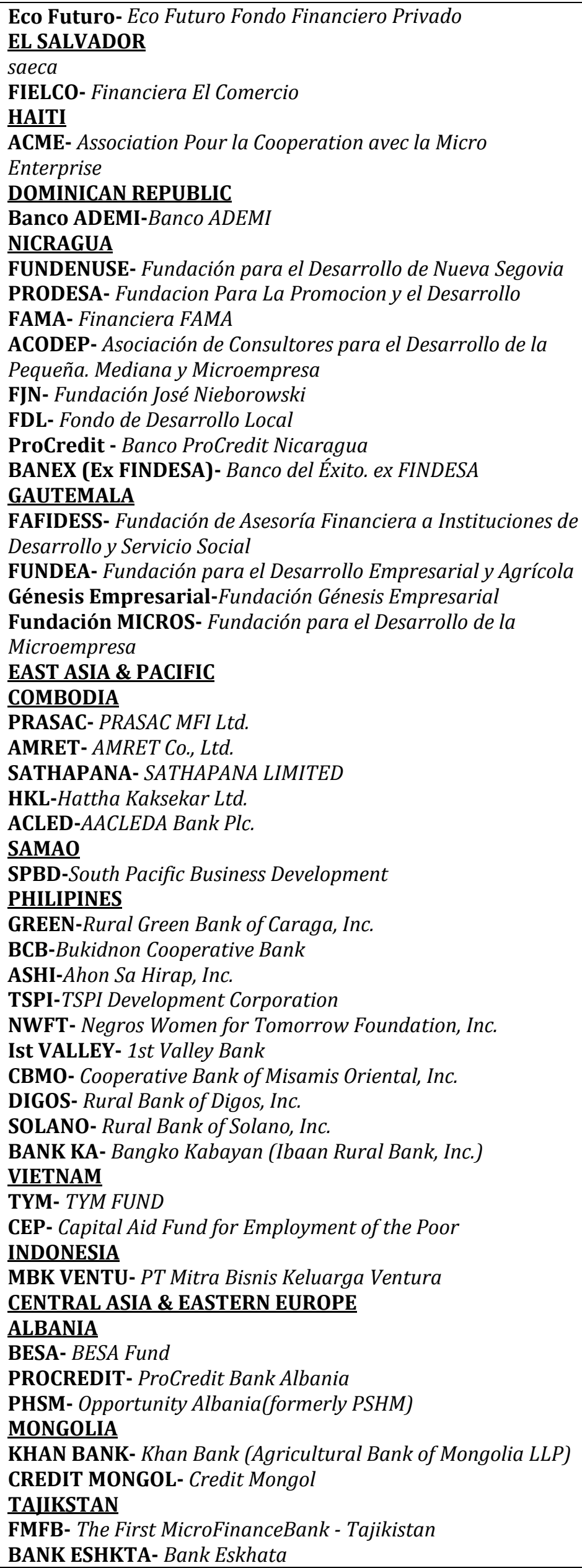 \\
\hline
\end{tabular}




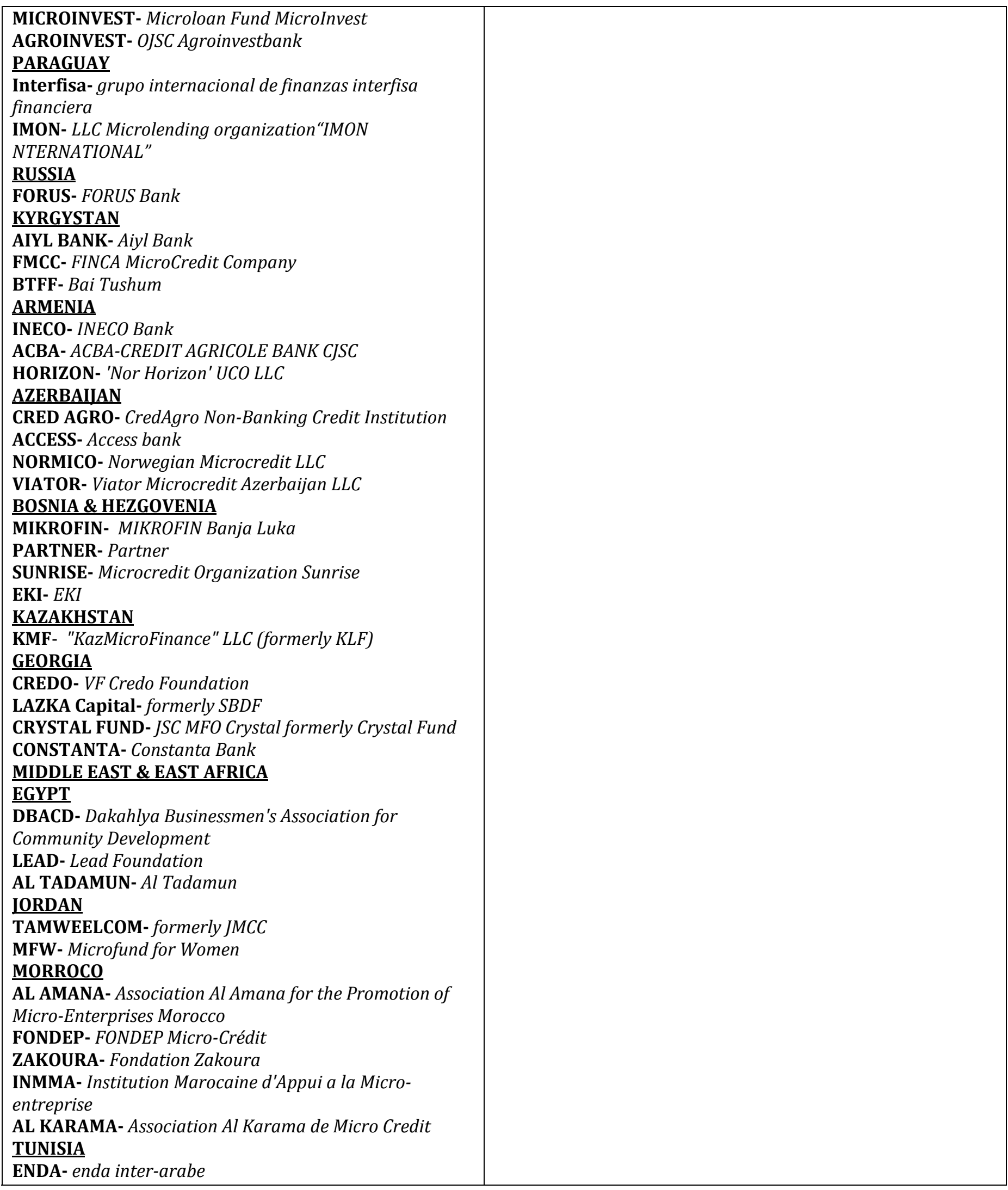




\section{APPENDIX B SDI Calculations (Benjamin Formula)}

\begin{tabular}{|c|c|c|c|c|c|c|c|c|c|c|c|}
\hline \multirow{2}{*}{$\begin{array}{c}\text { ASIA } \\
\text { MFI }\end{array}$} & \multicolumn{2}{|c|}{ SDI } & \multirow[b]{2}{*}{ MFI } & \multicolumn{2}{|c|}{ SDI } & \multirow[b]{2}{*}{ MFI } & \multicolumn{2}{|c|}{ SDI } & \multirow[b]{2}{*}{ MFI } & \multicolumn{2}{|c|}{ SDI } \\
\hline & 2005 & 2006 & & 2005 & 2006 & & 2005 & 2006 & & 2005 & 2006 \\
\hline KASHF & 0.184 & 0.114 & DECSI & -0.101 & 0.003 & Caritas & 1.054 & 0.505 & Ist Valley & 1.937 & 0.447 \\
\hline FMBL & 2.985 & 0.844 & ADCSI & 0.596 & 1.267 & CMAC Cus & 0.112 & - & CBMO & 1.280 & 1.288 \\
\hline ASASAH & 0.226 & 1.037 & ACSI & -0238 & -0.329 & CMAC Tac & 0.312 & 0.293 & DIGOS & 0.844 & 0.681 \\
\hline NSSC & 0.254 & - & WISDOM & 0.773 & 0.097 & Caja Nor & 0.236 & 0.228 & SOLANO & 1.474 & 1.926 \\
\hline VYCCU & -0.104 & - & OMO & 0.565 & 0.119 & FINCA & 0.399 & 0.490 & Bangko Ka & 1.523 & 1.254 \\
\hline NIRDHAN & 0.339 & 0.313 & BG & 1.072 & 0.194 & Movim. M R & 0.192 & 0.298 & TYM & 2.671 & 2.927 \\
\hline PGBB & 0.775 & - & PRIDE & 0.078 & 0.154 & Promujer & 0.498 & 0.273 & CEP & 2.247 & 2.180 \\
\hline CBB & 0.443 & 0.086 & FINCA & 0.122 & - & CMAC Arq & 0.047 & 0.043 & MBK Ventu & 0.644 & 0.373 \\
\hline BANDHAN & 0.183 & -0.146 & CML & 0.121 & 0.370 & CMAC Tru & 0.278 & 0.150 & C. ASIA \& & E. EUR & PE \\
\hline BASIX & 0.298 & 0.221 & FAULU & 0.322 & 0.622 & Interfisa & 0.295 & 0.128 & BESA & 0.363 & 0.108 \\
\hline SHARE MF & -0.037 & 0.392 & MEDNET & 0.317 & 2.988 & FIELCO & 0.106 & 0.152 & ProCredit & 0.245 & 0.215 \\
\hline Mahaseman & -0.003 & - & FINCA & 0.111 & 0.190 & FUNDENUSE & -0.407 & - & PSHM & 0.504 & 0.144 \\
\hline Cashpoor & 1.045 & 0.396 & UML & 1.039 & - & Prodesa & -0.148 & -0.212 & Khan Bank & 0.202 & 0.038 \\
\hline IASC & 0.338 & - & Centenary & 0.211 & 0.112 & FAMA & 0.088 & - & CredMongol & 0.639 & 0.569 \\
\hline KBSLAB & 0.683 & 0.704 & FINCA & 0.388 & - & ACODEP & -0.074 & -0.111 & FMFB & 2.129 & 1.186 \\
\hline ESAF & 0.306 & -0.013 & SOCREMO & 0.323 & 0.300 & FJN & 0.028 & - & Bank Eskhata & 0.247 & 0.555 \\
\hline SNFL & 1.037 & 0.930 & FCC & 1.555 & 0.296 & FINDESA & 0.068 & 0.009 & MicroInvest & 0.383 & 0.420 \\
\hline GK & 0.200 & -0.007 & TCHUMA & 0.275 & 0.334 & FDL & 0.012 & 0.059 & Agroinvest & 0.470 & 0.337 \\
\hline B TANGAIL & -0.044 & 0.072 & N BANCO & 0.428 & -0.033 & ProCredit & 0.112 & 0.246 & IMON & 1.308 & 0.378 \\
\hline DESHA & 0.121 & - & LAPO & 0.068 & 0.017 & Fafidess & -0.008 & - & FORUS & 0.237 & 0.519 \\
\hline ASA & -0.190 & 0.538 & SEAP & -0.124 & -0.215 & Fundea & 0.384 & - & AIYL Bank & 1.270 & 1.210 \\
\hline BRAC & 1.225 & 0.999 & SEF-ZAF & 0.368 & 0.214 & Genesis Em & 0.267 & 0.294 & FMCC & 0.256 & 0.044 \\
\hline RDRS & 1.580 & 1.623 & CETZAM & 2.526 & 1.064 & Fundacion M & 1.176 & - & BTFF & 1.591 & 0.778 \\
\hline SHAKTI & 0.372 & 0.092 & FINCA & 0.568 & 0.148 & Banco Sol & 0.167 & 0.406 & INECO & 0.175 & 0.271 \\
\hline TMSS & 0.900 & 0.681 & \multirow{2}{*}{\multicolumn{3}{|c|}{ LATIN AMERICA }} & COAC SAC & 0.273 & 0.289 & ACBA & 0.548 & 0.504 \\
\hline IDF & 0.019 & 0.038 & & & & PROcredit & 0.251 & 0.083 & HORIZON & 0.189 & 0.146 \\
\hline FMFB & 1.335 & 0.189 & ProMujar & 0.564 & 0.382 & Coac S Jose & 0.189 & 0.321 & C AGRO & 0.916 & 0.000 \\
\hline BRAC & 1.274 & 0.804 & CRECER & 0.114 & 0.055 & Fundacion E & -0.205 & -0.316 & ACCESS & 0.683 & 0.621 \\
\hline ARMP & 0.873 & 0.250 & PRODEM & 0.284 & 0.115 & D-Miro & 0.117 & -0.063 & NORMICR & 0.302 & 0.434 \\
\hline \multicolumn{3}{|c|}{ AFRICA } & FIE & 0.358 & 0.217 & COAC Jardin & 0.264 & 0.274 & Viator & -0.028 & 0.172 \\
\hline K-REP & 0.372 & 0.193 & Bnaco L A & 0.501 & 0.210 & FODEMI & 0.116 & 0.075 & MIKROFIN & 0.105 & -0.284 \\
\hline EBS & -0.015 & -0.153 & FADES & 0.754 & 0.324 & Finca & -0.544 & -0.081 & PARTNER & 0.226 & -0.071 \\
\hline Kadet & 0.653 & 0.915 & Agrocapital & 0.841 & 0.461 & Fundecoca & 1.137 & - & SUNRISE & 0.117 & -0.137 \\
\hline KWFT & 0.241 & 0.250 & Foncresol & 0.596 & - & CrediMujer & 0.813 & 0.408 & EKI & 0.221 & -0.124 \\
\hline MDSL & 0.150 & -1.857 & FunBodem & 0.613 & 0.288 & FMM Pop & -0.013 & 0.173 & KMF & -0.054 & -0.046 \\
\hline SMEP & 0.412 & 0.467 & BANCOSOL & 0.260 & 0.118 & Finamerica & 0.254 & 0.312 & CREDO & 0.881 & 0.597 \\
\hline RCPB & 0.100 & 0.038 & Eco Futuro & 0.250 & 0.103 & CMM Bog & 0.252 & 0.229 & LAZIKA & 1.038 & 0.503 \\
\hline Pamecas & 0.194 & 0.038 & Fundacion C & 0.467 & 0.725 & FMM Buca & -0.149 & -0.160 & C FUND & 0.312 & 0.447 \\
\hline ACEP & 0.594 & - & AMC de RL & 0.280 & 0.221 & WWB Ca & 0.144 & 0.203 & Constanta & 0.685 & 0.581 \\
\hline CMS & 0.560 & 0.520 & ACME & 0.302 & 0.386 & WMM Med & 0.385 & 0.150 & \multicolumn{3}{|c|}{ M. EAST \& N. AFRICA } \\
\hline Soro Y & 1.176 & 2.029 & HDH & 0.413 & 1.151 & ADEMI & 0.273 & - & DBACD & 0.492 & 0.175 \\
\hline K. Jagima & -0.403 & 0.179 & World Rel & 0.243 & 0.215 & \multicolumn{3}{|c|}{ E.ASIA \& PACIFIC } & LEAD & 1.497 & -0.341 \\
\hline ACEP & 1.658 & - & Finca & 0.284 & 0.216 & PRASAC & 2.636 & 1.879 & Al Tadamun & 2.044 & 0.411 \\
\hline CDS & 0.441 & 0.430 & MCHL & 0.720 & - & AMRET & 1.066 & 0.789 & Tamwelcom & 0.033 & 0.052 \\
\hline ProCredit & -0.024 & 0.017 & BanGente & 0.965 & 0.591 & SATHA & 0.954 & 1.194 & MFW & -0.093 & 0.082 \\
\hline KSF & 0.347 & - & Edpy. C Tac & 0.644 & 0.532 & HKL & 1.479 & 0.860 & AL AMANA & 0.091 & 0.097 \\
\hline Opportunity & 0.318 & -0.019 & MiBanco & 0.092 & 0.143 & ACLEDA & 1.165 & 1.113 & Fondep & 0.078 & -0.295 \\
\hline Sat & 0.051 & 0.134 & Bantra & 0.219 & 0.269 & SPBD & -3.255 & -2.785 & Zakoura & 0.046 & 0.171 \\
\hline Alide & 1.24 & 0.666 & CMAC May & 0.303 & 0.181 & GREEN & 0.611 & - & Inmaa & 0.029 & -0.056 \\
\hline VF & 0.405 & 0.427 & Edpy. Cofian & 0.767 & 0.848 & BCB & 0.359 & 0.343 & Al Karama & -0.043 & 0.087 \\
\hline PADME & 0.481 & 5.834 & IDESI LL & 0.271 & - & ASHI & 2.565 & 1.971 & Enda & 0.096 & -0.234 \\
\hline FECECAM & 0.185 & 1.443 & Fondesurco & 0.673 & 0.698 & TSPI & 0.784 & 0.664 & & & \\
\hline NovoBanco & 3.344 & 1.387 & EDPY.Edyf & 0.667 & 0.559 & NWFT & 0.706 & 0.562 & & & \\
\hline
\end{tabular}

Source: Author own calculations based on the Balance sheets of 204 MFIs for year 2005 \& 2006 


\section{$\underline{\text { APPENDIX C Subsidy Dependence Index Calculations }}$}

\begin{tabular}{|c|c|c|c|c|c|c|c|c|c|c|}
\hline & \multicolumn{3}{|c|}{ PAKISTAN } & \multicolumn{5}{|c|}{ NEPAL } & \multicolumn{2}{|c|}{ INDIA } \\
\hline MFIs & KASHF & FMBL & ASASAH & NSSC & VYCCU & NIRDHAN & PGBB & CBB & \begin{tabular}{|l|} 
BANDHAN \\
\end{tabular} & BASIX \\
\hline Avg. Assets, 2005 & 17608749 & 22210207 & 758361 & 2289996 & 633430 & 7860265 & 9373834 & 3207017 & 5587633 & 21286800 \\
\hline Avg. Assets, 2006 & 26912556 & 25998850 & 2349083 & 2789798 & 877182 & 10091829 & 9215449 & 4494839 & 19753756 & 31972598 \\
\hline Ave. Equity (E), 2005 & 9576291 & 11658707 & -100065 & 102731 & 79774 & 470611 & 956637 & 190753 & 289202 & 5510323 \\
\hline Ave. Equity (E),2006 & 12996676 & 11695891 & -196428 & 94678 & 96983 & 597779 & 928396 & 288479 & 1503931 & 5943501 \\
\hline Opp. Cost of society (m), 2005 & 0.11 & 0.11 & 0.11 & 0.08125 & 0.08125 & 0.08125 & 0.08125 & 0.08125 & 0.1075 & 0.1075 \\
\hline Opp. Cost of society $(\mathrm{m}), 2006$ & 0.11 & 0.11 & 0.11 & 0.08 & 0.08 & 0.08 & 0.08 & 0.08 & 0.1119 & 0.1119 \\
\hline Subsidy on Equity. E*m, 2005 & 1053392 & 1282458 & -11007 & 8347 & 6482 & 38237 & 77727 & 15499 & 31089 & 592360 \\
\hline Subsidy on Equity. E*m, 2006 & 1429634 & 1286548 & -21607 & 7574 & 7759 & 47822 & 74272 & 23078 & 168290 & 665078 \\
\hline Ave. Public debt (A), 2005 & 7347530 & 803583 & 795309 & 1876833 & 33919 & 5198146 & 6969816 & 2470314 & 4078123 & 12755419 \\
\hline Ave. Public debt (A),2006 & 12923550 & 803583 & 2360773 & - & - & 6565411 & - & 3309558 & 14708114 & 20918123 \\
\hline Exp. Int. Public debt. $A^{*} c, 2005$ & 275455 & 8982 & 128880 & 100750 & 2339 & 225985 & 167047 & 100967 & 301076 & 1156719 \\
\hline Exp. Int. Public debt. A*c , 2006 & 586969 & 58186 & 200944 & 0 & - & 256822 & - & 126589 & 1383559 & 1781165 \\
\hline Rate paid public debt (c), 2005 & 0.037 & 0.011 & 0.162 & 0.054 & 0.069 & 0.043 & 0.024 & 0.041 & 0.074 & 0.091 \\
\hline Rate paid public debt (c), 2006 & 0.045 & 0.072 & 0.085 & - & - & 0.039 & - & 0.038 & 0.094 & 0.085 \\
\hline Disc. Public debt. $A^{*}(m-c), 2005$ & 532773 & 79412 & -41396 & 51742 & 417 & 196364 & 399250 & 99746 & 137323 & 214489 \\
\hline Disc. Public debt. $A^{*}(\mathrm{~m}-\mathrm{c}), 2006$ & 834621 & 30208 & 58741 & - & - & 268411 & - & 138175 & 262278 & 559573 \\
\hline Rev. Grants (RG), 2005 & 315931 & 242265 & 22257 & 0 & 0 & 151834 & 0 & 0 & 70228 & 30326 \\
\hline Rev. Grants (RG), 2006 & 1460171 & 44437 & 213222 & 0 & 0 & 107907 & 0 & 0 & 95448 & 0 \\
\hline K (RG + DX), 2005 & 315931 & 242265 & 22257 & 0 & 0 & 151834 & - & 0 & 70228 & 30326 \\
\hline $\mathrm{K}(\mathrm{RG}+\mathrm{DX}), 2006$ & 1460171 & 44437 & 213222 & 0 & 0 & 107907 & - & 0 & 95448 & 0 \\
\hline Accounting Profit (P), 2005 & 1793615 & 33223 & -77551 & 43985 & 18944 & 190658 & 128252 & 80025 & 126649 & 626830 \\
\hline Accounting Profit (P), 2006 & 3486377 & 493658 & -154041 & 0 & 0 & 152580 & - & 245185 & 1422331 & 1088988 \\
\hline Taxes, 2005 & 0 & 21130 & 1150 & 0 & 0 & 27252 & 39822 & 37019 & 0 & 289678 \\
\hline Taxes, 2006 & 0 & 173656 & 2371 & 0 & - & 39546 & - & 72330 & 0 & 417688 \\
\hline Acc. profit less Taxes (AP), 2005 & 1793615 & 12093 & -78702 & 43985 & 18944 & 163406 & 88430 & 43007 & 126649 & 337151 \\
\hline Acc. profit less Taxes & 3486377 & 320002 & -156413 & 0 & - & 113034 & - & 172856 & 1422331 & 671301 \\
\hline Subsidy. $S\left\{E^{*} m+A(m-c)+K-A P\right\} 05$ & 108481 & 1592041 & 48556 & 16104 & -12045 & 223030 & 388547 & 72238 & 111991 & 500024 \\
\hline Subsidy. S $\left\{E^{*} m+A(m-c)+K-A P\right\} 06$ & 238049 & 1041191 & 406768 & - & - & 311107 & - & -11602 & -896315 & 553350 \\
\hline Ave. Loan port (net) LP, 2005 & 10382474 & 4750703 & 419140 & 734596 & 496007 & 4591939 & 4682632 & 1343421 & 5057057 & 17833248 \\
\hline Ave. Loan port (net) LP, 2006 & 18696545 & 8906457 & 1298048 & - & - & 6360390 & - & 2202891 & 18254340 & 25245331 \\
\hline Rev. From lending (LP*i) , 2005 & 2990136 & 749071 & & 152516 & 66053 & 890185 & 728579 & 243385 & 1172776 & 4182719 \\
\hline Rev. From lending (LP*i), 2006 & 5233457 & 2023666 & 400415 & 0 & - & 1169663 & - & 387691 & 4160964 & 6263409 \\
\hline Yield on lending (i), 2005 & 0.288 & 0.158 & 0.549 & 0.208 & 0.133 & 0.194 & 0.156 & 0.181 & 0.232 & 0.235 \\
\hline Yield on lending (i), 2006 & 0.280 & 0.227 & & - & - & 0.184 & - & 0.176 & 0.228 & 0.248 \\
\hline SDI (S/LP*i), 2005 & 0.036 & 2.125 & 0.211 & 0.106 & -0.182 & 0.251 & 0.533 & 0.297 & 0.095 & 0.120 \\
\hline SDI (S/LP*i), 2006 & 0.045 & 0.515 & & - & - & 0.266 & - & -0.030 & -0.215 & 0.088 \\
\hline Change in Yield, 2005 & 0.010 & 0.335 & 0.116 & 0.022 & -0.024 & 0.049 & 0.083 & 0.054 & 0.022 & 0.028 \\
\hline Change in Yield, 2006 & 0.013 & 0.117 & 0.313 & - & - & 0.049 & - & -0.005 & -0.049 & 0.022 \\
\hline Nominal Subsidy free yield, 2005 & 0.298 & 0.493 & 0.665 & 0.230 & 0.109 & 0.242 & 0.239 & 0.235 & 0.254 & 0.263 \\
\hline Nominal Subsidy free yield, 2006 & 0.293 & 0.344 & 0.622 & - & - & 0.233 & - & 0.171 & 0.179 & 0.270 \\
\hline Inflation, 2005 & 0.091 & 0.091 & 0.091 & 0.068 & 0.068 & 0.068 & 0.068 & 0.068 & 0.043 & 0.043 \\
\hline Inflation, 2006 & 0.079 & 0.079 & 0.079 & 0.076 & 0.076 & 0.076 & 0.076 & 0.076 & 0.058 & 0.058 \\
\hline Real Subsidy- free yield, 2005 & 0.191 & 0.369 & 0.526 & 0.151 & 0.038 & 0.163 & 0.159 & 0.156 & 0.203 & 0.211 \\
\hline Real Subsidy- free yield, 2006 & 0.198 & 0.245 & 0.503 & - & - & 0.146 & - & 0.088 & 0.114 & 0.200 \\
\hline True Profit, 2005 & 944911 & -309584 & -59563 & -7758 & 18527 & -184793 & -310820 & -56739 & -80902 & 92336 \\
\hline True Profit, 2006 & 1191585 & 245357 & -428375 & - & - & -263285 & - & 34681 & 1064605 & 111728 \\
\hline Return on Assets (ROA), 2005 & 0.102 & 0.001 & -0.104 & 0.019 & 0.030 & 0.021 & 0.009 & 0.013 & 0.023 & 0.016 \\
\hline Return on Assets (ROA), 2006 & 0.130 & 0.012 & -0.067 & 0.000 & 0.000 & 0.011 & - & 0.038 & 0.072 & 0.021 \\
\hline Subsidy-adjusted ROA, 2005 & 0.054 & -0.014 & -0.079 & -0.003 & 0.029 & -0.024 & -0.033 & -0.018 & -0.014 & 0.004 \\
\hline Subsidy-adjusted ROA, 2006 & 0.044 & 0.009 & -0.182 & - & - & -0.026 & - & 0.008 & 0.054 & 0.003 \\
\hline Return on Equity (ROE), 2005 & 0.187 & 0.001 & 0.787 & 0.428 & 0.237 & 0.347 & 0.092 & 0.225 & 0.438 & 0.061 \\
\hline Return on Equity (ROE), 2006 & 0.268 & 0.027 & 0.796 & 0.000 & 0.000 & 0.189 & - & 0.599 & 0.946 & 0.113 \\
\hline Subsidy-adjusted ROE, 2005 & 0.099 & -0.027 & 0.595 & -0.076 & 0.232 & -0.393 & -0.325 & -0.297 & -0.280 & 0.017 \\
\hline Subsidy-adjusted ROE, 2006 & 0.092 & 0.021 & 2.181 & - & - & -0.440 & - & 0.120 & 0.708 & 0.019 \\
\hline
\end{tabular}

\begin{tabular}{|c|c|c|c|c|c|c|c|c|c|c|}
\hline \multirow[b]{2}{*}{ MFIs } & \multicolumn{8}{|c|}{ INDIA } & \multicolumn{2}{|c|}{ BANGLADESH } \\
\hline & SHARE & M`man & C'poor & IASC & KBSLAB & ESAF & SNFL & GK & TANGAIL & DESHA \\
\hline Avg. Assets, 2005 & 71581967 & 3809349 & 11400591 & 4701233 & 5261030 & 3801892 & 8450623 & 4456509 & 17514700 & 1983869 \\
\hline Avg. Assets, 2006 & 99905948 & - & 18846991 & - & 8866516 & 9557650 & 13349553 & 9910050 & 22544752 & - \\
\hline Ave. Equity (E), 2005 & 6811304 & 280877 & 242656 & 233952 & 1243794 & 26619 & 2555963 & 195423 & 6957322 & 275994 \\
\hline Ave. Equity (E),2006 & 7914527 & - & -59344 & - & 1301187 & 238625 & 2929703 & 613022 & 7985354 & - \\
\hline Opp. Cost of society (m), 2005 & 0.1075 & 0.1075 & 0.1075 & 0.1075 & 0.1075 & 0.1075 & 0.1075 & 0.1075 & 0.14 & 0.14 \\
\hline Opp. Cost of society( m), 2006 & 0.1119 & 0.1119 & 0.1119 & 0.1119 & 0.1119 & 0.1119 & 0.1119 & 0.1119 & 0.1533 & 0.1533 \\
\hline Subsidy on Equity. E*m, 2006 & 885636 & - & -6641 & - & 145603 & 26702 & 327834 & 68597 & 1224155 & 0 \\
\hline Ave. Public debt (A), 2005 & 36487587 & 3003896 & 6354329 & 4029946 & 1635879 & 3121284 & 5778011 & 3668549 & 3392200 & 1116302 \\
\hline
\end{tabular}




\begin{tabular}{|c|c|c|c|c|c|c|c|c|c|c|}
\hline Ave. Public debt (A),2006 & 50290131 & - & 12108259 & - & 2887036 & 7596364 & 10339405 & 8576228 & 4764398 & - \\
\hline Exp. Int. Public debt. A*c, 2005 & 4616065 & 326683 & 779899 & 394035 & 182231 & 224398 & 481789 & 308560 & 358911 & 52940 \\
\hline Exp. Int. Public debt. A*c , 2006 & 4592068 & 0 & 1060615 & - & 301140 & 835956 & 843267 & 775531 & 693650 & 0 \\
\hline Rate paid public debt (c), 2005 & 0.127 & 0.109 & 0.123 & 0.098 & 0.111 & 0.072 & 0.083 & 0.084 & 0.106 & 0.047 \\
\hline Rate paid public debt (c), 2006 & 0.091 & - & 0.088 & - & 0.104 & 0.110 & 0.082 & 0.090 & 0.146 & - \\
\hline Disc. Public debt. A*(m-c), 2005 & -693649 & -3765 & -96809 & 39184 & -6374 & 111140 & 139347 & 85809 & 115997 & 103343 \\
\hline Disc. Public debt. A*(m-c), 2006 & 1035397 & - & 294299 & - & 21919 & 14077 & 313713 & 184149 & 36733 & - \\
\hline Rev. Grants (RG), 2005 & 13560 & 78878 & 566490 & 2241 & 227805 & 104026 & 107318 & 331345 & 2718 & 15818 \\
\hline Rev. Grants (RG), 2006 & 0 & - & 70516 & 0 & 408390 & 70624 & 111012 & 121772 & 0 & 0 \\
\hline K (RG + DX), 2005 & 13560 & 78878 & 566490 & 2241 & 227805 & 104026 & 107318 & 331345 & 2718 & 15818 \\
\hline K (RG + DX), 2006 & 0 & - & 70516 & - & 408390 & 70624 & 111012 & 121772 & 0 & 0 \\
\hline Accounting $\mathbf{P}$ & 3231017 & 174905 & -645270 & 30139 & 40477 & 111272 & 64552 & 340681 & 1683330 & 139125 \\
\hline Accounting Profit (P), 2006 & 370501 & - & -506555 & - & 69389 & 242759 & 133884 & 486426 & 1390117 & \\
\hline Taxes, 2005 & 1647181 & 0 & 0 & 23759 & 0 & 0 & 35593 & 0 & 0 & 0 \\
\hline Taxes, 2006 & 149117 & - & 0 & - & 0 & 0 & 49576 & 0 & 0 & \\
\hline Acc. profit less Taxes (AP), 2005 & 1583836 & 174905 & -645270 & 6380 & 40477 & 111272 & 28959 & 340681 & 1683330 & 139125 \\
\hline Acc. profit less Taxes (AP), 2006 & 221385 & - & -506555 & - & 69389 & 242759 & 84308 & 486426 & 1390117 & 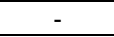 \\
\hline Subsidy. $S\left\{E^{*} m+A(m-c)+K-A P\right\} 05$ & -1531709 & -69597 & 1141036 & 60195 & 314662 & 106755 & 492473 & 97481 & -590589 & 18674 \\
\hline Subsidy. $S\left\{E^{*} m+A(m-c)+K-A P\right\} 06$ & 1699648 & - & 864730 & - & 506523 & -131356 & 668250 & -111908 & -129229 & 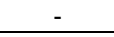 \\
\hline Ave. Loan port (net) LP, 2005 & 61141854 & 2712690 & 8786812 & 3763564 & 3470237 & 1977482 & 7006393 & 3324699 & 14841347 & 1029730 \\
\hline Ave. Loan port (net) LP, 2006 & 86883559 & - & 15566085 & - & 5424679 & 6890359 & 11652467 & 7964135 & 19808984 & - \\
\hline Rev. From lending (LP*i) , 2005 & 13200801 & 693025 & 1529481 & 677772 & 680535 & 438239 & 769831 & 745263 & 4342429 & 410091 \\
\hline Rev. From lending (LP*i), 2006 & 10689914 & - & 2237638 & 0 & 1058356 & 1567886 & 1258431 & 1892928 & 5530700 & 0 \\
\hline Yield on lending (i), 2005 & 0.216 & 0.255 & 0.174 & 0.180 & 0.196 & 0.222 & 0.110 & 0.224 & 0.293 & 0.398 \\
\hline Yield on lending (i), 2006 & 0.123 & - & 0.144 & - & 0.195 & 0.228 & 0.108 & 0.238 & 0.279 & - \\
\hline SDI (S/LP*i), 2005 & -0.116 & -0.100 & 0.746 & 0.089 & 0.462 & 0.244 & 0.640 & 0.131 & -0.136 & 0.046 \\
\hline SDI (S/LP*i), 2006 & 0.159 & - & 0.386 & 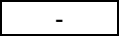 & 0.479 & -0.084 & 0.531 & -0.059 & -0.023 & 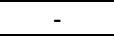 \\
\hline Change in Yield, 2005 & -0.025 & 026 & 0.130 & 0.016 & 0.091 & 0.054 & 0.070 & 0.029 & -0.040 & 0.018 \\
\hline Change in Yield, 2006 & 0.020 & - & 0.056 & - & 0.093 & -0.019 & 0.057 & -0.014 & -0.007 & - \\
\hline Nominal Subsidy free yield, 2005 & 0.191 & 0.230 & 0.304 & 0.196 & 0.287 & 0.276 & 0.180 & 0.253 & 0.253 & 0.416 \\
\hline Nominal Subsidy free yield, 2006 & 0.143 & - & 0.199 & - & 0.288 & 0.208 & 0.165 & 0.224 & 0.273 & - \\
\hline Inflation, 2005 & 0.043 & 0.043 & 0.043 & 0.043 & 0.043 & 0.043 & 0.043 & 0.043 & 0.070 & 0.070 \\
\hline Inflation, 2006 & 0.058 & 0.058 & 0.058 & 0.058 & 0.058 & 0.058 & 0.058 & 0.058 & 0.068 & 0.068 \\
\hline Real Subsidy- free yield, 2005 & 0.142 & 0.180 & 0.251 & 0.147 & 0.234 & 0.224 & 0.132 & 0.202 & 0.170 & 0.323 \\
\hline Real Subsidy-free yield, 2006 & 0.080 & - & 0.134 & - & 0.218 & 0.142 & 0.101 & 0.157 & 0.192 & - \\
\hline True Profit, 2005 & 2263924 & 99792 & -1114951 & -35045 & -180954 & -103894 & -217707 & -76473 & 1564614 & 19965 \\
\hline True Profit, 2006 & -814013 & - & -871370 & - & -360920 & 158058 & -340416 & 180505 & 1353384 & - \\
\hline Return on Assets (ROA), 2005 & 0.022 & 0.046 & -0.057 & 0.001 & 0.008 & 0.029 & 0.003 & 0.076 & 0.096 & 0.070 \\
\hline Return on Assets (ROA), 2006 & 0.002 & - & -0.027 & - & 0.008 & 0.025 & 0.006 & 0.049 & 0.062 & - \\
\hline Subsidy-adjusted ROA, 2005 & 0.032 & 0.026 & -0.098 & -0.007 & -0.034 & -0.027 & -0.026 & -0.017 & 0.089 & 0.010 \\
\hline Subsidy-adjusted ROA, 2006 & -0.008 & - & -0.046 & - & -0.041 & 0.017 & -0.026 & 0.018 & 0.060 & - \\
\hline Return on Equity (ROE), 2005 & 0.233 & 0.623 & -2.659 & 0.027 & 0.033 & 4.180 & 0.011 & 1.743 & 0.242 & 0.504 \\
\hline Return on Equity (ROE), 2006 & 0.028 & - & 8.536 & - & 0.053 & 1.017 & 0.029 & 0.793 & 0.174 & - \\
\hline Subsidy-adjusted ROE, 2005 & 0.332 & 0.355 & -4.595 & -0.150 & -0.145 & -3.903 & -0.085 & -0.391 & 0.225 & 0.072 \\
\hline Subsidy-adjusted ROE, 2006 & -0.103 & 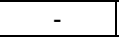 & 14.683 & 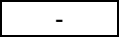 & -0.277 & 0.662 & -0.116 & 0.294 & 0.169 & 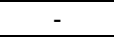 \\
\hline
\end{tabular}

\begin{tabular}{|c|c|c|c|c|c|c|c|c|c|}
\hline & & \multicolumn{5}{|c|}{ BANGLADESH } & \multicolumn{3}{|c|}{ AGHANISTAN } \\
\hline MFIs & ASA & BRAC & RDRS & SHAKTI & TMSS & IDF & FMFB & BRAC & ARMP \\
\hline Avg. Assets, 2005 & 282427681 & 455553076 & 16565143 & 13247931 & 28038026 & 3351500 & 16999311 & 10005745 & 6366986 \\
\hline Avg. Assets, 2006 & 326696475 & 520794762 & 18487496 & 15219390 & 36146687 & 4011832 & 28428091 & 22870780 & 15310880 \\
\hline Ave. Equity (E), 2005 & 145680852 & 154814306 & 10740226 & 5294703 & 6579242 & 911247 & 5643801 & 1488650 & 4592441 \\
\hline Ave. Equity (E),2006 & 180348377 & 173625278 & 10318542 & 4408283 & 7558775 & 1123831 & 6439358 & 4029111 & 7427257 \\
\hline Opp. Cost of society (m), 2005 & 0.14 & 0.14 & 0.14 & 0.14 & 0.14 & 0.14 & 0.09 & 0.09 & 0.09 \\
\hline Opp. Cost of society ( m), 2006 & 0.1533 & 0.1533 & 0.1533 & 0.1533 & 0.1533 & 0.1533 & 0.09 & 0.09 & 0.09 \\
\hline Subsidy on Equity. E*m, 2005 & 20395319 & 21674003 & 1503632 & 741258 & 921094 & 127575 & 507942 & 133978 & 413320 \\
\hline Subsidy on Equity. $E^{*} m, 2006$ & 27647406 & 26616755 & 1581833 & 675790 & 1158760 & 172283 & 579542 & 362620 & 668453 \\
\hline Ave. Public debt (A), 2005 & 41362661 & 71299951 & 1906768 & 1286150 & 11252959 & 654789 & 203459 & 6663664 & 1710000 \\
\hline Ave. Public debt (A),2006 & 23416865 & 89420491 & 3755089 & 1097475 & 15206284 & 674993 & 2720657 & 15840680 & 6975179 \\
\hline Exp. Int. Public debt. A*c , 2005 & 2974149 & 6638143 & 36269 & 88587 & 390988 & 30044 & 1255 & 317578 & 106534 \\
\hline Exp. Int. Public debt. $A^{*} c, 2006$ & 1384442 & 7392855 & 75247 & 94866 & 535365 & 17446 & 161559 & 1044603 & 377152 \\
\hline Rate paid public debt (c), 2005 & 0.072 & 0.093 & 0.019 & 0.069 & 0.035 & 0.046 & 0.006 & 0.048 & 0.062 \\
\hline Rate paid public debt (c), 2006 & 0.059 & 0.083 & 0.020 & 0.086 & 0.035 & 0.026 & 0.059 & 0.066 & 0.054 \\
\hline Disc. Public debt. $A^{*}(m-c), 2005$ & 2816624 & 3343850 & 230678 & 91474 & 1184426 & 61627 & 17057 & 282152 & 47366 \\
\hline Disc. Public debt. $A^{*}(\mathrm{~m}-\mathrm{c}), 2006$ & 2205363 & 6315306 & 500408 & 73376 & 1795758 & 86030 & 83300 & 58 & 250614 \\
\hline Rev. Grants (RG), 2005 & 0 & 62499161 & 354337 & 143488 & 2699696 & 10503 & 949945 & 166 & 361132 \\
\hline Rev. Grants (RG), 2006 & 0 & 79767488 & 781664 & 151943 & 3205956 & 14553 & 672461 & 3010996 & 1827116 \\
\hline K (RG + DX), 2005 & 0 & 62499161 & 354337 & 143488 & 2699696 & 10503 & 949945 & 2126166 & 361132 \\
\hline K (RG + DX), 2006 & 0 & 79767488 & 781664 & 151943 & 3205956 & 14553 & 672461 & 3010996 & 1827116 \\
\hline Accounting Profit (P), 2005 & 41311257 & 16737712 & 370060 & 561614 & 1395858 & 252833 & 174323 & 312284 & 104992 \\
\hline Accounting Profit (P), 2006 & 47585559 & 36748507 & 463568 & 927121 & 2356265 & 324256 & 1284376 & 0 & 2197798 \\
\hline Taxes, 2005 & 0 & 437901 & 0 & 0 & 0 & 0 & 85925 & 0 & 0 \\
\hline Taxes, 2006 & 40768 & 956702 & 0 & 0 & 0 & 0 & 256875 & 0 & 0 \\
\hline
\end{tabular}




\begin{tabular}{|c|c|c|c|c|c|c|c|c|c|}
\hline Acc. profit less Taxes (AP), 2005 & 41311257 & 16299811 & 370060 & 561614 & 1395858 & 252833 & 88398 & 312284 & 104992 \\
\hline Acc. profit less Taxes (AP), 2006 & 47544791 & 35791805 & 463568 & 927121 & 2356265 & 324256 & 1027501 & 0 & 2197798 \\
\hline Subsidy. $S\left\{E^{*} m+A(m-c)+K-A P\right\} 05$ & -18099314 & 71217203 & 1718587 & 414606 & 3409358 & -53128 & 1386546 & 2230012 & 716826 \\
\hline Subsidy. $S\left\{E^{*} m+A(m-c)+K-A P\right\} 06$ & -17692022 & 76907745 & 2400337 & -26012 & 3804210 & -51389 & 307802 & 3754674 & 548385 \\
\hline Ave. Loan port (net) LP, 2005 & 228239856 & 235842760 & 9324321 & 12039428 & 19632595 & 3071859 & 5276316 & 5292134 & 5636813 \\
\hline Ave. Loan port (net) LP, 2006 & 280323700 & 289105574 & 10385324 & 14150373 & 27547590 & 3539746 & 12697195 & 13390898 & 12187088 \\
\hline Rev. From lending (LP*i) , 2005 & 63111619 & 68750683 & 1437714 & 2304428 & 4526169 & 741154 & 1340680 & 1857641 & 1096065 \\
\hline Rev. From lending $(L P * i), 2006$ & 78168091 & 89437885 & 1864762 & 3101635 & 6436718 & 863810 & 4017199 & 5811962 & 3017715 \\
\hline Yield on lending (i), 2005 & 0.277 & 0.292 & 0.154 & 0.191 & 0.231 & 0.241 & 0.254 & 0.351 & 0.194 \\
\hline Yield on lending (i), 2006 & 0.279 & 0.309 & 0.180 & 0.219 & 0.234 & 0.244 & 0.316 & 0.434 & 0.248 \\
\hline SDI $(S / L P * i), 2005$ & -0.287 & 1.036 & 1.195 & 0.180 & 0.753 & -0.072 & 1.034 & 1.200 & 0.654 \\
\hline I (S/LP*i), 2006 & -0.2 & & 37 & -0. & 0.591 & -0.059 & 0.077 & 0.646 & 0.182 \\
\hline Change in Yield, 2005 & -0.6 & 0.302 & 84 & 0. & 0.174 & -0.017 & 0.263 & 0.421 & 0.127 \\
\hline Change in Yield, 2006 & -0.063 & 0.266 & 0.231 & -0.002 & 0.138 & -0.015 & 0.024 & 0.280 & 0.045 \\
\hline Nominal Subsidy free yield, 2005 & 0.197 & 0.593 & 0.339 & 0.226 & 0.404 & 0.224 & 0.517 & 0.772 & 0.322 \\
\hline Nominal Subsidy free yield, 2006 & 0.21 & 0.575 & 0.411 & 0.217 & 0.372 & 0.230 & 0.341 & 0.714 & 0.293 \\
\hline Inflation, 2005 & 0.070 & 0.070 & 0.070 & 0.070 & 0.070 & 0.070 & 0.110 & 0.110 & 0.110 \\
\hline Inflation, 2006 & 0.068 & 0.068 & 0.068 & 0.068 & 0.068 & 0.068 & 0.163 & 0.163 & 0.163 \\
\hline Real Subsidy-free yield, 2005 & 0.118 & 0.489 & 0.250 & 0.145 & 0.312 & 0.143 & 0.367 & 0.597 & 0.191 \\
\hline Real Subsidy- free yield, 2006 & 0.139 & 0.476 & 0.321 & 0.140 & 0.285 & 0.152 & 0.153 & 0.474 & 0.111 \\
\hline True Profit, 2005 & 38494633 & -49543200 & -214956 & 326653 & -2488264 & 180703 & -878604 & -2096034 & -303506 \\
\hline True Profit, 2006 & 45339428 & -50290990 & -818504 & 701802 & -2645450 & 223673 & 271739 & -3392054 & 120067 \\
\hline Return on Assets (ROA), 2005 & 0.146 & 0.036 & 0.022 & 0.042 & 0.050 & 0.075 & 0.005 & 0.031 & 0.016 \\
\hline Return on Assets (ROA), 2006 & 5 & 0.0 & 0.025 & 0. & 0.065 & 0.081 & 0.036 & 0.000 & 0.144 \\
\hline Subsidy-adjusted & & -0.109 & -0.013 & 0.025 & -0.089 & 0.054 & -0.052 & -0.209 & -0.048 \\
\hline Subsidy-adjusted ROA, 2006 & .139 & -0.097 & -0.044 & 0.046 & -0.073 & 0.056 & 0.010 & -0.148 & 0.008 \\
\hline Return on Equity (ROE), 2005 & 0.284 & 0.105 & 0.034 & 0.106 & 0.212 & 0.277 & 0.016 & 0.210 & 0.023 \\
\hline Return on Equity (ROE), 2006 & 0.263 & 0.206 & 0.045 & 0.210 & 0.312 & 0.289 & 0.160 & 0.000 & 0.296 \\
\hline Subsidy-adjusted ROE, 2005 & 0.264 & -0.320 & -0.020 & 0.062 & -0.378 & 0.198 & -0.156 & -1.408 & -0.066 \\
\hline Subsidy-adjusted ROE, 2006 & 0.251 & -0.290 & -0.079 & 0.159 & -0.350 & 0.199 & 0.042 & -0.842 & 0.016 \\
\hline
\end{tabular}

\begin{tabular}{|c|c|c|c|c|c|c|c|c|c|c|}
\hline & \multicolumn{6}{|c|}{ KENYA } & B. FASO & \multicolumn{3}{|c|}{ SENEGAL } \\
\hline MFIs & KREP & EBS & Kadet & KWFT & MDSL & SMEP & RCPB & Pamecas & ACEP & CMS \\
\hline Avg. Assets, 2005 & 43621978 & 122442953 & 3774798 & 29620584 & 1372488 & 8256376 & 80570447 & 32783228 & 34919188 & 82244252 \\
\hline Avg. Assets, 2006 & 63567785 & 222815952 & 5621035 & 42455331 & 1592243 & 9002177 & 88179575 & 43812513 & - & 108570060 \\
\hline Ave. Equity (E), 2005 & 10419189 & 19222018 & 1522918 & 9475538 & 477110 & 2508572 & 10071131 & 8994961 & 24042592 & 14730557 \\
\hline Ave. Equity (E),2006 & 11905982 & 26801022 & 2583405 & 12309389 & 56928 & 2734088 & 12887180 & 10485234 & - & 21438442 \\
\hline Opp. Cost of society (m), 2 & 0.129 & 0.129 & 0.129 & 0.129 & 0.129 & 0.129 & & & 0.100 & 0.100 \\
\hline Opp. Cost of society $(\mathrm{m}), 2006$ & 0.136 & 0.136 & 136 & 0.136 & 36 & 0.136 & & 100 & 0.100 & .100 \\
\hline Subsidy on Equity. E*m, 2005 & 1342304 & 2476373 & 196198 & 1220734 & 466 & 323179 & 1007113 & 9496 & 2404259 & 056 \\
\hline Subsidy c & 162 & 3655659 & 352376 & & 7765 & & 128 & & & \\
\hline Ave. Public de & 668 & 0 & 973005 & 358 & 773600 & 2969243 & 1534359 & & 3132613 & \\
\hline Ave. Public & 10454191 & 484925 & 1151850 & 13461374 & 924176 & 2671380 & 1534359 & 312 & & 539 \\
\hline Exp. Int. Public d & 582264 & 0 & 104881 & 383506 & 88668 & \begin{tabular}{|l|}
275828 \\
\end{tabular} & 0 & & 214959 & 230 \\
\hline Exp. Int. Public debt. A*c, 2006 & 1240258 & 0 & & & & 257234 & 0 & & 0 & 730 \\
\hline Rate paid pu & & 0.000 & & & & & 0.000 & & 0.069 & \\
\hline Rate paid ${ }_{1}$ & & 0.000 & & & & & & & - & \\
\hline Disc. Public debt. & 278 & 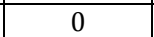 & & & & 106699 & & & 3303 & \\
\hline Disc. & & 534 & & & & 107142 & & & & \\
\hline & & 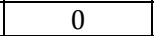 & 08 & & & & 49438 & & 2813 & \\
\hline $\operatorname{Rev}$ & & & 89 & & & & & & & \\
\hline & 0 & 0 & & & & c & 49438 & & 2813 & \\
\hline $\mathrm{K}$ ( & 0 & 0 & & & & & & & & \\
\hline Accountir & 84182 & 908654 & 745678 & 5356 & -52443 & 184468 & \begin{tabular}{|l|}
1737088 \\
\end{tabular} & & 0 & 55 \\
\hline Accou & 2181881 & 15834501 & 895558 & 2109996 & 999440 & & 2219745 & 1755711 & - & 921331 \\
\hline Taxes, & & 2152298 & 98229 & & 0 & 56804 & 0 & 0 & 0 & 0 \\
\hline & & 5018047 & & & 18449 & 29892 & 0 & 0 & - & 0 \\
\hline Acc. $p$ & & & & & & 127664 & 37088 & 2757 & 0 & 0455 \\
\hline Acc. $p$ & & & & & & & & & & \\
\hline Sub & & & & & & & & & 2515375 & \\
\hline Subsi & & & & & -83 & 448 & & & 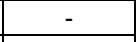 & \\
\hline Ave. & 3015 & 5670 & 176 & & 105 & 525 & 922 & & 32461617 & \\
\hline Ave & 438 & 116586 & 450 & 249 & 939 & 6055916 & 59786903 & 780 & - & \\
\hline Rev. F & 622 & 9559696 & 766081 & 266 & \begin{tabular}{|l|}
360573 \\
\end{tabular} & \begin{tabular}{|l|}
1299403 \\
\end{tabular} & 6291836 & 768 & 5961295 & 1021 \\
\hline Rev. Fr & 9490007 & 20871012 & 934107 & 9236248 & 437512 & 1448866 & 8205702 & 122 & 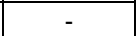 & 11989370 \\
\hline Yield & & 9 & & & 42 & 0.247 & 0.126 & & 0.184 & 2 \\
\hline Yield on lending (i), 2006 & 16 & 0.179 & 0.328 & 71 & 0.369 & .240 & 0.137 & 91 & - & 0.184 \\
\hline SDI (S/LP*i), 2005 & & -0.238 & 0.582 & & 0.152 & 0.233 & -0.052 & 53 & .422 & 0.361 \\
\hline SDI (S/LP*i), 2006 & & & & & -1.914 & 0.310 & & 4 & - & 0.313 \\
\hline Change in $Y$ & & & & & & 0.057 & & & 0.077 & 073 \\
\hline & & & & & & & & & - & 0.058 \\
\hline Nominal Subsidy free yield, 2005 & 0.245 & 0.128 & 0.685 & 0.386 & 0.394 & 0.305 & 0.120 & 0.180 & 0.261 & 0.275 \\
\hline
\end{tabular}




\begin{tabular}{|c|c|c|c|c|c|c|c|c|c|c|}
\hline Nominal Subsidy free yield, 2006 & 0.224 & 0.122 & 0.607 & 0.431 & -0.396 & 0.313 & 0.124 & 0.171 & - & 0.241 \\
\hline Inflation, 2005 & 0.103 & 0.103 & 0.103 & 0.103 & 0.103 & 0.103 & 0.064 & 0.017 & 0.017 & 0.017 \\
\hline Inflation, 2006 & 0.145 & 0.145 & 0.145 & 0.145 & 0.145 & 0.145 & 0.023 & 0.021 & 0.021 & 0.021 \\
\hline Real Subsidy- free yield, 2005 & 0.129 & 0.023 & 0.528 & 0.256 & 0.264 & 0.183 & 0.052 & 0.160 & 0.240 & 0.254 \\
\hline Real Subsidy- free yield, 2006 & 0.224 & 0.122 & 0.607 & 0.431 & -0.396 & 0.313 & 0.124 & 0.171 & - & 0.241 \\
\hline True Profit, 2005 & 170754 & 4756356 & 249672 & 458924 & -116185 & 20965 & 1334214 & 669853 & 111116 & 1473144 \\
\hline True Profit, 2006 & 1263151 & 10341110 & 441251 & 193653 & 899424 & -75828 & 2066310 & 1643324 & - & 1612786 \\
\hline Return on Assets (ROA), 2005 & 0.010 & 0.039 & 0.224 & 0.049 & 0.038 & 0.015 & 0.022 & 0.021 & 0.000 & 0.008 \\
\hline Return on Assets (ROA), 2006 & 0.023 & 0.049 & 0.188 & 0.048 & 0.616 & 0.003 & 0.025 & 0.040 & - & 0.008 \\
\hline Subsidy-adjusted ROA, 2005 & 0.004 & 0.039 & 0.066 & 0.015 & -0.085 & 0.003 & 0.017 & 0.020 & 0.003 & 0.018 \\
\hline Subsidy-adjusted ROA, 2006 & 0.020 & 0.046 & 0.078 & 0.005 & 0.565 & 0.008 & 0.023 & 0.038 & - & 0.015 \\
\hline Return on Equity (ROE), 2005 & 0.043 & 0.247 & 0.554 & 0.154 & 0.110 & 0.051 & 0.172 & 0.078 & 0.000 & 0.046 \\
\hline Return on Equity (ROE), 2006 & 0.122 & 0.404 & 0.408 & 0.165 & -17.23 & 0.011 & 0.172 & 0.167 & - & 0.043 \\
\hline Subsidy-adjusted ROE, 2005 & 0.016 & 0.247 & -0.164 & 0.048 & 0.244 & 0.008 & 0.132 & 0.074 & 0.005 & 0.100 \\
\hline Subsidy-adjusted ROE, 2006 & 0.106 & 0.386 & -0.171 & 0.016 & -14.58 & -0.028 & 0.160 & 0.157 & - & 0.075 \\
\hline
\end{tabular}

\begin{tabular}{|c|c|c|c|c|c|c|c|c|c|c|}
\hline \multirow[b]{2}{*}{ MFIs } & \multicolumn{2}{|c|}{ MALI } & \multicolumn{2}{|c|}{ CAMEROON } & \multicolumn{4}{|c|}{ GHANA } & \multicolumn{2}{|c|}{ BENIN } \\
\hline & Soro Y & K. Jagima & ACEP & CDS & P.Cred. & KSF & Opp. & SAT & ALIDE & VF \\
\hline Avg. Assets, 2005 & 1626794 & 6894969 & 4067141 & 11074192 & 8654646 & 430535 & 5495897 & 5359851 & 323198 & 9854034 \\
\hline Avg. Assets, 2006 & 2157989 & 10934243 & - & 13821889 & 14708064 & - & 13772384 & 7652886 & 538100 & 9668823 \\
\hline Ave. Equity (E), 2005 & 1176395 & -1400382 & 3804466 & 832358 & 2573290 & 351837 & 2886077 & 3632247 & 159405 & 3890365 \\
\hline Ave. Equity (E),2006 & 1092883 & -1169578 & - & 936689 & 3276167 & - & 4725700 & 4687988 & 287523 & 4074355 \\
\hline Opp. Cost of society (m), 2005 & 0.100 & 0.100 & 0.177 & 0.177 & 0.100 & 0.100 & 0.100 & 0.100 & 0.100 & 0.100 \\
\hline Opp. Cost of society $(\mathrm{m}), 2006$ & 0.100 & 0.100 & 0.153 & 0.153 & 0.100 & 0.100 & 0.100 & 0.100 & 0.100 & 0.100 \\
\hline Subsidy on Equity. E*m, 2005 & 117639 & -140038 & 672135 & 147053 & 257329 & 35184 & 288608 & 363225 & 15940 & 389037 \\
\hline Subsidy on Equity. E*m, 2006 & 109288 & -116958 & - & 143594 & 327617 & - & 472570 & 468799 & 28752 & 407435 \\
\hline Ave. Public debt (A), 2005 & 187756 & 1652344 & 1430 & 2256415 & 1353262 & 60346 & 1527602 & 812419 & 0 & 4320666 \\
\hline Ave. Public debt (A),2006 & 713333 & 3151113 & - & 2943243 & 1632825 & - & 4136795 & 1201266 & 22989 & 3851362 \\
\hline Exp. Int. Public debt. A*c, 2005 & 15894 & 28635 & 0 & 333140 & 240433 & 5988 & 150927 & 60499 & 0 & 307692 \\
\hline Exp. Int. Public debt. A*c , 2006 & 46583 & 80023 & - & 391996 & 187552 & 0 & 732949 & 248470 & 597 & 354374 \\
\hline Rate paid public debt (c), 2005 & 0.085 & 0.017 & 0.000 & 0.148 & 0.178 & 0.099 & 0.099 & 0.074 & - & 0.071 \\
\hline Rate paid public debt (c), 2006 & 0.065 & 0.025 & - & 0.133 & 0.115 & - & 0.177 & 0.207 & 0.026 & 0.092 \\
\hline Disc. Public debt. A*(m-c), 2005 & 2882 & 136599 & 253 & 65501 & 105107 & 46 & 1833 & 20743 & 0 & 124375 \\
\hline Disc. Public debt. $A^{*}(\mathrm{~m}-\mathrm{c}), 2006$ & 24751 & 235088 & - & 59203 & 24270 & - & 319270 & -128344 & 1702 & 30762 \\
\hline Rev. Grants (RG), 2005 & 161804 & 162380 & 0 & 38297 & 0 & 0 & 45939 & 210530 & 88157 & 0 \\
\hline Rev. Grants (RG), 2006 & 14424 & - & - & 14916 & 0 & 0 & 0 & 110926 & 94613 & 0 \\
\hline K (RG + DX), 2005 & 161804 & 162380 & 0 & 38297 & 0 & 0 & 45939 & 210530 & 88157 & 0 \\
\hline K (RG + DX), 2006 & 14424 & - & - & 14916 & 0 & 0 & 0 & 110926 & 94613 & 0 \\
\hline Accounting Profit (P), 2005 & 54221 & 333250 & 166148 & 78967 & 632756 & 16205 & 45091 & 704984 & 28364 & 188843 \\
\hline Accounting Profit (P), 2006 & 79310 & - & - & 82934 & 697986 & 0 & 832633 & 409996 & 50546 & 27495 \\
\hline Taxes, 2005 & 0 & 0 & 0 & 0 & 227846 & 0 & 24025 & 88617 & 0 & 0 \\
\hline Taxes, 2006 & 5161 & - & - & 0 & 237057 & 0 & 210600 & 85557 & 364 & 0 \\
\hline Acc. profit less Taxes (AP), 2005 & 54221 & 333250 & 166148 & 78967 & 404910 & 16205 & 21066 & 616367 & 28364 & 188843 \\
\hline Acc. profit less Taxes (AP), 2006 & 84471 & - & - & 82934 & 460929 & 0 & 622033 & 324439 & 50182 & 27495 \\
\hline Subsidy. $S\left\{E^{*} m+A(m-c)+K-A P\right\} 05$ & 228104 & 174309 & 506240 & 171884 & -252688 & 19025 & 315314 & -21869 & 75733 & 324568 \\
\hline Subsidy. S $\left\{E^{*} m+A(m-c)+K-A P\right\} 06$ & 232935 & - & - & 134780 & -157582 & - & -468733 & 126942 & 74885 & 410702 \\
\hline Ave. Loan port (net) LP, 2005 & 1207161 & 3392114 & 3862264 & 5514785 & 5733253 & 362375 & 2877678 & 3063204 & 231574 & 7964406 \\
\hline Ave. Loan port (net) LP, 2006 & 1745503 & - & - & 7677888 & 10103990 & - & 9120134 & 5060796 & 419164 & 7136151 \\
\hline Rev. From lending (LP*i) , 2005 & 239533 & 458224 & 406226 & 1064078 & 3669247 & 96599 & 1662133 & 1633530 & 64761 & 1576154 \\
\hline Rev. From lending (LP*i), 2006 & 154663 & - & - & 1230413 & 5569896 & - & 5081296 & 2359175 & 127176 & 1611192 \\
\hline Yield on lending (i), 2005 & 0.198 & 0.135 & 0.105 & 0.193 & 0.640 & 0.267 & 0.578 & 0.533 & 0.280 & 0.198 \\
\hline Yield on lending (i), 2006 & 0.089 & - & - & 0.160 & 0.551 & - & 0.557 & 0.466 & 0.303 & 0.226 \\
\hline SDI (S/LP*i), 2005 & 0.952 & 0.380 & 1.246 & 0.162 & -0.069 & 0.197 & 0.190 & -0.013 & 1.169 & 0.206 \\
\hline SDI (S/LP*i), 2006 & 1.506 & - & - & 0.110 & -0.028 & - & -0.092 & 0.054 & 0.589 & 0.255 \\
\hline Change in Yield, 2005 & 0.189 & 0.051 & 0.131 & 0.031 & 0.044 & 0.053 & 0.110 & -0.007 & 0.327 & 0.041 \\
\hline Change in Yield, 2006 & 0.133 & - & - & 0.018 & 0.016 & - & 0.051 & 0.025 & 0.179 & 0.058 \\
\hline Nominal Subsidy free yield, 2005 & 0.387 & 0.084 & 0.236 & 0.224 & 0.596 & 0.319 & 0.687 & 0.526 & 0.607 & 0.239 \\
\hline Nominal Subsidy free yield, 2006 & 0.222 & - & - & 0.178 & 0.536 & - & 0.506 & 0.491 & 0.482 & 0.283 \\
\hline Inflation, 2005 & 0.064 & 0.064 & 0.020 & 0.020 & 0.151 & 0.151 & 0.151 & 0.151 & 0.054 & 0.054 \\
\hline Inflation, 2006 & 0.015 & - & 0.051 & 0.051 & 0.109 & 0.109 & 0.109 & 0.109 & 0.038 & 0.038 \\
\hline Real Subsidy- free yield, 2005 & 0.304 & 0.019 & 0.212 & 0.200 & 0.386 & 0.146 & 0.466 & 0.326 & 0.525 & 0.176 \\
\hline Real Subsidy- free yield, 2006 & 0.222 & - & - & 0.178 & 0.536 & - & 0.506 & 0.491 & 0.482 & 0.283 \\
\hline True Profit, 2005 & 110465 & 34271 & 165895 & 24831 & 510017 & 16158 & 26706 & 385094 & 59793 & 64469 \\
\hline True Profit, 2006 & 123646 & - & - & 8815 & 485198 & - & 941303 & 341856 & 46133 & 3267 \\
\hline Return on Assets (ROA), 2005 & 0.033 & 0.048 & 0.041 & 0.007 & 0.047 & 0.038 & 0.004 & 0.115 & 0.088 & 0.019 \\
\hline Return on Assets (ROA), 2006 & 0.039 & - & - & 0.006 & 0.031 & - & 0.045 & 0.042 & 0.093 & 0.003 \\
\hline Subsidy-adjusted ROA, 2005 & 0.068 & 0.005 & 0.041 & 0.002 & 0.059 & 0.038 & 0.005 & 0.072 & 0.185 & 0.007 \\
\hline Subsidy-adjusted ROA, 2006 & 0.057 & - & - & 0.001 & 0.033 & - & 0.068 & 0.045 & 0.086 & 0.000 \\
\hline Return on Equity (ROE), 2005 & 0.046 & 0.238 & 0.044 & 0.095 & 0.157 & 0.046 & 0.007 & 0.170 & 0.178 & 0.049 \\
\hline Return on Equity (ROE), 2006 & 0.077 & - & - & 0.089 & 0.141 & - & 0.132 & 0.069 & 0.175 & 0.007 \\
\hline Subsidy-adjusted ROE, 2005 & 0.094 & 0.024 & 0.044 & 0.030 & 0.198 & 0.046 & 0.009 & 0.106 & 0.375 & 0.017 \\
\hline Subsidy-adjusted ROE, 2006 & 0.113 & - & - & 0.009 & 0.148 & - & 0.199 & 0.073 & 0.160 & 0.001 \\
\hline
\end{tabular}




\begin{tabular}{|c|c|c|c|c|c|c|c|c|c|}
\hline \multirow[b]{2}{*}{ MFIs } & \multicolumn{2}{|c|}{ BENIN } & \multirow{2}{*}{\begin{tabular}{|l|} 
ANGOLA \\
NBANCO \\
\end{tabular}} & \multicolumn{6}{|c|}{ ETHIOPIA } \\
\hline & PADME & FECAM & & DECSI & ADCSI & ACSI & WISDOM & OMO & BG \\
\hline Avg. Assets, 2005 & 50065365 & 65954580 & 6915311 & 80266115 & 11659250 & 60566391 & 3320157 & 10653517 & 954638 \\
\hline Avg. Assets, 2006 & 50253971 & 60029419 & 10865508 & 110809729 & 17960913 & 81886961 & 9898018 & 15013429 & 1449933 \\
\hline Ave. Equity (E), 2005 & 18640445 & 2254349 & 5040325 & 21701844 & 8837801 & 19906848 & 2183908 & 1387509 & 670072 \\
\hline Ave. Equity (E),2006 & 17703702 & 370582 & 4934945 & 24463191 & 12814543 & 25359601 & 2451838 & 1672033 & 961110 \\
\hline Opp. Cost of society (m), 2005 & 0.100 & 0.100 & 0.677 & 0.070 & 0.070 & 0.070 & 0.070 & 0.070 & 0.070 \\
\hline Opp. Cost of society ( m), 2006 & 0.100 & 0.100 & 0.195 & 0.070 & 0.070 & 0.070 & 0.070 & 0.070 & 0.070 \\
\hline Subsidy on Equity. E*m, 2005 & 1864045 & 225435 & 3413207 & 1519129 & 618646 & 1393479 & 152874 & 97126 & 46905 \\
\hline Subsidy on Equity. E*m, 2006 & 1770370 & 37058 & 962847 & 1712423 & 897018 & 1775172 & 171629 & 117042 & 67278 \\
\hline Ave. Public debt (A), 2005 & 23529281 & 8653225 & 0 & 32621145 & 0 & 13604672 & 311068 & 3932065 & 153758 \\
\hline Ave. Public debt (A),2006 & 24492969 & 8326087 & 495172 & 56433820 & 497997 & 17326856 & 1143735 & 6888517 & 271199 \\
\hline Exp. Int. Public debt. A*c, 2005 & 983328 & 348657 & 0 & 1328511 & 0 & 712019 & 9290 & 62162 & 6276 \\
\hline Exp. Int. Public debt. A*c, 2006 & 1406872 & 381216 & 39614 & 1897332 & 29880 & 875489 & 46181 & 141148 & 14885 \\
\hline Rate paid public debt (c), 2005 & 0.042 & 0.040 & - & 0.041 & - & 0.052 & 0.030 & 0.016 & 0.041 \\
\hline Rate paid public debt (c), 2006 & 0.057 & 0.046 & 0.080 & 0.034 & 0.060 & 0.051 & 0.040 & 0.020 & 0.055 \\
\hline Disc. Public debt. A*(m-c), 2005 & 1369600 & 516666 & 0 & 1933603 & 0 & 648448 & 218160 & 331044 & 9099 \\
\hline Disc. Public debt. & 1042425 & 451393 & 56998 & 2053036 & 4980 & 337391 & & 341049 & 4099 \\
\hline Rev. Grants & 114932 & 199128 & 0 & 0 & 0 & 684742 & 49 & 3272 & 0 \\
\hline Rev. Grants (RG), 2006 & 143466 & 185942 & 0 & 0 & 0 & 544204 & & 317 & 0 \\
\hline K (RG + DX), 2005 & 114932 & 199128 & 0 & 0 & 0 & 684742 & 249 & 3272 & 0 \\
\hline$K(R G+D X)$, & 143466 & 185942 & 0 & 0 & 0 & 544204 & 062 & 16317 & 0 \\
\hline Accounting Profit (P), 2005 & 1092735 & 888227 & 211421 & 4014498 & 481214 & 4589773 & 44927 & 103437 & 44467 \\
\hline Accounting Profit (P), 2006 & 3248146 & 5643630 & 42792 & 4723924 & 310270 & 7024607 & 289941 & 478258 & 64914 \\
\hline Taxes, 2005 & 0 & 231116 & 42132 & 0 & 0 & 0 & 0 & 0 & 0 \\
\hline Taxes, 2006 & 222304 & 256039 & 0 & 0 & 0 & 0 & 0 & 0 & 1681 \\
\hline Acc. profit less Taxes $(A$ & 1092735 & 657110 & 253553 & 4014498 & 481214 & 4589773 & 44927 & 103437 & 44467 \\
\hline Acc. profit & & 589 & & 472 & & 7024607 & & & 63233 \\
\hline Subsidy. S \{ & 225 & 284119 & 3666760 & -56 & 137432 & -1863104 & 169011 & & 100471 \\
\hline Subsidy. $S\left\{\mathrm{E}^{*}\right.$ & 6426711 & 6574063 & 977054 & -95 & 591728 & -4367840 & 369 & & 8144 \\
\hline Ave. Loan po & 39488961 & 34682010 & 2704428 & 59064956 & 8884008 & 43196349 & 2568405 & 5842419 & 567205 \\
\hline Ave. Loan port (net) LP, 2006 & 32993041 & 27873871 & 5606416 & 78252475 & 13422490 & 63886896 & 4104064 & 9973216 & 1021184 \\
\hline Rev. From lending (LP*i) , 2005 & 7853635 & 5234490 & 1321529 & 7493522 & 765961 & 7451712 & 344416 & 677409 & 124053 \\
\hline Rev. From lending $(L P * i), 2006$ & 1406872 & 4734166 & 2812734 & 8827640 & 839355 & 11231999 & 742107 & 1226722 & 309468 \\
\hline Yield on lending (i), 2005 & 0.199 & 0.151 & 0.489 & 0.127 & 0.086 & 0.173 & 0.134 & 0.116 & 0.219 \\
\hline Yield on lending (i), 2006 & 0.043 & 0.170 & 0.502 & 0.113 & 0.063 & 0.176 & 0.181 & 0.123 & 0.303 \\
\hline SDI (S/LP*i), 2005 & 0.287 & 0.054 & 2.775 & -0.075 & 0.179 & -0.250 & 0.491 & 0.484 & 0.810 \\
\hline SDI (S/LP*i), 2006 & 4.568 & 1.389 & 0.347 & -0.109 & 0.705 & -0.389 & -0.061 & -0.003 & 0.026 \\
\hline Change $\mathrm{i}$ & & & & ת & & 0.043 & 0.057 & 56 & 0.177 \\
\hline Change & 5 & 0. & & 0 & 4 & 0.068 & 11 & 00 & 0.008 \\
\hline Nominal Su & & & 44 & & 2 & 0.129 & 1 & 72 & 0.396 \\
\hline Nominal Subs & & 6 & 76 & & 7 & 0.107 & 170 & 0.123 & 0.311 \\
\hline Inflation, 2005 & & & & & & 0.116 & 6 & 0.116 & 0.116 \\
\hline Inflation, 2006 & 0.038 & 0.038 & 0.117 & & 0.136 & 0.136 & 0.136 & 0.136 & 0.136 \\
\hline Real Subsidy- free yield, 2005 & 0.192 & 0.100 & 1.293 & 0.001 & 0.013 & 0.012 & 0.067 & 0.050 & 0.251 \\
\hline Real Subsidy- free yield, 2006 & 0.237 & 0.406 & 0.676 & 0.101 & 0.107 & 0.107 & 0.170 & 0.123 & 0.311 \\
\hline True Profit, 2005 & 391797 & 58684 & 253553 & 2080895 & 481214 & 3256583 & 5678 & -230879 & 53566 \\
\hline True Profit, 2006 & 4656341 & 6537004 & 14206 & 2670888 & 305290 & 6143012 & 216998 & 120893 & 59133 \\
\hline Return on Assets (ROA), 2005 & 0.022 & 0.010 & 0.037 & 0.050 & 0.041 & 0.076 & 0.014 & 0.010 & 0.047 \\
\hline Return on Assets (ROA), 2006 & 0.069 & 0.098 & 0.004 & 0.043 & 0.017 & 0.086 & 0.029 & 0.032 & 0.044 \\
\hline Subsidy-adjusted ROA, 2005 & 0.008 & 0.001 & 0.037 & 0.026 & 0.041 & 0.054 & 0.002 & -0.022 & 0.056 \\
\hline Subsidy-adjusted ROA, 2006 & 0.093 & 0.109 & 0.001 & 0.024 & 0.017 & 0.075 & 0.022 & 0.008 & 0.041 \\
\hline Return on Equity (ROE), 2005 & 0.059 & 0.291 & 0.050 & 0.185 & 0.054 & 0.231 & 0.021 & 0.075 & 0.066 \\
\hline 2006 & & 15.920 & 0.009 & 0.193 & 0.024 & 0.277 & 0.118 & 0.286 & 0.066 \\
\hline d ROE, 2005 & 0.021 & 0.026 & 0.050 & 0.096 & 0.054 & 0.164 & 0.003 & -0.166 & 0.080 \\
\hline Subsidy-adjusted ROE, 2006 & 0.263 & 17.640 & 0.003 & 0.109 & 0.024 & 0.242 & 0.089 & 0.072 & 0.062 \\
\hline
\end{tabular}

\begin{tabular}{|c|c|c|c|c|c|c|c|c|c|}
\hline & \multicolumn{2}{|c|}{ TAZANIA } & \multicolumn{6}{|c|}{ UGANDA } & \multirow{2}{*}{\begin{tabular}{|c|} 
MALAWI \\
FINCA \\
\end{tabular}} \\
\hline MFIs & PRIDE & FINCA & CML & FAULU & MEDNET & FINCA & UML & C’nary & \\
\hline Avg. Assets, 2005 & 12778961 & 6406658 & 7527438 & 5153390 & 3841072 & 7935389 & 16545587 & 112327803 & 2211132 \\
\hline Avg. Assets, 2006 & 16309044 & - & 11723245 & 6323821 & 3041731 & 10524707 & - & 138516560 & \\
\hline Ave. Equity (E), 2005 & 3514060 & 1852642 & 1264561 & 1213724 & 837829 & 1383184 & 3879603 & 15432277 & 195060 \\
\hline Ave. Equity (E),2006 & 3650140 & - & 1332762 & 1126056 & 386457 & 2118496 & - & 18868648 & - \\
\hline Opp. Cost of society (m), 2005 & 0.151 & 0.151 & 0.196 & 0.196 & 0.196 & 0.196 & 0.196 & 0.196 & 0.331 \\
\hline Opp. Cost of society ( m), 2006 & 0.154 & 0.154 & 0.187 & 0.187 & 0.187 & 0.187 & 0.187 & 0.187 & 0.323 \\
\hline Subsidy on Equity. E*m, 2005 & 531150 & 280027 & 248423 & 238436 & 164592 & 271726 & 762148 & 3031671 & 64532 \\
\hline Subsidy on Equity. E*m, 2006 & 562487 & 0 & 249227 & 210572 & 72267 & 396159 & 0 & 3528437 & - \\
\hline Ave. Public debt (A), 2005 & 1080423 & 2340523 & 1799971 & 2470972 & 1289758 & 3072019 & 7158988 & 0 & 583264 \\
\hline Ave. Public debt (A),2006 & 3735512 & - & 4259825 & 3218917 & 990650 & 2705318 & - & 0 & - \\
\hline
\end{tabular}




\begin{tabular}{|c|c|c|c|c|c|c|c|c|c|}
\hline Exp. Int. Public debt. A*c, 2005 & 117180 & 277469 & 279471 & 384876 & 213629 & 566273 & 512077 & 0 & 37602 \\
\hline Exp. Int. Public debt. $A^{*} c, 2006$ & 465113 & 0 & 626277 & 460629 & 2456 & 90682 & - & 0 & 0 \\
\hline Rate paid public debt (c), 2005 & 0.108 & 0.119 & 0.155 & 0.156 & 0.166 & 0.184 & 0.072 & - & 0.064 \\
\hline Rate paid public debt (c), 2006 & 0.125 & - & 0.147 & 0.143 & 0.002 & 0.034 & - & - & - \\
\hline Disc. Public debt. $A^{*}(\mathrm{~m}-\mathrm{c}), 2005$ & 46126 & 76301 & 74134 & 100547 & 39744 & 37225 & 894307 & 0 & 155360 \\
\hline Disc. Public debt. A*(m-c), 2006 & 110530 & - & 170310 & 141308 & 182795 & 415212 & - & 0 & 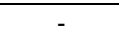 \\
\hline Rev. Grants (RG), 2005 & 11538 & 79918 & 0 & 221127 & 921 & 82894 & 12150 & 0 & 142446 \\
\hline Rev. Grants (RG), 2006 & 0 & - & 0 & 5747 & 625821 & 175838 & - & 0 & - \\
\hline K (RG + DX), 2005 & 11538 & 79918 & 0 & 221127 & 921 & 82894 & 12150 & 0 & 142446 \\
\hline K (RG + DX), 2006 & 0 & 0 & 0 & 5747 & 625821 & 175838 & - & 0 & 0 \\
\hline Accounting Profit (P), 2005 & 495818 & 191464 & 270719 & 270212 & 15901 & 254509 & 148101 & 4228168 & 87299 \\
\hline Accounting Profit (P), 2006 & 225647 & - & 99946 & 353376 & 2072474 & 426753 & - & 6017655 & - \\
\hline Taxes, 2005 & 0 & 0 & 0 & 94829 & 0 & 62237 & 50856 & 1329718 & 0 \\
\hline Taxes, 2006 & 0 & - & 0 & 16360 & 10906 & 102086 & - & 1079632 & - \\
\hline Acc. profit less Taxes (AP), 2005 & 495818 & 191464 & 270719 & 175383 & 15901 & 192272 & 97244 & 2898450 & 87299 \\
\hline Acc. profit less Taxes (AP), 2006 & 225647 & 0 & 99946 & 369736 & 2083380 & 324667 & 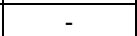 & 4938022 & - \\
\hline Subsidy. S $\left\{E^{*} m+A(m-c)+K-A P\right\} 05$ & 92995 & 244781 & 51837 & 384727 & 189356 & 199574 & 1571360 & 133221 & 449636 \\
\hline Subsidy. S $\left\{E^{*} m+A(m-c)+K-A P\right\} 06$ & 447370 & - & 519483 & 727363 & 2819729 & 662542 & - & -1409585 & - \\
\hline Ave. Loan port (net) LP, 2005 & 11779655 & 4826915 & 4106754 & 3210230 & 2478155 & 5604097 & 10616046 & 47812259 & 1812905 \\
\hline Ave. Loan port (net) LP, 2006 & 14509939 & - & 7692288 & 3343003 & 1653315 & 6823122 & - & 67321850 & - \\
\hline Rev. From lending (LP*i) , 2005 & 5377351 & 3740325 & 2084254 & 1816118 & 1053350 & 4216410 & 2068980 & 14014209 & 1433737 \\
\hline Rev. From lending (LP*i), 2006 & 6011296 & - & 2742221 & 1667902 & 937409 & 5263164 & 0 & 18976732 & 0 \\
\hline Yield on lending (i), 2005 & 0.456 & 0.775 & 0.508 & 0.566 & 0.425 & 0.752 & 0.195 & 0.293 & 0.791 \\
\hline Yield on lending (i), 2006 & 0.414 & - & 0.356 & 0.499 & 0.567 & 0.771 & - & 0.282 & - \\
\hline SDI (S/LP*i), 2005 & 0.017 & 0.065 & 0.025 & 0.212 & 0.180 & 0.047 & 0.759 & 0.010 & 0.314 \\
\hline SDI (S/LP*i), 2006 & 0.074 & - & 0.189 & 0.436 & 3.008 & 0.126 & - & -0.074 & - \\
\hline Change in Yield, 2005 & 0.008 & 0.051 & 0.013 & 0.120 & 0.076 & 0.036 & 0.148 & 0.003 & 0.248 \\
\hline Change in Yield, 2006 & 0.031 & - & 0.068 & 0.218 & 1.706 & 0.097 & - & -0.021 & - \\
\hline Nominal Subsidy free yield, 2005 & 0.464 & 0.826 & 0.520 & 0.686 & 0.501 & 0.788 & 0.343 & 0.296 & 1.039 \\
\hline Nominal Subsidy free yield, 2006 & 0.445 & - & 0.424 & 0.717 & 2.272 & 0.868 & - & 0.261 & - \\
\hline Inflation, 2005 & 0.086 & 0.086 & 0.082 & 0.082 & 0.082 & 0.082 & 0.082 & 0.082 & 0.155 \\
\hline Inflation, 2006 & 0.064 & 0.064 & 0.066 & 0.066 & 0.066 & 0.066 & 0.066 & 0.066 & 0.140 \\
\hline Real Subsidy-free yield, 2005 & 0.348 & 0.681 & 0.406 & 0.559 & 0.388 & 0.653 & 0.242 & 0.198 & 0.765 \\
\hline Real Subsidy- free yield, 2006 & 0.445 & - & 0.424 & 0.717 & 2.272 & 0.868 & - & 0.261 & - \\
\hline True Profit, 2005 & 438155 & 35246 & 196586 & 146291 & 24764 & 72153 & 809212 & 2898450 & 385105 \\
\hline True Profit, 2006 & 115117 & - & 270256 & 516791 & 2891996 & 266383 & - & 4938022 & - \\
\hline Return on Assets (ROA), 2005 & 0.039 & 0.030 & 0.036 & 0.034 & 0.004 & 0.024 & 0.006 & 0.026 & 0.039 \\
\hline Return on Assets (ROA), 2006 & 0.014 & - & 0.009 & 0.058 & 0.685 & 0.031 & - & 0.036 & - \\
\hline Subsidy-adjusted ROA, 2005 & 0.034 & 0.006 & 0.026 & 0.028 & 0.006 & 0.009 & 0.049 & 0.026 & 0.174 \\
\hline Subsidy-adjusted ROA, 2006 & 0.007 & - & 0.023 & 0.082 & 0.951 & 0.025 & - & 0.036 & - \\
\hline Return on Equity (ROE), 2005 & 0.141 & 0.103 & 0.214 & 0.145 & 0.019 & 0.139 & 0.025 & 0.188 & 0.448 \\
\hline Return on Equity (ROE), 2006 & 0.062 & - & 0.075 & 0.328 & 5.391 & 0.153 & - & 0.262 & - \\
\hline Subsidy-adjusted ROE, 2005 & 0.125 & 0.019 & 0.155 & 0.121 & 0.030 & 0.052 & 0.209 & 0.188 & 1.974 \\
\hline Subsidy-adjusted ROE, 2006 & 0.032 & - & 0.203 & 0.459 & 7.483 & 0.126 & - & 0.262 & - \\
\hline
\end{tabular}

\begin{tabular}{|c|c|c|c|c|c|c|c|c|c|}
\hline & \multicolumn{4}{|c|}{ MOZAMBIQUE } & \multicolumn{2}{|c|}{ NIGERIA } & \multirow{2}{*}{\begin{tabular}{|c|} 
S. AFRICA \\
SEFZAF \\
\end{tabular}} & \multicolumn{2}{|c|}{ ZAMBIA } \\
\hline MFIs & SOCREMO & FCC & TCHUMA & N BANCO & LAPO & SEAP & & CETZAM & FINCA \\
\hline Avg. Assets, 2005 & 6771644 & 1286543 & 3280577 & 10987764 & 4055066 & 341411 & 4524450 & 1708123 & 1243396 \\
\hline Avg. Assets, 2006 & 10763070 & 1271222 & 3304176 & 13715963 & 7515169 & 470914 & 5758416 & 1860369 & 2085092 \\
\hline Ave. Equity (E), 2005 & 2417384 & 753651 & 1926489 & 3339394 & 1881269 & 41181 & 2110209 & 1366870 & 663744 \\
\hline Ave. Equity (E),2006 & 3258026 & 782104 & 1840952 & 3304627 & 2712789 & 73594 & 2376422 & 1508049 & 1038728 \\
\hline Opp. Cost of society (m), 2005 & 0.195 & 0.195 & 0.195 & 0.195 & 0.179 & 0.179 & 0.106 & 0.282 & 0.282 \\
\hline Opp. Cost of society( m), 2006 & 0.186 & 0.186 & 0.186 & 0.186 & 0.169 & 0.169 & 0.112 & 0.232 & 0.232 \\
\hline Subsidy on Equity. $E^{*} m, 2005$ & 470665 & 146736 & 375087 & 650180 & 337650 & 7391 & 224210 & 385594 & 187242 \\
\hline Subsidy on Equity. E*m, 2006 & 604690 & 145158 & 341681 & 613339 & 458461 & 12437 & 265446 & 349113 & 240466 \\
\hline Ave. Public debt (A), 2005 & 2428257 & 11452 & 764234 & 2146025 & 968408 & 55665 & 2177943 & 0 & 0 \\
\hline Ave. Public debt (A),2006 & 4174558 & 34864 & 891158 & 2161488 & 2962696 & 54543 & 3076417 & 0 & 396489 \\
\hline Exp. Int. Public debt. $A^{*} c, 2005$ & 182396 & 144 & 124633 & 209564 & 5283 & 10798 & 230212 & 0 & 0 \\
\hline Exp. Int. Public debt. A*c, 2006 & 445157 & 16 & 150234 & 286348 & 215698 & 9330 & 243608 & 0 & 20257 \\
\hline Rate paid public debt (c), 2005 & 0.075 & 0.013 & 0.163 & 0.098 & 0.005 & 0.194 & 0.106 & - & - \\
\hline Rate paid public debt (c), 2006 & 0.107 & 0.000 & 0.169 & 0.132 & 0.073 & 0.171 & 0.079 & - & 0.051 \\
\hline Disc. Public debt. A*(m-c), 2005 & 620944 & 3644 & 128198 & 500406 & 168527 & -807 & 1194 & 0 & 0 \\
\hline Disc. Public debt. $A^{*}(\mathrm{~m}-\mathrm{c}), 2006$ & 329641 & 6455 & 15165 & 114824 & 284998 & -112 & 100028 & 0 & 71530 \\
\hline Rev. Grants (RG), 2005 & 0 & 302242 & 35077 & 0 & 467677 & 0 & 451191 & 680023 & 609104 \\
\hline Rev. Grants (RG), 2006 & 0 & 56441 & 15476 & 0 & 0 & 0 & 444401 & 396516 & 0 \\
\hline K (RG + DX), 2005 & 0 & 302242 & 35077 & 0 & 467677 & 0 & 451191 & 680023 & 609104 \\
\hline K (RG + DX), 2006 & 0 & 56441 & 15476 & 0 & 0 & 0 & 444401 & 396516 & 0 \\
\hline Accounting Profit (P), 2005 & 151520 & 415287 & 216587 & -265058 & 954951 & 32516 & 265320 & 0 & 292545 \\
\hline Accounting Profit (P), 2006 & 174596 & 113510 & 109441 & 1658267 & 915927 & 628007 & 345726 & 0 & 271904 \\
\hline Taxes, 2005 & 48487 & 0 & 10170 & 0 & 0 & 0 & 0 & 0 & 12109 \\
\hline Taxes, 2006 & 71507 & 0 & 21314 & 267295 & 0 & 0 & 0 & 0 & 403 \\
\hline Acc. profit less Taxes (AP), 2005 & 103034 & 415287 & 206417 & 265058 & 954951 & 32516 & - & 0 & 280436 \\
\hline
\end{tabular}




\begin{tabular}{|c|c|c|c|c|c|c|c|c|c|}
\hline Acc. profit less Taxes (AP), 2006 & 103090 & 113510 & 88127 & 1390972 & 915927 & 62801 & 345726 & 0 & 271501 \\
\hline Subsidy. $S\left\{E^{*} m+A(m-c)+K-A P\right\} 05$ & 988575 & 867909 & 331946 & 1415644 & 18903 & -25932 & 676595 & 1065617 & 515911 \\
\hline Subsidy. S $\left\{E^{*} m+A(m-c)+K-A P\right\} 06$ & 831241 & 94544 & 284195 & -662809 & -172468 & -50476 & 464149 & 745629 & 40495 \\
\hline Ave. Loan port (net) LP, 2005 & 4684205 & 576055 & 2552237 & 7668575 & 2580376 & 261063 & 3619405 & 621281 & 774655 \\
\hline Rev. From lending (LP*i) , 2005 & 2820434 & 591339 & 1301712 & 3748603 & 1501244 & 143437 & 2251886 & 454997 & 992188 \\
\hline Rev. From lending (LP*i), 2006 & 4292632 & 523057 & 1308881 & 6332662 & 2369948 & 165537 & 2867394 & 898047 & 1178354 \\
\hline Yield on lending (i), 2005 & 0.602 & 1.027 & 0.510 & 0.489 & 0.582 & 0.549 & 0.622 & 0.732 & 1.281 \\
\hline SDI (S/LP*i), 2005 & 0.351 & 1.468 & 0.255 & 0.378 & 0.013 & -0.181 & 0.300 & 2.342 & 0.520 \\
\hline SDI (S/LP*i), 2006 & 0.194 & 0.181 & 0.217 & -0.105 & -0.073 & -0.305 & 0.162 & 0.830 & 0.034 \\
\hline Change in Yield, 2005 & 0.211 & 1.507 & 0.130 & 0.185 & 0.007 & -0.099 & 0.187 & 1.715 & 0.666 \\
\hline Change in Yield, 2006 & 0.111 & 0.187 & 0.109 & 0.063 & -0.031 & -0.141 & 0.098 & 0.621 & 0.040 \\
\hline Nominal Subsidy free yield, 2005 & 0.813 & 2.533 & 0.640 & 0.673 & 0.589 & 0.450 & 0.809 & 2.448 & 1.947 \\
\hline Nominal Subsidy free yield, 2006 & 0.686 & 1.221 & 0.613 & 0.539 & 0.398 & 0.322 & 0.705 & 1.368 & 1.194 \\
\hline Inflation, 2005 & 0.072 & 0.072 & 0.072 & 0.072 & 0.135 & 0.135 & 0.034 & 0.183 & 0.183 \\
\hline Inflation, 2006 & 0.132 & 0.132 & 0.132 & 0.132 & 0.082 & 0.082 & 0.046 & 0.090 & 0.090 \\
\hline Real Subsidy- free yield, 2006 & 0.686 & 1.221 & 0.613 & 0.539 & 0.398 & 0.322 & 0.705 & 1.368 & 1.194 \\
\hline True Profit, 2005 & 517910 & 721173 & 43142 & -765464 & 318747 & 33323 & 452385 & 680023 & 328669 \\
\hline True Profit, 2006 & 226552 & 50614 & 57486 & 1276148 & 630930 & 62913 & 198702 & 396516 & 199971 \\
\hline Return on Assets (ROA), 2005 & 0.015 & 0.323 & 0.063 & -0.024 & 0.235 & 0.095 & 0.000 & 0.000 & 0.226 \\
\hline Return on Assets (ROA), 2006 & 0.010 & 0.089 & 0.027 & 0.101 & 0.122 & 1.33 & 0.060 & 0.000 & 0.130 \\
\hline Subsidy-adjusted ROA, 2005 & 0.076 & 0.561 & 0.013 & -0.070 & 0.079 & 0.098 & 0.100 & 0.398 & 0.264 \\
\hline Subsidy-adjusted ROA, 2006 & 0.021 & 0.040 & 0.017 & 0.093 & 0.084 & 1.33 & 0.035 & 0.213 & 0.096 \\
\hline Return on Equity (ROE), 2005 & 0.043 & 0.551 & 0.107 & -0.079 & 0.508 & 0.790 & 0.000 & 0.000 & 0.423 \\
\hline Return on Equity (ROE), 2006 & 0.032 & 0.145 & 0.048 & 0.421 & 0.338 & 0.853 & 0.145 & 0.000 & 0.261 \\
\hline Subsidy-adjusted ROE, 2005 & 0.214 & 0.957 & 0.022 & -0.229 & 0.169 & 0.809 & 0.214 & 0.498 & 0.495 \\
\hline Subsidy-adjusted ROE, 2006 & 0.070 & 0.065 & 0.031 & 0.386 & 0.233 & 0.853 & 0.084 & 0.263 & 0.193 \\
\hline
\end{tabular}

\begin{tabular}{|c|c|c|c|c|c|c|c|c|c|c|}
\hline & \multicolumn{10}{|c|}{ BOLIVIA } \\
\hline MFIs & PMujar & CRECER & PRODEM & FIE & Procredit & \begin{tabular}{|l|} 
FADES \\
\end{tabular} & AgroC & F’SOl & F Bodem & B SOL \\
\hline Avg. Assets, 2005 & 11606647 & 14553352 & 123018548 & 73804409 & 159346236 & 17543819 & 17989573 & 1770063 & 4195589 & 156655139 \\
\hline Avg. Assets, 2006 & 15398134 & 22423709 & 160035557 & 108322336 & 209338962 & 21863930 & 21363587 & 1961172 & 5178477 & 201233718 \\
\hline Ave. Equity (E), 2005 & 7540209 & 6216810 & 10339789 & 8728598 & 16555682 & 4819006 & 10152455 & 1402758 & 1728469 & 19307591 \\
\hline Ave. Equity (E),2006 & 8487753 & 7915212 & 13201077 & 11822853 & 20940749 & 5943657 & 10629008 & 1579107 & 1986147 & \\
\hline Opp. Cost of society (m), 2005 & 0.16615 & 0.16615 & 0.16615 & 0.16615 & 0.16615 & 0.16615 & 0.16615 & 0.16615 & 0.16615 & 0.16615 \\
\hline Opp. Cost of society( m), 2006 & 0.1189 & 0.1189 & 0.1189 & 0.1189 & 0.1189 & & & 0.1189 & & \\
\hline Subsidy on Equity. E*m, 2005 & 1252806 & 1032923 & 1717956 & 1450256 & 2750727 & 800678 & 1686830 & 233068 & & \\
\hline Subsidy on Equity. E*m, 2006 & 1009194 & 941119 & 1569608 & 1405737 & 2489855 & 706701 & 1263789 & 187756 & 236153 & \\
\hline Ave. Public debt (A), 2005 & 3667464 & 6978828 & 38088773 & 32078806 & 54020932 & 14438089 & 7149265 & 222563 & 619 & \\
\hline Ave. Public debt (A),2006 & 5891600 & 13026723 & 46791309 & 46257772 & 67730302 & 14974097 & 9865511 & - & 211 & \\
\hline Exp. Int. Public debt. A*c, 2005 & 139966 & 434788 & 2465199 & 1999797 & 2660359 & 779395 & 531298 & 16029 & & 134 \\
\hline \begin{tabular}{|l|} 
Exp. Int. Public debt. $A^{*} c, 2006$ \\
\end{tabular} & 346291 & 929275 & 3787972 & 3149827 & 4095446 & 918016 & 770847 & 0 & & 347 \\
\hline \begin{tabular}{|l|} 
Rate paid public debt (c), 2005 \\
\end{tabular} & & & & & & & & .072 & & \\
\hline Rate pa & & & & & & & & & & \\
\hline Disc. Pul & 83 & 44 & 51 & 3330097 & & 93 & & 20950 & & \\
\hline \begin{tabular}{|l|} 
Disc. Publ \\
\end{tabular} & & & 14 & 2350222 & 57687 & 05 & 162 & & 43232 & 44484 \\
\hline Rev. G & & & 0 & 0 & 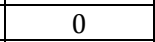 & & & 66588 & 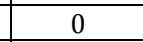 & \\
\hline Rev. $C$ & & & 0 & 0 & & & 0 & & & \\
\hline K (I & 24 & & 0 & 0 & 0 & 0 & 0 & 66588 & 0 & 0 \\
\hline $\mathrm{K}(\mathrm{R}$ & 474582 & & 0 & 0 & 0 & 0 & 0 & 0 & 0 & 0 \\
\hline Accounting Pro & 1048787 & 605463 & 2979799 & 2707268 & 1824985 & 367996 & 326433 & 217634 & 229855 & 5565039 \\
\hline Accounting Prof & 927856 & 1806482 & 3746 & 2698403 & 934 & 559463 & 644781 & 0 & 512 & 0168 \\
\hline Taxes, 2005 & 0 & 0 & & & & 0 & 0 & 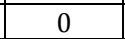 & 0 & \\
\hline & 0 & 0 & & & & 0 & 0 & 0 & 0 & \\
\hline Ac & 48787 & 05463 & & & & 7996 & 26433 & 17634 & 9855 & \\
\hline Acc & & & & & & & & & & \\
\hline $\begin{array}{c}\text { Subsidy. } S\left\{E^{*} m+A(m-c)+K-A P\right\} \\
05\end{array}$ & 1196426 & 220025 & 3276408 & 2815302 & 7624994 & 2052175 & 2016950 & \begin{tabular}{|l|}
102972 \\
\end{tabular} & 354083 & 87 \\
\hline $\begin{array}{c}\text { Subsidy. } S\left\{E^{*} m+A(m-c)+K-\right. \\
\text { AP\}06 }\end{array}$ & 40 & 1 & 338029 & 53408 & 34 & 1009 & 70 & - & 2 & 22602 \\
\hline Ave. Loan port (net) LP, 2005 & & 85 & & & & 95 & 106 & 864 & & \\
\hline & 11913956 & 19166740 & 120 & 242 & 57267 & \begin{tabular}{l|l}
18764309 \\
\end{tabular} & 16154465 & 701469 & 43 & \\
\hline Rev. Fro & 545 & 5640463 & 20741501 & 12875728 & 24441057 & 3750150 & 3275659 & 286620 & 849139 & \\
\hline Rev. Frc & 3772437 & 6455583 & 26650215 & 17638841 & 487 & 4048587 & 3843060 & 0 & 1088035 & 954 \\
\hline Yield on 1 & & & & & & & 0.237 & 0.228 & 231 & 220 \\
\hline Yield & & & & & & & 38 & 0.000 & 33 & 217 \\
\hline SDI (S/LF & & 39 & & 0.219 & 0.312 & 0.547 & 0.616 & 0.359 & 0.417 & 0.114 \\
\hline SDI (S/LP*i), 2006 & & -0.028 & & 0.099 & 0.124 & 0.249 & 0.266 & - & 0.173 & 0.001 \\
\hline Change in Yield, 2005 & 0.136 & & 0.034 & 0.046 & 0.060 & 0.119 & 0.146 & 0.082 & 0.096 & 0.025 \\
\hline Change in Yield, 2006 & 0.081 & -0.013 & 0.003 & 0.021 & 0.024 & 0.054 & 0.063 & & 0.040 & 0.000 \\
\hline
\end{tabular}




\begin{tabular}{|c|c|c|c|c|c|c|c|c|c|c|}
\hline $\begin{array}{l}\text { Nominal Subsidy free yield, } \\
2005\end{array}$ & 0.470 & 0.488 & 0.251 & 0.255 & 0.253 & 0.338 & 0.384 & 0.310 & 0.327 & 0.245 \\
\hline $\begin{array}{l}\text { Nominal Subsidy free yield, } \\
2006\end{array}$ & 0.397 & 0.324 & 0.224 & 0.229 & 0.212 & 0.270 & 0.301 & - & 0.273 & 0.217 \\
\hline Inflation, 2005 & 0.054 & 0.054 & 0.054 & 0.054 & 0.054 & 0.054 & 0.054 & 0.054 & 0.054 & 0.054 \\
\hline Inflation, 2006 & 0.043 & 0.043 & 0.043 & 0.043 & 0.043 & 0.043 & 0.043 & 0.043 & 0.043 & 0.043 \\
\hline Real Subsidy- free yield, 2005 & 0.394 & 0.411 & 0.187 & 0.191 & 0.189 & 0.269 & 0.313 & 0.243 & 0.259 & 0.181 \\
\hline Real Subsidy- free yield, 2006 & 0.340 & 0.269 & 0.174 & 0.179 & 0.162 & 0.218 & 0.248 & - & 0.220 & 0.167 \\
\hline True Profit, 2005 & 56380 & 812898 & -1558452 & -1365045 & -4874267 & -1251497 & -330120 & 130096 & -66898 & 308669 \\
\hline True Profit, 2006 & 99053 & 1123450 & 1231579 & -347671 & -1378479 & -302942 & 242619 & - & 48281 & 2397479 \\
\hline Return on Assets (ROA), 2005 & 0.090 & 0.110 & 0.019 & 0.027 & 0.009 & 0.021 & 0.018 & 0.123 & 0.055 & 0.028 \\
\hline Return on Assets (ROA), 2006 & 0.060 & 0.081 & 0.019 & 0.018 & 0.012 & 0.026 & 0.030 & 0.000 & 0.056 & 0.023 \\
\hline Subsidy-adjusted ROA, 2005 & 0.005 & 0.056 & -0.013 & -0.018 & -0.031 & -0.071 & -0.018 & 0.073 & -0.016 & 0.002 \\
\hline Subsidy-adjusted ROA, 2006 & 0.006 & 0.050 & 0.008 & -0.003 & -0.007 & -0.014 & 0.011 & - & 0.009 & 0.012 \\
\hline Return on Equity (ROE), 2005 & 0.139 & 0.258 & 0.223 & 0.225 & 0.087 & 0.076 & 0.032 & 0.155 & 0.133 & 0.224 \\
\hline Return on Equity (ROE), 2006 & 0.109 & 0.228 & 0.228 & 0.169 & 0.123 & 0.094 & 0.061 & 0.000 & 0.147 & 0.228 \\
\hline Subsidy-adjusted ROE, 2005 & 0.007 & 0.131 & -0.151 & -0.156 & -0.294 & -0.260 & -0.033 & 0.093 & -0.039 & 0.016 \\
\hline Subsidy-adjusted ROE, 2006 & 0.012 & 0.142 & 0.093 & -0.029 & -0.066 & -0.051 & 0.023 & - & 0.024 & 0.118 \\
\hline
\end{tabular}

\begin{tabular}{|c|c|c|c|c|c|c|c|c|c|c|}
\hline & BOLIVIA & \multicolumn{2}{|c|}{ EL SALVADOR } & HAITI & \multicolumn{3}{|c|}{ HONDOROS } & $\mathbf{T} \& \mathbf{T}$ & VENZ & PERU \\
\hline MFIs & E Futuro & Fund C & AMC RL & ACME & HDH & W. Rel & FINCA & MCHL & BanGente & Ed. C T \\
\hline Avg. Assets, 2005 & 20009819 & 2345214 & 7509094 & 4114458 & 5069360 & 6497866 & 4375596 & 3741015 & 23439645 & 8618713 \\
\hline Avg. Assets, 2006 & 26684967 & 2964846 & 10374065 & 5401569 & 5565637 & 8625197 & 4875627 & - & 38224530 & 11797308 \\
\hline Ave. Equity (E), 2005 & 2142293 & 2129182 & 1737848 & 2240257 & 2582377 & 4653272 & 1898301 & 1147138 & 3917214 & 1925885 \\
\hline Ave. Equity (E),2006 & 2918306 & 2253529 & 2345475 & 2624782 & 1928874 & 5403175 & 1955507 & - & 4561688 & 2473121 \\
\hline Opp. Cost of society (m), 2005 & 0.16615 & 0.1 & 0.1 & 0.27375 & 0.18831 & 0.18831 & 0.18831 & 0.09104 & 0.16809 & 0.2553 \\
\hline Opp. Cost of society( m), 2006 & 0.1189 & 0.1 & 0.1 & 0.2824 & 0.1744 & 0.1744 & 0.1744 & 0.1092 & 0.1548 & 0.2393 \\
\hline Subsidy on Equity. E*m, 2005 & 355942 & 212918 & 173785 & 613270 & 486287 & 876258 & 357469 & 104435 & 658444 & 491678 \\
\hline Subsidy on Equity. E*m, 2006 & 346987 & 225353 & 234547 & 741238 & 336396 & 942314 & 341040 & - & 706149 & 591818 \\
\hline Ave. Public debt (A), 2005 & 2689163 & 168381 & 5616304 & 1696719 & 1804109 & 1025071 & 875046 & 2077291 & 11185390 & 6415240 \\
\hline Ave. Public debt (A),2006 & 4051673 & 646527 & 7800594 & 2540108 & 2541671 & 2753139 & 1476448 & - & 13119726 & 9096688 \\
\hline Exp. Int. Public debt. $A^{*} c, 2005$ & 106622 & 3975 & 407202 & 343433 & 318295 & 170707 & 177600 & 100789 & 454065 & 537045 \\
\hline Exp. Int. Public debt. $A^{*} c, 2006$ & 265311 & 22469 & 619080 & 388473 & 263439 & 335510 & 267458 & - & 413570 & 985772 \\
\hline Rate paid public debt (c), 2005 & 0.040 & 0.024 & 0.073 & 0.202 & 0.176 & 0.167 & 0.203 & 0.049 & 0.041 & 0.084 \\
\hline Rate paid public debt (c), 2006 & 0.065 & 0.035 & 0.079 & 0.153 & 0.104 & 0.122 & 0.181 & - & 0.032 & 0.108 \\
\hline Disc. Public debt. $A^{*}(\mathrm{~m}-\mathrm{c}), 2005$ & 340182 & 12863 & 154428 & 121044 & 21437 & 22324 & -12820 & 88327 & 1426087 & 423124 \\
\hline Disc. Public debt. A*(m-c), 2006 & 216433 & 42184 & 160979 & 328854 & 179829 & 144638 & -9966 & - & 1617364 & 1191065 \\
\hline Rev. Grants (RG), 2005 & 0 & 0 & 122792 & 76464 & 181835 & 0 & 26461 & 140558 & 0 & 0 \\
\hline Rev. Grants (RG), 2006 & 0 & 0 & 76195 & 97351 & 22953 & 0 & 4161 & - & 0 & 0 \\
\hline K (RG + DX), 2005 & 0 & 0 & 122792 & 76464 & 181835 & 0 & 26461 & 140558 & 0 & 0 \\
\hline K (RG + DX), 2006 & 0 & 0 & 76195 & 97351 & 22953 & 0 & 4161 & - & 0 & 0 \\
\hline Accounting Profit (P), 2005 & 255209 & 137988 & 281891 & 484766 & 368341 & 628739 & 44026 & -1832 & 471111 & 688283 \\
\hline Accounting Profit (P), 2006 & 497756 & 78844 & 434733 & 537398 & -249009 & 791781 & 97283 & - & 1001864 & 816317 \\
\hline Taxes, 2005 & 0 & 0 & 67234 & 0 & 0 & 0 & 0 & 1574 & 296963 & 258964 \\
\hline Taxes, 2006 & 0 & 0 & 150289 & 0 & 0 & 0 & 0 & - & 357193 & 308243 \\
\hline Acc. profit less Taxes (AP), 2005 & 255209 & 137988 & 214657 & 484766 & 368341 & 628739 & 44026 & -3407 & 174148 & 429319 \\
\hline Acc. profit less Taxes (AP), 2006 & 497756 & 78844 & 284444 & 537398 & -249009 & 791781 & 97283 & - & 644672 & 508074 \\
\hline Subsidy. S $\left\{E^{*} m+A(m-c)+K-A P\right\} 05$ & 440915 & 87793 & 236348 & 326011 & 321218 & 269843 & 327084 & 336727 & 1910384 & 485484 \\
\hline Subsidy. S $\left\{E^{*} m+A(m-c)+K-A P\right\} 06$ & 65663 & 188693 & 187278 & 630046 & 788186 & 295170 & 237953 & - & 1678841 & 1274809 \\
\hline Ave. Loan port (net) LP, 2005 & 15879357 & 2021982 & 5643823 & 3209982 & 3940481 & 4551670 & 3238388 & 2455679 & 18928445 & 7319741 \\
\hline Ave. Loan port (net) LP, 2006 & 20802681 & 2388280 & 7939094 & 3930724 & 4357245 & 6607984 & 3831948 & - & 31892177 & 10529860 \\
\hline Rev. From lending (LP*i) , 2005 & 3713252 & 361380 & 1433961 & 1731873 & 1333092 & 2208761 & 1682856 & 686508 & 2874027 & 2474183 \\
\hline Rev. From lending (LP*i), 2006 & 4808242 & 401948 & 2006439 & 2410319 & 885990 & 2985184 & 1906797 & - & 4774433 & 3442837 \\
\hline Yield on lending (i), 2005 & 0.234 & 0.179 & 0.254 & 0.540 & 0.338 & 0.485 & 0.520 & 0.280 & 0.152 & 0.338 \\
\hline Yield on lending (i), 2006 & 0.231 & 0.168 & 0.253 & 0.613 & 0.203 & 0.452 & 0.498 & - & 0.150 & 0.327 \\
\hline SDI (S/LP*i), 2005 & 0.119 & 0.243 & 0.165 & 0.188 & 0.241 & 0.122 & 0.194 & 0.490 & 0.665 & 0.196 \\
\hline SDI (S/LP*i), 2006 & 0.014 & 0.469 & 0.093 & 0.261 & 0.890 & 0.099 & 0.125 & - & 0.352 & 0.370 \\
\hline Change in Yield, 2005 & 0.028 & 0.043 & 0.042 & 0.102 & 0.082 & 0.059 & 0.101 & 0.137 & 0.101 & 0.066 \\
\hline Change in Yield, 2006 & 0.003 & 0.084 & 0.024 & 0.141 & 0.301 & 0.048 & 0.065 & - & 0.053 & 0.125 \\
\hline Nominal Subsidy free yield, 2005 & 0.262 & 0.222 & 0.296 & 0.641 & 0.420 & 0.545 & 0.621 & 0.417 & 0.253 & 0.404 \\
\hline Nominal Subsidy free yield, 2006 & 0.234 & 0.252 & 0.276 & 0.754 & 0.504 & 0.500 & 0.562 & - & 0.203 & 0.452 \\
\hline Inflation, 2005 & 0.054 & 0.047 & 0.047 & 0.157 & 0.088 & 0.088 & 0.088 & 0.069 & 0.160 & 0.016 \\
\hline Inflation, 2006 & 0.043 & 0.040 & 0.040 & 0.131 & 0.056 & 0.056 & 0.056 & 0.083 & 0.137 & 0.020 \\
\hline Real Subsidy- free yield, 2005 & 0.197 & 0.167 & 0.238 & 0.418 & 0.305 & 0.419 & 0.489 & 0.325 & 0.080 & 0.382 \\
\hline Real Subsidy- free yield, 2006 & 0.184 & 0.204 & 0.227 & 0.552 & 0.425 & 0.421 & 0.480 & - & 0.059 & 0.424 \\
\hline True Profit, 2005 & -84973 & 125125 & -62563 & 287259 & 165069 & 606415 & 30385 & -232292 & -1251939 & 6195 \\
\hline True Profit, 2006 & 281323 & 36660 & 47270 & 111193 & -451791 & 647143 & 103088 & - & -972692 & -682991 \\
\hline Return on Assets (ROA), 2005 & 0.013 & 0.059 & 0.029 & 0.118 & 0.073 & 0.097 & 0.010 & -0.001 & 0.007 & 0.050 \\
\hline Return on Assets (ROA), 2006 & 0.019 & 0.027 & 0.027 & 0.099 & -0.045 & 0.092 & 0.020 & - & 0.017 & 0.043 \\
\hline Subsidy-adjusted ROA, 2005 & -0.004 & 0.053 & -0.008 & 0.070 & 0.033 & 0.093 & 0.007 & -0.062 & -0.053 & 0.001 \\
\hline Subsidy-adjusted ROA, 2006 & 0.011 & 0.012 & 0.005 & 0.021 & -0.081 & 0.075 & 0.021 & - & -0.025 & -0.058 \\
\hline Return on Equity (ROE), 2005 & 0.119 & 0.065 & 0.124 & 0.216 & 0.143 & 0.135 & 0.023 & -0.003 & 0.044 & 0.223 \\
\hline
\end{tabular}




\begin{tabular}{|c|c|c|c|c|c|c|c|c|c|c|}
\hline Return on Equity (ROE), 2006 & 0.171 & 0.035 & 0.121 & 0.205 & -0.129 & 0.147 & 0.050 & - & 0.141 & 0.205 \\
\hline Subsidy-adjusted ROE, 2005 & -0.040 & 0.059 & -0.036 & 0.128 & 0.064 & 0.130 & 0.016 & -0.202 & -0.320 & 0.003 \\
\hline Subsidy-adjusted ROE, 2006 & 0.096 & 0.016 & 0.020 & 0.042 & -0.234 & 0.120 & 0.053 & - & -0.213 & -0.276 \\
\hline
\end{tabular}

\begin{tabular}{|c|c|c|c|c|c|c|c|c|c|c|}
\hline & \multicolumn{10}{|c|}{ PERU } \\
\hline MFIs & MiBanco & Bantra & C Maynas & Edpy. Cofi & IDESI LL & Fondsurco & ED.Edyf & Caritas & C Cusco & C Tacna \\
\hline Avg. Assets, 2005 & 204431029 & 346163953 & 29289123 & 22760767 & 929386 & 1625918 & 58622651 & 7590386 & 86185265 & 51687146 \\
\hline Avg. Assets, 2006 & 319464851 & 393993555 & 38612177 & 40882214 & & 2005581 & 81254531 & 9794496 & 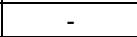 & 62902239 \\
\hline Ave. Equity (E), 2005 & 40083604 & 37406584 & 4369272 & 3973619 & 257697 & 872633 & 9691252 & 1473316 & 15125770 & 8188704 \\
\hline Ave. Equity (E),2006 & 47601847 & 37809129 & 5924799 & 6274155 & - & 1017571 & 13755347 & 3617355 & - & 10397595 \\
\hline Opp. Cost of society (m), 2005 & 0.2553 & 0.2553 & 0.2553 & 0.2553 & 0.2553 & 0.2553 & 0.2553 & 0.2553 & 0.2553 & 0.2553 \\
\hline Opp. Cost of society ( m), 2006 & 0.2393 & 0.2393 & 0.2393 & 0.2393 & 0.2393 & 0.2393 & 0.2393 & 0.2393 & 0.2393 & 0.2393 \\
\hline Subsidy on Equity. $E^{*} m, 2005$ & 10233344 & 9549901 & 1115475 & 1014465 & 65790 & 222783 & 2474177 & 376138 & 3861609 & 2090576 \\
\hline Subsidy on Equity. E*m, 2006 & 11391122 & 9047724 & 1417804 & 1501405 & - & 243505 & 3291654 & 865633 & - & 2488145 \\
\hline Ave. Public debt (A), 2005 & 35134814 & 68504345 & 6494638 & 18303772 & 607490 & 729357 & 47290572 & 5937059 & 6936907 & 8789669 \\
\hline Ave. Public debt (A),2006 & 84054666 & 84110962 & 7465602 & 34133630 & & 902040 & 65302396 & 5956712 & - & 10381654 \\
\hline Exp. Int. Public debt. A*c, 2005 & 2577823 & 3727033 & 242084 & 1328552 & 59091 & 48297 & 3016091 & 5807 & 237566 & 576068 \\
\hline Exp. Int. Public debt. A*c, 2006 & 6553258 & 6187030 & 410664 & 3061404 & 0 & 75623 & 4619987 & 36898 & 0 & 758772 \\
\hline Rate paid public debt (c), 2005 & 0.073 & 0.054 & 0.037 & 0.073 & 0.097 & 0.066 & 0.064 & 0.001 & 0.034 & 0.066 \\
\hline Rate paid public debt (c), 2006 & 0.078 & 0.074 & 0.055 & 0.090 & - & 0.084 & 0.071 & 0.006 & - & 0.073 \\
\hline Disc. Public debt. A*(m-c), 2005 & 2680804 & 6526012 & 729968 & 1410973 & 31832 & 60866 & 4061889 & 882792 & 800681 & 739482 \\
\hline Disc. Public debt. A*(m-c), 2006 & 13561023 & 13940723 & 1375855 & 5106774 & - & 140235 & 11006876 & 1388544 & - & 1725558 \\
\hline Rev. Grants (RG), 2005 & 0 & 0 & 0 & 0 & 0 & 0 & 0 & 452939 & 0 & 0 \\
\hline Rev. Grants (RG), 2006 & 0 & 0 & 0 & 0 & - & 20148 & 0 & 208808 & - & 0 \\
\hline K (RG + DX), 2005 & 0 & 0 & 0 & 0 & 0 & 0 & 0 & 452939 & 0 & 0 \\
\hline K (RG + DX), 2006 & 0 & 0 & 0 & 0 & 0 & 20148 & 0 & 208808 & - & 0 \\
\hline Accounting Profit (P), 2005 & 18594207 & 15498245 & 1994258 & 1431239 & 88640 & 180913 & 4198069 & 342044 & 9246343 & 3533938 \\
\hline Accounting Profit (P), 2006 & 22213033 & 3965852 & 3042228 & 1237155 & - & 130558 & 6144424 & 966711 & - & 4008772 \\
\hline Taxes, 2005 & 349035 & 5254827 & 711733 & 540080 & 0 & 0 & 1515506 & 0 & 3239321 & 1243125 \\
\hline Taxes, 2006 & 526003 & 684211 & 938177 & 499373 & - & 0 & 2239035 & 0 & - & 1419173 \\
\hline Acc. profit less Taxes (AP), 2005 & 18245173 & 10243417 & 1282525 & 891159 & 88640 & 180913 & 2682563 & 342044 & 6007022 & 2290813 \\
\hline Acc. profit less Taxes (AP), 2006 & 21687030 & 3281642 & 2104051 & 737782 & - & 130558 & 3905388 & 966711 & - & 2589599 \\
\hline Subsidy. S $\left\{E^{*} m+A(m-c)+K-A P\right\} 05$ & -533 & 583 & 562919 & 1534279 & 8982 & 102736 & 3853502 & 1369824 & -1344732 & 539245 \\
\hline Subsidy. S $\left\{E^{*} m+A(m-c)+K-A P\right\} 06$ & 3265115 & 19706806 & 689608 & 5870398 & - & 273329 & 10393142 & 1496274 & - & 1624103 \\
\hline Ave. Loan port (net) LP, 2005 & 164376185 & 287147011 & 21167839 & 17649764 & 666538 & 1434591 & 46793425 & 5227103 & 62454947 & 36461947 \\
\hline Ave. Loan port (net) LP, 2006 & 259697139 & 317183786 & 28741908 & 29589402 & 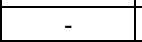 & 1835010 & 65376626 & 8521272 & - & 47281821 \\
\hline Rev. From lending $(L P * i), 2005$ & 59759801 & 109366881 & 7149420 & 5974194 & 397854 & 387931 & 16688707 & 2120102 & 16228496 & 9565535 \\
\hline Rev. From lending (LP*i), 2006 & 95339599 & 124394110 & 9766221 & 9288847 & 0 & 526317 & 23802005 & 3413508 & - & 11703321 \\
\hline Yield on lending (i), 2005 & 0.364 & 0.381 & 0.338 & 0.338 & 0.597 & 0.270 & 0.357 & 0.406 & 0.260 & 0.262 \\
\hline Yield on lending (i), 2006 & 0.367 & 0.392 & 0.340 & 0.314 & - & 0.287 & 0.364 & 0.401 & - & 0.248 \\
\hline SDI (S/LP*i), 2005 & -0.089 & 0.053 & 0.079 & 0.257 & 0.023 & 0.265 & 0.231 & 0.646 & -0.083 & 0.056 \\
\hline SDI (S/LP*i), 2006 & 0.034 & 0.158 & 0.071 & 0.632 & - & 0.519 & 0.437 & 0.438 & - & 0.139 \\
\hline Change in Yield, 2005 & -0.032 & 0.020 & 0.027 & 0.087 & 0.013 & 0.072 & 0.082 & 0.262 & -0.022 & 0.015 \\
\hline Change in Yield, 2006 & 0.012 & 0.060 & 0.024 & 0.214 & - & 0.140 & 0.156 & 0.178 & - & 0.036 \\
\hline Nominal Subsidy free yield, 2005 & 0.331 & 0.401 & 0.364 & 0.425 & 0.610 & 0.342 & 0.439 & 0.668 & 0.238 & 0.277 \\
\hline Nominal Subsidy free yield, 2006 & 0.380 & 0.453 & 0.364 & 0.528 & - & 0.427 & 0.520 & 0.578 & - & 0.284 \\
\hline Inflation, 2005 & 0.016 & 0.016 & 0.016 & 0.016 & 0.016 & 0.016 & 0.016 & 0.016 & 0.016 & 0.016 \\
\hline Inflation, 2006 & 0.020 & 0.020 & 0.020 & 0.020 & 0.020 & 0.020 & 0.020 & 0.020 & 0.020 & 0.020 \\
\hline Real Subsidy-free yield, 2005 & 0.310 & 0.379 & 0.343 & 0.403 & 0.585 & 0.321 & 0.416 & 0.641 & 0.219 & 0.257 \\
\hline Real Subsidy- free yield, 2006 & 0.352 & 0.424 & 0.337 & 0.498 & - & 0.399 & 0.490 & 0.547 & - & 0.259 \\
\hline True Profit, 2005 & 15564368 & 3717405 & 552556 & -519814 & 56808 & 120047 & -1379326 & -993687 & 5206341 & 1551331 \\
\hline True Profit, 2006 & 8126007 & -10659081 & 728196 & -4368992 & - & -29825 & -7101487 & -630641 & - & 864041 \\
\hline Return on Assets (ROA), 2005 & 0.089 & 0.030 & 0.044 & 0.039 & 0.095 & 0.111 & 0.046 & 0.045 & 0.070 & 0.044 \\
\hline Return on Assets (ROA), 2006 & 0.068 & 0.008 & 0.054 & 0.018 & - & 0.065 & 0.048 & 0.099 & 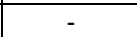 & 0.041 \\
\hline Subsidy-adjusted ROA, 2005 & 0.076 & 0.011 & 0.019 & -0.023 & 0.061 & 0.074 & -0.024 & -0.131 & 0.060 & 0.030 \\
\hline Subsidy-adjusted ROA, 2006 & 0.025 & -0.027 & 0.019 & -0.107 & - & -0.015 & -0.087 & -0.064 & - & 0.014 \\
\hline Return on Equity (ROE), 2005 & 0.455 & 0.274 & 0.294 & 0.224 & 0.344 & 0.207 & 0.277 & 0.232 & 0.397 & 0.280 \\
\hline Return on Equity (ROE), 2006 & 0.456 & 0.087 & 0.355 & 0.118 & - & 0.128 & 0.284 & 0.267 & - & 0.249 \\
\hline d ROE, 2005 & & & 0.126 & -0.131 & 0.220 & & -0.142 & -0.674 & 0.344 & 0.189 \\
\hline Subsidy-adjusted ROE, 2006 & 0.171 & -0.282 & 0.123 & -0.696 & - & -0.029 & -0.516 & -0.174 & - & 0.083 \\
\hline
\end{tabular}

\begin{tabular}{|c|c|c|c|c|c|c|c|c|c|c|}
\hline \multirow[b]{2}{*}{ MFIs } & \multicolumn{6}{|c|}{ PERU } & \multicolumn{2}{|c|}{ PARAGAUY } & \multicolumn{2}{|c|}{ NICARAGUA } \\
\hline & Caja Nor & FINCA & Mov.M R & Promujer & C Arq & C Truj & Interfisa & FIELCO & FNUSE & Prodesa \\
\hline Avg. Assets, 2006 & 46622565 & 1876943 & 2259531 & 5128152 & 198356663 & 200966625 & 32867527 & 23964517 & - & 14324336 \\
\hline Ave. Equity (E),2006 & 5995212 & 1732196 & 1257503 & 2908242 & 37577942 & 30107446 & 3680611 & 4691881 & - & 5549440 \\
\hline Opp. Cost of society (m), 2005 & 0.2553 & 0.2553 & 0.2553 & 0.2553 & 0.2553 & 0.2553 & 0.2991 & 0.2991 & 0.12101 & 0.12101 \\
\hline Opp. Cost of society( m), 2006 & 0.2393 & 0.2393 & 0.2393 & 0.2393 & 0.2393 & 0.2393 & 0.3014 & 0.3014 & 0.1158 & 0.1158 \\
\hline Subsidy on Equity. E*m, 2005 & 1183842 & 387207 & 112586 & 544836 & 7508628 & 5830216 & 798833 & 1025685 & 362829 & 427366 \\
\hline
\end{tabular}




\begin{tabular}{|c|c|c|c|c|c|c|c|c|c|c|}
\hline Subsidy on Equity. E*m, 2006 & 1434654 & 414515 & 300921 & 695942 & 8992402 & 7204712 & 1109336 & 1414133 & 0 & 642625 \\
\hline Exp. Int. Public debt. $A^{*} c, 2005$ & 208894 & 5386 & 3359 & 60556 & 310708 & 1779307 & 16473 & 39887 & 351311 & 444939 \\
\hline Exp. Int. Public debt. A*c, 2006 & 351817 & 9322 & 17282 & 158988 & 720238 & 4122183 & 96253 & 126671 & - & 616791 \\
\hline Rate paid public debt (c), 2006 & 0.073 & 0.081 & 0.067 & 0.082 & 0.169 & 0.140 & 0.109 & 0.055 & - & 0.074 \\
\hline Disc. Public debt. $A^{*}(\mathrm{~m}-\mathrm{c}), 2005$ & 442937 & 4100 & 36437 & 145294 & 316584 & 2686244 & 189120 & 262449 & 103314 & 338634 \\
\hline Disc. Public debt. A*(m-c), 2006 & 804119 & 18336 & 44833 & 305329 & 296606 & 2909767 & 169058 & 563845 & - & 348951 \\
\hline K (RG + DX), 2005 & 0 & 0 & 0 & 208379 & 0 & 0 & 0 & 0 & 0 & 0 \\
\hline K (RG + DX), 2006 & 0 & 0 & 0 & 111956 & 0 & 0 & 0 & 0 & - & 0 \\
\hline Accounting Profit (P), 2005 & 2271796 & 216174 & 62099 & 593787 & 16136630 & 11607436 & 306518 & 1286405 & 1085257 & 1040759 \\
\hline Accounting Profit (P), 2006 & 2297306 & 124415 & 137345 & 805740 & 19849937 & 14392455 & 1419505 & 1694976 & - & 1546052 \\
\hline Taxes, 2005 & 873318 & 0 & 0 & 0 & 5202458 & 4142735 & 43763 & 173803 & 0 & 0 \\
\hline Taxes, 2006 & 935150 & 0 & 0 & 0 & 7078634 & 5102197 & 157478 & 245597 & - & 0 \\
\hline Acc. profit less Taxes (AP), 2005 & 1398479 & 216174 & 62099 & 593787 & 10934172 & 7464701 & 262756 & 1112602 & 1085257 & 1040759 \\
\hline Ave. Loan port (net) LP, 2006 & 32833826 & 1270229 & 1895147 & 4380810 & 152506631 & 96497005 & 23367411 & 16987232 & - & 12822532 \\
\hline Rev. From lending (LP*i) , 2005 & 7564365 & 649169 & 756547 & 1187808 & 36710357 & 31256419 & 5648775 & 3520054 & 1282311 & 973120 \\
\hline Rev. From lending (LP*i), 2006 & 10057957 & 810400 & 937616 & 1834223 & 47242794 & 44046154 & 7897081 & 5763957 & - & 1777546 \\
\hline Yield on lending (i), 2005 & 0.307 & 0.629 & 0.442 & 0.399 & 0.305 & 0.269 & 0.290 & 0.306 & 0.206 & 0.103 \\
\hline Yield on lending (i), 2006 & 0.306 & 0.638 & 0.495 & 0.419 & 0.310 & 0.456 & 0.338 & 0.339 & - & 0.139 \\
\hline SDI (S/LP*i), 2005 & 0.030 & 0.270 & 0.115 & 0.257 & -0.085 & 0.034 & 0.128 & 0.050 & -0.483 & -0.282 \\
\hline SDI (S/LP*i), 2006 & 0.087 & 0.381 & 0.222 & 0.168 & -0.074 & 0.019 & 0.002 & 0.092 & - & -0.312 \\
\hline Change in Yield, 2005 & 0.009 & 0.170 & 0.051 & 0.102 & -0.026 & 0.009 & 0.037 & 0.015 & -0.099 & -0.029 \\
\hline Change in Yield, 2006 & 0.027 & 0.239 & 0.098 & 0.067 & -0.022 & 0.005 & 0.001 & 0.028 & - & -0.032 \\
\hline Nominal Subsidy free yield, 2005 & 0.316 & 0.798 & 0.493 & 0.501 & 0.279 & 0.278 & 0.327 & 0.322 & 0.106 & 0.074 \\
\hline Nominal Subsidy free yield, 2006 & 0.333 & 0.877 & 0.593 & 0.486 & 0.287 & 0.461 & 0.339 & 0.367 & - & 0.107 \\
\hline Inflation, 2005 & 0.016 & 0.016 & 0.016 & 0.016 & 0.016 & 0.016 & 0.068 & 0.068 & 0.096 & 0.096 \\
\hline Inflation, 2006 & 0.020 & 0.020 & 0.020 & 0.020 & 0.020 & 0.020 & 0.096 & 0.096 & 0.091 & 0.091 \\
\hline Return on Equity (ROE), 2006 & 0.227 & 0.072 & 0.109 & 0.277 & 0.340 & 0.309 & 0.343 & 0.309 & - & 0.279 \\
\hline Subsidy-adjusted ROE, 2005 & 0.206 & 0.140 & 0.058 & 0.113 & 0.361 & 0.209 & 0.028 & 0.248 & 0.327 & 0.199 \\
\hline Subsidy-adjusted ROE, 2006 & 0.093 & 0.061 & 0.074 & 0.134 & 0.332 & 0.212 & 0.297 & 0.189 & - & 0.216 \\
\hline
\end{tabular}

\begin{tabular}{|c|c|c|c|c|c|c|c|c|c|c|}
\hline \multirow[b]{2}{*}{ MFIs } & \multicolumn{6}{|c|}{ NICRAGUA } & \multicolumn{4}{|c|}{ GAUTEMALA } \\
\hline & FAMA & ACODEP & FJN & BANEX & FDL & ProCredit & Fafidess & Fundea & Gen Em & Fund $M$ \\
\hline Avg. Assets, 2005 & 21528055 & 16071309 & 15515604 & 61571226 & 33313561 & 66964869 & 4005974 & 7481605 & 31438580 & 1188871 \\
\hline Avg. Assets, 2006 & - & 26617653 & - & 96391196 & 48716064 & 96963820 & - & 9079499 & 39481428 & 1437154 \\
\hline Ave. Equity (E), 2005 & 8481120 & 4037574 & 3793335 & 6770607 & 6501037 & 10419893 & 2694242 & 6387717 & 6528873 & 617873 \\
\hline Ave. Equity (E),2006 & - & 6221517 & - & 10536484 & 8701131 & 13524628 & - & 7165802 & 7070748 & 704527 \\
\hline Opp. Cost of society (m), 2005 & 0.12101 & 0.12101 & 0.12101 & 0.12101 & 0.12101 & 0.12101 & 0.13033 & 0.13033 & 0.13033 & 0.13033 \\
\hline Opp. Cost of society( m), 2006 & 0.1158 & 0.1158 & 0.1158 & 0.1158 & 0.1158 & 0.1158 & 0.1276 & 0.1276 & 0.1276 & 0.1276 \\
\hline Subsidy on Equity. E*m, 2005 & 1026300 & 488587 & 459031 & 819311 & 786691 & 1260911 & 351141 & 832511 & 850908 & 80527 \\
\hline Subsidy on Equity. $E^{*} m, 2006$ & - & 720452 & - & 1220125 & 1007591 & 1566152 & - & 914356 & 902227 & 89898 \\
\hline Ave. Public debt (A), 2005 & 12422120 & 7034132 & 10652795 & 37767974 & 25175990 & 33748939 & 662470 & 580978 & 23397828 & 441390 \\
\hline Ave. Public debt (A),2006 & - & 13683136 & - & 57923958 & 37666631 & 46736110 & - & 548682 & 30689059 & 599513 \\
\hline Exp. Int. Public debt. A*c , 2005 & 904006 & 513870 & 985981 & 3083897 & 2002830 & 2283491 & 60975 & 31532 & 2398470 & 35520 \\
\hline Exp. Int. Public debt. $A^{*} c, 2006$ & 0 & 1106171 & - & 5083042 & 3061084 & 3103529 & 0 & 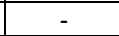 & 2900570 & 0 \\
\hline Rate paid public debt (c), 2005 & 0.073 & 0.073 & 0.093 & 0.082 & 0.080 & 0.068 & 0.092 & 0.054 & 0.103 & 0.080 \\
\hline Rate paid public debt (c), 2006 & - & 0.081 & - & 0.088 & 0.081 & 0.066 & - & 0.000 & 0.095 & 0.000 \\
\hline Disc. Public debt. $A^{*}(m-c), 2005$ & 599195 & 337330 & 303114 & 1486406 & 1043717 & 1800468 & 25365 & 44187 & 650969 & 22007 \\
\hline Disc. Public debt. $A^{*}(m-c), 2006$ & - & 478336 & & 1624552 & 1300712 & 2308512 & - & 70012 & 1015354 & 76498 \\
\hline Rev. Grants (RG), 2005 & 0 & 0 & 972211 & 0 & 0 & 0 & 54150 & 21046 & 148462 & 12000 \\
\hline Rev. Grants (RG), 2006 & - & 0 & - & 0 & 0 & 0 & - & - & 118297 & 0 \\
\hline K (RG + DX), 2005 & 0 & 0 & 972211 & 0 & 0 & 0 & 54150 & 21046 & 148462 & 12000 \\
\hline K (RG + DX), 2006 & - & 0 & - & 0 & 0 & 0 & - & - & 118297 & 0 \\
\hline Accounting Profit (P), 2005 & 2005470 & 1432070 & 1923230 & 3167408 & 2284003 & 3677749 & 526420 & 637613 & 790912 & 28079 \\
\hline Accounting Profit (P), 2006 & - & 2408590 & - & 5181817 & 2603978 & 1953382 & - & - & 588316 & 0 \\
\hline
\end{tabular}




\begin{tabular}{|c|c|c|c|c|c|c|c|c|c|c|}
\hline Taxes, 2005 & 0 & 0 & 0 & 954843 & 0 & 1160575 & 0 & 103044 & 231220 & 0 \\
\hline Taxes, 2006 & - & 0 & - & 1545179 & 0 & 690192 & - & - & 147914 & 0 \\
\hline Acc. profit less Taxes (AP), 2005 & 2005470 & 432070 & 1923230 & 2212565 & 2284003 & 2517173 & 526420 & 534569 & 559692 & 28079 \\
\hline Acc. profit less Taxes (AP), 2006 & - & 2408590 & - & 3636637 & 2603978 & 1263191 & - & - & 440402 & 0 \\
\hline Subsidy. $S\left\{E^{*} m+A(m-c)+K-A P\right\} 05$ & -379974 & -606153 & -188873 & 93152 & -453596 & 544206 & -95765 & 363175 & 1090646 & 86456 \\
\hline Subsidy. $S\left\{E^{*} m+A(m-c)+K-A P\right\} 06$ & - & -1209802 & $\sigma$ & -791960 & -295675 & 2611474 & - & - & 1595476 & 166396 \\
\hline Ave. Loan port (net) LP, 2005 & 18411633 & 12246121 & 12798777 & 46568016 & 27878711 & 54830469 & 3640724 & 5706404 & 28810231 & 810324 \\
\hline Ave. Loan port (net) LP, 2006 & - & 21751444 & & 74288324 & 40789718 & 77822112 & - & 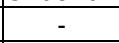 & 35916427 & 489381 \\
\hline Rev. From lending ( & 37355 & 5335100 & 1262424 & 13571259 & 2567751 & 17453679 & 12390 & 1656044 & 8302988 & 108850 \\
\hline Rev. From lending (I & - & 7823219 & 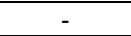 & 21383646 & 5709976 & 22370458 & - & - & 10246853 & 0 \\
\hline Yield on lending (i), 2 & 0.094 & 0.436 & 0.099 & 0.291 & 0.092 & 0.318 & 0.223 & 0.290 & 0.288 & 0.134 \\
\hline Yield on lending (i), 20 & - & 360 & - & 0.288 & 140 & 0.287 & - & - & 285 & 0.000 \\
\hline SDI (S/LP*i), 2005 & 0.219 & -0.114 & -0.150 & 0.007 & -0.177 & 0.031 & -0.118 & 0.219 & 0.131 & 0.794 \\
\hline SDI (S/LP*i), 2006 & - & -0.155 & - & -0.037 & -0.052 & 0. & - & - & 156 & - \\
\hline Change in Yield, 2005 & -0.021 & -0.049 & -0.015 & 0.002 & -0.016 & 0. & -0.026 & 0.064 & 0.038 & 0.107 \\
\hline Change in Yie & - & -0.067 & - & -0.011 & -0.005 & & - & - & 45 & - \\
\hline Nominal Sub & 0.074 & 0.386 & 0.084 & 0.293 & 0.076 & & 0.197 & 0.354 & 26 & 0.241 \\
\hline Nominal Sub & & 92 & & 0.277 & 135 & & - & - & & - \\
\hline Infla & 096 & 0.096 & 096 & 0.096 & .096 & & .084 & 0.084 & & .084 \\
\hline Infla & 091 & 91 & 091 & 0.091 & 091 & & .065 & 0.065 & 065 & 0.065 \\
\hline ubsidy- $f$ & 0.020 & 265 & -0.011 & 0.180 & -0.018 & 0.2 & 0.104 & 0.249 & 0.223 & 0.145 \\
\hline Real Subsidy- free y & - & 0.184 & - & 0.170 & 0.040 & 0.214 & - & - & 0.250 & - \\
\hline True Profit, 2005 & 406275 & 094740 & 647904 & 726159 & 1240287 & 716706 & 446905 & 469336 & -239738 & -5928 \\
\hline True Profit, 2006 & - & 1930254 & - & 2012085 & 1303266 & -1045322 & - & & -693249 & $\begin{array}{ll}-76498 \\
\end{array}$ \\
\hline Return on Assets (ROA), & 0.093 & 0.089 & 0.124 & 0.036 & 0.069 & 0.0 & 0.131 & 0.071 & 0.018 & 0.024 \\
\hline Return on Assets (ROA), 2006 & 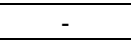 & 0.090 & - & 0.038 & 0.053 & 0.013 & - & 0.000 & 0.011 & 0.000 \\
\hline Subsidy-adjusted ROA, 2005 & .065 & 0.068 & .042 & 0.012 & 0.037 & 0.011 & 0.112 & 0.063 & -0.008 & -0.005 \\
\hline Subsidy-adjusted ROA, 2006 & - & 0.073 & - & 0.021 & 0.027 & -0.011 & - & -0.008 & -0.018 & -0.053 \\
\hline Return on Equity (ROE), 2005 & .236 & 0.355 & 507 & 0.327 & 0.351 & & 195 & 0.084 & & 0.045 \\
\hline n on E & - & 387 & - & 0.345 & 0.299 & & - & 0.000 & 62 & 0.000 \\
\hline Subsidy-adj & 166 & 0.271 & .171 & .107 & 0.191 & & .166 & 0.073 & -0.037 & -0.010 \\
\hline Subsidy-adjusted ROE, 2006 & - & 0.310 & & 0.191 & 0.150 & -0.077 & 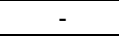 & -0.010 & -0.098 & -0.109 \\
\hline
\end{tabular}

\begin{tabular}{|c|c|c|c|c|c|c|c|c|c|}
\hline & \multicolumn{9}{|c|}{ ECUADOR } \\
\hline MFIs & Banco S & CO SAC & PROcredit & Coac S J & Fund E & D-Miro & C Jardin & FODEMI & Finca \\
\hline Avg. Assets, 2005 & 277128518 & 6639549 & 67150050 & 9935534 & 4491310 & 5987431 & 37043748 & 2702434 & 17323000 \\
\hline Avg. Assets, 2006 & 319364370 & 8154551 & 107103291 & 13005691 & 6465463 & 7606689 & 55458231 & 3724529 & 23647000 \\
\hline Ave. Equity (E), 2005 & 22141828 & 1814370 & 9987622 & 2395373 & 1247615 & 4111210 & 6554978 & 1610094 & 5323500 \\
\hline Ave. Equity (E),2006 & 28457597 & 2108446 & 10481296 & 2810407 & 1606931 & 5485953 & 8671147 & 2148398 & 9019000 \\
\hline Opp. Cost of society (m), 2005 & 0.09338 & 0.09338 & 0.09338 & 0.09338 & 0.09338 & 0.09338 & 0.09338 & 0.09338 & 0.09338 \\
\hline Opp. Cost of society ( m), 2006 & 0.0952 & 0.0952 & 0.0952 & 0.0952 & 0.0952 & 0.0952 & 0.0952 & 0.0952 & 0.0952 \\
\hline Subsidy on Equity. E*m, 2005 & 2067604 & 169426 & 932644 & 223680 & 116502 & 383905 & 612104 & 150351 & 497108 \\
\hline Subsidy on Equity. E*m, 2006 & 2709163 & 200724 & 997819 & 267551 & 152980 & 522263 & 825493 & 204527 & 858609 \\
\hline Ave. Public debt (A), 2005 & 56389850 & 1226775 & 42524951 & 318506 & 3243695 & 1031189 & 337691 & 343068 & 3243500 \\
\hline Ave. Public debt (A),2006 & 72855782 & 1377185 & 55326951 & 864321 & 4858532 & 1486782 & 607470 & & 8922000 \\
\hline Exp. Int. Public de & 395 & 123281 & & 25715 & & 16 & 21665 & 24 & 316000 \\
\hline Exp. Int. Public de & 539 & 141514 & 427 & $\Omega_{1}$ & 521 & 91320 & & 07 & 722000 \\
\hline Rate paid public de & & 0.100 & & .081 & & & & & 0.097 \\
\hline Rate paid public debt (c), 2006 & 0.074 & 0.103 & $0.0>-0$ & 0.000 & & 0.061 & 0.038 & 0.070 & 0.081 \\
\hline Disc. Public debt. A*(m-c), 2005 & 1213289 & -8725 & 13 & 4027 & 28244 & 36676 & 9869 & 312 & -13122 \\
\hline Disc. Public debt. $A^{*}(\mathrm{~m}-\mathrm{c}), 2006$ & 1543138 & -10406 & 994126 & 82283 & 1911 & 50222 & 34880 & 21784 & 127374 \\
\hline Rev. Grants (RG), 2005 & 0 & 0 & 0 & 0 & 0 & 30000 & 0 & 2587 & 0 \\
\hline Rev. Grants (RG), 2006 & 0 & 0 & 0 & 0 & 0 & 27500 & 0 & 0 & 0 \\
\hline K (RG + DX), 2005 & 0 & 0 & 0 & 0 & 0 & 30000 & 0 & 12587 & 0 \\
\hline K (RG + DX), 2006 & 0 & 0 & 0 & 0 & 0 & 27500 & 0 & 0 & 0 \\
\hline Accoun & 52492 & 3684 & & 35239 & 039 & & 0668 & 98736 & 2259000 \\
\hline Accounting Pro & & 28939 & & 193002 & 425592 & 81 & 203 & 095 & 2284000 \\
\hline Taxes, 20 & 135 & 6804 & & 72 & & & & & 626000 \\
\hline Tax & & 10719 & & 45239 & 0 & 6726 & 168397 & 7585 & 605000 \\
\hline Acc. profit less Taxes (AP), & 3197878 & 16880 & 103 & 173067 & 93039 & 498998 & 112054 & 197736 & 1633000 \\
\hline Acc. profit less Taxes (AP), 2006 & & 18220 & & 147763 & 425592 & 809707 & 178806 & 267510 & 1679000 \\
\hline Subsidy. $S\left\{E^{*} m+A(m-c)+K-A P\right\} 05$ & 83015 & 143821 & 455753 & 54640 & -148293 & -48417 & 509918 & -16987 & -1149014 \\
\hline Subsidy. S $\left\{E^{*} m+A(m-c)+K-A P\right\} 06$ & 4338747 & 172098 & -17055 & 202071 & -270701 & -209723 & 681567 & -41198 & -693017 \\
\hline Ave. Loan port (net) LP, 2005 & 182462559 & 5218977 & 55343613 & 8064480 & 3879317 & 5119670 & 28392239 & 2489242 & 15086000 \\
\hline Ave. Loan port (net) LP, 2006 & 214526414 & 6389970 & & 10166670 & 5675566 & 6386896 & 43769287 & 3489004 & 20451500 \\
\hline Rev. From lending $\left(L P *_{i}\right), 2005$ & 23429507 & 1047336 & & 1190138 & & 640865 & 4176361 & & 1880000 \\
\hline Rev. From lending $(L P * i), 2006$ & 27701173 & 1223544 & 12143000 & 1367249 & 638825 & 753406 & 5758262 & 449110 & 2519000 \\
\hline Yield on lending (i), 2005 & & 0.201 & & 0.148 & 0.121 & 0.125 & 0.147 & 0.123 & 0.125 \\
\hline Yield on lending ( & & 0.191 & & 0.134 & & & 132 & 0.129 & 0.123 \\
\hline & & & & 0.046 & & -0.076 & 0.122 & -0.056 & -0.611 \\
\hline CDOc & & & & & -0.424 & -0.278 & & -0.092 & -0.275 \\
\hline Change in Yield, 2005 & 0.000 & 0.028 & 0.008 & 0.007 & -0.038 & -0.009 & 0.018 & -0.007 & -0.076 \\
\hline
\end{tabular}




\begin{tabular}{|c|c|c|c|c|c|c|c|c|c|}
\hline Change in Yield, 2006 & 0.020 & 0.028 & 0.000 & 0.022 & -0.051 & -0.035 & 0.017 & -0.011 & -0.034 \\
\hline Nominal Subsidy free yield, 2005 & 0.129 & 0.228 & 0.156 & 0.154 & 0.083 & 0.116 & 0.165 & 0.116 & 0.048 \\
\hline Nominal Subsidy free yield, 2006 & 0.149 & 0.220 & 0.304 & 0.156 & 0.061 & 0.083 & 0.149 & 0.117 & 0.089 \\
\hline Inflation, 2005 & 0.024 & 0.024 & 0.024 & 0.024 & 0.024 & 0.024 & 0.024 & 0.024 & 0.024 \\
\hline Inflation, 2006 & 0.030 & 0.030 & 0.030 & 0.030 & 0.030 & 0.030 & 0.030 & 0.030 & 0.030 \\
\hline Real Subsidy- free yield, 2005 & 0.102 & 0.199 & 0.129 & 0.127 & 0.058 & 0.089 & 0.138 & 0.090 & 0.024 \\
\hline Real Subsidy-free yield, 2006 & 0.115 & 0.184 & 0.266 & 0.122 & 0.030 & 0.051 & 0.115 & 0.085 & 0.057 \\
\hline True Profit, 2005 & 1984589 & 25605 & 476891 & 169040 & 264795 & 432322 & 102185 & 167337 & 1646122 \\
\hline True Profit, 2006 & -1629583 & 28626 & 1014874 & 65480 & 423681 & 731985 & 143926 & 245726 & 1551626 \\
\hline Return on Assets (ROA), 2005 & 0.012 & 0.003 & 0.015 & 0.017 & 0.065 & 0.083 & 0.003 & 0.073 & 0.094 \\
\hline Return on Assets (ROA), 2006 & 0.000 & 0.002 & 0.019 & 0.011 & 0.066 & 0.106 & 0.003 & 0.072 & 0.071 \\
\hline Subsidy-adjusted ROA, 2005 & 0.007 & 0.004 & 0.007 & 0.017 & 0.059 & 0.072 & 0.003 & 0.062 & 0.095 \\
\hline Subsidy-adjusted ROA, 2006 & -0.005 & 0.004 & 0.009 & 0.005 & 0.066 & 0.096 & 0.003 & 0.066 & 0.066 \\
\hline Return on Equity (ROE), 2005 & 0.144 & 0.009 & 0.103 & 0.072 & 0.235 & 0.121 & 0.017 & 0.123 & 0.307 \\
\hline Return on Equity (ROE), 2006 & -0.003 & 0.009 & 0.192 & 0.053 & 0.265 & 0.148 & 0.021 & 0.125 & 0.186 \\
\hline Subsidy-adjusted ROE, 2005 & 0.090 & 0.014 & 0.048 & 0.071 & 0.212 & 0.105 & 0.016 & 0.104 & 0.309 \\
\hline Subsidy-adjusted ROE, 2006 & -0.057 & 0.014 & 0.097 & 0.023 & 0.264 & 0.133 & 0.017 & 0.114 & 0.172 \\
\hline
\end{tabular}

\begin{tabular}{|c|c|c|c|c|c|c|c|c|c|}
\hline \multirow[b]{2}{*}{ MFIs } & \multicolumn{2}{|c|}{ COSTA RICA } & \multicolumn{6}{|c|}{ COLOMBIA } & \multirow{2}{*}{\begin{tabular}{|c|} 
DOM. REP \\
ADEMI \\
\end{tabular}} \\
\hline & Fundcoca & Cred Muj & FMM P & Finamer & CMM Bog & FMM Buca & WWB Ca & WMM Med & \\
\hline Avg. Assets, 2005 & 1197286 & 660748 & 41881039 & 37709541 & 19743718 & 33986060 & 94054220 & 15056841 & 96521375 \\
\hline Avg. Assets, 2006 & - & 588192 & 67794193 & 52617509 & 29176968 & 63157638 & 135497260 & 25065323 & 105920332 \\
\hline Ave. Equity (E), 2005 & 685397 & 179390 & 21797351 & 6658916 & 4427149 & 6546221 & 24693642 & 4001064 & 11519717 \\
\hline Ave. Equity (E),2006 & - & 180042 & 28519260 & 7597426 & 5783452 & 11093742 & 32978149 & 5013946 & 14736931 \\
\hline Opp. Cost of society (m), 2005 & 0.24656 & 0.24656 & 0.14561 & 0.14561 & 0.14561 & 0.14561 & 0.14561 & 0.14561 & 0.24109 \\
\hline Opp. Cost of society ( m), 2006 & 0.2219 & 0.2219 & 0.1289 & 0.1289 & 0.1289 & 0.1289 & 0.1289 & 0.1289 & 0.1948 \\
\hline Subsidy on Equity. E*m, 2005 & 168992 & 44230 & 3173912 & 969605 & 644637 & 953195 & 3595641 & 582595 & 2777289 \\
\hline Subsidy on Equity. E*m, 2006 & - & 39951 & 3676133 & 979308 & 745487 & 1429983 & 4250883 & 646298 & 2870754 \\
\hline Ave. Public debt (A), 2005 & 488379 & 460043 & 19424696 & 7264579 & 14829665 & 25271114 & 67849085 & 10806128 & 31423556 \\
\hline Ave. Public debt (A),2006 & - & 394409 & 38218613 & 8537576 & 22607293 & 49031436 & 100401088 & 19637792 & - \\
\hline Exp. Int. Public debt. A*c, 2005 & 103117 & 50886 & 1934445 & 364225 & 1425490 & 2801060 & 7178600 & 1039340 & 1718829 \\
\hline Exp. Int. Public debt. $A^{*} c, 2006$ & 0 & 40065 & 3933268 & 341127 & 1982533 & 4415220 & 8629585 & 1849713 & 0 \\
\hline Rate paid public debt (c), 2005 & 0.211 & 0.111 & 0.100 & 0.050 & 0.096 & 0.111 & 0.106 & 0.096 & 0.055 \\
\hline Rate paid public debt (c), 2006 & - & 0.102 & 0.103 & 0.040 & 0.088 & 0.090 & 0.086 & 0.094 & - \\
\hline Disc. Public debt. $A^{*}(m-c), 2005$ & 17298 & 62542 & 893985 & 693570 & 733858 & 878666 & 2700905 & 534141 & 5857077 \\
\hline Disc. Public debt. A*(m-c), 2006 & - & 47454 & 993111 & 759366 & 931547 & 1904933 & 4312115 & 681598 & - \\
\hline Rev. Grants (RG), 2005 & 0 & 4979 & 0 & 0 & 0 & 0 & 26241 & 0 & 0 \\
\hline Rev. Grants (RG), 2006 & - & 592 & 0 & 0 & 0 & 0 & 0 & 0 & - \\
\hline K (RG + DX), 2005 & 0 & 4979 & 0 & 0 & 0 & 0 & 26241 & 0 & 0 \\
\hline K (RG + DX), 2006 & - & 592 & 0 & 0 & 0 & 0 & 0 & 0 & - \\
\hline Accounting Profit (P), 2005 & 28718 & -13963 & 5379180 & 979183 & 885220 & 3040296 & 5918637 & 454756 & 5906534 \\
\hline Accounting Profit (P), 2006 & - & 36216 & 4071553 & 453346 & 1165313 & 5445930 & 6643381 & 1203240 & - \\
\hline Taxes, 2005 & 0 & 0 & 55901 & 187798 & 17099 & 0 & 22667 & 0 & 1534935 \\
\hline Taxes, 2006 & - & 0 & 99113 & 215943 & 29557 & 2973 & 49508 & 0 & - \\
\hline Acc. profit less Taxes (AP), 2005 & 28718 & -13963 & 5323280 & 791385 & 868121 & 3040296 & 5895970 & 454756 & 4371599 \\
\hline Acc. profit less Taxes (AP), 2006 & - & 36216 & 3972439 & 237403 & 1135756 & 5442957 & 6593873 & 1203240 & - \\
\hline Subsidy. $S\left\{E^{*} m+A(m-c)+K-A P\right\} 05$ & 157571 & 125715 & -1255382 & 871790 & 510375 & -1208434 & 426817 & 661980 & 4262766 \\
\hline Subsidy. $S\left\{E^{*} m+A(m-c)+K-A P\right\} 06$ & - & 51780 & 696805 & 1501271 & 541279 & -2108041 & 1969126 & 124655 & - \\
\hline Ave. Loan port (net) LP, 2005 & 844369 & 566584 & 37271686 & 31864634 & 17974025 & 28113671 & 80944722 & 13212365 & 71284934 \\
\hline Ave. Loan port (net) LP, 2006 & - & 486496 & 62406497 & 44897047 & 27111209 & 54447235 & 119158423 & 22895330 & - \\
\hline Rev. From lending $(L P * i), 2005$ & 190567 & 201737 & 9275796 & 7191565 & 4170921 & 6934929 & 20822769 & 3117305 & 24969467 \\
\hline Rev. From lending (LP*i), 2006 & - & 177311 & 14523166 & 8795543 & 5596554 & 11477776 & 26160602 & 5228836 & - \\
\hline Yield on lending (i), 2005 & 0.226 & & 0.249 & 0.226 & 0.232 & 0.247 & 0.257 & 0.236 & .350 \\
\hline Yield on lending (i), 2006 & - & 0.364 & 0.233 & 0.196 & 0.206 & 0.211 & 0.220 & 0.228 & - \\
\hline SDI (S/LP*i), 2005 & 0.827 & 0.623 & -0.135 & 0.121 & 0.122 & -0.174 & 0.020 & 0.212 & 0.171 \\
\hline SDI (S/LP*i), 2006 & - & 0.292 & 0.048 & 0.171 & 0.097 & -0.184 & 0.075 & 0.024 & - \\
\hline Change in Yield, 2005 & 0.187 & 0.222 & -0.034 & 0.027 & 0.028 & -0.043 & 0.005 & 0.050 & 0.060 \\
\hline Change in Yield, 2006 & - & 0.104 & 0.012 & 0.039 & 0.022 & -0.045 & 0.019 & 0.006 & - \\
\hline Nominal Subsidy free yield, 2005 & 0.412 & 0.578 & 0.215 & 0.253 & 0.260 & 0.204 & 0.263 & 0.286 & 0.410 \\
\hline Nominal Subsidy free yield, 2006 & - & 0.468 & 0.245 & 0.234 & 0.229 & 0.166 & 0.239 & 0.234 & - \\
\hline Inflation, 2005 & 0.138 & 0.138 & 0.051 & 0.051 & 0.051 & 0.051 & 0.051 & 0.051 & 0.042 \\
\hline Inflation, 2006 & 0.115 & 0.115 & 0.043 & 0.043 & 0.043 & 0.043 & 0.043 & 0.043 & 0.076 \\
\hline Real Subsidy- free yield, 2005 & 0.241 & & & & & & & 0.2 & 0.353 \\
\hline Real Subsidy- free yield, 2006 & - & & & & & 7 & 0.188 & 0.1 & - \\
\hline True Profit, 2005 & 11420 & -81484 & 4429295 & 97815 & 134263 & 2161630 & 3168824 & -79385 & -1485478 \\
\hline True Profit, 2006 & - & -11829 & 2979328 & -521963 & 204208 & 3538025 & 2281758 & 521642 & - \\
\hline Return on Assets (ROA), 2005 & 0.024 & -0.021 & 0.127 & 0.021 & 0.044 & 0.089 & 0.063 & 0.030 & 0.045 \\
\hline Return on Assets (ROA), 2006 & - & 0.062 & 0.059 & 0.005 & 0.039 & 0.086 & 0.049 & 0.048 & 0.000 \\
\hline Subsidy-adjusted ROA, 2005 & 0.010 & -0.123 & 0.106 & 0.003 & 0.007 & 0.064 & 0.034 & -0.005 & -0.015 \\
\hline Subsidy-adjusted ROA, 2006 & - & -0.020 & 0.044 & -0.010 & 0.007 & 0.056 & 0.017 & 0.021 & - \\
\hline Return on Equity (ROE), 2005 & 0.042 & -0.078 & 0.244 & 0.119 & 0.196 & 0.464 & 0.239 & 0.114 & 0.379 \\
\hline Return on Equity (ROE), 2006 & - & 0.201 & 0.139 & 0.031 & 0.196 & 0.491 & 0.200 & 0.240 & 0.000 \\
\hline
\end{tabular}




\begin{tabular}{|l|c|c|c|c|c|c|c|c|c|}
\hline Subsidy-adjusted ROE, 2005 & 0.017 & -0.454 & 0.203 & 0.015 & 0.030 & 0.330 & 0.128 & -0.020 & -0.129 \\
\hline Subsidy-adjusted ROE, 2006 & - & -0.066 & 0.104 & -0.069 & 0.035 & 0.319 & 0.069 & 0.104 & - \\
\hline
\end{tabular}

\begin{tabular}{|c|c|c|c|c|c|c|c|c|c|c|}
\hline & \multicolumn{10}{|c|}{ PHILIPINES } \\
\hline MFIs & GREEN & BCB & ASHI & TSPI & NWFT & Ist Valley & CBMO & DIGOS & SOLANO & Bangko Ka \\
\hline Avg. Assets, 2005 & 27026126 & 3698346 & 1928059 & 10612229 & 9346342 & 15991589 & 6303909 & 4427255 & 4291449 & 21726223 \\
\hline Avg. Assets, 2006 & - & 4437864 & 2559700 & 14132176 & 10985633 & 24477895 & 7780781 & 5734154 & 4781483 & 25441566 \\
\hline Ave. Equity (E), 2005 & 3422816 & 472059 & 877923 & 4036764 & 1571892 & 2265262 & 1584987 & 557522 & 945496 & 3382158 \\
\hline Ave. Equity (E),2006 & - & 612187 & 1137348 & 5075999 & 1691182 & 3158722 & 1909281 & 682717 & 1238221 & 4105317 \\
\hline Opp. Cost of society (m), 2005 & 0.102 & 0.102 & 0.102 & 0.102 & 0.102 & 0.102 & 0.102 & 0.102 & 0.102 & 0.102 \\
\hline Opp. Cost of society ( m), 2006 & 0.098 & 0.098 & 0.098 & 0.098 & 0.098 & 0.098 & 0.098 & 0.098 & 0.098 & 0.098 \\
\hline Subsidy on Equity. E*m, 2005 & 348614 & 48079 & 89416 & 411144 & 160097 & 230717 & 161431 & 56784 & 96299 & 344473 \\
\hline Subsidy on Equity. E*m, 2006 & - & 59872 & 111233 & 496433 & 165398 & 308923 & 186728 & 66770 & 121098 & 401500 \\
\hline Ave. Public debt (A), 2005 & 4510630 & 1570647 & 658420 & 1098835 & 4908240 & 4161134 & 2118632 & 522721 & 122771 & 263243 \\
\hline Ave. Public debt (A),2006 & - & 1840645 & 884446 & 1172591 & 5549371 & 6305544 & 2528942 & 735322 & 87494 & 418872 \\
\hline Exp. Int. Public debt. A*c, 2005 & 488301 & 230372 & 129053 & 43172 & 447884 & 268436 & 213094 & 38459 & 3770 & 10605 \\
\hline Exp. Int. Public debt. A*c, 2006 & 0 & 210842 & 81403 & 243034 & 656503 & 1228794 & 250563 & 68647 & 4737 & 21599 \\
\hline Rate paid public debt (c), 2005 & 0.108 & 0.147 & 0.196 & 0.039 & 0.091 & 0.065 & 0.101 & 0.074 & 0.031 & 0.040 \\
\hline Rate paid public debt (c), 2006 & - & 0.115 & 0.092 & 0.207 & 0.118 & 0.195 & 0.099 & 0.093 & 0.054 & 0.052 \\
\hline $\begin{array}{l}\text { Disc. Public debt. } A^{*}(m-c), \\
2005\end{array}$ & -28894 & -70402 & -61993 & 68744 & 52021 & 155375 & 2689 & 14780 & 8734 & 16206 \\
\hline $\begin{array}{c}\text { Disc. Public debt. A*(m-c), } \\
2006\end{array}$ & - & -30827 & 5096 & -128354 & -113774 & -612112 & -3233 & 3268 & 3820 & 19367 \\
\hline Rev. Grants (RG), 2005 & 0 & 0 & 221476 & 178750 & 59023 & 229606 & 118 & 0 & 0 & 0 \\
\hline Rev. Grants (RG), 2006 & - & 0 & 185005 & 187362 & 1804 & 0 & 0 & 0 & 0 & 0 \\
\hline K (RG + DX), 2005 & 0 & 0 & 221476 & 178750 & 59023 & 229606 & 118 & 0 & 0 & 0 \\
\hline K (RG + DX), 2006 & - & 0 & 185005 & 187362 & 1804 & 0 & 0 & 0 & 0 & 0 \\
\hline Accounting Profit (P), 2005 & 483199 & 160864 & 130742 & 879574 & 86463 & 433547 & 379122 & 166864 & 313519 & 811282 \\
\hline Accounting Profit (P), 2006 & 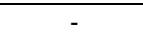 & 230652 & 256552 & 994816 & 92072 & 1038047 & 466694 & 219109 & 374573 & 1126249 \\
\hline Taxes, 2005 & 146411 & 0 & 0 & 0 & 0 & 54680 & 0 & 89189 & 88867 & 240329 \\
\hline Taxes, 2006 & - & 0 & 0 & 0 & 0 & 359118 & 0 & 70859 & 112658 & 292706 \\
\hline $\begin{array}{l}\text { Acc. profit less Taxes (AP), } \\
2005\end{array}$ & 336788 & 160864 & 130742 & 879574 & 86463 & 378867 & 379122 & 77674 & 224652 & 570953 \\
\hline $\begin{array}{l}\text { Acc. profit less Taxes (AP), } \\
2006\end{array}$ & - & 230652 & 256552 & 994816 & 92072 & 678929 & 466694 & 148250 & 261915 & 833543 \\
\hline $\begin{array}{c}\text { Subsidy. } S\left\{E^{*} m+A(m-c)+K-A P\right\} \\
05\end{array}$ & -17068 & -183186 & 118157 & -220936 & 184678 & 236831 & -214885 & -6110 & -119619 & -210274 \\
\hline $\begin{array}{c}\text { Subsidy. } S\left\{E^{*} m+A(m-c)+K-\right. \\
\text { AP\}06 }\end{array}$ & - & -201607 & 44782 & -439376 & 644 & 117 & -283200 & -78212 & 997 & -412676 \\
\hline Ave. Loan port (net) LP, 2005 & 17244619 & 2421623 & 1190092 & 7228220 & 5922787 & 12992413 & 4057537 & 2716347 & 2835560 & 8384635 \\
\hline Ave. Loan port (net) LP, 2006 & - & 2752581 & 1649109 & 9347679 & 7289683 & 18608111 & 5165674 & 3629306 & 2646700 & 10355036 \\
\hline $\begin{array}{l}\text { Rev. From lending (LP*i) } \\
2005\end{array}$ & 5154412 & 672771 & 356336 & 4355633 & 2406093 & 1194739 & 945789 & 592803 & 494857 & 1858336 \\
\hline Rev. From lending (LP*i), 2006 & - & 1026408 & 543860 & 6232225 & 2850749 & 4184513 & 1119197 & 789756 & 509013 & 2624921 \\
\hline Yield on lending (i), 2005 & 0.299 & 0.278 & 0.299 & 0.603 & 0.406 & 0.092 & 0.233 & 0.218 & 0.175 & 0.222 \\
\hline Yield on lending (i), 2006 & - & 0.373 & 0.330 & 0.667 & 0.391 & 0.225 & 0.217 & 0.218 & 0.192 & 0.253 \\
\hline SDI (S/LP*i), 2005 & -0.003 & -0.272 & 0.332 & -0.051 & 0.077 & 0.198 & -0.227 & -0.010 & -0.242 & -0.113 \\
\hline SDI (S/LP*i), 2006 & - & -0.196 & 0.082 & -0.071 & -0.014 & -0.235 & -0.253 & -0.099 & -0.269 & -0.157 \\
\hline Change in Yield, 2005 & -0.001 & -0.076 & 0.099 & -0.031 & 0.031 & 0.018 & -0.053 & $\begin{array}{ll}-0.002 \\
\end{array}$ & -0.042 & -0.025 \\
\hline Change in Yield, 2006 & - & -0.073 & 0.027 & -0.047 & -0.005 & -0.053 & -0.055 & -0.022 & -0.052 & -0.040 \\
\hline $\begin{array}{l}\text { Nominal Subsidy free yield, } \\
2005\end{array}$ & 0.298 & 0.202 & 0.399 & 0.572 & 0.437 & 0.110 & 0.180 & 0.216 & 0.132 & 0.197 \\
\hline $\begin{array}{l}\text { Nominal Subsidy free yield, } \\
2006\end{array}$ & - & 0.300 & 0.357 & 0.620 & 0.386 & 0.172 & 0.162 & 0.196 & 0.141 & 0.214 \\
\hline Inflation, 2005 & 0.076 & 0.076 & 0.076 & 0.076 & 0.076 & 0.076 & 0.076 & 0.076 & 0.076 & 0.076 \\
\hline Inflation, 2006 & 0.062 & 0.062 & 0.062 & 0.062 & 0.062 & 0.062 & 0.062 & 0.062 & 0.062 & 0.062 \\
\hline Real Subsidy-free yield, 2005 & 0.206 & 0.117 & 0.300 & 0.461 & 0.336 & 0.031 & 0.096 & 0.130 & 0.052 & 0.112 \\
\hline Real Subsidy- free yield, 2006 & - & 0.300 & 0.357 & 0.620 & 0.386 & 0.172 & 0.162 & 0.196 & 0.141 & 0.214 \\
\hline True Profit, 2005 & 365682 & 231266 & -28740 & 632081 & -24581 & -6114 & 376316 & 62894 & 215918 & 554747 \\
\hline True Profit, 2006 & - & 261479 & 66451 & 935809 & 204042 & 1291040 & 469927 & 144982 & 258095 & 814176 \\
\hline Return on Assets (ROA), 2005 & 0.012 & 0.043 & 0.068 & 0.083 & 0.009 & 0.024 & 0.060 & 0.018 & 0.052 & 0.026 \\
\hline Return on Assets (ROA), 2006 & - & 0.052 & 0.100 & 0.070 & 0.008 & 0.028 & 0.060 & 0.026 & 0.055 & 0.033 \\
\hline Subsidy-adjusted ROA, 2005 & 0.014 & 0.063 & -0.015 & 0.060 & -0.003 & 0.000 & 0.060 & 0.014 & 0.050 & 0.026 \\
\hline Subsidy-adjusted ROA, 2006 & - & 0.059 & 0.026 & 0.066 & 0.019 & 0.053 & 0.060 & 0.025 & 0.054 & 0.032 \\
\hline Return on Equity (ROE), 2005 & 0.098 & 0.341 & 0.149 & 0.218 & 0.055 & 0.167 & 0.239 & 0.139 & 0.238 & 0.169 \\
\hline Return on Equity (ROE), 2006 & - & 0.377 & 0.226 & 0.196 & 0.054 & 0.215 & 0.244 & 0.217 & 0.212 & 0.203 \\
\hline Subsidy-adjusted ROE, 2005 & 0.107 & 0.490 & -0.033 & 0.157 & -0.016 & -0.003 & 0.237 & 0.113 & 0.228 & 0.164 \\
\hline Subsidy-adjusted ROE, 2006 & - & 0.427 & 0.058 & 0.184 & 0.121 & 0.409 & 0.246 & 0.212 & 0.208 & 0.198 \\
\hline
\end{tabular}

\section{MFIs ic debt. $A^{*}(m-c)$ ic debt. $A^{*}(m-c)$, nts (RG), 2005 $\left\{E^{*} m+A(m-c)+K-\right.$ ort (net) LP, 2005 lending ( $L P^{*} \mathrm{i}$ ) free yield, 2006}

Avg. Assets, 2005

Avg. Assets, 2006

Ave. Equity (E), 2005

Subsidy on Equity. $\mathrm{E}^{*} \mathrm{~m}, 2006$

Ave. Public debt (A), 2005

Public debt (A), 2006

B698346 192805

10612229 Rate paid public debt (c), 200

Rate paid public debt (c), 2006 Grants (RG), 2006 K (RG + DX), 2005

K (RG + DX), 2006 Accounting Profit (P), 2006 Taxes, 2005 2005

$$
2006
$$
05

$$
2005
$$
ld on lending (i) 2006 SDI (S/LP*i), 2005

(S/LP*i), 2006

Change in Yield, 2005

Nominal Subsidy free yield, 2005

Inflation, 2005

ssidy- free yield, 2005

rue Profit, 2005

e Profit, 2006

Return on Assets (ROA) 2006

Subsidy-adjusted ROA, 2005

ubsidy-adjusted ROA, 2006

Return on Equity (ROE), 2006

Subsidy-adjusted ROE, 2005

Subsidy-adjusted ROE, 2006

\begin{tabular}{|l|l|l|l|}
\hline SPBD & TYM & CEP & MBK Ventu \\
\hline
\end{tabular}




\begin{tabular}{|c|c|c|c|c|c|c|c|c|c|}
\hline Avg. Assets, 2005 & 11267676 & 12899465 & 5830234 & 3667092 & 107722619 & 694580 & 3477510 & 8989815 & 490348 \\
\hline Avg. Assets, 2006 & 19645402 & 19177850 & 10230152 & \begin{tabular}{|l|}
5435837 \\
\end{tabular} & 175606211 & 882944 & 4197151 & 11309940 & 978851 \\
\hline Ave. Equity (E), 2005 & 9184320 & 4388086 & 1404744 & 1454118 & 30008802 & -904775 & 2046015 & 5059229 & 37568 \\
\hline Ave. Equity (E),2006 & 9628782 & 4806694 & 2379568 & 1386827 & 40362227 & -924103 & 2354975 & 6187063 & 74843 \\
\hline Opp. Cost of society (m), 2005 & 0.173 & 0.173 & 0.173 & 0.173 & 0.173 & 0.098 & 0.110 & 0.110 & 0.141 \\
\hline Opp. Cost of society ( m), 2006 & 0.164 & 0.164 & 0.164 & 0.164 & 0.164 & 0.098 & 0.112 & 0.112 & 0.160 \\
\hline Subsidy on Equity. E*m, 2005 & 1592010 & 760631 & 243498 & 252057 & 5201726 & -88216 & 225573 & 557780 & 5279 \\
\hline Subsidy on Equity. E*m, 2006 & 1579024 & 788250 & 390225 & 227426 & 6619002 & -90100 & 263286 & 691714 & 11960 \\
\hline Ave. Public debt (A), 2005 & 1366866 & 7549124 & 4035716 & 1800785 & 19194259 & 1569701 & 40284 & 1521179 & 420487 \\
\hline Ave. Public debt (A),2006 & 7473995 & 12468449 & 7238674 & 3040766 & 29565709 & 1771309 & 87168 & 1694814 & 832545 \\
\hline Exp. Int. Public debt. A*c, 2005 & 69065 & 660851 & 415729 & 136965 & 1895744 & 22456 & 0 & 71868 & 0 \\
\hline Exp. Int. Public debt. A*c, 2006 & 576940 & 1086513 & 195327 & 267968 & 2603286 & 35581 & 0 & 76968 & 0 \\
\hline Rate paid public debt (c), 2005 & 0.051 & 0.088 & 0.103 & 0.076 & 0.099 & 0.014 & 0.000 & 0.047 & 0.000 \\
\hline Rate paid public debt (c), 2006 & 0.077 & 0.087 & 0.027 & 0.088 & 0.088 & 0.020 & 0.000 & 0.045 & 0.000 \\
\hline Disc. Public debt. A*(m-c), 2005 & 167868 & 647714 & 283822 & 175183 & 1431388 & 130590 & 4441 & 95842 & 59083 \\
\hline Disc. Public debt. A*(m-c), 2006 & 648721 & 958188 & 991743 & 230687 & 2245194 & 137121 & 9745 & 112512 & 133041 \\
\hline Rev. Grants (RG), 2005 & 13282 & 79433 & 60000 & 72510 & 51392 & 27792 & 0 & 1057245 & 0 \\
\hline Rev. Grants (RG), 2006 & 10085 & 1367 & 0 & 123686 & 0 & 21747 & 0 & 217624 & 0 \\
\hline K (RG + DX), 2005 & 13282 & 79433 & 60000 & 72510 & 51392 & 27792 & 0 & 1057245 & 0 \\
\hline K (RG + DX), 2006 & 10085 & 1367 & 0 & 123686 & 0 & 21747 & 0 & 217624 & 0 \\
\hline Accounting Profit (P), 2005 & 771384 & 1209762 & 343315 & 326241 & 5422371 & -34404 & 302539 & 1847348 & 16182 \\
\hline Accounting Profit (P), 2006 & 841711 & 1670811 & 509725 & 565898 & 8386541 & -22400 & 280518 & 1303133 & 78423 \\
\hline Taxes, 2005 & 154254 & 248241 & 65950 & 65903 & 1100607 & 0 & 0 & 0 & 2801 \\
\hline Taxes, 2006 & 170445 & 332345 & 106601 & 117533 & 1697499 & 0 & 0 & 0 & 19902 \\
\hline Acc. profit less Taxes (AP), 2005 & 617129 & 961521 & 277366 & 260337 & 4321764 & -34404 & 302539 & 1847348 & 13381 \\
\hline Acc. profit less Taxes (AP), 2006 & 671266 & 1338466 & 403123 & 448365 & 6689043 & -22400 & 280518 & 1303133 & 58521 \\
\hline $\begin{array}{c}\text { Subsidy. } S\left\{E^{*} m+A(m-c)+K-A P\right\} \\
05\end{array}$ & 1156031 & 526257 & 309954 & 239412 & 2362742 & 104571 & -72524 & -136481 & 50981 \\
\hline $\begin{array}{c}\text { Subsidy. } S\left\{E^{*} m+A(m-c)+K-\right. \\
\text { AP\}06 }\end{array}$ & 1566564 & 409339 & 978846 & 133434 & 2175153 & 91168 & -7487 & 1283 & 86479 \\
\hline Ave. Loan port (net) LP, 2005 & 9659063 & 9812099 & 5105299 & 3010935 & 84617443 & 494316 & 2802571 & 7789705 & 259023 \\
\hline Ave. Loan port (net) LP, 2006 & 16433021 & 14539024 & 9293352 & 4776086 & 129128320 & 594285 & 3218109 & 9404809 & 680904 \\
\hline Rev. From lending $\left(L P *^{*}\right), 2005$ & 3330233 & 3976590 & 1592250 & 988848 & 23668741 & 207693 & 654550 & 1943379 & 132573 \\
\hline Rev. From lending (LP*i), 2006 & 5203450 & 5787902 & 2555557 & 1543893 & 32573917 & 246022 & 712471 & 2400775 & 409357 \\
\hline Yield on len & 45 & 0.405 & 0.312 & 0.328 & 0.280 & 0.420 & 0.234 & 0.249 & 0.512 \\
\hline Yield on lending (i), 2006 & 17 & 0.398 & 75 & 0.323 & 52 & 0.4 & 0.221 & 0.255 & 0.601 \\
\hline SDI (S/LP*i), 2005 & 77 & 32 & 95 & 42 & & & -0.111 & 70 & 0.385 \\
\hline SDI (S/LP & 1 & 0.071 & 83 & 86 & 0. & 1 & -0.011 & 17 & 0.211 \\
\hline Change in Yield, 2005 & 0.120 & 0.054 & 0.061 & 0.080 & 0.028 & 0.212 & -0.026 & -0.018 & 0.197 \\
\hline Change in Yield, 2006 & 0.095 & 0.028 & 0.105 & 0.028 & 0.017 & 0.153 & -0.002 & -0.030 & 0.127 \\
\hline $\begin{array}{l}\text { Nominal Subsidy free yield, } \\
2005\end{array}$ & 0.464 & 0.459 & 0.373 & 0.408 & 0.308 & 0.632 & 0.208 & 0.232 & 0.709 \\
\hline Nominal Subsidy free yield, 2006 & 0.412 & 0.426 & 0.380 & 0.351 & 0.269 & 0.567 & 0.219 & 0.225 & 0.728 \\
\hline Inflation, 2005 & 0.057 & 0.057 & 0.057 & 0.057 & 0.057 & 0.018 & 0.084 & 0.084 & 0.105 \\
\hline Inflation, 2006 & 0.047 & 0.047 & 0.047 & 0.047 & 0.047 & 0.038 & 0.077 & 0.077 & 0.131 \\
\hline Real Subsidy-free yield & 0.386 & 0.381 & 0.299 & 0.333 & 0.238 & 0.602 & 0.114 & 0.136 & 0.547 \\
\hline Real Subsidy- free yield, 2006 & 0.412 & 0.426 & 0.380 & 0.351 & 0.269 & 0.567 & 0.219 & 0.225 & 0.728 \\
\hline True Profit, 2005 & 435979 & 234374 & -66456 & 12644 & 2838984 & -192786 & 298098 & 694261 & -45702 \\
\hline True Profit, 2006 & 12460 & 378911 & -588620 & 93992 & 4443848 & -181269 & 270773 & 972997 & -74520 \\
\hline Return on Assets (ROA), 2005 & 0.055 & 0.075 & 0.048 & 0.071 & 0.040 & -0.050 & 0.087 & 0.205 & 0.027 \\
\hline Return on Assets (ROA), 2006 & 0.034 & 0.070 & 0.039 & 0.082 & 0.038 & -0.025 & 0.067 & 0.115 & 0.060 \\
\hline Subsidy-adjusted ROA, 2005 & 0.039 & 0.018 & -0.011 & 0.003 & 0.026 & -0.278 & 0.086 & 0.077 & -0.093 \\
\hline Subsidy-adjusted ROA, 2006 & 0.001 & 0.020 & -0.058 & 0.017 & 0.025 & -0.205 & 0.065 & 0.086 & -0.076 \\
\hline Return on Equity (ROE), 2005 & 0.067 & 0.219 & 0.197 & 0.179 & 0.144 & 0.038 & 0.148 & 0.365 & 0.356 \\
\hline Return on Equity (ROE), 2006 & 0.070 & 0.278 & 0.169 & 0.323 & 0.166 & 0.024 & 0.119 & 0.211 & 0.782 \\
\hline Subsidy-adjusted ROE, 2005 & 0.047 & 0.053 & -0.047 & 0.009 & 0.095 & 0.213 & 0.146 & 0.137 & -1.217 \\
\hline Subsidy-adjusted ROE, 2006 & 0.001 & 0.079 & -0.247 & 0.068 & 0.110 & 0.196 & 0.115 & 0.157 & -0.996 \\
\hline
\end{tabular}

\begin{tabular}{|c|c|c|c|c|c|c|c|c|c|c|}
\hline \multirow[b]{2}{*}{ MFIs } & \multicolumn{3}{|c|}{ ALBANIA } & \multicolumn{2}{|c|}{ MONGOLIA } & \multicolumn{5}{|c|}{ TAJIKSTAN } \\
\hline & BESA & ProCredit & Opport. & Kh. Bank & Credit M & FMFB & Bank Esk & MicInv. & Agroinv. & IMON \\
\hline Avg. Assets, & 1502386 & 213202833 & 13036610 & 143742162 & 2207852 & 6842992 & 10975914 & 935077 & 57819833 & 3195091 \\
\hline Avg. Assets, 2006 & 488658 & 258 & 221 & 231188532 & & 12354475 & 0002 & & & \\
\hline Ave. Equ & 6 & & & 10368813 & & 4212094 & 4565 & & & \\
\hline Ave & 272 & & & 200 & & 549 & 365 & & & \\
\hline Opp. Cost & & & & & & & 33 & & & 0.233 \\
\hline Opp. Co & 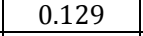 & & & 0.4 & & 0.2 & 44 & & 14 & 0.2 \\
\hline Subsidy on Equi & 63118 & 716263 & 1003186 & 2442685 & 271328 & 980112 & 843400 & 165624 & 2508839 & 311323 \\
\hline Subsidy on Equi & 1646583 & 2850628 & 1187900 & 4297913 & 249287 & 1338168 & 1420129 & 195029 & 3593343 & 215855 \\
\hline Ave. Public debt (A), 2005 & 9899503 & 14969602 & 5231820 & 12181699 & 911031 & 299496 & 1935027 & 172515 & 12530747 & 1787301 \\
\hline Ave. Public debt (A),2006 & 11913045 & 13088094 & 12369437 & 15778285 & 1524213 & 1774655 & 6100520 & 898207 & 15564279 & 5310399 \\
\hline Exp. Int. Public debt. $A^{*} c, 20($ & 321850 & & & 239669 & & & 127456 & 25324 & 685313 & 18174 \\
\hline Exp. Int. Public debt. $A^{*} c, 2006$ & 476170 & 414319 & 1333606 & 268755 & 191529 & 154549 & 427027 & 128681 & 1354698 & 227168 \\
\hline
\end{tabular}




\begin{tabular}{|c|c|c|c|c|c|c|c|c|c|c|}
\hline Rate paid public debt (c), 2005 & 0.033 & 0.032 & 0.078 & 0.020 & 0.151 & 0.032 & 0.066 & 0.147 & 0.055 & 0.010 \\
\hline Rate paid public debt (c), 2006 & 0.040 & 0.032 & 0.108 & 0.017 & 0.126 & 0.087 & 0.069 & 0.143 & 0.087 & 0.043 \\
\hline Disc. Public debt. A*(m-c), 2005 & 972510 & 1477607 & 276199 & 2630095 & 77410 & 60172 & 322805 & 14818 & 2230467 & 397713 \\
\hline Disc. Public debt. A*(m-c), 2006 & 1065378 & 1279280 & 266999 & 3114110 & 135262 & 277934 & 1059669 & 90212 & 2438316 & 1066977 \\
\hline Rev. Grants (RG), 2005 & 293309 & 0 & 285166 & 0 & 0 & 0 & 0 & 30138 & 0 & 44567 \\
\hline Rev. Grants (RG), 2006 & 167234 & 0 & 1765255 & 0 & 0 & 0 & 0 & 36076 & 0 & 18614 \\
\hline K (RG + DX), & 293309 & 0 & 285166 & 0 & 0 & 0 & 0 & 30138 & 0 & 44567 \\
\hline $\mathbf{K}(\mathbf{R G}+$ & 167234 & 0 & 1765255 & 0 & 0 & 0 & 0 & 36076 & 0 & 18614 \\
\hline Accounting P & 1522298 & 4510667 & 835244 & 5772064 & 93111 & 275562 & 1544166 & 129731 & 3445184 & 276556 \\
\hline Accounting $\mathrm{Pr}$ & 2810819 & 5611277 & 2915723 & 15306118 & 57962 & 590026 & 2401509 & 199661 & 6192906 & 904043 \\
\hline Taxes, 2005 & 0 & 1291728 & 0 & 2001097 & 26746 & 10129 & 387567 & 0 & 890602 & 100296 \\
\hline Taxes, 2006 & 0 & 1606979 & 0 & 5013762 & 21635 & 185512 & 612988 & 49913 & 1773180 & 257154 \\
\hline Acc. profit less Taxes (AP), 2005 & 1522298 & 3218939 & 835244 & 3770967 & 66365 & 265434 & 1156599 & 129731 & 2554582 & 176260 \\
\hline Acc. profit less Taxes (AP), 2006 & 2810819 & 4004298 & 2915723 & 10292355 & 36327 & 404514 & 1788521 & 149748 & 4419726 & 646889 \\
\hline Subsidy. $S\left\{E^{*} m+A(m-c)+K-A P\right\} 05$ & 1106639 & 974932 & 729307 & 1301813 & 282373 & 774850 & 9607 & 80850 & 2184723 & 577343 \\
\hline Subsidy. $S\left\{E^{*} m+A(m-c)+K-A P\right\} 06$ & 68375 & 125611 & 304430 & -2880332 & 348223 & 1211588 & 691278 & 171569 & 1611934 & 654556 \\
\hline Ave. Loan port ( & 19665249 & 99683029 & 11440218 & 87182226 & 1815055 & 2082239 & 4144571 & 763558 & 33821338 & 3036217 \\
\hline 2006 & 24631931 & 105577206 & 19372585 & 158251775 & 2431495 & 5443087 & 8064444 & 1535067 & 49727124 & 6017066 \\
\hline, 2005 & 4603 & 18606911 & 2553277 & 2494 & 65 & 51 & 1274470 & 339934 & 8444496 & 700045 \\
\hline 2006 & 6569957 & 20927660 & 5075287 & 45317200 & 853746 & 1485451 & 2544545 & 656717 & 12870566 & 2172367 \\
\hline 005 & 0.234 & 0.187 & 0.223 & 0.286 & 0.340 & 0.247 & 0.308 & 0.445 & 0.250 & 0.231 \\
\hline Yield o & 0.267 & 0.198 & 0.262 & 0.286 & 0.351 & 0.273 & 0.316 & .428 & 0.259 & 0.361 \\
\hline SDI (S/LP*i), 2005 & 0.240 & 0.052 & 0.286 & 0.052 & 0.458 & 1.510 & 0.008 & 0.238 & 0.259 & 0.825 \\
\hline SDI (S/L & 0.010 & 0.006 & 0.060 & -0.064 & 0.408 & 0.816 & 0.27 & 0.261 & 0.125 & 0.301 \\
\hline Change it & 0.056 & 0.010 & 0.064 & 0.015 & 0.156 & 0.372 & 0.002 & 0.106 & 0.065 & 0.190 \\
\hline Chang & 0.003 & 0.001 & 0.016 & -0.018 & 0.143 & 0.223 & 0.08 & 0.112 & 0.032 & 0.109 \\
\hline Nominal Su & 0.290 & 0.196 & 0.287 & 0.301 & 0.495 & 0.619 & 0.310 & 0.551 & 0.314 & 0.421 \\
\hline Nominal Sul & & 0.199 & 0.278 & & 0.494 & 0.495 & 0.401 & 40 & 0.291 & 0.470 \\
\hline Inflation, 2 & 024 & 0.024 & 24 & 0.1 & 0.127 & 5 & 0.095 & & 0.095 & 0.095 \\
\hline In & 4 & 0.024 & 0.024 & 0.0 & 51 & 0. & 0.095 & 95 & 0.095 & 0.095 \\
\hline Real Subsidy & 261 & 0.169 & 0.257 & 0.1 & 0.327 & 0.478 & 0.196 & 0.417 & 0.200 & 0.297 \\
\hline Real Subsidy & 270 & 0.199 & 0.278 & 0.268 & 0.494 & 0.495 & 0.401 & 0.540 & 0.291 & 0.470 \\
\hline True Profit, & 56479 & 1741331 & 273879 & 1140872 & -11045 & 205262 & 833793 & 84774 & 324116 & -266020 \\
\hline True Profit, 2006 & 1578207 & 2725018 & 883469 & 7178245 & -98935 & 126579 & 728850 & 23460 & 1981410 & \begin{tabular}{|l|}
-438701 \\
\end{tabular} \\
\hline Return on Assets (ROA), 2005 & 0.071 & 0.015 & 0.064 & 0.026 & 0.030 & 0.039 & 0.105 & 0.139 & 0.044 & 0.055 \\
\hline Return on Assets (ROA), 2006 & 0.110 & 0.015 & 132 & 0.045 & 0.013 & 0.033 & 0.090 & 0.080 & 0.051 & 0.101 \\
\hline Subsidy-adjusted ROA, 2005 & 0.012 & 0.008 & 0.021 & 0.008 & -0.005 & 0.030 & 0.076 & 0.091 & 0.006 & -0.083 \\
\hline Subsidy-adjusted ROA, 2006 & 0.062 & 0.011 & 0.040 & 0.031 & -0.035 & 0.010 & 0.040 & 0.013 & 0.023 & -0.069 \\
\hline Return on Equity ( $R$ & 0.146 & 0.155 & 0.109 & 0.364 & 0.058 & 0.063 & 0.319 & 0.182 & 0.237 & 0.132 \\
\hline Return on Equ & 221 & 0.182 & 0.318 & 0.515 & 0.031 & 0.074 & 0.307 & 0.187 & 0.300 & 0.730 \\
\hline Subsidy-adjusted ROE, 2005 & 0.025 & 0.084 & 0.036 & 0.110 & -0.010 & 0.049 & 0.230 & 0.119 & 0.030 & -0.199 \\
\hline Subsidy-adjusted ROE, 2006 & 0.124 & 0.124 & 0.096 & 0.358 & -0.085 & 0.023 & 0.125 & 0.029 & 0.134 & -0.495 \\
\hline
\end{tabular}

\begin{tabular}{|c|c|c|c|c|c|c|c|c|c|c|c|}
\hline \multirow[b]{2}{*}{ MFIs } & \multirow{2}{*}{$\begin{array}{c}\text { RUSIA } \\
\text { FORUS }\end{array}$} & \multicolumn{3}{|c|}{ KYRGYSTAN } & \multicolumn{3}{|c|}{ ARMENIA } & \multicolumn{4}{|c|}{ AZERBAIJAN } \\
\hline & & A Bank & FMCC & BTFF & INECO & ACBA & HOZON & C AGRO & ACCES & NMICRO & Viator \\
\hline Avg. Assets, 2005 & 28924470 & 44560466 & 11348483 & 8045470 & 20736132 & 66288713 & 1388225 & 4805007 & 15346385 & 1543750 & 2254215 \\
\hline Avg. Assets, 2006 & 49701336 & 53673564 & 18898921 & 13393974 & 49037694 & 111737516 & 1824331 & 7767155 & 38605695 & 2175590 & 2956073 \\
\hline Ave. Equity (E), 2005 & 12892275 & 13749093 & 2534062 & 3820620 & 9868360 & 15082806 & 300957 & 4349024 & 6454633 & 1091386 & 2090569 \\
\hline Ave. Equity (E),2006 & 14018138 & 16569775 & 4108399 & 4602882 & 14657130 & 33639789 & 520117 & 4937601 & 6785567 & 1327625 & 2723646 \\
\hline Opp. Cost of society (m), 2 & 0.107 & 0.266 & 0.266 & 0.266 & 0.180 & 0.180 & 0.180 & 0.170 & 0.170 & 0.170 & 0.170 \\
\hline Opp. Cost of society ( m), 2006 & 0.104 & 0.232 & 232 & 0.232 & 0.165 & 0.165 & 0.165 & 0.179 & 0.179 & 179 & 0.179 \\
\hline Subsidy on Equity. E*m, 2005 & 1377282 & 3657259 & 4060 & 1016285 & 1774726 & 2712492 & 54124 & 740552 & 99095 & 5841 & 355982 \\
\hline Subsidy on Equity. I & 146 & 3844188 & 49 & 1067869 & 2422824 & $55 t$ & 85975 & 56 & 902 & 114 & 443 \\
\hline Ave. Public d & 1562 & 2539 & 66 & 4028671 & 4667377 & 252 & 1066231 & 329 & & 5551 & 5000 \\
\hline Ave. Public debt (A),2006 & 19565895 & 31406736 & 11708404 & 8557333 & 9573947 & 37007274 & 1285262 & 2649862 & 29575393 & 705726 & 175000 \\
\hline Exp. Int. Public debt. A*c, 2005 & 1186980 & 1143027 & 1062351 & 276441 & 280025 & 2245687 & 28413 & 7158 & 760666 & 22305 & 12070 \\
\hline Exp. Int. Public debt. A*c, 2006 & 446876 & 1824484 & 1424000 & 1005748 & 533084 & 3711293 & 44327 & 177938 & 2580941 & 34273 & 11900 \\
\hline Rate paid public debt (c), 2005 & 0.076 & 0.045 & 0.159 & 0.069 & 0.060 & 0.089 & 0.027 & 0.018 & 0.090 & .073 & 0.097 \\
\hline Rate paid public debt (c), 2006 & 0.023 & 0.058 & 0.122 & 0.118 & 0.056 & 0.100 & 0.034 & 67 & 0.087 & 049 & 0.068 \\
\hline Disc. Public debt. & & & & & 559357 & & & & & 29895 & 9215 \\
\hline Disc. Public deb & 1592869 & 5461879 & 1292350 & 53 & 1049490 & 2406009 & 168126 & 327 & 2701224 & 91770 & 19355 \\
\hline Rev. Grants (RG & S & 55496 & 0 & 51065 & 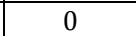 & 0 & 0 & 53478 & 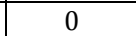 & 14215 & 264133 \\
\hline Rev. $C$ & 0 & & 0 & 24883 & 0 & 0 & 0 & & 0 & 17527 & 197535 \\
\hline K (F & 0 & 496 & 0 & 51065 & 0 & - & 0 & 53478 & 0 & 14215 & 264133 \\
\hline K (RG + & 0 & 1235 & 0 & 24883 & 0 & 0 & 0 & 41116 & 0 & 17527 & 197535 \\
\hline Accounting Profit (P), 2005 & 1784176 & 3325981 & 881317 & 574479 & 3051892 & 3231167 & 209699 & 209413 & 219690 & 176699 & 717654 \\
\hline Accounting Profit (P), 2006 & 666553 & 3076459 & 2532000 & 862752 & 3853241 & 5414558 & 248933 & 584658 & 238806 & 202002 & 616413 \\
\hline Taxes, 2005 & 681048 & 568232 & 210375 & 146634 & 606345 & 712822 & 53975 & 947 & 73375 & 42408 & 0 \\
\hline Taxes, 2006 & 139107 & 319116 & 257000 & 159138 & 777791 & 1325851 & 32869 & 134082 & 40184 & 44440 & 0 \\
\hline Acc. profit less Taxes (A & 1103128 & 2757748 & 670942 & 427845 & 2445547 & 2518346 & 155724 & 208466 & 146315 & 134291 & 717654 \\
\hline Acc. profit less Taxes (AP), 2006 & 527445 & 2757343 & 2275000 & 703614 & 3075450 & 4088707 & 216063 & 450576 & 198622 & 157562 & 616413 \\
\hline Subsidy. $S\left\{E^{*} m+A(m-c)+K-A P\right\}$ & 755873 & 6414016 & 675321 & 1410519 & -111464 & 2496914 & 61739 & 646318 & 1628313 & 95660 & -88324 \\
\hline
\end{tabular}




\begin{tabular}{|c|c|c|c|c|c|c|c|c|c|c|c|}
\hline 05 & & & & & & & & & & & \\
\hline Subsidy. S $\left\{E^{*} m+A(m-c)+K-A P\right\} 06$ & 2526815 & 6599959 & -29502 & 1368690 & 396863 & 3877960 & 38039 & 767723 & 3714504 & 188848 & 86920 \\
\hline Ave. Loan port (net) LP, 2005 & 21627297 & 40251299 & 10179767 & 4980330 & 17819279 & 42917221 & 1214405 & 4476259 & 12228732 & 1405104 & 1805270 \\
\hline Ave. Loan port (net) LP, 2006 & 31438855 & 48316828 & 14979574 & 8293740 & 27252171 & 71110146 & 1549614 & 24110263913 & 32019417 & 2023173 & 2583647 \\
\hline Rev. From lending (LP*i) , 2005 & 7933649 & 6843559 & 4475424 & 1211429 & 3876012 & 8821435 & 497822 & 940147 & 3525677 & 522077 & 727280 \\
\hline Rev. From lending (LP*i), 2006 & 7599734 & 7442295 & 7166000 & 2468857 & 5785436 & 14277920 & 494847 & 8041607348 & 9180253 & 649192 & 1053936 \\
\hline Yield on lending (i), 2005 & 0.367 & 0.170 & 0.440 & 0.243 & 0.218 & 0.206 & 0.410 & 0.210 & 0.288 & 0.372 & 0.403 \\
\hline Yield on lending (i), 2006 & 0.242 & 0.154 & 0.478 & 0.298 & 0.212 & 0.201 & 0.319 & 0.334 & 0.287 & 0.321 & 0.408 \\
\hline SDI $(S / L P * i), 2005$ & 0.095 & 0.937 & 0.151 & 1.164 & -0.029 & 0.283 & 0.124 & 0.687 & 0.462 & 0.183 & -0.121 \\
\hline SDI $(S / L P * i), 2006$ & 0.332 & 0.887 & -0.004 & 0.554 & 0.069 & 0.272 & 0.077 & 0.000 & 0.405 & 0.291 & 0.082 \\
\hline Change in Yield, 2005 & 0.035 & 0.159 & 0.066 & 0.283 & -0.006 & 0.058 & 0.051 & 0.144 & 0.133 & 0.068 & -0.049 \\
\hline Change in Yield, 2006 & 0.080 & 0.137 & -0.002 & 0.165 & 0.015 & 0.055 & 0.025 & 0.000 & 0.116 & 0.093 & 0.034 \\
\hline Nominal Subsidy free yield, 2005 & 0.402 & 0.329 & 0.506 & 0.526 & 0.211 & 0.264 & 0.461 & 0.354 & 0.421 & 0.440 & 0.354 \\
\hline Nominal Subsidy free yield, 2006 & 0.322 & 0.291 & 0.476 & 0.463 & 0.227 & 0.255 & 0.344 & 0.334 & 0.403 & 0.414 & 0.442 \\
\hline Inflation, 2005 & 0.127 & 0.044 & 0.044 & 0.044 & 0.006 & 0.006 & 0.006 & 0.116 & 0.116 & 0.116 & 0.116 \\
\hline Inflation, 2006 & 0.097 & 0.056 & 0.056 & 0.056 & 0.029 & 0.029 & 0.029 & 0.083 & 0.083 & 0.083 & 0.083 \\
\hline Real Subsidy-free yield, 2005 & 0.244 & 0.274 & 0.443 & 0.463 & 0.204 & 0.256 & 0.451 & 0.214 & 0.274 & 0.290 & 0.213 \\
\hline Real Subsidy- free yield, 2006 & 0.322 & 0.291 & 0.476 & 0.463 & 0.227 & 0.255 & 0.344 & 0.334 & 0.403 & 0.414 & 0.442 \\
\hline True Profit, 2005 & 621409 & -2756757 & -1260 & -394234 & 1886190 & 215577 & -7615 & 94234 & -529218 & 90181 & 444306 \\
\hline True Profit, 2006 & -1065424 & -2755771 & 982650 & -300821 & 2025960 & 1682698 & 47937 & 33 & -2502602 & 48265 & 399523 \\
\hline Return on Assets (ROA), 2005 & 0.038 & 0.062 & 0.059 & 0.053 & 0.118 & 0.038 & 0.112 & 0.043 & 0.010 & 0.087 & 0.318 \\
\hline Return on Assets (ROA), 2006 & 0.011 & 0.051 & 0.120 & 0.053 & 0.063 & 0.037 & 0.118 & 0.058 & 0.005 & 0.072 & 0.209 \\
\hline Subsidy-adjusted ROA, 2005 & 0.021 & -0.062 & 0.000 & -0.049 & 0.091 & 0.003 & -0.005 & 0.020 & -0.034 & 0.058 & 0.197 \\
\hline Subsidy-adjusted ROA, 2006 & -0.021 & -0.051 & 0.052 & -0.022 & 0.041 & 0.015 & 0.026 & 0.015 & -0.065 & 0.022 & 0.135 \\
\hline Return on Equity (ROE), 2005 & 0.086 & 0.201 & 0.265 & 0.112 & 0.248 & 0.167 & 0.517 & 0.048 & 0.023 & 0.123 & 0.343 \\
\hline Return on Equity (ROE), 2006 & 0.038 & 0.166 & 0.554 & 0.153 & 0.210 & 0.122 & 0.415 & 0.091 & 0.029 & 0.119 & 0.226 \\
\hline Subsidy-adjusted ROE, 2005 & 0.048 & -0.201 & 0.000 & -0.103 & 0.191 & 0.014 & -0.025 & 0.022 & -0.082 & 0.083 & 0.213 \\
\hline Subsidy-adjusted ROE, 2006 & -0.076 & -0.166 & 0.239 & -0.065 & 0.138 & 0.050 & 0.092 & 0.023 & -0.369 & 0.036 & 0.147 \\
\hline
\end{tabular}

\begin{tabular}{|c|c|c|c|c|c|c|c|c|c|}
\hline \multirow[b]{2}{*}{ MFIs } & \multicolumn{4}{|c|}{ BOSNIA } & \multirow{2}{*}{$\begin{array}{c}\text { KAZTAN } \\
\text { KMF } \\
\end{array}$} & \multicolumn{4}{|c|}{ GEORGIA } \\
\hline & MIKROFIN & PARTNER & SUNRISE & EKI & & CREDO & Lazika & C FUND & Constanta \\
\hline Avg. Assets, 2005 & 34669400 & 35079439 & 15032974 & 31570118 & 10805891 & 2129818 & 820822 & 1111535 & 7493648 \\
\hline Avg. Assets, 2006 & 56254421 & 51538989 & 23384935 & 47976734 & 27516518 & 4008172 & 1297400 & 1869970 & 20081106 \\
\hline Ave. Equity (E), 2005 & 12401952 & 11222901 & 4866110 & 7612796 & 4515763 & 1354136 & 646445 & 602160 & 6317600 \\
\hline Ave. Equity (E),2006 & 16199471 & 14717787 & 6279300 & 11534285 & 6118309 & 1625513 & 758545 & 702355 & 7109821 \\
\hline Opp. Cost of society (m), 2005 & 0.096 & 0.096 & 0.096 & 0.096 & 0.110 & 0.216 & 0.216 & 0.216 & 0.216 \\
\hline Opp. Cost of society ( m), 2006 & 0.080 & 0.080 & 0.080 & 0.080 & 0.110 & 0.188 & 0.188 & 0.188 & 0.188 \\
\hline Subsidy on Equity. E*m, 2005 & 1192200 & 1078857 & 467779 & 731818 & 496734 & 292940 & 139845 & 130265 & 1366686 \\
\hline Subsidy on Equity. E*m, 2006 & 1297578 & 1178895 & 502972 & 923896 & 673014 & 304784 & 142227 & 131692 & 1333091 \\
\hline Ave. Public debt (A), 2005 & 21858559 & 23477852 & 10079781 & 22504437 & 6197970 & 690188 & 160964 & 438328 & 1145424 \\
\hline Ave. Public debt (A),2006 & 39617704 & 34873772 & 16816647 & 35505986 & 21160162 & 2263525 & 543004 & 986263 & 12695278 \\
\hline Exp. Int. Public debt. A*c, 2005 & 1186688 & 1098655 & 470439 & 551604 & 579944 & 38748 & 0 & 38986 & 94891 \\
\hline Exp. Int. Public debt. A*c, 2006 & 2406351 & 1863163 & 1031337 & 1522596 & 1830587 & 149507 & 1748 & 95801 & 1285714 \\
\hline Rate paid public debt (c), 2005 & 0.054 & 0.047 & 0.047 & 0.025 & 0.094 & 0.056 & 0.000 & 0.089 & 0.083 \\
\hline Rate paid public debt (c), 2006 & 0.061 & 0.053 & 0.061 & 0.043 & 0.087 & 0.066 & 0.003 & 0.097 & 0.101 \\
\hline Disc. Public debt. $A^{*}(m-c), 2005$ & 914576 & 1158271 & 498531 & 1611748 & 101833 & 110560 & 34821 & 55837 & 152899 \\
\hline Disc. Public debt. A*(m-c), 2006 & 767027 & 930227 & 315676 & 1321433 & 497031 & 274904 & 100066 & 89124 & 1094650 \\
\hline Rev. Grants (RG), 2005 & 0 & 0 & 0 & 97283 & 160112 & 372857 & 32811 & 45832 & 314430 \\
\hline Rev. Grants (RG), 2006 & 0 & 2056143 & 0 & 2244744 & 109242 & 83156 & 11759 & 8132 & 377259 \\
\hline K (RG + DX), 2005 & 0 & 0 & 0 & 97283 & 160112 & 372857 & 32811 & 45832 & 314430 \\
\hline K (RG + DX), 2006 & 0 & 2056143 & 0 & 2244744 & 109242 & 83156 & 11759 & 8132 & 377259 \\
\hline Accounting Profit (P), 2005 & 2360346 & 1669935 & 887381 & 1700701 & 1564107 & 388324 & 18882 & 172835 & 379562 \\
\hline Accounting Profit (P), 2006 & 5262830 & 5404960 & 1954999 & 6127307 & 2968049 & 189208 & 140159 & 40691 & 1267638 \\
\hline Taxes, 2005 & 0 & 0 & 0 & 0 & 437973 & 0 & 0 & 30305 & 28636 \\
\hline Taxes, 2006 & 0 & 0 & 0 & 0 & 873141 & 0 & 20446 & 8138 & 276968 \\
\hline Acc. profit less Taxes (AP), 2005 & 2360346 & 1669935 & 887381 & 1700701 & 1126134 & 388324 & 18882 & 142530 & 50926 \\
\hline Acc. profit less Taxes (AP), 2006 & 5262830 & 5404960 & 1954999 & 6127307 & 2094907 & 189208 & 119713 & 32553 & 990671 \\
\hline Subsidy. $S\left\{E^{*} m+A(m-c)+K-A P\right\} 05$ & -253571 & 567193 & 78928 & 740148 & -367455 & 388034 & 188596 & 89405 & 1483089 \\
\hline Subsidy. $S\left\{E^{*} m+A(m-c)+K-A P\right\} 06$ & -3198225 & -1239696 & -1136351 & -1637234 & -815620 & 473636 & 134340 & 196394 & 1814331 \\
\hline Ave. Loan port (net) LP, 2005 & 32266905 & 31260781 & 13866672 & 28965943 & 8437069 & 1748963 & 761400 & 942252 & 6190463 \\
\hline Ave. Loan port (net) LP, 2006 & 49917814 & 45995206 & 21056289 & 45200187 & 18534925 & 3452107 & 1265167 & 1370416 & 13813998 \\
\hline Rev. From lending (LP*i) , 2005 & 5631183 & 6194038 & 3700191 & 5068151 & 3718422 & 532996 & 221690 & 412287 & 2704660 \\
\hline Rev. From lending (LP*i), 2006 & 9030445 & 9889844 & 6435483 & 9410923 & 8333076 & 1109658 & 387183 & 633892 & 4909038 \\
\hline Yield on lending (i), 2005 & 0.175 & 0.198 & 0.267 & 0.175 & 0.441 & 0.305 & 0.291 & 0.438 & 0.437 \\
\hline Yield on lending (i), 2006 & 0.181 & 0.215 & 0.306 & 0.208 & 0.450 & 0.321 & 0.306 & 0.463 & 0.355 \\
\hline SDI (S/LP*i), 2005 & -0.045 & 0.092 & 0.021 & 0.146 & -0.099 & 0.728 & 0.851 & 0.217 & 0.548 \\
\hline SDI (S/LP*i), 2006 & -0.354 & -0.125 & -0.177 & -0.174 & -0.098 & 0.427 & 0.347 & 0.310 & 0.370 \\
\hline Change in Yield, 2005 & -0.008 & 0.018 & 0.006 & 0.026 & -0.044 & 0.222 & 0.248 & 0.095 & 0.240 \\
\hline Change in Yield, 2006 & -0.064 & -0.027 & -0.054 & -0.036 & -0.044 & 0.137 & 0.106 & 0.143 & 0.131 \\
\hline Nominal Subsidy free yield, 2005 & 0.167 & 0.216 & 0.273 & 0.201 & 0.397 & 0.527 & 0.539 & 0.532 & 0.676 \\
\hline Nominal Subsidy free yield, 2006 & 0.117 & 0.188 & 0.252 & 0.172 & 0.406 & 0.459 & 0.412 & 0.606 & 0.487 \\
\hline Inflation, 2005 & 0.036 & 0.036 & 0.036 & 0.036 & 0.076 & 0.082 & 0.082 & 0.082 & 0.082 \\
\hline
\end{tabular}




\begin{tabular}{|c|c|c|c|c|c|c|c|c|c|}
\hline Inflation, 2006 & 0.036 & 0.036 & 0.036 & 0.036 & 0.086 & 0.082 & 0.082 & 0.082 & 0.082 \\
\hline Real Subsidy- free yield, 2005 & 0.126 & 0.174 & 0.228 & 0.159 & 0.299 & 0.411 & 0.422 & 0.416 & 0.549 \\
\hline Real Subsidy- free yield, 2006 & 0.117 & 0.188 & 0.252 & 0.172 & 0.406 & 0.459 & 0.412 & 0.606 & 0.487 \\
\hline True Profit, 2005 & 1445771 & 511664 & 388851 & -8330 & 864189 & -95093 & -48750 & 40860 & -116403 \\
\hline True Profit, 2006 & 4495803 & 2418591 & 1639323 & 2561130 & 1488634 & -168852 & 7888 & -64703 & -481239 \\
\hline Return on Assets (ROA), 2005 & 0.068 & 0.048 & 0.059 & 0.054 & 0.104 & 0.182 & 0.023 & 0.128 & 0.047 \\
\hline Return on Assets (ROA), 2006 & 0.094 & 0.105 & 0.084 & 0.128 & 0.076 & 0.047 & 0.092 & 0.017 & 0.049 \\
\hline Subsidy-adjusted ROA, 2005 & 0.042 & 0.015 & 0.026 & 0.000 & 0.080 & -0.045 & -0.059 & 0.037 & -0.016 \\
\hline Subsidy-adjusted ROA, 2006 & 0.080 & 0.047 & 0.070 & 0.053 & 0.054 & -0.042 & 0.006 & -0.035 & -0.024 \\
\hline Return on Equity (ROE), 2005 & 0.190 & 0.149 & 0.182 & 0.223 & 0.249 & 0.287 & 0.029 & 0.237 & 0.056 \\
\hline Return on Equity (ROE), 2006 & 0.325 & 0.367 & 0.311 & 0.531 & 0.342 & 0.116 & 0.158 & 0.046 & 0.139 \\
\hline Subsidy-adjusted ROE, 2005 & 0.117 & 0.046 & 0.080 & -0.001 & 0.191 & -0.070 & -0.075 & 0.068 & -0.018 \\
\hline Subsidy-adjusted ROE, 2006 & 0.278 & 0.164 & 0.261 & 0.222 & 0.243 & -0.104 & 0.010 & -0.092 & -0.068 \\
\hline
\end{tabular}

\begin{tabular}{|c|c|c|c|c|c|c|c|c|c|c|c|}
\hline & \multicolumn{3}{|c|}{ EGYPT } & \multicolumn{2}{|c|}{ JORDON } & \multicolumn{5}{|c|}{ MORROCO } & TUNSIA \\
\hline MFIs & DBACD & LEAD & Al TAD. & Tamwl. & MFW & AL AMA. & Fondep & Zakoura & Inmaa & Al KAR. & Enda \\
\hline Avg. Assets, 2005 & 16383646 & 6187250 & 2292461 & 6089330 & 5554616 & 69531686 & 9340710 & 18991401 & 1409057 & 1040007 & 5538500 \\
\hline Avg. Assets, 2006 & 18969678 & 10802774 & 2936538 & 7923125 & 8247182 & 170225364 & 21358952 & 62711806 & 1743082 & 1677725 & 10323297 \\
\hline Ave. Equity (E), 2005 & 9583425 & 4294533 & 872478 & 3228597 & 4483606 & 23707753 & 3879317 & 13088207 & 116140 & 801515 & 4327381 \\
\hline Ave. Equity (E),2006 & 10963573 & 7259072 & 1357669 & 3689117 & 5574406 & 29253461 & 6745270 & 15635049 & 276909 & 1035319 & 5891100 \\
\hline Opp. Cost of society (m), 2005 & 0.131 & 0.131 & 0.131 & 0.076 & 0.076 & 0.115 & 0.115 & 0.115 & 0.115 & 0.115 & 0.100 \\
\hline Opp. Cost of society ( m), 2006 & 0.126 & 0.126 & 0.126 & 0.082 & 0.082 & 0.115 & 0.115 & 0.115 & 0.115 & 0.115 & 0.100 \\
\hline Subsidy on Equity. E*m, 2005 & 1259454 & 564388 & 114661 & 245599 & 341068 & 2726392 & 446121 & 1505144 & 13356 & 92174 & 432738 \\
\hline Subsidy on Equity. E*m, 2006 & 1381410 & 914643 & 171066 & 301770 & 455986 & 3364148 & 775706 & 1798031 & 31845 & 119062 & 589110 \\
\hline Ave. Public debt (A), 2005 & 6303188 & 1892717 & 1379978 & 1674871 & 987268 & 28184137 & 4745052 & 9399395 & 570922 & 212575 & 900012 \\
\hline Ave. Public debt (A),2006 & 7581328 & 3543817 & 1500638 & 2577730 & 2502950 & 89798500 & 12712146 & 32520524 & 662298 & 591969 & 3570235 \\
\hline Exp. Int. Public debt. A*c, 2005 & 715535 & 227029 & 58729 & 40116 & 55637 & 2161583 & 207008 & 846096 & 18001 & 4187 & 30118 \\
\hline Exp. Int. Public debt. A*c, 2006 & 784817 & 342184 & 80449 & 127181 & 195650 & 6398839 & 806754 & 2030561 & 26635 & 18052 & 267470 \\
\hline Rate paid public debt (c), 2005 & 0.114 & 0.120 & 0.043 & 0.024 & 0.056 & 0.077 & 0.044 & 0.090 & 0.032 & 0.020 & 0.033 \\
\hline Rate paid public debt (c), 2006 & 0.104 & 0.097 & 0.054 & 0.049 & 0.078 & 0.071 & 0.063 & 0.062 & 0.040 & 0.030 & 0.075 \\
\hline Disc. Public debt. A*(m-c), 2005 & 112830 & 21711 & 122628 & 87292 & 19465 & 1079592 & 338673 & 234835 & 47655 & 20259 & 59883 \\
\hline Disc. Public debt. A*(m-c), 2006 & 170430 & 104336 & 108632 & 83678 & 9091 & 3927988 & 655143 & 1709299 & 49529 & 50025 & 89554 \\
\hline Rev. Grants (RG), 2005 & 0 & 3915064 & 364137 & 10011 & 1062294 & 130759 & 27363 & 226584 & 89803 & 5560 & 199260 \\
\hline Rev. Grants (RG), 2006 & 0 & 2209428 & 25359 & 4355 & 42313 & 0 & 31325 & 254087 & 22942 & 18098 & 144285 \\
\hline K (RG + DX), 2005 & 0 & 3915064 & 364137 & 10011 & 1062294 & 130759 & 27363 & 226584 & 89803 & 5560 & 199260 \\
\hline K (RG + DX), 2006 & 0 & 2209428 & 25359 & 4355 & 42313 & 0 & 31325 & 254087 & 22942 & 18098 & 144285 \\
\hline Accounting Profit (P), 2005 & 799977 & 3580116 & 573277 & 419408 & 1636490 & 4076465 & 869133 & 2281635 & 152729 & 162726 & 732777 \\
\hline Accounting Profit (P), 2006 & 1473946 & 3909284 & 350694 & 455780 & 484087 & 6898484 & 4172427 & 2891021 & 155248 & 180643 & 1309410 \\
\hline Taxes, 2005 & 0 & 0 & 0 & 0 & 0 & 3894 & 0 & 0 & 0 & 0 & 0 \\
\hline Taxes, 2006 & 0 & 0 & 0 & 0 & 0 & 6633 & 0 & 0 & 0 & 0 & 0 \\
\hline Acc. profit less Taxes (AP), 2005 & 799977 & 3580116 & 573277 & 419408 & 1636490 & 4072572 & 869133 & 2281635 & 152729 & 162726 & 732777 \\
\hline Acc. profit less Taxes (AP), 2006 & 1473946 & 3909284 & 350694 & 455780 & 484087 & 6891850 & 4172427 & 2891021 & 155248 & 180643 & 1309410 \\
\hline Subsidy. S $\left\{E^{*} m+A(m-c)+K-A P\right\} 05$ & 572307 & 921046 & 28149 & -76506 & -213664 & -135829 & -56975 & -315072 & -1915 & -44732 & -40895 \\
\hline Subsidy. $S\left\{E^{*} m+A(m-c)+K-A P\right\} 06$ & 77895 & -680877 & -45636 & -65977 & 23303 & 400286 & -2710254 & 870395 & -50932 & 6541 & -486462 \\
\hline Ave. Loan port (net) LP, 2005 & 7533015 & 2148561 & 1017671 & 4494323 & 4221606 & 65987339 & 7389409 & 29055179 & 1037396 & 894027 & 4950225 \\
\hline Ave. Loan port (net) LP, 2006 & 10011149 & 3894247 & 1659206 & 6652702 & 6724517 & 151222408 & 18767114 & 58557979 & 1439862 & 1449883 & 8769785 \\
\hline Rev. From lending $(L P * i), 2005$ & 2359061 & 692139 & 28849 & 1218705 & 1706924 & 16953493 & 2485507 & 8316461 & 404339 & 405660 & 922497 \\
\hline Rev. From lending (LP*i), 2006 & 3122343 & 1449345 & 63363 & 1766717 & 2442661 & 32635631 & 8200320 & 14247809 & 575964 & 581240 & 1542361 \\
\hline Yield on lending (i), 2005 & 0.313 & 0.322 & 0.028 & 0.271 & 0.404 & 257 & 336 & 286 & 0.390 & 0.454 & 0.186 \\
\hline Yield on lending (i), 2006 & 0.312 & 0.372 & 38 & 0.266 & 53 & 1 & 37 & 43 & 00 & 0. & 0.176 \\
\hline SDI (S/LP*i), 2005 & 0.243 & 1.331 & 0.976 & -0.063 & -0.125 & -0.008 & -0.023 & -0.038 & -0.005 & -0.110 & -0.044 \\
\hline SDI (S/LP*i), 2006 & 0.025 & -0.470 & -0.720 & -0.037 & 0.010 & 0.012 & -0.331 & 0.061 & -0.088 & 0.011 & -0.315 \\
\hline Change in Yield, 2005 & 0.076 & 0.429 & 0.028 & -0.017 & -0.051 & -0.002 & -0.008 & -0.011 & -0.002 & -0.050 & -0.008 \\
\hline Change in Yield, 2006 & 0.008 & -0.175 & -0.028 & -0.010 & 0.003 & 0.003 & -0.144 & 0.050 & -0.035 & 0.005 & -0.055 \\
\hline Nominal Subsidy free yield, 2005 & 0.389 & 0.751 & 0.056 & 0.254 & 0.354 & 0.255 & 0.329 & 0.275 & 0.388 & 0.404 & 0.178 \\
\hline Nominal Subsidy free yield, 2006 & 0.320 & 0.197 & 0.011 & 0.256 & 0.367 & 0.218 & 0.293 & 0.258 & 0.365 & 0.405 & 0.120 \\
\hline Inflation, 2005 & 0.049 & 0.049 & 0.049 & 0.035 & 0.035 & 0.010 & 0.010 & 0.010 & 0.010 & 0.010 & 0.020 \\
\hline Inflation, 2006 & 0.076 & 0.076 & 0.076 & 0.063 & 0.063 & 0.033 & 0.033 & 0.033 & 0.033 & 0.033 & 0.045 \\
\hline Real Subsidy-free yield, 2005 & 0.325 & 0.670 & 0.007 & 0.212 & 0.308 & 0.243 & 0.316 & 0.263 & 0.374 & 0.390 & 0.155 \\
\hline Real Subsidy- free yield, 2006 & 0.226 & 0.112 & -0.061 & 0.182 & 0.286 & 0.179 & 0.251 & 0.218 & 0.321 & 0.361 & 0.072 \\
\hline True Profit, 2005 & 687147 & -356659 & 86513 & 322105 & 554732 & 2862220 & 503097 & 1820216 & 15271 & 136906 & 473634 \\
\hline True Profit, 2006 & 1303516 & 1595520 & 216703 & 367747 & 432683 & 2963862 & 3485960 & 927635 & 82777 & 112521 & 1075572 \\
\hline Return on Assets (ROA), 2005 & 0.049 & 0.579 & 0.250 & 0.069 & 0.295 & 0.059 & 0.093 & 0.120 & 0.108 & 0.156 & 0.132 \\
\hline Return on Assets (ROA), 2006 & 0.078 & 0.362 & 0.119 & 0.058 & 0.059 & 0.040 & 0.195 & 0.046 & 0.089 & 0.108 & 0.127 \\
\hline Subsidy-adjusted ROA, 2005 & 0.042 & -0.058 & 0.038 & 0.053 & 0.100 & 0.041 & 0.054 & 0.096 & 0.011 & 0.132 & 0.086 \\
\hline Subsidy-adjusted ROA, 2006 & 0.069 & 0.148 & 0.074 & 0.046 & 0.052 & 0.017 & 0.163 & 0.018 & 0.047 & 0.067 & 0.104 \\
\hline Return on Equity (ROE), 2005 & 0.083 & 0.834 & 0.657 & 0.130 & 0.365 & 0.172 & 0.224 & 0.174 & 1.315 & 0.203 & 0.169 \\
\hline Return on Equity (ROE), 2006 & 0.134 & 0.539 & 0.258 & 0.124 & 0.087 & 0.236 & 0.619 & 0.185 & 0.561 & 0.174 & 0.222 \\
\hline Subsidy-adjusted ROE, 2005 & 0.072 & -0.083 & 0.099 & 0.100 & 0.124 & 0.121 & 0.130 & 0.139 & 0.131 & 0.171 & 0.109 \\
\hline Subsidy-adjusted ROE, 2006 & 0.119 & 0.220 & 0.160 & 0.100 & 0.078 & 0.101 & 0.517 & 0.059 & 0.299 & 0.109 & 0.183 \\
\hline
\end{tabular}


Appendix D DEA Efficiencies for $R^{s}$ (R-S) for 2005

\begin{tabular}{|c|c|c|c|c|c|c|c|c|c|c|c|c|c|c|c|c|c|}
\hline \multirow[t]{2}{*}{ MFIs } & \multirow[t]{2}{*}{ Coun } & \multicolumn{4}{|c|}{ LR-ACE } & \multicolumn{4}{|c|}{ LR $^{\text {s }}$-ACE } & \multicolumn{4}{|c|}{ R-ACE } & \multicolumn{4}{|c|}{$\mathbf{R}^{s}$-ACE } \\
\hline & & crste & vrste & scale & & crste & vrste & scale & & crste & vrste & scale & & crste & vrste & scale & \\
\hline ARMP & AFG & 0.676 & 0.766 & 0.882 & rs & 0.676 & 0.766 & 0.882 & drs & 0.401 & 0.402 & 0.998 & irs & 0.043 & 0.071 & 0.605 & $\mathrm{drs}$ \\
\hline FMF & $G$ & 0.341 & 50 & 0.976 & rs & 286 & 0.315 & 0.906 & drs & 324 & 0.326 & 997 & irs & .076 & .089 & .851 & $\mathrm{drs}$ \\
\hline BESA & LB & 1.000 & 1.000 & 1.000 & - & 1.000 & 1.000 & 1.000 & - & 0.771 & 0.800 & 0.964 & irs & 0.437 & 0.452 & 0.968 & drs \\
\hline ProCr & LB & 0.655 & 0.745 & 0.878 & drs & 601 & 0.745 & 0.807 & drs & 0.645 & 0.680 & 0.949 & drs & 0.407 & 0.602 & 0.677 & drs \\
\hline PSHM & ALB & 0.778 & 0.859 & 0.906 & drs & 0.774 & 0.858 & 0.902 & drs & 0.647 & 0.650 & 0.996 & irs & 0.228 & 0.248 & 0.919 & drs \\
\hline $\mathrm{AC}$ & RM & 0.654 & 0.715 & 0.914 & drs & 628 & 0.708 & 0.888 & drs & 0.633 & 0.665 & 0.952 & drs & 0.253 & 0.435 & 0.581 & drs \\
\hline HORIZON & ARM & 0.891 & 0.956 & 0.932 & irs & 0.710 & 0.753 & 0.943 & irs & 0.862 & 0.940 & 0.917 & irs & 0.190 & 0.218 & 0.871 & irs \\
\hline INECO & $\mathbf{R M}$ & 0.847 & 0.909 & 0.932 & drs & 0.638 & 0.699 & 0.913 & drs & 0.847 & 0.909 & 0.932 & drs & 0.301 & 0.585 & 0.514 & drs \\
\hline CRED AGR & AZE & 0.868 & 0.874 & 0.993 & drs & 0.868 & 0.874 & 0.993 & drs & 0.658 & 0.668 & 0.985 & irs & 0.055 & 0.056 & 0.996 & - \\
\hline MFBA & $\mathbf{Z E}$ & 0.691 & 0.807 & 0.856 & drs & 0.691 & 0.807 & 0.856 & drs & 0.549 & 0.549 & 1.000 & & 0.078 & 0.176 & 0.445 & drs \\
\hline NORMICRC & AZE & 0.912 & 0.969 & 0.941 & irs & 0.753 & 0.789 & 0.955 & irs & 0.868 & 0.941 & 0.922 & irs & 0.193 & 0.207 & 0.930 & irs \\
\hline tor & $E$ & 0.897 & 0.921 & 0.974 & irs & 0.754 & 0.763 & 0.988 & irs & 0.862 & 0.892 & 0.966 & irs & 0.252 & 0.252 & 1.000 & - \\
\hline ASA & BAN & 0.993 & 1.000 & 0.993 & drs & 0.916 & 1.000 & 0.916 & drs & 0.993 & 1.000 & 0.993 & drs & 0.391 & 1.000 & 0.391 & $\mathrm{drs}$ \\
\hline BRAC & $\mathbf{N}$ & 0.793 & 0.975 & 0.813 & drs & 0.700 & 0.975 & 0.718 & drs & 0.732 & 0.798 & 0.917 & drs & 0.000 & 0.001 & 0.224 & drs \\
\hline B TANGAIL & AN & 0.864 & 0.894 & 0.966 & drs & 0.805 & 0.907 & 0.888 & drs & 0.812 & 0.812 & 1.000 & - & 0.219 & 0.459 & 0.476 & $\mathrm{drs}$ \\
\hline DESHA & BAN & 0.750 & 0.777 & 0.965 & irs & 0.720 & 0.727 & 0.990 & irs & 0.661 & 0.697 & 0.948 & irs & 0.141 & 0.157 & 0.902 & irs \\
\hline IDF & BAN & 0.801 & 0.813 & 0.985 & irs & 0.787 & 0.787 & 0.999 & - & 0.701 & 0.722 & 0.972 & irs & 0.167 & 0.170 & 0.986 & irs \\
\hline RDRS & $\mathbf{N}$ & 0.581 & 0.605 & 0.961 & drs & 0.581 & 0.605 & 0.961 & drs & 0.411 & 0.411 & 1.000 & - & 0.002 & 0.003 & 0.672 & drs \\
\hline SHAKTI & BAN & 0.859 & 0.925 & 0.928 & drs & 0.859 & 0.926 & 0.927 & drs & 0.614 & 0.615 & 0.999 & - & 0.125 & 0.208 & 0.600 & $\mathrm{drs}$ \\
\hline TMSS & BAN & 0.661 & 0.756 & 0.875 & drs & 0.659 & 0.756 & 0.872 & drs & 0.534 & 0.534 & 1.000 & - & 0.040 & 0.101 & 0.396 & $\mathrm{drs}$ \\
\hline FECECAM & EN & 0.508 & 0.559 & 0.908 & drs & 0.424 & 0.556 & 0.764 & drs & 0.481 & 0.485 & 0.992 & drs & 0.114 & 0.420 & 0.273 & $\mathrm{drs}$ \\
\hline ALIDE & BEN & 0.697 & 1.000 & 0.697 & irs & 0.669 & 1.000 & 0.669 & irs & 0.359 & 1.000 & 0.359 & irs & 0.011 & 1.000 & 0.011 & irs \\
\hline PADME & EN & 0.741 & 0.815 & 0.909 & drs & 0.709 & 0.806 & 0.880 & drs & 0.697 & 0.703 & 0.992 & drs & 0.198 & 0.389 & 0.509 & $\mathrm{drs}$ \\
\hline VF & BEN & 0.758 & 0.761 & 0.997 & drs & 0.722 & 0.745 & 0.968 & drs & 0.711 & 0.715 & 0.995 & irs & 0.229 & 0.229 & 1.000 & - \\
\hline RCPB & & 0.681 & 0.800 & 0.851 & drs & 0.681 & 0.800 & 0.851 & drs & 0.460 & 0.466 & 0.987 & drs & 0.125 & 0.403 & 0.311 & $\mathrm{drs}$ \\
\hline Agrocapita & BOL & 0.717 & 0.796 & 0.900 & drs & 0.714 & 0.796 & 0.898 & drs & 0.569 & 0.571 & 0.996 & irs & 0.129 & 0.148 & 0.867 & drs \\
\hline BANC & $\mathrm{OL}$ & 0.737 & 0.910 & 0.810 & drs & 0.730 & 0.910 & 0.802 & drs & 0.648 & 0.682 & 0.951 & drs & 0.293 & 0.574 & 0.510 & $\mathrm{drs}$ \\
\hline Bnaco L A & BOL & 0.759 & 0.985 & 0.771 & drs & 0.759 & 0.985 & 0.771 & drs & 0.561 & 0.596 & 0.941 & drs & 0.197 & 0.406 & 0.485 & drs \\
\hline CREC & $\mathrm{OL}$ & 0.857 & 0.930 & 0.921 & drs & 0.743 & 0.911 & 0.815 & drs & 0.804 & 0.840 & 0.958 & drs & .214 & 0.496 & 0.431 & drs \\
\hline Eco Futuro & BOL & 0.705 & 0.795 & 0.887 & drs & 0.705 & 0.802 & 0.878 & drs & 0.607 & 0.607 & 1.000 & - & 0.206 & 0.319 & 0.647 & drs \\
\hline FADES & OL & 0.839 & 1.000 & 0.839 & drs & 0.820 & 0.993 & 0.826 & drs & 0.668 & 0.668 & 1.000 & - & 0.094 & 0.219 & 0.429 & drs \\
\hline FIE & BOL & 0.786 & 0.943 & 0.833 & drs & 0.786 & 0.943 & 0.833 & drs & 0.632 & 0.641 & 0.985 & drs & 0.165 & 0.449 & 0.368 & drs \\
\hline Foncre & BOL & 0.893 & 0.937 & 0.953 & irs & 0.893 & 0.937 & 0.953 & irs & 0.719 & 0.780 & 0.921 & irs & 120 & 0.151 & 0.795 & irs \\
\hline FunB & BOL & 0.845 & 0.861 & 0.981 & irs & 0.700 & 0.700 & 0.999 & - & 0.781 & 0.808 & 0.966 & irs & 0.196 & 0.214 & 0.920 & irs \\
\hline PRODEM & BOL & 0.701 & 0.902 & 0.777 & drs & & 0.902 & 0.749 & drs & 0.622 & 0.645 & 65 & drs & 90 & 44 & 48 & $\mathrm{drs}$ \\
\hline ProMujar & BOL & 0.737 & 0.813 & 0.906 & drs & 0.674 & 0.791 & 0.852 & drs & 0.651 & 0.652 & 0.999 & irs & 0.093 & 0.183 & 0.509 & $\mathrm{drs}$ \\
\hline EKI & BOS & 0.863 & 0.963 & 0.896 & $\mathrm{drs}$ & 0.863 & 0.963 & 0.896 & drs & 0.592 & 0.593 & 0.997 & ars & 0.267 & 0.356 & 0.752 & drs \\
\hline MIKROFIN & BOS & 0.992 & 1.000 & 0.992 & $\mathrm{drs}$ & 1.000 & 1.000 & 1.000 & - & 0.730 & 0.731 & 0.999 & irs & 0.484 & 0.523 & 0.925 & drs \\
\hline $\mathbf{P A}$ & BOS & 0.906 & 0.952 & 0.952 & $\mathrm{drs}$ & 0.912 & 0.956 & 0.954 & drs & 0.725 & 0.729 & 0.995 & drs & 0.402 & 0.455 & 0.884 & $\mathrm{drs}$ \\
\hline SUNRISE & BOS & 0.838 & 0.926 & 0.906 & drs & 0.817 & 0.934 & 0.876 & drs & 0.721 & 0.725 & 0.994 & irs & 0.334 & 0.400 & 0.834 & $\mathrm{drs}$ \\
\hline ACEP & M & 0.923 & 0.932 & 0.990 & irs & 0.796 & 0.803 & 0.992 & irs & 0.839 & 0.864 & 0.971 & irs & 0.123 & 0.128 & 0.956 & irs \\
\hline CDS & AM & 0.548 & 0.549 & 1.000 & - & 0.472 & 0.522 & 0.904 & drs & 0.521 & 0.521 & 0.999 & irs & 0.139 & 0.187 & 0.746 & $\mathrm{drs}$ \\
\hline CMM Bog & COL & 0.847 & 0.956 & 0.886 & drs & 0.765 & 0.955 & 0.801 & drs & 0.762 & 0.762 & 1.000 & - & 0.221 & 0.469 & 0.472 & drs \\
\hline Finamerica & COL & 0.797 & 0.921 & 0.865 & drs & 0.721 & 0.922 & 0.782 & drs & 0.713 & 0.713 & 1.000 & - & 0.253 & 0.522 & 0.484 & $\mathrm{drs}$ \\
\hline FMM Buca & COL & 0.898 & 0.910 & 0.986 & drs & 0.785 & 0.921 & 0.852 & drs & 0.883 & 0.884 & 1.000 & - & 0.390 & 0.737 & 0.530 & drs \\
\hline FMM Pop & COL & 1.000 & 1.000 & 1.000 & - & 0.872 & 1.000 & 0.872 & drs & 1.000 & 1.000 & 1.000 & - & 0.361 & 0.835 & 0.433 & $\mathrm{drs}$ \\
\hline WMM Med & COL & 0.897 & 0.937 & 0.957 & drs & 0.869 & 0.926 & 0.938 & drs & 0.848 & 0.848 & 1.000 & - & 0.192 & 0.328 & 0.587 & $\mathrm{drs}$ \\
\hline WWB Ca & COL & 0.946 & 1.000 & 0.946 & drs & 0.907 & 1.000 & 0.907 & drs & 0.922 & 0.946 & 0.975 & drs & 0.484 & 0.829 & 0.583 & $\mathrm{drs}$ \\
\hline ACLEDA & DM & 0.704 & 0.858 & 0.820 & drs & 0.651 & 0.858 & 0.759 & drs & 0.630 & 0.646 & 0.976 & drs & 0.126 & 0.556 & 0.227 & $\mathrm{drs}$ \\
\hline AMRET & COM & 0.794 & 0.810 & 0.981 & drs & 0.619 & 0.748 & 0.828 & drs & 0.776 & 0.777 & 0.999 & irs & 0.159 & 0.346 & 0.461 & $\mathrm{drs}$ \\
\hline CEB & COM & 0.798 & 0.798 & 1.000 & - & 0.728 & 0.760 & 0.958 & drs & 0.718 & 0.721 & 0.996 & irs & 0.127 & 0.167 & 0.763 & drs \\
\hline HKL & COM & 0.755 & 0.759 & 0.995 & irs & 0.707 & 0.710 & 0.996 & irs & 0.661 & 0.671 & 0.985 & irs & 0.125 & 0.125 & 1.000 & - \\
\hline PRASAC & COM & 0.755 & 0.848 & 0.890 & drs & 0.696 & 0.822 & 0.847 & drs & 0.650 & 0.655 & 0.992 & drs & 0.118 & 0.230 & 0.513 & $\mathrm{drs}$ \\
\hline CrediMujer & CR & 0.854 & 1.000 & 0.854 & irs & 0.652 & 0.895 & 0.728 & irs & 0.825 & 1.000 & 0.825 & irs & 0.154 & 0.539 & 0.286 & irs \\
\hline Fundecoca & CR & 0.764 & 1.000 & 0.764 & irs & 0.654 & 1.000 & 0.654 & irs & 0.750 & 1.000 & 0.750 & irs & 0.129 & 1.000 & 0.129 & irs \\
\hline ADEMI & DOM & 1.000 & 1.000 & 1.000 & - & 0.875 & 0.982 & 0.891 & $\mathrm{drs}$ & 1.000 & 1.000 & 1.000 & - & 0.605 & 0.955 & 0.634 & $\mathrm{drs}$ \\
\hline Banco Sol & ECU & 0.878 & 1.000 & 0.878 & drs & 0.839 & 1.000 & 0.839 & drs & 0.878 & 1.000 & 0.878 & drs & 0.678 & 1.000 & 0.678 & $\mathrm{drs}$ \\
\hline COAC Jardin & ECU & 1.000 & 1.000 & 1.000 & - & 1.000 & 1.000 & 1.000 & 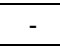 & 0.796 & 0.807 & 0.986 & drs & 0.344 & 0.407 & 0.845 & $\mathrm{drs}$ \\
\hline Coac S Jose & ECU & 0.884 & 0.889 & 0.995 & irs & 0.884 & 0.890 & 0.994 & irs & 0.577 & 0.587 & 0.983 & irs & 0.289 & 0.306 & 0.944 & irs \\
\hline COAC SAC & ECU & 1.000 & 1.000 & 1.000 & 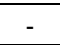 & 1.000 & 1.000 & 1.000 & - & 0.831 & 0.862 & 0.964 & irs & 0.311 & 0.343 & 0.908 & rs \\
\hline
\end{tabular}




\begin{tabular}{|c|c|c|c|c|c|c|c|c|c|c|c|c|c|c|c|c|c|}
\hline \multirow[t]{2}{*}{ MFIs } & \multirow[t]{2}{*}{ Coun } & \multicolumn{4}{|c|}{ LR-ACE } & \multicolumn{4}{|c|}{ LR $^{s}$-ACE } & \multicolumn{4}{|c|}{ R-ACE } & \multicolumn{4}{|c|}{$R^{s}$-ACE } \\
\hline & & crste & vrste & scale & & crste & vrste & scale & & rste & vrste & scale & & rste & vrste & scale & \\
\hline D-Miro & $\mathrm{CU}$ & 0.869 & 0.870 & 0.999 & irs & .747 & 0.803 & 0.929 & drs & 0.813 & 0.821 & 991 & irs & .259 & .287 & 0.900 & $\mathrm{drs}$ \\
\hline Finca & $\overline{\mathrm{CU}}$ & 1.000 & 1.000 & 1.000 & 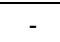 & 820 & 1.000 & 0.820 & drs & 0.988 & 0.994 & 0.994 & drs & .444 & .733 & .606 & $\mathrm{drs}$ \\
\hline FODI & $\mathbf{U}$ & 0.737 & 0.746 & 988 & irs & 41 & 0.752 & 0.985 & irs & 606 & 37 & 952 & irs & 68 & 186 & 905 & irs \\
\hline Fundacion Es & ECU & 0.898 & 0.899 & 1.000 & - & 785 & 0.812 & 0.967 & drs & 0.841 & 0.848 & 0.992 & irs & 0.272 & 0.292 & 0.931 & drs \\
\hline PRC & ECU & 0.867 & 1.000 & 0.867 & drs & 0.876 & 1.000 & 0.876 & drs & 0.724 & 0.734 & 0.987 & drs & 0.413 & 0.633 & 653 & $\mathrm{drs}$ \\
\hline Al Tadamun & EGY & 0.700 & 0.728 & 0.962 & irs & 0.417 & 0.426 & 0.981 & irs & 0.700 & 0.728 & 0.962 & irs & 0.156 & 0.164 & 0.949 & irs \\
\hline D & $\mathrm{GY}$ & 0.662 & 0.668 & 0.991 & drs & 530 & 0.550 & 0.963 & drs & \begin{tabular}{|l|}
0.662 \\
\end{tabular} & 0.668 & 0.991 & drs & 172 & .226 & 0.760 & $\mathrm{drs}$ \\
\hline AMC de RL & ELS & 0.722 & 0.730 & 0.988 & drs & 0.625 & 0.698 & 0.895 & drs & \begin{tabular}{|l|}
0.664 \\
\end{tabular} & 0.667 & 0.996 & irs & 0.152 & 0.204 & 0.744 & $\mathrm{drs}$ \\
\hline Fund & ELS & 0.695 & 0.733 & 0.948 & irs & 695 & 0.733 & 0.948 & irs & \begin{tabular}{|l|}
0.576 \\
\end{tabular} & 0.627 & 0.918 & irs & 59 & .211 & 0.753 & irs \\
\hline ACSI & ETH & 0.831 & 0.898 & 0.925 & drs & 0.838 & 0.917 & 0.914 & drs & \begin{tabular}{|l|}
0.702 \\
\end{tabular} & 0.749 & 0.937 & drs & 309 & 0.603 & 0.513 & $\mathrm{drs}$ \\
\hline A & TH & 0.994 & 1.000 & 0.994 & drs & 94 & 1.000 & 0.994 & drs & \begin{tabular}{|l|}
0.592 \\
\end{tabular} & 0.594 & 0.998 & irs & 95 & 197 & 0.988 & irs \\
\hline BG & ETH & 0.604 & 0.678 & 0.892 & irs & 0.604 & 0.678 & 0.892 & irs & 0.354 & 0.397 & 0.892 & irs & 0.027 & 0.037 & 0.727 & irs \\
\hline D & ETH & 1.000 & 1.000 & 1.000 & 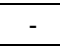 & 1.000 & 1.000 & 1.000 & & 1.000 & 1.000 & 1.000 & - & 36 & 732 & 0.596 & drs \\
\hline OMO & ETH & 0.687 & 0.709 & 0.969 & drs & 0.687 & 0.709 & 0.969 & drs & 0.401 & 0.401 & 1.000 & - & 0.094 & 0.094 & 0.999 & - \\
\hline WISDOI & ETH & 0.739 & 0.742 & 0.996 & drs & 0.739 & 0.742 & 0.996 & drs & 0.501 & 17 & 0.969 & irs & 84 & 85 & 0.989 & irs \\
\hline KSF & HA & 0.700 & 1.000 & 0.700 & irs & 0.677 & 1.000 & 0.677 & irs & \begin{tabular}{|l|}
0.537 \\
\end{tabular} & 1.000 & 0.537 & irs & 0.122 & 1.000 & 0.122 & irs \\
\hline OI SASL & GHA & 0.570 & 0.611 & 0.934 & drs & 0.492 & 0.548 & 0.897 & drs & 0.538 & 0.557 & 0.966 & drs & 46 & 12 & 90 & $\mathrm{drs}$ \\
\hline ProCredit & GHA & 0.800 & 0.834 & 0.958 & drs & 0.621 & 0.726 & 0.855 & drs & 0.798 & & 0.957 & drs & & 466 & & $\mathrm{drs}$ \\
\hline Sat & GHA & 0.606 & 0.609 & 0.994 & irs & 0.506 & 0.506 & 1.000 & + & 0.582 & 0.589 & 0.988 & irs & 32 & 39 & 55 & drs \\
\hline C FUND & GOE & 0.923 & 1.000 & 0.923 & irs & 0.742 & 0.798 & 0.930 & irs & 0.892 & 0.990 & 0.901 & irs & & 36 & 78 & irs \\
\hline Constanta & GOE & 0.844 & 0.893 & 0.945 & drs & 0.701 & 0.785 & 0.893 & drs & 0.685 & 0.782 & 0.876 & drs & 38 & 99 & 0.658 & $\mathrm{drs}$ \\
\hline & $\overline{\mathrm{DE}}$ & 0.642 & 0.645 & 0.996 & irs & 0.625 & 0.637 & 0.982 & irs & 0.510 & 0.527 & 0.969 & irs & & 37 & & - \\
\hline SBDF & GOE & 0.797 & 0.882 & 0.903 & irs & 0.774 & 0.869 & 0.890 & irs & 0.584 & 0.684 & 0.854 & irs & 34 & 45 & 0.759 & irs \\
\hline Fafidess & GUA & 0.864 & 0.864 & 1.000 & - & 0.781 & 0.788 & 0.991 & drs & 0.793 & 0.803 & 0.987 & irs & & 270 & & - \\
\hline Fundacion M & GUA & 0.537 & 0.582 & 0.923 & irs & 0.533 & 0.582 & 0.916 & irs & 0.427 & 0.469 & 0.911 & irs & 0.062 & 0.077 & 0.799 & irs \\
\hline Fundea & GUA & 0.759 & 0.769 & 0.987 & drs & 0.640 & 0.709 & 0.903 & drs & 0.711 & 0.713 & 0.997 & irs & 0.147 & 0.212 & 0.695 & $\mathrm{drs}$ \\
\hline Genesis En & GUA & 0.824 & 0.957 & 0.861 & drs & 0.745 & 0.950 & 0.785 & drs & 0.742 & 0.750 & 0.988 & drs & 88 & 0.505 & 0.373 & drs \\
\hline ACME & HAI & 1.000 & 1.000 & 1.000 & - & 0.754 & 0.766 & 0.985 & drs & 1.000 & 1.000 & 1.000 & - & 39 & 0.339 & 0.999 & - \\
\hline Finca & HON & 0.870 & 0.871 & 0.999 & irs & 0.668 & 0.676 & 0.989 & drs & 0.861 & 0.863 & 0.998 & irs & 0.242 & 0.242 & 0.999 & - \\
\hline HDH & HON & 0.702 & 0.717 & 0.979 & drs & 0.658 & 0.681 & 0.965 & drs & \begin{tabular}{|l|}
0.604 \\
\end{tabular} & 0.605 & 0.998 & irs & 26 & 0.143 & 0.883 & $\mathrm{drs}$ \\
\hline World R & HON & 0.751 & 0.792 & 0.948 & drs & 0.673 & 0.736 & 0.914 & drs & 0.676 & 0.676 & 1.000 & - & & 0.249 & & $\mathrm{drs}$ \\
\hline BANDHAI & & & & & drs & & & & drs & & & & irs & & & & - \\
\hline BASIX & IND & 0.733 & 0.834 & 0.879 & drs & 0.692 & 0.837 & 0.826 & drs & 0.649 & 0.650 & 1.000 & - & 30 & 0.373 & 0.349 & drs \\
\hline Cashpoor & IND & 0.448 & 0.463 & 0.967 & drs & 0.352 & 0.416 & 0.847 & drs & \begin{tabular}{|l|}
0.427 \\
\end{tabular} & 0.427 & 0.999 & - & 47 & 0.095 & 0.493 & $\mathrm{drs}$ \\
\hline ESAF & IND & 0.661 & 0.674 & 0.980 & drs & 0.656 & 0.672 & 0.977 & drs & \begin{tabular}{|l|}
0.503 \\
\end{tabular} & 0.505 & 0.997 & irs & & 0.147 & & irs \\
\hline & & & & & drs & & & & drs & & & & irs & & & & - \\
\hline IASC & IND & 0.833 & 0.842 & 0.989 & drs & 0.833 & 0.842 & 0.989 & drs & \begin{tabular}{|l|}
0.734 \\
\end{tabular} & & 0.996 & irs & 36 & & & irs \\
\hline KBSLAB & & 0.617 & & & irs & 574 & 0.580 & & drs & 0.573 & & & irs & & & & drs \\
\hline Mahaseman & IND & 0.753 & 0.760 & 0.990 & drs & 0.621 & 0.633 & 0.980 & drs & 0.730 & 0.730 & 1.000 & - & 0.284 & 0.285 & 0.999 & - \\
\hline SHARE MF & IND & 0.799 & 0.913 & & drs & 0.773 & 0.909 & 0.850 & drs & 0.739 & & 0.998 & drs & 98 & 78 & 0.292 & $\mathrm{drs}$ \\
\hline SNFL & IND & 0.949 & 0.977 & 0.972 & drs & 0.949 & 0.977 & 0.972 & drs & 0.545 & 0.546 & 0.998 & irs & 0.078 & 0.079 & 0.987 & irs \\
\hline MBK Vent & IND & 0.631 & 0.792 & & irs & 0.513 & 0.670 & 0.766 & irs & 0.593 & & 0.749 & irs & & & 0.370 & irs \\
\hline JMCC & JOR & 0.671 & 0.687 & 0.977 & drs & 0.651 & 0.694 & 0.939 & drs & \begin{tabular}{|l|}
0.582 \\
\end{tabular} & 0.586 & 0.992 & irs & 0.148 & 0.183 & 0.810 & drs \\
\hline MFW & JOR & 0.755 & 0.756 & 0.999 & irs & 0.622 & 0.673 & 0.925 & drs & \begin{tabular}{|l|}
0.729 \\
\end{tabular} & 0.734 & 0.992 & irs & 03 & 0.250 & 0.813 & $\mathrm{drs}$ \\
\hline KLF & KAZ & 0.893 & 0.893 & 1.000 & - & 0.688 & 0.812 & 0.848 & drs & \begin{tabular}{|l|}
0.892 \\
\end{tabular} & 0.893 & 0.999 & irs & 0.242 & 0.464 & 0.521 & $\mathrm{drs}$ \\
\hline EBS & KEN & 0.572 & 0.602 & 0.950 & drs & 0.298 & 0.633 & 0.470 & drs & \begin{tabular}{|l|}
0.572 \\
\end{tabular} & 0.602 & 0.950 & drs & 0.265 & 0.633 & 0.418 & drs \\
\hline Kadet & KEN & 0.427 & 0.428 & 0.996 & irs & 0.372 & 0.373 & 0.998 & irs & 0.387 & 0.392 & 0.988 & irs & 0.028 & 0.028 & 1.000 & - \\
\hline K-REP & KEN & 0.585 & 0.691 & 0.846 & drs & 0.554 & 0.689 & 0.804 & drs & \begin{tabular}{|l|}
0.521 \\
\end{tabular} & 0.521 & 1.000 & - & 46 & 0.367 & 0.400 & $\mathrm{drs}$ \\
\hline KWFT & KEN & 0.643 & 0.671 & 0.958 & drs & 0.505 & 0.645 & 0.783 & drs & 0.619 & 0.619 & 1.000 & - & 0.168 & 0.412 & 0.407 & $\mathrm{drs}$ \\
\hline MDSL & KEN & 0.777 & 0.849 & 0.915 & irs & 0.653 & 0.702 & 0.931 & irs & \begin{tabular}{|l|}
0.734 \\
\end{tabular} & 0.815 & 0.900 & irs & 0.192 & 0.268 & 0.715 & irs \\
\hline SMEP & KEN & 0.622 & 0.637 & 0.976 & drs & 0.537 & 0.601 & 0.894 & drs & 0.573 & 0.576 & 0.995 & irs & 0.131 & 0.180 & 0.728 & $\mathrm{drs}$ \\
\hline AIYL Ban & KYR & 0.972 & 1.000 & 0.972 & drs & 0.972 & 1.000 & 0.972 & drs & 0.660 & 0.704 & 0.938 & drs & 0.017 & 0.039 & 0.438 & drs \\
\hline BTFF & KYR & 0.625 & 0.628 & 0.996 & drs & 0.621 & 0.627 & 0.991 & drs & 0.597 & 0.597 & 1.000 & - & 0.012 & 0.012 & 0.940 & $\mathrm{drs}$ \\
\hline FMCC & KYR & 0.918 & 1.000 & 0.918 & drs & 0.826 & 0.983 & 0.840 & drs & 0.794 & 0.882 & 0.900 & drs & 0.219 & 0.433 & 0.505 & $\mathrm{drs}$ \\
\hline FINCA & MAL & 1.000 & 1.000 & 1.000 & - & 0.677 & 0.681 & 0.994 & irs & 1.000 & 1.000 & 1.000 & - & 0.349 & 0.349 & 1.000 & - \\
\hline ndo Jagin & MAL & 0.371 & 0.402 & 0.923 & drs & 0.376 & 0.409 & 0.919 & drs & 0.253 & 0.254 & 0.998 & irs & 0.071 & 0.105 & 0.680 & $\mathrm{drs}$ \\
\hline Soro $\mathrm{Y}$ & MAL & 0.643 & 0.675 & 0.953 & irs & 0.643 & 0.675 & 0.953 & irs & 0.298 & 0.306 & 0.974 & irs & 0.024 & 0.024 & 1.000 & - \\
\hline CreditMongol & MON & 0.803 & 0.826 & 0.973 & irs & 0.689 & 0.706 & 0.976 & irs & 0.736 & 0.765 & 0.961 & irs & 0.104 & 0.107 & 0.975 & irs \\
\hline Khan Bank & MON & 0.838 & 0.873 & 0.960 & drs & 0.665 & 0.784 & 0.849 & drs & 0.838 & 0.873 & 0.960 & drs & 0.241 & 0.742 & 0.325 & $\mathrm{drs}$ \\
\hline AL AMANA & MOR & 0.801 & 1.000 & 0.801 & drs & 0.807 & 1.000 & 0.807 & drs & 0.651 & 0.651 & 0.999 & - & 0.148 & 0.604 & 0.244 & drs \\
\hline Al Karama & MOR & 0.850 & 0.932 & 0.912 & irs & 0.789 & 0.848 & 0.931 & irs & \begin{tabular}{|l|}
0.777 \\
\end{tabular} & 0.859 & 0.904 & irs & 0.260 & 0.292 & 0.890 & irs \\
\hline
\end{tabular}




\begin{tabular}{|c|c|c|c|c|c|c|c|c|c|c|c|c|c|c|c|c|c|}
\hline \multirow[t]{2}{*}{ MFIs } & \multirow[t]{2}{*}{ Coun } & \multicolumn{4}{|c|}{ LR-ACE } & \multicolumn{4}{|c|}{ LR $^{s}$-ACE } & \multicolumn{4}{|c|}{ R-ACE } & \multicolumn{4}{|c|}{$R^{s}$-ACE } \\
\hline & & crste & vrste & scale & & sec & vrste & scale & & 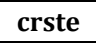 & vrste & scale & & e & vrste & . & \\
\hline Fondep & MOR & 0.773 & 0.834 & 0.928 & $\mathrm{drs}$ & 0.758 & 0.846 & 0.896 & drs & 0.677 & 0.678 & 0.999 & irs & 0.155 & 0.284 & 0.547 & $\mathrm{drs}$ \\
\hline Inmaa & $\mathbf{O R}$ & 0.673 & 0.706 & 0.953 & irs & 000 & 1.000 & 1.000 & - & 583 & 49 & 0.899 & irs & 000 & .000 & 1.000 & - \\
\hline Zakoura & IOR & 0.787 & 0.974 & 0.808 & $\mathrm{drs}$ & 0.772 & 0.985 & 0.784 & drs & 0.659 & 0.701 & 0.941 & drs & 180 & 0.553 & 0.325 & $\mathrm{drs}$ \\
\hline NVO BANCO & MOZ & 0.792 & 0.856 & 0.926 & $\mathrm{drs}$ & 0.624 & 0.728 & 0.857 & drs & 0.766 & 0.829 & 0.923 & drs & 187 & 0.333 & 0.562 & drs \\
\hline SOCI & MOZ & 0.795 & 0.801 & 0.992 & $\mathrm{drs}$ & 0.562 & 0.624 & 0.901 & drs & \begin{tabular}{|l|}
0.793 \\
\end{tabular} & 0.801 & 0.990 & drs & 0.161 & 0.230 & 0.699 & drs \\
\hline TCHUMA & MOZ & 0.866 & 0.866 & 0.999 & irs & 0.703 & 0.706 & 0.996 & irs & \begin{tabular}{|l|}
0.751 \\
\end{tabular} & 0.756 & 0.992 & irs & 0.222 & 0.222 & 0.999 & - \\
\hline CBB & NEP & 0.635 & 0.640 & 0.993 & irs & 0.484 & 0.492 & 0.984 & drs & \begin{tabular}{|l|}
0.635 \\
\end{tabular} & 0.640 & 0.993 & irs & 186 & 0.196 & 0.950 & irs \\
\hline NIRDHA & NEP & 0.622 & 0.632 & 0.985 & $\mathrm{drs}$ & 0.617 & 0.631 & 0.978 & drs & \begin{tabular}{|l|}
0.500 \\
\end{tabular} & 0.501 & 0.997 & irs & 17 & 0.122 & 0.962 & $\mathrm{drs}$ \\
\hline NSSC & EP & 0.626 & 0.634 & 0.988 & irs & 0.398 & 0.409 & 0.972 & drs & \begin{tabular}{|l|}
0.626 \\
\end{tabular} & 0.634 & 0.988 & irs & 10 & 230 & 0.915 & irs \\
\hline PGBB & NEP & 0.608 & 0.615 & 0.988 & $\mathrm{drs}$ & 0.596 & 0.611 & 0.976 & drs & 0.534 & 0.534 & 0.999 & - & & 0.118 & 0.996 & irs \\
\hline VYCCU & $\mathbf{P P}$ & 1.000 & 1.000 & 1.000 & - & .000 & 1.000 & 1.000 & - & \begin{tabular}{|l|}
0.924 \\
\end{tabular} & & 0.924 & irs & & 000 & & irs \\
\hline ACODEP & NIC & 0.960 & 0.963 & 0.998 & drs & 0.723 & 0.887 & 0.815 & drs & \begin{tabular}{|l|}
0.957 \\
\end{tabular} & 0.961 & 0.996 & drs & 0.391 & 664 & 89 & drs \\
\hline & NIC & 0.891 & 0.897 & 0.994 & drs & 0.778 & 0.889 & 0.875 & drs & \begin{tabular}{|l|}
0.872 \\
\end{tabular} & & 1.000 & - & & 551 & & drs \\
\hline FDL & NIC & 0.763 & 0.847 & 0.901 & $\mathrm{drs}$ & 0.720 & 0.852 & 0.845 & drs & 0.703 & 0.703 & 1.000 & - & 0.195 & 0.552 & 53 & drs \\
\hline & NIC & 0.878 & 0.890 & 0.987 & $\mathrm{drs}$ & 0.758 & 0.878 & 0.864 & drs & \begin{tabular}{|l|}
0.878 \\
\end{tabular} & & 0.989 & drs & & & & $\mathrm{drs}$ \\
\hline FJN & NIC & 0.874 & 0.889 & 0.983 & $\mathrm{drs}$ & 0.747 & 0.874 & 0.855 & drs & \begin{tabular}{|l|}
0.840 \\
\end{tabular} & 0.840 & 0.999 & irs & 0.248 & 0.465 & 0.534 & $\mathrm{drs}$ \\
\hline FUNDE & NIC & 0.952 & 0.955 & 0.997 & irs & 0.809 & & & drs & \begin{tabular}{|l|}
0.938 \\
\end{tabular} & & & irs & & & & drs \\
\hline ProCredit & NIC & 0.884 & 0.946 & 0.934 & drs & 0.775 & 0.948 & 0.818 & drs & 0.849 & 0.851 & 0.998 & drs & 0.392 & 0.773 & 0.507 & drs \\
\hline & NIC & 1.000 & 1.000 & 1.000 & - & 1.000 & 1.000 & 1.000 & - & 1.000 & & & - & & 87 & & irs \\
\hline LAPO & NIG & 0.746 & 0.747 & 0.998 & irs & 0.560 & 0.578 & 0.969 & drs & \begin{tabular}{|l|}
0.745 \\
\end{tabular} & 0.747 & 0.997 & irs & 0.212 & 24 & 0.946 & $\mathrm{drs}$ \\
\hline & & & & & & & & & irs & & & & irs & & & & irs \\
\hline ASASAH & PAK & 0.910 & 0.924 & 0.985 & irs & 0.754 & 0.819 & 0.921 & irs & \begin{tabular}{|l|}
0.725 \\
\end{tabular} & 0.731 & 0.993 & irs & 98 & 37 & 0.883 & irs \\
\hline & & 0 & 0.337 & & & 3 & & & $\mathrm{drs}$ & 36 & & & drs & & & & $\mathrm{drs}$ \\
\hline KASHF & PAK & 0.681 & 0.681 & 1.000 & - & 0.621 & 0.664 & 0.935 & drs & 0.681 & 0.681 & 1.000 & 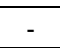 & 88 & 0.321 & 0.586 & $\mathrm{drs}$ \\
\hline FIEI & & 0 & 0.872 & & - & 0 & & 0.8 & drs & 71 & & & irs & & & & $\mathrm{drs}$ \\
\hline Inter & PAR & 0.899 & 0.900 & 1.000 & - & 0.663 & 0.792 & 0.837 & drs & \begin{tabular}{|l}
0.899 \\
\end{tabular} & 0.900 & 1.000 & - & & 0.532 & 0.380 & $\mathrm{drs}$ \\
\hline & $\mathbf{R}$ & 2 & 1.000 & & drs & 32 & 1. & 0.732 & $\mathrm{drs}$ & 7 & & & drs & & & & drs \\
\hline Caj & PER & 0.737 & 0.772 & 0.955 & $\mathrm{drs}$ & 0.662 & 0.767 & 0.863 & drs & \begin{tabular}{|l|}
0.707 \\
\end{tabular} & 0.707 & 1.000 & - & 36 & 0.501 & 0.471 & $\mathrm{drs}$ \\
\hline & PER & 0.758 & 0.796 & & $\mathrm{drs}$ & 0.679 & 0.742 & 0.915 & drs & 0.618 & & 2 & drs & 3 & & & drs \\
\hline CMA & PER & 1.000 & 1.000 & 1.000 & - & 1.000 & 1.000 & 1.000 & - & 1.000 & 1.0 & 1.000 & - & 64 & 1.000 & 0.864 & $\mathrm{drs}$ \\
\hline CMA & PER & 1.000 & 1.000 & & - & 941 & 1. & 0.941 & drs & 1.000 & & 00 & - & 3 & 47 & 8 & drs \\
\hline CMA & PER & 0.798 & 0.839 & 0.951 & $\mathrm{drs}$ & 0.674 & 0.827 & 0.816 & drs & 0.754 & 0.754 & 1.000 & - & 0.270 & 0.500 & 0.541 & $\mathrm{drs}$ \\
\hline $\mathrm{CM}$ & PER & 0.830 & 0.863 & 0.962 & $\mathrm{drs}$ & 0.807 & 0.858 & 0.941 & drs & \begin{tabular}{|l}
0.796 \\
\end{tabular} & & 0.985 & drs & & 5 & 88 & drs \\
\hline CMA & PER & 0.903 & 0.997 & 0.905 & $\mathrm{drs}$ & 0.899 & 0.997 & 0.901 & drs & \begin{tabular}{|l}
0.819 \\
\end{tabular} & 0.836 & 0.979 & drs & 51 & 0.764 & 0.721 & $\mathrm{drs}$ \\
\hline Edpy. C Tac & PER & 0.893 & 0.894 & 0.999 & irs & 0.766 & 0.828 & 0.925 & drs & \begin{tabular}{|l|}
0.831 \\
\end{tabular} & 0.841 & 0.988 & irs & 9 & 90 & 0.998 & irs \\
\hline Edpy. Cofian & PER & 0.810 & 0.829 & 0.978 & $\mathrm{drs}$ & 0.700 & 0.795 & 0.881 & drs & \begin{tabular}{|l|}
0.781 \\
\end{tabular} & 0.781 & 1.000 & - & 0.237 & 0.366 & 0.646 & $\mathrm{drs}$ \\
\hline EDPY.Edyf & & 0.815 & 0.895 & 0.910 & drs & 0.666 & 0.874 & 0.762 & drs & \begin{tabular}{|l|}
0.769 \\
\end{tabular} & 0.769 & 1.000 & - & 85 & 0.540 & 0.344 & $\mathrm{drs}$ \\
\hline FINCA & PER & 0.803 & 0.844 & 0.952 & irs & 0.584 & 0.602 & 0.971 & irs & 0.803 & 0.844 & 0.952 & irs & 0.250 & 0.250 & 1.000 & - \\
\hline Fondesurco & PER & 0.782 & 0.827 & 0.946 & irs & 0.724 & 0.763 & 0.949 & irs & 0.692 & 0.756 & 0.915 & irs & 113 & 0.146 & 0.774 & irs \\
\hline MiBanco & PER & 0.850 & 1.000 & 0.850 & $\mathrm{drs}$ & 0.766 & 1.000 & 0.766 & drs & \begin{tabular}{|l|}
0.803 \\
\end{tabular} & 0.914 & 0.879 & drs & 0.395 & 0.991 & 0.398 & drs \\
\hline Movim. M R & & 0.828 & 0.848 & 0.976 & irs & 0.722 & 0.737 & 0.979 & irs & \begin{tabular}{|l|}
0.725 \\
\end{tabular} & 0.750 & 0.967 & irs & 8 & 0.228 & 0 & - \\
\hline Promujer & PER & 0.883 & 0.888 & 0.994 & irs & 0.704 & 0.705 & 0.999 & drs & \begin{tabular}{|l|}
0.856 \\
\end{tabular} & 0.864 & 0.991 & irs & 0.197 & 0.198 & 0.999 & - \\
\hline ASHI & & 0.629 & 0.630 & 0.998 & irs & 0.538 & 0.548 & 0.982 & irs & \begin{tabular}{|l|}
0.556 \\
\end{tabular} & 0.568 & 0.978 & irs & 59 & 0.159 & 1.000 & - \\
\hline Bangko $\mathrm{K}$ & PHI & 0.564 & 0.577 & 0.976 & $\mathrm{drs}$ & 0.446 & 0.482 & 0.925 & drs & \begin{tabular}{|l|}
0.564 \\
\end{tabular} & 0.577 & 0.976 & drs & 0.192 & 0.328 & 0.584 & drs \\
\hline BCB & & 0.847 & 0.864 & 0.980 & irs & 0.623 & 0.626 & 0.996 & irs & \begin{tabular}{|l|}
0.847 \\
\end{tabular} & 0.864 & 0.980 & irs & 23 & 0.223 & 0.997 & irs \\
\hline CBMO & PHI & 0.731 & 0.733 & 0.997 & irs & 0.622 & 0.633 & 0.983 & drs & 0.721 & 0.725 & 0.994 & irs & 0.191 & 0.222 & 0.858 & drs \\
\hline DIGOS & & 0.655 & 0.660 & 0.992 & irs & 1.000 & 1.000 & 1.000 & - & 0.624 & 0.634 & 0.984 & irs & 1.000 & 1.000 & 1.000 & - \\
\hline GREEN & PHI & 0.693 & 0.727 & 0.954 & $\mathrm{drs}$ & 0.545 & 0.694 & 0.785 & drs & \begin{tabular}{|l|}
0.682 \\
\end{tabular} & 0.687 & 0.993 & drs & 0.169 & 0.489 & 0.345 & drs \\
\hline Ist Valley & PHI & 0.838 & 0.850 & 0.985 & $\mathrm{drs}$ & 0.756 & 0.842 & 0.898 & drs & \begin{tabular}{|l|}
0.799 \\
\end{tabular} & 0.799 & 1.000 & - & 0.193 & 0.383 & 0.503 & drs \\
\hline NWFT & & & & 0.965 & drs & 0.539 & 0.626 & 0.861 & drs & \begin{tabular}{|l|}
0.687 \\
\end{tabular} & 0.701 & & drs & & & & drs \\
\hline SOLANO & PHI & 0.780 & 0.807 & 0.967 & irs & 0.689 & 0.692 & 0.994 & irs & \begin{tabular}{|l|}
0.780 \\
\end{tabular} & 0.807 & 0.967 & irs & 0.278 & 0.334 & 0.832 & irs \\
\hline & & & 0.903 & 0.828 & $\mathrm{drs}$ & 0.614 & 0.759 & 0.809 & drs & 0.709 & 0.903 & 0.784 & drs & 0.284 & 0.621 & 0.458 & drs \\
\hline FORUS & RUS & 0.688 & 0.734 & 0.937 & $\mathrm{drs}$ & 0.590 & 0.726 & 0.812 & drs & \begin{tabular}{|l|}
0.648 \\
\end{tabular} & 0.648 & 1.000 & - & 0.216 & 0.451 & 0.479 & drs \\
\hline SEF-ZAF & חת & 1.000 & 1.000 & 1.000 & 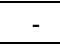 & 0.742 & 0.758 & 0.979 & drs & 1.000 & 1.000 & 1.000 & - & 0.316 & 0.317 & 0.999 & 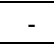 \\
\hline SPBD & SAM & 0.708 & 0.876 & 0.809 & irs & 0.551 & 0.803 & 0.686 & irs & \begin{tabular}{|l|}
0.681 \\
\end{tabular} & 0.876 & 0.777 & irs & 0.125 & 0.527 & 0.236 & irs \\
\hline ACEP & SEN & 1.000 & 1.000 & 1.000 & 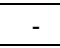 & 0.991 & 1.000 & 0.991 & drs & \begin{tabular}{|l|}
0.823 \\
\end{tabular} & 0.835 & 0.986 & drs & 0.306 & 0.357 & 0.855 & drs \\
\hline CMS & SEN & 0.672 & 0.751 & 0.895 & $\mathrm{drs}$ & 0.656 & 0.751 & 0.873 & drs & 0.586 & 0.595 & 0.985 & drs & 0.260 & 0.393 & 0.662 & $\mathrm{drs}$ \\
\hline Pamecas & SEN & 0.654 & 0.826 & 0.792 & $\mathrm{drs}$ & 0.654 & 0.828 & 0.790 & drs & \begin{tabular}{|l|}
0.505 \\
\end{tabular} & 0.505 & 1.000 & - & 0.161 & 0.360 & 0.447 & drs \\
\hline MCHL & $T \& T$ & 0.656 & 0.686 & 0.957 & irs & 0.635 & 0.667 & 0.951 & irs & 0.521 & 0.569 & 0.916 & irs & 0.142 & 0.172 & 0.829 & irs \\
\hline Agroinvest & TAJ & 0.809 & 0.810 & 0.999 & drs & 0.599 & 0.709 & 0.845 & drs & 0.809 & 0.810 & 0.999 & drs & 0.169 & 0.563 & 0.300 & drs \\
\hline Bank Eskhata & TAJ & 0.899 & 0.900 & 0.999 & irs & 0.402 & 0.430 & 0.935 & drs & 0.899 & 0.900 & 0.999 & irs & 0.226 & 0.351 & 0.643 & drs \\
\hline
\end{tabular}




\begin{tabular}{|c|c|c|c|c|c|c|c|c|c|c|c|c|c|c|c|c|c|}
\hline FMFB TAJ & TAJ & 0.430 & 0.431 & 0.998 & irs & 0.358 & 0.364 & 0.981 & drs & 0.430 & 0.431 & 0.998 & irs & 0.029 & 0.032 & 0.901 & drs \\
\hline IMON & TAJ & 0.835 & 0.839 & 0.995 & irs & 0.694 & 0.697 & 0.996 & irs & 0.778 & 0.787 & 0.989 & irs & 0.114 & 0.114 & 1.000 & - \\
\hline MicroInvest & TAJ & 0.809 & 0.884 & 0.914 & irs & 0.684 & 0.740 & 0.923 & irs & 0.765 & 0.847 & 0.903 & irs & 0.183 & 0.211 & 0.866 & irs \\
\hline FINCA TAN & TAN & 0.914 & 0.960 & 0.953 & drs & 0.733 & 0.820 & 0.894 & drs & 0.883 & 0.936 & 0.943 & drs & 0.321 & 0.449 & 0.715 & drs \\
\hline PRIDE & TAN & 0.917 & 1.000 & 0.917 & drs & 0.806 & 0.967 & 0.834 & drs & 0.839 & 0.890 & 0.943 & drs & 0.283 & 0.569 & 0.498 & drs \\
\hline Enda & TUN & 0.836 & 0.873 & 0.958 & drs & 0.778 & 0.835 & 0.932 & drs & 0.763 & 0.763 & 0.999 & irs & 0.223 & 0.280 & 0.799 & drs \\
\hline CERUDEB & UGA & 0.611 & 0.643 & 0.951 & drs & 0.408 & 0.614 & 0.665 & drs & 0.611 & 0.643 & 0.951 & drs & 0.241 & 0.614 & 0.392 & drs \\
\hline CMFL & UGA & 0.837 & 0.843 & 0.992 & drs & 0.510 & 0.580 & 0.880 & drs & 0.837 & 0.843 & 0.992 & drs & 0.250 & 0.366 & 0.683 & drs \\
\hline FAULU & UGA & 0.763 & 0.763 & 0.999 & - & 0.527 & 0.555 & 0.950 & drs & 0.763 & 0.763 & 0.999 & - & 0.214 & 0.241 & 0.891 & $\mathrm{drs}$ \\
\hline FINCA UGA & UGA & 0.989 & 1.000 & 0.989 & drs & 0.733 & 0.837 & 0.876 & drs & 0.989 & 1.000 & 0.989 & drs & 0.401 & 0.586 & 0.684 & $\mathrm{drs}$ \\
\hline MEDNET & UGA & 0.660 & 0.662 & 0.997 & irs & 0.552 & 0.555 & 0.995 & drs & 0.626 & 0.631 & 0.992 & irs & 0.144 & 0.144 & 1.000 & - \\
\hline UML & UGA & 0.839 & 0.959 & 0.875 & drs & 0.598 & 0.730 & 0.820 & drs & 0.839 & 0.959 & 0.875 & drs & 0.208 & 0.460 & 0.452 & drs \\
\hline BanGente & VEN & 0.864 & 0.946 & 0.914 & drs & 0.720 & 0.911 & 0.790 & drs & 0.806 & 0.828 & 0.974 & drs & 0.206 & 0.493 & 0.418 & drs \\
\hline CEP & VIET & 0.699 & 0.797 & 0.877 & drs & 0.710 & 0.815 & 0.872 & drs & 0.578 & 0.579 & 0.998 & irs & 0.143 & 0.244 & 0.586 & drs \\
\hline TYM & VIET & 0.715 & 0.718 & 0.996 & drs & 0.723 & 0.724 & 0.999 & . & 0.549 & 0.564 & 0.973 & irs & 0.143 & 0.144 & 0.992 & irs \\
\hline CETZAM & ZAM & 1.000 & 1.000 & 1.000 & - & 0.686 & 0.703 & 0.975 & irs & 1.000 & 1.000 & 1.000 & - & 0.078 & 0.078 & 1.000 & - \\
\hline FINCA ZAM & ZAM & 0.883 & 0.886 & 0.996 & irs & 0.623 & 0.651 & 0.957 & irs & 0.824 & 0.833 & 0.989 & irs & 0.122 & 0.122 & 1.000 & - \\
\hline Mean & & 0.786 & 0.833 & 0.945 & & 0.700 & 0.781 & 0.900 & & \begin{tabular}{|l|l|}
0.707 \\
\end{tabular} & 0.735 & 0.966 & & 0.222 & 0.369 & 0.691 & \\
\hline
\end{tabular}

\section{Appendix E DEA Efficiencies for treating positive Subsidy as an input for 2005}

\begin{tabular}{|c|c|c|c|c|c|c|c|c|c|c|c|c|c|c|c|c|c|c|c|c|c|}
\hline & \multirow[t]{2}{*}{ cou } & \multicolumn{4}{|c|}{ LR-ACE } & \multicolumn{4}{|c|}{ LR-ACES } & \multicolumn{3}{|c|}{ L-ACE } & \multicolumn{3}{|c|}{ L-ACES } & \multicolumn{3}{|c|}{ R- ACE } & \multicolumn{3}{|c|}{ R-ACES ${ }^{i}$} \\
\hline & & e & rste & 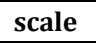 & & 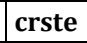 & vrste & 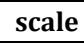 & & & vrste & le & 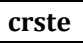 & vrste & $s$ & & vrste & 5 & te & rste & sca \\
\hline & & & & 0 & & & & & drs & & & $\angle$ ars $\mid 0$ & & & drs & 80 & & 94 irs & & & 1 \\
\hline & & & & 0.860 & & & & & drs & & & & & & $\mathrm{rs}$ & & & $60 \mathrm{drs}$ & & & \\
\hline & & & & 0.978 & drs & & & & drs & & & & & & & 316 & & $94 \mathrm{drs}$ & 325 & & \\
\hline & & & 1 & 1.000 & & 0 & & 1 & & & & 0 & & & 1 & & & 82 irs & & & 21 \\
\hline & & & & & drs & & & & drs & & & \begin{tabular}{l|l}
$\mathrm{drs}$ & 0 \\
\end{tabular} & & & & & & $8 \mathrm{drs}$ & & & \\
\hline & & & 9 & 0.910 & drs & & & 0.910 & drs & & & \begin{tabular}{|l|l|l|}
$2 \mathrm{drs}$ & 0 \\
\end{tabular} & & & & & & 997 irs & & & \\
\hline & & & & & & & & & & & & & & & & & & & & & \\
\hline & & & 0 & 0.999 & drs & 0 & & 0. & drs & & & \begin{tabular}{l|l}
$\mathrm{drs}$ & 0 \\
\end{tabular} & & & & & & $\mathrm{drs}$ & & & \\
\hline & & & & & & & & & irs & & & \begin{tabular}{l|l} 
irs & 0 \\
\end{tabular} & & & 3 irs & & & 5 irs & & & \\
\hline- & & 0 & 6 & 0.983 & & & & & irs & & & \begin{tabular}{|l|l|}
5 irs & 0 \\
\end{tabular} & & & 35 irs & & & 55 irs & & & irs \\
\hline & & & & & drs & & & & $\mathrm{drs}$ & & & \begin{tabular}{l|l}
$\mathrm{drs}$ & 0 \\
\end{tabular} & & & drs & & & $6 \mathrm{drs}$ & & & 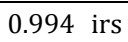 \\
\hline 10 & & & 0 & 0.947 & irs & & & 0.943 & irs & 0. & & \begin{tabular}{l|l}
5 irs & 0 \\
\end{tabular} & 2 & & 5 irs & 34 & & 0.888 irs & & & 2 irs \\
\hline & & & & & drs & & & & $\mathrm{drs}$ & & & drs 0 & & & & & & $6 \mathrm{drs}$ & & & \\
\hline & & 54 & & 0.934 & irs & & & 0.884 & irs & & & \begin{tabular}{l|l} 
irs & 0 \\
\end{tabular} & & & irs & & & 0.913 irs & & & 1 \\
\hline & & & & & drs & & & & $\mathrm{drs}$ & & & & & & & & & 5 irs & & & -2 \\
\hline & & & & 0.936 & drs & & & & $\mathrm{drs}$ & & & \begin{tabular}{l|l}
$\mathrm{drs}$ & 0 \\
\end{tabular} & & & & & & 0.989 irs & & & ins \\
\hline & & & & & drs & & & & $\mathrm{drs}$ & & & & & & & & & 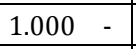 & & & \\
\hline & & & & 0. & drs & & & & $\mathrm{drs}$ & & & & & & & & & $\mathrm{drs}$ & & & \\
\hline & & & & & & & & & & & & \begin{tabular}{l|l} 
irs & 0 \\
\end{tabular} & & & 5 & & & 9 irs & & & \\
\hline & & & 3 & 0.966 & drs & & & 0 & $\mathrm{drs}$ & ( & & & & & & & & 9 irs & & & \\
\hline & & & & & & & & & irs & & & & & & & & & 7 irs & & & \\
\hline & & & & 0.9 & drs & & & & $\mathrm{drs}$ & & & & & & & & & $3 \mathrm{drs}$ & & & $\mathrm{c}$ \\
\hline & & & & & drs & & & & $\mathrm{drs}$ & & & & & & & & & & & & \\
\hline & & & & 0.759 & drs & & & & $\mathrm{drs}$ & & & & & & & & & & & & \\
\hline & & & & & drs & & & & irs & & & \begin{tabular}{l|l}
$\mathrm{drs}$ & 0 \\
\end{tabular} & & & & & & $0 \mathrm{drs}$ & & & \\
\hline & & & & 0.914 & drs & 2 & & 0.8 & drs & 0 & & & & & & & & 99 irs & & & 0 \\
\hline & & & & & drs & & & & $\mathrm{drs}$ & & & & & & & & & $\mathrm{drs}$ & & & \\
\hline & & & & 0.832 & drs & & & 0.8 & $\mathrm{drs}$ & & & \begin{tabular}{l|l}
$\mathrm{drs}$ & 0
\end{tabular} & & & & & & $0 \mathrm{drs}$ & & & \\
\hline & & & & 0.905 & irs & 0.894 & & 0.905 & irs & & & \begin{tabular}{l|l}
8 irs & 0 \\
\end{tabular} & & & 3 irs & & & 0.889 irs & & & Irs \\
\hline & BOL & 8 & 0.861 & 0.985 & irs & 0.850 & 0.865 & 0.982 & irs & 0.697 & 0.7 & \begin{tabular}{l|l}
0.995 irs & 0
\end{tabular} & & & 5 irs & & & 0.968 irs & & & irs \\
\hline & & & & & drs & 0.722 & & & $2 \mathrm{drs}$ & & & \begin{tabular}{l|l}
$\mathrm{drs}$ & 0 \\
\end{tabular} & & & drs & & & $\mathrm{drs}$ & & & drs \\
\hline & BOL & 5 & 13 & 0.904 & drs & 0.735 & 0 . & 0. & drs & 0. & 0 & \begin{tabular}{|l|l|l|}
$2 \mathrm{drs}$ & 0 \\
\end{tabular} & 4 & 91 & $\mathrm{drs}$ & & & $97 \mathrm{drs}$ & & & 0 \\
\hline & & & & & drs & & & & $\mathrm{drs}$ & & & \begin{tabular}{l|l}
$\operatorname{drs}$ & 0 \\
\end{tabular} & & & & & & drs & & & 0 \\
\hline & 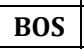 & & 0.953 & 0.951 & $\mathrm{drs}$ & 0.972 & 0. & 0. & drs & 02 & & \begin{tabular}{l|l}
$7 \mathrm{drs}$ & 0 \\
\end{tabular} & 2 & & $0 \mathrm{drs}$ & & & 91 irs & & & 0. \\
\hline & & 35 & 0.9 & 0.9 & $\mathrm{drs}$ & & & & & 0.7 & & \begin{tabular}{l|l}
$d r s$ & 1 \\
\end{tabular} & & & 1. & 0 & & $\mathrm{drs}$ & 0 & c & 0 \\
\hline & t & 30 & 0.947 & 0.982 & irs & 0.930 & 48 & 0.981 & irs & 0.796 & 0. & 0.989 irs $\quad 0$ & 0.796 & 0.805 & 0.989 irs & 0.801 & 0.832 & 0.962 irs & 0.822 & 867 & 0.948 irs \\
\hline & & 64 & 54 & 0.999 & drs & & & & 4 irs & 0.460 & & \begin{tabular}{l|l}
$\mathrm{drs}$ & 0 \\
\end{tabular} & 0. & & $7 \mathrm{drs}$ & 12 & 7 & 0.991 irs & 58 & 66 & 0.987 irs \\
\hline & & 341 & 0.956 & 0.880 & drs & 0.893 & 0.980 & 0.911 & $\mathrm{drs}$ & 0.744 & 0.922 & $0.807 \mathrm{drs} \quad 0$ & 0.802 & 0.969 & $0.827 \mathrm{drs}$ & 0.706 & 0.742 & $0.951 \mathrm{drs}$ & 0.832 & 0.834 & 0.999 irs \\
\hline & & & 34 & 0.858 & drs & 0.825 & 51 & 0.867 & $7 \mathrm{drs}$ & 0.708 & 0.934 & \begin{tabular}{l|l}
$\mathrm{drs}$ & 0 \\
\end{tabular} & 0.768 & 0 & $2 \mathrm{drs}$ & 35 & 7 & $69 \mathrm{drs}$ & 68 & 0.768 & 1.000 \\
\hline & COL & 76 & 0.983 & 0.993 & irs & & & 0.993 & 3 irs & 0.881 & & $0.974 \mathrm{drs} \quad 0$ & 0.881 & 0.928 & $49 \mathrm{drs}$ & 921 & 0.935 & 0.985 irs & 0.921 & 935 & 985 irs \\
\hline WWB Ca & COL & 000 & 1.000 & 1.000 & & 1.000 & 1.000 & 1.000 & & .855 & 1.000 & $0.855 \mathrm{drs} \quad 1$ & 1.000 & 1.000 & 1.000 & 1.000 & 1.000 & 1.000 & 1.000 & 1.000 & .000 \\
\hline
\end{tabular}




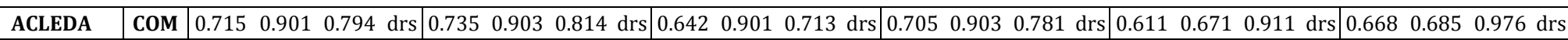
\begin{tabular}{ll|l|llllllll|lllllllllllllllllll} 
AMRET & COM & 0.801 & 0.813 & 0.986 & drs & 0.818 & 0.823 & 0.994 & drs & 0.592 & 0.707 & 0.838 & drs & 0.592 & 0.724 & 0.818 & drs & 0.733 & 0.738 & 0.992 & drs & 0.797 & 0.799 & 0.998 & irs \\
\hline
\end{tabular}

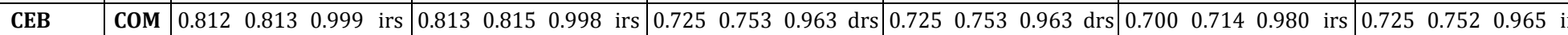

\begin{tabular}{l|l|llll|lllll|lllll|lllllllllllll} 
HKL & COM & 0.755 & 0.758 & 0.995 & irs & 0.755 & 0.759 & 0.995 & irs & 0.705 & 0.709 & 0.996 & irs & 0.705 & 0.709 & 0.996 & irs & 0.612 & 0.631 & 0.971 & irs & 0.660 & 0.685 & 0.963 & irs \\
\hline
\end{tabular}

\begin{tabular}{l|l|lllllllllllllllllllllllllll} 
PRASAC & COM & 0.755 & 0.848 & 0.890 & drs & 0.755 & 0.848 & 0.890 & drs & 0.696 & 0.816 & 0.853 & drs & 0.696 & 0.816 & 0.853 & drs & 0.579 & 0.629 & 0.921 & drs & 0.643 & 0.651 & 0.988 & drs \\
\hline
\end{tabular} \begin{tabular}{|l|c|llll|llll|lllll|lllllllllll}
\hline CrediMujer & CR & 0.852 & 1.000 & 0.852 & irs & 0.852 & 1.000 & 0.852 & irs & 0.631 & 0.856 & 0.737 & irs & 0.631 & 0.856 & 0.737 & irs & 0.771 & 1.000 & 0.771 & irs & 0.780 & 1.000 & 0.780 & irs
\end{tabular} \begin{tabular}{|l|l|llll|lllll|lllll|llllllllllll}
\hline Fundecoca & CR & 0.807 & 1.000 & 0.807 & irs & 0.807 & 1.000 & 0.807 & irs & 0.659 & 1.000 & 0.659 & irs & 0.659 & 1.000 & 0.659 & irs & 0.787 & 1.000 & 0.787 & irs & 0.787 & 1.000 & 0.787 & ir \\
\hline
\end{tabular} \begin{tabular}{l|l|llll|lllll|lllllllllllllll} 
ADEMI & DOM & 1.000 & 1.000 & 1.000 & - & 1.000 & 1.000 & 1.000 & - & 0.755 & 0.926 & 0.815 & $\mathrm{drs}$ & 0.758 & 0.926 & 0.819 & $\mathrm{drs}$ & 1.000 & 1.000 & 1.000 & - & 1.000 & 1.000 & 1.000
\end{tabular} \begin{tabular}{l|l|llll|lllll|lllllllllllllllll} 
Banco Sol & ECU & 1.000 & 1.000 & 1.000 & - & 1.000 & 1.000 & 1.000 & - & 0.760 & 1.000 & 0.760 & $\mathrm{drs}$ & 1.000 & 1.000 & 1.000 & - & 0.970 & 1.000 & 0.970 & $\mathrm{drs}$ & 1.000 & 1.000 & 1.000 & -
\end{tabular}

\begin{tabular}{|l|l|llll|llll|lllll|llllllllllll}
\hline COAC Jardin & ECU & 1.000 & 1.000 & 1.000 & - & 1.000 & 1.000 & 1.000 & - & 1.000 & 1.000 & 1.000 & - & 1.000 & 1.000 & 1.000 & - & 1.000 & 1.000 & 1.000 & - & 1.000 & 1.000 & 1.000 \\
\hline
\end{tabular}

\begin{tabular}{|l|l|llll|llll|llllllllllllllllll}
\hline Coac S Jose & ECU & 0.886 & 0.893 & 0.993 & irs & 1.000 & 1.000 & 1.000 & - & 0.886 & 0.893 & 0.993 & irs & 1.000 & 1.000 & 1.000 & - & 0.699 & 0.723 & 0.966 & irs & 0.700 & 0.823 & 0.851 irs
\end{tabular}

\begin{tabular}{l|l|llll|llll|lllll|llllllllllll} 
COAC SAC & ECU & 1.000 & 1.000 & 1.000 & - & 1.000 & 1.000 & 1.000 & - & 1.000 & 1.000 & 1.000 & - & 1.000 & 1.000 & 1.000 & - & 0.792 & 0.815 & 0.972 & irs & 0.873 & 0.955 & 0.914 & irs \\
\hline
\end{tabular}

\begin{tabular}{l|l|lllllllll} 
PROcredit & ECU & 0.880 & 1.000 & 0.880 & drs & 1.000 & 1.000 & 1.000 & -
\end{tabular}

\begin{tabular}{|l|l|llllllll}
\hline Al Tadamun & EGY & 0.664 & 0.709 & 0.936 & irs & 0.789 & 0.877 & 0.899 & irs \\
\hline
\end{tabular} $\begin{array}{lllllllllllllllll}0.850 & 1.000 & 0.850 & \mathrm{drs} & 1.000 & 1.000 & 1.000 & - & 0.761 & 0.762 & 0.999 & \text { irs } & 0.834 & 0.838 & 0.996 & \text { irs }\end{array}$ \begin{tabular}{ll|lllllllll|lllllllllllllllllllll} 
DBACD & EGY & 0.868 & 0.869 & 1.000 & - & 0.868 & 0.869 & 1.000 & - & 0.529 & 0.538 & 0.983 & drs & 0.529 & 0.546 & 0.970 & drs & 0.868 & 0.869 & 1.000 & - & 0.868 & 0.869 & 1.000 & -
\end{tabular} \begin{tabular}{l|l|llll|lllll|llllllllllllllllll} 
LEAD & EGY & 0.358 & 0.360 & 0.994 & irs & 0.358 & 0.360 & 0.994 & irs & 0.316 & 0.326 & 0.971 & drs & 0.316 & 0.326 & 0.971 & drs & 0.322 & 0.328 & 0.980 & irs & 0.322 & 0.330 & 0.977 & irs \\
\hline
\end{tabular} \begin{tabular}{ll|lllllllll|llllll|lllllllllllll} 
AMC de RL & ELS & 0.725 & 0.732 & 0.991 & $\mathrm{drs}$ & 0.739 & 0.743 & 0.994 & $\mathrm{drs}$ & 0.610 & 0.677 & $0.902 \mathrm{drs}$ & 0.616 & 0.691 & 0.892 & $\mathrm{drs}$ & 0.629 & 0.635 & 0.991 & $\mathrm{irs}$ & 0.692 & 0.701 & 0.987 & $\mathrm{irs}$ \\
\hline
\end{tabular} \begin{tabular}{lllllll|llll|lllll|llllllllll} 
Fundacion & ELS & 0.702 & 0.763 & 0.920 & irs & 0.703 & 0.819 & 0.859 & irs & 0.698 & 0.763 & 0.914 & irs & 0.698 & 0.815 & 0.856 & irs & 0.568 & 0.619 & 0.918 & irs & 0.587 & 0.720 & 0.815 & irs \\
\hline
\end{tabular} \begin{tabular}{l|l|llll|llllll} 
ADCSI & ETH & 1.000 & 1.000 & 1.000 & - & 1.000 & 1.000 & 1.000 & -
\end{tabular} \begin{tabular}{l|l|lllllllllll} 
BG & ETH & 0.604 & 0.682 & 0.886 & irs & 0.604 & 0.682 & 0.886 & irs & 0.0
\end{tabular} \begin{tabular}{l|l|llll|lllllll} 
OMO & ETH & 0.707 & 0.709 & 0.996 & $\mathrm{drs}$ & 0.707 & 0.711 & 0.994 & $\mathrm{drs}$ & 0.7 \\
\hline
\end{tabular} $1.0001 .0001 .000-1.0001 .0001 .000$ \begin{tabular}{l|l|lllllllllllllllllllllllllllll} 
OI SASL & GHA & 0.570 & 0.613 & 0.931 & $\mathrm{drs}$ & 0.613 & 0.618 & 0.992 & $\mathrm{drs}$ & 0.461 & 0.508 & 0.908 & $\mathrm{drs}$ & 0.461 & 0.509 & 0.907 & $\mathrm{drs}$ & 0.499 & 0.528 & 0.946 & $\mathrm{drs}$ & 0.589 & 0.590 & 0.998 & $\mathrm{irs}$ \\
\hline
\end{tabular} \begin{tabular}{l|l|l|lllllllllllllllllllllllllllll} 
C FUND & GOE & 0.919 & 0.991 & 0.928 & irs & 0.929 & 1.000 & 0.929 & irs & 0.702 & 0.754 & 0.931 irs & 0.702 & 0.754 & 0.931 & irs & 0.790 & 0.936 & 0.844 & irs & 0.889 & 1.000 & 0.889 & irs \\
\hline
\end{tabular} \begin{tabular}{ll|l|llll|lllllllllllllllllllllllllll} 
Constanta & GOE & 0.844 & 0.893 & 0.945 & drs & 0.844 & 0.893 & 0.945 & drs & 0.692 & 0.771 & 0.898 & drs & 0.692 & 0.771 & 0.898 & drs & 0.664 & 0.753 & 0.883 & drs & 0.664 & 0.768 & 0.865 & drs \\
\hline
\end{tabular} \begin{tabular}{l|l|llll|llll|lllll|llllllllllll} 
CREDO & GOE & 0.642 & 0.654 & 0.982 & irs & 0.642 & 0.654 & 0.982 & irs & 0.625 & 0.637 & 0.982 & irs & 0.625 & 0.637 & 0.982 & irs & 0.464 & 0.490 & 0.947 & irs & 0.495 & 0.523 & 0.948 & irs \\
\hline
\end{tabular} \begin{tabular}{l|l|l|lll|llll|lllllllllllllllllll} 
SBDF & GOE & 0.797 & 0.889 & 0.896 & irs & 0.797 & 0.889 & 0.896 & irs & 0.774 & 0.869 & 0.890 & irs & 0.774 & 0.869 & 0.890 & irs & 0.516 & 0.658 & 0.785 & irs & 0.561 & 0.677 & 0.828 & irs \\
\hline
\end{tabular} \begin{tabular}{|l|l|llll|llll|lllll|llllllllllll}
\hline Fundacion M & GUAT & 0.537 & 0.582 & 0.923 & irs & 0.537 & 0.582 & 0.923 & irs & 0.533 & 0.582 & 0.916 & irs & 0.533 & 0.582 & 0.916 & irs & 0.396 & 0.473 & 0.838 & irs & 0.425 & 0.505 & 0.841 & irs \\
\hline
\end{tabular} \begin{tabular}{l|l|lllllllllllllllllllllllllllllll} 
Fundea & GUAT & 0.755 & 0.771 & 0.979 & drs & 0.767 & 0.771 & 0.994 & drs & 0.621 & 0.684 & 0.909 & drs & 0.621 & 0.684 & 0.909 & drs & 0.656 & 0.660 & 0.994 & irs & 0.718 & 0.728 & 0.986 & irs \\
\hline
\end{tabular} \begin{tabular}{|l|c|llll|llll|lllllllllllllllllll}
\hline Genesis Em & GUAT & 0.821 & 0.957 & 0.858 & drs & 0.836 & 0.965 & 0.866 & drs & 0.729 & 0.954 & 0.765 & drs & 0.729 & 0.959 & 0.761 & drs & 0.690 & 0.741 & 0.932 & drs & 0.774 & 0.784 & 0.987 & drs \\
\hline
\end{tabular} \begin{tabular}{l|l|llll|lllll|llllll|lllllllllll} 
ACME & HAI & 1.000 & 1.000 & 1.000 & - & 1.000 & 1.000 & 1.000 & - & 0.652 & 0.656 & 0.994 & irs & 0.652 & 0.656 & 0.994 & irs & 1.000 & 1.000 & 1.000 & - & 1.000 & 1.000 & 1.000 & - \\
\hline
\end{tabular} \begin{tabular}{l|l|lllllllll|llllllllllllllllllll} 
Finca & HON & 0.868 & 0.869 & 0.999 & irs & 0.873 & 0.876 & 0.997 & irs & 0.606 & 0.608 & 0.996 & irs & 0.606 & 0.608 & 0.996 & irs & 0.816 & 0.822 & 0.993 & irs & 0.860 & 0.867 & 0.992 & irs \\
\hline
\end{tabular}

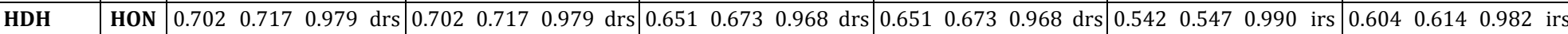
\begin{tabular}{ll|l|llll|llll|llllllllllllllllll} 
World Rel & HON & 0.751 & 0.795 & 0.944 & drs & 0.788 & 0.798 & 0.987 & drs & 0.639 & 0.692 & 0.923 & drs & 0.639 & 0.693 & 0.922 & drs & 0.618 & 0.632 & 0.977 & drs & 0.734 & 0.741 & 0.990 & irs \\
\hline
\end{tabular} \begin{tabular}{l|l|llll|llll|llllllllllllllllllll} 
BANDHAN & IND & 0.937 & 0.939 & 0.998 & drs & 0.986 & 0.989 & 0.997 & irs & 0.937 & 0.939 & 0.998 & drs & 0.986 & 0.989 & 0.997 & irs & 0.680 & 0.694 & 0.980 & irs & 0.680 & 0.694 & 0.979 & irs \\
\hline
\end{tabular} \begin{tabular}{l|l|l|llllllllllllllllllllllllllllll} 
BASIX & IND & 0.746 & 0.834 & 0.894 & $\mathrm{drs}$ & 0.764 & 0.876 & 0.872 & $\mathrm{drs}$ & 0.685 & 0.834 & 0.821 & $\mathrm{drs}$ & 0.748 & 0.873 & 0.856 & $\mathrm{drs}$ & 0.633 & 0.643 & 0.985 & $\mathrm{drs}$ & 0.688 & 0.694 & 0.991 & $\mathrm{drs}$ \\
\hline
\end{tabular} \begin{tabular}{lll|llllllll|llllllllllllllllllll} 
Cashpoor & IND & 0.447 & 0.465 & 0.962 & drs & 0.452 & 0.465 & 0.971 & drs & 0.352 & 0.416 & 0.847 & drs & 0.352 & 0.416 & 0.847 & drs & 0.398 & 0.401 & 0.992 & drs & 0.422 & 0.424 & 0.993 & irs \\
\hline
\end{tabular} \begin{tabular}{l|l|llll|llll|lllllllllllllllllllll} 
ESAF & IND & 0.704 & 0.751 & 0.937 & irs & 0.719 & 0.754 & 0.953 & irs & 0.672 & 0.689 & 0.975 & irs & 0.672 & 0.689 & 0.975 & irs & 0.683 & 0.684 & 0.999 & irs & 0.683 & 0.684 & 0.999 & irs \\
\hline
\end{tabular} \begin{tabular}{l|l|l|llllllll|lllll|llllllllllll} 
GK & IND & 0.686 & 0.699 & 0.981 & irs & 0.713 & 0.725 & 0.984 & irs & 0.667 & 0.668 & 0.998 & irs & 0.713 & 0.719 & 0.992 & irs & 0.576 & 0.600 & 0.961 & irs & 0.579 & 0.609 & 0.951 & irs \\
\hline
\end{tabular} \begin{tabular}{l|l|l|llll|llll|lllll|lllllllllll}
\hline IASC & IND & 0.998 & 1.000 & 0.998 & irs & 0.998 & 1.000 & 0.998 & irs & 0.855 & 0.899 & 0.951 irs & 0.875 & 0.924 & 0.947 & irs & 0.998 & 1.000 & 0.998 & irs & 0.998 & 1.000 & 0.998 & irs \\
\hline
\end{tabular} \begin{tabular}{l|l|llll|llll|lllll|llllllllllll} 
KBSLAB & IND & 0.650 & 0.666 & 0.976 & irs & 0.650 & 0.666 & 0.976 & irs & 0.580 & 0.580 & 0.999 & irs & 0.580 & 0.580 & 0.999 & irs & 0.594 & 0.617 & 0.964 & irs & 0.599 & 0.626 & 0.957 & irs \\
\hline
\end{tabular} \begin{tabular}{|l|l|llll|llll|lllll|llllllllllll} 
SNFL & IND & 0.977 & 0.985 & 0.992 & irs & 0.977 & 0.985 & 0.992 & irs & 0.977 & 0.985 & 0.992 & irs & 0.977 & 0.985 & 0.992 & irs & 0.754 & 0.760 & 0.992 & irs & 0.754 & 0.760 & 0.992 & irs \\
\hline
\end{tabular} \begin{tabular}{|l|l|llll|lllll|lllllllllllllllllll}
\hline MBK Ventu & INDO & 0.630 & 0.938 & 0.671 & irs & 0.636 & 0.943 & 0.674 & irs & 0.512 & 0.719 & 0.712 & irs & 0.512 & 0.719 & 0.712 & irs & 0.553 & 0.938 & 0.590 & irs & 0.587 & 0.943 & 0.622 & irs \\
\hline
\end{tabular} \begin{tabular}{l|l|llll|llll|lllll|lllllllllll} 
Kadet & KEN & 0.425 & 0.427 & 0.996 & irs & 0.427 & 0.429 & 0.995 & irs & 0.372 & 0.373 & 0.998 & irs & 0.372 & 0.373 & 0.998 & irs & 0.361 & 0.371 & 0.974 & irs & 0.380 & 0.395 & 0.963 & irs \\
\hline
\end{tabular} \begin{tabular}{l|l|llll|lllllllllllllllllllllllll} 
K-REP & KEN & 0.600 & 0.707 & 0.848 & drs & 0.600 & 0.713 & 0.842 & drs & 0.555 & 0.707 & 0.784 & drs & 0.567 & 0.713 & 0.796 & drs & 0.516 & 0.529 & 0.976 & drs & 0.545 & 0.548 & 0.994 & drs \\
\hline
\end{tabular} \begin{tabular}{l|l|llllllllllllllllllllllllllll} 
KWFT & KEN & 0.643 & 0.680 & 0.944 & drs & 0.673 & 0.683 & 0.985 & drs & 0.484 & 0.629 & 0.769 & drs & 0.513 & 0.643 & 0.798 & drs & 0.583 & 0.603 & 0.967 & drs & 0.662 & 0.667 & 0.993 & drs \\
\hline
\end{tabular} \begin{tabular}{l|l|llll|lllllllllllllllllllllllllll} 
MDSL & KEN & 0.769 & 0.814 & 0.945 & irs & 0.816 & 1.000 & 0.816 & irs & 0.614 & 0.664 & 0.925 & irs & 0.614 & 0.664 & 0.925 & irs & 0.628 & 0.698 & 0.900 & irs & 0.774 & 1.000 & 0.774 & irs \\
\hline
\end{tabular} \begin{tabular}{ll|l|lllllllll|llllllllllllllllllllll} 
SMEP & KEN & 0.618 & 0.639 & 0.966 & drs & 0.630 & 0.639 & 0.985 & drs & 0.524 & 0.582 & 0.900 & drs & 0.524 & 0.587 & 0.893 & drs & 0.528 & 0.530 & 0.996 & irs & 0.594 & 0.602 & 0.985 & irs \\
\hline
\end{tabular} \begin{tabular}{ll|l|llll|llll|llllllllllllllllll} 
AIYL Bank & KYR & 0.998 & 1.000 & 0.998 & drs & 0.998 & 1.000 & 0.998 & drs & 0.991 & 1.000 & 0.991 & drs & 0.991 & 1.000 & 0.991 & drs & 0.856 & 0.856 & 1.000 & - & 0.856 & 0.856 & 1.000 & -
\end{tabular} \begin{tabular}{ll|l|llll|llll|lllllllllllllllllll} 
BTFF & KYR & 0.758 & 0.758 & 0.999 & - & 0.758 & 0.758 & 0.999 & - & 0.633 & 0.636 & 0.996 irs & 0.633 & 0.636 & 0.996 & irs & 0.758 & 0.758 & 0.999 & - & 0.758 & 0.758 & 0.999
\end{tabular} \begin{tabular}{|l|l|llll|llll|llllllllllllllllllll} 
FMCC & KYR & 0.918 & 1.000 & 0.918 & $\mathrm{drs}$ & 0.920 & 1.000 & 0.920 & $\mathrm{drs}$ & 0.788 & 0.927 & 0.850 & $\mathrm{drs}$ & 0.788 & 0.927 & 0.850 & $\mathrm{drs}$ & 0.734 & 0.856 & 0.858 & $\mathrm{drs}$ & 0.820 & 0.882 & 0.929 & $\mathrm{drs}$ \\
\hline
\end{tabular} \begin{tabular}{l|l|llll|llll|llllll|lllllllllllll} 
FINCA & MAL & 1.000 & 1.000 & 1.000 & - & 1.000 & 1.000 & 1.000 & - & 0.563 & 0.579 & 0.974 & irs & 0.563 & 0.579 & 0.974 & irs & 1.000 & 1.000 & 1.000 & - & 1.000 & 1.000 & 1.000 & -
\end{tabular} \begin{tabular}{l|l|llll|llll|lllllllllllllllllll} 
Soro Y & MALI & 0.643 & 0.675 & 0.953 & irs & 0.643 & 0.675 & 0.953 & irs & 0.643 & 0.675 & 0.953 & irs & 0.643 & 0.675 & 0.953 & irs & 0.298 & 0.320 & 0.930 & irs & 0.298 & 0.320 & 0.930 & irs \\
\hline
\end{tabular} \begin{tabular}{|l|l|lllllllllllllllllllllllllll}
\hline CreditMongol & MON & 0.800 & 0.830 & 0.965 & irs & 0.802 & 0.835 & 0.961 & irs & 0.689 & 0.706 & 0.976 & irs & 0.689 & 0.706 & 0.976 & irs & 0.681 & 0.727 & 0.936 irs & 0.719 & 0.778 & 0.925 & irs \\
\hline
\end{tabular} \begin{tabular}{|l|l|lllllllll|lllllllllllllllll}
\hline Khan Bank & MON & 0.988 & 1.000 & 0.988 & drs & 0.988 & 1.000 & 0.988 & drs & 0.650 & 0.920 & 0.706 & drs & 0.721 & 0.920 & 0.784 & drs & 0.988 & 1.000 & 0.988 & drs & 0.988 & 1.000 & 0.988 & drs \\
\hline
\end{tabular} \begin{tabular}{|l|l|l|lllllllllllllllllllllllllllllllll}
\hline FCC & MOZ & 0.802 & 0.897 & 0.894 & irs & 0.802 & 0.897 & 0.894 & irs & 0.379 & 0.409 & 0.925 & irs & 0.379 & 0.409 & 0.925 & irs & 0.802 & 0.897 & 0.894 & irs & 0.802 & 0.897 & 0.894 & irs \\
\hline
\end{tabular} \begin{tabular}{|l|l|lllllllllllllllllllllllllll}
\hline Novo Banco & MOZ & 0.792 & 0.861 & 0.921 & drs & 0.795 & 0.861 & 0.923 & drs & 0.585 & 0.674 & 0.868 & drs & 0.585 & 0.674 & 0.868 & drs & 0.729 & 0.816 & 0.894 & drs & 0.757 & 0.818 & 0.925 & drs \\
\hline
\end{tabular} \begin{tabular}{l|l|lllllllllllllllllllllllllll} 
SOCREMO & MOZ & 0.772 & 0.803 & 0.961 & $\mathrm{drs}$ & 0.791 & 0.803 & 0.985 & $\mathrm{drs}$ & 0.531 & 0.583 & 0.910 & $\mathrm{drs}$ & 0.531 & 0.583 & 0.910 & $\mathrm{drs}$ & 0.696 & 0.730 & 0.953 & $\mathrm{drs}$ & 0.773 & 0.775 & 0.996 & $\mathrm{drs}$ \\
\hline
\end{tabular} \begin{tabular}{l|l|llllllll|llllllllllllllllll} 
TCHUMA & MOZ & 0.866 & 0.871 & 0.993 & irs & 0.866 & 0.871 & 0.993 & irs & 0.653 & 0.662 & 0.987 & irs & 0.653 & 0.662 & 0.987 & irs & 0.748 & 0.756 & 0.989 & irs & 0.748 & 0.757 & 0.988 & irs \\
\hline
\end{tabular} \begin{tabular}{l|l|l|lllllllllllllllllllllllllllll} 
CBB & NEP & 0.870 & 0.926 & 0.940 & irs & 0.870 & 0.926 & 0.940 & irs & 0.492 & 0.551 & 0.893 & irs & 0.492 & 0.551 & 0.893 & irs & 0.870 & 0.926 & 0.940 & irs & 0.870 & 0.926 & 0.940 & irs \\
\hline
\end{tabular} \begin{tabular}{l|l|lllllllllllllllllllllllllllll} 
NIRDHAN & NEP & 0.651 & 0.664 & 0.981 & irs & 0.666 & 0.675 & 0.987 & irs & 0.627 & 0.630 & 0.996 & drs & 0.627 & 0.631 & 0.993 & drs & 0.579 & 0.590 & 0.981 & irs & 0.579 & 0.590 & 0.981 & irs \\
\hline
\end{tabular} NSSC \begin{tabular}{l|llll|llll} 
NEP & 0.861 & 1.000 & 0.861 & irs & 0.871 & 1.000 & 0.871 & irs \\
\hline
\end{tabular} \begin{tabular}{|lllllllll|lllll|lllll}
0.627 & 0.630 & 0.996 & drs & 0.627 & 0.631 & 0.993 & drs & 0.579 & 0.590 & 0.981 & irs & 0.579 & 0.590 & 0.981 & irs \\
0.390 & 0.656 & 0.595 & irs & 0.462 & 1.000 & 0.462 & irs & 0.861 & 1.000 & 0.861 & irs & 0.871 & 1.000 & 0.871 & irs
\end{tabular} 


\begin{tabular}{|c|c|c|c|c|c|c|c|c|c|c|c|c|c|c|c|c|c|c|c|c|}
\hline & & & & 99 irs & & & & & & & 98 irs & & 2 & 98 irs & 4 & 4 & 999 irs & 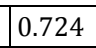 & 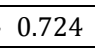 & + \\
\hline & & & & $93 \mathrm{drs}$ & 0 & & & & & & $15 \mathrm{~d}$ & & & & & & 37 & & & \\
\hline & & & & $7 \mathrm{drs}$ & & & & & & & & & & & & & & & & \\
\hline & & & & 99 irs & & & & $s$ & & & ars & & & 3 in & & & 39 irs & & & \\
\hline & & & & 4 irs & & & & & & & s & & & & & & 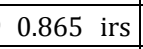 & & & \\
\hline & & 7 & & 97 irs & 7 & & & & & & & & & & & & $97 \mathrm{i}$ & & 8 & \\
\hline & & & & irs & & & & & & & & & & & & & & & & \\
\hline & & 374 & 0.878 & $5 \mathrm{drs}$ & 0.991 & & & irs & & & drs & & & $52 \mathrm{~d}$ & & & $38 \mathrm{~d}$ & & & \\
\hline & & & & $\mathrm{drs}$ & & & & irs & & & drs & & & & & & & & & \\
\hline & & 07 & 0 & $7 \mathrm{drs}$ & 0 & & & - & & & drs & & & st & & & o dis & & & \\
\hline & & & & $\mathrm{drs}$ & & & & irs & & & drs & & & & & & & & & \\
\hline & & 588 & 6 & $2 \mathrm{drs}$ & 8 & & & & & & drs & & & & & & & & & 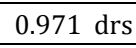 \\
\hline & & & & drs & & & & & & & & & & & & & & & & \\
\hline & & 389 & 92 & 6 irs & 0.889 & & & & & & $\mathrm{drs}$ & & & & & & irs & & & \\
\hline & & & & $\mathrm{drs}$ & & & & & & & drs & & & & & & & & & \\
\hline & & 02 & & $\mathrm{drs}$ & 0. & & & $s$ & & & $\mathrm{drs}$ & & & & & & irs & & & \\
\hline & & & & drs & & & & & & & & & & & & & 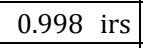 & & & \\
\hline 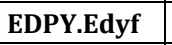 & & 323 & & $\mathrm{drs}$ & 0 & & & & & & drs & & & $3 \mathrm{~d}$ & & & & & & \\
\hline & & & & irs & & & & & & & | & & & 411 & & & 11 & & & \\
\hline & & 92 & & 3 irs & 0 & & & & & & 2 irs & & & 2 il & & & $2 \mathrm{i}$ & & & \\
\hline & & & & 0113 & & & & & & & & & & 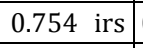 & & & 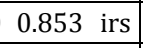 & & & \\
\hline 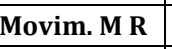 & & 28 & & 74 irs & 0 & & & & & & irs & & & 4 ir & & & 9 i & & & \\
\hline & & & & 4 irs & & & & & & & 5 irs & & & $\begin{array}{lll}513 \\
\end{array}$ & & & 8 irs & & & \\
\hline & & 29 & & 7 irs & 5 & & & ir & & & 3 irs & & & 3 irs & & & 0 irs & & & \\
\hline & & & & 7 drs & & & & & & & drs & & & c & & & 4 irs & & & \\
\hline & & 90 & & $5 \mathrm{drs}$ & 0 & & & $s$ & & & drs & & & & & & & & & - \\
\hline & & & & & & & & & & & & & & & & & & & & \\
\hline & & & & $0 \quad-$ & 000 & & & - & & & $\mathrm{c}$ & & & 9 & & & 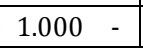 & & & - \\
\hline & & & & 6 irs & & & & & & & irs & & & 0 & & & & & & \\
\hline & & & & & 000 & & & - & & & $\mathrm{drs}$ & & & 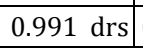 & & & 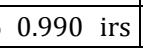 & & & \\
\hline & & & & drs & & & & & & & drs & & & & & & 9 irs & & & 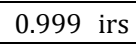 \\
\hline & & 4 & & $\mathrm{drs}$ & 50 & & & $s$ & & & drs & & & & & & 1 & & & - \\
\hline & & & & irs & & & & & & & irs & & & 0 & & & $4 \mathrm{i}$ & & & 7 ir \\
\hline & & & & $\mathrm{drs}$ & & & & - & & & drs & & & & & & & & & \\
\hline & & & & 5 irs & & & & - & & & ars & & & 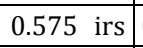 & & & 411 & & & \\
\hline & & & & 4 irs & 0 & & & $\mathrm{rs}$ & & & & & & & & & 4 & & & \\
\hline & & & & 0.995 irs & & & & & & & 5 irs & & & 6 irs & & 7 & 8 irs & & 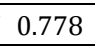 & 11 \\
\hline 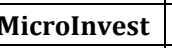 & & & & 0.900 irs & & & & $s$ & & & 1 irs & & & 7 irs & & 8 & 9 & & 8 &. \\
\hline INe & & & & $9 \mathrm{drs}$ & & & & irs & & & c & & & 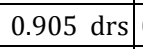 & & 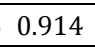 & $s$ & & 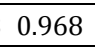 & 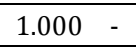 \\
\hline & & & & & & & & & & & & & & & & 2 & & 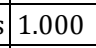 & 0 & \\
\hline ER & & & & drs & & & & & & & drs & & & & & 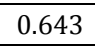 & $s$ & 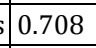 & 9 & 8 irs \\
\hline & & & & Irs & & & & & & & & & & 4 irs & & 0 & & 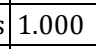 & 0 & 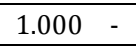 \\
\hline & & & & s & & & & s & & & rs & & & -5 & & - & O & 5 & 3 & IIS \\
\hline & & & & rs & & & & - & & & $\mathrm{drs}$ & & & 5 & & & & & & 0 \\
\hline & & 3 & & 7 irs & 0 & & & irs & & & irs & & & 3 irs & & & 2 irs & & & 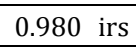 \\
\hline & & & & 3 drs & & & & & & & $4 \mathrm{drs}$ & & & 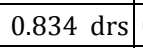 & & & ars & & & 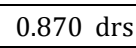 \\
\hline & & 1 & & $0 \mathrm{drs}$ & 0. & & & $\mathrm{rs}$ & & & $\mathrm{drs}$ & & & $0 \mathrm{drs}$ & & & $90 \mathrm{drs}$ & 08 & & $\mathrm{dr}$ \\
\hline & & & & 0 & & & & - & & & 5 irs & & & $\begin{array}{lll}5115 \\
\end{array}$ & & & 0 & & & 0 \\
\hline $\mathrm{NC}$ & & 383 & 17 & $2 \mathrm{irs}$ & 0.883 & 7 & & & 5 & 0. & 6 in & 5 & 4 & 6 & 24 & 31 & 34 & 824 & 81 & 34 \\
\hline & & & & & & & & & & & & & & & & & & & & \\
\hline
\end{tabular}

\section{Appendix F Efficiencies DEA for treating negative Subsidy as an output for 2005}

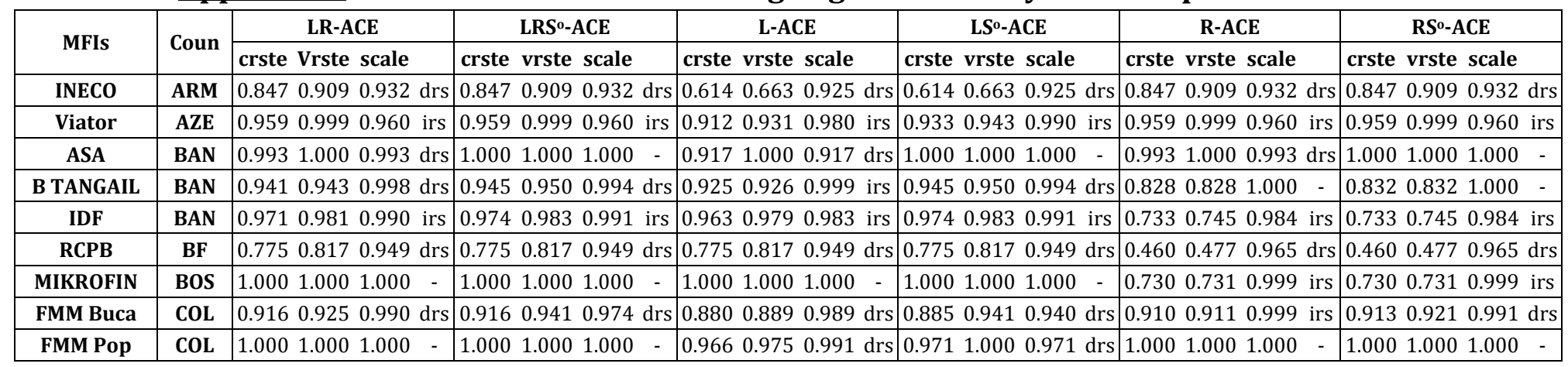




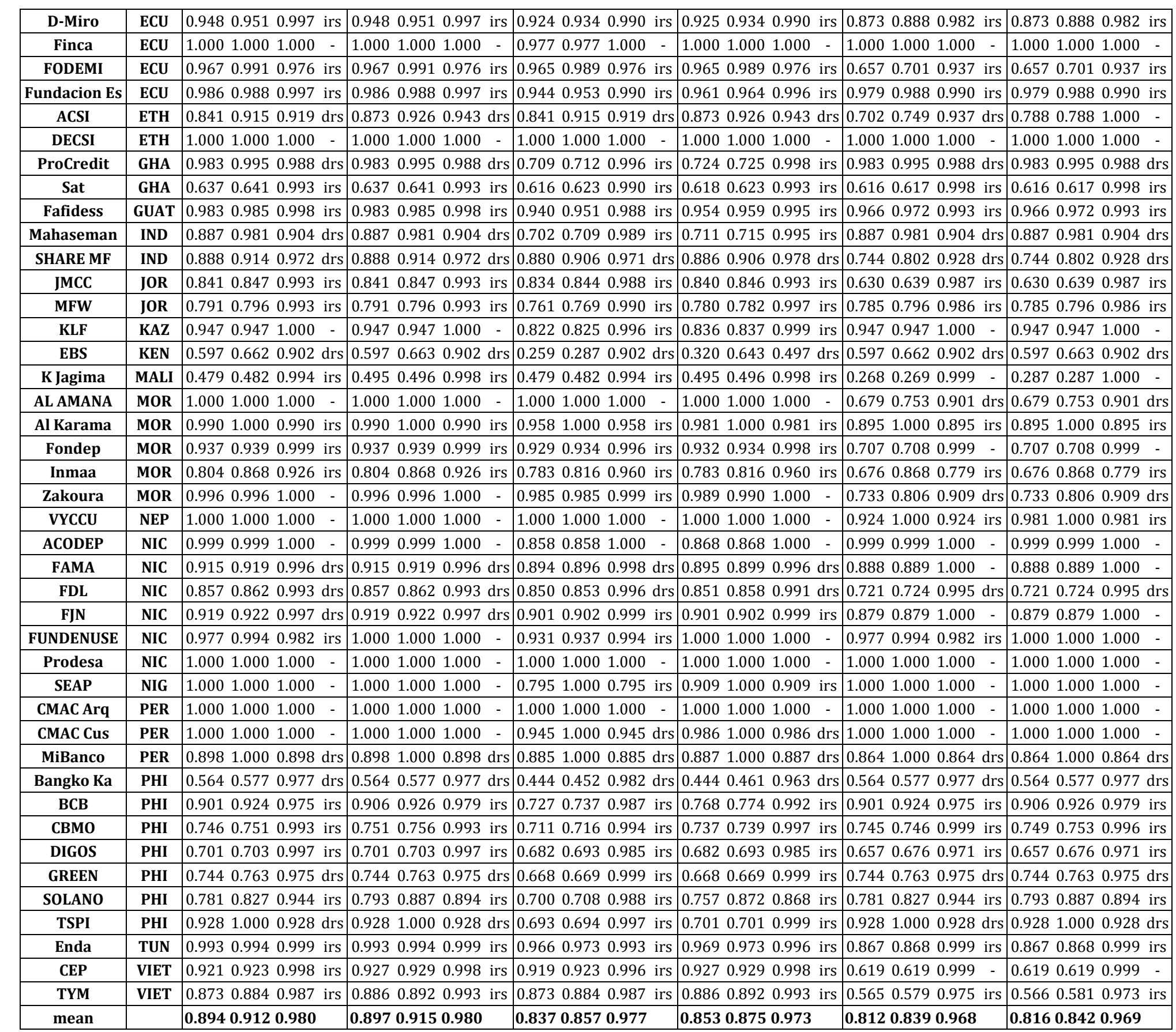

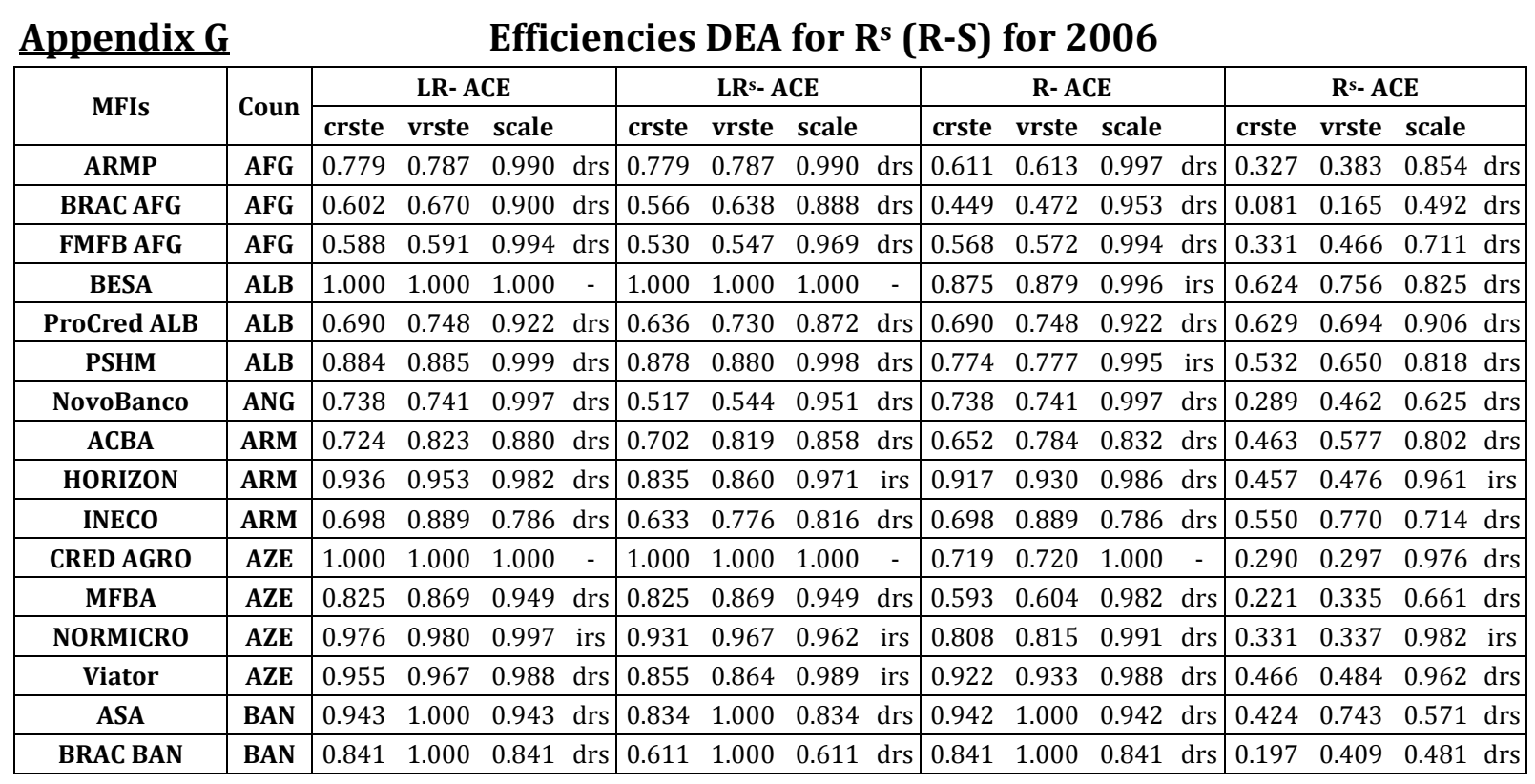




\begin{tabular}{|c|c|c|c|c|c|c|c|c|c|c|c|c|c|c|c|c|}
\hline URO & $\mathrm{N}$ & 862 & 880 & 979 & $\mathrm{drs}$ & \begin{tabular}{|l|l|}
0.803 \\
\end{tabular} & 0.869 & 0.924 & $\mathrm{drs}$ & 0.771 & 0.780 & 0.988 & $\mathrm{drs}$ & \begin{tabular}{|l|l|}
0.477 \\
\end{tabular} & 0.621 & 0.767 \\
\hline & $\mathbf{N}$ & 000 & .000 & 000 & & 000 & & 1.000 & & & & 1.000 & - & 34 & & 0.971 \\
\hline & & & & 69 & $\mathrm{drs}$ & 36 & & 44 & $\mathrm{drs}$ & 78 & 83 & 92 & $\mathrm{drs}$ & 417 & 08 & 321 \\
\hline & $\mathbf{N}$ & 89 & 30 & 944 & $\mathrm{drs}$ & 29 & 27 & 865 & $\mathrm{drs}$ & 74 & & 980 & $\mathrm{drs}$ & 50 & & 707 \\
\hline & & & & 56 & $\mathrm{drs}$ & & & & $\mathrm{drs}$ & 36 & & & drs & & & 41 \\
\hline & $\mathrm{N}$ & 37 & 0.834 & 384 & irs & 713 & 34 & 355 & irs & 79 & & 998 & irs & 21 & & 26 \\
\hline & & & 97 & 93 & $\mathrm{drs}$ & 56 & & & $\mathrm{drs}$ & & & & $\mathrm{drs}$ & & & 71 \\
\hline & $\mathrm{N}$ & 335 & 0.836 & 998 & irs & 0.783 & & 994 & irs & 32 & & 0.982 & irs & 51 & & 0.781 \\
\hline & & & 56 & 958 & $\mathrm{drs}$ & & & & $\mathrm{drs}$ & & & & $\mathrm{drs}$ & & & $86 \mathrm{~d}$ \\
\hline$N_{\varepsilon}$ & OL & 884 & 0.784 & 1.000 & 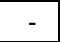 & 765 & & .999 & irs & 92 & & 0.994 & irs & 69 & & 09 \\
\hline & & & 57 & 883 & $\mathrm{drs}$ & & & & $\mathrm{drs}$ & & & & $\mathrm{drs}$ & & & 59 \\
\hline & $\mathrm{OL}$ & 327 & 0.948 & 0.873 & $\mathrm{drs}$ & \begin{tabular}{|l|}
0.827 \\
\end{tabular} & & 0.873 & $\mathrm{drs}$ & 0.629 & 99 & 0.900 & $\mathrm{drs}$ & 407 & & 585 \\
\hline & & & 87 & 85 & $\mathrm{drs}$ & 0 & & 57 & $\mathrm{drs}$ & 62 & & & drs & & & 76 \\
\hline & $\mathrm{OL}$ & 83 & 0.788 & 0.995 & $\mathrm{drs}$ & 0.781 & 0.788 & 991 & $\mathrm{drs}$ & 0.658 & 61 & .996 & $\mathrm{drs}$ & 01 & & 10 \\
\hline & & & 68 & 990 & $\mathrm{drs}$ & 6 & & 0 & $\mathrm{drs}$ & & & & $\mathrm{drs}$ & & & 35 \\
\hline & ) $\mathbf{L}$ & 990 & 0.823 & 0.960 & $\mathrm{drs}$ & 0.793 & & 0.964 & $\mathrm{drs}$ & 0.627 & & 0.963 & $\mathrm{drs}$ & 394 & & 32 \\
\hline & 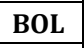 & & 19 & 87 & irs & 05 & & & irs & & & & drs & & & 39 \\
\hline & )L & 42 & 0.807 & 920 & $\mathrm{drs}$ & \begin{tabular}{|l|}
0.727 \\
\end{tabular} & & 902 & $\mathrm{drs}$ & 0.645 & & 960 & $\mathrm{drs}$ & 91 & & 70 \\
\hline & & & & 4 & drs & & & & & & & & drs & & & tr \\
\hline & $\mathrm{OS}$ & 87 & 1.000 & 987 & $\mathrm{drs}$ & 0.996 & & 0.996 & $\mathrm{drs}$ & 443 & & 98 & irs & & & 388 \\
\hline & & & & 0 & & & & & & & & & irs & & & 0 \\
\hline & $S$ & 00 & 1.000 & 000 & - & 000 & & 000 & & 886 & & 997 & irs & 94 & & $999 \mathrm{dr}$ \\
\hline & & & & & -5 & & & & & & & & irs & & & 29 \\
\hline & 1 & 99 & 0.599 & 000 & - & 883 & & 0.999 & irs & 0.519 & & 0.993 & $\mathrm{drs}$ & 04 & & $779 \mathrm{dr}$ \\
\hline & L & 51 & & 0.973 & $\mathrm{drs}$ & & & 0 & & & & & drs & & & 12 \\
\hline & & & 0.897 & 948 & drs & 50 & & 0. & drs & 537 & & 39 & drs & & & 13 \\
\hline & $L_{2}$ & & & 992 & drs & & & & & & & & drs & & & 93 \\
\hline & L & 83 & 0.994 & 0.988 & drs & 0.955 & & 0.963 & $\mathrm{drs}$ & 0.882 & & 0.981 & $\mathrm{drs}$ & 63 & & $38 \mathrm{dr}$ \\
\hline & $\mathrm{L}$ & 34 & & 92 & $\mathrm{drs}$ & & & & & 0 & & & $\mathrm{drs}$ & & & 36 \\
\hline & & & & 991 & drs & 0.972 & & 0.972 & drs & 99 & & 58 & drs & 31 & & $0.734 \mathrm{dr}$ \\
\hline & $\mathbf{M}$ & 10 & & 0.896 & $\mathrm{drs}$ & & & 0 . & $\mathrm{drs}$ & 16 & & 27 & $\mathrm{drs}$ & & & 596 \\
\hline & & 52 & 0.868 & 982 & $\mathrm{drs}$ & 0.757 & & 0.943 & $\mathrm{drs}$ & 37 & & 85 & $\mathrm{drs}$ & & & $0.744 \mathrm{dr}$ \\
\hline & $M$ & 49 & 0 & 0.998 & drs & 0. & & 0. & drs & 0 & & & - & & & 920 \\
\hline & $\mathbf{M}$ & 378 & 0.881 & 0.997 & drs & 0.838 & 0.841 & 0.996 & irs & 0.754 & 59 & 0.993 & $\mathrm{drs}$ & 08 & & $0.916 \mathrm{dr}$ \\
\hline & $\mathbf{M}$ & 42 & & 0.988 & $\mathrm{drs}$ & & & & $\mathrm{drs}$ & & & & $\mathrm{drs}$ & & & $306 \mathrm{dr}$ \\
\hline & & 00 & 1.000 & 000 & 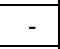 & 47 & & 47 & irs & 00 & & 00 & - & 96 & & 0.396 irs \\
\hline & & 63 & & 963 & $\mathrm{drs}$ & 0 . & & & $\mathrm{drs}$ & & & & $\mathrm{drs}$ & & & $795 \mathrm{dr}$ \\
\hline & $\mathbf{U}$ & 00 & 1.000 & 000 & - & 000 & 1. & 1.000 & - & 56 & 98 & 0.948 & $\mathrm{drs}$ & 02 & & $0.939 \mathrm{dr}$ \\
\hline & & & & 0.988 & irs & & & & irs & & & & & & & 8 \\
\hline & & & & & & & & & 110 & & & & s & & & 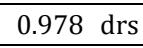 \\
\hline & & 12 & 22 & 0.989 & drs & 0.8 & & 0.968 & $\mathrm{drs}$ & & & 0.987 & $\mathrm{drs}$ & 76 & & 668 \\
\hline & $U$ & 00 & 1.000 & 1.000 & - & 919 & 1.000 & 0.919 & $\mathrm{drs}$ & 552 & 58 & 0.993 & $\mathrm{drs}$ & 78 & & $0.626 \mathrm{dr}$ \\
\hline & & 9 & & 0.983 & irs & & & & irs & & & & & & & 6 \\
\hline & & & & 984 & $\mathrm{drs}$ & 18 & & 56 & $\mathrm{drs}$ & & & & $\mathrm{drs}$ & & & 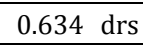 \\
\hline & & & & 0.957 & $\mathrm{drs}$ & & & & $\mathrm{drs}$ & & & & $\mathrm{drs}$ & & & 9 \\
\hline & & & & & drs & & & & irs & & & & drs & & & 2 \\
\hline & & 792 & 0.794 & 0.997 & $\mathrm{drs}$ & 0.626 & 0. & 8 & $\mathrm{drs}$ & 92 & & 97 & drs & 98 & & 34 \\
\hline & & & & & drs & & & & $\mathrm{drs}$ & & & & $\mathrm{drs}$ & & & $.889 \mathrm{dr}$ \\
\hline & & 14 & 0.821 & 0.992 & $\mathrm{drs}$ & 880 & 0. & & & & & & $\mathrm{drs}$ & 77 & & .763 \\
\hline & & & & & irs & & & & 115 & & & & irs & & & .863 irs \\
\hline & & 52 & 1.000 & 0.952 & drs & 0.981 & 1. & 0.981 & $\mathrm{drs}$ & 783 & & 18 & $\mathrm{drs}$ & 27 & & $.927 \mathrm{dr}$ \\
\hline & & & & & irs & & & & irs & & & & irs & & & 1.953 \\
\hline & & 558 & 0.661 & 0.995 & irs & 0.587 & 0.6 & 17 & irs & 95 & & & - & & & .800 \\
\hline & & & & 00 & - & & & & - & & & & - & & & $0.970 \mathrm{dr}$ \\
\hline & I & 850 & 0.851 & 0.999 & $\mathrm{drs}$ & 0.851 & 0.852 & 1.000 & - & 465 & 0.465 & 1.000 & - & 382 & 39 & $0.981 \mathrm{dr}$ \\
\hline & & 31 & 0.681 & 1.000 & - & & & 0.997 & $\mathrm{dr}$ & 0 & & 000 & - & & & $0.997 \mathrm{dr}$ \\
\hline & 2 & 815 & 0.843 & 0.967 & drs & 0.741 & 0.842 & 0.879 & drs & 0.783 & 0.817 & 0.958 & drs & 0.425 & 782 & $0.544 \mathrm{dr}$ \\
\hline & & & 0.728 & 0.952 & drs & 0.687 & & 0.945 & drs & 0.505 & & 0.970 & drs & 256 & & $0.521 \mathrm{dr}$ \\
\hline & $\mathrm{HA}$ & 0.788 & 0.804 & 0.980 & $\mathrm{drs}$ & 0.725 & 0.769 & 0.943 & $\mathrm{drs}$ & 0.709 & 0.738 & 0.961 & $\mathrm{drs}$ & 0.344 & .575 & $0.598 \mathrm{dr}$ \\
\hline & & & & 1.000 & & & & & irs & & & 000 & - & & & 0.954 \\
\hline Cons & $\overline{O E}$ & 0.708 & 0.711 & 0.995 & $\mathrm{drs}$ & 0.617 & 0.628 & 0.983 & drs & 0.680 & 0.687 & 0.990 & drs & 0.296 & 395 & 0.750 \\
\hline & & & & 0.993 & irs & & & & irs & & & 985 & irs & & & 0.867 \\
\hline SBDF & GOE & 0.961 & 1.000 & 0.961 & irs & 0.940 & 1.000 & 0.940 & irs & 0.722 & 0.723 & 1.000 & - & 0.265 & 0.315 & $0.841 \mathrm{irs}$ \\
\hline
\end{tabular}




\begin{tabular}{|c|c|c|c|c|c|c|c|c|c|c|c|c|c|c|c|c|}
\hline Genesis Em & GUAT & 0.924 & 0.969 & 0.954 & drs & 0.905 & 0.947 & 0.955 & drs & 0.742 & 0.758 & 0.978 & drs & 0.349 & 0.618 & $0.564 \mathrm{drs}$ \\
\hline ACME & HAI & 0.960 & 0.960 & 0.999 & irs & 0.749 & 0.808 & 0.926 & drs & 0.960 & 0.960 & 0.999 & irs & 0.385 & 0.625 & $0.617 \mathrm{drs}$ \\
\hline Finca HON & ON & \begin{tabular}{|l|}
0.909 \\
\end{tabular} & 0.919 & 0.989 & $\mathrm{drs}$ & \begin{tabular}{|l|}
0.845 \\
\end{tabular} & 0.849 & 0.996 & $\mathrm{drs}$ & 0.789 & 0.790 & 0.999 & irs & 0.352 & 0.540 & $0.651 \mathrm{drs}$ \\
\hline HDH & HON & 0.881 & 0.891 & 0.989 & irs & 0.881 & 0.891 & 0.989 & irs & 0.320 & 0.320 & 0.999 & - & 0.002 & 0.003 & $.654 \mathrm{drs}$ \\
\hline Wor & ON & 0.910 & 0.927 & 0.981 & drs & 0.841 & 0.856 & 0.983 & drs & 0.844 & 0.867 & 0.974 & drs & 0.413 & 0.590 & $0.699 \mathrm{drs}$ \\
\hline BANDHAN & IND & 1.000 & 1.000 & 1.000 & - & 1.000 & 1.000 & 1.000 & - & 0.777 & 0.813 & 0.955 & drs & 0.708 & 0.801 & $0.883 \mathrm{drs}$ \\
\hline BASIX & IND & 0.806 & 0.857 & 0.940 & $\mathrm{drs}$ & 0.790 & 0.853 & 0.926 & $\mathrm{drs}$ & 0.637 & 0.652 & 0.977 & drs & 0.344 & 0.522 & $0.659 \mathrm{drs}$ \\
\hline Cashpoor & IND & \begin{tabular}{|l|}
0.757 \\
\end{tabular} & 0.801 & 0.945 & drs & \begin{tabular}{|l|}
0.752 \\
\end{tabular} & 0.801 & 0.939 & $\mathrm{drs}$ & 0.562 & 0.563 & 0.998 & drs & 0.275 & 0.322 & $0.856 \mathrm{drs}$ \\
\hline $\mathbf{F}$ & D & \begin{tabular}{|l|}
0.932 \\
\end{tabular} & 0.953 & 0.978 & $\mathrm{drs}$ & \begin{tabular}{|l|}
0.937 \\
\end{tabular} & 0.953 & 0.984 & $\mathrm{drs}$ & 0.624 & 0.624 & 1.000 & - & 0.449 & 0.490 & $0.916 \mathrm{drs}$ \\
\hline GK & IND & \begin{tabular}{|l|}
0.855 \\
\end{tabular} & 0.857 & 0.998 & $\mathrm{drs}$ & \begin{tabular}{|l|}
0.817 \\
\end{tabular} & 0.830 & 0.984 & $\mathrm{drs}$ & 0.793 & 0.793 & 1.000 & - & 0.557 & 0.608 & $0.916 \mathrm{drs}$ \\
\hline KBSI & IND & 0.619 & 0.619 & 0.999 & drs & 0.582 & 0.584 & 0.995 & drs & 0.566 & 0.566 & 1.000 & - & 0.265 & 0.285 & $0.929 \mathrm{drs}$ \\
\hline SHARE MF & IND & 0.863 & 0.935 & 0.923 & drs & 0.863 & 0.935 & 0.923 & drs & 0.531 & 0.547 & 0.972 & drs & 0.308 & 0.467 & $0.659 \mathrm{drs}$ \\
\hline SNFL & IND & 1.000 & 1.000 & 1.000 & - & 1.000 & 1.000 & 1.000 & - & 0.658 & 0.729 & 0.902 & irs & 0.273 & 0.303 & 900 irs \\
\hline MBK Ven & INDO & 0.818 & 0.829 & 0.988 & $\mathrm{drs}$ & 0.682 & 0.729 & 0.936 & irs & 0.774 & 0.789 & 0.982 & drs & 0.314 & 0.363 & 0.865 irs \\
\hline JMCC & $R$ & 0.847 & 0.851 & 0.996 & irs & 0.850 & 0.853 & 0.996 & irs & 0.657 & 0.663 & 0.992 & drs & 0.409 & 0.474 & $862 \mathrm{drs}$ \\
\hline MFW & JOR & 0.920 & 0.920 & 1.000 & - & 0.912 & 0.913 & 0.999 & irs & 0.724 & 0.738 & 0.981 & drs & 0.384 & 0.565 & $0.681 \mathrm{drs}$ \\
\hline KLF & $\mathbf{A Z}$ & \begin{tabular}{|l|}
0.794 \\
\end{tabular} & 0.801 & 0.992 & drs & \begin{tabular}{|l|}
0.712 \\
\end{tabular} & 0.774 & 0.920 & drs & \begin{tabular}{|l|}
0.794 \\
\end{tabular} & 0.801 & 0.992 & drs & 79 & 0.767 & $754 \mathrm{drs}$ \\
\hline EBS & KEN & \begin{tabular}{|l|}
0.639 \\
\end{tabular} & 0.691 & 0.924 & drs & \begin{tabular}{|l|}
0.506 \\
\end{tabular} & 0.795 & 0.636 & drs & 0.639 & 0.691 & 0.924 & drs & 0.506 & 0.795 & $0.636 \mathrm{drs}$ \\
\hline Kadet & KEN & 0.579 & 0.588 & 0.985 & drs & 0.533 & 0.537 & 0.991 & irs & \begin{tabular}{|l|}
0.463 \\
\end{tabular} & 0.469 & 0.986 & drs & 0.090 & 0.148 & $610 \mathrm{drs}$ \\
\hline K-REP & KEN & 0.721 & 0.755 & 0.955 & drs & 0.707 & 0.759 & 0.932 & drs & 0.627 & 0.636 & 0.986 & drs & 0.368 & 0.595 & $0.619 \mathrm{drs}$ \\
\hline KWFT & EN & 0.684 & 0.691 & 0.991 & drs & \begin{tabular}{|l|}
0.619 \\
\end{tabular} & 0.654 & 0.946 & drs & 0.644 & 0.651 & 0.989 & drs & 34 & 97 & $671 \mathrm{drs}$ \\
\hline MDSL & KEN & \begin{tabular}{|l|}
0.993 \\
\end{tabular} & 1.000 & 0.993 & irs & \begin{tabular}{|l|}
1.000 \\
\end{tabular} & 1.000 & 1.000 & - & 0.993 & 1.000 & 0.993 & irs & 1.000 & 1.000 & 1.000 \\
\hline SMEP & KEN & \begin{tabular}{|l|}
0.913 \\
\end{tabular} & 1.000 & 0.913 & irs & 1.000 & 1.000 & 1.000 & - & 0.612 & 0.621 & 0.985 & irs & 00 & 1.000 & .000 \\
\hline AIYL Ban & KYR & \begin{tabular}{|l|}
0.978 \\
\end{tabular} & 1.000 & 0.978 & drs & \begin{tabular}{|l|}
0.978 \\
\end{tabular} & 1.000 & 0.978 & drs & 0.576 & 0.658 & 0.875 & drs & 0.057 & 0.075 & $0.756 \mathrm{drs}$ \\
\hline BTFF & KYR & \begin{tabular}{|l|}
0.839 \\
\end{tabular} & 0.839 & 1.000 & - & \begin{tabular}{|l|}
0.687 \\
\end{tabular} & 0.692 & 0.993 & drs & \begin{tabular}{|l|}
0.839 \\
\end{tabular} & 0.839 & 1.000 & - & 342 & 0.357 & $0.958 \mathrm{drs}$ \\
\hline FMCC & KYR & 0.793 & 0.810 & 0.979 & drs & 0.743 & 0.793 & 0.937 & drs & 0.731 & 0.747 & 0.978 & drs & 0.418 & 0.609 & $0.686 \mathrm{drs}$ \\
\hline Kando Jagin & MALI & 0.521 & 0.522 & 0.998 & irs & 0.521 & 0.522 & 0.998 & irs & 0.410 & 0.413 & 0.994 & drs & 34 & 0.274 & $0.854 \mathrm{drs}$ \\
\hline Soro $Y$ & MALI & 0.621 & 0.640 & 0.971 & irs & 0.621 & 0.640 & 0.971 & irs & 0.319 & 0.326 & 0.979 & drs & 0.057 & 0.068 & $0.845 \mathrm{drs}$ \\
\hline CreditN & MON & \begin{tabular}{|l|}
0.877 \\
\end{tabular} & 0.883 & 0.994 & drs & \begin{tabular}{|l|}
0.803 \\
\end{tabular} & 0.822 & 0.977 & irs & 0.732 & 0.748 & 0.979 & drs & 0.237 & 0.266 & $0.891 \mathrm{drs}$ \\
\hline Khan & MON & 0.802 & 1.000 & 0.802 & $\mathrm{drs}$ & 0.754 & 1.000 & 0.754 & drs & 0.802 & 1.000 & 0.802 & drs & 0.669 & 1.000 & $0.669 \mathrm{drs}$ \\
\hline AL AMANA & MOR & 0.897 & 1.000 & 0.897 & drs & 0.904 & 1.000 & 0.904 & drs & 0.564 & 0.665 & 0.849 & drs & 0.417 & 0.619 & $0.674 \mathrm{drs}$ \\
\hline Al Karama & MOR & \begin{tabular}{|l|}
0.822 \\
\end{tabular} & 0.824 & 0.998 & $\mathrm{drs}$ & \begin{tabular}{|l|}
0.788 \\
\end{tabular} & 0.809 & 0.974 & irs & 0.674 & 0.689 & 0.978 & drs & 0.344 & 0.345 & $0.997 \mathrm{drs}$ \\
\hline Fondep & MOR & 1.000 & 1.000 & 1.000 & 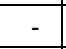 & 0.980 & 1.000 & 0.980 & drs & 1.000 & 1.000 & 1.000 & - & 0.863 & 1.000 & $0.863 \mathrm{drs}$ \\
\hline Inmaa & MOR & 0.915 & 0.927 & 0.987 & irs & 0.902 & 0.933 & 0.967 & irs & 0.725 & 0.734 & 0.988 & drs & 0.382 & 0.390 & $0.981 \mathrm{drs}$ \\
\hline Zakoura & MOR & 0.882 & 0.957 & 0.921 & $\mathrm{drs}$ & 0.882 & 0.957 & 0.921 & $\mathrm{drs}$ & 0.582 & 0.601 & 0.970 & drs & 0.292 & 0.475 & $0.614 \mathrm{drs}$ \\
\hline FCC & MOZ & \begin{tabular}{|l|}
0.821 \\
\end{tabular} & 0.825 & 0.995 & irs & \begin{tabular}{|l|}
0.419 \\
\end{tabular} & 0.432 & 0.970 & irs & 0.821 & 0.825 & 0.995 & irs & 0.374 & 0.400 & 0.935 irs \\
\hline NOVO BANCO & MOZ & \begin{tabular}{|l|}
1.000 \\
\end{tabular} & 1.000 & 1.000 & - & \begin{tabular}{|l|}
0.846 \\
\end{tabular} & 1.000 & 0.846 & $\mathrm{drs}$ & 1.000 & 1.000 & 1.000 & - & 0.541 & 1.000 & $0.541 \mathrm{drs}$ \\
\hline SOCREMO & MOZ & \begin{tabular}{|l|}
0.811 \\
\end{tabular} & 0.846 & 0.959 & $\mathrm{drs}$ & \begin{tabular}{|l|}
0.737 \\
\end{tabular} & 0.775 & 0.952 & $\mathrm{drs}$ & 0.750 & 0.750 & 1.000 & - & 0.281 & 0.545 & $0.516 \mathrm{drs}$ \\
\hline TCHUMA & MOZ & 0.926 & 0.944 & 0.981 & $\mathrm{drs}$ & 0.791 & 0.795 & 0.996 & irs & 0.894 & 0.896 & 0.998 & irs & 0.359 & 0.478 & $0.750 \mathrm{drs}$ \\
\hline CBB & NEP & 0.637 & 0.851 & 0.749 & irs & 0.586 & 0.813 & 0.721 & irs & 0.637 & 0.849 & 0.751 & irs & 0.551 & 0.802 & 0.686 irs \\
\hline NIRDHAN & NEP & 0.705 & 0.706 & 0.999 & irs & 0.704 & 0.704 & 0.999 & irs & 0.545 & 0.545 & 1.000 & - & 0.313 & 0.321 & $0.975 \mathrm{drs}$ \\
\hline ACODEP & NIC & 1.000 & 1.000 & 1.000 & - & 0.868 & 1.000 & 0.868 & $\mathrm{drs}$ & 1.000 & 1.000 & 1.000 & - & 0.711 & 1.000 & $0.711 \mathrm{drs}$ \\
\hline FDL & NIC & \begin{tabular}{|l|}
0.826 \\
\end{tabular} & 0.837 & 0.988 & drs & \begin{tabular}{|l|}
0.803 \\
\end{tabular} & 0.838 & 0.957 & drs & 0.746 & 0.759 & 0.984 & drs & 0.491 & 0.688 & $0.715 \mathrm{drs}$ \\
\hline FINDESA & NIC & 1.000 & 1.000 & 1.000 & - & 0.864 & 1.000 & 0.864 & drs & 1.000 & 1.000 & 1.000 & - & 0.792 & 1.000 & $0.792 \mathrm{drs}$ \\
\hline ProCred NIC & NIC & 0.815 & 0.851 & 0.958 & drs & 0.781 & 0.842 & 0.927 & drs & 0.736 & 0.743 & 0.990 & drs & 0.435 & 0.668 & $0.651 \mathrm{drs}$ \\
\hline Prodesa & NIC & \begin{tabular}{|l|}
1.000 \\
\end{tabular} & 1.000 & 1.000 & - & \begin{tabular}{|l|}
1.000 \\
\end{tabular} & 1.000 & 1.000 & - & 1.000 & 1.000 & 1.000 & - & 1.000 & 1.000 & 1.000 \\
\hline LAPO & NIG & 0.849 & 0.874 & 0.972 & drs & \begin{tabular}{|l|}
0.767 \\
\end{tabular} & 0.864 & 0.888 & drs & 0.762 & 0.792 & 0.962 & drs & 0.408 & 0.675 & $0.604 \mathrm{drs}$ \\
\hline SEAP & NIG & 0.980 & 1.000 & 0.980 & irs & 0.754 & 1.000 & 0.754 & irs & 0.980 & 1.000 & 0.980 & irs & 0.483 & 1.000 & 0.483 irs \\
\hline ASASAH & PAK & \begin{tabular}{|l|}
0.438 \\
\end{tabular} & 0.442 & 0.991 & drs & \begin{tabular}{|l|} 
\\
\end{tabular} & 0.403 & 0.993 & irs & 0.354 & 0.358 & 0.989 & drs & 0.022 & 0.023 & $0.954 \mathrm{drs}$ \\
\hline FMBL & PAK & \begin{tabular}{|l|}
0.493 \\
\end{tabular} & 0.493 & 1.000 & - & \begin{tabular}{|l|}
0.392 \\
\end{tabular} & 0.398 & 0.984 & drs & 0.493 & 0.493 & 1.000 & - & 0.232 & 0.266 & $0.872 \mathrm{drs}$ \\
\hline KASHF & PAK & \begin{tabular}{|l|}
0.779 \\
\end{tabular} & 0.787 & 0.991 & drs & \begin{tabular}{|l|}
0.748 \\
\end{tabular} & 0.768 & 0.973 & drs & 0.698 & 0.702 & 0.993 & drs & 0.451 & 0.524 & $0.861 \mathrm{drs}$ \\
\hline FIELCO & PAR & \begin{tabular}{|l|}
0.961 \\
\end{tabular} & 0.980 & 0.981 & drs & \begin{tabular}{|l|}
0.708 \\
\end{tabular} & 0.804 & 0.880 & drs & 0.961 & 0.980 & 0.981 & drs & 0.516 & 0.798 & $0.646 \mathrm{drs}$ \\
\hline Interfisa & PAR & 0.990 & 1.000 & 0.990 & $\mathrm{drs}$ & 0.778 & 0.868 & 0.896 & drs & 0.990 & 1.000 & 0.990 & drs & 0.587 & 0.867 & $0.677 \mathrm{drs}$ \\
\hline Bantra & PER & 1.000 & 1.000 & 1.000 & - & 0.843 & 1.000 & 0.843 & drs & 1.000 & 1.000 & 1.000 & - & 0.479 & 1.000 & $0.479 \mathrm{drs}$ \\
\hline Caja Nor & PER & 0.775 & 0.788 & 0.983 & $\mathrm{drs}$ & 0.730 & 0.780 & 0.936 & drs & 0.702 & 0.715 & 0.982 & drs & 0.387 & 0.594 & $0.652 \mathrm{drs}$ \\
\hline Caritas & PER & \begin{tabular}{|l|}
0.926 \\
\end{tabular} & 0.944 & 0.981 & drs & \begin{tabular}{|l|}
0.853 \\
\end{tabular} & 0.856 & 0.997 & irs & \begin{tabular}{|l|}
0.777 \\
\end{tabular} & 0.796 & 0.977 & drs & 0.231 & 0.387 & $0.597 \mathrm{drs}$ \\
\hline CMAC Arq & PER & 1.000 & 1.000 & 1.000 & - & 1.000 & 1.000 & 1.000 & - & 1.000 & 1.000 & 1.000 & - & 1.000 & 1.000 & 1.000 \\
\hline CMAC May & PER & 0.892 & 0.898 & 0.993 & drs & 0.806 & 0.842 & 0.957 & drs & 0.860 & 0.865 & 0.994 & drs & 0.499 & 0.716 & $0.697 \mathrm{drs}$ \\
\hline CMAC Tac & PER & \begin{tabular}{|l|}
0.868 \\
\end{tabular} & 0.886 & 0.980 & $\mathrm{drs}$ & \begin{tabular}{|l|}
0.842 \\
\end{tabular} & 0.853 & 0.987 & $\mathrm{drs}$ & 0.780 & 0.806 & 0.968 & drs & 0.572 & 0.643 & $0.890 \mathrm{drs}$ \\
\hline CMAC Tru & PER & \begin{tabular}{|l|}
0.932 \\
\end{tabular} & 1.000 & 0.932 & $\mathrm{drs}$ & \begin{tabular}{|l|}
0.895 \\
\end{tabular} & 1.000 & 0.895 & $\mathrm{drs}$ & 0.871 & 0.914 & 0.952 & drs & 0.740 & 0.844 & $0.876 \mathrm{drs}$ \\
\hline Edpy. C Tac & PER & 1.000 & 1.000 & 1.000 & - & 1.000 & 1.000 & 1.000 & 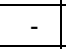 & 1.000 & 1.000 & 1.000 & - & 1.000 & 1.000 & 1.000 \\
\hline Edpy. Cofian & PER & 0.756 & 0.762 & 0.992 & drs & 0.705 & 0.724 & 0.974 & drs & 0.701 & 0.706 & 0.993 & drs & 0.184 & 0.254 & $0.722 \mathrm{drs}$ \\
\hline EDPY.Edyf & PER & 0.905 & 0.915 & 0.989 & drs & 0.811 & 0.868 & 0.934 & drs & 0.845 & 0.858 & 0.986 & drs & 0.288 & 0.491 & $0.588 \mathrm{drs}$ \\
\hline
\end{tabular}




\begin{tabular}{|c|c|c|c|c|c|c|c|c|c|c|c|c|c|}
\hline & ZR & 927 & .930 & 997 irs & 678 & 0.690 & .983 irs & 0.927 & 0.930 & 0.997 irs & 0.332 & 0.363 & 0.914 \\
\hline & & & 971 & $999 \mathrm{drs}$ & 918 & 0.964 & .952 irs & 854 & & $0.995 \mathrm{drs}$ & & & 0.892 \\
\hline & & & & $47 \mathrm{drs}$ & & & $39 \mathrm{drs}$ & & 00 & $15 \mathrm{drs}$ & & & 05 \\
\hline & & & & $94 \mathrm{drs}$ & & & 79 irs & & & 98 irs & & & 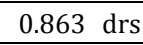 \\
\hline & & & & $2 \mathrm{drs}$ & & & $97 \mathrm{drs}$ & & & $73 \mathrm{drs}$ & & & 29 \\
\hline & & 36 & 50 & $982 \mathrm{drs}$ & 39 & & 996 irs & & & 990 drs & & & 0 \\
\hline & & & & $6 \mathrm{drs}$ & & & $71 \mathrm{drs}$ & & & $76 \mathrm{drs}$ & & & 71 \\
\hline & & 2 & 64 & $998 \mathrm{drs}$ & 99 & 11 & $0.998 \mathrm{drs}$ & & & $98 \mathrm{drs}$ & & & 57 \\
\hline & & & & $0 \quad-$ & & & $96 \mathrm{drs}$ & & & $00 \quad-$ & & & 7 \\
\hline & & & 93 & $996 \mathrm{drs}$ & & & 96 irs & 59 & & $94 \mathrm{drs}$ & 17 & & 21 \\
\hline & & & & $6 \mathrm{drs}$ & & & $70 \mathrm{drs}$ & & & $92 \mathrm{drs}$ & & & 91 \\
\hline & & 59 & 0.780 & $0.972 \mathrm{drs}$ & 0.661 & & $0.873 \mathrm{drs}$ & 0.721 & 48 & $0.963 \mathrm{drs}$ & 366 & & 578 \\
\hline & & & & $0 \quad-$ & & & 05 irs & & & 50 & & & - \\
\hline & & 360 & 0.925 & $0.930 \mathrm{drs}$ & 0.754 & 0.915 & $0.823 \mathrm{drs}$ & 0.852 & 16 & $330 \mathrm{drs}$ & 85 & & 541 \\
\hline & & & & $2 \mathrm{drs}$ & & & $52 \mathrm{drs}$ & & & $2 \mathrm{drs}$ & & & 88 \\
\hline & & 99 & 0.970 & $0.926 \mathrm{drs}$ & \begin{tabular}{|l|}
0.822 \\
\end{tabular} & & $0.942 \mathrm{drs}$ & 30 & & $0.934 \mathrm{drs}$ & & & 621 \\
\hline & & & & 93 irs & 0 & & 92 irs & & & 95 irs & & & \\
\hline & $\mathrm{N}$ & 547 & 0.658 & $0.983 \mathrm{drs}$ & \begin{tabular}{|l|}
0.590 \\
\end{tabular} & 0.631 & $0.935 \mathrm{drs}$ & 0.613 & & $94 \mathrm{drs}$ & & & 0.811 \\
\hline & & & & $85 \mathrm{drs}$ & 8 & & $54 \mathrm{drs}$ & & & $93 \mathrm{drs}$ & & & 36 \\
\hline & AJ & 94 & 0.632 & $940 \mathrm{drs}$ & 0.594 & 0.632 & $0.941 \mathrm{drs}$ & 0.350 & 74 & $34 \mathrm{drs}$ & & & 0.722 \\
\hline & & 22 & & $997 \mathrm{drs}$ & 0.684 & & 382 drs & 22 & & $97 \mathrm{drs}$ & & & 32 \\
\hline & & 3 & 3 & 00 & 492 & & $90 \mathrm{drs}$ & & & 00 & & & 09 \\
\hline & & & & $00 \quad-$ & 74 & & 98 irs & & & $97 \mathrm{drs}$ & & & .909 \\
\hline & & & & 999 irs & 0 & & 53 irs & & & 99 irs & & & 95 \\
\hline & & & & $925 \mathrm{drs}$ & & & $26 \mathrm{drs}$ & & & 70 drs & & & 11 \\
\hline & & 905 & & $986 \mathrm{drs}$ & 39 & & 32 drs & 59 & & 79 drs & & & 18 \\
\hline & & & & $0.923 \mathrm{drs}$ & & & 22 drs & 0 & & $86 \mathrm{drs}$ & & & 0.569 \\
\hline & & 335 & 0.843 & $0.990 \mathrm{drs}$ & 0.758 & 0.791 & $0.958 \mathrm{drs}$ & 0.770 & 70 & 1.000 & & & .528 \\
\hline & & 38 & 0.652 & $0.978 \mathrm{drs}$ & & & $0.992 \mathrm{drs}$ & 0 & & $986 \mathrm{drs}$ & & & 0.603 \\
\hline & & 345 & 0.924 & $0.914 \mathrm{drs}$ & 0.690 & 0.799 & $0.863 \mathrm{drs}$ & 0.845 & 0.924 & $0.914 \mathrm{drs}$ & 09 & 36 & 0.556 \\
\hline & & & & $1.000 \quad-$ & 0.840 & & $0.910 \mathrm{drs}$ & 53 & & $0.999 \mathrm{drs}$ & 0.508 & & 0.627 \\
\hline & IET & 801 & 0.803 & $0.997 \mathrm{drs}$ & 0.792 & 0.803 & $0.987 \mathrm{drs}$ & 0.683 & 0.688 & $0.993 \mathrm{drs}$ & 0.461 & 544 & 0.847 \\
\hline & & 701 & & 0.996 irs & 0. & & 0.982 irs & 0. & & 00 & & & 0.994 \\
\hline ETZ & $\mathbf{M}$ & 000 & 1.000 & 1.000 & 0.795 & 0.822 & 0.966 irs & 1.000 & 1.000 & 1.000 & 266 & .277 & 0.962 \\
\hline & & & & 0.999 irs & & & $0.896 \mathrm{dr}$ & & & 0.999 irs & & & 0.852 \\
\hline MEAN & & 835 & 0.859 & 973 & 0.776 & 0.823 & 944 & .732 & 0.751 & 976 & 0.428 & 0.561 & 0.773 \\
\hline
\end{tabular}

\section{Appendix H}

\begin{tabular}{|c|c|c|c|c|c|c|c|c|c|c|c|c|c|c|c|c|c|c|c|c|c|}
\hline \multirow{2}{*}{ MFIs } & \multirow{2}{*}{ Cou } & \multicolumn{4}{|c|}{ LR-ACE } & \multicolumn{4}{|c|}{ LR-ACES $^{i}$} & \multicolumn{3}{|c|}{ L-ACE } & \multicolumn{3}{|c|}{ L-ACES $S^{i}$} & \multicolumn{3}{|c|}{ R-ACE } & \multicolumn{3}{|c|}{ R-ACES } \\
\hline & & ste & vrste & scale & & e & vrste & scale & & e & vrste & scale & te & vrste & sc: & te & vrste & s & ste & vrste & 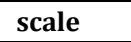 \\
\hline & $\mathbf{G}$ & & & & irs & & & & & & & 8 irs & & & 8 irs & & & 99 & & & $7 \mathrm{i}$ \\
\hline & & 44 & 0.671 & 0.960 & $\mathrm{drs}$ & 44 & 0.671 & 0.960 & $\mathrm{drs}$ & 27 & 0.638 & $0.984 \mathrm{drs}$ & & 38 & $0.984 \mathrm{drs}$ & & 94 & $09 \mathrm{drs}$ & & 94 & $99 \mathrm{drs}$ \\
\hline & & & & 0 & $\mathrm{drs}$ & & & 99 & 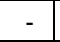 & & & $6 \mathrm{drs}$ & & & $5 \mathrm{drs}$ & & & 9 irs & & & 9 irs \\
\hline & & 00 & 1.000 & 1.000 & - & 00 & 1.000 & 1.000 & & & 1.000 & 1.000 & & 1.000 & 1.000 & & & 0.990 irs & 00 & 000 & 000 \\
\hline & $\mathbf{B}$ & & 0 & 0 & irs & & & & & & & $\mathrm{drs}$ & & & & & & 98 irs & & & 0 \\
\hline & ALB & 887 & 0.888 & 0.999 & irs & 0.887 & 0.888 & 0.999 & irs & 0. & 0.879 & $0.998 \mathrm{drs}$ & 77 & 79 & $98 \mathrm{drs}$ & & 66 & 92 irs & 59 & 6 & 2 \\
\hline & & & & & & & & & - & & & 8 irs & & & 8 irs & & & 1 & & & 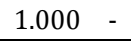 \\
\hline & M & 867 & 0.890 & 0.974 & drs & 0.867 & 0.890 & 0.974 & drs & & 0. & $0.852 \mathrm{drs}$ & & 0 & $0.852 \mathrm{drs}$ & & & $39 \mathrm{drs}$ & & 77 & $9 \mathrm{drs}$ \\
\hline & & & & & drs & & & & & & & 3 irs & & & 8 irs & & & $1 \mathrm{drs}$ & & & \\
\hline & $\mathbf{R M}$ & 000 & 1.000 & 1.000 & - & 1.000 & 0 & & - & & & $0.985 \mathrm{drs}$ & & & 0.984 irs & & & 0 & & & 0 \\
\hline & $\mathbf{E E}$ & & & & - & & & & - & & & 1. & & & 1 & & & 5 irs & & & 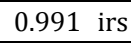 \\
\hline & AZE & 831 & 0.869 & 0.957 & drs & 0.831 & 9 & 0.957 & $\mathrm{drs}$ & 1 & 0 & $0.957 \mathrm{drs}$ & & & $0.957 \mathrm{drs}$ & & 21 & $82 \mathrm{drs}$ & & & $2 \mathrm{drs}$ \\
\hline & $\mathbf{Z E}$ & & 0.986 & 0.99 & irs & 0 & & & irs & & & 79 irs & & & 79 irs & & & $4 \mathrm{drs}$ & & & $\mathrm{drs}$ \\
\hline & $\mathbf{Z E}$ & 958 & 0.965 & 0.993 & $\mathrm{drs}$ & 1.000 & & 1 & - & 0 & & 0.985 irs & & & 0.977 irs & & & $4 \mathrm{drs}$ & & & drs \\
\hline & $\mathrm{IN}$ & 00 & 1 & 1.000 & - & 1.000 & & & - & & & $50 \mathrm{drs}$ & & & $0 \mathrm{drs}$ & & & 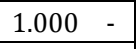 & & & 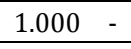 \\
\hline & $\mathbf{N}$ & 914 & 1.000 & 0.91 & $\mathrm{drs}$ & 0.914 & & 0 & $\mathrm{drs}$ & & & $8 \mathrm{drs}$ & & & $18 \mathrm{drs}$ & & & $14 \mathrm{drs}$ & & & drs \\
\hline & AN & 8 & 0.5 & 0.999 & irs & 0.578 & & 0.9 & irs & & & $4 \mathrm{drs}$ & & & $34 \mathrm{drs}$ & & & $84 \mathrm{irs}$ & & 22 & 84 irs \\
\hline & AN & 705 & 0.730 & 0.967 & drs & 0.705 & 0.730 & 0.967 & drs & 0.703 & 0.727 & $0.966 \mathrm{drs}$ & 0.703 & 0.727 & $0.966 \mathrm{drs}$ & 83 & 89 & $0.990 \mathrm{drs}$ & 83 & 89 & $90 \mathrm{drs}$ \\
\hline FEC & EN & 491 & 0.512 & 0.959 & drs & 0.491 & & 0.959 & drs & 0.457 & & $0.954 \mathrm{drs}$ & 0. & & $0.954 \mathrm{drs}$ & & & $0.968 \mathrm{drs}$ & & & $968 \mathrm{drs}$ \\
\hline & EN & 760 & 0.854 & 0.890 & irs & 0.760 & 0.854 & 0.890 & irs & 0.744 & 0.854 & 0.872 irs & 0.744 & 0.854 & 0.872 irs & 0.474 & 0.478 & $0.992 \mathrm{drs}$ & 0.482 & 0.485 & $0.993 \mathrm{drs}$ \\
\hline 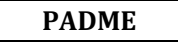 & & 718 & 0.719 & 0.999 & irs & 0.718 & 0.719 & 0.999 & irs & 0.656 & & $0.980 \mathrm{drs}$ & & & $0.980 \mathrm{drs}$ & & & 0.999 irs & & & 0.999 irs \\
\hline VF & BEN & 835 & 0.836 & 0.998 & irs & 0.835 & 0.836 & 0.998 & irs & 0.782 & 0.785 & 0.996 irs & 0.782 & 0.785 & 0.996 irs & 0.744 & 0.767 & 0.970 irs & 0.744 & 0.767 & 0.970 irs \\
\hline
\end{tabular}




\begin{tabular}{|c|c|c|c|c|c|c|c|c|c|c|c|c|c|c|c|c|c|c|c|c|c|c|c|}
\hline & DL & & 0.785 & 1.000 & & & & & & & & & & & 6 & 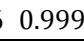 & & 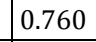 & 9 & ח & 1 & - & 1 \\
\hline & & & & & drs & & 00 & & & & & & & & & & 0 & & & $72 \mathrm{drs}$ & & & 000 \\
\hline & & 29 & 48 & & & 34 & 48 & & $s$ & & & & & & & & $7 \mathrm{drs}$ & & & 8 drs & & & - \\
\hline & & & & & & & & & & & & & $6 \mathrm{drs}$ & & & & 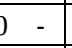 & & & 8 irs & & & \\
\hline & & 7 & 768 & & $\mathrm{drs}$ & 67 & 0 & & $\mathrm{drs}$ & & & & & & & & - & & & $99 \mathrm{drs}$ & & & \\
\hline & & & & & & & & & & & & & $\mathrm{rs}$ & & & & $\mathrm{drs}$ & & & $\mathrm{drs}$ & & & \\
\hline & $\mathrm{OL}$ & 3 & 0 & & irs & 3 & & & irs & & & & 0 irs & & & & 0 irs & & & 8 irs & & & \\
\hline & & & & & $\mathrm{drs}$ & & & & $\mathrm{drs}$ & & & & $3 \mathrm{drs}$ & & & & $3 \mathrm{drs}$ & & & $5 \mathrm{drs}$ & & & \\
\hline 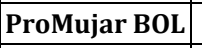 & & & 0 & & $\mathrm{drs}$ & 4 & & & $\mathrm{drs}$ & & & & 9 irs & & & & 9 irs & & & $6 \mathrm{drs}$ & & & \\
\hline & & & & & - & & & & -1 & & & & 3 irs & & & & 8 irs & & & 6 irs & & & \\
\hline & $\mathbf{L}$ & 952 & 0.978 & & drs & 5 & 0.9 & & $\mathrm{drs}$ & 0. & & & $4 \mathrm{drs}$ & & & & $4 \mathrm{drs}$ & & & $0.997 \mathrm{drs}$ & & & \\
\hline & & & & & drs & & & & $\mathrm{drs}$ & & & & $2 \mathrm{drs}$ & & & & $2 \mathrm{drs}$ & & & $1.000-$ & & & \\
\hline & & & 0 & & drs & & 1.0 & & - & & & & $\mathrm{drs}$ & & & & $4 \mathrm{drs}$ & & & $5 \mathrm{drs}$ & & & 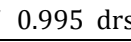 \\
\hline & & & & & drs & & & & drs & & & & $\mathrm{drs}$ & & & & $8 \mathrm{drs}$ & & & $3 \mathrm{drs}$ & & & \\
\hline & & & 1 & & 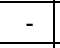 & 0 & & & - & & & & $3 \mathrm{drs}$ & & & & $0 \mathrm{drs}$ & & & $0 \quad-$ & & & \\
\hline & & & & & drs & & & & $\mathrm{drs}$ & & & & $6 \mathrm{drs}$ & & & & $\mathrm{drs}$ & & & $\mathrm{drs}$ & & & $\mathrm{drs}$ \\
\hline & & & 0.8 & & drs & & & & $\mathrm{drs}$ & & & & & & & & - & & & $1 \mathrm{drs}$ & & & \\
\hline & & & & & irs & & & & irs & & & & & & & & 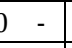 & & & 3 irs & & & \\
\hline & & 7 & 0 & 1 & & 8 & & & 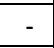 & & & & 3 irs & & & & irs & & & $3 \mathrm{drs}$ & & & \\
\hline & & & & & drs & & & & $\mathrm{drs}$ & & & & - & & & & 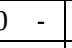 & & & $\mathrm{rs}$ & & & $d x$ \\
\hline & & & 1 & & & & & & 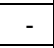 & & & & 0 irs & & & & 0 irs & & & & & & \\
\hline & & & & & & & & & - & & & & & & & & & & & 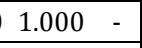 & & & \\
\hline & & & & & - & & & & - & & & & - & & & & - & & & 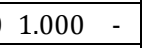 & & & \\
\hline & & & & & irs & & & & irs & & & & 3 irs & & & & 5 irs & & & 9 irs & & & \\
\hline & & & & & irs & & & & irs & & & & 7 irs & & & & irs & & & 7 irs & & & \\
\hline & & & & & drs & & & & - & & & & & & & & & & & $4 \mathrm{drs}$ & & & \\
\hline & & & & & drs & & & & $\mathrm{drs}$ & & & & 7 irs & & & & 7 irs & & & $9 \mathrm{drs}$ & & & \\
\hline & & & 0.8 & & irs & & & & irs & & & & & & & & & & & 37 irs & & & \\
\hline & & & & & irs & & & & irs & & & & 4 irs & & & & 4 irs & & & 70 irs & & & \\
\hline & & & & & irs & & & & irs & & & & & & & & & & & 8 irs & & & \\
\hline & & & & & $\mathrm{drs}$ & & & & $\mathrm{drs}$ & & & & 6 irs & & & & 6 irs & & & $0 \mathrm{drs}$ & & & \\
\hline & & & 1 & & & & & & - & & & & 3 irs & & & & & & & 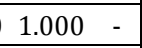 & & & \\
\hline & & & 0 & & $\mathrm{drs}$ & 0 & & & $\mathrm{drs}$ & & & & $1 \mathrm{drs}$ & & & & $1 \mathrm{drs}$ & & & $9 \quad$ & & & \\
\hline & $\mathrm{OE}$ & 2 & 0.8 & & irs & 0 & & & irs & & & & 1 irs & & & & & & & & & & \\
\hline & & & 1 & & irs & 9 & & & irs & & & & 6 irs & & & & 5 irs & & & 1 & & & \\
\hline & $\Gamma$ & & & & $\mathrm{drs}$ & & & & $\mathrm{drs}$ & & & & & & & & & & & & & & \\
\hline & & 4 & 1 & & $\mathrm{drs}$ & 0 & & & $\mathrm{drs}$ & & & & 4 irs & & & & 4 irs & & & $\mathrm{drs}$ & & & \\
\hline & & & & & $\mathrm{drs}$ & & & & $\mathrm{drs}$ & & & & 1 irs & & & & & & & & & & \\
\hline & & & 0 & & irs & c & & & irs & & & & 1 irs & & & & irs & & & drs & & & \\
\hline & & & & & & & & & drs & & & & $s$ & & & & & & & & & & \\
\hline & & & & & drs & & & & drs & & & & & & & & & & & & & & - \\
\hline & & & & & drs & & & & $\mathrm{drs}$ & & & & & & & & & & & $7 \mathrm{drs}$ & & & \\
\hline & & & & & irs & & & & irs & & & & 7 irs & & & & 5 irs & & & 77 irs & & & s \\
\hline & & & & & drs & & & & $\mathrm{drs}$ & & & & $0 \mathrm{drs}$ & & 40 & & drs & & & $6 \mathrm{drs}$ & t & 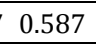 & . \\
\hline & & & & & & & & & - & & & & & & 1 & & 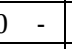 & & & 64 irs & & & 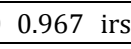 \\
\hline & 0 & & 0 & & $s$ & & & & 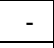 & & & & $\mathrm{rs}$ & & 3 & & $s$ & & 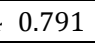 & $\mathrm{drs}$ & 5 & & \\
\hline & & & & & & & & & - & & & & $\mathrm{rs}$ & & & & 3 irs & & & & & & \\
\hline & & & 0.5 & & $\mathrm{drs}$ & & & & $\mathrm{drs}$ & & & & 3 irs & & 1 & & 3 irs & & 0 & drs & 5 & & 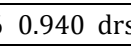 \\
\hline & & & & & $\mathrm{drs}$ & & & & $\mathrm{drs}$ & & & & & & & & & & & & & & $\mathrm{dr}$ \\
\hline & & & & & $\mathrm{drs}$ & & & & $\mathrm{drs}$ & & & & $s$ & & 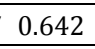 & & $0 \mathrm{drs}$ & & 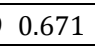 & $7 \mathrm{drs}$ & t & 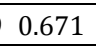 & $7 \mathrm{drs}$ \\
\hline & & & & & irs & & & & irs & & & & 3 irs & & & & & & & 2 irs & & & \\
\hline & & & 1 & & drs & 0 & & & $\mathrm{drs}$ & & & & $3 \mathrm{drs}$ & & 3 & & $8 \mathrm{drs}$ & & 0 & $3 \mathrm{drs}$ & 5 & 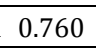 & $3 \mathrm{drs}$ \\
\hline & & & & & - & & & & - & & & & & & & & & & & \begin{tabular}{ll|}
0 & - \\
\end{tabular} & & & 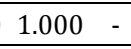 \\
\hline & I & & 0 & & irs & & & & irs & & & & 3 irs & & & & 8 irs & & 0 & 8 irs & & 7 & irs \\
\hline & & & & & irs & & & & irs & & & & & & & & & & & 3 ars & & & 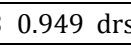 \\
\hline & & 0 & 0 & & - & 2 & 0 & & - & $0 . \varepsilon$ & 0 & & 4 irs & 0 & 0 & & 4 irs & 32 & 0 & $0 \mathrm{drs}$ & 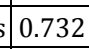 & 3 & $0 \mathrm{drs}$ \\
\hline & & & & & drs & & & & - & & & & & & & & 0 & & & $7 \mathrm{drs}$ & & & Min \\
\hline & & 833 & 0.839 & & irs & 0.960 & 1.000 & 0.960 & irs & 0.787 & 0.807 & 0.975 & 5 irs & 0.797 & 1.000 & 0.797 & 7 irs & 0.674 & 0.691 & $75 \mathrm{drs}$ & 331 & 00 & 31 irs \\
\hline & & & & & & & & & & & & & & & & & & & & & & & 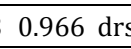 \\
\hline & & 752 & 0.757 & 0. & $\mathrm{drs}$ & 0.862 & 0.864 & 97 & $\mathrm{drs}$ & 0.333 & 0.350 & 0.952 & 2 irs & 0.333 & 0.354 & 0.942 & 2 irs & 0.752 & 0.757 & $93 \mathrm{drs}$ & 0.862 & 864 & $997 \mathrm{drs}$ \\
\hline & & & & & & & & & & & & & & & & & & & & & & & 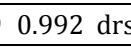 \\
\hline & $\mathbf{Z}$ & 927 & 0.939 & 0 & $\mathrm{drs}$ & 0.963 & 0.983 & 0 & $\mathrm{drs}$ & 0.770 & 0.782 & 0.9 & 5 irs & 0.770 & 0.782 & 0. & 5 irs & 0.864 & 0.895 & $65 \mathrm{drs}$ & 0.924 & 0.937 & $0.986 \mathrm{drs}$ \\
\hline & & & 0 & & irs & 0.7 & $\mathrm{c}$ & & irs & & 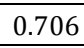 & & & & 3 & & & & & 0.977 & & & 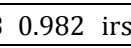 \\
\hline
\end{tabular}




\begin{tabular}{|c|c|c|c|c|c|c|c|c|c|c|c|c|c|c|c|}
\hline & & $\mathrm{rs}$ & rs & 9 & 4 & 33 irs & & 4 & 33 irs & 0 & 8 & 8 irs & 8 & 8 & \\
\hline WISD & $\mathbf{H}$ & $\begin{array}{llll}0.684 & 0.685 & 0.999 & \text { irs }\end{array}$ & $\begin{array}{llll}0.684 & 0.685 & 0.999 & \text { irs }\end{array}$ & 0.367 & 0.371 & 0.987 irs & 0.367 & 0.371 & 0.987 irs & 684 & 0.685 & 0.999 irs & 0.684 & 0.685 & 0.999 \\
\hline & & 420. & 0.8420 & 04 & 0.713 & $0.987 \mathrm{drs}$ & 09 & 0.723 & $981 \mathrm{drs}$ & 317 & 318 & $998 \mathrm{drs}$ & 817 & 8 & $98 \mathrm{drs}$ \\
\hline ProC & IA & $37 \mathrm{drs}$ & 0.7390 .7490$. & 697 & 0.700 & $0.995 \mathrm{drs}$ & 697 & 0.700 & $0.995 \mathrm{drs}$ & 0.520 & 521 & $97 \mathrm{drs}$ & 0.520 & 21 & $97 \mathrm{drs}$ \\
\hline BA & D & $\begin{array}{llll}1.000 & 1.000 & 1.000 & -\end{array}$ & $\begin{array}{llll}1.000 & 1.000 & 1.000 & -\end{array}$ & 1.000 & 1.000 & 1.000 & 000 & 1.000 & 1.000 & 785 & 334 & $941 \mathrm{drs}$ & 785 & 354 & $19 \mathrm{drs}$ \\
\hline & D & 0.9500 .9590$. & 0.9500 .9590$. & 50 & 59 & $0.990 \mathrm{drs}$ & 50 & 0.959 & $0.990 \mathrm{drs}$ & 0.626 & 636 & 0.986 irs & 0.626 & 36 & 86 \\
\hline 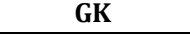 & D & 0.8640 .8660 & 0.8640 .8660$. & 0.798 & 0.804 & $0.992 \mathrm{drs}$ & 0.798 & 0.804 & $0.992 \mathrm{drs}$ & 0.796 & 0.808 & 0.985 irs & .796 & 808 & 985 i \\
\hline & $\mathbf{R}$ & $\mathrm{s}$ & 0.9100 & 02 & 0. & $0.999 \mathrm{drs}$ & 0.902 & 0. & $0.999 \mathrm{drs}$ & 0.666 & 77 & 0.984 irs & 0.666 & 77 & 84 irs \\
\hline & $\mathbf{Z}$ & 0.7980 .8010 & 0.7980 .8010$. & 0.680 & 0.680 & 1.000 & 0.681 & 0.683 & $0.998 \mathrm{drs}$ & 0.798 & 0.801 & $0.996 \mathrm{drs}$ & 0.798 & 0.801 & $96 \mathrm{drs}$ \\
\hline & & 0.6391 .0 & 0.6451 & 9 & 0 & $0.695 \mathrm{drs}$ & & & & 39 & & $39 \mathrm{drs}$ & & & drs \\
\hline DSL & $\mathbf{N}$ & 1.0001 .0001 .000 & 1.0001 .0001 .000 & 0.766 & 1.000 & 0.766 irs & 1.000 & 1.000 & 1.000 & 1.000 & 1.000 & 1.000 & 1.000 & 1.000 & 1.000 \\
\hline & & 90.8 & 0.8090 & 4 & 0. & $76 \mathrm{drs}$ & & & & & & 1 & & & \\
\hline Kha & $\mathbf{O N}$ & $\begin{array}{llll}0.802 & 1.000 & 0.802 & d r s\end{array}$ & $\begin{array}{llll}0.802 & 1.000 & 0.802 \mathrm{drs}\end{array}$ & 0.748 & 1.000 & $0.748 \mathrm{drs}$ & 0.748 & 1.000 & $0.748 \mathrm{drs}$ & 0.802 & 1.000 & $0.802 \mathrm{drs}$ & 0.802 & 00 & 02 drs \\
\hline & $\mathbf{R}$ & $0-$ & $0-$ & 1 & & $92 \mathrm{drs}$ & & & & & & 1 & & & \\
\hline In & $\mathbf{O R}$ & $0.9721 .000 \quad 0.972$ irs & $0.9721 .000 \quad 0.972$ irs & 0.894 & 1.000 & 0.894 irs & 0.899 & 1.000 & 0.899 irs & 0.744 & 0.806 & 0.923 irs & 0.744 & 06 & 23 irs \\
\hline 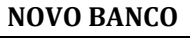 & $\mathbf{O z}$ & $\begin{array}{llll}1.000 & 1.000 & 1.000 & -\end{array}$ & $1.0001 .0001 .000 \quad-$ & 0.765 & 0.766 & $0.998 \mathrm{drs}$ & 0.777 & 0.796 & $0.975 \mathrm{drs}$ & 00 & & 1.000 & & & 1 \\
\hline & $\mathbf{P}$ & $\begin{array}{llll}0.640 & 1.000 & 0.640 & \text { irs }\end{array}$ & $\begin{array}{llll}0.640 & 1.000 & 0.640 & \text { irs }\end{array}$ & 0.589 & 1.000 & 0.589 irs & 0.589 & 1. & 0.589 irs & 40 & & 0.640 irs & 40 & & 40 irs \\
\hline & $\mathbf{C}$ & $1.0001 .0001 .000 \quad-$ & $1.0001 .0001 .000 \quad-$ & 0.849 & 0.850 & $0.999 \mathrm{drs}$ & 0.856 & 0.864 & $0.990 \mathrm{drs}$ & 1.000 & 1.000 & $1.000 \quad-$ & 1.000 & 00 & 1.000 \\
\hline & $\mathbf{C}$ & 0.8630 .8830$. & 0.8630. & 0. & 0 & $33 \mathrm{drs}$ & 23 & & $3 \mathrm{drs}$ & 52 & & drs & & & drs \\
\hline $\mathbf{F}$ & C & 1.0001 .0001 .000 - & 1.0001 .0001 .000 & 0.803 & 0.869 & $0.924 \mathrm{drs}$ & 0.803 & 0.869 & $0.924 \mathrm{drs}$ & 1.000 & 1.000 & $1.000 \quad-$ & 000 & 1.000 & $1.000 \quad-$ \\
\hline & & $\begin{array}{lllll}1.000 & 1.000 & 1.000 & -\end{array}$ & 1.0001. & 0 & & $00 \quad-$ & 0 & & $1.000 \quad-$ & & & $00-$ & & & -1 \\
\hline U & G & $\begin{array}{lllll}0.872 & 0.886 & 0.984 & \mathrm{drs}\end{array}$ & 0.8720 .8860$. & 0.722 & 0.766 & $0.942 \mathrm{drs}$ & 0.724 & 0.767 & $0.944 \mathrm{drs}$ & 0.797 & 0.804 & 0.992 irs & 0.797 & 0.804 & 0.992 irs \\
\hline & & 1.0001. & 1.0 & & & & & & & & & 1 & & & - \\
\hline Ban & HI & 0.5650 .5 & $\begin{array}{llll}0.565 & 0.585 & 0.966 & d r s\end{array}$ & 0.453 & 0.457 & $0.992 \mathrm{drs}$ & 0.455 & 0.458 & $0.994 \mathrm{drs}$ & 0.565 & 0.581 & $0.972 \mathrm{drs}$ & 0.565 & 0.585 & $0.966 \mathrm{drs}$ \\
\hline & & 0.8750 & irs & 0. & 0 & 22 irs & 8 & & 39 irs & & & 5 irs & & & 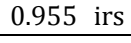 \\
\hline MO & HI & $\begin{array}{llll}0.765 & 0.775 & 0.987 \text { irs }\end{array}$ & $\begin{array}{llll}0.765 & 0.775 & 0.987 \text { irs }\end{array}$ & 0.708 & 0.708 & 1.000 & 0.716 & 0.717 & 0.999 irs & 0.721 & 0.739 & 0.976 irs & 0.721 & 0.739 & 0.976 irs \\
\hline & & irs & irs & 0 & & 0 & & & irs & 8 & & 4 irs & & & \\
\hline Ist I & PHI & $\begin{array}{llll}0.831 & 0.838 & 0.991 \mathrm{drs}\end{array}$ & $\begin{array}{llll}0.833 & 0.838 & 0.993 \mathrm{drs}\end{array}$ & 0.781 & 0.781 & 1.000 & 0.787 & 0.792 & $0.994 \mathrm{drs}$ & 0.771 & 0.773 & $0.998 \mathrm{drs}$ & 0.771 & 0.774 & $0.996 \mathrm{drs}$ \\
\hline & & $0.787 \quad 0$ & drs & 0. & 0 & $0.939 \mathrm{drs}$ & 17 & 0. & 0. & 2 & & 95 irs & 2 & & TS \\
\hline SOLANO & PHI & $0.7531 .000 \quad 0.753$ irs & 0.7531 .0000 .753 irs & 0.521 & 1.000 & 0.521 irs & 0.535 & 1.000 & 0.535 irs & 0.753 & 1.000 & 0.753 irs & 0.753 & 1.000 & 0.753 irs \\
\hline & II & 0.9380. & 0.9380 & 0.643 & 0. & $0.882 \mathrm{drs}$ & 0.650 & 0.741 & $0.877 \mathrm{drs}$ & 0.916 & 0.916 & 1.000 & 0.916 & 0.916 & 1.000 \\
\hline imecas & EN & $\begin{array}{llll}0.663 & 0.675 & 0.983 \mathrm{drs}\end{array}$ & $\begin{array}{llll}0.663 & 0.675 & 0.983 \mathrm{drs}\end{array}$ & 0.643 & 0.647 & $0.993 \mathrm{drs}$ & 0.643 & 0.647 & $0.993 \mathrm{drs}$ & 0.549 & 0.552 & $0.995 \mathrm{drs}$ & 0.549 & 0.552 & $0.995 \mathrm{drs}$ \\
\hline Bank E & AJ & $\begin{array}{llll}0.923 & 0.925 & 0.998 & \mathrm{drs}\end{array}$ & $\begin{array}{lll}0.923 & 0.925 & 0.998 \mathrm{drs}\end{array}$ & 0.450 & 0.455 & $0.988 \mathrm{drs}$ & 0.457 & 0.464 & $0.985 \mathrm{drs}$ & 0.923 & 0.925 & $0.998 \mathrm{drs}$ & 0.923 & 0.925 & $0.998 \mathrm{drs}$ \\
\hline Enda & TUN & 0.9270 .9290 .997 irs & 0.9270 .9290 .997 irs & 0.833 & 0.834 & $0.998 \mathrm{drs}$ & 0.841 & 0.841 & $1.000 \quad-$ & 0.890 & 0.895 & 0.994 irs & 0.890 & 0.895 & 0.994 irs \\
\hline CERUDE & GA & $\begin{array}{llll}0.568 & 0.628 & 0.904 \mathrm{drs}\end{array}$ & $\begin{array}{llll}0.568 & 0.645 & 0.880 & \mathrm{drs}\end{array}$ & 0.565 & 0.627 & $0.901 \mathrm{drs}$ & 0.565 & 0.645 & $0.876 \mathrm{drs}$ & 0.366 & 0.497 & $0.736 \mathrm{drs}$ & 0.366 & 0.517 & $0.708 \mathrm{drs}$ \\
\hline & VIET & $\begin{array}{llll}0.845 & 0.846 & 0.999 & \text { irs }\end{array}$ & $\begin{array}{llll}0.846 & 0.847 & 0.999 & \text { irs }\end{array}$ & 0.819 & 0.820 & $0.999 \mathrm{drs}$ & 0.822 & 0.822 & 0.999 irs & 0.691 & 0.698 & 0.990 irs & 0.691 & 0.698 & 0.990 irs \\
\hline & VIET & $\begin{array}{llll}0.721 & 0.766 & 0.941 & \text { irs }\end{array}$ & $\begin{array}{llll}0.721 & 0.766 & 0.941 \text { irs }\end{array}$ & 0.701 & 0.766 & 0.915 irs & 0.701 & 0.766 & 0.915 irs & 0.583 & 0.621 & 0.940 irs & 0.583 & 0.621 & 0.940 irs \\
\hline 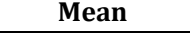 & & $\begin{array}{|lrl|}868 & .901 & .964 \\
\end{array}$ & \begin{tabular}{|lrl} 
& .968 & .964 \\
\end{tabular} & 0.778 & & & 0.786 & & & 0.100 & & & & & \\
\hline
\end{tabular}

\section{Appendix I}

\begin{tabular}{|c|c|c|c|c|c|c|c|c|c|c|c|c|c|c|c|c|}
\hline \multirow{2}{*}{ MFI } & \multirow{2}{*}{ Cou } & \multicolumn{5}{|c|}{ LR ACE } & \multicolumn{5}{|c|}{ L ACE } & \multicolumn{5}{|c|}{ R ACE } \\
\hline & & effch & techch & pech & sech & tfpch & effch & techch & pech & sech & tfpch & effch & techch & pech & sech & tfpch \\
\hline ARMP & AFG & 1.154 & 0.878 & 1.030 & 1.120 & 1.012 & 1.154 & 0.876 & 1.030 & 1.120 & 1.011 & 1.673 & 0.886 & 1.675 & 0.999 & 1.483 \\
\hline BRAC AFG & AFG & 1.423 & 0.943 & 1.398 & 1.018 & 1.341 & 1.385 & 0.951 & 1.352 & 1.024 & 1.317 & 1.688 & 0.846 & 1.523 & 1.108 & 1.429 \\
\hline FMFB AFG & AFG & 1.689 & 0.926 & 1.635 & 1.033 & 1.564 & 1.777 & 0.896 & 1.643 & 1.082 & 1.593 & 1.879 & 0.849 & 1.776 & 1.058 & 1.595 \\
\hline BESA & ALB & 1.000 & 0.939 & 1.000 & 1.000 & 0.939 & 1.000 & 0.938 & 1.000 & 1.000 & 0.938 & 1.117 & 0.851 & 1.076 & 1.038 & 51 \\
\hline ProCred ALB & ALB & 1.046 & 0.962 & 1.003 & 1.043 & 1.007 & 0.896 & 1.116 & 0.979 & 0.915 & 0.999 & 1.061 & 0.949 & 1.097 & 0.967 & 1.007 \\
\hline PSHM & ALB & 1.136 & 0.918 & 1.030 & 1.103 & 1.043 & 1.133 & 0.906 & 1.024 & 1.107 & 1.027 & 1.293 & 0.879 & 1.269 & 1.019 & 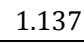 \\
\hline NovoBanco & ANG & 0.738 & 0.773 & 0.741 & 0.997 & 0.571 & 1.078 & 0.824 & 1.003 & 1.075 & 0.889 & 0.738 & 0.746 & 0.741 & 0.997 & 0.551 \\
\hline ACBA & ARM & 1.107 & 0.995 & 1.142 & 0.970 & 1.102 & 1.123 & 0.982 & 1.157 & 0.971 & 1.102 & 1.035 & 0.995 & 1.144 & 0.905 & 1.030 \\
\hline HORIZON & ARM & 1.058 & 0.939 & 0.994 & 1.064 & 0.993 & 1.150 & 0.841 & 1.053 & 1.092 & 0.966 & 1.179 & 0.841 & 0.972 & 1.214 & 0.992 \\
\hline INECO & ARM & 0.825 & 1.066 & 0.926 & 0.891 & 0.879 & 1.037 & 0.992 & 1.034 & 1.002 & 1.029 & 0.825 & 1.066 & 0.926 & 0.891 & 0.879 \\
\hline CRED AGRO & AZE & 1.144 & 0.950 & 1.120 & 1.021 & 1.086 & 1.144 & 0.950 & 1.120 & 1.021 & 1.086 & 1.154 & 0.945 & 1.111 & 1.039 & 1.090 \\
\hline MFBA & AZE & 1.189 & 0.867 & 1.078 & 1.103 & 1.031 & 1.189 & 0.867 & 1.078 & 1.103 & 1.031 & 1.168 & 0.886 & 1.141 & 1.023 & 1.035 \\
\hline NORMICRO & AZE & 1.076 & 0.899 & 1.017 & 1.058 & 0.967 & 1.289 & 0.836 & 1.270 & 1.015 & 1.078 & 1.045 & 0.842 & 0.885 & 1.180 & 0 \\
\hline Viator & AZE & 1.071 & 0.938 & 1.048 & 1.022 & 1.005 & 1.172 & 0.852 & 1.173 & 1.000 & 0.999 & 1.198 & 0.842 & 1.113 & 1.076 & 1.009 \\
\hline ASA & BAN & 0.982 & 0.977 & 1.000 & 0.982 & 0.960 & 0.955 & 1.009 & 1.000 & 0.955 & 0.964 & 0.974 & 0.967 & 1.000 & 0.974 & 0.942 \\
\hline BRAC BAN & BAN & 1.070 & 0.954 & 1.025 & 1.044 & 1.021 & 0.869 & 0.983 & 1.025 & 0.848 & 0.855 & 1.251 & 0.926 & 1.253 & 0.999 & 1.158 \\
\hline BURO TANGAIL & BAN & 1.019 & 0.946 & 1.018 & 1.001 & 0.964 & 0.969 & 0.995 & 1.021 & 0.949 & 0.964 & 1.024 & 0.898 & 1.024 & 1.000 & 0.920 \\
\hline IDF & BAN & 1.250 & 0.958 & 1.215 & 1.028 & 1.197 & 1.299 & 0.988 & 1.244 & 1.044 & 1.283 & 1.074 & 0.885 & 1.003 & 1.070 & 0.951 \\
\hline RDRS & BAN & 0.945 & 0.993 & 0.942 & 1.003 & 0.938 & 0.897 & 1.016 & 0.903 & 0.994 & 0.912 & 1.226 & 0.958 & 1.215 & 1.009 & 1.174 \\
\hline SHAKTI & BAN & 0.991 & 0.960 & 0.980 & 1.011 & 0.951 & 0.951 & 0.980 & 0.980 & 0.971 & 0.932 & 1.177 & 0.904 & 1.179 & 0.999 & 1.064 \\
\hline TMSS & BAN & 1.049 & 0.944 & 0.999 & 1.049 & 0.990 & 0.949 & 1.001 & 0.999 & 0.950 & 0.950 & 1.152 & 0.902 & 1.128 & 1.021 & 1.039 \\
\hline
\end{tabular}




\begin{tabular}{|c|c|c|c|c|c|c|c|c|c|c|c|c|c|c|c|c|}
\hline & $\mathrm{N}$ & 969 & 916 & 918 & 1.055 & 0.887 & 1.111 & 0.829 & 0.913 & 1.217 & 0.921 & 0.993 & 0.855 & 0.872 & 1.139 & 0.849 \\
\hline & & & 4 & & & 964 & & & 834 & 278 & 961 & 1.278 & & & & \\
\hline & & & & & 99 & 0.880 & 23 & & 323 & 1.122 & 860 & 966 & 924 & 22 & 48 & \\
\hline & $\mathbf{N}$ & 02 & 11 & 098 & 1.004 & 1.004 & \begin{tabular}{|l|l|}
1.077 \\
\end{tabular} & 72 & 966 & 10 & 339 & 81 & 806 & & & \\
\hline & & & & & 1.119 & 0.857 & & & 321 & 1.119 & 0.857 & 0.953 & .930 & 908 & 049 & \\
\hline & $\mathrm{OL}$ & 993 & 918 & 85 & 10 & 1.004 & 1.071 & 04 & 63 & 12 & 0.969 & 1.316 & 851 & 1.263 & & 1.119 \\
\hline & & 26 & 966 & & 1.090 & 0.991 & 1.045 & & 941 & 1.110 & 0.989 & 1.067 & .943 & 085 & & 005 \\
\hline & DL & 090 & 0.934 & 962 & 1.133 & 1.018 & 1.089 & 0.934 & 0.962 & 1.132 & 1.017 & 1.172 & .924 & 1.167 & & 82 \\
\hline & & & & & 1 & 0.926 & 1. & & & & 0.981 & 1.067 & .846 & & & \\
\hline Eco & $\mathrm{OL}$ & 110 & 0.899 & 991 & 1.120 & 0.998 & 1.105 & 0.889 & 0.990 & 16 & 0.982 & 1.160 & 888 & 123 & & 030 \\
\hline & & & & & & 0.775 & & & & & & & 61 & & & \\
\hline & $\mathbf{L}$ & 02 & 0.932 & 1 & & 0.934 & 0.997 & & 0.871 & 44 & 0.931 & 1.044 & 0.931 & 95 & 5 & 972 \\
\hline & & & & & & 0.972 & & & & & & & & & & \\
\hline & & & 0. & & & 0.965 & 1. & & & & & & 86 & 01 & & 86 \\
\hline & & & & & & 0. & & & & & & & & & & \\
\hline & & & 66 & 6 & & 1.093 & 1. & & 36 & & 92 & 20 & .909 & 67 & & 200 \\
\hline & & & & & & & & & & & & & & & & \\
\hline & & & & & & 1.094 & & & & & & & 11 & 93 & & 09 \\
\hline & & & & & & & & & & & & & & & & \\
\hline & & 97 & & & & 1. & & & & & & & 0.889 & 76 & & וסו \\
\hline & & & & & & & & & & & & & & & & \\
\hline & & & & & & 0.931 & & & & & & & 59 & 64 & & \\
\hline & & & & & & & & & & & & & & & & \\
\hline & & & & & & & & & & & & & & & ) & \\
\hline & & & & & & & & & & & & & & & & \\
\hline & & 44 & & 0 & & 1.000 & & & & & & & 33 & & & 27 \\
\hline & & & & & & & & & & & & & & & & \\
\hline & M & 80 & 0. & 5 & 1. & 1.032 & 1.232 & & & & & & 71 & 54 & & 31 \\
\hline & & & & & & & & & & & & & & & & \\
\hline & & 53 & 0. & 0 & 1 & 1.050 & 1. & & & & & & 66 & 25 & & 96 \\
\hline & & & & & & & & & & & & & & & & \\
\hline & & 3 & & & & 1. & 1. & & & & & & 75 & 00 & & 35 \\
\hline & & & & & & 0. & & & & & & & & & & \\
\hline & & 00 & & & & 1.109 & 1.000 & & & & & & 37 & 37 & 7 & 79 \\
\hline & & & & & & 13 & 1. & & & & & & 07 & & & \\
\hline & & 62 & $0 . \varepsilon$ & & & 0.752 & 0. & & & & & & 25 & 53 & 3 & 08 \\
\hline & & 64 & & & & 77 & 1. & & & & & & 08 & 296 & & 34 \\
\hline & $\mathbf{U}$ & 28 & & 0 & 1. & 0.938 & 1.185 & & 0 & 1. & & 23 & 00 & 30 & 7 & 978 \\
\hline & & 74 & & & & 50 & 1. & & & & & & 57 & & & 71 \\
\hline & ECU & 85 & 0.921 & 093 & 0.993 & 1.000 & 1.176 & & 1.165 & & & 15 & 841 & 237 & 33 & 022 \\
\hline & & 41 & & & & 0. & 1 & & & & & & & 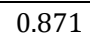 & P & 26 \\
\hline & GY & 341 & 0.900 & 233 & 1.088 & 1.207 & 1.719 & & 1.659 & & & & 59 & 1.227 & 0 & 1.160 \\
\hline & & & & & & 96 & & & & & & & 92 & 192 & 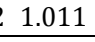 & 96 \\
\hline & GY & 370 & 0.934 & 370 & 1.000 & 1.279 & 1.051 & & 39 & 1. & 86 & 31 & 905 & 576 & 3 & 430 \\
\hline & & & & & & & 1 & & & & & & 64 & 14 & $t$ & \\
\hline & & 34 & 0.891 & 14 & 1. & 1.011 & 1.134 & & 14 & 40 & 11 & 22 & 894 & 865 & 6 & 003 \\
\hline & & & & & & & & & & & & & & 78 & 3 & \\
\hline A & $\mathrm{H}$ & 344 & 0.980 & 870 & 0.970 & 0.827 & 0.844 & & 0.870 & 0.970 & 27 & 75 & 069 & 732 & 8 & 828 \\
\hline & & & & & & & 0. & & & & & & 63 & 424 & \pm & \\
\hline D & $\Gamma \mathrm{TH}$ & 000 & 0.962 & 000 & 1.000 & 0.962 & 1.000 & & 1.000 & 00 & 30 & & 13 & 00 & 0 & 013 \\
\hline & & & & & & & & & & & & & & 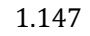 & 5 & \\
\hline & ГH & 920 & 1.046 & 74 & 1.053 & 0.962 & 0.484 & & 0.460 & 1. & 0. & & 98 & 358 & 7 & 461 \\
\hline & & & & & & & & & & & & & 57 & 50 & ) & \\
\hline & GHA & 385 & 0.918 & 877 & 1.009 & 0.813 & 1.222 & & 1.087 & 1.124 & 29 & 07 & 367 & 647 & 3 & 613 \\
\hline & & 08 & & & & 1 & 1. & & & & & & 369 & 337 & 1 & 151 \\
\hline & GOE & 088 & 0.916 & 1.000 & 1.088 & 0.997 & 0.958 & & 0.920 & 41 & 09 & 57 & 40 & 02 & 54 & 064 \\
\hline & & & & & & & 2 & & & & & & 87 & 912 & 1 & 0.908 \\
\hline & & 327 & & & & 1.127 & 1.347 & & & & & & 46 & 85 & 3 & 155 \\
\hline & & 05 & 0.864 & 16 & 1 & 1.040 & 1.214 & 49 & 31 & 77 & 1.031 & 1.401 & 835 & .990 & 5 & 169 \\
\hline & UAT & 125 & 0.874 & 14 & 1.110 & 0.984 & 1.235 & & 1.019 & 1.212 & & & 0.844 & 0.973 & 7 & 0.933 \\
\hline & & .924 & 0.896 & .949 & 0.974 & 0.828 & 1.038 & 0.867 & 1.037 & 1.001 & 0.900 & 0.924 & 0.878 & 0.945 & 0.978 & 0.811 \\
\hline FINCA & & 047 & 0.921 & 1.058 & 0.990 & 0.964 & 1.308 & 0.852 & 1.320 & 0.992 & 14 & 64 & 884 & 0.961 & 3 & 0.852 \\
\hline HDH & HON & 1.255 & 0.863 & 1.242 & 1.011 & 1.083 & 1.353 & 0.849 & 1.323 & 1.022 & 1.149 & 0.573 & 0.871 & 0.572 & 1.002 & 499 \\
\hline
\end{tabular}




\begin{tabular}{|c|c|c|c|c|c|c|c|c|c|c|c|c|c|c|c|c|}
\hline & ON & 212 & 900 & 170 & 1.035 & 1.091 & 1.265 & 0.837 & 1.173 & 1.078 & 1.058 & 1.367 & 0.842 & 1.370 & 0.997 & 1.151 \\
\hline & & 67 & & 65 & 02 & 094 & 064 & & 065 & 99 & 091 & 1.380 & & & 77 & \\
\hline & & & 98 & 41 & 1.058 & 0.989 & 150 & & 053 & 1.092 & 1.013 & 1.065 & & & 52 & 35 \\
\hline & & 00 & 61 & 71 & 0.960 & 1.633 & 133 & & 970 & 1.083 & 045 & 1.465 & 84 & & & \\
\hline & & & & 50 & 1.022 & 1.382 & 1.387 & & 362 & 1.018 & 1.388 & 1.244 & 85 & & 142 & 226 \\
\hline & D & 282 & 970 & 285 & 0.997 & 1.243 & 1.170 & 83 & 194 & 0.980 & 1.150 & 1.541 & 935 & 1.507 & 23 & 1.441 \\
\hline & & 05 & & 04 & 1.001 & 0.949 & 0.996 & & 1.005 & 0.991 & 0.942 & 1.047 & 928 & & & 971 \\
\hline SH & ID & 882 & .945 & 035 & 1.046 & 1.023 & 1.143 & 0.950 & 1.047 & 1.091 & 1.086 & 0.761 & 921 & 714 & 66 & 0.701 \\
\hline & & & & 0 & & 1.089 & 1.023 & & 10 & 1.013 & 1. & 1.246 & & & & \\
\hline & DO & 336 & 0.927 & 344 & 1.582 & 1.238 & 1.246 & 68 & 0.716 & 1.740 & 1.207 & 1.458 & 854 & 96 & & 245 \\
\hline & & 54 & & & & 1.094 & & & & & & & & & & \\
\hline & $\mathbf{R}$ & 227 & 0.899 & 26 & 00 & 1.103 & 1.548 & & 1.453 & 1.065 & 1.281 & 1.092 & 45 & & & 923 \\
\hline & & & & & & 48 & & & & & & & & & & \\
\hline & $\mathbf{N}$ & 93 & 0.8 & 21 & & 1.058 & 1.694 & & 21 & & & & 87 & & & 58 \\
\hline & & & & & & 28 & & & & & & & & & & \\
\hline & $\mathrm{N}$ & 34 & 0. & 93 & 30 & 1.122 & 1.266 & & 883 & 1.169 & 1.099 & 1.296 & 81 & & & 41 \\
\hline & & & & & & & & & & & & & & & & \\
\hline & & & & & & 1. & 1171 & & 08 & & & & & & & 38 \\
\hline & & & & & & & & & & & & & & & & \\
\hline & $\mathbf{R}$ & & & & & 82 & & & & & & & & & & \\
\hline & & & & & & & & & & & & & & & & \\
\hline & YR & & & & & 0.786 & & & & & & & & & & \\
\hline & & & & & & & & & & & & & & & & \\
\hline & LI & & & & & & & & & & & & & & & \\
\hline & & & & & & & & & & & & & & & & \\
\hline & ON & 79 & & & & & & & & & & & & & & 963 \\
\hline & & & & & & & & & & & & & & & & \\
\hline & $\mathbf{R}$ & 67 & 0.8 & 82 & & 0.864 & 1. & & & & & & 42 & & & 10 \\
\hline & & & & & & & & & & & & & & & & \\
\hline & $\mathbf{R}$ & 359 & 0.889 & 13 & 1. & 1.208 & 1.423 & & 1 & & & & 52 & & & 62 \\
\hline & & & & & & & & & & & & & 68 & & - & \\
\hline & $\mathbf{Z}$ & 23 & 1.022 & 82 & 1. & 0.841 & 0. & & 0 & & & & 22 & & & 41 \\
\hline & $\mathrm{Z}$ & & & & & & 1. & & & & & & & & & 57 \\
\hline & $\mathrm{OZ}$ & 051 & 0.952 & 074 & 0.978 & 1.001 & 1.320 & & 1.204 & 1. & 1. & 78 & 65 & 28 & & 932 \\
\hline & & & & & 0 & 37 & 1. & & & & & & 76 & & 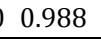 & 12 \\
\hline & $\mathbf{P}$ & 06 & & 82 & 1.141 & 1.121 & 1. & & & & & & 14 & & & 21 \\
\hline & $E P$ & & & & & & 1. & & & & & & 70 & & & 39 \\
\hline & IC & 02 & 0. & 045 & 1.055 & 1.010 & 1.229 & & 1. & 1. & 1. & & 20 & & & 40 \\
\hline & C & & & & & 10 & & & & & & & 06 & & & 29 \\
\hline & IIC & 162 & 0.933 & 096 & 1.060 & 1.084 & 1.124 & & 0.951 & 83 & 1. & 04 & 16 & & & 103 \\
\hline & IC & 33 & & 96 & 2 & 367 & 1.087 & & & 7 & & & 43 & & & 89 \\
\hline & IIC & 000 & 1.050 & 000 & 1.000 & 1.050 & 0.987 & 0.992 & 0.998 & 0.989 & 0.979 & & 1.071 & 00 & 0 & 1.071 \\
\hline & G & 51 & & & & 58 & 1. & & & & & & 41 & & 3 & 74 \\
\hline & IG & 954 & 0.980 & 00 & 0.954 & 0.935 & 1.069 & & 1.203 & 0.889 & 35 & 34 & 0.975 & 00 & 34 & .911 \\
\hline & & 83 & & & & 8 & & & & & & & 60 & & 2 & 30 \\
\hline & AK & 516 & 0.949 & 466 & 1.034 & 1.439 & 1.566 & & 1.540 & 1.017 & 1.498 & 1.516 & 0.941 & 466 & 34 & 426 \\
\hline & & & & & & & & & & & & & & & 5 & \\
\hline & AR & 124 & 0.914 & 120 & 1.003 & 1.027 & 1.097 & 0.827 & 0.926 & 1.185 & 08 & 1.212 & 361 & 64 & 41 & 043 \\
\hline & & & & & & & 1 & & & & & & 82 & & 7 & 47 \\
\hline a & ER & 103 & 0.921 & 000 & 1.103 & 1.015 & 1.165 & 0.822 & 1.000 & 1.165 & 0.957 & 99 & 796 & 00 & 99 & .034 \\
\hline & & & & & & & & & & & & & 93 & & 9 & \\
\hline & ER & 219 & 0.892 & 185 & 1.029 & 1.088 & 1.257 & & 1.154 & 1.090 & 1. & 1 & 345 & 73 & 5 & 200 \\
\hline & n & & & & & & 0. & & & & & & 12 & 0 & ) & 12 \\
\hline & ER & 132 & 0.931 & 1.071 & 1057 & 1.053 & 1.183 & 0. & 1.008 & 1.173 & 33 & 35 & 880 & 132 & 091 & 086 \\
\hline & ER & 45 & & & 1 & 1. & 1.089 & & 4 & 1. & & & 944 & 998 & 3 & 940 \\
\hline & ER & 033 & 0.968 & 1.003 & 1.030 & 0.999 & 1.029 & & 1.003 & 1026 & 07 & & 09 & 83 & 97 & 982 \\
\hline & $\mathbf{R}$ & & & & & 28 & 19 & & & & & & 74 & 80 & 1 & .032 \\
\hline & R & 342 & & 18 & 1.027 & 0.883 & 1.006 & & 26 & 1.087 & & & 05 & & 5 & .862 \\
\hline & & 20 & 0.922 & 22 & 1.096 & 1.033 & 1.240 & 31 & 99 & 1.241 & 30 & 1.201 & 863 & 042 & 52 & .037 \\
\hline & ER & 074 & 0.933 & .034 & 1.039 & 1.002 & 1.214 & 0.887 & 1.203 & 1.010 & 1.077 & 1.066 & 0.924 & 021 & 88 & 0.985 \\
\hline- & $\mathbf{R}$ & 42 & 0.904 & 040 & 1.195 & 1.122 & 1.266 & 0.840 & 052 & 1.204 & 1.063 & 1.343 & 0.871 & 1.071 & 1.254 & .170 \\
\hline & PER & 132 & 0.924 & 1.000 & 1.132 & 1.047 & 1.159 & 0.881 & 1.000 & 1.159 & 1.021 & 1.236 & 0.864 & 1.094 & $\begin{array}{l}+1.130 \\
\end{array}$ & 1.067 \\
\hline & ER & 1.104 & 0.933 & 1.081 & 1.021 & 1.030 & 1.156 & 0.853 & 1.163 & 0.994 & 0.986 & 1.199 & 0.922 & 1.151 & 1.041 & .105 \\
\hline
\end{tabular}




\begin{tabular}{|c|c|c|c|c|c|c|c|c|c|c|c|c|c|c|c|c|}
\hline ProMu & ER & 117 & 0.926 & 129 & 0.989 & 1.034 & 1.274 & 0.851 & 1.278 & 0.997 & 1.085 & 1.204 & 0.830 & 1.211 & 0.994 & 0.999 \\
\hline ASHI & HI & 165 & .925 & 175 & 0.991 & 1.077 & 1.155 & 909 & 1.150 & 05 & 1.050 & 1.295 & 866 & 1.297 & 0.998 & 121 \\
\hline B & HI & 15 & 0.986 & 97 & 1.018 & 1.001 & 1.025 & 81 & 024 & 1.001 & 1.005 & 1.015 & 986 & 997 & 018 & 001 \\
\hline BCB & HI & 049 & 0.922 & 031 & 1.018 & 0.968 & 1.103 & 46 & 099 & 1.004 & 0.934 & 1.110 & 76 & 60 & 47 & 73 \\
\hline & 1 & 33 & 0.961 & 30 & 03 & 0.993 & 1.148 & 06 & 50 & 98 & 1.040 & 1.069 & 00 & 51 & 17 & 962 \\
\hline DIGC & HI & 1.058 & 0.939 & 053 & 1.005 & 0.994 & 1.130 & 0.851 & 1.135 & 0.996 & 0.961 & 1.147 & 81 & 14 & 30 & 010 \\
\hline & HI & 72 & 45 & & 14 & 19 & 1.011 & 22 & 38 & & 0.932 & 1.020 & & & 19 & 939 \\
\hline NWFT & $\mathrm{HI}$ & 1.103 & 0.925 & 091 & 1.012 & 1.020 & 1.224 & 0.908 & 1.135 & 1.078 & 1.112 & 1.171 & 47 & 22 & 43 & 992 \\
\hline & HI & 982 & 0.969 & & & 0.951 & 0.759 & 68 & 98 & & 0.735 & 0.982 & & & & 951 \\
\hline TSPI & PHI & 1.128 & 0.945 & 054 & 1.070 & 1.067 & 1.203 & 0.928 & 1.117 & 1.077 & 1.117 & 1.127 & 0.902 & 024 & 00 & .017 \\
\hline & US & & & & & 0.830 & 67 & & & & & 50 & & & & 721 \\
\hline SEF & $A$ & 0.899 & 1.002 & 970 & 0.926 & 0.901 & 1.156 & 0.869 & 1.162 & 0.994 & 1.005 & 0.815 & 1.023 & 0.889 & 0.917 & .834 \\
\hline & $\mathbf{M}$ & 4 & 0.946 & & 1. & 50 & 1. & & 83 & 1. & 56 & 57 & & & & 941 \\
\hline CMS & EN & 0.962 & 0.959 & 875 & 1.099 & 0.922 & 0.905 & 0.961 & 0.839 & 1.078 & 0.869 & 1.069 & 0.898 & 28 & 40 & 960 \\
\hline & EN & 952 & 0.870 & 66 & 1. & 0.828 & 0.917 & 0.858 & 759 & 1.209 & 0.787 & 86 & & & & \\
\hline Agr & TAJ & 0.769 & 0.950 & 763 & 1.008 & 0.731 & 1.033 & 0.953 & 0.936 & 1.104 & 0.985 & 0.460 & 0.936 & 0. & 21 & 0.430 \\
\hline & TA] & 1.083 & 0.932 & 80 & & 1.010 & 1.296 & & 270 & 1. & 1.241 & 1.083 & & & & \\
\hline FI & TAJ & 1.416 & 0.958 & 414 & 1.002 & 1.357 & 1.355 & 0.958 & 1.362 & 0.995 & 1.298 & 1.423 & 46 & 6 & 6 & 1.346 \\
\hline & & 1.201 & 0.947 & & & 1.138 & 1.252 & & 251 & 1. & 1.1 & 1. & & & & 1.223 \\
\hline Micrs & TAJ & 1.153 & 0.939 & 049 & 1.099 & 1.083 & 1.177 & 0.906 & 1.136 & 1.036 & 1.067 & 1.332 & 64 & 1. & 13 & 1.151 \\
\hline & $\mathrm{IN}$ & 985 & 0.931 & 979 & 1. & 0.917 & 1.117 & 0.846 & 63 & 1.1 & 0.944 & 0.976 & & 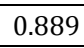 & & 895 \\
\hline & UN & 1.082 & 0.909 & 051 & 1.029 & 0.984 & 1.069 & 0.845 & 1.007 & 1.061 & 0.903 & 1.285 & 0.841 & 1.310 & 0.981 & .080 \\
\hline 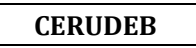 & $\mathrm{AA}$ & 920 & 0.852 & 838 & & 0.783 & 1.522 & 0.827 & 59 & 1. & 1.260 & 0.657 & 29 & 41 & & .544 \\
\hline & $\overline{G A}$ & 1.117 & 0.906 & 1.089 & 1.026 & 1.012 & 1.680 & 0.831 & 1.524 & 1.102 & 1.396 & 1.064 & 0.828 & 1.0 & 1.049 & 0.881 \\
\hline FAULU & GA & 851 & 0.917 & 0.863 & 0.986 & 0.780 & 1.058 & 0.849 & 1.034 & 1.023 & 0.898 & 0.868 & 0.866 & 0.874 & 0.992 & 0.752 \\
\hline FINCA UGA & UGA & 0.825 & 1.020 & 0.924 & 0.893 & 0.842 & 1.008 & 0.873 & 0.924 & 1.090 & 0.879 & 0.823 & 1.016 & 0.924 & 0.891 & 0.836 \\
\hline MEDNET & UGA & 1.520 & 1.003 & 1.515 & 1.003 & 1.524 & 1.216 & 0.879 & 1.290 & 0.942 & 1.068 & 1.799 & 0.952 & 752 & 026 & .713 \\
\hline BanGente & EN & 1.146 & 0.903 & 1.031 & 1.111 & 1.035 & 1.161 & 0.825 & 0.963 & 1.206 & 0.958 & 1.471 & 0.741 & 1.164 & 1.264 & 1.090 \\
\hline CEP & ET & 1.146 & 0.872 & 1.008 & 1.137 & 1.000 & 1.105 & 0.852 & 0.971 & 1.138 & 0.942 & 1.293 & 0.879 & 1.300 & 0.995 & .136 \\
\hline TYM & IET & 0.974 & 0.931 & 0.939 & 1.037 & 0.907 & 0.939 & 0.940 & 0.920 & 1.021 & 0.883 & 1.132 & 0.900 & 1.062 & 1.066 & 1.018 \\
\hline TZAM & ZAM & 1.000 & 1.055 & 1.000 & 1.000 & 1.055 & 1.122 & 0.863 & 1.146 & 0.980 & 0.969 & 1.000 & 1.063 & .000 & .000 & .063 \\
\hline INCA ZAM & AM & 0.906 & 1.012 & 0.992 & 0.913 & 0.917 & 0.635 & 0.925 & 0.624 & 1.019 & 0.588 & 0.969 & 0.990 & 1.059 & 0.915 & 0.959 \\
\hline Mean & & 1.081 & 0.935 & 1.034 & 1.046 & 1.011 & 1.127 & 0.903 & 1.049 & 1.074 & 1.017 & 1.123 & 0.899 & 1.0 & 1.061 & 1.011 \\
\hline
\end{tabular}

\section{Appendix $K \quad$ Malmquist DEA indices for $R^{s}(R-S)$ (Panel)}

\begin{tabular}{|c|c|c|c|c|c|c|c|c|c|c|c|}
\hline \multirow{2}{*}{ MFI } & \multirow{2}{*}{ Country } & \multicolumn{5}{|c|}{ LR ACE } & \multicolumn{5}{|c|}{ LR $^{\text {s-ACE }}$} \\
\hline & & effch & techch & pech & sech & tfpch & effch & techch & pech & sech & tfpch \\
\hline ARMP & AFG & 1.154 & 0.878 & 1.030 & 1.120 & 1.012 & 0.052 & 0.920 & 0.094 & 0.552 & 0.048 \\
\hline FMFB AFG & AFG & 1.608 & 0.963 & 1.609 & 0.999 & 1.549 & 1.855 & 0.893 & 1.740 & 1.066 & 1.656 \\
\hline BESA & ALB & 1.000 & 0.939 & 1.000 & 1.000 & 0.939 & 1.000 & 0.953 & 1.000 & 1.000 & 0.953 \\
\hline ProCred ALB & ALB & 1.046 & 0.962 & 1.003 & 1.043 & 1.007 & 1.058 & 0.985 & 0.979 & 1.081 & 1.043 \\
\hline PSHM & ALB & 1.136 & 0.918 & 1.030 & 1.103 & 1.043 & 1.134 & 0.918 & 1.025 & 1.107 & 1.041 \\
\hline ACBA & ARM & 1.107 & 0.995 & 1.142 & 0.970 & 1.102 & 1.118 & 0.986 & 1.157 & 0.966 & 1.103 \\
\hline HORIZON & ARM & 1.051 & 0.948 & 0.994 & 1.057 & 0.996 & 1.175 & 0.849 & 1.048 & 1.121 & 0.998 \\
\hline INECO & ARM & 0.825 & 1.066 & 0.926 & 0.891 & 0.879 & 0.993 & 0.970 & 1.085 & 0.915 & 0.963 \\
\hline CRED AGRO & AZE & 1.144 & 0.950 & 1.120 & 1.021 & 1.086 & 1.144 & 0.950 & 1.120 & 1.021 & 1.086 \\
\hline MFBA & AZE & 1.189 & 0.867 & 1.078 & 1.103 & 1.031 & 1.189 & 0.867 & 1.078 & 1.103 & 1.031 \\
\hline NORMICRO & AZE & 1.071 & 0.902 & 1.010 & 1.060 & 0.966 & 1.235 & 0.844 & 1.210 & 1.021 & 1.042 \\
\hline Viator & AZE & 1.065 & 0.943 & 1.046 & 1.018 & 1.005 & 1.134 & 0.860 & 1.133 & 1.001 & 0.975 \\
\hline ASA & BAN & 0.965 & 0.987 & 1.000 & 0.965 & 0.953 & 0.911 & 0.970 & 1.000 & 0.911 & 0.883 \\
\hline BRAC BAN & BAN & 1.067 & 0.969 & 1.025 & 1.041 & 1.035 & 0.869 & 0.983 & 1.025 & 0.848 & 0.855 \\
\hline BURO TANGAIL & BAN & 1.017 & 0.948 & 1.018 & 0.999 & 0.964 & 1.012 & 0.937 & 1.000 & 1.012 & 0.948 \\
\hline IDF & BAN & 1.249 & 0.958 & 1.215 & 1.028 & 1.196 & 1.271 & 0.970 & 1.216 & 1.045 & 1.234 \\
\hline SHAKTI & BAN & 0.991 & 0.960 & 0.980 & 1.011 & 0.951 & 0.965 & 0.976 & 0.977 & 0.988 & 0.942 \\
\hline TMSS & BAN & 1.049 & 0.945 & 0.999 & 1.049 & 0.991 & 0.949 & 1.001 & 0.999 & 0.950 & 0.950 \\
\hline FECECAM & BEN & 0.964 & 0.920 & 0.918 & 1.050 & 0.887 & 1.061 & 0.835 & 0.866 & 1.224 & 0.886 \\
\hline ALIDE & BEN & 1.055 & 0.914 & 0.834 & 1.266 & 0.964 & 1.066 & 0.901 & 0.834 & 1.278 & 0.961 \\
\hline PADME & BEN & 0.934 & 0.948 & 0.851 & 1.098 & 0.885 & 0.923 & 0.930 & 0.822 & 1.122 & 0.858 \\
\hline VF & BEN & 1.100 & 0.931 & 1.098 & 1.002 & 1.024 & 1.085 & 0.878 & 1.057 & 1.026 & 0.953 \\
\hline RCPB & BF & 0.919 & 0.933 & 0.821 & 1.119 & 0.857 & 0.923 & 0.929 & 0.821 & 1.124 & 0.857 \\
\hline Agrocapital & BOL & 1.092 & 0.922 & 0.985 & 1.109 & 1.007 & 1.071 & 0.906 & 0.963 & 1.112 & 0.970 \\
\hline BANCOSOL & BOL & 1.026 & 0.966 & 0.941 & 1.090 & 0.991 & 1.035 & 0.964 & 0.942 & 1.099 & 0.998 \\
\hline
\end{tabular}




\begin{tabular}{|c|c|c|c|c|c|c|c|c|c|c|c|}
\hline Bnaco L A & BOL & 1.090 & 0.934 & 0.962 & 1.133 & 1.018 & 1.090 & 0.934 & 0.962 & 1.133 & 1.018 \\
\hline CRECER & BOL & 1.020 & 0.909 & 0.956 & 1.067 & 0.927 & 1.144 & 0.841 & 0.979 & 1.169 & 0.962 \\
\hline Eco Futuro & BOL & 1.110 & 0.899 & 0.991 & 1.120 & 0.999 & 1.107 & 0.892 & 0.983 & 1.126 & 0.987 \\
\hline FADES & BOL & 0.905 & 0.857 & 0.770 & 1.175 & 0.775 & 0.922 & 0.838 & 0.772 & 1.195 & 0.773 \\
\hline FIE & BOL & 1.002 & 0.932 & 0.871 & 1.151 & 0.934 & 1.006 & 0.930 & 0.871 & 1.155 & 0.935 \\
\hline FunBodem & BOL & 1.058 & 0.907 & 1.042 & 1.015 & 0.960 & 1.293 & 0.843 & 1.302 & 0.993 & 1.089 \\
\hline PRODEM & BOL & 1.060 & 0.913 & 0.894 & 1.185 & 0.967 & 1.075 & 0.885 & 0.894 & 1.202 & 0.951 \\
\hline ProMujar BOL & BOL & 1.041 & 0.913 & 0.965 & 1.078 & 0.950 & 1.052 & 0.866 & 0.931 & 1.130 & 0.911 \\
\hline EKI & BOS & 1.143 & 0.956 & 1.036 & 1.103 & 1.093 & 1.154 & 0.965 & 1.036 & 1.113 & 1.113 \\
\hline MIKROFIN & BOS & 1.004 & 1.049 & 1.000 & 1.004 & 1.053 & 1.000 & 1.070 & 1.000 & 1.000 & 1.070 \\
\hline PARTNER & BOS & 1.097 & 0.997 & 1.041 & 1.054 & 1.094 & 1.096 & 1.011 & 1.041 & 1.053 & 1.109 \\
\hline SUNRISE & BOS & 1.158 & 0.937 & 1.080 & 1.072 & 1.085 & 1.218 & 0.914 & 1.071 & 1.137 & 1.113 \\
\hline CDS & CAM & 1.093 & 0.927 & 1.093 & 1.000 & 1.013 & 1.235 & 0.884 & 1.118 & 1.105 & 1.092 \\
\hline CMM Bog & COL & 1.113 & 0.893 & 1.024 & 1.087 & 0.994 & 1.222 & 0.832 & 1.019 & 1.199 & 1.017 \\
\hline Finamerica & COL & 1.057 & 0.874 & 0.976 & 1.084 & 0.924 & 1.180 & 0.834 & 0.975 & 1.210 & 0.984 \\
\hline FMM Buca & COL & 1.023 & 0.960 & 1.027 & 0.996 & 0.982 & 1.176 & 0.902 & 1.076 & 1.093 & 1.061 \\
\hline FMM Pop & COL & 0.983 & 0.949 & 0.995 & 0.988 & 0.933 & 1.095 & 0.904 & 0.993 & 1.102 & 0.990 \\
\hline WMM Med & COL & 1.042 & 0.925 & 0.999 & 1.043 & 0.964 & 1.058 & 0.916 & 1.018 & 1.040 & 0.969 \\
\hline WWB Ca & COL & 1.032 & 0.963 & 1.000 & 1.032 & 0.994 & 1.071 & 0.973 & 1.000 & 1.071 & 1.042 \\
\hline ACLEDA & COM & 1.008 & 0.921 & 0.924 & 1.092 & 0.928 & 1.061 & 0.899 & 0.924 & 1.148 & 0.953 \\
\hline AMRET & COM & 1.073 & 0.962 & 1.075 & 0.998 & 1.032 & 1.222 & 0.856 & 1.081 & 1.131 & 1.047 \\
\hline CEB & COM & 1.189 & 0.936 & 1.195 & 0.995 & 1.113 & 1.243 & 0.931 & 1.204 & 1.032 & 1.157 \\
\hline HKL & COM & 1.162 & 0.905 & 1.159 & 1.002 & 1.051 & 1.185 & 0.877 & 1.184 & 1.000 & 1.039 \\
\hline PRASAC & COM & 1.114 & 0.914 & 1.012 & 1.100 & 1.018 & 1.128 & 0.897 & 1.001 & 1.127 & 1.012 \\
\hline CrediMujer & CR & 1.170 & 0.957 & 1.000 & 1.170 & 1.121 & 1.300 & 0.853 & 1.000 & 1.300 & 1.110 \\
\hline Banco Sol & ECU & 1.048 & 0.929 & 1.000 & 1.048 & 0.974 & 1.014 & 0.969 & 1.000 & 1.014 & 0.982 \\
\hline COAC Jardin & ECU & 1.000 & 1.109 & 1.000 & 1.000 & 1.109 & 1.000 & 1.116 & 1.000 & 1.000 & 1.116 \\
\hline Coac S Jose & ECU & 1.036 & 0.978 & 1.028 & 1.008 & 1.013 & 1.036 & 0.977 & 1.021 & 1.015 & 1.012 \\
\hline COAC SAC & ECU & 0.862 & 0.873 & 0.900 & 0.957 & 0.752 & 0.862 & 0.873 & 0.900 & 0.957 & 0.752 \\
\hline D-Miro & ECU & 1.049 & 0.938 & 1.059 & 0.990 & 0.984 & 1.149 & 0.836 & 1.104 & 1.040 & 0.961 \\
\hline FINCA ECU & ECU & 1.000 & 0.953 & 1.000 & 1.000 & 0.953 & 1.121 & 0.841 & 1.000 & 1.121 & 0.943 \\
\hline FODEMI & ECU & 1.274 & 0.833 & 1.272 & 1.001 & 1.060 & 1.273 & 0.834 & 1.266 & 1.005 & 1.062 \\
\hline Fundacion Es & ECU & 1.077 & 0.930 & 1.094 & 0.984 & 1.002 & 1.169 & 0.844 & 1.184 & 0.987 & 0.987 \\
\hline ProCred ECU & ECU & 1.041 & 0.947 & 0.944 & 1.103 & 0.986 & 1.036 & 0.955 & 0.944 & 1.098 & 0.990 \\
\hline Al Tadamun & EGY & 1.230 & 0.950 & 1.180 & 1.042 & 1.169 & 1.664 & 0.845 & 1.578 & 1.054 & 1.405 \\
\hline DBACD & EGY & 1.200 & 1.000 & 1.192 & 1.006 & 1.200 & 1.168 & 0.973 & 1.150 & 1.016 & 1.137 \\
\hline AMC de RL & ELS & 1.128 & 0.922 & 1.124 & 1.004 & 1.040 & 1.249 & 0.835 & 1.118 & 1.117 & 1.043 \\
\hline Fundacion & ELS & 1.134 & 0.891 & 0.914 & 1.240 & 1.011 & 1.134 & 0.891 & 0.909 & 1.247 & 1.011 \\
\hline ACSI & ETH & 1.114 & 1.011 & 1.113 & 1.001 & 1.127 & 1.148 & 1.008 & 1.090 & 1.054 & 1.157 \\
\hline ADCSI & ETH & 0.844 & 0.980 & 0.870 & 0.970 & 0.827 & 0.844 & 0.980 & 0.870 & 0.970 & 0.827 \\
\hline BG & ETH & 1.104 & 0.940 & 0.868 & 1.272 & 1.037 & 0.975 & 0.941 & 0.842 & 1.158 & 0.917 \\
\hline DECSI & ETH & 1.000 & 0.962 & 1.000 & 1.000 & 0.962 & 1.000 & 0.935 & 1.000 & 1.000 & 0.935 \\
\hline OMO & ETH & 1.204 & 1.003 & 1.200 & 1.004 & 1.208 & 1.207 & 1.003 & 1.201 & 1.005 & 1.210 \\
\hline WISDOM & ETH & 0.920 & 1.046 & 0.874 & 1.053 & 0.962 & 0.801 & 0.827 & 0.761 & 1.051 & 0.662 \\
\hline OI SASL & GHA & 1.429 & 0.912 & 1.382 & 1.033 & 1.303 & 1.506 & 0.856 & 1.542 & 0.977 & 1.289 \\
\hline ProCred GHA & GHA & 0.865 & 0.926 & 0.870 & 0.993 & 0.800 & 1.106 & 0.851 & 1.004 & 1.101 & 0.941 \\
\hline Sat & GHA & 1.302 & 0.930 & 1.319 & 0.987 & 1.211 & 1.432 & 0.863 & 1.521 & 0.941 & 1.236 \\
\hline C FUND & GOE & 1.083 & 0.943 & 1.000 & 1.083 & 1.022 & 0.959 & 0.852 & 0.897 & 1.069 & 0.818 \\
\hline Constanta & GOE & 0.836 & 0.937 & 0.796 & 1.050 & 0.784 & 0.881 & 0.876 & 0.802 & 1.099 & 0.771 \\
\hline CREDO & GOE & 1.327 & 0.849 & 1.330 & 0.997 & 1.127 & 1.347 & 0.837 & 1.342 & 1.004 & 1.127 \\
\hline SBDF & GOE & 1.205 & 0.864 & 1.016 & 1.186 & 1.040 & 1.214 & 0.849 & 1.031 & 1.177 & 1.031 \\
\hline Genesis Em & GUAT & 1.121 & 0.877 & 1.014 & 1.105 & 0.983 & 1.214 & 0.834 & 1.000 & 1.214 & 1.012 \\
\hline ACME & HAI & 0.960 & 0.858 & 0.961 & 0.999 & 0.824 & 0.992 & 0.874 & 1.060 & 0.936 & 0.868 \\
\hline FINCA HON & HON & 1.045 & 0.917 & 1.055 & 0.990 & 0.958 & 1.265 & 0.859 & 1.257 & 1.007 & 1.087 \\
\hline HDH & HON & 1.255 & 0.863 & 1.242 & 1.011 & 1.083 & 1.340 & 0.853 & 1.307 & 1.025 & 1.143 \\
\hline World Rel & HON & 1.212 & 0.906 & 1.170 & 1.035 & 1.098 & 1.250 & 0.845 & 1.165 & 1.073 & 1.057 \\
\hline BANDHAN & IND & 1.067 & 1.025 & 1.065 & 1.002 & 1.094 & 1.067 & 1.027 & 1.065 & 1.002 & 1.096 \\
\hline BASIX & IND & 1.100 & 0.900 & 1.041 & 1.056 & 0.989 & 1.142 & 0.887 & 1.034 & 1.104 & 1.013 \\
\hline Cashpoor & IND & 1.690 & 0.963 & 1.771 & 0.955 & 1.629 & 2.133 & 0.959 & 1.970 & 1.083 & 2.045 \\
\hline ESAF & IND & 1.380 & 1.002 & 1.350 & 1.022 & 1.382 & 1.391 & 0.999 & 1.356 & 1.026 & 1.391 \\
\hline GK & IND & 1.282 & 0.971 & 1.285 & 0.997 & 1.244 & 1.221 & 0.971 & 1.238 & 0.986 & 1.186 \\
\hline KBSLAB & IND & 1.003 & 0.945 & 1.003 & 1.001 & 0.949 & 1.003 & 0.943 & 1.005 & 0.997 & 0.945 \\
\hline SHARE MF & IND & 1.081 & 0.946 & 1.035 & 1.045 & 1.022 & 1.117 & 0.941 & 1.039 & 1.075 & 1.051 \\
\hline
\end{tabular}




\begin{tabular}{|c|c|c|c|c|c|c|c|c|c|c|c|}
\hline SNFL & IND & 1.023 & 1.064 & 1.010 & 1.013 & 1.089 & 1.023 & 1.061 & 1.010 & 1.013 & 1.086 \\
\hline MBK Ventu & INDO & 1.333 & 0.928 & 0.850 & 1.569 & 1.237 & 1.351 & 0.950 & 0.743 & 1.818 & 1.283 \\
\hline JMCC & JOR & 1.263 & 0.866 & 1.238 & 1.020 & 1.093 & 1.303 & 0.848 & 1.230 & 1.060 & 1.106 \\
\hline MFW & JOR & 1.219 & 0.902 & 1.210 & 1.007 & 1.100 & 1.463 & 0.839 & 1.356 & 1.079 & 1.228 \\
\hline KLF & KAZ & 0.886 & 0.969 & 0.892 & 0.994 & 0.859 & 1.034 & 0.862 & 0.959 & 1.079 & 0.892 \\
\hline EBS & KEN & 1.070 & 0.998 & 1.121 & 0.955 & 1.068 & 1.697 & 0.770 & 1.255 & 1.352 & 1.306 \\
\hline Kadet & KEN & 1.356 & 0.904 & 1.371 & 0.989 & 1.226 & 1.430 & 0.842 & 1.441 & 0.993 & 1.204 \\
\hline K-REP & KEN & 1.233 & 0.913 & 1.093 & 1.128 & 1.125 & 1.276 & 0.873 & 1.103 & 1.157 & 1.114 \\
\hline KWFT & KEN & 1.047 & 0.956 & 1.029 & 1.017 & 1.001 & 1.224 & 0.858 & 1.016 & 1.205 & 1.051 \\
\hline MDSL & KEN & 1.279 & 0.980 & 1.171 & 1.091 & 1.254 & 1.531 & 0.855 & 1.368 & 1.119 & 1.309 \\
\hline SMEP & KEN & 1.149 & 0.908 & 1.135 & 1.012 & 1.044 & 1.261 & 0.836 & 1.132 & 1.114 & 1.055 \\
\hline AIYL Bank & KYR & 1.000 & 0.982 & 1.000 & 1.000 & 0.982 & 1.000 & 0.982 & 1.000 & 1.000 & 0.982 \\
\hline BTFF & KYR & 1.339 & 0.981 & 1.337 & 1.002 & 1.314 & 1.099 & 0.979 & 1.104 & 0.995 & 1.076 \\
\hline FMCC & KYR & 0.863 & 0.913 & 0.814 & 1.060 & 0.788 & 0.899 & 0.856 & 0.812 & 1.108 & 0.770 \\
\hline Kando Jagima & MALI & 1.404 & 0.872 & 1.299 & 1.080 & 1.225 & 1.387 & 0.874 & 1.277 & 1.086 & 1.213 \\
\hline Soro $\mathrm{Y}$ & MALI & 0.966 & 0.883 & 0.948 & 1.019 & 0.853 & 0.966 & 0.887 & 0.948 & 1.019 & 0.857 \\
\hline CreditMongol & MON & 1.092 & 0.903 & 1.064 & 1.026 & 0.986 & 1.165 & 0.859 & 1.159 & 1.005 & 1.001 \\
\hline Khan Bank & MON & 0.957 & 0.997 & 1.136 & 0.843 & 0.954 & 1.132 & 0.959 & 1.276 & 0.888 & 1.086 \\
\hline AL AMANA & MOR & 1.115 & 0.926 & 1.000 & 1.115 & 1.033 & 1.119 & 0.925 & 1.000 & 1.119 & 1.035 \\
\hline Al Karama & MOR & 0.967 & 0.893 & 0.884 & 1.094 & 0.864 & 0.994 & 0.870 & 0.949 & 1.047 & 0.865 \\
\hline Fondep & MOR & 1.293 & 0.939 & 1.199 & 1.078 & 1.214 & 1.284 & 0.886 & 1.182 & 1.086 & 1.137 \\
\hline Inmaa & MOR & 1.359 & 0.889 & 1.313 & 1.035 & 1.208 & 0.900 & 0.679 & 0.931 & 0.967 & 0.611 \\
\hline Zakoura & MOR & 1.120 & 0.878 & 0.988 & 1.134 & 0.983 & 1.142 & 0.871 & 0.977 & 1.170 & 0.995 \\
\hline NOVO BANCO & MOZ & 1.262 & 0.973 & 1.169 & 1.080 & 1.228 & 1.355 & 0.858 & 1.373 & 0.987 & 1.162 \\
\hline SOCREMO & MOZ & 1.017 & 0.974 & 1.053 & 0.966 & 0.991 & 1.311 & 0.846 & 1.243 & 1.055 & 1.110 \\
\hline TCHUMA & MOZ & 1.071 & 0.922 & 1.089 & 0.984 & 0.988 & 1.125 & 0.877 & 1.126 & 1.000 & 0.987 \\
\hline CBB & NEP & 1.006 & 1.114 & 0.882 & 1.141 & 1.121 & 1.189 & 1.007 & 1.001 & 1.188 & 1.198 \\
\hline NIRDHAN & NEP & 1.119 & 0.987 & 1.117 & 1.001 & 1.104 & 1.121 & 0.985 & 1.117 & 1.003 & 1.104 \\
\hline ACODEP & NIC & 1.006 & 1.010 & 1.006 & 1.000 & 1.016 & 1.200 & 0.879 & 1.127 & 1.064 & 1.054 \\
\hline FDL & NIC & 1.083 & 0.933 & 0.989 & 1.095 & 1.010 & 1.115 & 0.895 & 0.988 & 1.129 & 0.997 \\
\hline FINDESA & NIC & 1.095 & 0.992 & 1.090 & 1.005 & 1.086 & 1.140 & 0.947 & 1.139 & 1.000 & 1.079 \\
\hline ProCred NIC & NIC & 0.887 & 0.967 & 0.896 & 0.990 & 0.858 & 1.007 & 0.921 & 0.889 & 1.133 & 0.928 \\
\hline Prodesa & NIC & 1.000 & 1.050 & 1.000 & 1.000 & 1.050 & 1.000 & 1.006 & 1.000 & 1.000 & 1.006 \\
\hline LAPO & NIG & 1.147 & 0.921 & 1.181 & 0.971 & 1.056 & 1.368 & 0.918 & 1.517 & 0.902 & 1.256 \\
\hline SEAP & NIG & 0.989 & 0.919 & 1.000 & 0.989 & 0.909 & 1.036 & 0.889 & 1.000 & 1.036 & 0.921 \\
\hline ASASAH & PAK & 0.484 & 0.967 & 0.482 & 1.003 & 0.468 & 0.535 & 0.941 & 0.498 & 1.076 & 0.504 \\
\hline FMBL & PAK & 1.469 & 0.982 & 1.465 & 1.003 & 1.443 & 1.597 & 0.952 & 1.556 & 1.026 & 1.521 \\
\hline KASHF & PAK & 1.144 & 0.963 & 1.167 & 0.981 & 1.102 & 1.205 & 0.956 & 1.161 & 1.038 & 1.152 \\
\hline FIELCO & PAR & 1.101 & 0.969 & 1.101 & 1.000 & 1.067 & 1.105 & 0.839 & 1.033 & 1.069 & 0.927 \\
\hline Interfisa & PAR & 1.099 & 0.975 & 1.092 & 1.006 & 1.071 & 1.174 & 0.850 & 1.108 & 1.060 & 0.998 \\
\hline Bantra & PER & 1.041 & 0.988 & 1.000 & 1.041 & 1.028 & 1.151 & 0.833 & 1.000 & 1.151 & 0.959 \\
\hline Caja Nor & PER & 1.052 & 0.936 & 1.022 & 1.029 & 0.984 & 1.103 & 0.879 & 1.020 & 1.082 & 0.970 \\
\hline Caritas & PER & 1.219 & 0.895 & 1.185 & 1.029 & 1.091 & 1.257 & 0.838 & 1.154 & 1.090 & 1.053 \\
\hline CMAC Arq & PER & 1.000 & 0.943 & 1.000 & 1.000 & 0.943 & 1.000 & 0.942 & 1.000 & 1.000 & 0.942 \\
\hline CMAC May & PER & 1.098 & 0.961 & 1.071 & 1.026 & 1.055 & 1.194 & 0.876 & 1.020 & 1.171 & 1.046 \\
\hline CMAC Tac & PER & 1.044 & 0.973 & 1.015 & 1.029 & 1.017 & 1.043 & 0.994 & 0.995 & 1.049 & 1.037 \\
\hline CMAC Tru & PER & 1.033 & 0.968 & 1.003 & 1.030 & 0.999 & 0.996 & 1.004 & 1.003 & 0.993 & 1.000 \\
\hline Edpy. C Tac & PER & 1.074 & 0.953 & 1.068 & 1.005 & 1.023 & 1.184 & 0.881 & 1.102 & 1.074 & 1.044 \\
\hline Edpy. Cofian & PER & 0.921 & 0.957 & 0.918 & 1.003 & 0.881 & 1.006 & 0.911 & 0.910 & 1.105 & 0.916 \\
\hline EDPY.Edyf & PER & 1.102 & 0.950 & 1.022 & 1.078 & 1.047 & 1.218 & 0.836 & 0.994 & 1.225 & 1.019 \\
\hline FINCA PER & PER & 1.145 & 0.873 & 1.093 & 1.047 & 1.000 & 1.161 & 0.892 & 1.146 & 1.012 & 1.035 \\
\hline Fondesurco & PER & 1.240 & 0.906 & 1.040 & 1.192 & 1.124 & 1.266 & 0.840 & 1.052 & 1.204 & 1.063 \\
\hline MiBanco & PER & 1.076 & 0.971 & 1.000 & 1.076 & 1.045 & 1.095 & 0.922 & 1.000 & 1.095 & 1.009 \\
\hline Movim. M R & PER & 1.104 & 0.933 & 1.086 & 1.017 & 1.030 & 1.144 & 0.860 & 1.144 & 1.000 & 0.984 \\
\hline ProMujer PER & PER & 1.112 & 0.929 & 1.125 & 0.989 & 1.033 & 1.262 & 0.859 & 1.264 & 0.998 & 1.084 \\
\hline ASHI & PHI & 1.178 & 0.913 & 1.195 & 0.986 & 1.075 & 1.187 & 0.912 & 1.170 & 1.014 & 1.082 \\
\hline Bangko Ka & PHI & 1.002 & 0.998 & 0.997 & 1.005 & 1.000 & 1.100 & 0.929 & 1.177 & 0.935 & 1.022 \\
\hline BCB & PHI & 1.016 & 0.958 & 0.993 & 1.023 & 0.973 & 1.138 & 0.828 & 1.121 & 1.015 & 0.942 \\
\hline CBMO & PHI & 1.028 & 0.965 & 1.025 & 1.003 & 0.992 & 1.169 & 0.879 & 1.156 & 1.011 & 1.027 \\
\hline DIGOS & PHI & 1.054 & 0.944 & 1.049 & 1.004 & 0.994 & 0.637 & 0.544 & 0.640 & 0.996 & 0.347 \\
\hline Ist Valley & PHI & 0.969 & 0.948 & 0.958 & 1.011 & 0.919 & 1.060 & 0.904 & 0.986 & 1.075 & 0.958 \\
\hline NWFT & PHI & 1.103 & 0.925 & 1.090 & 1.012 & 1.021 & 1.225 & 0.912 & 1.226 & 1.000 & 1.117 \\
\hline SOLANO & PHI & 0.962 & 0.992 & 0.785 & 1.225 & 0.954 & 0.924 & 0.878 & 0.759 & 1.218 & 0.811 \\
\hline
\end{tabular}




\begin{tabular}{|c|c|c|c|c|c|c|c|c|c|c|c|}
\hline TSPI & PHI & 1.163 & 0.915 & 1.040 & 1.119 & 1.065 & 1.237 & 0.900 & 1.233 & 1.003 & 1.114 \\
\hline FORUS & RUS & 0.893 & 0.930 & 0.889 & 1.004 & 0.830 & 1.040 & 0.860 & 0.888 & 1.171 & 0.895 \\
\hline SEF-ZAF & SA & 0.899 & 0.998 & 0.970 & 0.926 & 0.897 & 1.107 & 0.876 & 1.155 & 0.958 & 0.970 \\
\hline SPBD & SAM & 0.999 & 0.954 & 0.713 & 1.401 & 0.952 & 1.106 & 0.845 & 0.683 & 1.619 & 0.935 \\
\hline CMS & SEN & 0.962 & 0.962 & 0.875 & 1.099 & 0.925 & 0.900 & 0.976 & 0.839 & 1.073 & 0.879 \\
\hline Pamecas & SEN & 0.952 & 0.874 & 0.766 & 1.243 & 0.832 & 0.945 & 0.858 & 0.784 & 1.205 & 0.810 \\
\hline Agroinvest & TAJ & 0.733 & 0.973 & 0.763 & 0.961 & 0.713 & 0.993 & 0.941 & 0.896 & 1.108 & 0.934 \\
\hline Bank Eskhata & TAJ & 1.026 & 0.979 & 1.028 & 0.999 & 1.005 & 1.705 & 0.681 & 1.847 & 0.924 & 1.161 \\
\hline FMFB TAJ & TAJ & 1.379 & 0.984 & 1.376 & 1.002 & 1.356 & 1.355 & 0.958 & 1.362 & 0.995 & 1.298 \\
\hline IMON & TAJ & 1.198 & 0.951 & 1.191 & 1.006 & 1.139 & 1.259 & 0.894 & 1.256 & 1.002 & 1.125 \\
\hline MicroInvest & TAJ & 1.152 & 0.942 & 1.049 & 1.098 & 1.085 & 1.142 & 0.910 & 1.097 & 1.041 & 1.039 \\
\hline $\begin{array}{l}\text { PRIDE } \\
\end{array}$ & TAN & 0.985 & 0.931 & 0.979 & 1.006 & 0.917 & 1.080 & 0.854 & 0.975 & 1.107 & 0.922 \\
\hline Enda & TUN & 1.082 & 0.912 & 1.051 & 1.029 & 0.987 & 1.074 & 0.853 & 1.072 & 1.001 & 0.916 \\
\hline CERUDEB & UGA & 0.788 & 0.920 & 0.831 & 0.948 & 0.725 & 1.292 & 0.869 & 0.932 & 1.386 & 1.123 \\
\hline CMFL & UGA & 0.992 & 0.972 & 0.997 & 0.995 & 0.963 & 1.486 & 0.841 & 1.365 & 1.089 & 1.250 \\
\hline FAULU & UGA & 0.820 & 0.933 & 0.838 & 0.979 & 0.765 & 0.979 & 0.857 & 0.939 & 1.043 & 0.839 \\
\hline FINCA UGA & UGA & 0.845 & 0.999 & 0.924 & 0.914 & 0.844 & 0.941 & 0.875 & 0.957 & 0.983 & 0.823 \\
\hline BanGente & VEN & 1.129 & 0.947 & 1.031 & 1.094 & 1.069 & 1.167 & 0.855 & 1.014 & 1.151 & 0.998 \\
\hline CEP & VIET & 1.146 & 0.873 & 1.008 & 1.137 & 1.001 & 1.116 & 0.861 & 0.989 & 1.128 & 0.960 \\
\hline TYM & VIET & 0.974 & 0.931 & 0.939 & 1.037 & 0.907 & 0.949 & 0.936 & 0.925 & 1.025 & 0.888 \\
\hline CETZAM & ZAM & 1.000 & 1.055 & 1.000 & 1.000 & 1.055 & 1.159 & 0.866 & 1.169 & 0.991 & 1.004 \\
\hline FINCA ZAM & ZAM & 1.037 & 0.928 & 1.034 & 1.002 & 0.961 & 0.912 & 0.894 & 0.957 & 0.953 & 0.816 \\
\hline Mean & & 1.071 & 0.943 & 1.029 & 1.041 & 1.010 & 1.108 & 0.895 & 1.041 & 1.064 & 0.992 \\
\hline
\end{tabular}

\section{Appendix $L$ Malmquist DEA indices for treating subsidies as an input (Panel)}

\begin{tabular}{|c|c|c|c|c|c|c|c|c|c|c|c|c|c|c|c|c|c|c|c|c|c|}
\hline \multirow{2}{*}{ MFI } & \multirow{2}{*}{ Cou } & \multicolumn{5}{|c|}{ LR-ACE } & \multicolumn{5}{|c|}{ LR-ACES ${ }^{i}$} & \multicolumn{5}{|c|}{ L-ACE } & \multicolumn{5}{|c|}{ L-ACES ${ }^{i}$} \\
\hline & & ffch & techch & pech & sech & tfpch & effch & h & pech & sech & tfpch & effch & t & pech & sech & tfpch & effch & tech & pech & sech & tfpch \\
\hline ARMP & AFG & 182 & 0.862 & 1.045 & 1.132 & 1.019 & 1.182 & 0.862 & 1.045 & 1.132 & 1.019 & 1.182 & 0.849 & 1.045 & 1.132 & 1.004 & 1.182 & 0.849 & 1.045 & 1.132 & 1.004 \\
\hline BRAC AFG & AFG & 1.569 & 0.842 & 1.399 & 1.121 & 1.321 & 1.569 & 0.842 & 1.399 & 1.121 & 1.321 & 1.591 & 0.813 & 1.352 & 1.176 & 1.293 & 1.591 & 0.813 & 1.352 & 1.176 & 1.293 \\
\hline FMFB AFG & AFG & 1.708 & 0.915 & 1.649 & 1.036 & 1.563 & 1.591 & 0.970 & 1.590 & 1.001 & 1.543 & 1.788 & 0.895 & 1.639 & 1.090 & 1.600 & 1.788 & 0.990 & 1.639 & 1.090 & 1.769 \\
\hline BESA & ALB & 1.000 & 0.925 & 1.000 & 1.000 & 0.925 & 1.000 & 1.060 & 1.000 & 1.000 & 1.060 & 1.000 & 0.937 & 1.000 & 1.000 & 0.937 & 1.000 & 1.093 & 1.000 & 1.000 & 1.093 \\
\hline $\mathrm{oCre}$ & B & 34 & 973 & & & 1.007 & 30 & 06 & & 1.030 & 1.361 & 0.896 & & & 1.010 & 0. & 1.366 & & 95 & 1.143 & \\
\hline PSHM & LB & 28 & 0.932 & & 90 & 1.051 & 1.128 & 0.962 & & 1 & 1.084 & 1.133 & 5 & & 07 & 1.025 & 33 & 9 & 4 & 07 & \\
\hline NovoBanco & ANG & 43 & 0.763 & 0.743 & 1.000 & 0.567 & 0.743 & 0.821 & 0.743 & 1.000 & 0.610 & 1.089 & 0.818 & 1.012 & 1.076 & 0.891 & 1.089 & 0.818 & 1.012 & 1.076 & 0.891 \\
\hline ACBA & ARM & 130 & 0.922 & 1.160 & 0.974 & 1.042 & 1.130 & 0.922 & 1.160 & 0.974 & 1.042 & 1.119 & 0.983 & 1.161 & 0.964 & 1.100 & 1.119 & 0.983 & 1.161 & 0.964 & 1.100 \\
\hline HORIZON & ARM & 1.056 & 0.940 & 0.956 & 1.105 & 0.992 & 1.090 & 0.970 & 1.000 & 1.090 & 1.057 & 1.187 & 0.813 & 1.049 & 1.132 & 0.965 & 1.187 & 0.865 & 1.000 & 1.187 & 1.027 \\
\hline CREL & AZE & 1.134 & 0.962 & 1.105 & 1.026 & 1.091 & 1.134 & 0.963 & 1.105 & 1.026 & 1.092 & 1.139 & 0.952 & 1.105 & 1.031 & 1.085 & 1.139 & 0.952 & 1.105 & 1.031 & 1.085 \\
\hline MFBA & AZE & 202 & 0.856 & 1.078 & 1 & 1.029 & 1.202 & 0.856 & 1.078 & 1.115 & 1.029 & 1.202 & 0.856 & 1.078 & 1.115 & 1.029 & 1.202 & 0.856 & 1.078 & 1.115 & 1 \\
\hline NORMICRO & AZE & 82 & 0.894 & 1.018 & 1.062 & 0.967 & 1.060 & 0.903 & 1.004 & 1.056 & 0.957 & 1.316 & 0.813 & 1.270 & 1.036 & 1.070 & 1.316 & 0.813 & 1.270 & 1.036 & 70 \\
\hline BRAC & BAN & 193 & 0.970 & 1.000 & 1.193 & 1.157 & 1.193 & 0.970 & 1.000 & 1.193 & 1.157 & 0.904 & 0.908 & 1.000 & 0.904 & 0.821 & 0.904 & 0.908 & 1.000 & 0.904 & 0.821 \\
\hline RDRS & BAN & 0.994 & 0.987 & 0.996 & 0.998 & 0.981 & 0.994 & 0.987 & 0.990 & 1.004 & 0.981 & 0.955 & 0.957 & 0.942 & 1.014 & 0.914 & 0.955 & 0.957 & 0.936 & 1.021 & 0.914 \\
\hline TMSS & BAN & 082 & 0.907 & 0.982 & 1.102 & 0.981 & 1.082 & 0.907 & 0.982 & 1.102 & 0.981 & 1.110 & 0.877 & 0.982 & 1.130 & 0.973 & 1.110 & 0.877 & 0.982 & 1.130 & 0.973 \\
\hline FECECAM & BEN & 0.960 & 0.919 & 0.909 & 1.056 & 0.882 & \begin{tabular}{|l|l|}
0.829 \\
\end{tabular} & 0.962 & 0.841 & 0.986 & 0.798 & 1.135 & 0.813 & 0.862 & 1.317 & 0.923 & 0.792 & 0.973 & 0.826 & 0.959 & 0.771 \\
\hline ALIDE & BEN & 101 & 0.842 & 0.860 & 1.280 & 0.928 & 1.101 & 0.842 & 0.860 & 1.280 & 0.928 & 1.130 & 0.813 & 0.860 & 1.313 & 0.918 & 1.130 & 0.813 & 0.860 & 1.313 & 0.9 \\
\hline PADME & BEN & 0.895 & 0.978 & 0.872 & 1.027 & 0.876 & 0.895 & 0.978 & 0.872 & 1.027 & 0.876 & 0.915 & 0.938 & 0.818 & 1.119 & 0.858 & 0.915 & 0.938 & 0.814 & 1.123 & 0 \\
\hline VF & BEN & 1.026 & 0.937 & 1.003 & 1.023 & 0.961 & 1.026 & 0.976 & 1.003 & 1.023 & 1.001 & 1. & & 56 & 1.008 & 0.938 & 75 & 71 & 54 & 20 & c \\
\hline Agr & BOL & 1.095 & 0.926 & 0.986 & 1.110 & 1.013 & 1.095 & 0.927 & 0.986 & 1.110 & 1.015 & 1.072 & 0.903 & 0.963 & 1.113 & 0.968 & 1.072 & 0.903 & 0.963 & 1.113 & 0.968 \\
\hline BANC & BOL & 022 & 0.987 & 0.923 & 1.108 & 1.009 & 1.279 & 1.682 & 1.056 & 1.211 & 2.150 & 1.045 & 0.946 & 0.923 & 1.133 & 0.989 & 1.350 & 1.658 & 1.056 & 1.278 & 2.23 \\
\hline Bnaco L A & BOL & 093 & 0.950 & 0.979 & 1.116 & 1.038 & 1.099 & 0.947 & 0.979 & 1.122 & 1.041 & 1.089 & 0.937 & 0.979 & 1.112 & 1.020 & 1.095 & 0.948 & 0.979 & 1.118 & 1.03 \\
\hline Eco Futuro & BOL & 1.068 & 0.929 & 0.990 & 1.078 & 0.992 & 1.081 & 1.089 & 0.947 & 1.142 & 1.177 & 1.105 & 0.888 & 0.989 & 1.118 & 0.982 & 1.081 & 1.089 & 0.946 & 1.143 & 1.177 \\
\hline FADES & BOL & 0.917 & 0.847 & 0.770 & 1.190 & 0.777 & 0.917 & 0.847 & 0.770 & 1.190 & 0.777 & 0.938 & 0.821 & 0.775 & 1.210 & 0.770 & 0.938 & 21 & 0.775 & 1.210 & 0.770 \\
\hline$r \pi$ & BOL & 0.976 & 0.969 & 0.854 & 1.143 & 0.945 & 0.989 & 0.970 & 0. & 1.161 & 0.959 & 0.990 & 0.940 & 0. & 1.160 & 0.931 & 1.009 & 58 & 0.852 & 1.184 & 0.967 \\
\hline FunBo & BOL & 1.079 & 905 & 1.063 & 5 & 76 & 1.071 & 0.908 & 1.058 & -2 & 0.973 & 1.313 & 32 & 1 & 1.002 & 1.093 & 1.313 & 0.832 & 1.311 & 1.002 & 1.09 \\
\hline PRODEM & BOL & 1.029 & 0.937 & 0.886 & 1.161 & 0.963 & 1.084 & 1.072 & 1.085 & 0.999 & 1.161 & 1.069 & 0.879 & 0.886 & 1.206 & 0.939 & 1.141 & 1.048 & 1.047 & 1.090 & 1.195 \\
\hline ProMujar BOL & BOL & 1.064 & 0.892 & 0.968 & 1.099 & 0.949 & 1.064 & 0.897 & 0.968 & 1.099 & 0.954 & 1.116 & 0.813 & 0.952 & 1.172 & 0.907 & 1.116 & 0.813 & 0.952 & 1.172 & 0.907 \\
\hline CDS & CAM & 1.064 & 0.951 & 1.054 & 1.009 & 1.011 & 1.041 & 1.014 & 1.034 & 1.007 & 1.055 & 1.272 & 0.869 & 1.167 & 1.090 & 1.106 & 1.116 & 1.036 & 1.101 & 1.014 & 1.156 \\
\hline CMM Bog & COL & 1.133 & 0.878 & 1.021 & 1.109 & 0.994 & 1.080 & 0.938 & 0.998 & 1.083 & 1.013 & 1.255 & 0.813 & 1.028 & 1.220 & 1.020 & 1.145 & 0.930 & 0.972 & 1.178 & 1.065 \\
\hline Fin & COL & 1.067 & 871 & 0.962 & 1.110 & 0.930 & 1.036 & 0.899 & 0.941 & 1.10 & 0.932 & \begin{tabular}{|l|l|} 
\\
\end{tabular} .208 & 0.824 & 0.962 & 1.256 & 0.995 & 1.099 & 0.884 & 0.943 & 1.165 & 0.971 \\
\hline WM & COL & 945 & 0.956 & 0.944 & 1.001 & 0.903 & 0.948 & 1.072 & 0.950 & 0.998 & 1.016 & 1.056 & 0.918 & 1.039 & 1.016 & 0.970 & 1.056 & 1.060 & 1.008 & 1.047 & \\
\hline $\mathrm{BCa}$ & COL & 1.000 & 0.945 & 1.000 & 1.000 & 0.945 & 1.000 & 0.932 & 1.000 & 1.000 & 0.932 & 1.132 & 0.946 & 1.000 & 1.132 & 1.071 & 0.970 & 1.012 & 1.000 & 0.970 & 0.982 \\
\hline $\mathrm{AC}$ & COM & 1.005 & 0.939 & 0.922 & 1.090 & 0.944 & \begin{tabular}{|l|}
0.979 \\
\end{tabular} & 0.982 & 0.929 & 1.054 & 0.962 & 1.088 & 0.869 & 0.922 & 1.180 & 0.946 & 0.981 & 0.990 & 0.929 & 1.056 & 0.972 \\
\hline AMRET & COM & 1.074 & 0.966 & 1.051 & 1.022 & 1.037 & 1.088 & 0.967 & 1.070 & 1.016 & 1.051 & 1.275 & 0.816 & 1.069 & 1.193 & 1.040 & 1.275 & 0.873 & 1.040 & 1.226 & 1.114 \\
\hline
\end{tabular}




\begin{tabular}{|c|c|c|c|c|c|c|c|c|c|c|c|c|c|c|c|c|c|c|c|c|c|}
\hline & & & & & & & & & & & & & & & & & & & & & \\
\hline & & & 382 & 0 & 1.006 & 447 & 87 & 997 & 81 & 1.005 & 64 & 42 & 317 & 42 & & 15 & 42 & 361 & 242 & 000 & \\
\hline & & & & & 19 & & & 05 & 06 & 19 & & & & 11 & $1 / 3$ & & & 41 & 011 & 170 & \\
\hline & & & & & 73 & & & & & & & & & & & & & & & & \\
\hline & & & & & & & & & & & & & & & & & & & & & \\
\hline & & & & & & & & & & & & & & & & & & & & & \\
\hline & & & & & 06 & 13 & & & & 85 & & & & & & & & & & & \\
\hline & & 62 & 370 & 000 & 0.957 & 750 & 62 & 903 & 300 & 0.957 & 0.778 & & 70 & 00 & 0.957 & 5 & 62 & & .900 & & 775 \\
\hline & & & & & & 51 & & & & & & & & & 00 & & & & 471 & & \\
\hline & & & & & & & & & & & & & & & & & & & & & \\
\hline & & & & & & & & & & & & & & & & & & & & & \\
\hline & & & & & & 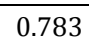 & & & & & & & & & & & & & & & \\
\hline & & 36 & 1 & 04 & 1.257 & 0.978 & 87 & 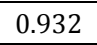 & 92 & 18 & 1.105 & & & & 11 & & & & & & 058 \\
\hline & & & & & & & & & & & 20 & & & & & & & & 24 & & \\
\hline & & & & & & 01 & & & & & & & & & & & & & & & \\
\hline & & & & & & & & & & & & & & & & & & & & & \\
\hline & & & & & & & & & & & & & & & & & & & & & \\
\hline & AT & & & 4 & 6 & 985 & & 0.880 & 05 & 10 & 32 & & & 8 & 67 & & & & & & \\
\hline & & & & & & 328 & & & & & & & & & 01 & & & & & & 897 \\
\hline & & & & & & & & & & & & & & & & & & & & & \\
\hline & & & & & & & & & & & & & & & & & & & & & \\
\hline & & & & & & & & & & & & & & & & & & & & & \\
\hline & & & & & & 88 & & & & & & & & & & & & & & & \\
\hline & & & & & & & & & & & & & & & & & & & & & \\
\hline & & & & & & & & & & & & & & & & & & & & & \\
\hline & & & & & & & & & & & & & & & & & & & & & 1.077 \\
\hline & & & & & & & & & & & & & & & & & & & & & 207 \\
\hline & & & & & & & & & & & & & & & & & & & & & 005 \\
\hline & & & & & & & & & & & & & & & & & & & & & \\
\hline & & & & & & & & & & & & & & & & & & & & & \\
\hline & & & & & & & & & & & & & & & & & & & & & \\
\hline & & & & & & & & & & & & & & & & & & & & & 82 \\
\hline & & & & & & & & & & & & & & & & & & & & & 74 \\
\hline & & & & & & & & & & & & & & & & & & & & & \\
\hline & & & & & & & & & & & & & & & & & & & & & \\
\hline & & & & & & & & & & & & & & & & & & & & & \\
\hline & & & & & 5 & & & & & & & & & & & & & & & & \\
\hline & & & & & & & & & & & & & & & & & & & & & \\
\hline & & & & & & & & & & & & & & & & & & 5 & & & \\
\hline & & & & & & & & & & & & & & & & & & & & & \\
\hline & & & & & & & & & & & & & & & & & & & & & \\
\hline & & & & & & & & & & & & & & & & & & & & & \\
\hline & & & & & & & & & & & & & & & & & & & & & \\
\hline & & & & & & & & & & 7 & 1 & & & 61 & 3 & & 5 & - & 1 & $L$ & \\
\hline & & & & & & & & & & & & & & & & & & & & & \\
\hline & & & & & & & & & & & & & & & & & & & & & \\
\hline & & & & & & & & & & & & & & & & & & & & & \\
\hline & & & & & & & & & & & & & & & & & & & & & \\
\hline & & & & & & & & & & 1 & & & & 5 & 03 & & & 3 & 45 & & \\
\hline & & & & & & & & & & 6 & & & & 01 & 9 & & & & 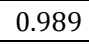 & & \\
\hline & & & & & & & & & & & & & & & & & & & & & \\
\hline & & & & & & & & & & & & & & & & & & & & & \\
\hline & & & & & & & & & & & & & & & & & & & & & \\
\hline & & & & & 3 & & & & & $\begin{array}{l}1.078 \\
\end{array}$ & 28 & 77 & 5 & 0.967 & 1.290 & & 11 & 5 & 967 & 7 & 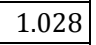 \\
\hline FI & PER & & 2 & 06 & 69 & 1. & 1.169 & 0.848 & 84 & 1.078 & 0.991 & 1. & 0. & 1.286 & 28 & 5 & 1 & & 286 & & 075 \\
\hline & & & & & & & & & & & & & & & & & & & & & \\
\hline & & & & & & & & & & & & & & & & & & & & & \\
\hline & & & & & & & & & & & & & & & & & & & & & \\
\hline & & & & & & & & & & & & & & & & & & & & 5 & \\
\hline & & & & & & & & & & 3 & & & 0 & 0.887 & 5 & & 0 & & 365 & & 874 \\
\hline & & & & & & & & & & & & & & & & & & & & & \\
\hline & & & & & & & & & & & & & & & & & & & & & \\
\hline & & & & & & & & & & & & & & & & & & & & & \\
\hline
\end{tabular}




\begin{tabular}{|c|c|c|c|c|c|c|c|c|c|c|c|c|c|c|c|c|c|c|c|c|c|}
\hline Agroinvest & TAJ & .727 & 0.949 & 0.727 & 1.001 & 0.690 & 0.720 & 0.957 & 0.728 & 0.989 & 0.689 & 1.050 & 0.930 & 0.892 & 1.176 & 0.976 & 1.073 & 0.931 & 0.884 & 1.214 & 0.999 \\
\hline FN & TAJ & 1.352 & 0.956 & 275 & 1. & 1.293 & 1.352 & 956 & 275 & 1.061 & 1.293 & 1.371 & 947 & 370 & 1.001 & 1.298 & 1.371 & 47 & 70 & 01 & 1.298 \\
\hline & AJ & 201 & 50 & 94 & 6 & 42 & 1.201 & 53 & 94 & 6 & 144 & 15 & 35 & 14 & & 97 & 315 & 335 & 314 & & 097 \\
\hline croIn & TAJ & 1.163 & 0.939 & 1.073 & 1.084 & 1.092 & 1.161 & 0.944 & 1.032 & 1.125 & 1.096 & 1.252 & 0.829 & 1.198 & 45 & 037 & 1.252 & 0.829 & 148 & 091 & .037 \\
\hline & $\mathbf{N}$ & 89 & 26 & 96 & & 16 & & & & & 352 & & 313 & 81 & 78 & 40 & 49 & 77 & 50 & 99 & 830 \\
\hline CMFL & UGA & 1.117 & 0.903 & 1.094 & 1.021 & 1.009 & 0.872 & 0.946 & 0.872 & 1.000 & 0.825 & 1.705 & 0.813 & 1.546 & 1.103 & 1.386 & 1.234 & 0.956 & 1.077 & 1.146 & 1.179 \\
\hline FAULU & UGA & 0.851 & 0.916 & 0.881 & 0.966 & 0.780 & 0.821 & 0.915 & 0.863 & 0.951 & 0.751 & 1.101 & 0.813 & 1.074 & 1.026 & 0.895 & 1.101 & 0.813 & .074 & 1.026 & 0.895 \\
\hline FINCA & UGA & 0.828 & 1.018 & 1.000 & 0.828 & 0.843 & 0.996 & 0.814 & 1.000 & 0.996 & 0.811 & 1.065 & 0.813 & 0.966 & 1.102 & 0.866 & 1.007 & 0.836 & 938 & 073 & 0.842 \\
\hline JET & UGA & 1.520 & 0.997 & 1.515 & 1.003 & 1.515 & 1.490 & 1.001 & 1.474 & 1.011 & 1.491 & 1.353 & 0.813 & 1.398 & 0.968 & 1.100 & 1.353 & 0.813 & .398 & 0.968 & 1.100 \\
\hline Banc & VEN & 1.161 & 0.897 & 1.046 & 1.110 & 1.041 & 1.108 & 0.990 & 1.046 & 1.059 & 1.097 & 1.168 & 0.817 & 0.944 & 1.237 & 0.954 & 1.168 & 0.817 & 0.944 & 1.237 & 0.954 \\
\hline CETZAM & ZAM & 1.000 & 1.055 & 1.000 & 1.000 & 1.055 & 1.000 & 1.055 & 1.000 & 1.000 & 1.055 & 1.203 & 0.813 & 1.198 & 1.004 & 0.978 & 1.203 & 0.813 & .198 & 1.004 & 0.978 \\
\hline FINCA ZAN & ZAM & 0.906 & 1.009 & 0.980 & 0.924 & 0.913 & 1.131 & 0.955 & 1.089 & 1.039 & 1.081 & 0.714 & 0.813 & 0.694 & 1.029 & 0.580 & 0.714 & 0.880 & 0.757 & 0.942 & 0.628 \\
\hline 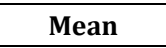 & & 1.07 & 0.929 & 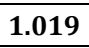 & 1.004 & - & 6 & 943 & 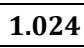 & 1.001 & 1.015 & 8 & 66 & .052 & 1.101 & .003 & 1.134 & 0.903 & 1.050 & 1.000 & 1.024 \\
\hline
\end{tabular}

\section{Appendix M Malmquist DEA indices for treating subsidies as an output (Panel)}

\begin{tabular}{|c|c|c|c|c|c|c|c|c|c|c|c|c|c|c|c|c|c|c|c|c|c|c|c|c|c|}
\hline \multirow{2}{*}{ MFI } & \multirow{2}{*}{ Cou } & \multicolumn{4}{|c|}{ LR-ACE } & \multicolumn{4}{|c|}{ LRS $^{\circ}$-ACE } & \multicolumn{4}{|c|}{ L-ACE } & \multicolumn{4}{|c|}{$\mathrm{LS}^{0}$-ACE } & \multicolumn{4}{|c|}{ R-ACE } & \multicolumn{4}{|c|}{$\mathrm{RS}^{0}$-ACE } \\
\hline & & effch $t$ & techch & pech & tfpch & effch & techch & pech & tfpch & effch & techch & pech & tfpch & effch & techch & pech & tfpch & effch $t$ & techch & pech & tfpch & effch & chch & pech & tfp \\
\hline IRO TAI & BAN & 0.946 & 1.060 & 1.018 & 1.002 & 0.946 & 1.060 & 1.007 & 1.002 & 0.797 & 1.243 & 1.014 & 0.990 & 0.795 & 1.213 & 1.002 & 0.965 & 0.917 & 1.027 & 0.919 & 0.942 & 0.916 & 1.027 & 0.907 & 0.941 \\
\hline Il & BAN & 10 & 7 & 0 & 1 & 1.010 & 1.217 & 0 & 1 & 0 & 0 & 0 & 3 & 1.010 & 278 & 1.000 & 291 & 39 & 022 & 925 & 960 & 939 & 1.022 & Th & 6 \\
\hline RCPB & BF & 0.869 & 0.993 & 0.841 & 0.862 & 0.869 & 0.993 & 0.841 & 0.862 & 0.869 & 0.993 & 0.841 & 0.862 & 0.869 & 0.993 & 0.841 & 0.862 & 0.873 & 1.019 & 0.946 & 0.890 & 0.873 & 1.019 & 0.946 & 0.890 \\
\hline MIK & BOS & 00 & 1.094 & 00 & 94 & 1.000 & 506 & 000 & 1 & 0 & 1.095 & 00 & 95 & 1.000 & 1.608 & 1.000 & 608 & 1.070 & 0.942 & 1.082 & 1.008 & 1.366 & 1.605 & 353 & 2.19 \\
\hline FMN & $\mathbf{L}$ & 55 & 0.979 & 32 & 33 & 1.054 & 0.980 & 1 & 1 & 1 & 986 & 87 & 1.079 & 1.092 & 0.985 & 1.029 & 76 & 919 & 1.013 & 0.982 & 0.931 & 919 & 1.013 & 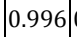 & 93 \\
\hline ro & ECU & 0.982 & 0.970 & 985 & 0.953 & 0.982 & 0.970 & 0.985 & 0 & 0.906 & 1.047 & 0.938 & 0.949 & 0.928 & 1.036 & 0.940 & 0.961 & 1.051 & 0.941 & 1.025 & 0.989 & 1.051 & 0.941 & 025 & 0.98 \\
\hline FI & ECU & 1.000 & 0.934 & 1.000 & 0.934 & 1.000 & 906 & 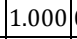 & & 8 & 1.017 & 92 & 0.974 & 0.957 & 0.988 & 0.992 & 6 & 3 & 0.940 & 997 & 0.924 & 983 & 0.913 & 7 & 0.89 \\
\hline FOD & ECU & 1.014 & 1.046 & 1.000 & 1.060 & 1.014 & 1.046 & 00 & 60 & 14 & 1.046 & 1.000 & 1.061 & 1.014 & 1.046 & 1.000 & 1.061 & 1.060 & 1.006 & 1.015 & 1.066 & 1.060 & 1.006 & 015 & 1.06 \\
\hline 年 & CU & 1.002 & 983 & 000 & 985 & 1.002 & 0.983 & 1 & 0 & 24 & 1.063 & 949 & 0.982 & 0.958 & 1.034 & 0.955 & 990 & 010 & 0.983 & 1.000 & 0.993 & 1.010 & 0.983 & 1.000 & 99 \\
\hline ACSI & $\Gamma \mathbf{H}$ & 47 & 9 & 80 & 1 & 1.000 & 18 & 0 & 1 & 7 & 9 & 30 & 3 & 1.000 & 18 & 1.000 & 8 & 2 & 8 & 54 & 43 & 000 & 6 & 1.000 & 71 \\
\hline DECSI & ETH & 1.000 & 0.962 & 1.000 & 0.962 & 1.000 & 1.008 & 1.000 & 1.008 & 1.000 & 0.930 & 1.000 & 0.930 & 1.000 & 1.002 & 1.000 & 1.002 & 1.000 & 1.013 & 1.000 & 1.013 & 1.000 & 1.061 & 1.000 & 1.061 \\
\hline 10 & $\mathrm{HA}$ & 39 & 005 & 751 & 43 & 0.739 & 1.005 & 1 & 0 & 6 & 1.077 & 14 & 1.030 & 0.956 & 060 & 1.010 & 4 & 608 & 991 & 0.651 & 0.602 & 0.608 & 0.991 & $0.651 \mid$ & 60 \\
\hline J & $\mathbf{R}$ & 1.066 & 1.036 & 1.092 & 1.104 & 1.066 & 1.036 & 1.092 & 1.103 & 1.067 & 1.044 & 1.093 & 1.114 & 1.067 & 1.041 & 1.093 & 1.110 & 1.043 & 1.013 & 1.058 & 1.057 & 1.043 & 1.013 & 1.058 & 1.057 \\
\hline KLF & KAZ & 0.820 & 1.017 & 0.849 & 0.834 & 0.820 & 1.017 & 0.849 & 0. & 0.843 & 1.011 & 0.863 & 0.852 & 0.844 & 1.002 & 0.863 & 0.846 & 0.820 & 1.017 & 0.849 & 0.834 & 0.820 & 1.017 & 0.849 & 0.83 \\
\hline LDS & KEN & 1.056 & 1.008 & 1.422 & 1.065 & 1.083 & 1.019 & 1.305 & 1.103 & 1.565 & 0.981 & 1.940 & 1.536 & 1.071 & 1.508 & 1.305 & 1.615 & 1.056 & 1.008 & 1.422 & 1.065 & 1.083 & 1.019 & 1.305 & 1.103 \\
\hline Fondep & OR & 1.046 & 1.043 & 1.045 & 1.091 & 1.046 & 1.589 & 1.045 & 1.663 & 0.973 & 1.040 & 1.005 & 1.012 & 1.047 & 1.597 & 1.045 & 1.672 & 1.368 & 1.028 & 1.359 & 1.406 & 1.368 & 1.567 & 1.359 & 2.142 \\
\hline maa & $\mathbf{O R}$ & 1.199 & 1.005 & 1.000 & 205 & 1.199 & 1.005 & 000 & 1 & 11 & 077 & 1.000 & 1.197 & 1.140 & 1.064 & 1.000 & 1.213 & 1.269 & 0.976 & 1.000 & 1.238 & 1.269 & 0.976 & 1.000 & 1.238 \\
\hline 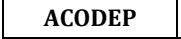 & NIC & 000 & 971 & 1.000 & 0.971 & 1.000 & 0.971 & 1.000 & 71 & 1.012 & 007 & 34 & 1.019 & 1.029 & 991 & 1.037 & 1.020 & 1.000 & 0.971 & 1.000 & 0.971 & 1.000 & 0.971 & 1.000 & 0.97 \\
\hline FDL & IC & 1.001 & 0.993 & 0.971 & 93 & 1.001 & 0.993 & 0.971 & 0. & 0.982 & 1.010 & 0.995 & 0.992 & 0.982 & 1.010 & 0.987 & 0.992 & 1.001 & 1.024 & 1.050 & 1.025 & 1.001 & 1.024 & 1.050 & 1.025 \\
\hline rodeca & C & 0 & 2 & 0 & 1 & 00 & 3 & 1 & 1 & 1 & 3 & 0 & 1 & 0 & 3 & 0 & 3 & 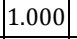 & 0 & 00 & 70 & 00 & 7 & 0 & 1 \\
\hline CIVAC Arq & PER & 1.000 & 0.949 & 1.000 & 0.949 & 1.000 & 0.947 & 1.000 & 0.947 & 0.917 & 1.088 & 1.000 & 0.998 & 0.917 & 1.088 & 1.000 & 0.998 & 1.000 & 0.912 & 1.000 & 0.912 & 1.000 & 0.910 & 1.000 & 0.910 \\
\hline Bangko Ka & PHI & 0.990 & 1.009 & 1.015 & 0.999 & 0.990 & 1.026 & 1.015 & 1.016 & 1.032 & 0.970 & 1.025 & 1.001 & 1.035 & 1.107 & 0.982 & 1.145 & 0.990 & 1.009 & 1.015 & 0.999 & 0.990 & 1.026 & 1.015 & 1.016 \\
\hline ВCB & HI & 5 & 9 & 0 & c & 99 & 8 & 1 & 0 & 0 & 0 & 5 & 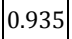 & 3 & 7 & 3 & 0 & 5 & 9 & 00 & 4 & 99 & 8 & 0 & 0 \\
\hline CBMO & PHI & 0.989 & 1.002 & 0.969 & 0.991 & 0.959 & 1.056 & 0.960 & 1.012 & 0.994 & 1.049 & 1.005 & 1.042 & 0.964 & 1.088 & 0.917 & 1.049 & 0.936 & 1.027 & 0.962 & 0.961 & 0.907 & 1.093 & 0.959 & 0.992 \\
\hline DIGOS & HI & 0.994 & 0.986 & 0.978 & 0.980 & 0.994 & 0.986 & 0.978 & 0.980 & 0.933 & 1.036 & 0.940 & 0.967 & 0.937 & 1.034 & 0.940 & 0.969 & 0.993 & 1.021 & 1.006 & 1.014 & 0.993 & 1.021 & 1.006 & 1.01 \\
\hline No & $\mathrm{HI}$ & 0.948 & 1.011 & 1.000 & 0.958 & 0.768 & 1.271 & 1.000 & 0. & 0.765 & 0.969 & 1.000 & 0.741 & 0.559 & 44 & 1.000 & 0.863 & 48 & 1.011 & 1.000 & 0.958 & 0.768 & 1.271 & 1.000 & 0.915 \\
\hline TSPI & PHI & 1.000 & 1.047 & 1.000 & 1.047 & 1.000 & 1.053 & 1.000 & 1.053 & 0.903 & 1.236 & 1.071 & 1.117 & 0.951 & 1.198 & 1.079 & 1.140 & 1.000 & 1.043 & 1.000 & 1.043 & 1.000 & 1.053 & .000 & 1.053 \\
\hline $\mathbf{E}$ & $\mathrm{JN}$ & 0.933 & 2 & 0.940 & 0 & 0.936 & 01 & 0.940 & 0. & 0. & 32 & 381 & 0.907 & 72 & 63 & 86 & 27 & 60 & 69 & 08 & 27 & 61 & 69 & 99 & 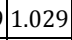 \\
\hline C & ET & 0.898 & 1.044 & 0.911 & 0.938 & 0.900 & 1.042 & 0.913 & 0.937 & 0.880 & 1.054 & 0.910 & 0.928 & 0.890 & 1.047 & 0.911 & 0.932 & 1.097 & 1.020 & 1.118 & 1.119 & 1.097 & 1.021 & 1.118 & 1.120 \\
\hline TYM & ET & 0.808 & 1.112 & 0.845 & 0.89 & 0.808 & 1.110 & 0.807 & 0. & 0.797 & 1.120 & 0.845 & 0.893 & 0.797 & 1.118 & 7 & 1 & 7 & 1.027 & 1.004 & 24 & 96 & 28 & 33 & 23 \\
\hline mean & & 0.978 & 1.016 & 0 & 0003 & 0.965 & 1.079 & 0.979 & 1 & 3 & 1.051 & 1.00 & 1 & 939 & 1.146 & 0.976 & 1.07 & 4 & 1.005 & 1.0 & 0.99 & 0.989 & 074 & 1.010 & . \\
\hline
\end{tabular}




\section{Bibliography}

Alam. Jehangir (2005) Self sustainability of Microfinance institutions- A critical evaluation of the performance of Grameen Bank of Bangladesh. Finance department, University of Chitagong, Bangladesh

Alfaro, Luis Noel. (1996) Sustainability and Outreach of Development Financial Institutions for Micro and Small Business, unpublished Ph.D. dissertation, The Ohio State University.

Amemiya, T. (1984), Tobit models: a survey, Journal of Econometrics 24, 3-61.

Armendáriz de Aghion, B and Jonathan Morduch (2004) Microfinance: Where do we Stand? in Charles Goodhart Edition. Financial Development and Economic Growth: Explaining the links (London: Palgrave)

Armendariz, B. and J. Morduch (2005) The Economics of Microfinance. Cambridge, MA: MIT Press.

Athanassopoulos A, D. (1997) Service quality and operating efficiency synergies for management control in the provision of financial services: Evidence from Greek bank branches. European Journal of Operational Research Vol. 98, pp. 300-313.

Balkenhol, B. (2007a) Microfinance and Public Policy: Outreach, Performance and Efficiency. ILO, Palgrave Edition, New York.

Balkenhol, B. (2007b) Microfinance, Efficiency Return and Public Policy. Microbanking Bulletin, Issue 14, Spring.

Barrès Isabelle (2007) Efficiency: Breaking it Down. Microbanking Bulletin, Issue 14 , Spring

Beatriz Armendariz \& Ariane Szafarz (2009) On Mission Drift In Microfinance Institutions. Working Papers CEB 09-015.RS, Université Libre de Bruxelles, Solvay Brussels School of Economics and Management, Centre Emile Bernheim (CEB).

Belli, P. (1996) Handbook on Economic Analysis of Investment Operations, Operations Policy Department. Washington, D.C., World Bank. 
Benjamin, M. P. Jr. (1994) Credit Schemes For Microenterprises: Motivation, Design, and Viability. Unpublished PhD dissertation, Georgetown University

Berger, A. N. and Humphrey, D. B. (1997) Efficiency of financial institutions: International survey and directions for future research. Europeon Journal of Operational Research. Vol. 98, pp. 175-212.

Bhatt, N. and Tang, S. (2001) Delivering Microfinance in Developing Countries: Controversies and policy perspective. Policy Study Organization.

Camanho, A. S. and Dyson, R. G. (2005) Cost efficiency, production and value-added models in the analysis of bank branch performance. Journal of Operational Research Society, Vol. 56, pp. 483-494.

Campion, A. and White, W. (1999) Institutional metamorphosis: transformation of microfinance NGOs in regulated financial institutions, Occasional Paper No. 3, MicroFinance Network, Washington, DC.

Chakraborty, K., B. Biswas, and W.C. Lewis. (2001) "Measurement of technical efficiency in public education: A stochastic and nonstochastic production function approach". South. Econ, J., Vol. 67, No. 4, pp. 889-905.

Charitonenko, S. (2003) Commercialization of Microfinance: The Philippines. Asian Development Bank, Manila, Philippines.

Charitonenko, S. and Rahman, S. M. (2002) Commercialization of Microfinance: Bangladesh. Asian Development Bank, Manila, Philippines.

Charitonenko, S., Campion A. and Fernando Nimal A. (2004) Commercialization of Microfinance: Perspective from South and Southeast Asia. Asian Development Bank, Manila, Philippines.

Charnes, A., Cooper W. W. and Rhodes, E. (1978) Measuring the efficiency of decision making units. European Journal of Operational Research Vol. 2, pp. 429444.

Chilingerian, J.A. (1995) Evaluating physician efficiency in hospitals: A multivariate analysis of best practices, European Journal of Operational Research 80, 548-574.

Christen, Robert Peck. (1997) Banking Services For the Poor: Managing For Financial Success: An Expanded and Revised Guidebook for Development Finance Institutions, Boston: Acción International

Christen, R. (2000), Bulletin Highlights, MicroBanking Bulletin, 4, February 2000, pp. 41-47

Christen, Robert Peck; Rhyne, Elisabeth; Vogel, Robert C.; and Cressida McKean. (1995) Maximizing the Outreach of Microenterprise Finance: An Analysis of 
Successful Microfinance Programs. Program and Operations Assessment Report No. 10, Washington, D.C.: United States Agency for International Development.

Christen, Robert Peck (2001) Commercialization and Mission Drift. The Transformation of Microfinance in Latin America. CGAP Occasional Paper \# 5, Washington DC., USA

Christen, R., \& Drake, D. (2002) Commercialization. The new reality of microfinance. In D. Drake, \& E. Rhyne (Eds.), The commercialization of microfinance. balancing business and development (pp. 2-22). Bloomfield:

Kumarian Press.

Christen, R. P. and Rosenberg, R. (2000) The Rush to Regulate: Legal Frameworks for Microfinance, CGAP Occassional Paper, Washington DC.

CGAP (2003) Microfinance Consensus Guidelines. Definitions of Selected Financial Terms. Ratios and Adjustments for Microfinance. 3rd edn. Consultative Group to Assist the Poorest: Washington. DC. USA.

Congo. Y. (2002) Performance of Microfinance Institutions in Burkina Faso. Discussion Paper No. 2002/01. WIDER. United Nations University, Helsinki, Finland.

Cull. R., Asli Demirguç-Kunt \& Morduch. J. ( 2007) Financial performance and outreach: a global analysis of leading microbanks. The Economic Journal,Vol. 117, pp. F107-F133

Dichter, T. W., \& Harper, M. (2007). What's wrong with microfinance. In T. W. Dichter, \& M. Harper (Eds.), What's wrong with microfinance. Essex, England: Practical Action Publishing.

Dewatripont, M and E. Maskin (1995) Credit and Efficiency in Centralized and Decentralized Economies, Review of Economic Studies, 62, 4, pp. 541-555.

Dunford, Christopher (2002) what's Wrong with Loan Size? Freedom from Hunger Publication available at:

http://www.ffhtechnical.org/publications/summary/loansize0302.html.

Farrel, M. (1957) The measurement of productive efficiency. Journal of royal statistical society, Vol. 120, No. 3, pp. 253-2811

Forster Sarah and Reille Xavier (2008) Foreign Capital Investment in Microfinance: Balancing Social and Financial Returns. Focus Note, CGAP. Available at http://collab2.cgap.org/gm/document-1.9.2584/FocusNote_44.pdf

Gillen, D. and Lall, A. (1997), Developing measures of airport productivity and performance: and application of Data Envelopment Analysis, Transportation Research - E 33, 4, 261-273. 
Gittinger. J. Price (1982) Economic Analysis of Agricultural Projects. Second Edition. Economic Development Institute of the World Bank. Baltimore, Johns Hopkins University Press. ISBN 0-8018-2912-7.

Goodman. P. (2005) Microfinance Investment Funds. Key Features. ADA Publications. Luxemburg.

Gutierrez-Nieto, B., Serrano Cinca C. and Mar Molinero C. (2009) Social Efficiency in Microfinance Institutions. Journal of the Operational Research Society, Vol. 60 No. 19, pp. 104-119

Gutierrez-Nieto, B., Serrano Cinca C. and Mar Molinero C. (2007) Microfinance Institutions and Efficiency. OMEGA: International Journal of Management Science, Ed Elsevier, Vol 35, No. 2, pp. 131-142

Hartarska, V. and D. Nadolnyak (2007) Do regulated microfinance institutions achieve better sustainability and outreach? Cross-country evidence. Applied Economics, Vol. 39, pp. 1207-1222.

Hashemi, Syed M. and Sidney, Ruth, Schuler (1997) Sustainable banking with the poor : a case study of Grameen Bank. JSI Working Paper No. 10, Arlington, Virginia, JSI Research and Training Institute.

Hatch, John and Frederick, Laura (1998) Poverty Assessment by Microfinance Institutions: A Review of Current Practice. Microenterprises Best Practices Project. Development Alternatives, USAID, Washington, DC. USA.

Hermes, Niels \& Lensink, Robert \& Meesters, Aljar, (2008) Outreach and Efficiency of Microfinance Institutions. Research Report 08002, University of Groningen, Research Institute SOM (Systems, Organisations and Management).

Hishigsuren, G. (2007). Evaluating mission drift in microfinance. Lessons for programs with social mission. Evaluation Review, 31(3), 203-260.

Holtmann, Martin; and Rochus Mommartz. (1996) Technical Guide for Analyzing the Efficiency of Credit-Granting Non-Government Organizations (NGOs), Saarbrücken and Fort Lauderdale: Breitenbach Verlag.

Hudon, M. (2006) Financial performances, management and ratings of the microfinance institutions: Do subsidies matter? Working paper, Universite Libre de Bruxelles, Belgium.

Hudon, M. and Traca, D. (2006) Subsidies and Sustainability in Microfinance. Working Paper WP-CEB 06-020, Solvay Business School, Brussels, Belgium. 
Hudon, M (2007) Fair interest rates when lending to the poors. Ethics and Economics, Vol. 5, No. 1

Hudon, M. and Traca, D. (2008) On the efficiency effects of Subsidies in Microfinance : An empirical Inquairy. Working Paper CEB 06-020. Solvay Business School, Brussels, Belgium.

Hulme, David and Paul, Mosley (1996) Finance Against Poverty. Volume I and II. London: Routledge, ISBN 0-415-09544-1 and 0-415-12430-1.

International Monetary Fund. International Financial Statistics, 2005 \& 2006, Washington, D.C.

Inter-American Development Bank (1994) Technical Guide for the Analysis of Microenterprise Finance Institutions. Microenterprise Division. Washington. D.C.

Katz, David A., and H. Gilbert Welch (1993) Discounting in Cost-Effectiveness Analysis of Healthcare Programmes. PharmacoEconomics, Vol. 3, No. 4, pp. 276285.

Khandker S., Khalily B., and Z., Khan (1995) Grameen Bank: Performance and Sustainability. Discussion Paper No. 306, Washington D.C., World Bank.

Kornai, J., Maskin, E. and G. Roland (2003) Understanding the Soft Budget constraint, Journal of Economic Literature, XLI, pp. 1095-1136.

Laschelles, D. (2008) Microfinance Banana Skin. Microbanking Bulletin, Issue 16, Spring 2008

Lewis, J. (2008) Microloan Sharks. Stanford Social Innovation Review, Summer 2008

Manos, R., and Yaron, J., (2009) Key Issues in Assessing the Performance of Microfinance Institutions. Paper presented at the 2nd International Workshop on Microfinance Management and Governance, Kristiansand, Norway

Mixmarket (2007) The Microfinance Information eXchange (MIX). Available at http://www.mixmarket.org/en/what.is.mix.asp.

McCarty, T., A. and S, Yaisawarng (1993) Technical Efficiency in New Jersey School Districts in H., Fried, C. A. K. Lovell and S. S. Schmidt, eds., The Measurement of Productive Efficiency: Techniques and Applications, Oxford University Press, New York, pp. 271-287.

Mehra, Rajnish; and Edward C. Prescott. (1985) The Equity Premium: A Puzzle. Journal of Monetary Economics, Vol. 15, No. 2, pp. 145-161. 
Mersland, R., and Strom, R. (2009) Microfinance Mission Drift?. World Development (In press) doi:10.1016/ j.worlddev.2009.05.006

MFI Solutions (2008) The Implications of Increased Commercialization of Microfinance Industry: What can we learn from the discussions that followed the Compartamos IPO? Published by MFI Solutions, LLC, USA and La Colmena Milenaria, A. C., Mexico

Modigliani, F.; and M. Miller. (1958) The Cost of Capital, Corporation Finance, and the Theory of Investment. American Economic Review, Vol. 49, No. 2, pp. 261-297.

Morduch, J. (1999a) The Microfinance Promise. Journal of Economic Literature, Vol. 37, pp. 1569-1614.

Morduch. J. (1999b) The role of subsidies in microfinance: evidence from the Grameen Bank. Journal of Development Economics, Vol. 60, pp. 22-248.

Morduch, J. (2000) The Microfinance Schism. World Development, Vol. 28, No. 4, pp 617-629

Morduch, J. (2004) Managing Tradeoffs. Special issue on "What role for microfinance? Reframing the questions." http://www.nyu.edu/projects/morduch/documents/microfinance/Managing_Tra deoffs.pdf

Morduch, J. (2005) Smart Subsidy for Sustainable Microfinance. In Finance for the Poor, Quarterly Newspaper, ADB, Vol. 6, No. 4, pp. 1-7.

Morduch, J. (2007) Smart Subsidies in Balkenhol, B. (2007) Microfinance and Public Policy. Outreach, Performance and Efficiency, ILO, Palgrave Edition, New York.

Navajas, S., Schreiner, M., Meyer, R.L., Gonzalez-Vega, C. and Rodriguez-Meza, J. (2002) Microcredit and the Poorest of the Poor: Theory and Evidence from Bolivia, in M. Zeller and R.L. Meyer (eds.), The Triangle of Microfinance: Financial Sustainability, Outreach, and Impact, Baltimore: The Johns Hopkins University Press

Pastor, J. M. (1999) Efficiency and Risk Management in Spanish Banking: a method to decompose risk. Applied financial economics, Vol. 9, pp. 371-384

Rosenberg, R., Christen, R. P. and Brigit H. (1997) Format for Appraisal of MicroFinance Institutions. Washington, D.C.: Consultative Group to Assist the Poorest.

Rosenberg, Richard (1994) Beyond Self-sufficiency: Licensed Leverage and Microfinance Strategy. manuscript. 
Rhyne, Elisabeth (1994) A New View of Finance Program Evaluation. In Otero, Maria and Rhyne, Elisabeth (Ed.) The New World of Microenterprise Finance.

Rhyne, E. (1998). The Yin and Yang of microfinance. Reaching the poor and sustainability. MicroBanking Bulletin, 2, 6-9.

Rhyne, E. and E. Otero (2006) Microfinance through the next decade: Visioning the who, what where, when and how. Paper commissioned by the Global Microcredit Summit 2006, Boston MA: ACCION International, 2006.

Sacay, O., B. Randhawa. and M. Agabin. (1996) The BAAC Success Story: A Specialized Agriculture Bank under Government Ownership. Financial Sector Development Department, World Bank, Washington, D.C.

Safavian, M., Graham, D., Gonzalez-Vega, C., and Whelan, D. (2000) The state of microfinance activity and regulation in Russia, Working Paper, The Ohio State University.

Schreiner, M. (1997) A Framework For the Analysis of the Performance and Sustainability of Subsidized Microfinance Organizations With Application to BancoSol of Bolivia and to the Grameen Bank of Bangladesh. PhD dissertation. The Ohio State University

Schreiner, M., and Yaron, J. (1999) The subsidy Dependence Index and recent attempts to adjust it. Savings and Development, Vol. 23, No. 4, pp. 375-405.

Schreiner, M., and Yaron, J. (2001). Development Finance Institutions: Measuring Their Subsidy. Washington. D.C.: World Bank.

Schreiner, M. (2001) Seven aspects of loan size. Journal of Microfinance, Vol. 3, No. 2, pp. $27-47$

Schreiner, M. (2002) Aspects of Outreach: A Framework for Discussion of the Social Benefits of Microfinance, Journal of International Development, 14(5), 591603

Schreiner, M. (2003) A Cost-Effectiveness Analysis of the Grameen Bank of Bangladesh. Development Policy Review, Vol. 21, No. 3, pp. 357-382.

SEEP. (1995) Financial Ratio Analysis of Micro-finance Institutions", New York: Pact Publications, books@pactpub.org

Seiford, L. M. and Zhu, J. (1999) Profitability and marketability of the top 55 U.S. commercial banks. Mngt Sci, Vol. 45, pp. 1270-1288. 
Sharma, M. (2004) Subsidy Dependence and Financial sustainability in development banks- A case study of Small Pacific Island Country. The University of South Pacific, Fiji Islands.

Sherman, H. D. and Gold, F. (1985) Bank branch operating efficiency: Evaluation with data envelopment analysis. J Banking Finance, Vol. 9, pp. 297-315.

Stiglitz, Joseph E., and Andrew Weiss (1981) Credit Rationing in Markets with Imperfect

Information. American Economic Review Vol. 71, No. 3, pp. 393-410.

Von Pischke, J. D. (1991) Finance at the Frontier: Debt Capacity and the Role of Credit in the Private Economy, Washington, D.C.: World Bank.

Von Pischke, J. D. (1996b) Measuring Microlender Financial Performance on a Cash Flow Basis. manuscript.

Von Pischke, J.D. (1998), Measuring the Trade-Off between Outreach and Sustainability of Microenterprise Lenders, Journal of International Development, $8(2), 225-239$

Woller, G. M. (2002). The promise and peril of microfinance commercialization. Small Enterprise Development, 13(4), 12-21.

Woller, G. and Woodworth, W. (2001) Microcredit as a grass-root policy for international Development. The Policy Studies Journal, Vol. 29, No. 2, pp. 267-282

Woller, G. M., Dunford, C., \& Woodworth, W. (1999). Where to microfinance?.

International Journal of Economic Development, 1(1), 29-64.

Yaron, J. (1992a) Successful Rural Finance Institutions. Discussion Paper No. 150, Washington. D.C.: World Bank, ISBN 0-8213-2018-1.

Yaron, J. (1992b) Assessing Development Finance Institutions: A Public Interest Analysis. Discussion Paper No. 174. Washington. D.C.: World Bank, ISBN 0-82132203-6.

Yaron, J. (1994) What Makes Rural Finance Institutions Successful?. World Bank Research Observer. Vol. 9, No. 9, pp. 49-70

Yaron, J., M. Benjamin. and G. Piprek. (1997) Rural Finance: Issues, Design and Best Practices. Washington. D.C.: World Bank

Yaron, J. (2004) State-Owned Development Finance Institutions: Background, Political Economy and Performance Assessment. Available at ww.iadb.org/res/publications/pubfiles/pubS-492.pdf 
Zeller, M. and Meyer. R. L. (2002) (eds) The Triangle of Microfinance: Financial Sustainability, Outreach and Impact. The John Hopkins University Press, Baltimore, MD, USA, ISBN: 0-8018-7226-X 


\section{Curriculum Vitae}

Oct, 2005-Sep, 2009: Doctoral Candidate, Chair for Development Economics, University of Göttingen, Germany

2001: Master in Economics (in Development Economics), The University of Manchester, UK

1998: Master of Science (Economics), Quaid-i-Azam University, Islamabad, Pakistan

1995: Bachelor of Science, Government College, Punjab University, Lahore, Pakistan

1993: Intermediate Examination, Government College, BISE, Lahore, Pakistan

1991: Secondary School Certificate, Divisional Public School, Lahore, Pakistan 